\title{
Language Variation - European Perspectives VIII
}

Edited by

Hans Van de Velde

Nanna Haug Hilton

Remco Knooihuizen 
Language Variation - European Perspectives VIII 


\section{Studies in Language Variation (sILV)}

ISSN 1872-9592

The series aims to include empirical studies of linguistic variation as well as its description, explanation and interpretation in structural, social and cognitive terms. The series will cover any relevant subdiscipline: sociolinguistics, contact linguistics, dialectology, historical linguistics, anthropology/anthropological linguistics. The emphasis will be on linguistic aspects and on the interaction between linguistic and extralinguistic aspects - not on extralinguistic aspects (including language ideology, policy etc.) as such.

For an overview of all books published in this series, please see benjamins.com/catalog/silv

\section{Editors}

Peter Auer

Universität Freiburg

\section{Editorial Board}

Arto Anttila

Stanford University

Gaetano Berruto

Università di Torino

Jenny Cheshire

University of London

Katie Drager

University of Hawai'i at Mānoa

Katarzyna Dziubalska-Kołaczyk

Adam Mickiewicz University in Poznań

Jürg Fleischer

Philipps-Universität Marburg

Peter Gilles

University of Luxembourg

Brian D. Joseph

The Ohio State University

\section{Frans Hinskens}

Meertens Instituut \&

Radboud Universiteit Nijmegen

\section{Paul Kerswill}

University of York
Johannes Kabatek

Universität Zürich

Pieter Muysken

Radboud University Nijmegen

Pia Quist

University of Copenhagen

Anne-Catherine Simon

Université catholique de Louvain

Sali A. Tagliamonte

University of Toronto

Øystein Alexander Vangsnes

UiT The Arctic University of Norway

Juan A. Villena Ponsoda

Universidad de Málaga

\section{Volume 25}

Language Variation - European Perspectives VIII

Selected papers from the Tenth International Conference on Language Variation in Europe (ICLaVE 10), Leeuwarden, June 2019

Edited by Hans Van de Velde, Nanna Haug Hilton and Remco Knooihuizen 


\section{Language Variation - European Perspectives VIII}

Selected papers from the Tenth International Conference on Language Variation in Europe (ICLaVE 10), Leeuwarden, June 2019

Edited by

Hans Van de Velde

Fryske Akademy \& Utrecht University

Nanna Haug Hilton

University of Groningen

Remco Knooihuizen

University of Groningen

John Benjamins Publishing Company

Amsterdam / Philadelphia 
The paper used in this publication meets the minimum requirements of the American National Standard for Information Sciences - Permanence of Paper for Printed Library Materials, ANSI z39.48-1984.

DOI 10.1075/silv.25

Cataloging-in-Publication Data available from Library of Congress: LCCN 2021010868 (PRINT) / 2021010869 (E-BOOK)

ISBN 9789027208859 (HB)

ISBN 978902725982 O (Е-ВOOK)

(C) 2021 - John Benjamins B.V.

No part of this book may be reproduced in any form, by print, photoprint, microfilm, or any other means, without written permission from the publisher.

John Benjamins Publishing Company · https://benjamins.com 


\section{Table of contents}

Introduction

Remco Knooihuizen, Nanna Haug Hilton and Hans Van de Velde

CHAPTER 1

The volatile linguistic shape of 'Town Frisian'/'Town Hollandic'

Arjen P. Versloot

CHAPTER 2

Is there an interlanguage speech acceptability deficit?

Rias van den Doel and Adriaan Walpot

CHAPTER 3

Revisiting the vowel mergers of East Anglia: Correlations of MOAN, MOWN and Goose

Kerri-Ann Butcher

CHAPTER 4

Modeling regional variation in voice onset time of Jutlandic

varieties of Danish

Rasmus Puggaard

CHAPTER 5

"Organically German"? Changing ideologies of national belonging

Janet M. Fuller

CHAPTER 6

Exploring an approach for modelling lectal coherence

Karen V. Beaman

CHAPTER 7

"I'm dead posh in school": Attitudes and linguistic behaviour

of Merseyside adolescents

Rachel Byrne

CHAPTER 8

Benim: A new pronoun in Swedish 


\section{CHAPTER 9}

Identification of clusters of lexical areas using geographical factors:

A case study in the Occitan language area

Clément Chagnaud, Guylaine Brun-Trigaud and Philippe Garat

CHAPTER 10

(Il)literacy and language change: Non-standard relative constructions

in historical Basque

Dorota Krajewska and Eneko Zuloaga

CHAPTER 11

Dialect contact in the vowel system of Mišótika Cappadocian

Nicole Vassalou, Dimitris Papazachariou and Mark Janse

CHAPTER 12

Leaders of language change: Macro and micro perspectives

Meredith Tamminga

CHAPTER 13

Ethnic variation in real time: Change in Australian English diphthongs

James Grama, Catherine E. Travis and Simon Gonzalez

Index 


\title{
Introduction
}

\author{
Remco Knooihuizen ${ }^{1}$, Nanna Haug Hilton ${ }^{1,2}$ \\ and Hans Van de Velde ${ }^{3,4}$ \\ ${ }^{1}$ Rijksuniversiteit Groningen / ${ }^{2}$ EFTA / ${ }^{3}$ Fryske Akademy / \\ ${ }^{4}$ Universiteit Utrecht
}

\section{Introduction}

Since its first edition in Barcelona in 2000, the International Conference on Language Variation in Europe (ICLaVE) has established itself as one of the prime venues for the academic study of variation and change in the languages and language varieties spoken in Europe. The conference traditionally offers theoretical and empirical research, quantitative and qualitative methods, and welcomes connections with other fields within the humanities and social sciences.

The tenth edition of ICLaVE took place from 26 to 28 June 2019 in Leeuwarden, the Netherlands. Leeuwarden (or Ljouwert) is the capital of the province of Fryslân, where Frisian is recognised as an official language in addition to Dutch. The organising institution, Fryske Akademy, is a research institute focusing on fundamental and applied scientific research into Frisian language, history, and culture, as well as on minority languages and multilingualism more generally. As such, the call for panels and papers particularly invited submissions focusing on minority, regional, and other small languages. Other research areas highlighted in the call were language technology and language variation, language variation on social media, and language variation in multilingual communities.

First, eight thematic panel sessions were selected (see below for an overview). Second, the call for papers resulted in 266 submitted abstracts, that were submitted to a peer reviewing procedure. At the conference, 101 regular papers grouped in thematic sessions, 76 papers in the eight thematic panels, and 28 poster presentations in two poster sessions were presented. The programme also included plenary invited lectures by Meredith Tamminga (Pennsylvania), Benedikt Szmrecsanyi (Leuven), Roeland van Hout (Nijmegen), and Arjen Versloot (Amsterdam).

The paper and poster presentations cover many different languages: in alphabetical order, varieties of Afrikaans, Basque, Cappadocian, Catalan, Chinese, Danish, Dutch, English, Estonian, Faroese, Finnish, Frisian, Galician, German, 
Greek, Icelandic, Italian, Karelian, Latvian, Lithuanian, Low Saxon, Luxembourgish, Northern Saami, Norwegian, Occitan, Polish, Portuguese, Russian, Slovenian, Sorbian, Spanish, Swedish, Udmurt, Welsh, Wymysorys, and Yiddish. This list represents a great diversity in terms of both family classification and sociopolitical status, much of which is even hidden by the broad language labels used in this overview. We were especially delighted to see so many lesser-spoken languages represented at the conference.

This diversity is also represented in the background of the 250 conference participants, who travelled to Leeuwarden from 34 countries. Most of them came from Europe, but there were also participants from Australia, Brazil, Canada, South Africa and the USA.

\section{Plenaries}

The plenary lecture by Meredith Tamminga, "Leaders of language change: Micro and macro perspectives" (Chapter 12 in this volume), deals with the question of who leads language change. Sociolinguistics has traditionally identified the personality traits and social situations of leaders of change, but has also found that leaders in one change are not necessarily leaders in another. Tamminga's study of covariation patterns in five vowel changes in Philadelphia English shows that these patterns are diachronically stable: the same speakers tend to be relatively innovative or conservative with multiple changes, even if the true leaders of language change are potentially group outliers. Tamminga argues that the relation between intra-speaker coherence and community-level change offers fruitful new areas of research in language variation and change.

Benedikt Szmrecsanyi's plenary lecture, "Variation squared", aimed to bridge the gap between the intra-speaker approach to variation from comparative sociolinguistics and the inter-speaker focus from quantitative dialectometry. Using data on three syntactic alternations in nine varieties of English, Szmrecsanyi presented a method which takes the quantified constraints on variation in each variety as input for a dialectometric comparison. Such work shows the stability of probabilistic grammars across varieties of English and finds a clear split between 'native' and 'non-native' varieties, but also shows little coherence across the three alternations, which suggests that probabilistic grammars in the aggregate are a collection of independent and independently constrained alternations. The work that forms the basis for this plenary lecture is published as Szmrecsanyi et al. (2019).

In his plenary, "Homo e-loquens", Roeland van Hout claimed that linguists need to address the pervasiveness of variability and changeability of language (Labov, e-language) in a fundamental way, to understand what language is and 
how language structure (Chomsky, i-language) evolves. Drawing on his work on dialectology (Franco et al. 2019), urban language variation (Van de Velde et al. 2013) and e(lectronic) language (van Halteren et al. 2018) in the Dutch language area, he explained how social behaviour unifies and structures language variation and language structure. Building on previous work (van Hout \& Muysken 2016), he argued that chance is an inherent property of human language. It means that unconscious and conscious choices are active, that language has infinite ways of expressing meaning and that many subsystems are involved. He warned that we should be careful with simple explanations of observed patterns of language variation and change and was reluctant about the possibility of predicting language change.

Finally, the plenary lecture by Arjen Versloot, "The moving target of language variation" (included in this volume as Chapter 1, "The volatile linguistic shape of 'Town Frisian' and 'Town Hollandic'), offers a historical sociolinguistic account of bilingualism in the province of Fryslân, with particular attention paid to the contact variety known as Town Frisian. Tracing back the origin of different features in this variety to particular Frisian, Dutch or Hollandic varieties is hampered by the close similarities between these varieties as well as centuries of subsequent contact and change. A feature associated with Frisian today may well stem from 16th-century Hollandic, or may have been associated with (L2) Dutch at the time when Town Frisian was formed. Versloot suggests ways to solve this puzzle for Town Frisian, and warns against back-projection of present-day data onto situations of historical contact-induced change.

\section{Panels}

ICLaVE 10 included eight thematic panel sessions organised around key discussion questions. A brief summary of each panel follows below.

Coherence: Outcome of cause of language change (organised by Karen V. Beaman, Gregory R. Guy, and Frans Hinskens) - The orderly heterogeneity of linguistic variation traditionally focuses on individual features, but how do multiple features co-vary across speakers and speech communities? This session addressed the questions of how to define coherence, how coherence patterns across different levels of the language, and how coherence in language variation relates to the actuation and propagation of linguistic change.

Review of the dialectal classifications in Europe (organised by Gotzon Aurrekoetxea and Ariane Ensunza) - The established dialect classifications in the languages of Europe are based on dialect atlases grounded in the neogrammarian paradigm. A century of developments in linguistic theory (not least the 
emergence of social dialectology) and methodology (e.g., dialectometry) opens up possibilities for a review of these classifications. Contributions to this panel reviewed dialectal classifications in individual language areas, with joint discussion of the state of the art. This panel forms the basis for a large editorial project, presenting an overview of dialect classifications in fifty languages spoken in Europe (Aurrekoetxea et al. 2020).

European minority and diaspora languages (organised by Matt Coler and Andrew Nevins) - This panel highlighted the range of linguistic variation present in minority and/or diaspora languages, either in Europe or (in the case of diaspora languages also) in European languages elsewhere. Contributions focused on phonetic, phonological, morphological and syntactic variation from both diachronic and synchronic perspectives, with attention to socio- and ethnolinguistic factors and contact phenomena. A selection of papers from this panel is included in Coler \& Nevins (forthcoming).

Dialect use online: What, when, by whom, and for what purpose? (organised by Unn Røyneland and David Britain) - Across Europe, non-standard language features are being used on social media platforms. This panel addressed the questions what social meanings are expressed by social media dialect use, and whether these reflect already existing language ideologies or linguistic vitalities of dialect usage. Contributions represented a range of different language areas - Danish, Dutch (in Flanders and Limburg), Frisian, German (in Germany and Switzerland), Greek (in Greek and Cyprus), Italian and Norwegian; there are plans to publish these separately in a special issue of the International Journal of the Sociology of Language.

Perspectives on phonemic splits in English (organised by Sandra Jansen and Natalie Braber) - The ғоот/sTRUT and тRAP/вAтH splits have resulted in salient isoglosses in England. This panel focused on the development and social evaluation of these splits (as well as similar phonemic splits or unmergers) with a variety of approaches from traditional sociolinguistic interviews to experimental and crowdsourcing methods, with the aim of furthering our understanding of splits as a phonological and sociolinguistic process.

Multilingual online practices in Russia and beyond (organised by Kapitolina Fedorova and Vlada Baranova) - Russia traditionally has a very dominant monolingual language ideology, but the internet is a less stringently policed space. This panel investigated the use and attitudes towards multilingual practices in Russian online spaces, looking both at minorities within Russia (traditional minorities such as the Udmurt, and immigrant minorities such as Kazachs and Uzbeks) and at the Russian diaspora (in Egypt, Finland, and the UK).

Enriching variationist analysis with distributional semantics methods (organised by Dirk Speelman and Benedikt Szmrecsanyi) - Quantitative analysis of linguistic variation benefits from increasingly large corpora of spontaneous language use. 
Semantic predictors of variation therefore become difficult to code for manually. This panel explored the advances in (semi)automatic methods of introducing semantics in variationist sociolinguistics, e.g. through collostructional analysis and semantic vector space modelling, from a range of theoretical perspectives.

Frequency effects in language change (organised by Marjoleine Sloos) - Effects of lexical frequency have been observed in variation and change, often with higher-frequency items changing earlier. Contributions to this panel on data from Frisian, Dutch, French, Portuguese, and English, investigated how frequency effects can inform us about the mental representation of phonological and/or morphological units, and how that information of linguistic structures can help us understand language change.

\section{Thematic sessions}

The 101 regular papers were grouped in thematic sessions. The eighteen themes, listed in alphabetical order, illustrate the diversity of topics and research methods that are covered by ICLaVE: acquisition of variation, adolescents, attitudes and social meaning, computational sociolinguistics, crowd sourcing, dialect levelling, historical change, historical sociolinguistics, ideology, language contact, lexical change, lifespan change, new methods, saliency and priming, standard language, sociophonetics, syntactic variation and urban vernaculars.

\section{This volume}

This volume contains thirteen papers from the conference. These were selected after a peer-review process from a total of twenty papers submitted to the editors for consideration. The chapters are representative of the broad range of topics and approaches that find a home at ICLaVE, and are included in this volume in order of distance of the geographical area under investigation to the conference venue in Leeuwarden. In addition to the chapters resulting from the plenary lectures by Tamminga and Versloot (see above), it contains the following papers.

Rias van den Doel and Adriaan Walpot (Chapter 2) delve deeper into the attitudes towards non-native speaker accents of English in Europe. Their survey of Dutch and French speakers of English shows that attitudes towards own-accented English tend to be more negative than those towards other-accented English. They argue that this 'acceptability deficit' occurs irrespective of level of proficiency, and that it may not be conducive to efficient communication in English as a Lingua Franca. 
The paper by Kerri-Ann Butcher (Chapter 3) revisits patterns of vowel merger and distinction in East Anglian English. The MOAN and MOWn vowels, traditionally distinct in the variety, are merging in apparent time, whereas the MOAN and GOose vowels, traditionally not clearly distinguished, are changing in opposite directions. These developments are linked to dialect contact resulting from counter-urbanisation in the area.

Rasmus Puggaard's study of voice onset time in a large corpus of traditional dialect recordings from Jutland, Denmark (Chapter 4), shows that short VOTs, which are commonly associated with the northern part of the peninsula and with /t/ only, are found across Jutland and for all fortis plosives. The regional variation described in the study may in part be attributed to dialect contact patterns, but the statistical modelling suggests multiple continua of variation.

The contribution by Janet Fuller (Chapter 5) gives an analysis of terms for ethnicity in newspaper discourses of national belonging in Germany. The term Biodeutsche( $r$ ) 'bio[logically] German', in particular, indexes an ongoing focus on ethnic descent as a prerequisite for Germanness, but simultaneously the term is often used mockingly, which undermines this traditional focus and opens the door to more inclusive discourses.

In a paper from the Coherence panel, Karen V. Beaman (Chapter 6) investigates the question of whether lectal coherence enables or inhibits linguistic change. Using phonological and morphosyntactic data from two varieties of Central Swabian German, Beaman proposes a model based on covariation, implicational scaling, and the lattice theory of mathematics. The model suggests that more coherent lects are more resistant to change.

In Rachel Byrne's study of attitudes and linguistic behaviour of adolescents in Merseyside, England (Chapter 7), she shows that speakers from the Wirral use a fronted realisation of the NURSE vowel, though not merged with SQUARE, to index their identities as being from Merseyside, but not from Liverpool. Interview data suggests that they are overtly aware of local and class associations of this feature, which they use to position themselves variably along these two dimensions.

Nathan J. Young presents an in-depth study of the first-person pronoun benim in the Swedish multi-ethnolect of Stockholm (Chapter 8). Young presents a syntactic and socio-pragmatic overview of the use of this originally Turkish loan by its predominantly male users in the Swedish hip-hop scene, and proposes an evolutionary trajectory that involves both second-language acquisition and earlier self-aggrandising pronouns in the Stockholm working-class vernacular.

A new dialectometrical method is proposed in the paper by Clément Chagnaud, Guylaine Brun-Trigaud, and Philippe Garat (Chapter 9). They use multidimensional statistical analysis of linguistic atlas data from Occitan to find clusters of 
lexical areas: sets of lexical items from the same semantic domain often pattern similarly geographically. The spatial patterns discovered in this way do not match traditional dialect boundaries, but follow watershed regions or historical administrative divisions instead.

The historical sociolinguistic circumstances of the development of the Basque relative pronoun zein 'which' are the topic of the paper by Dorota Krajewska and Eneko Zuloaga (Chapter 10). An analysis of letters and documents from the 16th to 19th centuries suggests that zein is a calque from Romance languages by highly literate bilingual writers. The pronoun became part of an emergent written register in Basque, with further changes driven by less literate and monolingual Basque speakers.

The article by Nicole Vassalou, Dimitris Papazachariou, and Mark Janse (Chapter 11) shows diachronic change in the vowel systems of two communities of Mišótika Cappadocian speakers in Northern Greece. The degree of change compared to data from the early 20th century differs between these communities as a function of the amount of dialect contact. In both communities, however, dialect contact and therefore linguistic change is led by male speakers over female speakers.

Also James Grama, Catherine E. Travis, and Simon Gonzalez (Chapter 13) offer a real-time diachronic overview of vowel changes, now in five English diphthongs by speakers of different ethnic backgrounds in Sydney, Australia. While there are few ethnic linguistic differences in Sydney today, the patterns of change do differ between groups, with especially Chinese Australians showing a different adoption of changes in progress.

References to further publications arising from work presented at ICLaVE|10 are included in the bibliography, where such publications were known to the editors at the time of going to press of this volume.

\section{Acknowledgments}

The editorial team would like to express their thanks to all authors who submitted their papers from ICLaVE|10 for inclusion in this volume, to the large number of peer reviewers whose comments invariably improved the quality of the contributions, and to the series editors for their support in preparing this volume. We also thank the Fryske Akademy for secretarial support, and Merel Lobo for her help in proofreading bibliographies and indexing. 


\section{References}

Aurrekoetxea, Gotzon, Ariane Ensunza Aldamizetxebarria, Hans Van de Velde \& Jožica Škofic (eds.). 2020. DIACLEU: Dialect classification of languages in Europe [Website]. http://diacleu. eu/ (7 January 2021).

Boer, Meike M. de \& Willemijn F. L. Heeren. 2020. Cross-linguistic filled pause realization: The acoustics of $u h$ and $u m$ in native Dutch and non-native English. Journal of the Acoustical Society of America 148(6). 3612-3622. https://doi.org/10.1121/10.0002871

Brand, Sophie \& Mirjam Ernestus. 2019. Understanding reduced words: The relevance of reduction degree and frequency of occurrence. In Sasha Calhoun, Paola Escudero, Marija Tabain \& Paul Warren (eds.), Proceedings of the 19th International Congress of Phonetic Sciences, Melbourne, Australia 2019, 91-101. Canberra: Australasian Speech Science and Technology Association Inc.

Coler, Matt \& Andrew Nevins. forthcoming. Minoritized and diaspora languages of Europe and linguistic contact. Berlin: Language Science Press.

De Smet, Isabeau \& Freek Van de Velde. 2020. A corpus-based quantitative analysis of twelve centuries of preterite and past participle morphology in Dutch. Language Variation and Change 32(2). 241-265. https://doi.org/10.1017/So954394520000101

Doreleijers, Kristel, Marjo van Koppen \& Jos Swanenberg. 2020. De dynamiek van geslachtsmarkering in de Noord-Brabantse dialecten. Taal en Tongval 72(1). https://doi.org/10.5117/TET2020.1.DORE

Franco, Karlien, Dirk Geeraerts, Dirk Speelman \& Roeland van Hout. 2019. Concept characteristics and variation in lexical diversity in two Dutch dialect areas. Cognitive Linguistics 30(1). 205-242. https://doi.org/10.1515/cog-2017-0136

Goldshtein, Yonatan \& Rasmus Puggaard. 2019. Overblik over danske dialektoptagelser. Ord \& Sag 39. 18-28.

Grondelaers, Stefan, Dirk Speelman, Chloé Lybaert \& Paul van Gent. 2020. Getting a (big) databased grip on ideological change: Evidence from Belgian Dutch. Journal of Linguistic Geography 8(1). 49-65. https://doi.org/10.1017/jlg.2020.2

Halteren, Hans van, Roeland van Hout \& Romy Roumans. 2018. Tweet geography: Tweet based mapping of dialect features in Limburg. Computational Linguistics in the Netherlands Journal 8. 138-162. https://www.clinjournal.org/clinj/article/view/84/76

Hilte, Lisa, Reinhild Vandekerckhove \& Walter Daelemans. 2020. Modeling adolescents' online writing practices: The sociolectometry of non-standard writing on social media. Zeitschrift für Dialektologie und Linguistik 87(2). 173-201. https://doi.org/10.25162/zdl-2020-0007

Hout, Roeland van \& Pieter C. Muysken. 2016. Taming chaos: Chance and variability in the language sciences. In Klaas Landsman \& Ellen van Wolde (eds.), The challenge of chance: A multidisciplinary approach from science and the humanities, 249-266. Dordrecht: Springer Verlag. https://doi.org/10.1007/978-3-319-26300-7_14

Jansen, Sandra \& Natalie Braber. 2020. FOOT-fronting and FOOT-STRUT splitting: Vowel variation in the East Midlands. English Language \& Linguistics [Online First].

https://doi.org/10.1017/S1360674320000325

Kopf, Kristin. 2021a. Genitiv- und von-Attribute. In Marek Konopka, Angelika Wöllstein \& Ekkehard Felder (eds.), Bausteine einer Korpusgrammatik des Deutschen, vol. 2(1). Heidelberg: Heidelberg University Publishing. 
Kopf, Kristin. 2021b. Stellung des adnominalen Genitivs. In Marek Konopka, Angelika Wöllstein \& Ekkehard Felder (eds.), Bausteine einer Korpusgrammatik des Deutschen, vol. 2(1). Heidelberg: Heidelberg University Publishing.

Lundquist, Björn, Ida Larsson, Maud Westendorp, Eirik Tengesdal \& Anders Nøklestad. 2019. Nordic word order database: Motivations, methods, material and infrastructure. Nordic Atlas of Language Structures (NALS) Journal 4(1). 1-33. https://doi.org/10.5617/nals.7529

Nodari, Rosalba \& Chiara Meluzzi. 2020a. Rhotic degemination in Rome Italian. Studi e Saggi Linguistici 58(2).

Nodari, Rosalba \& Chiara Meluzzi. 2020b. Spie sociolinguistiche e percezione della provenienza geografica nell' italiano di Roma. Studi Italiani di Linguistica Teorica e Applicata 49.

Orozco, Rafael \& Luz Marcela Hurtado. 2021. A variationist study of subject pronoun expression in Medellín, Colombia. Languages 6(1). 5. https://doi.org/10.3390/languages60100005

Pischlöger, Christian. forthcoming. Jangyš! Uspeh udmurtskogo jazyka v internete s 'ošibkami'. In Eva Toulouze, Elena Popova \& Nikolaj Anisimov (eds.), Sovremennaja udmurtskaja kultura. Tallinn: Tallinn University Press.

Ruutma, Mirjam. 2019. Do contact languages influence the distribution of prepositions in Estonian dialects? Nordic Journal of Linguistics 42(3). 365-384.

https://doi.org/10.1017/S033258651900009X

Schweden, Theresa. 2019. Möllers Karl, Schulten Mama und Schmidtenbuur: Soziopragmatik der Personenreferenz im Niederdeutschen synchron und diachron. Zeitschrift für Dialektologie und Linguistik 86(2). 134-154. https://doi.org/10.25162/zdl-2019-0004

Schweden, Theresa. 2020. s Kaufmanns Ingrid und de Fischer Kurt. Struktur und Soziopragmatik onymischer Genitivphrasen und Komposita im Pfälzischen. In Luise Kempf, Damaris Nübling \& Mirjam Schmuck (eds.), Linguistik der Eigennamen (Linguistik - Impulse \& Tendenzen 8), 397-424. Berlin: De Gruyter. https://doi.org/10.1515/9783110685886-016

Strelluf, Christopher. 2020. needs+PAST PARTICIPLE in regional Englishes on Twitter. World Englishes 39(1). 119-134. https://doi.org/10.1111/weng.12451

Sundgren, Eva. 2019. Individuell språklig variation och förändring: Sex informanter inspelade 1967, 1996 och 2018. Svenska landsmål och svenskt folkliv 142. 141-169.

Szmrecsanyi, Benedikt, Jason Grafmiller \& Laura Rosseel. 2019. Variation-based distance and similarity modelling: A case study in World Englishes. Frontiers in Artificial Intelligence 2. 23. https://doi.org/10.3389/frai.2019.00023

Van de Velde, Hans, Evie Tops \& Roeland van Hout. 2013. The spreading of uvular [R] in Flanders. In L. Spreafico \& A. Vietti (eds.), Rhotics: New data and perspectives, 225-248. Bolzano: Bolzano University Press.

Voeten, Cesko C. 2020. Individual differences in the adoption of sound change. Language and Speech [Online First]. https://doi.org/10.1177/0023830920959753

von Essen, María Clara. 2020. On the different ways of being a bidialectal immigrant: The case of Argentineans in Spain. Lengua y Migración/Language and Migration 12(2). 7-43.

Wittenberg, Eva \& Andreas Trotzke. forthcoming. A psycholinguistic investigation into diminutive strategies in the East Franconian Noun Phrase: Little schnitzels stay big, but little crooks become nicer. Journal of Germanic Linguistics.

Young, Nathan J. forthcoming. The sociolectal and stylistic variability of rhythm in Stockholm. Language and Speech.

Zenner, Eline, Laura Rosseel \& Dirk Speelman. 2020. Starman or Sterrenman: An acquisitional perspective on the social meaning of English in Flanders. International Journal of Bilingualism [Online First]. https://doi.org/10.1177/1367006920960816 



\title{
The volatile linguistic shape of 'Town Frisian'/'Town Hollandic'
}

\author{
Arjen P. Versloot \\ Universiteit van Amsterdam
}

Speech communities are communication communities and reflect current or historical ties within societies. Language contact is thus an expression of cultural contact. Often, when these contacts took place in the past, little is known about the sociological context, and a linguistic analysis is one of the few sources that provide us access to historical situations. Historical linguistics aims to decipher the origin and sources of the linguistic 'code': the presence or absence of borrowings in various linguistic domains have been linked to different cultural and political conditions under which the language contact took place.

Two aspects are crucial to a successful interpretation of past events: (1) that the linguistic phenomena are correctly interpreted in terms of their linguistic origin, something that turns out to not always be as evident as it may seem at first glance, and (2) that the available data are a reliable reflection of the linguistic composition of the language at the time of language contact. Given the lack of accurate and detailed historical attestations, many such analyses are based on much younger stages of the languages, assuming a relatively high stability of linguistic markers.

The interpretation of 'Town Frisian', a Dutch variety spoken in a few historical cities in the Dutch province of Fryslân since the 16th century, is a case where both these problematic aspects have insufficiently been addressed, leading to conclusions untenable after closer scrutiny. It is illustrated that the linguistic composition of the varieties was fairly dynamic, and that, on top of it, its perception by linguists and speakers was equally volatile, so that the concepts of Dutch, Frisian and Town Frisian equal 'moving targets' in terms of content and assigned identities. This article focusses on the linguistic aspects of these shifting identities.

Keywords: Frisian, Town Frisian, mixed languages, language contact, historical dialectology 


\section{Introduction}

The Dutch province of Fryslân is nowadays officially bilingual, with Dutch and Frisian as the two partners (BiZa 2014). Moreover, the Low Saxon dialects, spoken in the south-east of the province enjoy official recognition under the European Charter for Regional or Minority Languages since $1998 .{ }^{1}$ In descriptions of the traditional vernaculars of the province, which has existed in roughly its current boundaries already since the Middle Ages, another group of varieties appears, the so-called Town Frisian dialects (e.g. van der Sijs 2011: 24-25). The geographical distribution of the traditional vernaculars is shown in Figure 1. The situation in the map is an anachronism: it shows the dominant vernaculars of the local inhabitants in the first half of the 20th century and sometime before. Nowadays, L1 speakers of both the Low Saxon and the Town Frisian varieties have become minorities even in their historical core regions (Provincie Fryslân 2014). The map also hides the fact that, also in the 19th and 20th centuries, many places and many individuals were multilingual.

This being said, we will focus on the vernaculars, marked in pink on the map and included under the label 'Town Frisian'. This label is problematic for various reasons. First of all, this is not a form of Frisian, but a Dutch variety, and secondly, it is not only spoken in some of the historical cities of Fryslân, but also in rural areas: the region of Het Bildt, the island of Ameland and in some villages on the island of Terschelling/Skylge. In all these places, Frisian was the dominant vernacular in the Middle Ages and at various moments in the Early Modern Period (ca. 1500-1800), Town Frisian became the first language of the inhabitants. Despite the factual differences among them and the contrasts perceived by their speakers, all these varieties show close linguistic similarities (Van de Velde et al. 2019: 3, 4; van Bree 2001). In the publication by Van de Velde et al., these varieties have been labelled 'Frisian-Dutch contact varieties', which is in fact a much better label. Still, for reasons of brevity and tradition, we will stick to the term 'Town Frisian' (TF) and ask the reader to acknowledge its ambiguity.

The topic of this contribution concerns the relation between changing linguistic characteristics of Town Frisian and Frisian over the centuries and the way it affects our perception of the amount of input of Frisian in the total shape of Town Frisian. This paper will concentrate on the linguistic aspects and less so on the purely sociological aspects of these varieties; see Jonkman (1993) for the TF dialect of Leeuwarden and Jansen (2010) for Ameland. The label 'Frisian' is used to denote

1. https://www.coe.int/en/web/conventions/full-list/-/conventions/treaty/148/declarations? auth=adpW1NPl (consulted 25-07-2020). 


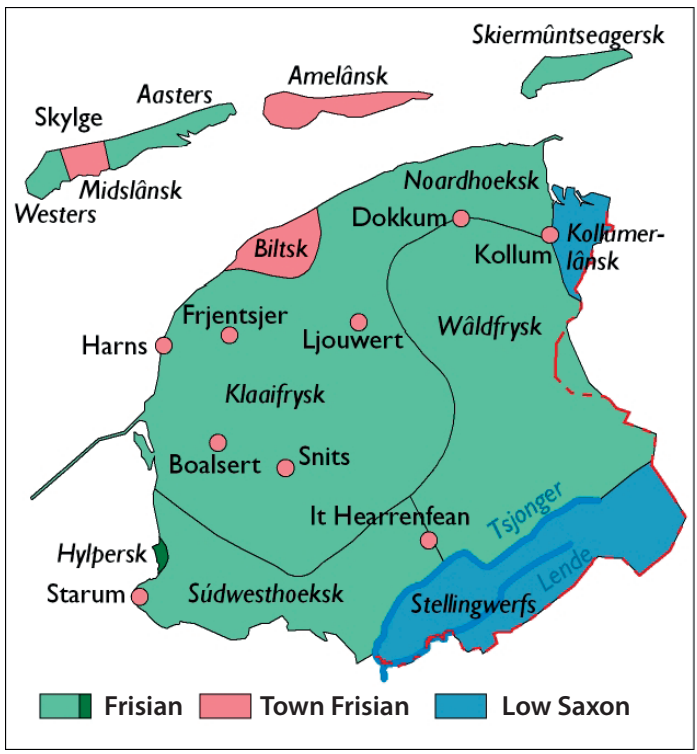

Figure 1. Map showing the traditional vernaculars in the province Fryslân (Frisian labels)

the West Frisian variety, which is only one of the contemporary Frisian varieties. ${ }^{2}$ It is worth noting that a similar instance of language shift from Frisian to Dutch has taken place in North Holland, the northernmost part of which is still called Westfriesland. A Frisian linguistic substratum in the traditional dialects of North Holland has been pointed out and studied on several occasions, more recently in van Bree (2012) en de Vaan (2017). This is even more relevant for the history of Town Frisian, because - as will be outlined below - it was in particular the Dutch variety of Holland that contributed to the non-Frisian components of Town Frisian. See Section 5 for a more detailed discussion of the consequences for the history of Town Frisian.

2. Other varieties of Frisian are spoken in Germany: in the Saterland municipality in Niedersachsen and in the Kreis ('county') of Nordfriesland in Schleswig-Holstein. These varieties differ that much from one another (Swarte, Hilton \& Gooskens 2013) that it seems more appropriate to talk about Frisian as a language sub-family within the West Germanic branch. West Frisian is the variety with the largest number of speakers today, c. 500,000, whereas the total number of speakers of all the other varieties will not exceed 5,000, mostly older people. 


\section{The linguistic character of Town Frisian}

It appears from anecdotal experiences that Town Frisian is perceived as 'Frisian' in the ears of people from outside the province; at the same time, such external Dutch-speaking observers will notice on closer inspection that they are able to understand quite a lot of it, in contrast to 'real' Frisian, which is not directly intelligible for total outsiders. ${ }^{3}$ The reason for this difference is that from a contemporaneous perspective the phonetics, the syntax and various morphological inflectional and derivational affixes of Town Frisian show strong similarities with Frisian, whereas other domains, in particular the primary vocabulary and their phonology, converge with Dutch (van Bree 2001; van Bree \& Versloot 2008). This has led to the perception of Town Frisian as some kind of mixed language. This is e.g. expressed by Heeringa (2005: 117), who states that "[...] the [TF] varieties are not clearly Frisian or Dutch. [...] These findings [based on Levenshtein distances] confirm our conclusion that Town Frisian should be considered as a mixed variety". Given the strong similarities in phonetics between Frisian and Town Frisian, such a conclusion does not come as a surprise when using Levenshtein distances as the measure.

What exactly a 'mixed language' is, varies strongly according to the theoretical frame and point of view of the observer. For non-specialists, everything that shows similarities to more than one language they are familiar with, is a 'mixture' or 'mixed language'. From that perspective, it is surely correct to call Town Frisian a mixed language (Fokkema 1960: 137). But this is not the type of definition linguists usually work with. There are various definitions from multiple scholars. A fairly general one states that mixed languages are "[...] varieties that emerged in situations of community bilingualism, and whose structures show an etymological split that is not marginal, but dominant, so that is it difficult to define the variety's linguistic parentage as involving just one ancestor language." (Bakker \& Matras 2003: 1). This etymological split is often a so-called 'grammar-lexicon split' or "a split between the INFL-language and the lexifier language of most of the potentially unbound core lexicon." (Matras 2003: 170). We will come back to this theoretical issue below.

Before delving deeper into the problematic issues of Town Frisian from a theoretical point of view, it is important to briefly sketch the common ground for every theory about its emergence. In Fryslân, including the cities and the islands,

3. There is little controlled experimental evidence for these claims. In particular Charolotte Gooskens has conducted much research in the field of mutual intelligibility of Germanic languages. However, the various studies use different methods, e.g. regarding the type of intelligibility test and the way differences between languages have been measured, in particular the consideration of non-cognates in the computation of overall Levenshtein distances between varieties. Some impressions may be gained from Gooskens \& Heeringa (2004: 80) and Gooskens (2007: 453). 
Frisian was spoken during the Middle Ages. Around 1500, a language shift took place in some of the cities: Frisian was given up as a first language and replaced by something we now call Town Frisian. Fokkema (1937), in his dissertation on Town Frisian, and van Bree (2001: 130) date the rise of Town Frisian to the early 16th century, like many others do. Sluis et al. (2016: 73), who focus on the variety of Het Bildt, are not explicit about the time of the mixture process there, but they seem to consider the 17 th and 18 th centuries in particular. Het Bildt region was reclaimed from the sea in 1504 and colonized with settlers both from Holland and Friesland. The 16th century is also estimated for Midsland on Terschelling and the western part of Ameland (van Bree 2001: 135, Jonkman \& Versloot 2016: 71-77), whereas the eastern part of Ameland switched from Frisian to TF only in the late 18th century (Schouten et al. 1785).

All views on the emergence of TF agree on the facts that:

- TF is to be classified as a dialect of Dutch, not of Frisian;

- TF shows traces of its Frisian substratum (or adstratum);

- TF shows traces of contact with particularly Hollandic Dutch dialects - after all, Holland has been the dominant province of the Low Countries since the fall of Antwerp in 1585 and had been Friesland's most powerful neighbour already before that time;

- Some traces of TF are more similar to present-day Standard Dutch than to Hollandic dialects.

Opinions strongly diverge on the question about the proportion of the Dutch, Hollandic and Frisian components and the issue, particularly raised by this author and further exemplified in this paper, of the stability of the three components between the time of the establishment of TF in the Early Modern period and its first extensive descriptions in the late 19th and early 20th centuries.

Taking their interpretation of the various proportions and linguistic sources of origin of the features of TF as a starting point, linguists have tried to reconstruct the actual nature and sociological context of the language shift, such as a reconstruction of the number and origin of non-Frisian speakers in the cities, and the relative success of the language shift in terms of potential substratum features and possibly traces of hybridization ('mixed language'). In the early 20th century, the Dutch dialectologist Kloeke (1927: 81) defined Town Frisian as 'Dutch in Frisian mouths'. Kloeke was in a way a sociolinguist avant la lettre. His interpretation primarily reflects the Dutch basis of the vocabulary in combination with a Frisian sounding pronunciation. The identification of various linguistic domains with different forms and intensities of language contact was developed in the 20th century and, among others, further developed by Van Coetsem (1988), who distinguished between recipient language agentivity, e.g. in the case of lexical borrowing, and source language 
agentivity, observable in the retention of $\mathrm{L} 1$ features of the speaker when acquiring a new L2 (imposition). The latter process includes in particular pronunciation and syntax (see also: van Bree \& Versloot 2008: 21-31, 234-235). A similar hierarchy of stable and unstable domains can be found in Thomason \& Kaufman (1991). The widespread similarities between TF and Frisian in the domains of phonetics, syntax and morphological affixes on the one hand, and the overlap in lexicon between TF and Dutch led to a more detailed interpretation of Kloeke's observation in a way that the 'Frisian' elements in TF represent the relics from a language acquisition process of Frisian speakers learning Dutch.

Dies impliziert dann auch, daß das Stadtfriesische bei seiner Entstehung als Niederländisch intendiert war und sich aus dem Niederländischen mit einem friesischen Substrat entwickelt hat. Das Stadtfriesische ist somit das Ergebnis eines an einer bestimmten Stelle abgebrochenen Zweitsprachenerwerbsprozesses, nach welchem eine Konventionalisierung stattgefunden hat, wodurch das Stadtfriesische den Status einer selbständigen Sprachvarietät erhalten hat.

(van Bree 2001: 133; emphasis by the current author) ${ }^{4}$

This idea of a new language variety, a hybrid in a way, grown from mostly Dutch lexical components and many Frisian grammatical elements, was strongly advocated by Fokkema $(1937,1960)$. Sluis et al. (2016) took this idea to identify Town Frisian, in this case the specific variety of Het Bildt, as a 'mixed language' on the basis of South Hollandic and Frisian in the light of the definition that defines a mixed language as a variety "[...] showing a split between the source language of the 'grammar' and that of the 'lexicon', with variation within the class of 'function words'” (Matras 2003: 152). Sluis et al. (2016: 75) also invoke the aspect of a deliberate identity-building aspect, using work from Thomason, in line with van Bree's interpretation of Town Frisian as a distinct, and thus potentially identity-building, linguistic variety. However, diametrically opposite to van Bree, Sluis et al. (2016: 77) claim: "Widespread Frisian-South Hollandic bilingualism, as well as immigration of speakers of Frisian, put the South Hollandic dialect spoken by the initial settlers of Het Bildt under pressure, and caused a near-complete grammatical convergence with Frisian." In their view, the lexicon reflects the substratum component and the grammar comes from 'outside', the adstratum. This is quite a novel approach and seems to go against what we know about stable and unstable domains in language

4. English translation: "This then also implies that Town Frisian was intended as Dutch when it was created and has developed from Dutch with a Frisian substrate. Town Frisian is thus the result of a second language acquisition process that was interrupted at a certain point, after which a conventionalization has taken place, assigning Town Frisian the status of an independent language variety." 
contact. ${ }^{5}$ A more extreme form of the idea of Town Frisian as a mixed language was presented by Gosses (1933) and more recently reiterated by de Haan (1992: 10-12). It states that Town Frisian was intended as Frisian, but partly relexified in order to enable communication with 'foreigners'. The large overlap of Frisian and Dutch vocabulary, which is also mostly pronounced in a 'Frisian' way (using Frisian phonotactics) can be counted as 'Frisian' under this hypothesis. In a way, it comes close to evaluation of the various linguistic domains by Sluis et al. However it may be, under both interpretations, Town Frisian (including the Bildt dialect) is considered a new language variety arisen from the confrontation of Frisian and Dutch with a grammar-lexicon split. ${ }^{6}$

It is definitely true that in the current bipolar field of Standard Dutch and (Standard) Frisian, the TF varieties are by many of their speakers felt to be different and an expression of a local or regional identity, which is e.g. shown by the existence and the aims of the cultural society Stichting Bildts Aigene in Het Bildt. ${ }^{7}$ Such a local identity is less strong in the cities, but also there, TF can be used in specific groups or circumstances to lend a given couleur local to language use (Jonkman 1993). The question is, however, whether this reflects the circumstances at the time of emergence of these varieties or that it is the consequence of much later developments.

A different view on the origin and character of TF - even acknowledging the same general facts as listed above - is advocated by Hof (1956); Jonkman (1993); de Haan et al. (2013); Versloot (2017), stressing the Hollandic component in TF and claiming that TF was not a new, hybrid variety in the 16th century but perceived as the regional expression of Dutch, within its bandwidth and thus not the outcome of an interrupted language acquisition process. The shape of TF in the 19th and 20th centuries is the result of centuries of change, not only in TF, e.g. as a consequence

5. An interesting instance of a gradual impact from outside can be found in Warchoł (2003), who describes the way a Polish urban variety of basically monolingual Polish speakers was influenced by Ukrainian through bilingual L1 Ukrainian/L2 Polish speakers from the surrounding villages. The impact can be found in various domains, such as phonetics, prosody, phonology, morphology and lexis. Despite the intense impact, the language remained fundamentally Polish and did not become grammatically Ukrainian, nor did it grow into a new 'mixed language'.

6. De Haan (1992), a generativist, advocates the primacy of grammar over lexicon. That is probably why he considers TF as a Frisian variety. He also explicitly states that massive relexification goes along with a shift in cultural or ethnic identity (p. 19). The primacy of grammar, in particular syntax, over lexicon in the identification of language can also be found in Emonds \& Faarlund (2014), who claim that English is a North Germanic language, despite its differences in lexicon, because of structural syntactic similarities that they ascribe to the period of language contact in the Danelaw in the 9th-11th centuries. Neither De Haan's nor Emonds \& Faarlund's ideas about TF and English are widely accepted.

7. https://bildtsaigene.nl/ (25 July 2020). 
of Frisian adstratum over time (compare fn. 5: Warchoł 2003), but also changes in Frisian, Hollandic and Dutch, obscuring the view on the 16th-century linguistic constellation. Bakker \& Matras (2003: 12) mention a view on 'mixed languages' where they can be the product of a gradual development. However, the dominant opinion about 'mixed languages' is that the genetically split character was part of the genesis of the variety. The rest of the article is concerned with the proper diachronic interpretation of the Dutch, Hollandic and Frisian components of TF, in particular at the moment of TF's initial establishment in the 16th century, rather than with the question whether present-day TF could be perceived as a 'mixed language' from a purely synchronic, contemporaneous point of view, potentially as the result of gradual mixing.

Two aspects are crucial to a successful interpretation of past events:

1. that the linguistic phenomena are correctly interpreted in terms of their linguistic origin, something that turns out to not be as evident as it may seem at first glance; and

2. that the available data are a reliable reflection of the linguistic composition of the language at the time of initial language contact.

The complication in the case of Dutch, Frisian and Town Frisian is that the three language varieties are genetically closely related and have been part of the same political and cultural configuration for centuries. So even without any scenario of language shift or widespread bilingualism, they are expected to share many features. This makes it a difficult task to unambiguously identify TF features as substratum, superstratum or adstratum features in a language contact scenario. In most studies on 'mixed languages', the contributing partners are quite different, sometimes even from entirely different language families as in Media Lengua, based on Spanish and Quechua (see more examples in Bakker \& Matras 2003).

The second aspect is explicitly addressed by van Bree (2001: 131), who notices that we have a reasonable knowledge about Dutch and Frisian in the 16th and 17th centuries, but that we know very little about the language of the cities, Het Bildt and Ameland in those days. It may be added that also our knowledge of spoken Hollandic varieties in the 16th century is limited. Still, van Bree assumes that Town Frisian as we know it from the earliest written records in the late 18th (Jeltema 1768) and in particular late 19th century (Winkler 1874: 461-496) was very similar to the language of the 16th century. Such an assumption is in line with a widely held interpretation that the late-19th century dialects from the earliest dialect recordings represent an archaic and hitherto fairly stable language form with roots in the late Middle Ages or Early Modern period; see Versloot (2020) for a critical discussion of this concept.

Versloot (2017: 128-130) enumerates the possible relations between Frisian and TF-varieties, which can be held responsible for unique similarities between 
them in their recent appearances. Some similarities obscure our view on the times when TF emerged in the 16th century:

1. Shared archaisms, which are no longer found in Standard Dutch;

2. Changes in TF between the 16th and the 20th centuries. Some of these changes may be the consequence of convergence with Frisian, others with Standard Dutch, but it would be wrong to back-project them to the time of the 16th century to make inferences about the socio-linguistic context in which TF emerged;

3. A variant on aspect two are shared Frisian-TF innovations not found in Standard Dutch, taking place between the 16th and the 20th centuries; some may originate in Frisian, others in Town Frisian, and for others we may not be able to pinpoint such an exclusive origin;

4. Similarities between Frisian and TF due to the convergence of Frisian with forms of Dutch which are no longer found in Standard Dutch;

The rest of this paper will be devoted to the demonstration of aspects two and four. The second aspect has been little studied, as Jeltema (1768) is generally considered to be the first text in Leeuwarden Town Frisian, which means that nothing is positively known about the linguistic features of Town Frisian from the 16th until the late 18 th century. The fourth aspect which has not been treated in so much detail either concerns the fact that also earlier forms of Frisian show rather fundamental influences from Hollandic Dutch, which accounts for many of the later FrisianTown Frisian similarities and which can mistakenly be interpreted as Frisian substratum features in Town Frisian. A special category are linguistic phenomena that differ from Standard Dutch and could be of Hollandic origin as well as Frisian and, moreover, may be due to an earlier Frisian substratum in Holland. ${ }^{8}$

A final note on the use of the term Town Frisian (apart from the earlier geographical caveat). Despite the shifting terminology applied in history, one should realize that the predecessor of present-day Town Frisian was not perceived as a distinct variety, but rather as a regionally coloured version of the common 'Low German' language of the Netherlands until c. 1750-1800 (see e.g. Wassenbergh 1802). Using the term TF for the language of the Frisian cities or Het Bildt before 1800 is therefore a terminological anachronism. Still, we will do so, to stress the continuity of those varieties (the 19th-century forms were not the result of abrupt innovations) and to have a unique label, to distinguish them from other forms of Dutch.

8. See for more details of historical linguistic facts in earlier publications: van Bree \& Versloot (2008: 219-231); de Haan, Bloemhoff \& Versloot (2013: 724-733); Versloot (2017), which is a reply to Sluis et al. (2016). 


\section{Changes in Frisian that made Town Frisian similar to Frisian}

\subsection{5th-century changes in Frisian}

In the century preceding the language shift in the cities (or at least in the capital, Leeuwarden), one can observe a massive restructuring of Frisian in the direction of Dutch, as illustrated by the maps in Figures 2 and 3. Figure 2 (left) shows that the inherited word sella 'to sell' (note the similarity with English) was replaced by a calque from Middle Dutch (MDu.) vercopen $>$ forkaepia. ${ }^{9}$

The background colour of the map shows the trend surface, which is a way to depict the gradualness of the sociolinguistic reality and is in a way also an expression of the uncertainty of the precise localizations. The six major cities of Friesland are explicitly marked in the map. They are supposed to be the origin of expansion of the innovative forms. In particular the four westernmost cities, closest to Holland, are the locus of the spread of the innovative form (always in the light colour).

The verb (for)kaepia was a regular weak verb in Old Frisian, but it was irregularized in Early Modern Frisian with a past tense and past participle koft (Versloot 2020: 420-421). The form koft is typically Hollandic (not Flemish or Brabantic) and demonstrates the specific origin of this borrowing (Figure 2, right). The core region of koft is found in the north-west, with its high density of cities. These facts support the hypothesis that changes in the language were introduced through trading contacts (note the words 'buy' and 'sell') with speakers of a Hollandic Dutch vernacular. The form koft, which is now archaic both in TF and Frisian, where it has been replaced by kocht on the basis of Standard Dutch (ge)kocht, looks like a TF-Frisian parallel from a modern perspective, but actually attests to the heavy influence of particularly the Hollandic form of Dutch already in the 15th century. ${ }^{10}$

More 15th-century Dutchisms are demonstrated in Figure 3. Figure 3 (left) illustrates the replacement of Old Frisian */i:k/ 'I' by a Hollandic form with short $i: / \mathrm{l} k /$. Forms of the pronoun 'I' in various minor Frisian dialects, such as the archaic dialect of Hindeloopen or East Frisian varieties (e.g. Wangeroog Frisian iik), indicate that the pronoun had a long /i:/ in Old Frisian: ${ }^{\star} / \mathrm{i}: \mathrm{k} /$, opposite to Dutch /ik/. Spellings with $<y, i j>$, indicating a long vowel /i:/, can be found in the 15th century in peripheral parts of Friesland, most distant from the main cities, indicating that

9. The maps presented in this section are based on an analysis of the West Frisian charters (Sipma \& Vries 1927-1977). The charters have been localized (on municipality level), using mentioned place names and, for some of them, information from the biography of the scribes. See for a full account Versloot (2008: 28-40).

10. This 'foreign' origin of koft is also acknowledged by Fokkema (1937: 174) and van Bree (2001: 135), who are proponents of the hybridization theory (van Bree has a more nuanced opinion in van Bree \& Versloot 2008). 

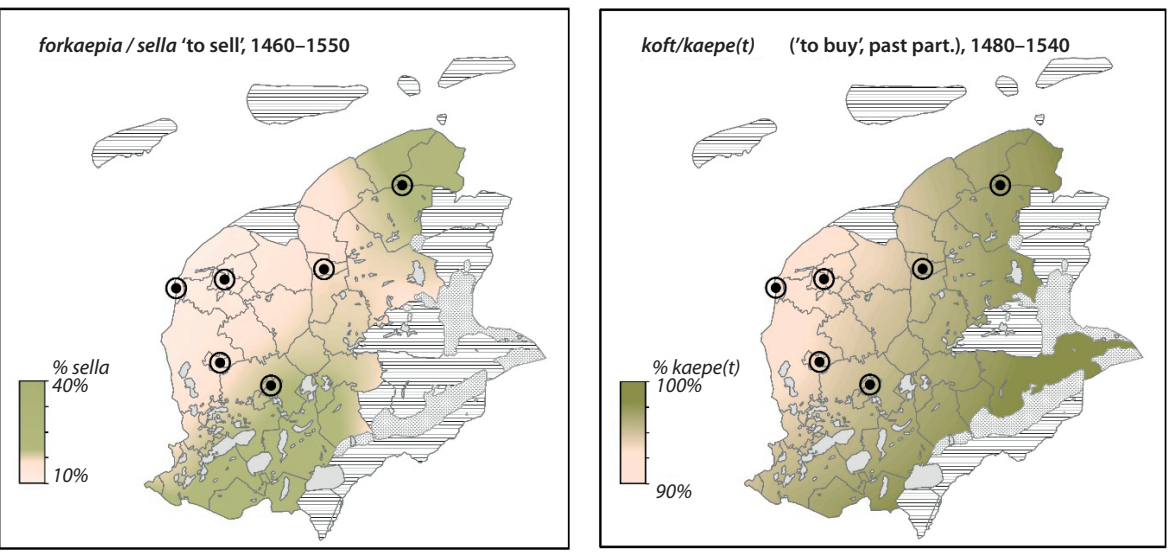

$\square$ lakes

韭 no data

peat bogs

$\odot$ main cities

Figure 2. Lexical and morphological changes in 15th-century Frisian (1)
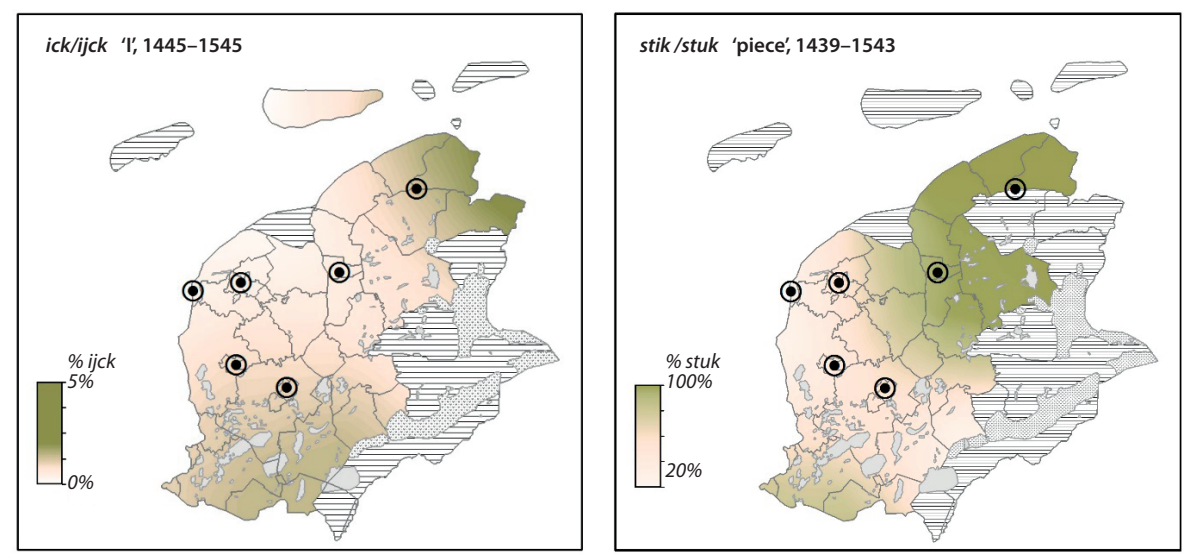

Figure 3. Lexical and morphological changes in 15 th century Frisian (2)

Frisian $i$ ik was replaced by Dutch $i k$. The low percentages of $<y, \mathrm{ij}>$ spellings even in the periphery indicate that this change may have started early in the 15 th century. Another lexical-phonological change that had its origins in the west of the province is the replacement of Old Frisian stuk ${ }^{\star}$ [stok:] 'piece' by Hollandic stik [strk]; Standard Dutch has stuk [støk] (Figure 3, right). The form stik is an exclusively Hollandism-Flemish form ${ }^{11}$ and its appearance in Friesland underlines the strong connection to Holland, independent of (early emerging) standardization tendencies in Dutch, favouring the Brabantic form stuk. 
This makes the similarities between in Frisian and TF in the following constructed sentence:

- F/TF: ik ferkoft in stikfleis

- St.Dutch: ik verkocht een stuk vlees

'I sold a piece of meat'

the mere result of Dutchification/Hollandification of Frisian, mostly in the 15th century, rather than any impact of Frisian on Town Frisian as it could be perceived from the perspective of the 20th century. ${ }^{12}$ The Modern Frisian form without language contact would be: ${ }^{*} y k$ selde in stok flêsk.

One can easily add more examples of early borrowings from Dutch, even from function words, all dated to the 15th century:

- OFri. and(e) 'and' is replaced by MDu. ende

- OFri. thet 'that' is replaced by MDu. dat

The Dutch influence not only affected the lexicon, including function words, but also the morphology. The entire plural formation of Frisian has been restructured on the basis of MDu. in the late Middle Ages. The dominant OFri. masculine ending -ar was replaced by -an, probably under the influence of $\mathrm{MDu}$. -en, already in the 13 th century (Versloot 2014). The OFri. feminine ending - $a$ was replaced by -en in the late 15th century (Versloot 2008: 159) and a new suffix - $s$ was introduced from Dutch in the same 15 th century to mark plurals of words ending in a $-2+n, m, l, r$, e.g. riuchters 'judges' in a charter from 1448 as one of the earliest examples. The result is that the dominant plural endings are -en and $-s$ in Dutch, TF and Frisian in basically the same lexical items, despite small differences. ${ }^{13}$

As a final example, one can mention the formation of diminutives in Frisian. Historically, the Frisian diminutive $-k$ suffix was morphologically transparent: it created weak-inflected nouns and did not affect the gender of the derivation (Hofmann 1961). Through contact with Dutch, Frisian adopted the suffix -ke(n) and its palatalized variant -tje(n) always with neuter gender of the derived noun and a plural in -s (de Vaan 2017: 122-126). ${ }^{14}$

12. See for fleis Versloot (2020: 419-420).

13. Modern Dutch: Audring, Jenny. (2020); Modern Frisian: Dyk, Siebren. (2020). The -s-plurals in the nouns on $-\partial+n, m, l, r$ only slowly spread to their current distribution in Frisian. Around 1600 , the $-(e) n$ appeared still in ca. $40 \%$ of such words and the absolute dominance of $-s$ was not reached before ca. 1800. There are no such figures available for Town Frisian.

14. Because Frisian also possessed a suffix in $-k$ - and had instances of palatalization of $-k->-t s-$, one cannot easily say that the Frisian system was entirely replaced by the Dutch one. But it was certainly largely reshaped by the influence from Dutch, with the consistent neuter gender of diminutive forms and the $-s$-plurals as most outstanding features. 
By the end of the 15th century, Frisian had developed many structural similarities with Hollandic Dutch, which made it virtually irrelevant (in those instances) whether speakers applied recipient language agentivity or source language agentivity when they switched to Hollandic Dutch in the 16th century. From a historical linguistic perspective, such features were Hollandic.

\subsection{Convergence of Frisian with Dutch and/or Town Frisian in the 16th to 19th centuries}

The impact of Dutch on Frisian did not stop after the establishment of a 16th-century form of Hollandic Dutch as a first language in the Frisian cities. On the contrary: together with other factors such as the Reformation, which used Dutch as its language from the very onset, this created even more opportunities for speakers of Frisian to experience Dutch influence. Although the impact of Dutch on Frisian, in particular in more recent times, is widely acknowledged (e.g. Sjölin 1976; Breuker 1993) the effect in earlier centuries is easily underestimated, and in particular the role of the Frisian cities (including Town Frisian) in this process. This was expressed by the founding father of Frisian dialectology, Jan Jelles Hof: "There is no question of directly radiating influence. In villages in the immediate vicinity of the cities [...] the local dialect is no more urban in colour than in those far away from one of these sources of contamination." (Hof 1933: 7). ${ }^{15}$ In a similar vein is an article by Fokkema (1970a). As much as Hof's observation may be true for the early 20th century, the examples in Table 1 show that many of the changes in Frisian in the Early Modern period are not simply a rapprochement of Frisian to Standard Dutch (SD), but betray typically Town Frisian subtleties, such as binne vs. SD. zijn 'are' or gjin < gien vs. SD geen 'none'.

Moreover, most of these 'typically TF' features are also found in Hollandic dialects, in particular the ones from the northern part of Holland. We can explicitly dismiss the idea that these TF/Modern West Frisian forms represent genuine Frisian forms, potentially indirectly as Frisian substratum items in Holland, because of the actually attested forms in Frisian in the early 17 th century. ${ }^{16}$ The table

15. Original text: "Van direct uitstralenden invloed is geen sprake. In dorpen in de onmiddellijke omgeving der steden is [...] het plaatselijk dialect volstrekt niet stedelijker gekleurd, dan in die, op verderen afstand van een dezer besmettingshaarden gelegen.”

16. We may compare the TF-forms to the few snippets of local Frisian attested from North Holland in the 17th century (Versloot 2018). Some forms are attested there. Compare the West Frisian forms from the early 17 th century (first column in Table 1) to the Frisian form from North Holland, if attested: sint - sinnen; ( $i k$ ) gee - > attested is a comparable form ik stee 'I stand', 17 th c. West Frisian stea,stoe, Modern West Frisian ik stean; ho - ho/hoe; het - wot,wet; joe - sie; floesk - fleysch. The last two instances represent etymologically unambiguous Dutch influence on Frisian. 
Table 1. Frisian-Town Frisian convergence in the Early Modern period

\begin{tabular}{llllll}
\hline Frisian \pm 1640 & Frisian now & TF 20th c. & Standard Dutch & Change & \\
\hline sint & binne & binne & zijn & 16th-17th & '(we) are' \\
(ik) gæ & (ik) gean & gaan & (ik) ga_ & 16th-17th & '(I) go' \\
suwd, thuwz & súd, thús & súd, thús & zuid, thuis & 17 th & 'south, home' \\
da, ho & doe, hoe & doe, hoe & toen, hoe & 18 th & 'than, how' \\
habbe & hewwe & hewwe & hebben & 18 th & 'to have' \\
het & wat & wat & wat & 18th & 'what' \\
nin & gjin & gien & geen & 18th-19th 'no(ne)' \\
jæ & sij & sij & zij & 18th-19th 'they' \\
flæsk & fleis & fleis, flees & vlees & 19th & 'flesh, meat' \\
komd & kommen & kommen & gekomen & 19th & 'come (ppt)' \\
\hline
\end{tabular}

contains various function words, grammatical forms or otherwise lexemes of high frequency and almost all of them represent instances where Standard Dutch differs from present-day TF and Frisian. The regular use of these items in a running conversation may easily evoke the impression that TF heavily leans on Frisian in terms of substratum items. A detailed historical analysis shows two things:

1. that many similarities between Town Frisian and Frisian when differing from Standard Dutch cannot be ascribed to substratum or adstratum influence of Frisian on Town Frisian;

2. that at the time of the language shift in the main cities in the 16th century, the new speakers of TF could not rely on items as in Table 1 from their earlier Frisian L1 - assuming that TF has been stable in these items since the 16th century, which we do not know for sure.

The latter point is one of the biggest issues in our reasoning about the emergence of Town Frisian in the 16th century: how dynamic was this variety and what are the consequences of this dynamics for our estimation of the Frisian contribution to Town Frisian?

\section{Changes in Town Frisian after the establishment of Dutch L1 varieties in Friesland}

Town Frisian has been known since the late 18th century in the first text presented as written in 'the language of Leeuwarden' (Jeltema 1768). Since then, we have learned more about various forms of Town Frisian, not only from Leeuwarden, but also from other cities, Het Bildt, and Ameland, through the work by Wassenbergh 
(1802); Winkler (1874) and the surveys from 1879 and 1895 issued by the Aardrijkskundig Genootschap 'Geographical Society'. What we observe over that period is first and foremost a rapprochement to Standard Dutch (e.g. Winkler 1874: 464-465, Fokkema 1970b). Versloot (2017: 133) stresses the abandonment of typically Hollandic forms. After all, since the rise of Standard Dutch in the 18th century, dialectal Hollandic forms are not expected to have had much impact on Town Frisian anymore. Such changes comprise e.g. the words for 'two' or 'meat', which were twie and fleis in earlier forms of Town Frisian, and have been replaced by twee, flees (Standard Dutch twee, vlees) in the capital Leeuwarden in the first place, whereas the Bildt and Ameland varieties are more conservative in this respect.

But what happened between 1550 and 1768 ? One of the striking phonological differences between Hollandic dialects and Town Frisian in the 'classical' descriptions from the 20th century is the realization of PGmc. $\bar{e}^{-1}$, which appears as long /a:/ in Standard Dutch and Town Frisian, but as /e.i/ or / $\varepsilon$.i/ in North Hollandic dialects or $/ \varepsilon: /$ in archaic South Hollandic dialects (Heeroma 1935). An example is found in the word for 'sheep', skiep [i.ə] in Frisian, schaap [a:] in Dutch, skaap [a:] in

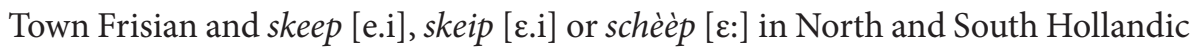
dialects. For Fokkema (1970c: 283), who ascribed the similarities between (North) Hollandic and Town Frisian to the fact that both were instances of Dutch on a local Frisian substratum, the different treatment of the PGmc. $e^{-1}$ was a clear example of the fact that Town Frisian could not have developed from North Hollandic.

However, closer scrutiny of the available historical data suggests that the differences may not have been that drastic in the Early Modern period. The North Hollandic /e.i/, with further widening of the diphthong to / $\varepsilon$.i/, seems to have developed from a more general [ $\varepsilon$ :] or [æ:], but this may well have taken place not before the 17th century (Versloot 2012: 110). On the side of Town Frisian, we get to know from Winkler $(1874: 476,480,489)$ and confirmed by some of the early surveys from the Geographical Society, that in cities like Harlingen, Franeker, Bolsward and in Het Bildt, the pronunciation [ $\varepsilon$ :] for /a:/ was still quite common in the late 19th century. While early 20th-century TF skaap is clearly distinct from North Hollandic skeep or skeip, this seems to be a fairly recent state of affairs; extrapolation of the scarce evidence we have from earlier periods suggests a common ${ }^{\star}[\varepsilon:]$ in the 16 th or 17 th centuries, being a regional realization of the Dutch phoneme /a:/.

Farmer Dirck Jansz, a native of Het Bildt, wrote personal notes in the beginning of the 17th century (Jansz. 1960) in a language that shows similarities in some points to the present-day Bildt dialect (Fokkema 1970d; see Table 2).

Table 2 also shows how close all these TF and Hollandic varieties are and how difficult it is to pinpoint the language of an early 17th-century author (see also Table 3). 
Table 2. Bildt-like spellings in Dirck Jansz.'s writings (early 17th c.)

\begin{tabular}{lllllll}
\hline $\begin{array}{l}\text { Dirck } \\
\text { Jansz. }\end{array}$ & $\begin{array}{l}\text { Mod. Bildt } \\
\text { dialect }\end{array}$ & $\begin{array}{l}\text { Modern } \\
\text { Frisian }\end{array}$ & TF- Leeuwarden & $\begin{array}{l}\text { Mod. } \\
\text { NHoll. }\end{array}$ & $\begin{array}{l}\text { Standard } \\
\text { Dutch }\end{array}$ & Gloss \\
\hline dartijen & dartyn & trettjin & dertien, dartien & dertien & dertien & '13' \\
kars & kars & kjers & kers, kars & kars & kers & 'cherry' \\
sne & snee & snie & sneeuw, snee & snei & sneeuw & 'snow' \\
heerst & hêst & hjerst & herst, harst & herrest & herfst & 'autumn' \\
\hline
\end{tabular}

Table 3. Interpretative problems in older writing from the Bildt region

\begin{tabular}{llll}
\hline DJ: & die dit soe dede & Godt soewde hem gewen, & blitschep na dit swaere Leewen \\
Bildt (B): & dy't dit soa deed, & God sou him geve, & blijens na dit sware leven \\
NHoll.: & die dit zô dee(d), & God zou hem geve, & bloiskip nei dit swere leven \\
St.Du.: & die dit zo dee $(d)$, & God zou hem geven, & blijdschap na dit zware leven \\
ModFr.: & dy't dit sa die, & God soe him jaan, & bliidskip nei dit swiere libben \\
glossing: & who this so did & God should him give & joy after this heavy life
\end{tabular}

This fragment from Dirk Jansz.'s text illustrates the difficulties in the judgment of earlier writing. In the comparison between present-day Modern Frisian and Standard Dutch, this fragment is clearly 'on the Dutch side'.

- Apart from a few peculiarities in spelling (soewde, leewen), one could claim that it is written in an early form of the emerging Dutch standard language.

- Compared to the Bildt version, it may just as well be seen as a direct ancestor of the Modern Bildt dialect, with the spelling $<\mathrm{s}>$ in word initial position, in contrast to voiced $<\mathrm{z}>$ in Dutch and most of 20th-c. North Hollandic. However, in various North Hollandic dialects, e.g. Amsterdam, Texel, Wieringen an unvoiced realisation is found as well in the 20th century (Daan 1969). <soewde> may represent ${ }^{*}$ [so.wdə], which can be read as a pre-stage for later sou [so.w]. The spellings with $<\mathrm{w}>$ in gewen, Leewen seem even more accurate, given the Modern Bildt (and Frisian) realisation with [v] or [v] in this position, opposite to Standard Dutch [v].

- The form blitschep shows nearness to Hollandic -skip, whereas the Bildt form blijens attests to Frisian influence with the Frisian suffix -ens. The relative clitic 't in Modern Bildt and Frisian is a 19th-century innovation that spread from Frisian into the Bildt dialect.

Depending on one's stance in the evaluation of earlier writing, one may claim that:

- DJ's writing offers a fairly reliable Bildt dialect of his age;

- DJ wrote some form of emerging Dutch Standard language with a few regional or personal idiosyncrasies, which may or may not be related to the spoken vernacular of his age in the Bildt region. 
The only serious analysis of Dirck Jansz.'s text was performed by Fokkema (1970d), who was particularly interested in similarities with Frisian, in line with his interpretation of TF varieties as Dutch-Frisian hybrids. A comparative analysis in the spirit of Table 3 is pending. The current author is in principle inclined to take the text at face value. That implies that differences between the language of this text and modern versions of the Bildt dialect imply changes in the spoken language between c. 1600 and 1900/2000.

One outstanding feature of Dirck Jansz.'s language has to be mentioned in this context: the unrounding of the rounded front vowels $/ \mathrm{y}(:) /, / \varnothing(:) /$ to $/ \mathrm{i}(:) /, / \mathrm{e}(:) /$. Examples are mellen (B: moln; but archaic TF meulen, mullen) 'mill', veegel (B: feugel) 'bird', bijten (B: bútten) 'outside', hijs (B: huus) 'house'. This phenomenon is known from Vlieland and Egmond, both dialect-geographically in North Holland, in the 19th and 20th centuries (Vos 2013: 34-35) but was apparently common in a much wider area in the early 17th century. If it was not for Jansz.'s text, nothing in the present-day Bildt dialect would suggest that this was once a phonological feature of the dialect.

A nearly contemporaneous source of the language of the cities may be the words marked with fris. in Kiliaan's (1599) first dictionary of the Dutch language. Fokkema (1970e, 1970f) analysed them under the assumption that the items represented some form of distorted Frisian. It seems, however, more likely to take them for Dutch from Friesland around 1600, which is the ancestor of the later Town Frisian. See van Bree \& Versloot (2008: 229-230) for examples. A full analysis of this source from the perspective of Town Frisian is also still pending.

A full analysis of all the older bits and pieces of evidence about earlier language forms in Het Bildt and the cities will reveal many items, especially in lexicon (e.g. Jansz.: aijwn 'onion' modern B: sipel) and lexical phonology (e.g. Jansz.: vroch 'early' with ${ }^{\star} / \mathrm{o} / \sim$ modern B: froech /u:/), where they differ from the languages as we know them since the late-19th and 20th centuries. One option is to ascribe all these differences to external influences, including various writing traditions, inaccuracies of the sources and their spellings and further individual idiosyncrasies. Even when these sources are not professionally conducted linguistic surveys and while we acknowledge the impact of the written language of those days and certain inaccuracies (such as potential indirect informants for Kiliaan's attestations), these sources are probably valuable pieces of information about the Dutch language in Friesland in the time around 1600. A comparison of those early sources to the later manifestations of the Town Frisian varieties demonstrates that they have experienced considerable changes between the 16th and the 19th centuries. 


\section{Dual route phenomena}

There is one more source for confusion in the evaluation of linguistic features of Town Frisian as 'Frisian' or 'Dutch' in origin and that is the potential 'dual route': etymologically Frisian elements may have entered Town Frisian, with its strong North Hollandic orientation, as Frisian substratum elements in Hollandic, rather than directly from the surrounding local Frisian vernacular. It should be born in mind that North Holland itself was a bilingual Dutch-Frisian region until the beginning of the 17th century, with Frisian as a receding variety (Versloot 2018). In fact, both explanations may be valid at the same time: Frisian speakers in the 16th century, learning some form of Hollandic, will have transferred identical items from their mother tongue into their then L2 without hesitation (Bree, van \& Versloot 2008: 216). An example of a possible dual route is given in Figure 4.

From Frisian to TF: del 'down'

Holland

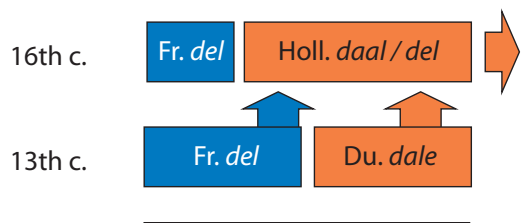

9th c.

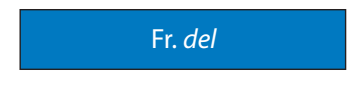

ICLAVE10 2019-06-28

Leeuwarden

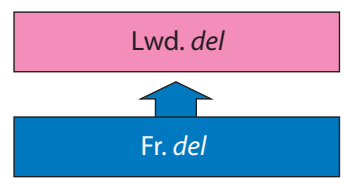

Fr. del

Figure 4. the dual route of del 'down'

One more intriguing example is the word for 'buttermilk': sûpe [supə] in Frisian, sup [syp] in Town Frisian, attested in Kiliaan as soepen *[supən]. The stem appears as an archaic word in North Hollandic as zuipe $(n)$ [zœ.ypə(n)] < 16th c. *[sy:pən], with the meaning 'buttermilk porridge'. The word can also be found with the meaning of 'buttermilk porridge' in the 17th-century East Frisian dialects of the Harlingerland - suhpe (König 1911: 47) and Wangerooge - woonsuup (Ehrentraut 1849: 405). In the Harlingerland dialect, a variant zyep ${ }^{*}[$ si:p] is attested with the meaning 'buttermilk' (König 1911: 63). Supa appears once in the mediaeval Frisian attestations in 1497 with the meaning 'buttermilk' (Sipma 1927: 300). ${ }^{17}$

17. Ende da deer vpt huus weren foergaren supa omtrent een tonna of oerhael ende oers nen dranck $v p t$ huus waes. 'And then there in the house were gathered supa about a barrel or one-and-a-half and otherwise no drink in the house was'. Supa seems to refer to a drink here, so likely 'buttermilk', rather than porridge. 
The first element of the Wangeroog word, woon, represents the archaic Frisian designation of 'buttermilk' (Århammar 1968: 54). From this complex of attestations, one can conclude that sûpe (etc.) originally designates 'buttermilk porridge' (sûpenbrij in modern West Frisian) and later shifted to the meaning 'buttermilk'. This 'new' meaning can be found in traditional dialects in Fryslân, Groningen and the northern parts of Drenthe. ${ }^{18}$ The word sûpe does not continue the Proto-Frisian word for the drink, but it developed regionally from the word for 'buttermilk porridge', with ellipsis of the first part (cf. Wangeroog woonsuup). In either meaning, the word is restricted to the wider Frisian area (from North Holland to East Friesland). The meaning 'porridge' is probably older, but the semantic innovation may have taken place sometime in the (late) Middle Ages. So, for any speaker of Frisian in the 16th century, being in contact with people from Holland about 'buttermilk', the word suppe (with Frisian [u]) or zuipe (n) with Hollandic [y], would do, although some confusion may be at stake. It is interesting that Kiliaan mentions the Frisian vowel $<\mathrm{oe}\rangle=[\mathrm{u}]$ but the Hollandic $<-\mathrm{en}>$, whereas the later Town Frisian form shows the Hollandic palatalization and without -en, but sticks to the regional meaning of 'buttermilk'.

Dual routes are also possible in other domains than the lexicon. A conspicuous example is the morpho-syntactic phenomenon of the so-called Frisian and Town Frisian gerund, a 'nominal' infinitive in - $\partial n$ vs. a 'verbal' infinitive in -ə (Versloot 2017: 124; Hoekstra 2012). This contrast has its roots in earlier West Germanic and is found in Frisian, various (mostly western) Dutch dialects, but e.g. also in Swiss German and 16th-century Low German. The details of the syntactic contexts triggering the gerund differ between varieties, but are remarkably consistent across all varieties of Frisian. In this respect, Town Frisian and North Hollandic dialects are fully on the side of Frisian. Speakers of Frisian in the 16th century, learning Hollandic, could simply transfer their L1 knowledge of this phenomenon into their new L2, Hollandic, matching at least the northern varieties of Hollandic. In North Hollandic, the exact conditioning of the gerund was probably a Frisian substratum feature. ${ }^{19}$

18. https://www.meertens.knaw.nl/kaartenbank/proxy/image/23240 (31-7-2020)

19. Middle Low German in fact had very similar patterns, which to the best of my knowledge have never been described in relation to Frisian; see Lasch $(1914: 222,224,227)$ for a very brief description. 


\section{Conclusion}

This paper has been concerned with two main questions:

1. how well can linguistic phenomena of Town Frisian varieties be correctly interpreted in terms of their linguistic origin (Sections 3 and 5)?

2. are the available data a reliable reflection of the linguistic composition of the language at the time of language contact (Section 4$)$ ?

It seems evident that the answer to question (1) heavily depends on the linguistic distance between the varieties. The close genetic relationship between Frisian and Dutch, not to mention the multiple varieties of Dutch, in combination with the continuous cohabitation and use by their speaker populations, makes the unambiguous interpretation of elements as 'Frisian', 'Dutch' and 'Hollandic' a hazardous enterprise. One thing should be sufficiently made clear and that is that taking the dialects in their 'classical' shape from 19th- and 20th-century descriptions may easily lead to incorrect interpretations.

While Section 3 was concerned with changes in Frisian over the ages, the discussion in Section 4 illustrated the fact that also Town Frisian itself may have changed considerably over time - and why should it not, when both Frisian and Dutch have changed since the 15th century. So, when we try to identify the Frisian, Hollandic or Dutch components in Town Frisian, we have to realise that our targets are both moving and shifting in character. This makes it complicated to disentangle which linguistic features of Town Frisian are actually the result of the 16th-century process of L2 acquisition and subsequent language shift. One has to distinguish carefully between the diachronic origin of features and the synchronic distribution over the different varieties.

The application of the theory of stability hierarchies of linguistic features, such as the one by van Coetsem or Thomason and Kaufman for the identification of the sociolinguistic constellation under which the language shift took place ("Frisian phonetics imply imposition from the substratum language", etc.) is inhibited by the fact that we have difficulties identifying the actual linguistic shape of the language of the 16th century. The languages come out as so volatile that a simple back-projection of 20th-century phonetic or syntactic features to the 16th century, under the assumption that they are 'stable' elements, seems a matter of overstretching the theory. Various studies of long-standing language contact show that over time language contact with a proportion of multilingual speakers (not necessarily the vast majority) can create patterns that may look like the effects of early, instant language contact. The fact that present-day Town Frisian 'sounds like' Frisian, i.e., both varieties share a lot of phonetic, phonotactic and prosodic features, does not 
necessary prove that Town Frisian sounded similarly 'Frisian' in the 16th century. It is even more likely that all three, Dutch, Town Frisian (as a regional form of Dutch) and Frisian, sounded very different from today's versions, which, however, does not exclude the possibility that 16th-century Town Frisian did indeed sound quite similar to 16th-century Frisian. It is just that we cannot infer the latter hypothesis from the 20th-century versions of the language, let alone draw conclusions from the 20th-century phonetics about the level of success, possible instances of (phonetic) hybridisation of Town Frisian in the 16th century. ${ }^{20}$ The probably unique aspect of the (Town) Frisian case is that, although the data are too scarce for an easy, fully fledged reconstruction, we have just enough information to know that a linear back-projection of the 19th- and 20th-century data leads to heavily distorted and most likely very wrong conclusions. This is in a way worrying news for historical linguists who try to make reconstructions about sometimes even pre-historical events on the basis of much younger linguistic data (see e.g. Schrijver 2014). It also poses an interesting case from which we can learn about the application of our sociolinguistic theories, such as linguistic stability hierarchies.

\section{References}

Århammar, Nils R. 1968. Die Herkunft des Inselnordfriesischen im Lichte der Wortgeographie. In Egidius G. A. Galema (ed.), Philologia Frisica anno 1966 (Fryske Akademy 319), 49-76. Grins: Wolters-Noordhoff.

Audring, Jenny. 2020. Number. Taalportaal. https://taalportaal.org/taalportaal/topic/pid/ topic-13998813298166667 (28 July 2020).

Bakker, Peter \& Yaron Matras. 2003. The study of mixed languages. In Peter Bakker \& Yaron Matras (eds.), The Mixed Language Debate. Theoretical and Empirical Advances, 1-20. Berlin: Mouton de Gruyter.

BiZa, Ministerie van Binnenlandse Zaken en Koninkrijksrelaties. 2014. Wet gebruik Friese taal. [Wet.] https://wetten.overheid.nl/BWBR0034047/2014-01-01 (25 July, 2020).

Bree, Cor van. 2001. "Stadtfriesisch" und andere nichtfriesische Dialekte der Provinz Fryslân. In Horst Haider Munske (ed.), Handbuch des Friesischen/Handbook of Frisian Studies, 129138. Tübingen: Max Niemeyer. https://doi.org/10.1515/9783110946925.129

Bree, Cor van \& Arjen Pieter Versloot. 2008. Oorsprongen van het Stadsfries. Ljouwert: Afûk. Bree, Cor van. 2012. Een Fries substraat in Noord-Holland? Oftewel: Noord- Hollandse frisismen op de methodologische pijnbank. It Beaken 74(1/2). 173-205.

20. The study by Warchoł (2003) mentioned earlier demonstrates the effect of language contact of two speaker populations with one-sided bilingualism over a longer period in basically every linguistic domain. Walker (1993) illustrates that languages spoken in one region by mostly multilingual speakers, tend to harmonize their phonemic inventories. This reflects the concept widely known as a 'Sprachbund'. 
Breuker, Pieter. 1993. Noarmaspekten fan it hjoeddeiske Frysk. Groningen: Stifting FFYRUG. Coetsem, Frans van. 1988. Loan phonology and the two transfer types in language contact. Dordrecht: Foris. https://doi.org/10.1515/9783110884869

Daan, Johanna Catharina. 1969. Dialektatlas van Noord-Holland. Antwerpen: De Sikkel.

Dyk, Siebren. 2020. Number. [Taalportaal.] https://taalportaal.org/taalportaal/topic/pid/ topic-14085316936215013. (28 July, 2020.)

Ehrentraut, Heinrich Georg. 1849. Friesisches Archiv: Eine Zeitschrift für friesische Geschichte und Sprache. Vol. I. Oldenburg: Rudolf Schwarz.

Emonds, Joseph E. \& Jan Terje Faarlund. 2014. English: The language of the Vikings. Olomouc: Palacký University. http://anglistika.upol.cz/vikings2014/

Fokkema, Klaas. 1937. Het stadsfries. Assen: Van Gorcum \& Comp., N.V.

Fokkema, Klaas. 1960. Hof en it ûntstean fan it Ljouwerters. In J. H. Brouwer, Klaes Dykstra \& M. K. Scholten (eds.), Fryske stúdzjes oanbean oan Prof. Dr. J. H. Brouwer op syn sechstichste jierdei 23 augustus 1960, 137-143. Assen.

Fokkema, Klaas. 1970a. De invloed van het Stadfries op het Fries. In Nei wider kimen. Kar út syn forsprate skriften, 292-301. Groningen: Wolters-Noordhoff.

Fokkema, Klaas. 1970b. Taalverhoudingen in Leeuwarden. In Nei wider kimen. Kar út syn forsprate skriften, 302-310. Groningen: Wolters-Noordhoff.

Fokkema, Klaas. 1970c. Het Westfries en het Stadsfries in het defensief. In Nei wider kimen. Kar út syn forsprate skriften, 280-291. Groningen: Wolters-Noordhoff.

Fokkema, Klaas. 1970d. De taal van een Bildtboer. In Nei wider kimen. Kar út syn forsprate skriften, 318-336. Groningen: Wolters-Noordhoff.

Fokkema, Klaas. 1970e. De Friese woorden bij Kiliaan. In Nei wider kimen. Kar út syn forsprate skriften, 65-83. Groningen: Wolters-Noordhoff.

Fokkema, Klaas. 1970f. De "Fries-Hollandse" woorden bij Kiliaan. In Nei wider kimen. Kar út syn forsprate skriften, 84-97. Groningen: Wolters-Noordhoff.

Gooskens, Charlotte S. \& Wilbert Heeringa. 2004. The Position of Frisian in the Germanic Language Area. In Dicky Gilbers \& Maartje Schreuder (eds.), On the boundaries of phonology and phonetics, 61-87. Groningen: University of Groningen.

Gooskens, Charlotte S. 2007. The contribution of linguistic factors to the intelligibility of closely related languages. Journal of Multilingual and Multicultural Development 28(6). 445-467. https://doi.org/10.2167/jmmd511.0

Gosses, G. 1933. Yetris it Stedsk. It Heitlân 11. 270-274 \& 303-308.

Haan, Germen J. de. 1992. Meertaligheid in Friesland. Dordrecht: ICG-Printing.

Haan, Germen J. de, Henk Bloemhoff \& Arjen Pieter Versloot. 2013. Language varieties in the province of Fryslân. In Frans Hinskens \& Johan Taeldeman (eds.), Language and Space / Dutch: An International Handbook on Linguistic Variation, 721-738. Berlin: De Gruyter Mouton.

Heeringa, Wilbert. 2005. Dialect variation in and around Frisia: classification and relationships. Us Wurk, tydskrift foar Frisistyk 3-4. 85-127.

Heeroma, Klaas. 1935. Hollandse dialektstudies: bijdrage tot de ontwikkelingsgeschiedenis van het algemeen beschaafd Nederlands. Groningen \& Batavia: J. B. Wolters.

Hoekstra, Eric. 2012. Fries substraat in de syntaxis van het West-Fries: oorsprong en implicatie van het onderscheid tussen infinitief en gerundium en hun syntactische distributie. It Beaken 74. 151-172.

Hof, Jan Jelles. 1956. Dit en dat oer it stedsk. Grins: Frysk Ynstitút oan de R.U. to Grins.

Hof, Jan Jelles. 1933. Friesche Dialectgeographie. Den Haag: Nijhoff. 
Hofmann, Dietrich. 1961. Die k-Diminutiva im nordfriesischen und in verwandten Sprachen. (Niederdeutsche Studien 7). Köln \& Graz: Böhlau Verlag.

Jansen, Mathilde. 2010. Language change on the Dutch Frisian island of Ameland: Linguistic and sociolinguistic findings. Utrecht: LOT. http://www.lotpublications.nl/publish/articles/003913/ bookpart.pdf

Jansz, Dirck \& Pieter Gerbenzon (ed.). 1960. Het aantekeningenboek van Dirck Jansz. Grins: Frysk Ynstitút oan de R.U. to Grins.

Jeltema, Anne. 1768. Het vermaak der slagterij, of Geschiedkundig verhaal van de hedendaagsche handelwijze, by zommige Friesche stedelingen gebruikelijk, aangaande het koopen en verzorgen van hun slagtvee, ...: Alles vervat in eenen boertigen brief van den 19 november 1768 , geschreven in eenen platte Leeuwarder taal. Leeuwarden: A. Jeltema.

Jonkman, Reitze J. 1993. It Leewarders: In taalsosjologysk ûndersyk nei it Stedsk yn ferhâlding ta it Nederlânsk en it Frysk yn Ljouwert. Ljouwert/Leeuwarden: Fryske Akademy.

Jonkman, Reitze J. \& Arjen Pieter Versloot. 2016. Fryslân, lân fan talen: In skiedenis. Leeuwarden: Afûk.

Kiliaan, Cornelis. 1599. Etymologicum Teutonicae linguae, sive: Dictionarium Teutonico-Latinum. Antwerpen: Plantijn.

Kloeke, G. G. 1927. De hollandsche expansie in de zestiende en zeventiende eeuw en haar weerspiegeling in de hedendaagsche nederlandsche dialecten; proeve eener historisch-dialect-geographische synthese, S-Gravenhage: M. Nijhoff.

König, Erich. 1911. Johannes Cadovius Müllers Memoriale linguae frisicae, nach der jeverschen Originalhandschrift. Norden; Leipzig: D. Soltau. https://archive.org/details/memoriale linguae00mlle

Lasch, Agathe. 1914. Mittelniederdeutsche Grammatik. Halle a/d S.: Max Niemeyer.

Matras, Yaron. 2003. Mixed languages: Re-examining the structural prototype. In Peter Bakker \& Yaron Matras (eds.), The Mixed Language Debate. Theoretical and Empirical Advances, 151-176. Berlin: Mouton de Gruyter. https://doi.org/10.1515/9783110197242.151

Provincie Fryslân. 2014. Streektalenatlas: Streektalen in beeld. Leeuwarden.

Schouten, P., J. de Groot, G. Warnars, S. Luchtmans, J. Luchtmans, A. Blusse \& P. Blusse. 1785. Tegenwoordige Staat der Vereenigde Nederlanden; dertiende deel; vervattende eenen aanvang der beschryving van Friesland. Amsterdam [...]: Tirion.

Schrijver, Peter. 2014. Language contact and the origins of the Germanic languages (Routledge Studies in Linguistics 13). New York: Taylor and Francis. https://www.pdf-archive.com/2016/04/03/ peter-schrijver-the-origins-of-the-germanic-languages/peter-schrijver-the-origins-of-thegermanic-languages.pdf

Sijs, Nicoline van der (ed.). 2011. Dialectatlas van het Nederlands. Amsterdam: Bert Bakker.

Sipma, Pieter. 1927. Oudfriesche Oorkonden (Oudfriese Taal- en Rechtsbronnen 1-4). Den Haag: M. Nijhoff.

Sipma, Pieter \& Oebele Vries. 1927-1977. Oudfriesche Oorkonden (Oudfriese Taal- en Rechtsbronnen 1-4). Den Haag: M. Nijhoff.

Sjölin, Bo. 1976. "Min Frysk" : een onderzoek naar het ontstaan van transfer en "code-switching in gesproken Fries. Grins: Frysk Ynstitut oan de Ryksuniversiteit.

Sluis, Paulus van, Eric Hoekstra \& Hans Van de Velde. 2016. Bildts as a mixed language. International Journal of the Sociology of Language 242. 59-80.

Swarte, Femke, Nanna Haug Hilton \& Charlotte Gooskens. 2013. Onderlinge verstaanbaarheid tussen Noord- en Westerlauwers Fries. Us Wurk 62(1-2). 21-46. 
Thomason, Sarah Grey \& Terrence Kaufman. 1991. Language contact, creolization, and genetic linguistics. Berkeley: University of California Press.

Vaan, Michiel de. 2017. The dawn of Dutch: Language contact in the Western Low Countries before 1200. Amsterdam: Benjamins. https://doi.org/10.1075/nss.30

Van de Velde, Hans, Duijff, Pieter, Siebren Dyk, Wilbert Heeringa \& Eric Hoekstra. 2019. FriesNederlandse contactvariëteiten in Fryslân: Rapport voor de Nederlandse Taalunie. Ljouwert/ Leeuwarden: Fryske Akademy.

Versloot, Arjen Pieter. 2008. Mechanisms of language change: vowel reduction in 15th century West Frisian. Utrecht: LOT. http://www.lotpublications.nl/mechanisms-of-language-changemechanisms-of-language-change-vowel-reduction-in-15th-century-west-frisian

Versloot, Arjen Pieter. 2012. Westgermaans ${ }^{\star} \mathrm{e} 1$ in het Noord-Hollands: Een Ingweoonse mythe? It Beaken 74(1/2). 100-121.

Versloot, Arjen Pieter. 2014. Die -ar-Plurale im Altwestfriesischen mit einem Exkurs über die sächlichen Plurale im Westfriesischen. Us Wurk 63. 93-114.

Versloot, Arjen Pieter. 2017. On the nature of mixed languages: The case of Bildts. International Journal of the Sociology of Language 248. 113-136. https://doi.org/10.1515/ijsl-2017-0033

Versloot, Arjen Pieter. 2018. Frysk út Noard-Hollân út de 17e iuw? Us Wurk 67. 1-37.

Versloot, Arjen Pieter. 2020. Historical dialectology: West Frisian in seven centuries. In Brunn Stanley \& Roland Kehrein (eds.), Handbook of the changing world language map, 405-422. Springer. https://www.springer.com/us/book/9783030024376.

https://doi.org/10.1007/978-3-030-02438-3_147

Vos, Stephan de. 2013. Woordenboek van de Derper taal. Egmond aan Zee: Vereniging Dorpsbelangen Egmond.

Walker, Alastair. 1993. Hü maning spräke jeeft et eentlik önj Fraschlönj - ån unti fiiw? Tydskrift foar Fryske Taalkunde (1-2). 138-143.

Warchol, Stefan. 2003. Sur la soi-disant interférence "indirecte" dans les patois de la région frontalière polono-ukrainienne. In Abstracts of Scholarly Papers, 13-31. Riga: Latvian language institute, University of Latvia.

Wassenbergh, Everwijn. 1802. Taalkundige bydragen tot den frieschen tongval. D.v.d. Sluis.

Winkler, Johann. 1874. Algemeen Nederduitsch en Friesch Dialecticon. Vol. 1. Den Haag: Martinus Nijhoff. http://www.dbnl.org/tekst/wink007alge01_01/.

https://doi.org/10.1007/978-94-011-8823-4 


\title{
Is there an interlanguage speech acceptability deficit?
}

\author{
Rias van den Doel and Adriaan Walpot \\ Universiteit Utrecht
}

\begin{abstract}
It may be assumed that non-native speakers (NNSs) of English are more accommodating towards other NNS accents, as a result of increased solidarity, intelligibility, or both. Emerging evidence suggests, however, that this is not true of all groups of NNSs, especially when judging those sharing the same L1. In an online survey we conducted among 67 Dutch and 45 French NNSs of English, we found that both groups of judges evaluated the speakers whose L1 they shared more negatively than any other accents. This does not only build on previous findings, but also suggests that communication among NNSs, instead of benefiting from an "intelligibility benefit", may be affected by what we have termed an "acceptability deficit".
\end{abstract}

Keywords: non-native Englishes, lingua franca English, attitudes, identification, intelligibility, acceptability

\section{Introduction}

As the most widely used non-native language in Europe (European Commission 2012), English has interacted with all European languages. While scholars disagree whether the ensuing contact phenomena have led to the emergence of fully-fledged varieties of European English, or even a single one (e.g. Van den Doel \& Quené 2013), different European countries show a great deal of public awareness of language mixing and hybridisation involving Englishes (Schneider 2016). This is clearly evident from the proliferation of lay terms denoting hybrid Englishes (McArthur 1995), which can be used pejoratively, humorously, and sometimes even affectionately (Lambert 2018: 9). The term "Dunglish", for instance, is frequently used by Dutch speakers of English ridiculing the 'broken' English spoken by those who share their L1 (cf. Edwards 2016: 99, 184). It is connected to a long-standing tradition in the Netherlands of producing deliberately inept direct translations 
from Dutch into English (O'Mill 1956, and Kousbroek 1984). Such satirical texts appear to be primarily intended to warn other speakers of Dutch off the use of any "Dunglish" usage - although their more recent incarnations as Internet memes tend to be more tongue-in-cheek (Make that the cat wise 2019). This delegitimisation of local English often goes hand in hand with concerns about the accented or ungrammatical English spoken by well-known public figures (e.g. football coaches or politicians; Dutch News 2014).

The negative attitudes to the accented English of other Dutch speakers may have a corollary in the widely reported tendency, on the part of Dutch students, to be particularly critical of their Dutch lecturers' accents in English (Wilkinson 2013: 20). For instance, Hendriks et al. (2018) found that Dutch students were more negative about their lecturers' local accents than was true of their German counterparts. This agrees with earlier findings that Dutch respondents outperformed other groups when finding fault with the accents of people whose L1 they share (Van den Doel \& Quené 2013). Such attitudes could well be particular to the Low Countries, where social pressure to have high proficiency in English may have increased anxiety about less prestigious local accents. They could also be indicative of a larger pattern of groups of non-native speakers (NNSs) refusing to show solidarity or appreciation for the English produced by anyone with the same L1.

The tendency to downgrade any non-native English (NNE) accent in favour of those produced by native speakers (NSs) has been widely attested (Tatsioka, Seidlhofer, Sifakis \& Ferguson 2018). This has been attributed to a pervasive form of self-effacing "native-speakerism" internalised by NNSs within the context of English-language teaching (Holliday 2005; Jenkins 2007). It may be suggested that such "native-speakerism" is the L2 equivalent of Standard Language Ideology (as described in Milroy 2006), as a result of which NNS reject all language variation except for one single standard variety of NS English. However, it is unclear whether NNSs believed to be affected by this condition do indeed reject all variation in NS English (e.g. between British and American English) or whether they are strongly exercised by NNS varieties other than those associated with their fellow L1 speakers.

It should be noted that most studies showing a clear NNS preference for NS varieties over NNS ones were conducted within a teaching context (e.g. Dalton-Puffer et al. 1997; Butler 2007, and McKenzie 2008). Typically, they offer respondents the choice between several NS accents on the one hand, and one or more exemplars of the local NNE accent on the other - rather than a range of other NNE accents. This raises the question of whether the more negative evaluation of local accents is entirely based on their non-nativeness, rather than on the recognition of a shared L1. The latter would become apparent if respondents single out the accents of fellow L1 users - rather than those of any other NNSs - for criticism. Arguably, the range of NNE accents evaluated in such studies should not be limited to local accents, and 
respondents should be asked explicitly to identify the latter. Given the considerable difficulties NNS respondents have in identifying non-native accents (see Hendriks et al. 2016: 8), it would also be important to incorporate NNSs' ability to recognise shared L1 accents into the design, something that previous work has largely ignored (for an exception, see Kristiansen et al. (2018)).

If it can be shown that particular groups of NNSs tend to downgrade accents in an L2 if they recognise the speakers as sharing their L1, this would be interesting for several reasons. Practically speaking, it would suggest that language users from those groups would benefit from pronunciation training when communicating with other users of the L1 in a different language such as English - for instance in an international classroom where English-medium instruction is used with both local and international students (cf. Hendriks et al. 2018). Such training could help those using English in a high-stakes context, such as a university lecture, to modify those features of their pronunciation which evoke strong reactions in fellow L1 users.

On a more abstract level, however, it raises questions about in-group attitudes. It has, for instance, been demonstrated that people who share an L1 may take advantage of a "matched interlanguage speech intelligibility benefit" (Wang \& Van Heuven 2015), as a result of which they find it easier to understand an L2 speaker whose L1 is the same as the listener's. It would be remarkable if, despite increased intelligibility, listeners still downgrade the accents they find easier to understand. This would imply that speakers are less concerned with practical considerations of communicative expediency, and more with negative attitudinal evaluations of the in-group. If this effect exists, it may be termed the "matched interlanguage speech acceptability deficit". Such a deficit may be characteristic of Dutch users of English, but perhaps of other groups of NNSs as well. If this is actually attested in different groups of NNSs, it would also present a challenge to the widely held assumption of mutual NNS solidarity - a mainstay of research into English as a lingua franca (Kappa 2016).

If, on the basis of social identity theory (Tajfel \& Turner 1979), it is claimed that groups "strive to maintain and enhance a positive social identity" (Vignoles \& Moncaster 2007), this would suggest some form of favouritism towards other in-group members. This would motivate NNS judges to be less critical of fellow L1 speakers' accents than of other NNSs - an effect that was indeed found for the Polish listeners in Van den Doel \& Quené (2013), but not for the Dutch judges. If the latter engaged in some form of in-group derogation, this would raise interesting questions. Vignoles \& Moncaster (2007: 107) suggest that in-group derogation may be an "identity position" in itself, allowing "national disidentifiers" to signal their allegiance to a more "liberal and internationalist culture". A recent small-scale survey of attitudes to Dutch English suggested that some Dutch students actually subscribed to this position (Walpot 2018: 35). Interestingly, it has even been 
suggested that local criticism of politicians' Dutch-accented English is prompted by what is perceived to be a Dutch propensity towards self-loathing (Engel 2014).

However, in-group derogation may also be a consequence of the "black-sheep effect" (Schmader \& Lickel 2006: 265). This suggests that in-group members act on feelings of vicarious embarrassment motivated by the actions of a group member whose undesirable behaviour is seen as a reflection on the group. In this instance, the undesirable behaviour would be the inability, or unwillingness, to use a less local and therefore more prestigious or educated-sounding variety of English. Seen from this perspective, Dutch students may well evaluate their Dutch lecturers's strong accents in English negatively because they feel these fall short of their prescriptivist notions of what would be an acceptable model or standard - or because these compromise their fond beliefs about the general level of English in higher education in the Netherlands. Such students' views were in fact attested in Walpot (2018: 37).

If the "black sheep effect" is invoked to explain students' more severe judgements of their lecturers' accents, this would presuppose that students see the latter as part of their in-group, for whose failure to use what they consider to be appropriate English they feel partly responsible. However, given the generational divide in the Netherlands as regards proficiency in English (Edwards 2014), it may well be that there is little solidarity between the generations, and that students see lecturers as part of an out-group. While the studies conducted by Hendriks et. al (2016, 2018) provide invaluable information about Dutch attitudes to matched L1 accents in an academic context, it would nonetheless be useful to extend the scope of these attitudinal studies to non-educational contexts, where participants might be less directly affected by considerations of intergenerational solidarity.

In order to corroborate earlier findings suggesting a possible matched interlanguage speech acceptability deficit (e.g. Van den Doel \& Quené 2013; Hendriks et al. 2018), it would be useful to investigate local attitudes to Dutch-accented English outside a teaching context, and to compare these with the same respondents' attitudes to other NNE accents. This would reveal any discrepancies between the Dutch listeners' judgements of matched and non-matched NNE accents. To determine if any increased severity towards matched accents is also attested in other NNS judges, it would be crucial to introduce a second set of judges, with a different L1, who are also presented with matched and non-matched NNE accents. Such NNS judges should preferably be drawn from a country with a different linguistic ecology, such as France, where different attitudes to English, and to the level of proficiency expected of educated citizens, prevail. If in both countries, NNS judges disprefer the local accent more than any other NNS accent, it seems unlikely they would be motivated primarily by some form of native-speakerism or standard language ideology.

It is often anecdotally reported that fluency in English is much less common in France than in the Netherlands. For instance, according to the EF English Proficiency 
Index, English proficiency in the Netherlands is the highest in the world, with the French trailing in 33rd place (Education First 2019). Similarly, the Eurobarometer (European Commission 2012) shows that $90 \%$ of Dutch people are sufficiently confident about their ability to have a conversation in English, as opposed to a mere 39\% in France. Such figures only have limited relevance - after all, the EF English Proficiency Index is only a test of receptive skills, and the Eurobarometer data represent self-assessment of one particular competence only. However, for want of anything better, they can be used to illustrate different perceptions, in France and the Netherlands, of the level of proficiency commonly achieved in English.

There are also reported to be striking differences in attitudes to English. In France, unlike the Netherlands, there has been considerable opposition to the encroachment of English into domains traditionally reserved for French - at least on an official level. According to Walsh (2015: 51), "ordinary" speakers of French actually tend to be quite positive about English; living in a French-speaking environment, they do not feel threatened by English in the way French intellectuals and policy-makers do. Nonetheless, public discourse appears to be preoccupied with resistance to the perceived hegemony of English in France and elsewhere (cf. Le Lièvre 2008: 54-76). Apart from criticism about politicians' English (e.g. Gensane 2017), there seems to be little interest in denouncing unacceptable levels of L1 influence on the English spoken by French citizens. In fact, the most common hybrid term for mixing English and French is "franglais" - which tends to refer to English-influenced French rather than French-accented English. There are terms such as "Frenglish" and "Franglish", but, unlike in the Netherlands, these do not appear to have been enlisted in any sustained efforts to satirise and delegitimise 'broken English' as spoken in France. Reportedly, there is even a tendency for educated French people to deliberately avoid using anything approximating NS-like English. While this has been attributed to "inverted snobbery" (Poirier 2013: para. 15), it can also be viewed as an "act of defiance" or simply as a "statement of national, linguistic or cultural identity" designed to emphasise in-group solidarity (Alice Henderson, personal communication, September 08, 2019). If such behaviour also occurs in the Netherlands, it has so far eluded any scholarly attention.

If any "matched interlanguage speech acceptability deficit" also affects speakers of French, this would imply that this effect is not a uniquely Dutch phenomenon, but also takes place in ostensibly different linguistic ecologies, where disparate expectations about socially approved levels of English prevail. It is only once these effects have been established that it would be expedient to investigate whether the various possible motivations for downgrading local accents are equally prominent in these different ecologies. Additional research could, for instance, examine the extent to which feelings of vicarious embarrassment and solidarity are interconnected with perceptions of in-group membership. 
In this study, then, our main objective is to seek empirical confirmation of previous suggestions that NNS judges tend to evaluate local accents negatively if they share the L1. Our assumption is that this should be explored in a comparison involving participants from different linguistic ecologies, such as France and the Netherlands. This would allow us to determine if any matched interlanguage speech acceptability deficit occurs in more than one isolated context, and if so, whether this affects judges from different countries to the same extent.

\section{Method}

If we use a survey to investigate the possible occurrence of any acceptability deficit when judges with different languacultural backgrounds (Agar 1995) are exposed to speakers with the same L1, it would be advisable to factor in the considerations discussed in Section 1. Firstly, all participants should be presented with a representative range of NNE accents - not limited to speakers with the same non-native language. In addition, these accent samples should be presented without explicit reference to educational contexts, or feature recordings of lectures or other educational sessions, to avoid participants being affected disproportionately by any perceived power differential or intergenerational biases. Respondents should be NNSs of English drawn from the Netherlands and from a country with a different linguistic ecology, such as France. Furthermore, given the importance attached to these respondents' ability to identify NNE accents other than their own, an advanced level of language proficiency and familiarity with variation in English would have to be assumed - competences which are typically associated with Continental Europeans with an academic background in English studies. And since we are interested in acceptability judgements rather than in perceptions of intelligibility as investigated in Wang and Van Heuven (2015), participants should be asked to evaluate these accents on the basis of social status and attractiveness, using attitudinal constructs commonly employed in verbal guise studies of this kind (Garrett 2010: 60-69). Since, in our survey, NNS participants are already asked to identify and evaluate a range of NNE accents, we felt that such constructs should be limited in number, in order not to discourage respondents by overly complex and labour-intensive tasks. It was considered, perhaps somewhat controversially, that a combination of constructs such as "authority", "pleasantness" and "intelligence" would be adequate to provide some insight into perceptions of power, status, competence and solidarity within an L2 context (cf. Garrett 2010: 63, 66). Since previous studies have not consistently employed the same constructs to test these perceived traits (which show considerable overlap in any event), we selected "authority" to reflect both power 
and status, "pleasantness" as a marker primarily of solidarity, and "intelligence" as an indication of both status and competence.

In keeping with our requirements, we decided to employ the format of an open-web questionnaire, featuring a judicious selection of NNE accents to be identified and evaluated on attitudinal constructs by academically trained students of English from France and the Netherlands. This was created, piloted and subsequently made available from a designated Utrecht University survey site, from October to November 2016. A copy may be found at https://survey2.hum. uu.nl/976217/. The URL of this freely accessible online survey was included in an email cover letter to the researchers' relevant academic networks in the Netherlands and France, asking them to take part in the survey and/or forward the email to others with the same background. Admittedly, this kind of snowball sampling makes it difficult to ensure that all participants had a background in academic English. However, it was considered that only those who were sufficiently confident about their language proficiency and ability to recognise variation in English would decide to participate. Regardless of self-reported levels of proficiency or academic background in English, this is something that all participants were expected to have in common.

\subsection{Materials}

Given our requirements, it was decided to present respondents not only with recordings of Dutch-accented and French-accented English, but also to include several other representative European accents in English. German, Italian, Spanish and Swedish were selected as additional English accents likely to be recognised by our respondents as different from their local accents, although the same may possibly be said of many other European accents. For each of these six accents, two audio recordings of different speakers were included, where possible one male and one female voice (but see below).

To arrive at a judicious selection, 38 speech samples were retrieved from the Speech Accent Archive (Weinberger 2015). This archive is widely used in research of this type because all speakers read the same passage called "Please Call Stella", in which most of the consonants, vowels, and clusters of English are incorporated. An additional reason why these samples are frequently used in online surveys is that their length is adequate to allow for identification and evaluation by lay judges (as in Van den Doel \& Quené 2013) without placing a disproportionate burden on their time and attention. Subsequently, the 38 speech samples were reviewed by language teaching experts at a university-affiliated language institute in the Netherlands. The judges were instructed to select only samples that were slightly accented and 
therefore comparable in accent strength. From a total of 20 samples which met these criteria, 12 were chosen, featuring a male and female speaker of each language. In the case of French, however, two female speakers were selected, since none of the male speakers met the judges' other criteria.

\subsection{Structure and design of the survey}

In the introduction to the survey, participants were debriefed, information was gathered about age, sex, nationality, and level of education, and assurances were provided about any privacy and confidentiality concerns participants would have. It was made clear that the survey was set up in such a way that no identifying information (name, e-mail address, IP address) could be traced. Subsequently, respondents could access the main body of the survey, in which they were asked to identify and evaluate a selection of accents. The identification and evaluation of the accents formed the main body of the survey (see Figure 1). For each accent sample, the relevant audio file retrieved from the Speech Accent Archive (Weinberger 2015), was provided as a high-quality audio stimulus (.mp3 file at $44.1 \mathrm{KHz} ., 16$-bit mono) on a separate web page and presented in random order.

Participants' ability to identify European NNE accents was measured by testing whether they answered the open question What is the speaker's first language? correctly. Because respondents were not given any preselected choices, they could supply the name of any language they considered to be correct. Subsequently, listeners' attitudes towards the accents were measured by asking them to what extent they agreed or disagreed, on a 5-point Likert scale, with two positively worded statements ("The speaker has authority"; "The speaker is pleasant to listen to") and one negatively worded statement ("The speaker sounds unintelligent") - as can be seen in Figure 1. The latter statement had been phrased negatively in order to keep participants focused. In an open comment box, participants were asked to provide extra information about the accent in question. It was hoped that this would help researchers to contextualise the responses provided. The main part of the survey was followed by a check-out page, which provided respondents with an email address, for further questions or comments.

\subsection{Participants and procedure}

In total, 112 participants took part in the survey, all of whom were either Dutch or French nationals, and were assumed to have native command of either Dutch or French. There were 67 Dutch participants (92.6\% aged 18-25; 67.2\% female) and 45 French participants ( $82.2 \%$ aged $18-25 ; 73.3 \%$ female). Because only age ranges were elicited, participants' mean age cannot be provided. 


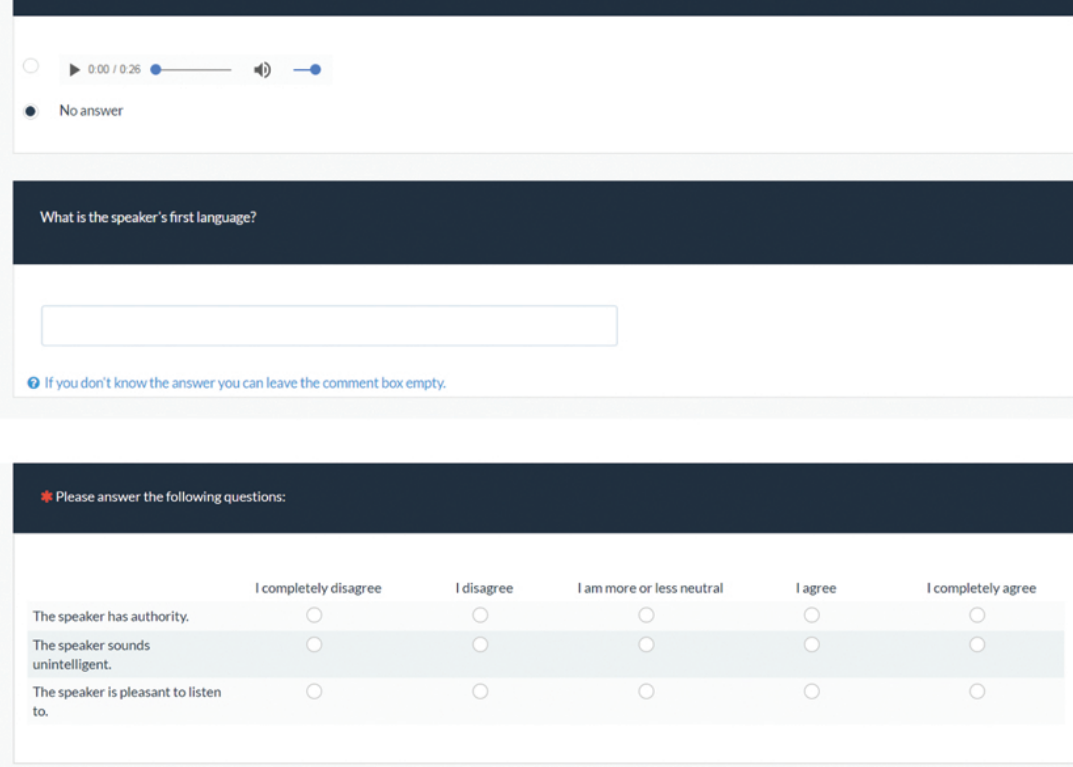

If you want to, you can use this comment box to provide extra information about why you like/dislike this particular accent:

Figure 1. Sample page of the main body of the survey

All submissions were entered into SPSS 26.0 and subjected to statistical analysis, whilst ensuring that submissions for the one negatively worded personality trait ("unintelligent") were recoded to agree with the scales used for the positively worded traits. A mixed-effects logistic regression model was used to analyse whether listeners' nationality (whether Dutch or French) affected participants' ability to identify speakers' L1, both in a general sense, and in a matched context. Subsequently, a mixed-effects linear regression model was used to investigate the effect of these two independent variables, together with the addition of a third variable (correct speaker identification) on participants' perceptions of the speakers' pleasantness, intelligence, and authority. Lastly, chi-square tests were carried out to analyse the relation between listener nationality and the different identification answers. 


\section{Results}

\subsection{Judges' ability to identify matched and non-matched accents}

Firstly, it was important to establish to what extent the Dutch and French participants were capable of identifying the NNE accents.

In the mixed-effects logistic regression, participants' identification answers were coded as 1's (correct identification) and 0's (incorrect identification). Furthermore, as a means to differentiate between matched and non-matched cases, the 12 audio samples were clustered into two groups based on speaker accent: a matched accent group, including either Dutch or French speakers, and a non-matched accent group, consisting of the remaining 5 speaker accents.

A mixed-effects logistic regression was fitted to the data. The models included listeners $(N=112)$ as random intercept, and listener nationality and speaker accent (both versions) as fixed factors. All variables are categorical. The estimates of the model - the probability of a correct identification - and their significance are shown in Table 1.

Table 1. Results of the mixed-effects logistic regressions with listener nationality, and speaker accent as fixed factors and listeners as random intercept. The reference level used for nationality is the French listener; for accent it is the non-matched accent

\section{Correct identification}

\begin{tabular}{lccc}
\hline Random effects: & Estimate & Std. Error & $\mathrm{p}$ value \\
\hline Participant (Intercept) & 1.546 & 0.800 & 0.053 \\
\hline Fixed effects: & Estimate & Std. Error & $\mathrm{p}$ value \\
\hline Intercept & -0.962 & 0.455 & $0.035^{*}$ \\
Dutch listener & 1.131 & 0.302 & $<0.001^{*}$ \\
Dutch listener ${ }^{*}$ Dutch accent & 4.343 & 0.936 & $<0.001^{*}$ \\
French listener ${ }^{*}$ French accent & 3.643 & 0.777 & $<0.001^{*}$ \\
\hline
\end{tabular}

* The asterisk indicates significance $(\alpha=0.05)$.

Table 1 shows that there is a significant effect of listener nationality. The probability of correctly identifying an NNE accent increases by 1.131 if a listener is Dutch rather than French. In addition, both Dutch and French judges are significantly better at identifying matched as opposed to non-matched accents. The estimate of 4.343 for Dutch listeners means that they have a higher chance of correctly identifying an NNE accent if it is Dutch. Similarly, French listeners have a higher chance of identifying an NNE accent if it is French (3.643). 


\subsection{Evaluation of matched versus non-matched NNE accents}

To establish whether Dutch and French judges are less positive about the accents of speakers whose L1 they share, and to what extent this is affected by the correct identification of the relevant accents, we analysed the Dutch and French judges' evaluation of the 12 different accent samples in terms of pleasantness of the accent, and the speakers' intelligence and authority. For each of these attitudinal constructs, participants had rated all 12 accent samples on a 5-point Likert scale, with a score of 5 representing the most positive assessment and a score of 1 the most negative.

An exploration of the data showed that 6 participants had evidently scored "intelligence" structurally differently from "pleasantness" and "authority" (i.e. all 12 speakers received scores of 5 for intelligence and of 1 for the other two items). The answers of these participants were polarised $(n=72)$. Additionally, 14 outliers were reported as missing values. In total, 1330 valid observations ( $99 \%$ of the data) were used for the quantitative analyses.

Three separate - but identically structured - mixed-effects linear regression models were fitted to the data. The robustness of the mixed-effects models allows the violation of normality. Following the procedure outlined in 3.1 in all models, listeners $(N=112)$ was taken as random intercept, and listener nationality and speaker accent were used as fixed factors. In addition, correct identification was taken as a third fixed factor. The attitudinal dependent variables are all numeric.

The estimates of the three models and their significance are shown in Table 2. As can be seen in Table 2, no significant effects of listener nationality were found with regard to participants' attribution of pleasantness, intelligence and authority. In other words, the two groups' overall assessment behaviour is consistent. Furthermore, differences in assessment between matched and non-matched accents were significant in all cases but one: Dutch listeners do not rate authority significantly differently in matched contexts, $p=.283$. Both the Dutch group and the French group attributed significantly lower pleasantness (Dutch -0.482 ; French -0.491) and intelligence (Dutch -.367; French -0.380) to matched accents. Additionally, the French attributed less authority to speakers with whom they share their L1 (-0.629). Since, in both groups, matched accents attract lower scores on two out of three attitudinal constructs, this provides evidence for the claim that both Dutch and French listeners evaluate fellow L1 speakers of English somewhat more negatively.

In this context, it was also interesting to investigate any differences in evaluation between listeners who had successfully recognised a matched accent and those who had failed to do so. In the Dutch group, a series of significant interactions were found between listener nationality, speaker accent and correct identification. 
Table 2. Results of the mixed-effects linear regressions with listener nationality, correct identification, and speaker accent as fixed factors and listeners as random intercept. The reference level used for nationality is the French listener; for accent, it is the non-matched accent; for identification, it is incorrect identification

\begin{tabular}{lccc}
\hline Pleasantness & & & \\
\hline Random effects: & Estimate & Std. Error & p value \\
\hline Participant (Intercept) & 0.109 & 0.055 & $0.048^{\star}$ \\
\hline Fixed effects: & Estimate & Std. Error & p value \\
\hline Intercept & 2.973 & 0.105 & $<0.001^{\star}$ \\
Dutch listener & -0.114 & 0.191 & 0.548 \\
Dutch listener ${ }^{\star}$ Dutch accent & -0.482 & 0.166 & $0.004^{\star}$ \\
French listener ${ }^{*}$ French accent & -0.491 & 0.213 & $0.021^{\star}$ \\
Dutch listener ${ }^{\star}$ Dutch accent ${ }^{*}$ Correct identification & -1.043 & 0.080 & $<0.001^{\star}$ \\
French listener ${ }^{*}$ French accent ${ }^{*}$ Correct identification & -0.403 & 0.371 & 0.277 \\
\hline
\end{tabular}

Intelligence

\begin{tabular}{lrrc}
\hline Random effects: & Estimate & Std. Error & p value \\
\hline Participant (Intercept) & 0.029 & 0.017 & 0.091 \\
\hline Fixed effects: & Estimate & Std. Error & p value \\
\hline Intercept & 3.507 & 0.082 & $<0.001^{\star}$ \\
Dutch listener & -0.055 & 0.086 & 0.521 \\
Dutch listener ${ }^{*}$ Dutch accent & -0.367 & 0.115 & $0.001^{*}$ \\
French listener ${ }^{*}$ French accent & -0.380 & 0.166 & $0.022^{*}$ \\
Dutch listener ${ }^{*}$ Dutch accent ${ }^{*}$ Correct identification & -0.839 & 0.067 & $<0.001^{*}$ \\
French listener ${ }^{\star}$ French accent ${ }^{*}$ Correct identification & -0.255 & 0.245 & 0.299 \\
\hline
\end{tabular}

Authority

\begin{tabular}{lccc}
\hline Random effects: & Estimate & Std. Error & p value \\
\hline Participant (Intercept) & 0.122 & 0.060 & $0.044^{*}$ \\
\hline Fixed effects: & Estimate & Std. Error & p value \\
\hline Intercept & 2.929 & 0.173 & $<0.001^{\star}$ \\
Dutch listener & 0.093 & 0.178 & 0.601 \\
Dutch listener ${ }^{\star}$ Dutch accent & -0.186 & 0.173 & 0.283 \\
French listener ${ }^{*}$ French accent & -0.629 & 0.174 & $<0.001^{\star}$ \\
Dutch listener ${ }^{*}$ Dutch accent ${ }^{*}$ Correct identification & -0.676 & 0.020 & $<0.001^{\star}$ \\
French listener ${ }^{*}$ French accent ${ }^{*}$ Correct identification & -0.255 & 0.189 & 0.178 \\
\hline
\end{tabular}

* The asterisk indicates significance $(\alpha=0.05)$. 
This suggests that the Dutch judges are prone to assessing a Dutch accent more negatively in terms of pleasantness (-1.043), intelligence $(-0.839)$ and authority $(-0.676)$ if they are aware the accent is Dutch. However, no such effects were found in the French group, suggesting that their evaluation of local accents is unaffected by their recognition of these. In other words, they evaluate a matched accent equally negatively, whether or not they are aware they are judging a fellow French speaker.

The tendency for all judges to be less positive about matched accents in English also emerged in some of the remarks provided in the open comment box. For reasons of brevity, these comments cannot be reproduced here in full, and our analysis of these cannot be discussed in detail, but it was interesting to note parallels with the quantitative data. For instance, the French judges, while struggling to identify both Dutch speakers, tended to be quite appreciative of these speakers' English, in some cases even comparing them favourably with NSs. The Dutch speakers did not receive such acclaim from the Dutch judges, whose comments were mostly what could be termed 'compensatory' (e.g. "could be worse"). Similarly, while the French speakers drew a wide range of different comments from the French judges, the Dutch judges appeared to be somewhat less exercised by them. Despite the bias against matched accents apparent in some judges, it should be noted that others expressed their pleasure in listening to their fellow L1 speakers.

\section{Discussion and conclusions}

To summarise, we found that both Dutch and French judges were much more successful at identifying matched accents than non-matched accents. Whereas the judges' overall evaluation of matched and non-matched accents appeared to be consistent, both groups judged the matched accents as somewhat less pleasant and their speakers as slightly less intelligent, with the French judges also evaluating the French speakers' authority more negatively. In addition, we found that Dutch judges tend to be less appreciative of fellow L1 speakers' accents if they had also identified these as Dutch. The tendency to be less accepting of matched accents was also evident from respondents' comments, although there were also judges who appreciated matched accents.

Naturally, caution must be exercised when interpreting these results. It could be argued, for instance, that they are an artefact of a survey which only employed a limited number of verbal guises, without any rigorous control over factors such as perceived strength of accent. However, the logistical difficulties in providing a wider range of perfectly matched guises for all speakers and accents would preclude any such endeavour, and would have placed additional demands on judges' willingness 
to participate. Nonetheless, we would welcome any follow-up research that manages to address these issues.

It could also be objected that these results are only meaningful if viewed within the context of participants' proficiency in English. While we collected no information on this, and wonder how reliably this could be done using the format of an online survey, it would of course have added an interesting dimension to the analysis - especially given the French and Dutch judges' different success rates in identifying NNE accents, something which Kristiansen et al. (2018) partly attribute to respondents' familiarity with L1 English. Yet it may still be maintained that a matched accent bias is a societally and linguistically relevant phenomenon in its own right - regardless of any connection with judges' L2 proficiency. The relative ease with which judges identified matched accents may actually suggest that L1 speakers are so strongly primed to detect these that the issue of their proficiency in English is moot. In fact, it could be argued that, if the detection and evaluation of a matched accent requires little actual L2 proficiency, this may be why some NNSs resort to this as a proxy for a more comprehensive assessment of their fellow L1 speakers' English.

While the effects of any acceptability deficit we found were not particularly strong, and should be interpreted with due caution, the results do suggest that a tendency to depreciate local NNE accents is not limited to participants from a specific linguistic ecology such as the Netherlands. The fact that similar effects are also attested for our French judges suggests that this may be a wider trend among NNSs, and challenges the widely held assumption that the latter, possibly from considerations of greater solidarity and increased intelligibility, always respond positively and constructively to the NNE accents of those whose L1 they share. The notion of the judgemental NNS is one that, if corroborated in follow-up studies involving respondents from other linguistic ecologies, would add a useful dimension to a discussion of NNSs' conflicting positions and attitudes - especially in a lingua franca context where the focus is on NNS-NNS interaction. But it is not only the assumption of mutual NNS solidarity, widely considered to be conducive to efficient lingua franca interaction, that may need to be revisited. If other studies confirm that NNSs tend to single out matched NNE accents for criticism, this would imply that NNSs' judgements are not simply motivated by a crude one-size-fits-all native-speakerism, or an uncritical adherence to standard language ideology, but are affected by their ability to discriminate and evaluate different NNE accents.

In the present study, we only aimed to find empirical confirmation of previous suggestions that NNE judges tend to downgrade local accents. The fact that this effect was attested in judges from different linguistic ecologies does not imply that the underlying motivations for evaluating fellow L1 speakers more negatively are the 
same in all contexts, or affect judges to the same extent. It may be speculated that for some Dutch judges, a perceived acceptability deficit is linked to a tendency towards a more internationalist orientation, while for others, or for some of their French counterparts, it could also be an expression of vicarious embarrassment originating from group solidarity (the "black sheep effect"). Follow-up studies could investigate if and to what extent such attitudes and perceptions are more prominent in some groups than others. They could also help to explain why it is only in some groups of listeners that the actual recognition of a matched accent goes hand in hand with a lower appreciation. All this would serve to contextualise the complex and ambivalent positions NNSs may have towards "hybrid Englishes", and would add a much-needed dimension to the study of NNEs such as Dutch and French English.

On a more practical level, a widely perceived acceptability deficit in speakers of the same L1 could have consequences for the use of English in educational settings. If NNE students are distracted by their instructors' strong local accents, this could be seen as a pedagogical issue, possibly to be remedied by means of expectation management or dedicated pronunciation training. Whereas recognition of a matched accent may only trigger a mild reaction in the context of a low-stakes online survey, it could have more dramatic effects in the high-stakes environment of an English-medium instruction classroom (as in Hendriks et al. $(2016,2018)$ ) especially if solidarity between teachers and students is absent. In such contexts, all stakeholders would do well to be aware of the judgements that NNSs may have formed about their fellow L1 speakers' accents in English.

\section{Acknowledgements}

We gratefully acknowledge the use of the Speech Accent Archive under the Creative Commons License. We would also like to thank our colleagues Anne-France Pinget and Alice Henderson for their invaluable help and encouragement.

\section{References}

Agar, Michael. 1995. Language shock: Understanding the culture of conversation. New York: William Morrow.

Butler, Yuko G. 2007. How are nonnative-English-speaking teachers perceived by young learners? Tesol Quarterly 41(4). 731-755. https://doi.org/10.1002/j.1545-7249.2007.tboo101.x

Dalton-Puffer, Christiane, Gunther Kaltenboeck \& Ute Smit. 1997. Learner attitudes and L2 pronunciation in Austria. World Englishes 16(1). 115-128.

https://doi.org/10.1111/1467-971X.00052 
Doel, Rias van den \& Hugo Quené. 2013. The endonormative standards of European English: Emerging or elusive? English World-Wide 34(1). 77-98. https://doi.org/10.1075/eww.34.1.04van

Dutch News. 2014. How bad is Mark Rutte's English? https://www.dutchnews.nl/features/2014/03/how_bad_is_mark_ruttes_english/. (24 March, 2019.)

Education First. 2019. EF English proficiency index. 9th edn. www.ef.com/epi. (26 April, 2020.) Edwards, Alison. 2014. The progressive aspect in the Netherlands and the ESL/EFL continuum. World Englishes 33(2). 173-94. https://doi.org/10.1111/weng.12080

Edwards, Alison. 2016. English in the Netherlands: Functions, forms and attitudes. Amsterdam: John Benjamins. https://doi.org/10.1075/veaw.g56

Engel, Stephanie. 2014. Is het Engels van Rutte echt zo beroerd? https://www.trouw.nl/home/ is-het-engels-van-rutte-echt-zo-beroerd- ab040950/. (24 March, 2019.)

European Commission. 2012. Eurobarometer 386: Europeans and their languages, FebruariMarch 2012 [Data file]. http://ec.europa.eu/public_opinion/archives/ebs/ebs_386_en.pdf. (26 April, 2020.)

Garrett, Peter. 2010. Attitudes to language. Cambridge: Cambridge University Press.

Gensane, Bernard. 2017. L'anglais de Macron. https://blogs.mediapart.fr/bernard-gensane/ blog/110717/l-anglais-de-macron. (23 August, 2019.)

Hendriks, Berna, Frank van Meurs \& Ann-Katrin Reimer. 2018. The evaluation of lecturers' nonnative-accented English: Dutch and German students' evaluations of different degrees of Dutch-accented and German-accented English of lecturers in higher education. Journal of English for Academic Purposes 34. 28-45. https://doi.org/10.1016/j.jeap.2018.03.001

Hendriks, Berna, Frank van Meurs \& Nanette Hogervorst. 2016. Effects of degree of accentedness in lecturers' Dutch-English pronunciation on Dutch students' attitudes and perceptions of comprehensibility. Dutch Journal of Applied Linguistics 5(1). 1-17.

https://doi.org/10.1075/dujal.5.1.01hen

Holliday, Adrian. 2005. The struggle to teach English as an international language. Oxford: Oxford University Press.

Jenkins, Jennifer. 2007. English as a lingua franca: Attitude and identity. Oxford: Oxford University Press.

Kappa, Katherine. 2016. Exploring solidarity and consensus in English as lingua franca interactions. Journal of Pragmatics 95. 16-33. https://doi.org/10.1016/j.pragma.2016.01.015

Kousbroek, Rudy. 1984. Escaped from the language lab. In De logologische ruimte, n.p. Amsterdam: Meulenhoff. Reprinted with annotations in https://core.ac.uk/download/pdf/ 62412144.pdf.

Kristiansen, Gitte, Eline Zenner \& Dirk Geeraerts. 2018. English as a lingua franca in Europe: The identification of L1 and L2 accents: A multifactorial analysis of pan-European. Review of Cognitive Linguistics 16(2). 494-518. https://doi.org/10.1075/rcl.oo019.kri

Lambert, James. 2018. A multitude of "lishes": The nomenclature of hybridity. English WorldWide 39(1). 1-33. https://doi.org/10.1075/eww.00001.lam

Le Lièvre, Françoise. 2008. L’Anglais en France, une langue multiple: Pratiques, représentations et postures d'apprentissage: Une étude en contexte universitaire. Tours: Université François-Rabelais: Ph.D. thesis.

Make That The Cat Wise. 2012. [Facebook page]. https://www.facebook.com/MakeThatTheCatWise/. (24 March, 2019.)

McArthur, Tom. 1995. The Anglo-hybrids. English Today 11(4). 2-2.

https://doi.org/10.1017/S0266078400008518 
McKenzie, Robert M. 2008. Social factors and non-native attitudes towards varieties of spoken English: A Japanese case study. International Journal of Applied Linguistics 18(1). 63-88. https://doi.org/10.1111/j.1473-4192.2008.00179.x

Milroy, James. 2006. The ideology of the standard language. In Carmen Llamas, Louise Mullany \& Peter Stockwell (eds), The Routledge Companion to Sociolinguistics, 153-159. New York, NY: Routledge.

O’Mill, John. 1956. Lyrical laria in Dutch and double Dutch. Laren: Andries Blitz.

Poirier, Agnes. 2013. Franglais row: Is the English language conquering France? https://www.bbc. com/news/magazine-22607506. (22 August, 2019.)

Schmader, Toni \& Brian Lickel. 2006. Stigma and shame: Emotional responses to the stereotypic actions of one's ethnic ingroup. In Shana Levin \& Colette van Laar (eds.), Stigma and group inequality: Social psychological perspectives, 261-285. Mahway, NJ: Lawrence Erlbaum.

Schneider, Edgar W. 2016. Hybrid Englishes: An exploratory survey. World Englishes 35(3). 339-354. https://doi.org/10.1111/weng.12204

Tajfel, Henry \& John C. Turner. 1979. An integrative theory of intergroup conflict. In William G. Austin \& Stephen Worchel (eds.), Social psychology of intergroup relations, 33-48. Monterey, CA: Brooks/Cole.

Tatsioka, Zoi, Barbara Seidlhofer, Nicos Sifakis \& Gibson Ferguson (eds.). 2018. Using English as a lingua franca in education in Europe (English in Europe 4). Berlin: Walter de Gruyter. https://doi.org/10.1515/9781501503115

Vignoles, Vivian L. \& Natalie J. Moncaster. 2007. Identity motives and in-group favouritism: A new approach to individual differences in intergroup discrimination. British Journal of Social Psychology 46(1). 91-113. https://doi.org/10.1348/014466605X85951

Walpot, Adriaan H. L. 2018. Which Englishes do the Dutch prefer? Anti-nationalism versus speaker authenticity. Utrecht: Utrecht University: MA thesis. http://dspace.library.uu.nl/ handle/1874/368482

Walsh, Olivia. 2015. Attitudes towards English in France. In Andrew Linn, Neil Bermel \& Gibson Ferguson (eds.), Attitudes towards English in Europe (English in Europe 2), 27-54. Berlin: Walter de Gruyter.

Wang, Hongyan \& Vincent van Heuven. 2015. The interlanguage speech intelligibility benefit as bias toward native-language phonology. i-Perception 6(1). 1-13. https://doi.org/10.1177/2041669515613661

Weinberger, Steven. 2015. Speech Accent Archive. George Mason University. http://accent.gmu. edu. (2 October, 2016.)

Wilkinson, Robert. 2013. English-medium instruction at a Dutch university: Challenges and pitfalls. In Aintzane Doiz, David Lasagabaster \& Juan M. Sierra (eds.), English-medium instruction at universities: Global challenges, 3-24. Bristol: Multilingual Matters. 



\title{
Revisiting the vowel mergers of East Anglia Correlations of MOAN, MOWN and GOOSE
}

\author{
Kerri-Ann Butcher \\ University of Cambridge
}

\begin{abstract}
This study revisits the longstanding distinction between /u:/ (MOAN) and $/ \Lambda \mathrm{u} /$ (MOWN) in East Anglia, where the Long Mid Mergers that resulted in a single GOAT vowel did not take place. Words such as 'road' and 'rowed' are therefore not homophonous. Recently, however, this distinction has started to break down. Acoustic analysis of 24 speakers indicates change in apparent time, where a merger by approximation of MOAN and MOWN is taking place in Lowestoft (northern East Anglia) for working-class speakers. Findings further suggest that a previously reported ongoing merger between MOAN and GOOSE, which occurred as a result of a chain shift, was not completed but may have had a hand in deferring the MOAN/MOWN merger in East Anglia over many years. Goose fronting is also reported as a change in apparent time.
\end{abstract}

Keywords: language variation and change, vowel mergers, sociophonetics, British English, levelling, dialectology

\section{Introduction}

The lexical sets of FACE and GOAT ${ }^{1}$ both reflect mergers of distinct Middle English (ME) vowels (Wells 1982a). These mergers (known as the Long Mid Mergers) took place in parallel prior to the 17th century across many varieties of English, but were not carried out in East Anglia, a non-administrative area in the East of England (Fisiak \& Trudgill 2001). As a result, in East Anglian English, those words descended from ME /ai/ and /a:/, e.g. 'days' and 'daze', maintained a phonemic distinction between /æi/ and /e:/, respectively, rather than merging under what is now referred to as the FACE set. In addition, words originating from $\mathrm{ME} / \mathrm{s} / \mathrm{and}$

1. GOAT and FACE refer to the lexical sets proposed by Wells (1982a), denoting the /əv/ and /ei/ vowels found in those varieties of English where the Long Mid Mergers have taken place. 
/su/, e.g. 'road' and 'rowed', upheld phonemic contrast between /u:/ and / $\mathrm{\Lambda u} /$, respectively (Trudgill 2004), failing to merge into what we know today as the GOAT set. While the distinction between /æi/ and /e:/ is now considered vestigial amongst East Anglia's modern dialects (Trudgill 2021), contrast between /u:/ and / $\mathrm{u}$ / survives more robustly and is far from obsolete. The latter distinction is therefore the focus of this current research. I follow Britain $(2002,2005,2009)$ and Trudgill (1988a, 2004) in assigning the lexical sets of MOAN and MOWN to represent the modern distinction between $/ \mathrm{u}: /$ and $/ \Lambda \mathrm{u} /$, realised as [ $\mathrm{vu}]$ and $[\Lambda \mathrm{u}]$ in East Anglian varieties. Clearly the longevity of the MOAN/MOWN distinction is quite exceptional and worthy of attention. Yet, research into its distribution and the extent of any ongoing merger across the modern dialects of East Anglia is remarkably sparse. The situation is complex. Records show that, while the GOOSE vowel has long been centralised in East Anglian English (Ellis 1889; Kökeritz 1932), it is also reported to surface as [vu], rendering it homophonous with MOAN (Trudgill 1988b). This presents a situation wherein MOAN is implicated in both (variable) merger-as-state $($ GOOSE $=$ MOAN), and merger-as-process $($ MOAN $>$ MOWN), which represents a change in the individual phonologies of speakers, or between generations (Maguire et al., 2013). It is arguably complications such as this that may have disfavoured a MOAN/ MOWN merger historically (Trudgill 1988b). This study examines recent structural changes concerning the MOAN, MOWN and GOOSE classes across three generations of East Anglian speakers, providing an initial, exploratory account of the mergers, some 40 years on since their last dedicated study.

\section{Background}

\subsection{The MOAN/MOWN merger}

Mergers are well known to spread at the expense of distinctions ('Herzog's Principle') (Herzog 1965; Labov 1994: 313) and are commonly observed cross-linguistically. In the case of East Anglia (see Figure 1 for relevant geography ${ }^{2}$ ), Trudgill \& Foxcroft (1978) report that the longstanding ME distinction between MOAN and MOWN was neutralised in the region's most southerly parts, such as north Essex and south Suffolk, by c.1975, bar a handful of relic forms. As a result, both MOAN and MOWN

2. See Trudgill (2001) for an outline of linguistic East Anglia. Important for this discussion is that the city of Norwich, which has been the focus of much of Trudgill's work, is located in Norfolk, northern East Anglia, while Suffolk is treated as southern East Anglia, with the exception of those locales north of and including Lowestoft (the locale in question), which straddles the north/south East Anglian linguistic divide. 
words now have $/ \Lambda \mathrm{u} /$ in the south. They note that the distinction survives more consistently in northerly parts of Suffolk, although there is variation in urban areas, such as Lowestoft, while Norfolk more or less consistently retains /u:/ and / $\mathrm{\Lambda u} /$ for MOAN and MOWN, respectively. In fact, Trudgill \& Foxcroft (1978) report that, while $77 \%$ of working-class speakers in Lowestoft show no merger and $23 \%$ have a variable merger, in Norwich, all working-class speakers fully retain the distinction. Evidently, the merger has, so far, been gradual geographically.
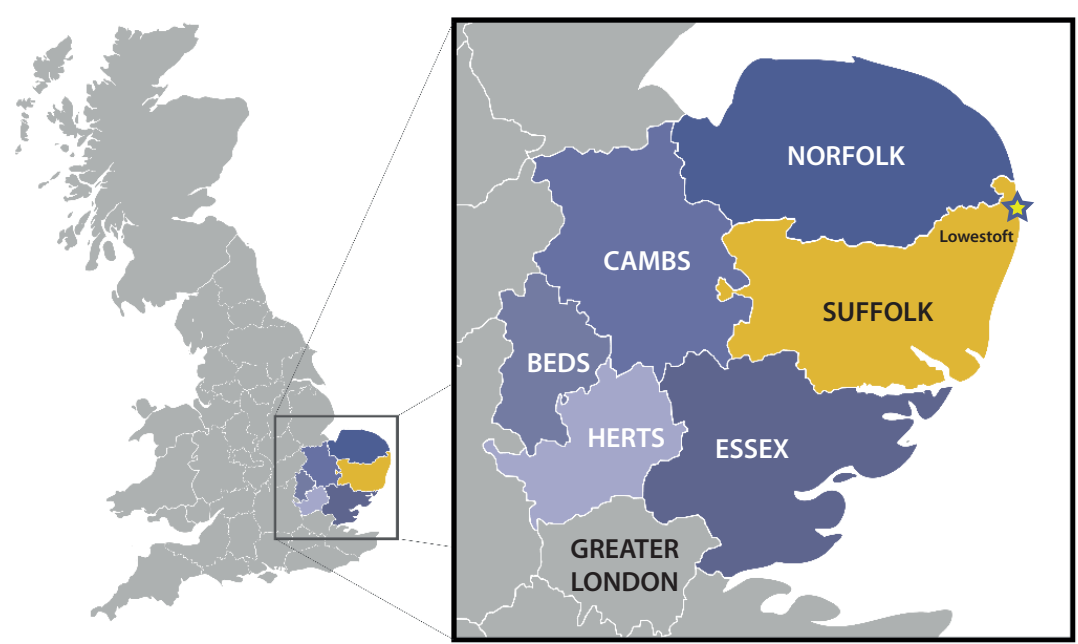

Figure 1. Geography of East Anglia (excluding Greater London)

Trudgill (1974: 119) notes that there is clear and consistent phonetic variation amongst those who maintain the distinction in Norwich; the further up both the socioeconomic and stylistic scales we look, the smaller the phonetic distinction becomes. However, at no point does it disappear, even for the middle middle class (MMC). Trudgill (ibid) brands this as "the normal state of affairs in MMC Norwich English", rather than as a linguistic change in progress. It is not until the late 1980s that Trudgill (1988a) reports that the MOAN/MOWN distinction is finally beginning to break down in northern East Anglia, and young speakers are beginning to favour a more fronted first element [eu] for MOAN words. Similarly, Britain (2005) demonstrates a more recent divergence in phonetic quality, but in the form of MowN fronting, recording traces of the distinction amongst adolescents in Terrington, north-west East Anglia. It is important to note a lack of conditioning in the case of MOAN/MOWN where "there is no vocalic split in Norwich between the sets of GOAT and GOAL" (Trudgill 1988a: 129), i.e. the quality of MOAN and MOWN is essentially 
the same in preceding coda / $/$ and in non-pre-coda- $/ /$ environments. This is unlike other varieties of Southern British English (SBE), which developed an allophonic split (Wells 1982b) where GOAT fronted but not before coda /1/. This lack of allophony in Norwich is likely the direct result of a lack of merger.

Whether or not a merger, such as this, proceeds below the level of consciousness is dependent upon the mechanism of the merger in question. Cases of merger by approximation, where the phonetic targets of two vowels gradually move closer together before eventually overlapping, generally proceed below the level of consciousness (Labov 1994: 321). Cases of merger by transfer, where words move from one phonemic category to another on a word by word basis, on the other hand, proceed above the level of consciousness and one member of the pair is usually stigmatised (ibid). In the case of MOAN/MOWN, Trudgill \& Foxcroft (1978) report both kinds. They suggest that some working-class speakers in the south of East Anglia with good exposure and proximity to London adopted the strategy of merger by transfer, while some middle-class speakers in the north of East Anglia with less exposure to London forms and more exposure to RP adopted merger by approximation. These findings suggest that both degree of exposure to other varieties and, indeed, the specifics of the varieties in question, have a strong bearing on speakers' phonetic targets and, in turn, their strategy of merger. Whether this is also the case in Lowestoft - the East Anglian locale under investigation - will be considered alongside the fundamental goal of determining whether there is strong evidence of a MOAN/MOWN merger for the working-class community. If so, we must ask: what is the mechanism by which the merger is taking place and what is its social distribution?

\subsection{The GOOSE/MOAN merger}

Trudgill (2004: 171) writes that alternations between MOAN words and those GOOSE words descended from ME /o:/ are frequent in the dialects of East Anglia, where Goose "may have /u:/ rather than / $\mathfrak{t}: /$ ". This renders the likes of 'boot' and 'boat' homophonous, as in [bout]. This is said to be highly variable from speaker to speaker, word to word, and social class to social class (Trudgill, 2021), and thus the status of a merger has always been rather unclear. Kökeritz (1932) shows in the early 20th century that a merger has not taken place in Suffolk, but documents close phonetic realisation of the two vowels. It is later suggested that this small amount of phonetic distinction is indicative of an imminent merger (Trudgill 1974: 70). Trudgill further asserts that Lowman's records from the 1930s show clear signs of at least a partial merger, which is more common in Norfolk than Suffolk. Although, it is not entirely clear whether a 'partial' merger refers to variable phonetic overlap, or 
incomplete lexical transfer. Trudgill (1974: 72) additionally notes that the Survey of English Dialects records from the 1960s provide no evidence of a complete merger in Norfolk and that we should expect none in Suffolk, as the MOAN/MOwN distinction appears to be lost. He (ibid) concludes that "the position with respect to the 'boat:boot' merger is not clear". Trudgill (2021) later provides brief comment on the merger's apparent lack of consistency in previously reported work, remarking that those alternations between GOOSE and MOAN that do occur may well have actually arisen as a result of lexical transfer under influence from earlier RP, where the unusually front Goose vowel (at the time) was considered salient, often leading to hypercorrection within the Goose set, as well as erroneous extension of $[\Lambda \mathrm{u}]$ to Goose words (see also Trudgill 1988b). Labov et al. (1972: 131) also report on the situation regarding GOOSE and MOAN, demonstrating how Norwich (Norfolk) exhibits a 'pattern 3' type chain shift (see Labov 1994 for further discussion). As we will see, the first two stages appear to have been carried out across East Anglia, but stage three may be unique to Norwich. The Norwich shift is documented as follows (Labov 1994: 206):

\section{1. $/ \mathrm{uw} / \rightarrow / \ddot{\mathrm{u}} \mathrm{Y}$ \\ 2. $/ \mathrm{ow} / \rightarrow / \mathrm{uw} /$ \\ 3. $/ \mathrm{uw} / \rightarrow /$ üw/}

Stages one and two provide an example of a 'drag' shift and the final stage is labelled as a 'push' (Labov 1994: 206), a pattern described as "so rare as to cause alarm" (Samuels 2006: 5). Stage one (fronting of GOOSE) is acknowledged early on, with Ellis (1889: 260) remarking on the vowel's similarity to "the French [y]" in both Norfolk and Suffolk, and Kökeritz (1932: 44) offering a description that suggests a central vowel approaching $[\mathrm{k}]$, often with some diphthongisation, for Suffolk speakers. Stage two represents the raising of MOAN, as it is dragged upwards to occupy the high back vowel space that Goose previously vacated. This is also well-known to have occurred across the dialects of East Anglia (Labov 1994; Labov et al., 1972, 1991; Trudgill 1974, 1988a, 1988b, 2004; Trudgill \& Foxcroft 1978; Britain 2005, 2009; Wells 1982b), and the result of stages one and two is, ostensibly, a system in which one-to-one mapping of the implicated phonemes is retained. It is stage three that Labov et al. (1972) report on in detail, providing an account of two young male speakers who produce a distinction between GOOSE and MOAN, which is not carried out through the nucleus, but through divergent offglides. Trudgill later corroborates these findings and writes that the distinction

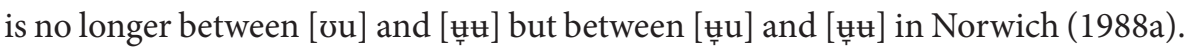
However, what is most striking is that, while Labov et al. (1972) note both boys to produce a distinction, only one of them was able to perceive the distinction. In 
other words, GOose and MOAN are involved in a near-merger in Norwich. First reported by Labov et al. (1972: 277-297), near-mergers have been used to account for a number of perplexing historic linguistic events, including the alleged merging and subsequent unmerging of the MEAT and MATE set in ME. Based on 'Garde's Principle' (Garde 1961) and the assumption that mergers are irreversible by linguistic means, Labov (1994: 371-390) concludes that those mergers reported as 'reversed' must never have truly reached completion and are thus near-mergers. In these cases, production and perception are out of step: a small distinction remains at the phonetic level, though it is perceived as a merger. Whether this ostensible example of a push that resulted in near-merger took place beyond Norwich is unclear and will be discussed here.

A final complication to add is that those words belonging to the MOAN set may have [ð], i.e. 'boat' may be shortened to [bot] in East Anglia (Trudgill 2004), although this is described as "sharply recessive" (Wells 1982b: 338). Trudgill's original Norwich study (1974: 113) reports that, while there is clearly stylistic and class variation, the working class only exhibit shortening of MOAN across $42 \%$ of tokens and the process is predominantly tied to 4 of the 29 lexical items documented. Trudgill (2021) later asserts that, although this shortening has been a productive process and survives in modern dialects, this may now be lexicalised. This shortening can also apply to the Goose set (Trudgill 1988b), but no instances are reported in the data here.

Labov and Trudgill's work from decades ago demonstrates great flux and complexity in the back-vowel system, suggesting a series of entwined, ongoing changes. This work aims to uncover the mechanism(s) underlying any continuing changes, should Lowestoft follow a similar trajectory.

\section{Methods}

\subsection{Speaker sample}

The data are taken from Lowestoft, an ex-fishing town located nine miles south of the Norfolk-Suffolk border, where the northern and southern linguistic zones of East Anglia meet. The situation described so far suggests that Norfolk and Suffolk or, equally, northern and southern East Anglia, pattern differently. Lowestoft's Suffolk location, but apparent inclusion in the northern linguistic zone (Trudgill, 2021), thus makes it a particularly interesting candidate for investigation. Further, the collapse of the fishing industry has caused dramatic change to the social and economic makeup of the town in recent years, and it has been subject to increased counter-urbanisation from the south-east of England (Fielding 1992; Gordon et al., 2017). This has brought local forms into contact with outside forms extensively. 
Analysis is based on 24 speakers, stratified by age and gender (see Table 1), all of whom were born in Lowestoft and reported having spent no longer than a year away at any time. The speakers were identified as working class, using blue-collar vs white-collar work as a marker. While this system is imperfect, further stratification within this social group may have led to fragmented results, given the sample size.

Table 1. Speaker sample

\begin{tabular}{lcccc}
\hline & Young (16-35) & Middle aged (36-65) & Old (66+) & Total \\
\hline Male & 4 & 4 & 4 & 12 \\
Female & 4 & 4 & 4 & 12 \\
Total & $\mathbf{8}$ & $\mathbf{8}$ & $\mathbf{8}$ & $\mathbf{2 4}$ \\
\hline
\end{tabular}

\subsection{Recording, data extraction and coding}

Recordings were made in January of 2019 using a Handy H4N recorder at a sampling rate of $44.1 \mathrm{kHz}$. I aimed to extract a minimum of 10 MOWN tokens, 10 MOAN tokens and 10 GOOSE tokens per speaker from a reading passage designed as part of a larger study of the variety, however, this was not always achieved. Tokens with a preceding $/ \mathrm{w} / \mathrm{or} / \mathrm{r} /$ were omitted due to the effects of formant undershooting on neighbouring vowels (Harrington \& Cassidy 1999), as well as tokens with coda /1/. MOAN words shortened to [ซ], e.g. 'home' and 'road', are included and reported on, but removed from the statistical models and Pillai calculations.

After these omissions, the total was MOAN $n=377$, MOWN $=191$ and Goose $n=187$. It is widely recognised that coda /1/ has inhibitory effects on fronting of GOOSE and should be treated separately in analysis (Labov et al., 2006). In this vein, coda /1/ has also been used as a reference point for fronting of GOAT (Hall-Lew 2009). A further 5 words per speaker from the GHOUL set (those GOOSE words with coda $/ /$ ) were therefore extracted $(n=120)$, as well as 5 words from each of the SOLE $(n=120)$ and souL $(n=120)$ sets. While GOAL is usually utilised to represent GOAT vowels in pre-coda- $/ 1 /$ position, this would not capture the potential distinction in East Anglia, thus I label words from the MOAN and MOwN sets in this environment as belonging to the SOLE and souL sets, respectively.

$\mathrm{F} 1$ and F2 measurements were taken at $1 / 3$ and $2 / 3$ of the total duration of each vowel and extracted from hand labelled TextGrids in Praat (Boersma \& Weenink 2020) using a script. All were inspected and corrected manually where necessary. Formant values were then normalised via the Lobanov method using the Vowels Package (Kendall \& Thomas 2010) in R (RStudio Team 2020). It is acknowledged that measurements taken at two points to represent the nucleus and offglide do not by any means reflect all points of potential differences or similarities that could 
be found along the two vowel trajectories, but ongoing work continues to address this and expand on these methods. Given the potentially diphthongal nature of GOose in East Anglian varieties, the chosen points of measurement aim to capture instances of a GOOSE/MOAN merger more accurately than more conventional measurements taken at the midpoint of the total duration of GOOSE or GHOUL might. This is deemed a reasonable adjustment given both the aims of the research and the complicated nature of the data. Finally, as a MOAN/MOWN (SOLE/SOUL) merger predominantly concerns the degree of distinction in the first element, for the purpose of this exploratory work, only measurements taken from the nuclei are subject to discussion, as they are considered a sufficient indicator of a MOAN/MOWN merger, after pre-analysis showed the offglide to be relatively stable.

\subsection{Statistical analysis}

Following acoustic analysis, a multivariate analysis of variance (MANOvA) was then performed for each speaker using Lobanov normalised F1 and F2 as dependent variables (for each of the MOAN/MOWN and GOOSE/MOAN datasets). Word class and both preceding and following segment were included as predictor variables. From this, a Pillai score was obtained. Pillai scores represent "the proportion of the variance in the dependent variable that can be accounted for, given the independent variable(s)" (Adank et al., 2004: 3106). As demonstrated in a number of recent sociophonetic studies, Pillai scores can be used to effectively measure the extent of merger in individual speakers (Hay et al., 2006; Kennedy 2006; Hall-Lew 2009; Nycz 2019). Thus, they are employed here to evaluate both the MOAN/MOWN and GOOSE/MOAN mergers. Scores range from 0 to 1 , where 0 represents complete overlap between the distributions of two vowels, and 1 represents none. Following this, a series of fixed-effects linear regression models were built with the 'Ime4' package in $\mathrm{R}$ (Bates et al., 2015) to assess the social factors that influence the extent of a MOAN/MOWN or GOOSE/MOAN merger, with Pillai score as the dependent variable, and age and gender as predictors. A mixed-effects model was then built to consider both the linguistic and social effects on GOOSE, with normalised F2 as the dependent variable. Preceding and following segment, gender and age were included as fixed predictors, while speaker and word were included as random effects. Pairwise comparisons were conducted using likelihood ratio tests to arrive at the best fit models in all cases (reported in Appendixes 1-4). 


\section{Results}

\subsection{The MOAN/MOWN merger}

The data suggest that age is the only clear social predictor of a merger of the MOAN and Mown vowels. Young speakers exhibit more phonetic overlap between these two phonemes when compared to both the old and middle-aged groups, and the differences reported are significant (Appendix 1). Figure 2 details Pillai scores of almost zero for YF3 and YM2 (0.012 and 0.011, respectively), with YM4 scoring 0.002 . This essentially indicates no difference in their productions of MOAN and MOWN vowels. The remaining young speakers appear to be in a transitional, but advanced, stage towards merger. Middle-aged speakers show greater variability in the degree of overlap between MOAN and MOWN, as Pillai scores range between 0.186 to 0.860 . MF2 appears to be an outlier, exhibiting an atypically high degree of merger. Closer auditory and visual inspection of the data (and analysis of minimal pairs) confirms that, while both diphthongs have centring first elements, a small distinction is seemingly present. This is, however, by no means consistent and varies between words (Figure 3).

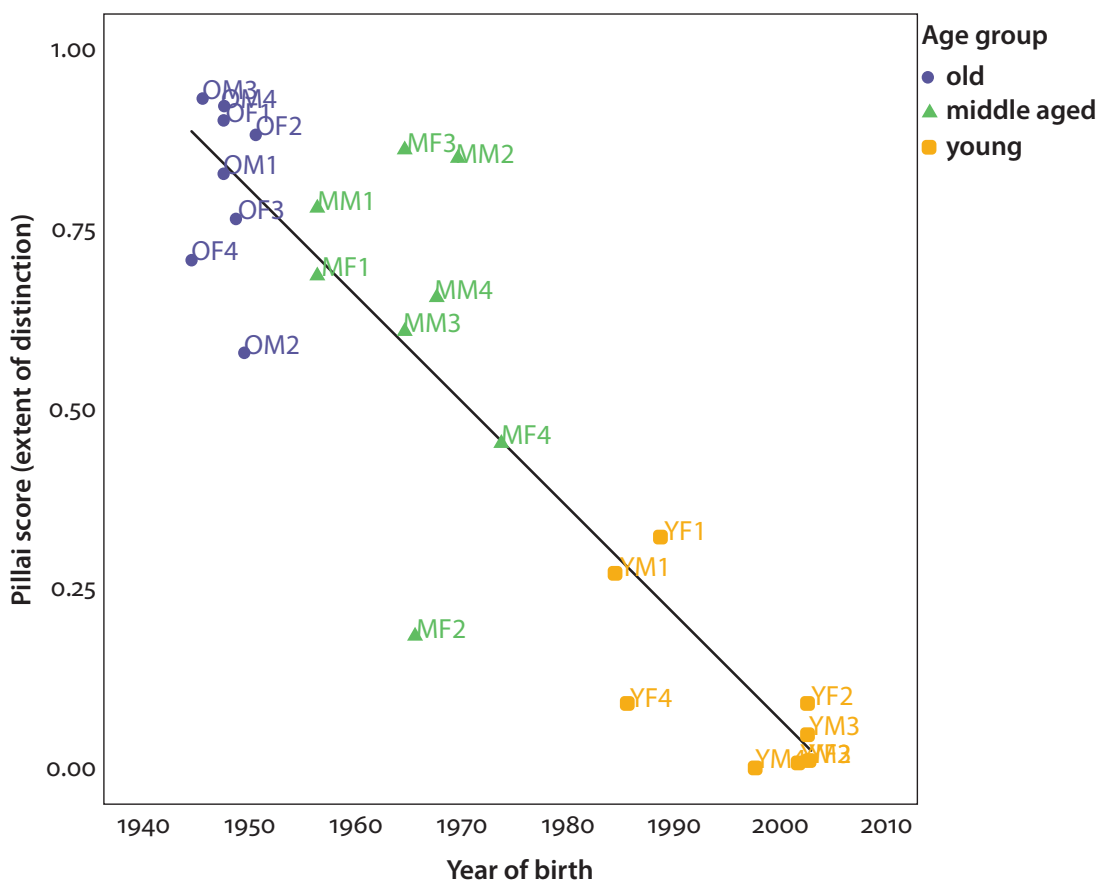

Figure 2. Year of birth vs. Pillai score, showing the extent of distinction between MOAN/MOWN (nuclei) across age groups with regression line 


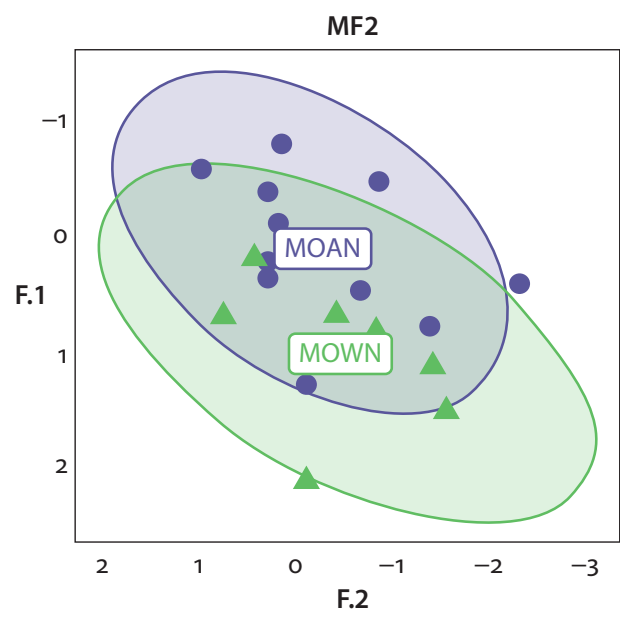

Figure 3. MF2's normalised formant values for the nuclei of MOAN and MOWN vowels (all tokens) with means and ellipses to one standard deviation

In fact, the distinction, when present, is incredibly modest and at the point of being inaudible. This potentially provides an example of a near-merger. Old speakers' Pillai scores range from 0.577 to 0.931 , indicating less overlap and variance in the vowels that uphold the distinction, when compared to the middle-aged group. There is no superficially obvious difference between genders across groups, which is reflected in the statistical analysis where there is no significant effect of gender.

The data in Figure 4 closely reflect the Pillai scores, but provide a more striking visualisation of this variation across generations, which indicates change in apparent time towards a merger. In terms of vowel quality, MOWN shows a reduction in dispersion of $\mathrm{F} 2$ values over time, potentially more so than MOAN. MOAN and MOWN F1 values for middle-aged speakers show an inwards, centring movement towards
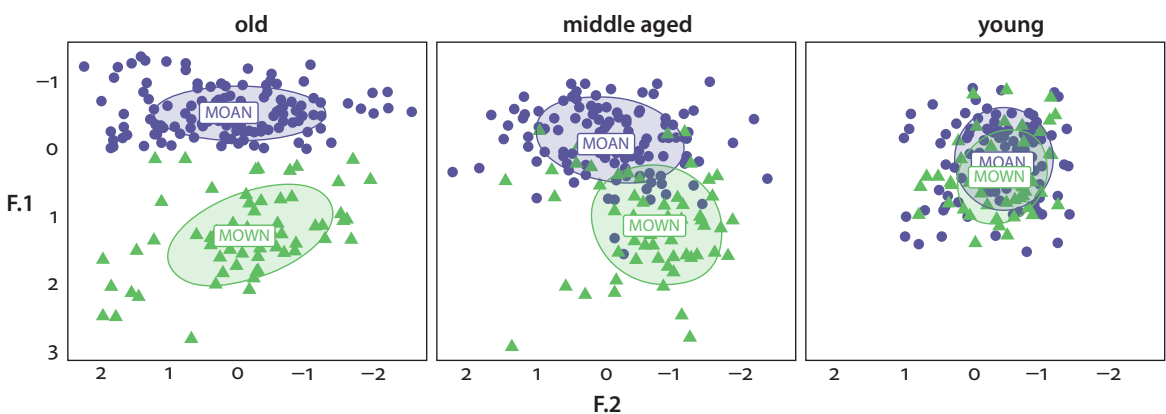

Figure 4. Normalised formant values for the nuclei of MOAN and MOWN vowels (all tokens) with means and ellipses to one standard deviation 
their contrasting counterpart. It is this fine-grained movement of F1 that signifies merger via approximation, rather than transfer, and fits with earlier reports of an intermediate form emerging (Britain 2009; Trudgill \& Foxcroft 1978).

Only 20 tokens of MOAN underwent reduction to [ซ], and these can be attributed to just four old speakers. The data suggest this feature is perhaps now a relic and potentially provides support towards Trudgill's (2004) recent reports that a number of words have been returned to the MOAN set via lexical transfer. Britain (2005) notes that fronting of $/ \Lambda \mathrm{u} /$ is commonplace in southern England and is now present in the Fenlands, north-west East Anglia, where adolescents regularly front MOWN words, but MOAN words far less frequently. Figure 4 may suggest the opposite, indicating that both sets could be backing very slightly over time.

Additionally, Figure 5 shows that young speakers are also backing both MOAN and MOWN vowels in pre-lateral (SOLE/sOuL) environments. This GOAT allophony, the shift of the first element of the 'standard' GOAT vowel from schwa [ə] to the quality of the LOT vowel in a pre-lateral environment, is common in other southern varieties of British English (Lindsey 2019: 30). Paired T-tests were used to ascertain whether the observed differences were significant (Table 2).
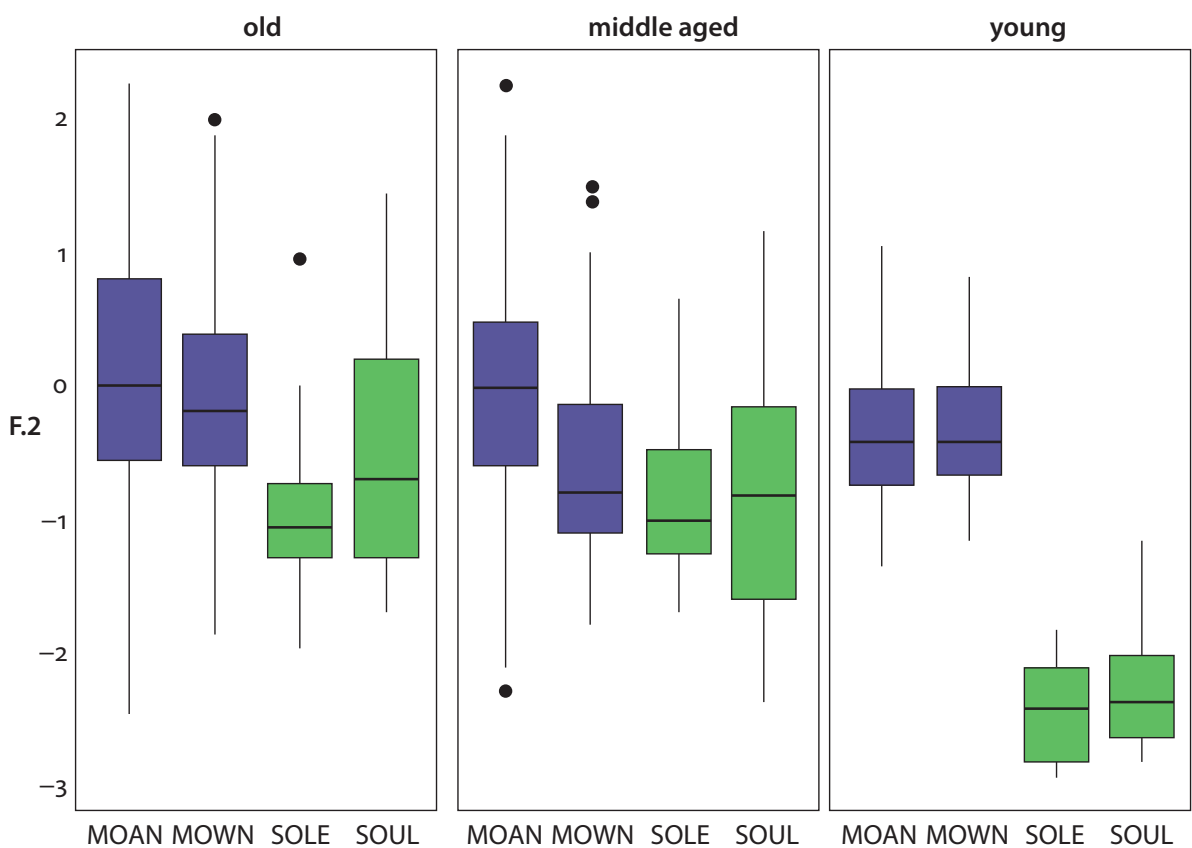

Figure 5. Boxplot showing normalised F2 values for MOAN vs. SOLE and MOWN vs. SOUL sets across age groups 
Table 2. Results from paired T-tests based on MOAN vs SOLE and MOWN vs SOUL sets across age groups

\begin{tabular}{llll}
\hline & Old & Middle aged & Young \\
\hline MOAN - SOLE & $t=2.821, p<0.05$ & $t=2.719, p<0.05$ & $t=13.100, p<0.001$ \\
MOWN - SOUL & $t=0.808, p=0.441$ & $t=0.418, p=0.686$ & $t=8.900, p<0.001$ \\
\hline
\end{tabular}

The difference between MOAN and SOLE words is significant for all groups, although clearly more so for young speakers, while the difference between MOwN and souL words is only significant for young speakers, who show clear backing of both sOLE and soul. The young speakers are the first generation to exhibit both merger and this type of consistent allophony, suggesting that a lack of merger between MOAN/ MOWN may have previously prevented backing of SOLE/soul and, in turn, this allophony.

\subsection{The GOOSE/MOAN merger}

Figure 6 shows a clear change in apparent time: the respective nuclei of GOosE and MOAN are shown to be moving apart. MOAN is predominantly shifting along the dimension of F1, while Goose shows more movement along F2. Old speakers show a good deal of overlap, potentially indicating variable, phonetic merger of some sort, but also demonstrate vast variation in $\mathrm{F} 2$ values. Both Goose and MOAN values range from extreme fronting of F2, to a rather high back position. Middle-aged speakers begin to show more concentrated F2 values for Goose, and their mean formant values for GOOSE and MOAN are clearly separate, although some degree of overlap is still present. Young speakers are generally shown to make a clear distinction between MOAN and GOOSE, and their F2 values are considerably more condensed.

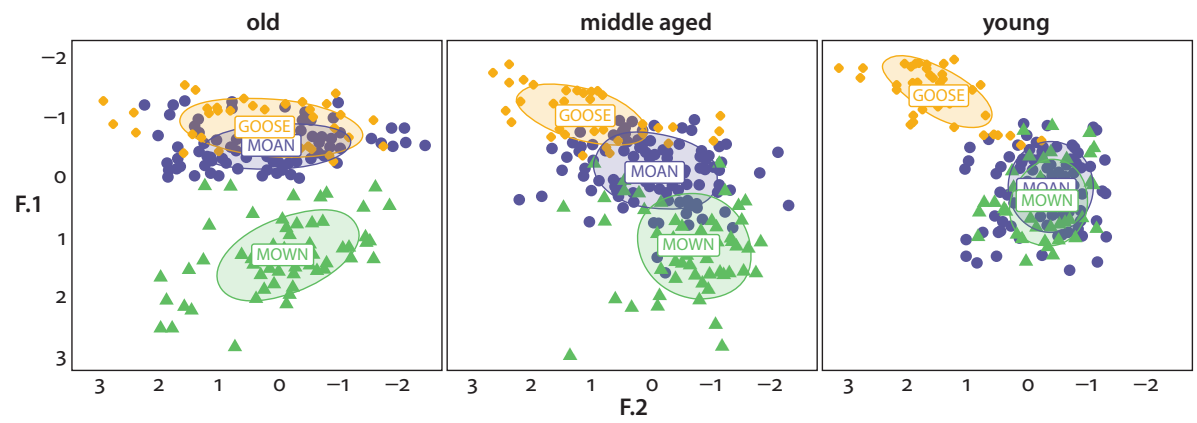

Figure 6. Normalised formant values for the nuclei of GOOSE, MOAN and MOWN vowels (all tokens) with means and ellipses to one standard deviation 
Figure 7 confirms that the extent of merger between the respective nuclei of GOOSE and MOAN is highly correlated with age, where the young group shows the greatest extent of distinction. The difference between young speakers when compared to both middle-aged and old speakers is shown to be significant in the model (Appendix 2). Middle-aged speakers retain the distinction to varying degrees, and this is, for the most part, done more robustly than the old speakers. The extent of distinction is, as expected, smallest for old speakers. In particular, two male speakers - OM4 and OM1 - have Pillai scores of 0.022 and 0.051 , respectively. These low Pillai scores may indicate a state of near-merger or even complete merger.

On inspection of the extent of merger for these speakers' offglides (Figure 8) OM4, again, shows a high degree of overlap, indicating potential near-merger or complete merger for both elements of the diphthong, however, OM1 shows the opposite, exhibiting a lesser extent of overlap between the two offglides (0.241). While Pillai scores do not capture particular directionality, this latter case may reflect some variation within the distribution of the offglide and potentially hint at what is originally reported by Labov et al. (1972) in stage three of the chain shift, where the offglides of 'toe' and 'too' were shown to move in different directions for

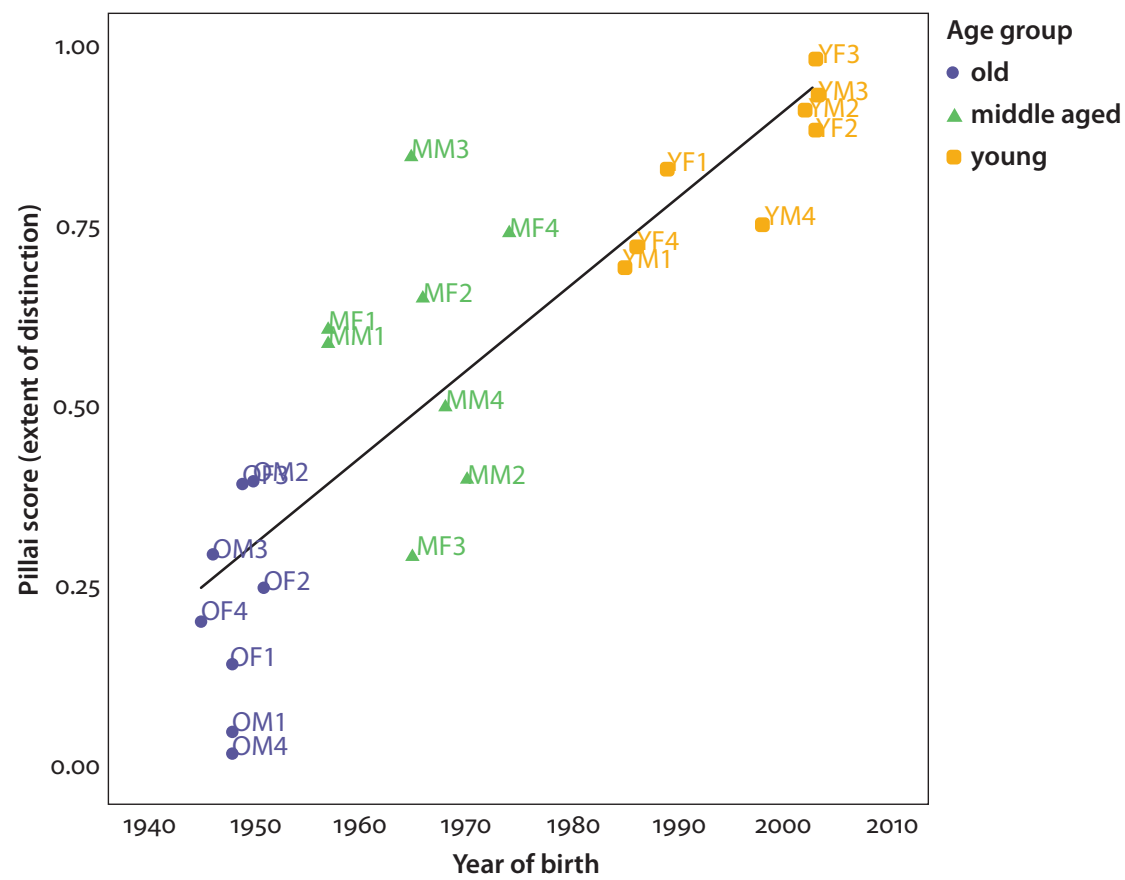

Figure 7. Year of birth vs. Pillai score, showing the extent of distinction between GOOSE/MOAN (nuclei) across age groups with regression line 


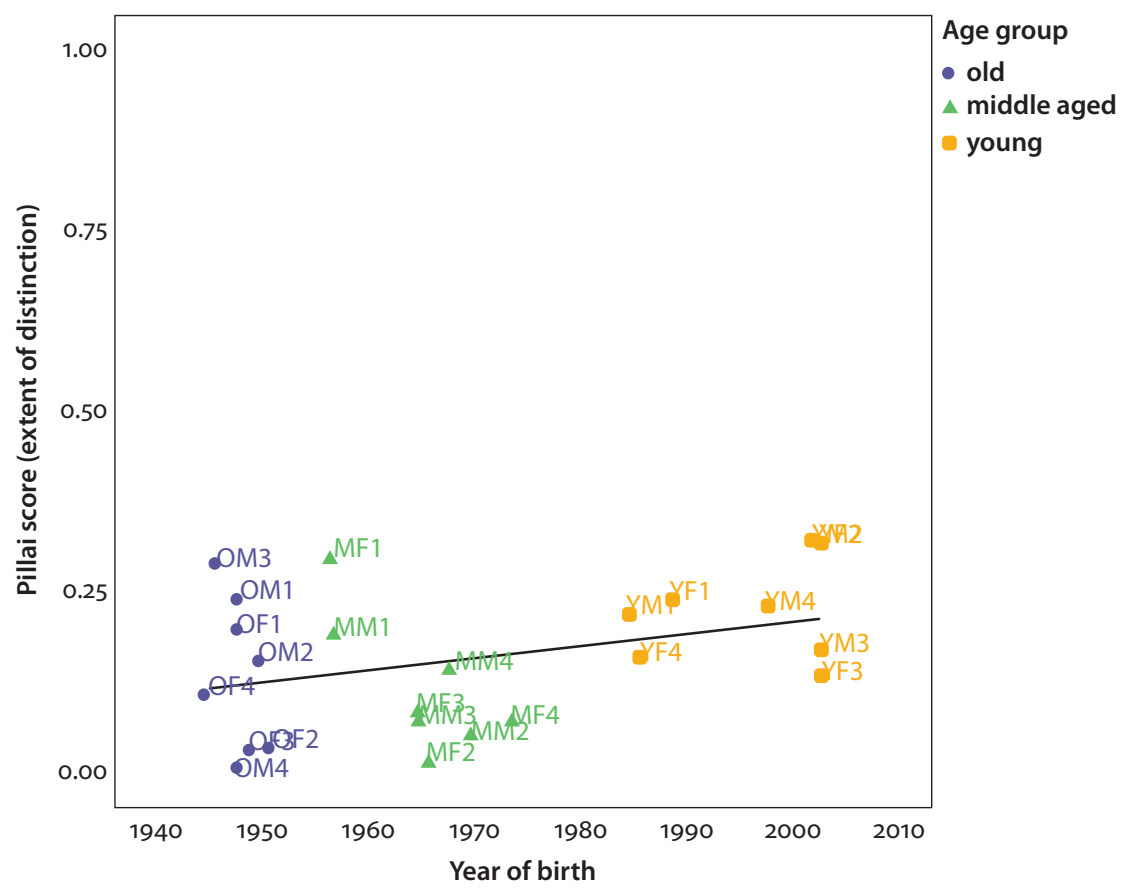

Figure 8. Year of birth vs. Pillai score, showing the extent of distinction between GOOSE/MOAN (offglide) across age groups with regression line

the two young speakers. More generally, there appears to be a steady change in progress for the offglides in apparent time, and the difference between young speakers when compared to both middle-aged and old speakers is shown as significant in the model (Appendix 3). This may reflect the apparent reduction in phonetic variation, which is merely part of the overall stabilisation towards two clearly distinct phonemes, more so than an obvious shift in phonetic quality. To summarise, then: there is a clear change in apparent time where the respective nuclei of GOosE and MOAN are becoming more distinct between generations, while the offglides have remained relatively stable over time, reaching a point of even greater stability for young speakers. 


\subsection{GOOSE fronting}

Analysis of the GOOSE/MOAN merger reveals another trend within the data, which is the fronting of GOOSE. Figure 9 shows that coda /1/ has an inhibitory effect on fronting, as Goose words show higher F2 values than GHOUL words across all groups. This has been reported in a number of studies (Hall-Lew 2005; Fridland 2008; Holmes-Elliott 2015), although in this study, GHOuL is shown not to be stable over time and is, instead, backing marginally. Age is the only significant social predictor of Goose fronting (Appendix 4), where the difference in F2 values between young speakers and old speakers is highly significant. The young and middle-aged speakers pattern closely together, and the range of F2 values for GOOSE is shown to be much more variable for old speakers than for these groups, which both show more advanced $\mathrm{F} 2$ values.
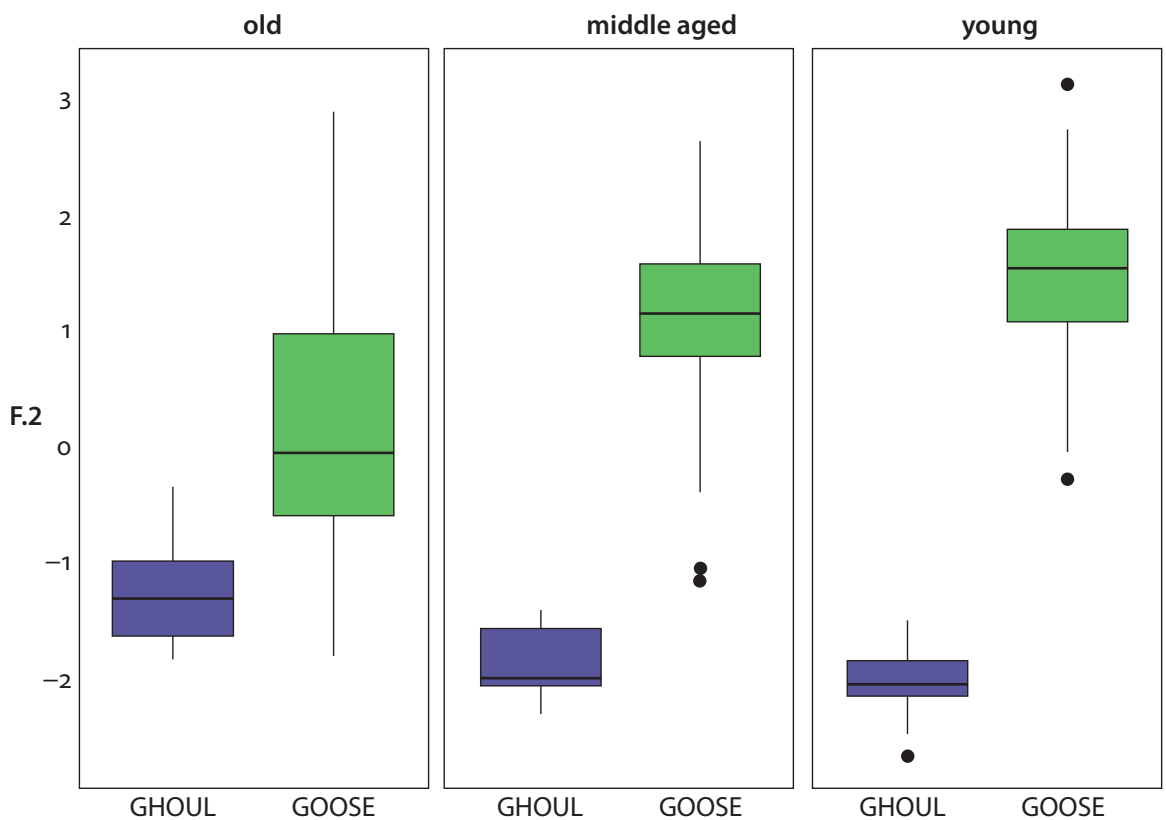

Figure 9. Boxplot showing normalised F2 values for GHOUL vs. GOOsE sets across age groups

Regarding preceding environment, the data in Figure 10 show that the highest F2 values are largely driven by preceding palatals (cf. Fridland 2008; Mesthrie 2010; Holmes-Elliott 2015). The difference between palatals when compared to both coronals and non-coronals is reported as significant for all age groups. 

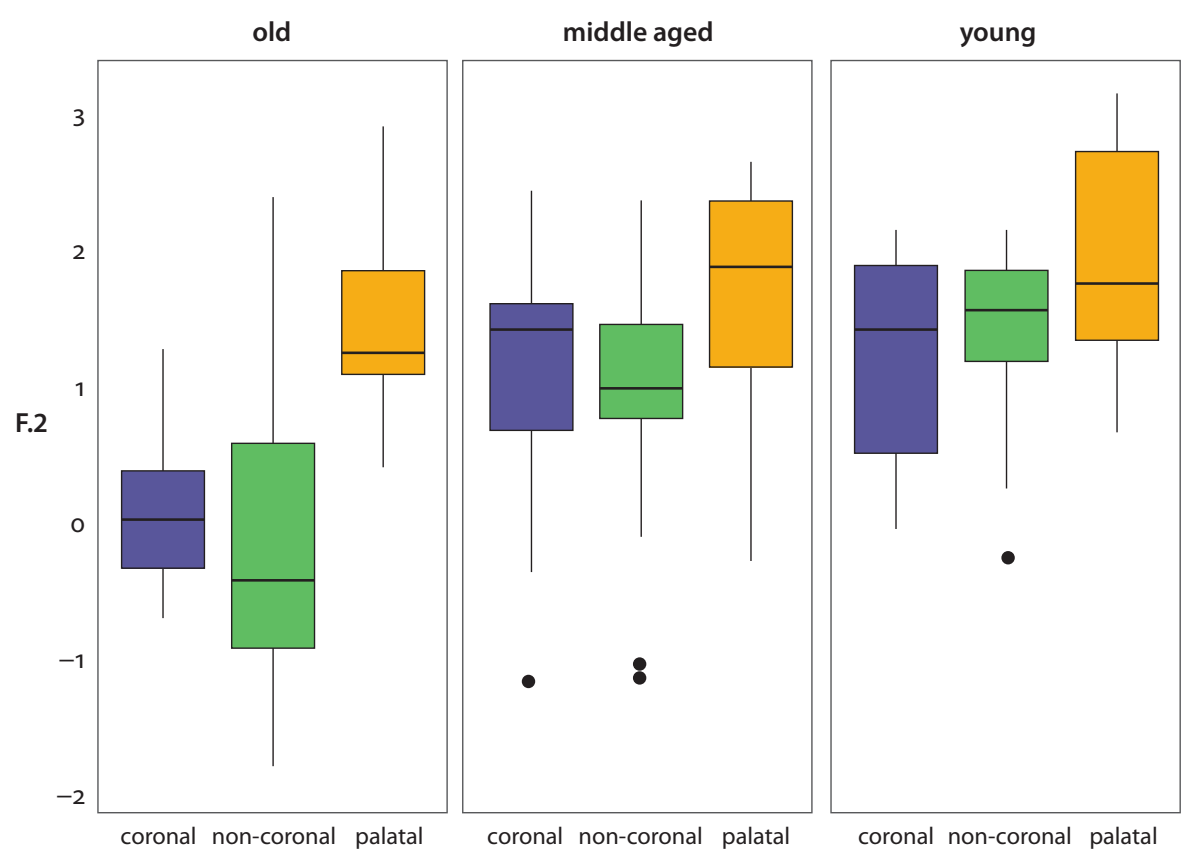

Figure 10. Boxplot showing normalised F2 values for GoosE by preceding environment and age group

\section{Discussion}

\subsection{The MOAN/MOWN merger}

Apparent time results point to an ongoing merger of the MOAN and MOWN vowels in Lowestoft, where the longstanding distinction is only retained by the middle-aged and old groups. The merger is markedly correlated with age, where the distinction appears to have abruptly collapsed for young speakers who now realise a single GOAT vowel, as in other varieties of SBE. These results support earlier findings from Trudgill \& Foxcroft (1978) who previously report that the distinction is beginning to suffer a marked loss in urban areas of northern Suffolk, such as Lowestoft. The working-class speakers reported on in this study, however, do not employ merger by transfer, as Trudgill \& Foxcroft (1978) earlier report for working-class speakers in southern East Anglia. The evidence summarised points to merger by approximation, as the phonetic difference between those who maintain the phonemic distinction was shown to decrease between generations. The resulting vowel resembled the quality of neither of the original phonemes and, in this case, both moved 
inwards along the dimension of F1. This aligns with Trudgill and Foxcroft's (1978) previous reports of a merger towards a single phoneme realised in an intermediate area of the original two-phoneme space for middle-class speakers in northern East Anglia, confirming that, class aside, geography plays a key role. Britain (2009) also describes the intermediate form as an interdialectal hybrid, which is a direct result of contact between innovation and the traditional form. An increase in spatial mobility for the younger generations, marked growth in counter-urbanisation to Lowestoft, (Fielding 1992; Gordon et al., 2017) and extensive new contact with outside varieties as a result of the fishing industry's recent collapse, all may have influenced this outcome. While the success of mergers varies case by case and is dependent on a series of linguistic factors, such as the number of minimal pairs that depend on the distinction or the number of distinctions already made along that phonetic dimension, Labov (1994: 343) describes the evidence for the absence of social affect on mergers across sociolinguistics as "massive" and "overwhelming", i.e. mergers by approximation are internally motivated changes from below (ibid: 327 ) characterised by "a gradual shift in the behaviour of successive generations, well below the level of conscious awareness" (Labov 1966: 128). Here, age was the only social predictor of merger, which was characterised by a gradual and continuous movement, so this holds within the limitations of the data. Indeed, beyond the emergence of GOAT allophony, these findings point to a relatively straightforward change for the working-class community reported on here.

Overall, while this study lacks the perception data to allow for confirmation of a complete merger, for these findings to later emerge as a case of near-merger, which has been subsequently reversed via some non-linguistic means, seems improbable. The young speakers' Pillai scores ranged between 0.002 and 0.323 , indicating a high degree of phonetic overlap, bordering on absolute for some. Not only should we also consider the overwhelming evidence of a single GOAT class across much of the English-speaking world, but we should look to the GOAT allophony shown by young speakers for both MOAN/SOLE and MOWN/soul. Historically absent from the dialect (Trudgill 1988a), its presence may hint that the dialect is levelling towards varieties located to the south, as London (and other southern) varieties contrast $[\mathrm{b} \sigma]$ and $[\Lambda \mho]$ in pre-lateral and non-pre-lateral environments,

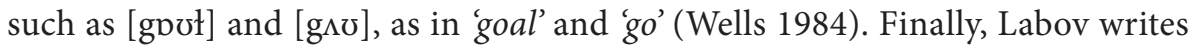
"if a merger was encouraged by overcrowding along a particular dimension, the reversal would be more difficult than otherwise" (1994: 330). The variety of English spoken by older generations in Lowestoft clearly exhibits non-ideal conditions in which to maintain distinctions or reverse mergers, due to overlap between the back vowels, not to mention it includes residual distinctions lost centuries ago for many varieties. Mergers by approximation, such as this, may take three or 
four generations to complete (Labov 1994: 323). All things considered, we would therefore expect the MOAN/MOWN merger to follow this chronology in Lowestoft and reach completion almost inevitably.

\subsection{The GOOSE/MOAN merger}

It was clearly established through the data that MOAN is implicated in a merger-in progress with MOWN, but what about MOAN's rather complicated relationship with GOOSE? The data suggest that a true phonemic merger between GOOSE and MOAN never reached completion, as demonstrated by their increasing separation across generations, which is now more or less consistent for young speakers. At the individual level it was suggested that, at best, there was either a variable, phonetic merger or a near-merger for some, destabilising the relationship between the two phonemes, but not derailing it completely to the point of phonemic merger. These findings reflect the notion that those mergers reported as 'reversed' must never have truly reached completion and are thus near-mergers (Labov et al., 1972). The above, however, can only be confirmed with perception tests. Returning to Labov et al's (1972) 'pattern 3' chain shift, the first question to ask is whether the data provide any evidence that East Anglian locales beyond Norwich followed it, or whether Norwich behaves distinctively. It appears, though, that the chain may have been disrupted at one or several points for this speech community. Stage one of the chain shift (fronting of GOOSE) was undoubtedly successful to a degree: the data show that the nucleus of Goose has high, albeit variable, F2 values for both old and middle-aged speakers. On the other hand, old speakers also show some very back realisations. This suggests that this first stage may only ever have been completed variably, with some Goose words left behind. These items then remained in a high back position and were available to overlap with MOAN words after it raised into the original high back position of GOose at stage two. Harrington et al. (2008: 2826) follow Ohala (1981) in arguing for the listener as a source of sound change, suggesting that $/ \mathrm{u} /$-fronting may have emerged when listeners failed to parse the fronting effects of either a preceding palatal or coronal consonant. Given that traditional East Anglian dialects exhibit generalised yod dropping where the palatal glide $/ \mathrm{j} /$ is variably dropped from sequences of $\mathrm{C}+/ \mathrm{ju} /$, it is possible that such an effect on phonetic reinterpretation could have been weakened, resulting in such variation. A second account of the variation seen between GOOSE and MOAN is to assume that stages one and two reached completion without problems and that some Goose words were later moved to the MOAN set by lexical transfer, as Trudgill writes (1988a). Otherwise, this variation could simply be the fallout of community exposure, which has been shown to affect perception in different ways (Warren \& Hay 2005; Hay 
et al., 2006). Given the vast amount of stylistic variation reported across the social classes (Trudgill 1988a) and the hypercorrection pertaining to GOOSE and MOAN/ MOwN earlier reported (Trudgill 1988b), it would not be surprising if exposure to speakers with near-mergers led to a situation where non-merged speakers fail to perceive a difference and apply the wrong differences in production, or exposure to non-merged speakers leads near-merged speakers to try and reverse (near-)merged realisations with error.

Stage three of the shift, where a push ostensibly resulted in the fronting of MOAN words and a near-merger with Goose, is not immediately obvious in the data. If present, the near-merger is potentially only relevant for old speakers, for whom the nuclei of MOAN and GOOSE appear to be just as likely to surface in similarly centralised positions as they do high, back positions. Labov et al. (1972) illustrate that the offglide is the differentiating feature for speakers in Norwich who have reached stage 3 of the shift, however, the Pillai scores reported here suggest the opposite: the offglides of GOOSE and MOAN in fact show greater extent of merger than the nuclei for all speakers, with the exception of two old speakers. It may well be that, if executed, this stage varied amongst individuals, however, these results are not wholly comparable with those of Labov et al. (1972), who used minimal pairs, rather than a reading passage. More fine-grained acoustic analysis of the offglides at the individual level could, however, potentially be revealing if the phonetic distinction is slight, as this may not be captured by Pillai measurements.

Overall, the extent to which the Lowestoft speakers participated in the full chain shift remains uncertain and requires more in-depth acoustic analyses, but the evidence for an unsuccessful phonemic merger between GOOSE and MOAN is less ambiguous, as both sets are realised as distinct by young speakers today. This incomplete merger is, however, not insignificant and it can be argued to have played an important role in the historical development of East Anglian English. Trudgill (1988b) earlier suggests that overlap between GOOSE and MOAN may have disfavoured a merger between MOAN and MOWN. This is clear from the data here, as a MOAN/MOWN merger only occurs in the group that successfully separates GOOSE from MOAN. Without MOAN's phonetic entanglement with GOOSE, the phonological merger of MOAN and MOWN may have occurred much sooner, as this complication amongst the back vowels potentially prolonged the systematic reorganisation we have come to see in more recent years. 


\subsection{GOOSE fronting}

The data show a change in apparent time, where Goose is shifting forward from an already non-back position across generations. The middle-aged speakers may have led this change, as they are shown as the first generation to separate Goose and MOAN with any degree of consistency. This may reflect a social indexing strategy, employed to differentiate themselves from the more traditional speakers. The results reveal that high F2 values for GOosE were significantly correlated with age, where young speakers have the most front productions. Age is usually the most important social predictor of Goose fronting (Holmes-Elliott 2015) and the fact that change is more advanced in young speakers is a common theme amongst the literature (Williams \& Kerswill 1999; Harrington et al., 2008; Hall-Lew 2005; Cheshire et al., 2008; Holmes-Elliott 2015; Baranowski 2017; Jansen 2017). A failure to identify either males or females as leaders of this change is not exceptional, as studies have shown that Goose does not always show consistent patterning for gender (Hall-Lew 2005). Goose fronting is not generally reported as socially salient, but instead as an endogenous change, tied to systemic linguistic factors (cf. Harrington et al., 2008; Holmes-Elliott 2015), one of which is influence from preceding environment. Holmes-Elliott (2015: 185) summarises the likely hierarchy of preceding environments to promote Goose fronting from across the literature as palatals $>$ coronals $>$ non-coronals. The data here largely echo these findings, as palatals are clearly fronted, while coronals and non-coronals resulted in lower F2s. In a similar vein to the observed backing of MOAN and MOWN in pre-lateral environments, GOOSE and GHOUL follow the same split that is seen in other varieties of SBE (Wells 1984), further suggesting some signs of levelling and external influence on the phonetic realisation of these forms, as the split has become more pronounced between generations. Looking forward, Labov's third principle of sound change predicts that GOOSE fronting precedes GOAT fronting, as "back vowels move to the front" (1994: 116). While the results here do not show a tendency for either MOAN or MOWN to front as part of a chain shift along with GOOSE, stabilisation towards a single GOAT vowel may now produce the right conditions in which fronting can occur, as in other varieties of English (cf. Haddican et al., 2013; Baranowski 2017).

\section{Conclusion}

The instability of the back vowels and this clash of (variable) merger-as-state $($ GOOSE $=$ MOAN) with merger-as-process $($ MOAN $>$ MOWN) has been shown to complicate and potentially prolong sound change in East Anglian English. A merger by approximation of MOAN and MOWN was shown as a change in apparent time along 
the north-south linguistic divide in East Anglia, and is likely near completion for some young speakers, while fully completed for some. It may be that without the earlier commencement of a chain shift and MOAN's raising to subsequently overlap variably with GOOSE, MOAN and MOWN might have met sooner and the distinction less successfully retained for so long. Lowestoft's relative isolation may also have played a role in this prolonged resistance to change. Life beyond the fishing industry in the town is markedly different now than in the years that came before. With less industry on its doorstep, the community has found new ways to subsist, which has led to considerable dialect contact through travel to nearby towns such as Norwich, as well as with those arriving as a direct result of increased counter-urbanisation in the region. The area in which the traditional dialects of East Anglia are spoken has shrunk considerably in recent years (Fisiak \& Trudgill 2001) and the effects of levelling have been felt more in the south of the region. The changes reported here along the linguistic divide between northern and southern East Anglia may represent a sign of things to come. A number of conservative features, such as yod dropping and lack of third personal singular -s marking, have been shown to be in their late stages of change in the southern locales of East Anglia (Butcher 2013; Potter 2018). Should their diffusion northwards be even half as successful as the loss of the ME distinction, this paints an uncertain picture for the dialect area as a whole.

\section{Acknowledgements}

Many thanks to Jennifer Nycz, Peter Trudgill, Bert Vaux and Connor McCabe, as well as the reviewers and editors of this volume, for all their helpful comments and suggestions.

\section{References}

Adank, Patti, Roel Smits, \& Roeland van Hout. 2004. A comparison of vowel normalization procedures for language variation research. Journal of the Acoustical Society of America 116. 3099-3107. https://doi.org/10.1121/1.1795335

Bates, Douglas, Martin Mächler, Ben Bolker \& Steve Walker. 2015. Fitting linear mixed-effects models using lme4. Journal of Statistical Software 67(1). 1-48. https://doi.org/10.18637/jss.v067.io1

Baranowski, Maciej. 2017. Class matters: The sociolinguistics of GOosE and GOAT in Manchester. English Language Variation and Change 29. 301-339. https://doi.org/10.1017/So954394517000217

Boersma, Paul \& David Weenink. 2020. Praat: Doing phonetics by computer. Version 6.1.16. http://www.praat.org. (6th June, 2020.)

Britain, David. 2002. Surviving Estuary English: Innovation diffusion, koineisation and local dialect differentiation in the English Fenland. Essex Research Reports in Linguistics 41. 74-103. 
Britain, David. 2005. Innovation diffusion: "Estuary English" and local dialect differentiation: The survival of Fenland Englishes. Linguistics 43(5). 995-1022. https://doi.org/10.1515/ling.2005.43.5.995

Britain, David. 2009. One foot in the grave? Dialect death, dialect contact, and dialect birth in England. International Journal of the Sociology of Language 196-197. 121-155.

Butcher, Kerri-Ann. 2013. An investigation into yod dropping in Ipswich. University of Essex: BA thesis.

Cheshire, Jenny, Sue Fox, Paul Kerswill \& Eivind Torgersen. 2008. Ethnicity, friendship network and social practices as the motor of dialect change: Linguistic innovation in London. Sociolinguistica 22. 1-23. https://doi.org/10.1515/9783484605299.1

Ellis, Alexander John. 1889. The existing phonology of English dialects compared with that of West Saxon speech (On Early English Pronunciation 5). Woodbridge: English Text Society.

Fielding, Anthony J. 1992. Migration and social mobility: South East England as an escalator region. Regional Studies 26(1). 1-15. https://doi.org/10.1080/00343409212331346741

Fisiak, Jacek \& Peter Trudgill. 2001. Preface. In Jacek Fisiak \& Peter Trudgill (eds.), East Anglian English, ix-xii. Woodbridge: D.S Brewer.

Fridland, Valerie. 2008. Patterns of /uw/, / /, and /ow/ fronting in Reno, Nevada. American Speech 83(4). 432-54. https://doi.org/10.1215/00031283-2008-030

Garde, Paul. 1961. Réflexions sur les différences phonétiques entre les langues slaves. Word 17. 34-62. https://doi.org/10.1080/00437956.1961.11659746

Gordon, Ian, Tony Champion, Neil McDonald \& Christine Whitehead. 2017. Review of research on migration influences and implications for population dynamics in the wider south east: Providing state of the art evidence to local authorities in the East of England. http://www.lse.ac.uk/business-and-consultancy/consulting/assets/documents/review-of-research-on-migration-influences-and-implications-for-population-dynamics-in-the-widersouth-east-technical-report.pdf. (6 June, 2020.)

Harrington, Jonathan \& Steve Cassidy. 1999. Techniques in speech acoustics (Text, Speech and Language Technology 8). The Netherlands: Kluwer Academic publishers. https://doi.org/10.1007/978-94-011-4657-9

Harrington, Jonathan, Felicitas Kleber \& Ulrich Reubold. 2008. Compensation for coarticulation, /u/-fronting, and sound change in standard southern British: An acoustic and perceptual study. The Journal of the Acoustical Society of America 123(5). 2825-2835. https://doi.org/10.1121/1.2897042

Haddican, Bill, Paul Foulkes, Vincent Hughes \& Hazel Richards. 2013. Interaction of social and linguistic constraints on two vowel changes in northern England. Language Variation and Change 25. 371-403. https://doi.org/10.1017/So954394513000197

Hall-Lew, Lauren. 2005. One shift, two groups: When fronting alone is not enough. Penn Working Papers in Linguistics 10(2). 105-116.

Hall-Lew, Lauren. 2009. Ethnicity and phonetic variation in a San Francisco neighborhood. Stanford University: Ph.D. thesis.

Hay, Jennifer, Paul Warren \& Katie Drager. 2006. Factors influencing speech perception in the context of a merger-in-progress. Journal of Phonetics 34(4). 458-484.

https://doi.org/10.1016/j.wocn.2005.10.001

Herzog, Marvin I. 1965. The Yiddish language in northern Poland: Its geography and history. Special issue of International Journal of American Linguistics 31(2).

Holmes-Elliott, Sophie. 2015. London calling: Assessing the spread of metropolitan features in the southeast. University of Glasgow: Ph.D. thesis. 
Jansen, Sandra. 2017. Change and stability in Goose, GOAT and ғOот: Back vowel dynamics in Carlisle English. English Language and Linguistics 23(1). 1-29. https://doi.org/10.1017/S1360674317000065

Kendall, Tyler \& Erik R. Thomas. 2010. Vowels: Vowel manipulation, normalization, and plotting in R. R package, version 1.1. http://ncslaap.lib.ncsu.edu/tools/norm/. (18 June, 2020.)

Kennedy, Marianna. 2006. Variation in the Pronunciation of English by New Zealand school children. Victoria University of Wellington: MA thesis.

Kökeritz, Helge. 1932. The phonology of the Suffolk dialect, descriptive and historical. Uppsala University: Appelbergs Boktryckeri Aktiebolag.

Labov, William. 1966. The social stratification of English in New York City. Washington D.C.: Centre for Applied Linguistics.

Labov, William. 1994. Principles of linguistic change. Volume 1: Internal factors. Oxford: Blackwell. Labov, William, Sharon Ash \& Charles Boberg. 2006. Atlas of North American English: Phonetics, phonology and sound change. Berlin: Mouton de Gruyter. https://doi.org/10.1515/9783110167467

Labov, William, Mark Karen \& Corey Miller. 1991. Near-mergers and the suspension of phonemic contrast. Language Variation and Change 3(1). 33-74.

https://doi.org/10.1017/S0954394500000442

Labov, William, Malcah Yaeger \& Richard Steiner. 1972. A quantitative study of sound change in progress. Philadelphia: U.S. Regional Survey.

Lindsey, Geoff. 2019. English after RP: Standard British pronunciation today. London: Palgrave Macmillan. https://doi.org/10.1007/978-3-030-04357-5

Maguire, Warren, Lynn Clark \& Kevin Watson. 2013. Introduction: What are mergers and can they be reversed? English Language and Linguistics 17(2). 229-239. https://doi.org/10.1017/S1360674313000014

Mesthrie, Rajend. 2010. Sociophonetics and social change: Deracialisation of the Goose vowel in South African English. Journal of Sociolinguistics 14(1). 3-33.

https://doi.org/10.1111/j.1467-9841.2009.00433.x

Nycz, Jennifer. 2019. Linguistic and social factors favoring acquisition of contrast in a new dialect. In Sasha Calhoun, Paola Escudero, Marija Tabain \& Paul Warren (eds.), Proceedings from the 19th International Congress of Phonetic Sciences, Melbourne, Australia, August 2019, 1480-1484. Canberra: Australasian Speech Science and Technology Association Inc.

Ohala, John. 1981. The listener as a source of sound change. In Carrie S. Masek, Robert A. Hendrick \& Mary Frances Miller (eds.), Papers from the parasession on language and behaviour, 178-203. Chicago: Chicago Linguistic Society.

Potter, Robert. 2018. A variationist multilocality study of unstressed vowels and verbal -s marking in the peripheral dialect of east Suffolk. University of Essex: Ph.D. thesis.

RStudio Team. 2020. RStudio: integrated development for R. RStudio. http://www.rstudio.com/. (6th June, 2020.)

Samuels, Bridget. 2006. Nothing to lose but their chains: Rethinking vocalic chain shifting. Harvard University: BA thesis.

Trudgill, Peter. 1974. The Social Differentiation of English in Norwich. Cambridge: Cambridge University Press.

Trudgill, Peter. 1988a. Norwich revisited: Recent linguistic changes in an English urban dialect. English World-Wide 9(1).33-49. https://doi.org/10.1075/eww.9.1.03tru

Trudgill, Peter. 1988b. The great East Anglian merger mystery. In Rémi Jolivet \& Florence Epars Heussi (eds.), Mélanges offerts en hommage à Mortéeza Mahmoudian. Tome II. (Cahiers de l'ILSL11). 415-23. Lausanne: Université de Lausanne. 
Trudgill, Peter. 2001. Modern East Anglia as a dialect area. In Jack Fisiak \& Peter Trudgill (eds.), East Anglian English, 1-12. Woodbridge: D.S Brewer.

Trudgill, Peter. 2004. The dialect of East Anglia: Phonology. In Bernd Kortmann \& Edgar Schneider (eds.), A handbook of varieties of English: A multimedia reference tool (Phonology 1), 163-177. New York: Mouton de Gruyter.

Trudgill, Peter. 2021. The English of East Anglia. Amsterdam: Benjamins.

Trudgill, Peter \& Tina Foxcroft. 1978. On the sociolinguistics of vocalic mergers: Transfer and approximation in East Anglia. In Peter Trudgill (ed.), Sociolinguistic patterns in British English, 69-79. London: Edward Arnold.

Warren, Paul \& Jen Hay. 2005. Using sound change to explore the mental lexicon. In Claire Fletcher-Flinn \& Gus Haberman (eds.), Cognition, language, and development: Perspectives from New Zealand, 101-121. Bowen Hills, Queensland: Australian Academic Press.

Wells, John. 1982a. Accents of English I: An introduction. Cambridge: Cambridge University Press. https://doi.org/10.1017/CBO9780511611759

Wells, John. 1982b. Accents of English II: The British Isles. Cambridge: Cambridge University Press. Wells, John. 1984. English accents in England. In Peter Trudgill (ed.), Language in the British Isles, 55-69. Cambridge: Cambridge University Press.

Williams, Ann \& Paul Kerswill. 1999. Dialect levelling: Change and continuity in Milton Keynes, Reading and Hull. In Paul Foulkes \& Gerard J. Docherty (eds.), Urban voices: Accent studies in the British Isles, 141-162. London: Arnold.

Appendix 1. Fixed effects linear regression analysis of the MOAN/MOWN merger

\begin{tabular}{llcccc}
\hline Predictor & & Estimate & Std. Error & t-value & p-value \\
\hline (Intercept) & 0.085 & 0.061 & 1.379 & 0.181 \\
Age (baseline: young) & & & & & \\
& Middle aged & 0.528 & 0.075 & 6.972 & $<0.001$ \\
& Old & 0.707 & 0.075 & 9.335 & $<0.001$
\end{tabular}

Gender (baseline: female)

$\begin{array}{lllll}\text { Male } & 0.043 & 0.061 & 0.703 & 0.448\end{array}$

\section{Appendix 2. Fixed effects linear regression analysis of the GOOSE/MOAN merger (nuclei)}

\begin{tabular}{lccccc}
\hline Predictor & Estimate & Std. Error & t-value & p-value \\
\hline $\begin{array}{l}\text { (Intercept) } \\
\text { Age (baseline: young) }\end{array}$ & 0.854 & 0.060 & 14.136 & $<0.001$ \\
& Middle aged & -0.259 & 0.074 & -3.508 & $<0.01$ \\
& Old & -0.619 & 0.074 & -8.368 & $<0.001$ \\
Gender (baseline: female) & & & & \\
& Male & -0.264 & 0.060 & -0.437 & 0.666 \\
\hline
\end{tabular}


Appendix 3. Fixed effects linear regression analysis

of the GOOSE/MOAN merger (offglides)

\begin{tabular}{lccccc}
\hline Predictor & Estimate & Std. Error & t-value & p-value \\
\hline $\begin{array}{l}\text { (Intercept) } \\
\text { Age (baseline: young) }\end{array}$ & 0.204 & 0.030 & 6.735 & $<0.001$ \\
& Middle aged & -0.110 & 0.038 & -2.901 & $<0.01$ \\
& Old & -0.091 & 0.038 & -2.408 & $<0.05$ \\
Gender (baseline: female) & & & & \\
& Male & 0.038 & 0.027 & 1.395 & 0.172 \\
\hline
\end{tabular}

Appendix 4. Mixed effects linear regression analysis of GoosE F2

\begin{tabular}{|c|c|c|c|c|c|}
\hline Predictor & & Estimate & Std. Error & t-value & p-value \\
\hline (Intercept) & & 2.415 & 0.237 & 10.183 & $<0.001$ \\
\hline \multicolumn{6}{|c|}{ Age (baseline: young) } \\
\hline & Middle aged & -0.368 & 0.234 & -1.571 & 0.129 \\
\hline & Old & -1.265 & 0.234 & -5.391 & $<0.001$ \\
\hline \multicolumn{6}{|c|}{ Gender (baseline: female) } \\
\hline & Male & -0.317 & 0.192 & -1.653 & 0.111 \\
\hline \multicolumn{6}{|c|}{ Preceding Environment (baseline: palatal) } \\
\hline & Coronal & -0.846 & 0.175 & -4.829 & $<0.001$ \\
\hline & Non-coronal & -1.097 & 0.192 & -5.546 & $<0.001$ \\
\hline
\end{tabular}





\title{
Modeling regional variation in voice onset time of Jutlandic varieties of Danish
}

\author{
Rasmus Puggaard \\ Universiteit Leiden
}

\begin{abstract}
It is a well-known overt feature of the Northern Jutlandic variety of Danish that /t/ is pronounced with short voice onset time and no affrication. This is not limited to Northern Jutland, but shows up across the peninsula. This paper expands on this research, using a large corpus to show that complex geographical patterns of variation in voice onset time is found in all fortis stops, but not in lenis stops. Modeling the data using generalized additive mixed modeling both allows us to explore these geographical patterns in detail, as well as test a number of hypotheses about how a number of environmental and social factors affect voice onset time.
\end{abstract}

Keywords: Danish, Jutlandic, phonetics, microvariation, regional variation, stop realization, voice onset time, aspiration, generalized additive mixed modeling

\section{Introduction}

A well-known feature of northern Jutlandic varieties of Danish is the use of a variant of / $t /$ known colloquially as the 'dry $t$ '. While the Standard Danish variant of / $t /$ has a highly affricated release, the 'dry t' does not. Puggaard (2018) showed that variation in this respect goes beyond just that particular phonetic feature and dialect area: the 'dry t' also has shorter voice onset time (VOT) than affricated variants, and a less affricated, shorter variant of /t/ is also found in the center of Jutland. This paper expands on Puggaard (2018) with the primary goals of providing a sounder basis for investigating the geographic spread of the variation, and to test whether the observed variation is limited to / $t$ / or reflects general patterns in plosive realization. I focus specifically on differences in VOT, and compare measurements of VOT from a large number of speakers on the Jutland peninsula. Testing is done on the basis of a large corpus of legacy recordings, which to a great extent manages to preserve an older stage of regional variation of Danish (Andersen 1981; Pedersen 1983; 
Goldshtein \& Puggaard 2019). Parts of the corpus have been used as a source for the Dictionary of Insular Dialects (Gudiksen \& Hovmark 2008), but the parts covering the Jutland peninsula have never before been used systematically for research.

There are many descriptions of Danish dialects available, including partial dictionaries, grammars, (morpho-)phonological descriptions, and topical descriptions of individual dialects (see references in Hovdhaugen et al. 2000). There are also holistic descriptions of the Danish dialect landscape (Bennike \& Kristensen 1912; Brøndum-Nielsen 1927; Skautrup 1968) which define dialect boundaries on the basis of isogloss bundles. With few exceptions, however, the descriptive work has lain dormant since the 1970s, leaving much of the existing work somewhat theoretically dated. ${ }^{1}$ A consequence of this is that progress in acoustic-phonetic methodology has barely improved our knowledge of regional phonetic variation in Danish (although see Ejstrup 2010; Goldshtein 2019); our knowledge of phonological variation is rich if spotty, while our knowledge of subphonemic systems is much poorer and mostly limited to what could be indicated with the notation systems of the early 20th century. Similarly, the recent great strides in available statistical computing has not improved our knowledge of geolinguistic variation in Denmark.

The initial hypothesis of this study is that the received knowledge about the cdry t' variant is wrong: it is not limited to northern Jutland. A number of theoretically motivated hypotheses follow: given recent findings of Chodroff and colleagues (Chodroff \& Wilson 2017; Chodroff et al. 2019) that variation in VOT tends to covary across laryngeal settings and places of articulation, I hypothesize that variation is not limited to /t/, but that all plosives follow similar patterns of variation. Early findings in VOT research (Lisker \& Abramson 1964) showed that voiced, voiceless, and aspirated plosives form internally consistent categories across languages, but later research has prompted Ladd (2011) to hypothesize that in a large enough typological study, there will be no such internally consistent categories, but rather an unbroken continuum - suggesting that the only principal limit on VOT variation comes from limits on perceptual acuity. The Jutlandic data might be able to inform our notions of the limits of variation in VOT in a small geographical area shared by one language community with the same set of phonemic plosives. I use generalized additive mixed modeling to investigate what variation is attributable to geography, without needing the assumption that this relationship is linear (Wieling et al. 2011, 2014); this method allows me to simultaneously test a number of hypotheses about the influence of other factors on VOT.

1. The lexicographic work, however, is still very much ongoing, centered around Jysk Ordbog (Jutlandic dictionary; JO; Hansen 2008) and Ømålsordbogen (Dictionary of Insular Dialects; e.g. Hovmark 2006). 


\section{Theoretical preliminaries}

\subsection{Voice onset time}

Measuring the relative time difference between the release of a plosive and the onset of voicing was popularized in a typological study by Lisker and Abramson (1964), who studied eleven languages and reported a relatively stable and neat three-way contrast between negative VOT indicating voiced plosives, near-null VOT indicating voiceless unaspirated plosives, and positive VOT indicating aspirated plosives. It has been confirmed by studies in psycholinguistics and neurolinguistics that VOT is responsible for categorical perception of laryngeal contrasts (e.g. Schouten \& van Hessen 1992; Simos et al. 1998).

Findings from later typological studies (e.g. Cho \& Ladefoged 1999) indicate that this neat three-way laryngeal distinction does not hold up against more data, and there are no known natural reasons why plosives would cluster in three groups on the basis of VOT. VOT has been shown to be affected by many different linguistic and extralinguistic factors, such as place of articulation (e.g. Docherty 1992; Cho \& Ladefoged 1999), height of the following vowel (e.g. Klatt 1975), speaker ethnicity (Ryalls et al. 1997, 2004), age (e.g. Benjamin 1982, but cf. e.g. Neiman et al. 1983), and gender (e.g. Torre \& Barlow 2009) - in addition to being highly speaker-specific (Allen et al. 2003). This leads to a number of specific hypotheses about the data under scrutiny (see Section 3.3). Consistent cues for laryngeal setting other than VOT have also been found, such as pitch onset (Hanson 2009; Kirby \& Ladd 2016) and closure duration in the case of singleton-geminate contrasts (e.g. Kraehenmann 2001). This means that VOT cannot tell the full story of either phonological laryngeal contrasts in plosives or variation in the realization of laryngeal contrasts. It is, however, a powerful indicator. A recent literature review (Abramson \& Whalen 2017) and a special issue of Journal of Phonetics (Cho et al. 2018) both celebrate 50 years of research on VOT, and show that VOT-related research is still very much ongoing. A recent major finding is that variation in VOT across speakers and across languages tends to covary for laryngeal settings and places of articulation; in other words, the range of across-speaker variation found for $/ \mathrm{p} /$ will on the one hand show parallels with that of $/ \mathrm{b} /$, and on the other hand show parallels with that of /t k/ (Chodroff \& Wilson 2017; Chodroff et al. 2019). 


\subsection{Danish plosives}

Standard Danish has six phonemic plosives in onset position /b d g p t k/, with a laryngeal distinction that relies on distinctions in positive VOT; as such, the lenis series $/ \mathrm{b} \mathrm{d} \mathrm{g/is} \mathrm{voiceless} \mathrm{unaspirated,} \mathrm{and} \mathrm{the} \mathrm{fortis} \mathrm{series} / \mathrm{pt} \mathrm{k} /$ is voiceless aspirated. Previous studies which measure the VOT of Danish plosives (Fischer-Jørgensen 1980; Mortensen \& Tøndering 2013) find relatively high VOT values for both laryngeal settings compared with other languages with an aspiration-based contrast, even in spontaneous speech. /t/ notably has strongly affricated release and is typically transcribed as [ $\mathrm{t}^{\mathrm{s}}$ ] (Grønnum 1998).

\subsection{The dialects of Jutland}

Although Standard Danish is now the primary means of communication throughout Denmark (Kristiansen 1998; Pedersen 2003), Kristiansen (2003a) judges that the majority of the speech community consisted of dialect speakers until the 1960s. In the late 1960s, however, Skautrup (1968: 96ff.) wrote that the dialects were in poor condition, and that the most likely features to survive were phonetic ones, which were unlikely to significantly influence mutual intelligibility. It was clear to Skautrup at the time that this development was more advanced on Zealand than on the Jutland peninsula or the smaller islands. The dialect leveling in Denmark had been long underway: in the 19th century, an obligatory education system was introduced and agrarian reforms led to increased mobility both in cities and rural areas (Skautrup 1968; Kristiansen 2003b), leading to disruption in the traditional dialects and the rise of the current standard language (based on High Copenhagen; Kristiansen 2003a). In the mid-20th century, dialect leveling was accelerated through the spread of national broadcasting in Standard Danish, and through government policies enforcing Standard Danish in the education system (Kristiansen 1990). While a recent research project finds that dialects are alive and well in parts of southern Denmark (Monka \& Hovmark 2016; Monka 2019), that same project also finds complete leveling in other regions strongly associated with dialect use, and in yet other regions complete replacement of the traditional dialect by a regionalized version of the standard language (Maegaard \& Monka 2019); dialect features may coexist with standard features, but take on different social functions that are not as geographically delimited as in the past (Scheuer et al. 2019). 
Figure 1 shows the major dialect areas of Jutland as defined by JO (K.03). ${ }^{2}$ Skautrup (1968: 97; 1937) bemoans the fact that there has been relatively little discussion of the basis of these divisions in Danish dialectology. He states that there are generally no sharp borders between Jutlandic dialect areas, but rather gradient phenomena running in parallel lines. Lines between areas are essentially drawn in transition areas between dialect "cores" (see Aakjær 1925). Skautrup judges that Danish dialects are mostly defined on the basis of isophones in the form of common phonological developments from previous stages of Danish or Norse. Differences in morphology and lexicon also play a role, but less so; syntax in particular seems to have played a very small role.

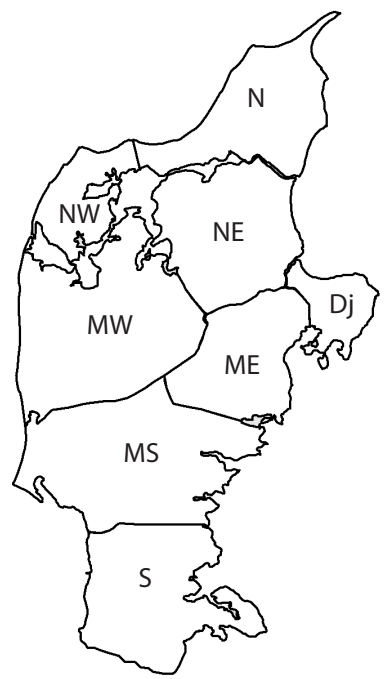

Figure 1. Traditional dialect areas of Jutland as defined by JO $(\mathrm{K} .03)^{3}$ $\mathrm{N}=$ Northern; $\mathrm{NW}=$ North-Western; $\mathrm{NE}=$ North-Eastern; $\mathrm{Dj}=\mathrm{Djursland}$; MW $=$ Mid-West ME = Mid-East; MS = Mid-South; $S=$ South

2. Dialect groups from this map will henceforth be written with initial capital letters.

3. Note that JO refers to the two Southernmost dialects as sønderjysk and sydjysk respectively; as there are no fitting English translations for these terms, Southern and Mid-Southern are used here. 
Skautrup (1968: 97ff) provides the clearest diagnostics for the dialect areas. The most important diagnostic is the article boundary, dubbed the "most famous Danish isogloss" by Thorsen (1912/1927), which is responsible for the relatively strict division between eastern and western dialects. In eastern dialects, as in Standard Danish, definiteness in nouns is marked with a suffix, while in western dialects, it is marked with a phrase-initial article. This is an exception to the generalization that the defining isoglosses in Danish dialectology are essentially phonological, but it should be noted that the article boundary also has major implications for both sentence prosody and segmental phonology (Skautrup 1952). Phonological boundaries of particular interest here are ones referring to plosives. In the Southern group, for example, historic ${ }^{*} / \mathrm{g} /$ is realized as a fricative $[-\chi]$ where it is either lost or weakened to a glide in Standard Danish. The Mid-Southern and central eastern groups show strong reduction of coda /-t/. A number of dialects have klusilspring (parasitic plosives), where stød - a suprasegmental glottal constriction that is specific to Danish - is in some contexts realized as a plosive following the vowel (e.g. Andersen 1955; Ejskjær 1990); this applies to the Mid-Western and Northern groups (Jensen 1902; Skautrup 1930). Finally, both the Northern and North-Eastern groups show widespread palatalization of coronals.

The diagnostics for the primary dialect groups do not yield many specific hypotheses about VOT. One might assume that dialects with a lot of plosive weakening will also have low VOT in general; however, as Standard Danish has cross-linguistically rather high VOT and rampant plosive weakening, this clearly does not pan out.

\subsection{Language variation and geography}

In the late 19th century, dialectology took a geographical turn (e.g. Wrede 1919). Rather than focusing on individual dialects, scholars started drawing detailed maps of distributions of features or lexical items; dialect atlases were produced for Germany (Wenker \& Wrede 1895) and France (Gilliéron \& Edmont 1902-1910), as well as Denmark (Bennike \& Kristensen 1912). In the wake of this work, a debate ensued about whether geolinguistic variation was of a purely continuous nature (Paris 1888) or whether individual dialects do, in fact, exist (Gauchat 1903). The conclusion seems to be that although the geographical distribution of features can be chaotic, there are adjacent bundles of important isoglosses, and there are areas not crossed by significant isoglosses. The field of dialect geography has yielded much rich descriptive work, but a commonality of studies of this era is that geography - in a pre-theoretical, Euclidian sense - is typically the only predictor of language variation (Chambers 2000; Britain 2010). Perhaps as a counterreaction, 
early variationist sociolinguistics (following Labov 1963) was relatively uninterested in geography, with the work of Trudgill (e.g. 1974) being a major exception.

Research into the relationship between geography and language variation is highly active in the rigorously data-driven field of dialectometry (Séguy 1973; see Wieling \& Nerbonne 2015 for a recent overview). Dialectometry has made large strides towards estimating the geographic basis of language variation using aggregate features and modern statistical methods. An explicit goal is to estimate how much variation can be explained with reference to geography. By aggregating pronunciations of a large number of words in a single analysis of variation in northern Dutch rather than focusing on well-known loci of variation, Nerbonne and Heeringa (2007) find that geographical distance accounts for more than half of the variation found in their data, making it logically the most influential predictor. ${ }^{4}$ While dialectometry often works with simple Euclidian space, the framework also allows for more socially influenced measures of space, as in e.g. Gooskens' (2005) study of variation in Norwegian using travel time rather than geographical distance as predictor. Furthermore, advances in statistics have made it possible to combine geographical predictors with large numbers of social predictors.

In this paper, I model geography simply using measures of longitude and latitude. As such, I implicitly make the assumption that there are no obvious differences between the natural area of Jutland and the organization of that area by humans. This is not a good assumption, but it is a highly practical one. The study is based on a legacy corpus recorded in the 1970s (see below), which is taken as the best available approximation of rural dialects in the early 20th century. Quantifying a human landscape is in itself a difficult task, and more so quantifying a human landscape as it looked a century ago.

4. Unless there are other predictors which are directly correlated with geographical distance. 


\section{Methodology}

\subsection{Corpus}

The research questions posed above will be answered using data from an extensive corpus of audio recordings made by the Peter Skautrup Centre for Jutlandic Dialect Research (Andersen 1981; Goldshtein \& Puggaard 2019). Recordings made during the most active years of data collection (1971-1976) have been digitized by the Royal Danish Library (RDL) and are available online in high quality. ${ }^{5}$ These recordings generally consist of sociolinguistic interviews with a single dialect speaker in their home. The informants mostly conform to the NORM criteria (non-mobile older rural males) often found in dialectological studies (Chambers \& Trudgill 1988), although a fair portion (22\%) of the informants were women. The primary purpose of the recordings was to gather material for lexicographical studies (Andersen 1981; Pedersen 1983; Gudiksen \& Hovmark 2008). A positive effect of this is that topics generally revolve around old cultural customs, and Hay and Foulkes (2016) report that speech about older events also tends to elicit older phonetic forms. Because speakers were explicitly chosen from a relatively uniform background - non-mobile, rural, previously employed in agriculture - there is little point in attempting to quantify social factors like class.

The RDL corpus contains recordings from 230 parishes in Jutland. 17 of these parishes were excluded from the study. There were three reasons for exclusion: (1) a small number of the recordings are group interviews, and these were excluded, unless they contained long stretches of speech from a single informant; (2) the quality was too poor; (3) the recording was too short to include a sufficient number of plosive tokens. This only affects areas with a reasonably high density of recordings. If a parish was represented with multiple recordings, one was chosen on the basis of either dialect authenticity judgments made by the original interviewers or audio quality. The audio quality of the recordings is generally similar across recordings, and relatively good.

The geographical coverage is shown in Figure 2; it is mostly fairly dense, but a bit thin in the center of the peninsula. The informants' median year of birth is 1896 (range 1871-1927), and their mean age at the time of recording was 77.4 years (range 45-101 years). This distribution is shown in Figures 3 and 4. For thirteen informants, no year of birth has been reported; these are expected to fall within the reported range. Most recording sessions consisted of multiple files (tapes), and the second file was generally chosen for analysis, so that the informant would have

5. https://dansklyd.statsbiblioteket.dk/samling/dialektsamlingen/ 
had time to accommodate to the presence of a recording device. All metadata and coordinates, including links to the original recordings, are available in the Dataverse repository (Puggaard 2020).

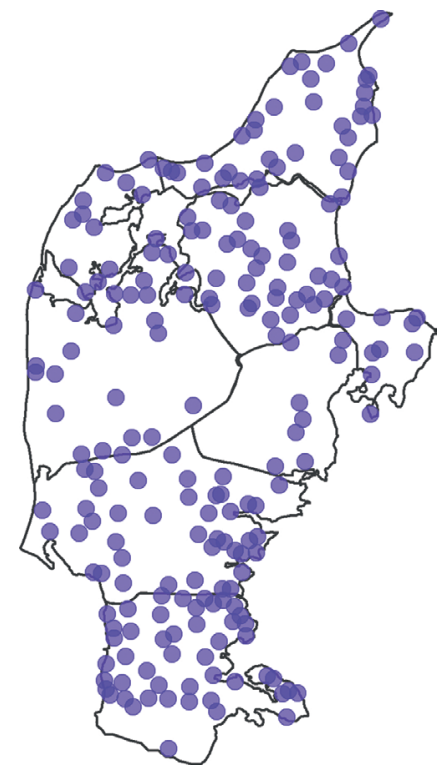

Figure 2. Geographical coverage in the current study

The distribution of informants across dialect areas by gender is seen in Table 1 . Gender has been shown to have an influence on VOT (e.g. Swartz 1992), particularly among elderly speakers (Torre \& Barlow 2009), and by including gender in the statistical model, we can check if this data can lend credence to those findings.

Table 1. Distribution of informants across dialect areas by gender

\begin{tabular}{lcrr}
\hline Dialect area & Informants & \multicolumn{1}{c}{ Male } & \multicolumn{1}{c}{ Female } \\
\hline Southern & 48 & $58.3 \%(n=28)$ & $41.7 \%(n=20)$ \\
Mid-Southern & 40 & $70 \%(n=28)$ & $30 \%(n=12)$ \\
Mid-Eastern & 9 & $66.7 \%(n=6)$ & $33.3(n=3)$ \\
Mid-Western & 25 & $92 \%(n=23)$ & $8 \%(n=2)$ \\
Djursland & 9 & $66.7 \%(n=6)$ & $33.3(n=3)$ \\
North-Eastern & 35 & $85.7 \%(n=30)$ & $14.3 \%(n=5)$ \\
North-Western & 12 & $91.7 \%(n=11)$ & $8.3 \%(n=1)$ \\
Northern & 35 & $91.4 \%(n=32)$ & $8.6 \%(n=3)$ \\
Total & 213 & $77 \%(n=164)$ & $23 \%(n=49)$ \\
\hline
\end{tabular}




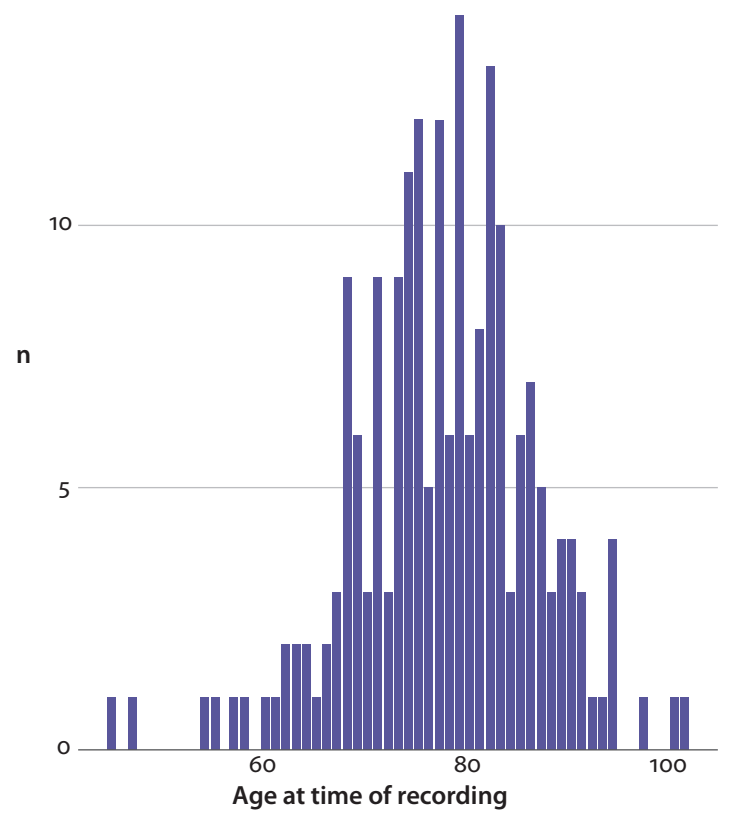

15

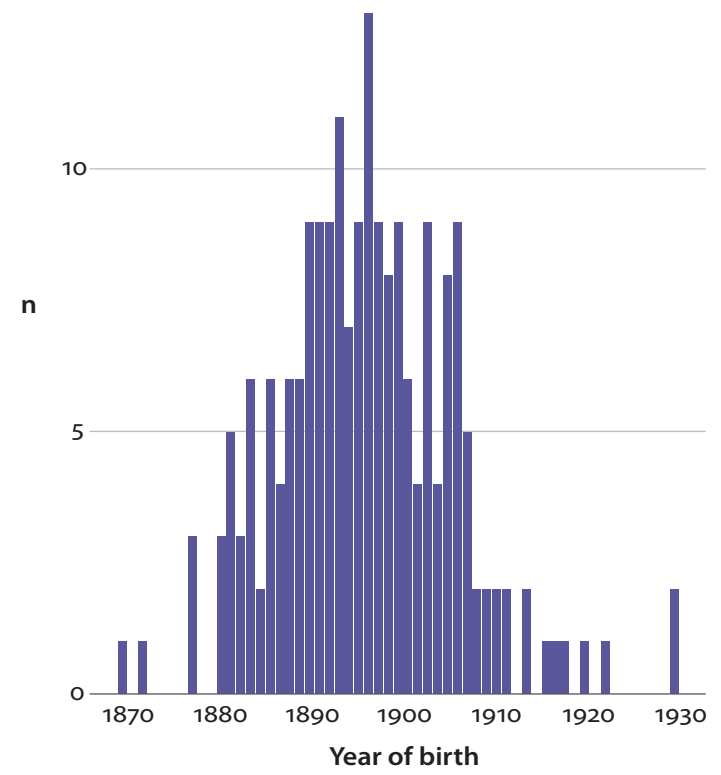

Figures 3-4. Age at the time of recording and year of birth of informants 


\subsection{Token selection}

In analyzing the recordings, I distinguish between the fortis series $/ \mathrm{p} \mathrm{t} \mathrm{k} /$ and lenis series / $\mathrm{b} \mathrm{d} \mathrm{g/} \mathrm{of} \mathrm{plosives.} \mathrm{This} \mathrm{distinction} \mathrm{is} \mathrm{contrastive} \mathrm{in} \mathrm{all} \mathrm{dialects,} \mathrm{although} \mathrm{the}$ implementation of the contrast differs; I do not intend to make claims about possible phonological features responsible for the contrast. For each speaker, all plosives were segmented until the 50th fortis plosive had been located. This leads to more fortis plosives than lenis plosives being segmented. The motivation for this is both practical and theoretical; the hypotheses guiding the study relied more on fortis plosives, which led to lenis plosives being prioritized less, due to the time-demanding nature of segmentation.

The segmented plosives were restricted to simple onset position, with palatalized tokens included because several dialects show allophonic palatalization of /k/ and /g/ (e.g. Bennike \& Kristensen 1912: 84ff.). Tokens in phonological $/ \mathrm{Cj} /$ clusters were included, because the phonetic implementation of these appeared phonetically identical to phonologically palatalized tokens. There were different criteria for the inclusion of fortis and lenis plosives. Since lenis plosives in function words (prepositions, pronouns, and high-frequency adverbs) were very often weakened to fricatives or fully voiced, segmentation was often difficult or impossible. For this reason, function words were excluded from the lenis category unless they were either stressed or clause-initial, since these prosodic environments enhance gestural features (Steriade 1994), and thus also increase VOT (Cho \& Keating 2001). All instances of the pronoun det 'it, that' were excluded. ${ }^{6}$ Function words were included in the fortis category, because they do not weaken as much, and because there are fewer high-frequency function words beginning with fortis plosives than lenis ones. A plausible result of this strategy is that the actual difference between lenis and fortis plosives is underestimated in this paper. Since we are generally more concerned with fortis plosives, this discrepancy is not too concerning. The distribution of plosives is shown in Table 2. While the lenis plosives are reasonably evenly distributed, the fortis ones are more skewed, with relatively few instances of (p), which was also the case in the study by Mortensen and Tøndering (2013). ${ }^{7}$

6. Due to this pronoun's extreme frequency in clause-initial position (Puggaard 2019), it would account for too many lenis tokens if included.

7. This is presumably due to /p/-initial words being rare in Old Germanic languages, although more have since entered Danish, mostly borrowed from Greek or Romance languages. For the same reason, the $/ \mathrm{b} / \sim / \mathrm{p} /$ contrast has historically been rather unstable in Danish (Hansen 1971: 165ff). 
Table 2. Distribution of plosives used in the study

\begin{tabular}{lr}
\hline Consonant & Number \\
\hline (b) & 2,212 \\
(d) & 2,369 \\
(g) & 2,273 \\
(p) & 1,386 \\
(t) & 5,169 \\
(k) & 4,095 \\
Total & $\mathbf{1 7 , 5 0 4}$ \\
\hline
\end{tabular}

\subsection{Acoustic analysis}

The plosives were segmented manually in Praat (Boersma \& Weenink 2018). ${ }^{8}$ The beginning of a plosive was indicated at the burst, which is identified in the waveform. If there were multiple bursts, which was often the case, the final one was chosen (following Cho \& Ladefoged 1999: 215). The end of a plosive was segmented at voicing onset, which was identified at the onset of periodicity in the waveform, in accordance with Francis et al's (2003) findings that this landmark is most similar to physiological measurements of voicing onset. This choice of landmark leads to relatively short VOT measurements, and partially inflates the differences between dialects as reported in this study and Standard Danish as reported by e.g. Mortensen and Tøndering (2013), who use the onset of higher formants as their landmark. The delimitation is exemplified in Figures 5 and 6. The VOTs for all recordings were extracted using a Praat script. This script, along with all TextGrids and measurements, are available in the Dataverse repository (Puggaard 2020).

Strictly speaking, this paper only investigates voicing lag, or positive VOT. There are a number of difficulties in measuring prevoicing in running speech, particularly in rapid speech. For intervocalic plosives, the first portion of the closure is essentially always voiced, due to voicing bleed from the preceding vowel (Davidson 2016); in rapid speech, voicing bleed may continue throughout most or all of the closure. There is no logical place to start measuring prevoicing when voicing is continuous, and if there were, its duration would not in itself be particularly meaningful (Möbius 2004); it would be essentially a measure of closure duration, which may be affected in other ways by environmental context and social factors, significantly

8. Semi-automatic methods of measuring VOT have been developed, such as SemiVOT (Keshet et al. 2014); however, this method relies on training data, and due to the highly variable nature of plosive implementation in the Jutlandic data, it was not feasible to provide a suitable set of training data. 

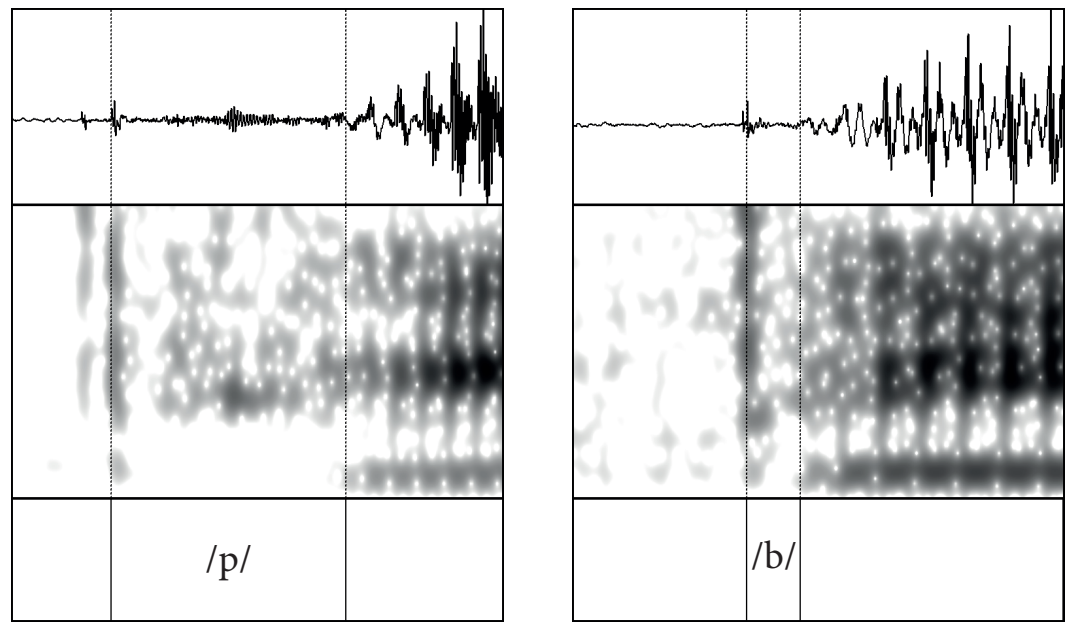

Figures 5-6. Delimitation of VOT exemplified for /b/ and /p/

complicating the modeling of the data. When a plosive is prevoiced, there is often still a brief pause in voicing around the release resulting in a short voicing lag. Other recent large-scale studies of VOT (e.g. Stuart-Smith et al. 2015; Chodroff \& Wilson 2017; Chodroff et al. 2019) have also relied exclusively on voicing lag.

In addition to VOT, each token was also coded for a number of details about the phonetic environment, which previous studies indicate influence VOT. These all serve as linear predictors in the statistical modeling, which has the added advantage of allowing us to test their influence, potentially lending credence to previous findings. These factors are:

\section{Vowel height}

Vowel height has been shown to influence VOT by e.g. Fischer-Jørgensen (1980); Higgins et al. (1998), and Berry and Moyle (2011); cf. Mortensen and Tøndering (2013), who found an influence only on lenis plosives in Danish. Standard Danish has been claimed to have six phonological levels of vowel height (Grønnum 1998), but only three levels were included here. This decision follows Mortensen and Tøndering's (2013) study, which found roughly the same results using a simplified three-way classification of vowel height and Grønnum's (2005: 105) physiological four-way classification of vowel aperture. ${ }^{9}$ Danish dialects further show a large degree of variability in vowel implementation (Ejstrup 2010), which means that coding more levels of vowel height would be either too impressionistic or much too time-demanding. The hypothesis is that higher vowels cause longer VOT.

9. Note that there are major differences between Grønnum's (2005) vowel height levels, which are based on acoustics, and her vowel aperture levels, which are based on articulation. 


\section{Vowel rounding}

Vowel rounding has been shown to influence VOT in interaction with place of articulation. The hypothesis (following Fischer-Jørgensen 1972) is that bilabials have longer VOT before rounded vowels, while other plosives have longer VOT before unrounded vowels.

\section{Vowel backness}

Vowel backness has also been shown to influence VOT in interaction with place of articulation. The hypothesis (following Gósy 2001) is that bilabials have longer VOT before back vowels, while other plosives have longer VOT before front vowels. Vowels are coded as back or non-back.

\section{Palatalization}

We hypothesize that palatalization will increase VOT in adding complexity to the plosive. It is coded as a binary distinction on the basis of auditory impression; no distinction is made between allophonic palatalization and underlying $/ \mathrm{Cj} /$.

\section{Stress}

Stress has been shown to increase VOT (e.g. Lisker \& Abramson 1967). Stress is coded as a binary distinction.

Place of articulation and phonological laryngeal setting

The phonological laryngeal setting (lenis/fortis) is trivially expected to account for most of the variation in the data. The literature further suggests that the place of articulation of a plosive influences its VOT. The results of Lisker and Abramson (1964) and Cho and Ladefoged (1999) indicate that a decent rule of thumb is that an occlusion further back in the oral cavity increases VOT, i.e. bilabial $<$ alveolar $<$ velar, although they also find a number of languages not following this pattern. In their study of Standard Danish VOT, Mortensen and Tøndering (2013) find longer VOT for $/ \mathrm{t} /$ than $/ \mathrm{k} /$. Plosives are coded by their phonological category, i.e. (b d g p t k).

Speech rate

Speech rate has also been shown to influence VOT; measuring speech rate of these recordings is far from straightforward, due to the lack of systematic transcriptions of the data, the presence of both informant and interviewer(s), and the general problem with delimiting Danish phonetic syllables (Schachtenhaufen 2010). Allen et al. (2003) reported that speech rate only partially accounts for idiolectal differences in VOT, indicating that modeling the individual informant as a random effect should account for global speech rate effects. 


\subsection{Statistical modeling}

In order to model the relationship between VOT and geography, the data was fitted to a generalized additive mixed model (GAMM), which can model a potentially non-linear influence of geographical area. Furthermore, descriptive statistics are provided based on the dialect areas. Statistics were calculated in the $\mathrm{R}$ statistical environment ( $R$ Core Team 2020) using a number of add-on packages. ${ }^{10}$ All R code is available in the Dataverse repository (Puggaard 2020).

GAMM is a method of non-linear statistical analysis that is well-suited for data that is dynamic across time or space (see Wood for a general introduction, and Sóskuthy 2017 and Wieling 2018 for linguistics-themed introductions). While a linear analysis of e.g. vowel formants will have to either measure formants at a chosen landmark or normalize across time steps, a GAMM analysis can take into account a full formant trajectory (Sóskuthy 2017). ${ }^{11}$ Similarly, rather than normalizing across dialect areas, it can take into account the full scope of possible geographical variation (see also e.g. Wieling et al. 2011, 2014).

The model has VOT as its dependent variable. Regional variation is included in the model through thin plate regression spline smooths (Wood 2003) for geographical area, modeled as the interaction between longitude and latitude; one smooth models the main effect of regional variation, and individual smooths model the individual phonemes. The model has separate random slopes for informants by phoneme, as well as the fixed effects alluded to above: vowel height, vowel rounding, vowel backness, palatalization, stress, informant gender, and phoneme. Stepwise likelihood ratio tests found this to be the most parsimonious model; each variable results in significantly improved model fit compared with nested models; versions with more elaborate random effects structures either resulted in insignificant changes to model fit, poorer model fit, or failure to converge. Recall from the previous section that we had specific hypotheses about interactions effects including place of articulation and backness and roundness, respectively. Such interactions did not significantly improve the model fit; I return to this point below. The model

10. The following packages were used: dplyr (Wickham et al. 2020a) for data management; ggplot2 (Wickham 2016; Wickham et al. 2020b) for visualizations; mgcv (Wood 2017, 2019) for generalized additive mixed modeling; itsadug (van Rij et al. 2020) for likelihood ratio tests, pairwise post-hoc tests, and two-dimensional visualization of GAMMs; and mgcViz (Fasiolo et al. 2019, 2020) for three-dimensional map-based visualization of GAMMs.

11. Other areas in linguistics where GAMMs have been fruitfully applied include pitch trajectories (Baayen et al. 2018), EEG trajectories (ibid; Meulman et al. 2015), eye tracking trajectories (Nixon et al. 2016), and articulatory trajectories (Wieling et al. 2016). 
is run with fast restricted estimated maximum likelihood (fREML) with discretized values for covariates to decrease computing load (Wood et al. 2017) using the scaled-t family to account for heavy-tailed residuals. When relevant, pairwise post-hoc testing is done using the Wald test.

\section{Results}

\subsection{Descriptive statistics}

VOT values for the different phonemes as grouped by dialect area can be seen in Table 3, which also shows the VOT values reported for Standard Danish by Mortensen and Tøndering (2013) for comparison. The results are projected onto maps in Figures 7-14. For all dialects and all phonemes, it is the case that the VOT values found here are shorter than what has been found for Standard Danish; this is partially due to differences in segmentation, and the study of Francis et al. (2003) can point us toward the influence of these differences. Their study suggests that for lenis plosives, the difference between the two measurement methods is negligible and only constitutes a few ms; for fortis plosives, the difference is between 15-20 ms on average. This suggests that the differences in Table 3 are not purely methodological: in almost all instances, VOT is actually shorter in the dialects, but for some areas, $(\mathrm{p})$ and $(\mathrm{k})$ are not obviously different when taking methodological differences into account.

For the fortis plosives, dialect area clearly influences VOT. This is not limited to $(t)$, and the pattern is roughly similar for all plosives. It is most pronounced for $(\mathrm{t})$ and least for $(\mathrm{k})$. The dialect areas seem to form clusters: essentially, south(-eastern) dialects have longer VOT, and north(-western) dialects have shorter VOT. The Northern dialect does not consistently have the shortest mean VOT values. Interestingly, in most cases, the minimum gap in VOT between a member of either dialect cluster seems to be approximately $10 \mathrm{~ms}$, which was found by Blumstein et al. (2005) to be the lower limit of what the human neural system can perceive. This indicates that any perceptible difference can also constitute a regional difference. For the lenis plosives, the only thing approaching a distinct result is the relatively high values of the Southern dialect and Djursland, which approach VOT values of Standard Danish. 
Table 3. VOT values in ms for each phoneme by dialect area. Displays mean values in msec as well standard deviation in parentheses () and interquartile ranges in brackets []

\begin{tabular}{|c|c|c|c|c|c|c|}
\hline Diale & (b) & (p) & (d) & $(t)$ & (g) & $(\mathrm{k})$ \\
\hline ou & $\begin{array}{c}9.3 \\
(\mathrm{SD}: 5.5) \\
{[5.4-12]}\end{array}$ & $\begin{array}{c}42.7 \\
(\mathrm{SD}: 18.7) \\
{[28.3-55.4]}\end{array}$ & $\begin{array}{c}14 \\
(\mathrm{SD}: 8.9) \\
{[8.2-18.1]}\end{array}$ & $\begin{array}{c}53.7 \\
(\mathrm{SD}: 20.5) \\
{[39.6-66.3]}\end{array}$ & $\begin{array}{c}16.7 \\
(\mathrm{SD}: 8.5) \\
{[10.6-21.9]}\end{array}$ & $\begin{array}{c}54.5 \\
(\mathrm{SD}: 19.6) \\
{[40.8-65.8]}\end{array}$ \\
\hline $\begin{array}{l}\text { Mid- } \\
\text { Southern }\end{array}$ & $\begin{array}{c}8.1 \\
(\mathrm{SD}: 5.6) \\
{[3.9-10.2]}\end{array}$ & $\begin{array}{c}38.5 \\
(\mathrm{SD}: 17.7) \\
{[25.8-47.5]}\end{array}$ & $\begin{array}{c}12.4 \\
(\mathrm{SD}: 8.9) \\
{[6-16.1]}\end{array}$ & $\begin{array}{c}52.3 \\
(\mathrm{SD}: 22.3) \\
{[37.5-63.6]}\end{array}$ & $\begin{array}{c}13.1 \\
(\mathrm{SD}: 9.7) \\
{[5.1-18.7]}\end{array}$ & $\begin{array}{c}45.9 \\
(\mathrm{SD}: 17.1) \\
{[34.2-57]}\end{array}$ \\
\hline $\begin{array}{l}\text { Mid- } \\
\text { Eastern }\end{array}$ & $\begin{array}{c}5.7 \\
(\mathrm{SD}: 4.7) \\
{[2.6-6.9]}\end{array}$ & $\begin{array}{c}41.5 \\
(\mathrm{SD}: 22.9) \\
{[23-53]}\end{array}$ & $\begin{array}{c}11.4 \\
(\mathrm{SD}: 8.8) \\
{[5.3-15.4]}\end{array}$ & $\begin{array}{c}51.7 \\
\text { (SD: 29.3) } \\
{[31.1-69.5]}\end{array}$ & $\begin{array}{c}12.7 \\
(\mathrm{SD}: 9.3) \\
{[5.8-17.2]}\end{array}$ & $\begin{array}{c}49.9 \\
(S D: 20.3) \\
{[36.5-62.3]}\end{array}$ \\
\hline jur & $\begin{array}{c}9.2 \\
(\mathrm{SD}: 8.1) \\
{[3.8-13.3]}\end{array}$ & $\begin{array}{c}46.2 \\
(\mathrm{SD}: 26) \\
{[29.5-60]}\end{array}$ & $\begin{array}{c}14.5 \\
(\mathrm{SD}: 8.5) \\
{[8.7-18.7]}\end{array}$ & $\begin{array}{c}53.8 \\
(\mathrm{SD}: 20.7) \\
{[39-67.4]}\end{array}$ & $\begin{array}{c}14.4 \\
(\mathrm{SD}: 9) \\
{[6.8-20.2]}\end{array}$ & $\begin{array}{c}48.3 \\
(\mathrm{SD}: 17.4) \\
{[35-60.1]}\end{array}$ \\
\hline $\begin{array}{l}\text { Mid- } \\
\text { Western }\end{array}$ & $\begin{array}{c}5.8 \\
\text { (SD: } 4.6) \\
{[3.2-7.1]}\end{array}$ & $\begin{array}{c}32 \\
(\mathrm{SD}: 18.5) \\
{[18.7-44.1]}\end{array}$ & $\begin{array}{c}10.2 \\
(\mathrm{SD}: 7.8) \\
{[4.3-12.9]}\end{array}$ & $\begin{array}{c}40.1 \\
(\mathrm{SD}: 17.2) \\
{[28.1-50]}\end{array}$ & $\begin{array}{c}10.8 \\
(\mathrm{SD}: 8.9) \\
{[3.3-15.4]}\end{array}$ & $\begin{array}{c}39.8 \\
(\mathrm{SD}: 18.1) \\
{[27-50.9]}\end{array}$ \\
\hline $\begin{array}{l}\text { North- } \\
\text { Eastern }\end{array}$ & $\begin{array}{c}6.8 \\
\text { (SD: } 5.4) \\
{[2.8-9.6]}\end{array}$ & $\begin{array}{c}30.6 \\
(\mathrm{SD}: 19.6) \\
{[16.5-40.1]}\end{array}$ & $\begin{array}{c}12.7 \\
(\mathrm{SD}: 10.3) \\
{[5-17.3]}\end{array}$ & $\begin{array}{c}42.5 \\
(\mathrm{SD}: 20.5) \\
{[28.7-52.7]}\end{array}$ & $\begin{array}{c}10.2 \\
(\mathrm{SD}: 8.3) \\
{[3.7-14.1]}\end{array}$ & $\begin{array}{c}41.5 \\
(\mathrm{SD}: 20.7) \\
{[27.4-52.4]}\end{array}$ \\
\hline $\begin{array}{l}\text { North- } \\
\text { Western }\end{array}$ & $\begin{array}{c}8.2 \\
(\mathrm{SD}: 6.2) \\
{[3.8-10.7]}\end{array}$ & $\begin{array}{c}31.8 \\
(\mathrm{SD}: 17.1) \\
{[20.3-42]}\end{array}$ & $\begin{array}{c}12.9 \\
(\mathrm{SD}: 9.2) \\
{[6.1-15.8]}\end{array}$ & $\begin{array}{c}36.3 \\
(\mathrm{SD}: 16.2) \\
{[24.4-45.8]}\end{array}$ & $\begin{array}{c}13.3 \\
(\mathrm{SD}: 9.1) \\
{[5.8-20]}\end{array}$ & $\begin{array}{c}42.9 \\
\text { (SD: } 17.2) \\
{[30.6-52.6]}\end{array}$ \\
\hline Northern & $\begin{array}{c}6.9 \\
\text { (SD: } 5.3) \\
{[2.9-9.8]}\end{array}$ & $\begin{array}{c}30.6 \\
(\mathrm{SD}: 17.5) \\
{[18-40.1]}\end{array}$ & $\begin{array}{c}11.5 \\
(S D: 9) \\
{[4.9-15.5]}\end{array}$ & $\begin{array}{c}42.2 \\
(\mathrm{SD}: 20.8) \\
{[27.1-53.1]}\end{array}$ & $\begin{array}{c}11.8 \\
(\mathrm{SD}: 8.7) \\
{[4.3-16.3]}\end{array}$ & $\begin{array}{c}41.8 \\
\text { (SD: } 17.8) \\
{[29.4-51.8]}\end{array}$ \\
\hline Std. Danish* & $11.7-19.2$ & $58.1-77$ & $18-29.2$ & $81.6-88.7$ & $25.1-34$ & $60.5-81$ \\
\hline
\end{tabular}

* The values for Standard Danish are taken from Mortensen and Tøndering (2013), who report mean values per phoneme by degree of opening; the ranges reported here are the shortest and longest of these values, respectively. Recall that there are differences in segmenting methodology, so these should not be directly compared to the values reported for dialects. 


\section{Lenis plosives}

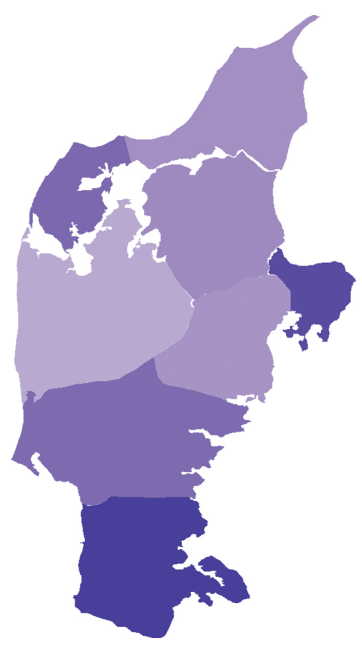

/d/

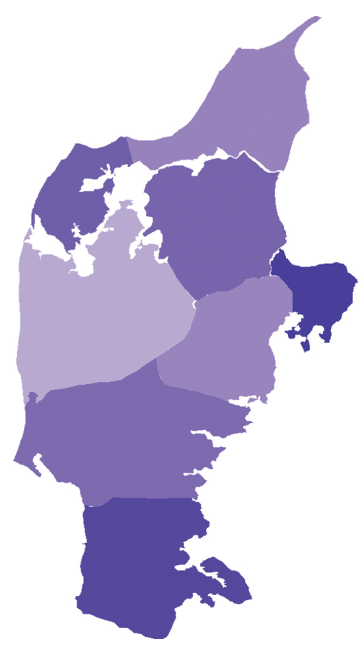

/b/

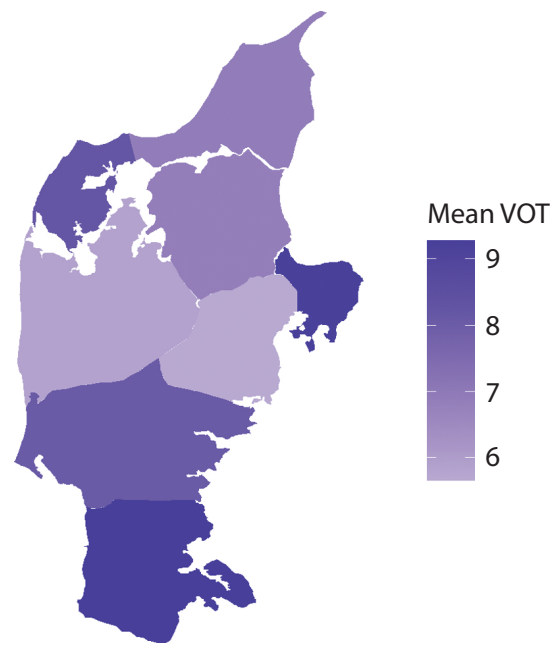

$/ g /$

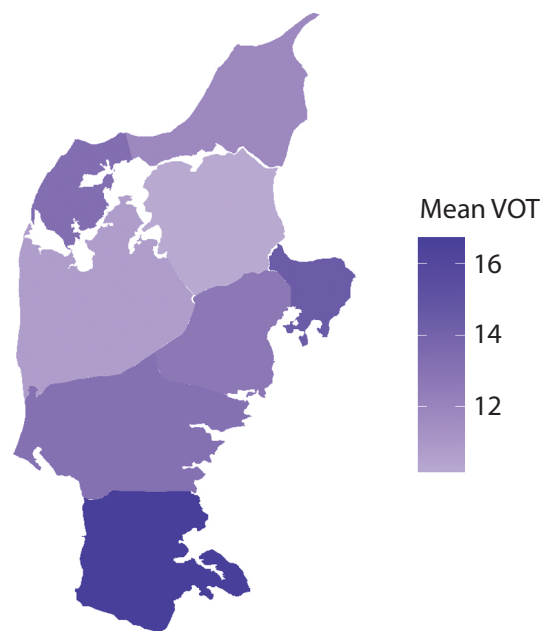

Mean VOT

(n)

(n)

Figures 7-14. Mean VOT values for lenis and fortis plosives and the individual plosives by dialect area projected onto maps

Mean VOT

14

13

12

11
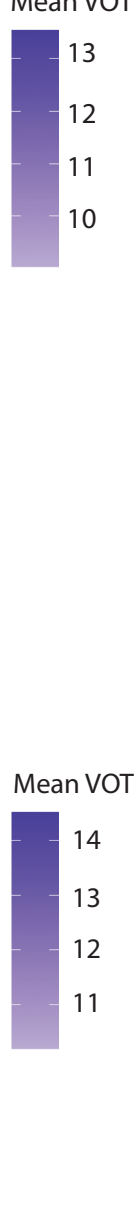


\section{Fortis plosives}

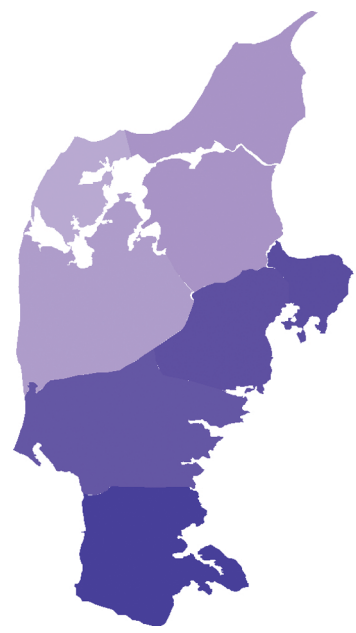

/t/

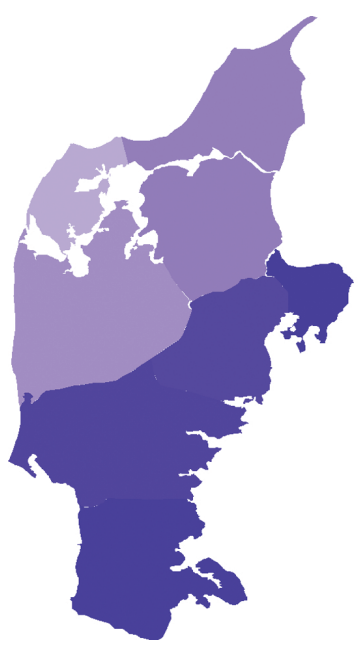

/p/
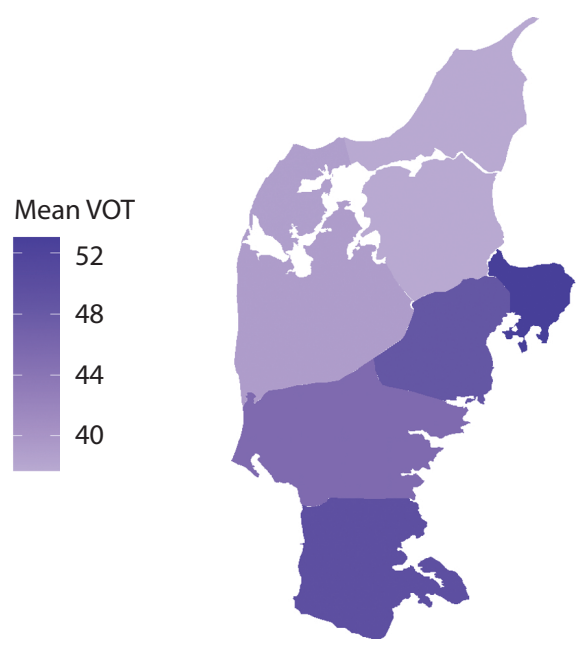

Mean VOT

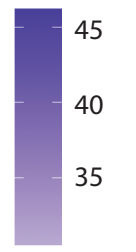

/k/

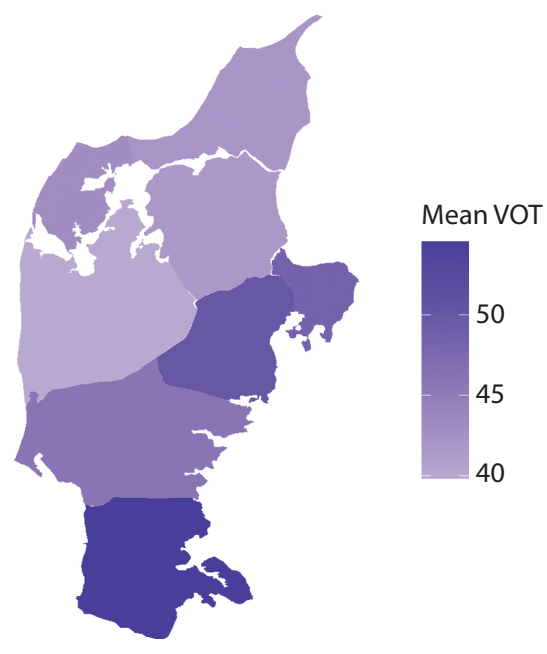




\subsection{Generalized additive mixed model}

This section presents the results of the GAMM. A likelihood ratio test found that a model which included the effect of area performed significantly better than a nested model without the effect of area, with $\chi^{2}(11)=221, p<.001$. With an effect size of $R^{2}=.66$, the model does a reasonably good job of explaining the data. The parametric coefficients and estimated significance of smooth terms can be seen in Tables 4 and 5. Table 4 shows the influence and significance of the linear predictors, and Table 5 shows the non-linear influence of geography. I unpack this information in the tables below, starting with the linear predictors.

Table 4. Parametric coefficients of GAMM

\begin{tabular}{lrrrrr}
\hline & estimate & SE & \multicolumn{1}{c}{ t } & p & \\
\hline (Intercept) & 33.689 & 0.936 & 35.988 & $<0.001$ & $* * *$ \\
gender=male & -0.461 & 0.328 & -1.408 & 0.159 & \\
palatalized=yes & 7.341 & 0.578 & 12.699 & $<0.001$ & $* * *$ \\
height=low & -2.371 & 0.235 & -10.073 & $<0.001$ & $* * *$ \\
height=mid & -2.170 & 0.240 & -9.033 & $<0.001$ & $* * *$ \\
backness=non-back & 2.024 & 0.343 & 5.899 & $<0.001$ & $* * *$ \\
roundness=round & 2.367 & 0.310 & 7.633 & $<0.001$ & $* * *$ \\
stress=yes & 2.486 & 0.182 & 13.688 & $<0.001$ & $* * *$ \\
consonant=b* & -28.079 & 0.852 & -32.960 & $<0.001$ & $* * *$ \\
consonant=d & -23.367 & 0.873 & -26.754 & $<0.001$ & $* * *$ \\
consonant=g & -23.150 & 0.881 & -26.261 & $<0.001$ & $* * *$ \\
consonant=t & 9.027 & 1.084 & 8.777 & $<0.001$ & $* * *$ \\
consonant=k & 9.513 & 1.153 & 13.688 & $<0.001$ & $* * *$ \\
\hline
\end{tabular}

${ }^{\star}$ Reference level $=\mathrm{p}$

Table 5. Approximate significance of smooth terms modeling geographical variation. edf $=$ estimated degrees of freedom, ref.df = referential degrees of freedom

\begin{tabular}{lrrrrr}
\hline & edf & ref.df & F & p & \\
\hline lon,lat & 16.490 & 19.646 & 4.228 & $<0.001$ & $* * *$ \\
lon,lat : b & 4.145 & 2.000 & 1.198 & 0.300 & \\
lon,lat : d & 2.001 & 5.238 & 2.240 & 0.107 & \\
lon,lat : g & 5.178 & 6.278 & 1.369 & 0.228 & \\
lon,lat : p & 2.000 & 2.000 & 9.276 & $<0.001$ & $* * *$ \\
lon,lat : t & 2.539 & 2.572 & 11.319 & $<0.001$ & $* * *$ \\
lon,lat : k & 3.844 & 3.988 & 3.944 & 0.003 & $* *$ \\
\hline
\end{tabular}


Gender: We hypothesized that male informants have shorter VOT than female informants. While the model shows a slight trend to that effect, it does not approach significance.

Palatalization and stress: The data strongly support the hypotheses that palatalized plosives and stress are associated with higher VOT.

Vowel height: The data support the hypothesis that following high vowels increase VOT, but does not support a more complex continuum effect of vowel height; post-hoc pairwise comparison finds no significant difference between mid and low vowels.

Vowel backness: The hypothesis was that following vowel backness influences VOT in interaction with plosive place of articulation, such that bilabials have higher VOT before back vowels. Recall from Section 3.4 above that the inclusion of such an interaction does not improve the model fit; in effect, this means that the added complexity of such an interaction effect cannot be justified by its additional explanatory value. The data instead show that following back vowels significantly decrease VOT relative to front vowels.

Roundness: As with backness, the hypothesis was that following vowel roundness influences VOT in interaction with plosive place of articulation, such that bilabials have higher VOT before round vowels. Once again, including such an interaction does not improve the model fit. The model rather finds that rounding in the following vowel significantly decreases VOT.

Phoneme: Post-hoc pairwise comparison of this factor strongly (and trivially) shows that phonological laryngeal setting has a large influence on VOT, with fortis plosives being longer than lenis ones. It partially supports the hypothesis that place of articulation has an influence on VOT, finding strong support for labial < alveolar/velar, but no support for alveolar < velar; all pairs are significantly different except $(\mathrm{d} \sim \mathrm{g})$ and $(\mathrm{t} \sim \mathrm{k})$. Mortensen and Tøndering (2013) found that / $\mathrm{t} /$ was significantly longer than $/ \mathrm{k} /$ in Standard Danish; the descriptive statistics (see Table 3) suggest that this finding may also hold within some dialect areas, but this has not been tested further. Geography: The findings related to the non-linear predictor of geography constitute the most significant findings of this study. There is a strong main effect of geography, suggesting that a primary geographical pattern is shared by all plosives. Additionally, all fortis plosives show further patterns of geographical variation. Table 5 only tells us that significant differences exist; in order to inspect these differences, we need to visualize the fitted values. In Figures 15 and 16, the effects of longitude and latitude are separated, and smooth curves are plotted for VOT by coordinates. These plots take the full fixed effects specification of the GAMM 

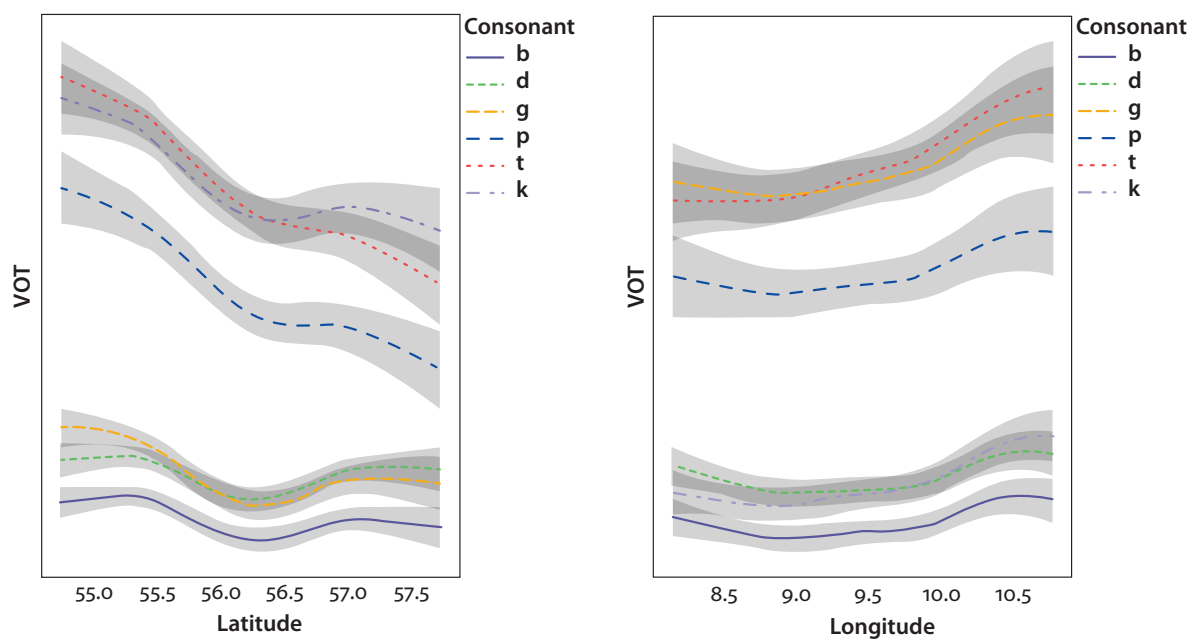

Figures 15-16. Non-linear smooths of fitted values with $95 \%$ confidence intervals for VOT by latitude and longitude, respectively

into account, meaning that the plots reflect default values for the fixed effects (the same as those seen in Table 4 above). Figure 15 shows an overall dip in VOT going south-north, which is most pronounced for the fortis plosives; among the fortis plosives, the pattern is clearest for $(\mathrm{t})$, least so for $(\mathrm{k})$. There is a clear dip in the center of the peninsula. In Figure 16, going west-east, the main pattern is a general increase in VOT relatively far towards the east coast. This pattern is clearest for (t). In Figure 17, the main effect of geography on VOT is projected onto a map. In Figures 18-20, the specific effects of the individual fortis plosives are projected onto maps; note that these effects can only be interpreted in conjunction with the main effect. Very high VOT is found in a small area around Djursland; high VOT is also found in the Southern dialect area, as well as the eastern part of the Mid-Southern area; as well as in a small area covering parts of the Northern and North-Eastern areas; the far north has somewhat shorter VOT, and a large area in the mid-western part of the peninsula has very short VOT. The additional geographical effects of the fortis plosives seen in Figures 18-20 are very similar: more so than can be seen from Figure 17, there is also a continual effect of decreasing VOT going north-south for the fortis plosives. The main effect of geography is highly non-linear, and with a few exceptions does not follow the major traditional dialect areas. The results are discussed further below. 

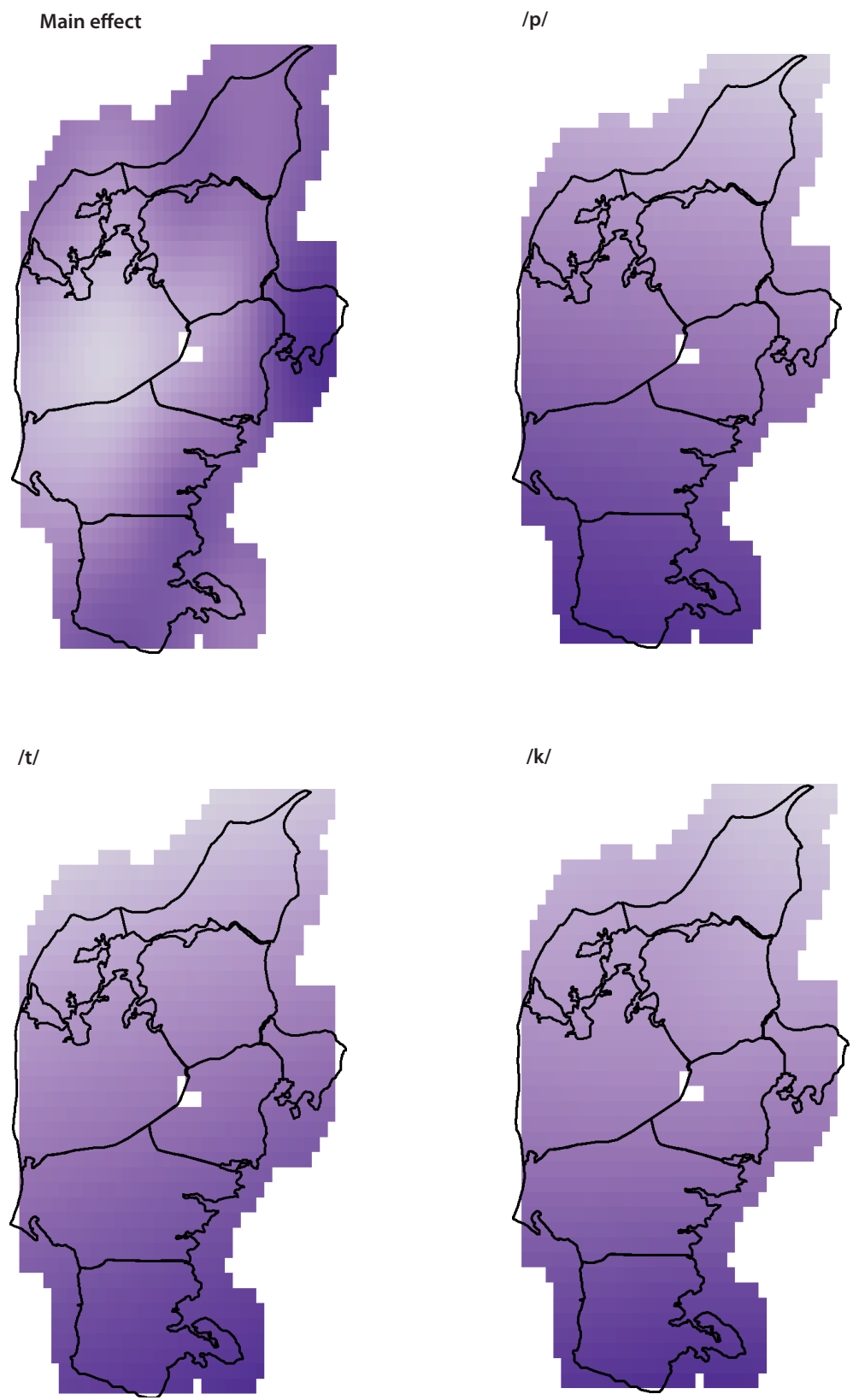

Figures 17-20. Fitted VOT values for main effect attributable to area, as well as effects of individual fortis plosives, plotted by coordinates. Darker shading indicates higher fitted values. Black lines indicate traditional dialect boundaries 


\section{Discussion and conclusions}

The primary goal of this paper was to uncover the extent of regional variation in plosive realization in Jutland. This follows up on the results of Puggaard (2018), which showed that a variant of / $\mathrm{t} /$ with short VOT is not, as previously assumed, limited to Northern Jutland. I have provided stronger support for that finding, and further found that variation is not limited to $/ \mathrm{t} /$, but reflects more general patterns, at least in the fortis plosives.

Shorter variants of plosives than in modern Standard Danish are consistently found across the Jutland peninsula. The longest values are found in southern Jutland, parts of mid-eastern Jutland, and Djursland. The long aspiration phases in southern Jutland are assumed to be part of the traditional dialect of this area, possibly due to areal influence from German, which has rather high VOT compared with the Jutlandic dialects (e.g. Hullebus et al. 2018). High VOT in eastern Jutland and Djursland may be due to Standard Danish influence from a number of major cities along the east coast, including Aarhus, the largest city of Jutland. This would be in line with Trudgill's (1974) gravity model of interdialectal influence, where sound change spreads on the basis of both population size and physical distance. However, there is no indication of a similar effect in the northern part of the peninsula, where the two largest urban areas at the turn of the 20th century (Aalborg and Randers) do not correspond to particularly high VOT. ${ }^{12}$ Locations of major cities are shown in Figure 21.

Given the overt status of the short, non-affricated / $t$ / variant in the north of Jutland, it is further noteworthy that the shortest VOT values are not found in the far north, but rather in the center of the peninsula. At this point, there is no good explanation for why VOT values are so short in the center of the peninsula; we must assume that it was simply a feature of the local variety. On the basis of both the descriptive statistics and the GAMM output, it is clear that variation follows consistent complicated geographical patterns. The GAMM results in particular suggest multiple continua of variation.

Using a large corpus of legacy recordings of elderly dialect speakers, I have shown that plosives in the traditional Jutlandic dialects are generally shorter than in modern Standard Danish. The results further lend credence to previous findings: palatalization and stress were both shown to increase VOT. High vowels increase VOT, but no difference was found between mid and low vowels. Front vowels and round vowels increase VOT, and the results do not lend credence to

12. Likewise, the city of Esbjerg is in an area with rather low VOT. Esbjerg is a special case, as it was a very young city at the turn of the 20th century, settled only a few decades earlier. 


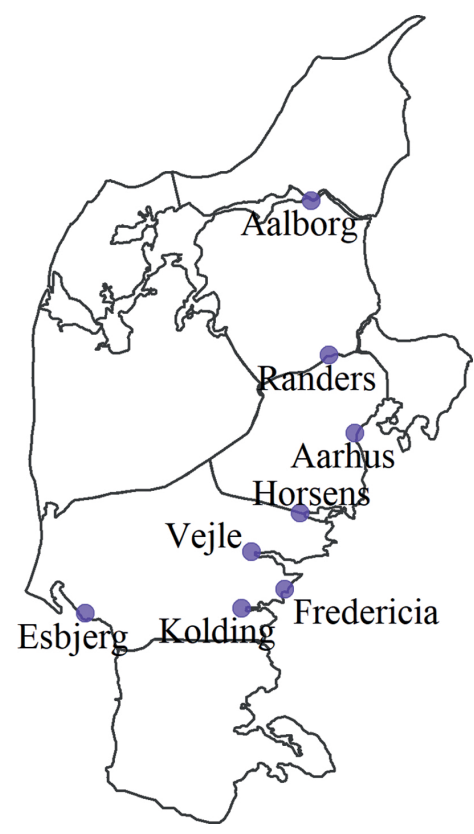

Figure 21. Cities with population sizes higher than 10,000 in the year 1901. Data from Matthiessen (1985)

previous findings about the influence of backness and roundness interacting with plosive place of articulation. The study also finds no effect of gender on VOT. Although the corpus used here was collected with lexicographic research in mind, I hope to have shown that it is also suitable for research in phonetics - and could potentially be suitable for a wide range of other research areas at all levels of linguistic description. A recent conference paper (Puggaard \& Goldshtein 2020) investigated regional patterns of stop affrication in the data analyzed here, and suggested implications for underlying phonological representations; Goldshtein (2019) used the corpus in his investigation of tone in southern Jutland; Goldshtein \& Ahlgren (forthc.) used the corpus to investigate discrepancies in the discursive constructions of dialect authenticity by dialect speakers and researchers in the interviews. No studies have used the corpus for research in syntax, but it should be well-suited for that as well. Finally, I hope to have shown the generalized additive mixed modeling can be fruitfully applied to studies of geographical distributions of phonetic variation. 


\section{Acknowledgements}

I would like to thank the editors and two anonymous reviewers for helpful comments on a previous version of this paper. I would also like to thank a number of people for commenting on various stages of this (or adjacent) manuscripts, or helping out in other ways: Míša Hejna, Martin Krämer, Yonatan Goldshtein, Cesko Voeten, Bert Botma, Janet Grijzenhout, Anna Jespersen, and the Peter Skautrup Centre for Jutlandic Dialect Research. Finally, I'd like to thank the people who stopped by the poster for a chat at ICLaVE|10, and other audiences in Aarhus, Drammen, Amsterdam, and online. Any remaining faults are, of course, my own.

\section{References}

Aakjær, Svend. 1925. Tingsted og Maalkærne. Frem A 1, 571-575.

Abramson, Arthur S. \& D. H. Whalen. 2017. Voice Onset Time (VOT) at 50. Theoretical and practical issues in measuring voicing distinctions. Journal of Phonetics 63. 75-86. https://doi.org/10.1016/j.wocn.2017.05.002

Allen, J. Sean, Joanne L. Miller \& David DeSteno. 2003. Individual talker differences in voiceonset-time. Journal of the Acoustical Society of America 113(1). 544-552. https://doi.org/10.1121/1.1528172

Andersen, Poul. 1955. "Klusilspring” i danske Dialekter. Nordisk Tidsskrift for Tale og Stemme 15(1). 70-77.

Andersen, Torben Arboe. 1981. Dialektbånd og databehandling. Ord \& Sag 1. 11-18.

Baayen, R. Harald, Jacolien van Rij, Cecile de Cat \& Simon N. Wood. 2018. Autocorrelated errors in experimental data in the language sciences. Some solutions offered by generalized additive mixed models. In Dirk Speelman, Kris Heylen \& Dirk Geeraerts (eds.), Mixed-effects regression models in linguistics (Quantitative Methods in the Humanities and Social Sciences), 49-69. Cham: Springer. https://doi.org/10.1007/978-3-319-69830-4_4

Benjamin, Barbaranne J. 1982. Phonological performance in gerontological speech. Journal of Psycholinguistic Research 11(2). 159-167. https://doi.org/10.1007/BF01068218

Bennike, Valdemar \& Marius Kristensen. 1912. Kort over de danske folkemål med forklaringer. Copenhagen: Gyldendalske Boghandel.

Berry, Jeff \& Maura Moyle. 2011. Covariation among vowel height effects on acoustic measures. Journal of the Acoustical Society of America 130(5). 365-371. https://doi.org/10.1121/1.3651095

Blumstein, Sheila E., Emily B. Myers \& Jesse Rissman. 2005. The perception of voice onset time. An fMRI investigation of phonetic category structure. Journal of Cognitive Neuroscience 17(9). 1353-1366. https://doi.org/10.1162/0898929054985473

Boersma, Paul \& David Weenink. 2018. Praat. Doing phonetics by computer. Version 6.0.43. https://fon.hum.uva.nl/praat/.

Britain, David. 2010. Conceptualizations of geographic space in linguistics. In Alfred Lameli, Roland Kehrein \& Stefan Rabanus (eds.), Language and space. An international handbook of linguistic variation. Volume 2: Language mapping (Handbooks of Linguistics and Communication Science 30/2), 69-102. Berlin \& New York: De Gruyter Mouton. https://doi.org/10.1515/9783110219166.1.69

Brøndum-Nielsen, Johs. 1927. Dialekter og dialektforskning. Copenhagen: J.H. Schulz. 
Chambers, J. K. 2000. Region and language variation. English World-Wide 21(2). 169-199. https://doi.org/10.1075/eww.21.2.02cha

Chambers, J. K. \& Peter Trudgill. 1998. Dialectology (Cambridge Textbooks in Linguistics). 2nd ed. Cambridge: Cambridge University Press. https://doi.org/10.1017/CBO9780511805103

Cho, Taehong, Gerard J. Docherty \& D. H. Whalen (eds.). 2018. Marking 50 years of research on voice onset time. Special issue of Journal of Phonetics 71.

Cho, Taehong \& Patricia A. Keating. 2001. Articulatory and acoustic studies on domain-initial strengthening in Korean. Journal of Phonetics 29. 155-190. https://doi.org/10.1006/jpho.2001.0131

Cho, Taehong \& Peter Ladefoged. 1999. Variation and universals in VOT. Evidence from 18 languages. Journal of Phonetics 27. 207-229. https://doi.org/10.1006/jpho.1999.0094

Chodroff, Eleanor, Alessandra Golden \& Colin Wilson. 2019. Covariation of stop voice onset time across languages. Evidence for a universal constraint on phonetic realization. Journal of the Acoustical Society of America 145(1). 106-115. https://doi.org/10.1121/1.5088035

Chodroff, Eleanor \& Colin Wilson. 2017. Structure in talker-specific phonetic realization. Covariation of stop consonant VOT in American English. Journal of Phonetics 61. 30-47. https://doi.org/10.1016/j.wocn.2017.01.001

Davidson, Lisa. 2016. Variability in the implementation of voicing in American English obstruents. Journal of Phonetics 54. 35-50. https://doi.org/10.1016/j.wocn.2015.09.003

Docherty, Gerard J. 1992. The timing of voicing in British English obstruents (Netherlands Phonetics Archives 9). Berlin \& New York: Foris. https://doi.org/10.1515/9783110872637

Ejskjær, Inger. 1990. Stød and pitch accents in the Danish dialects. Acta Linguistica Hafniensia 22(1). 49-75. https://doi.org/10.1080/03740463.1990.10411522

Ejstrup, Michael. 2010. På godt forskelligt dansk. Nydanske Sprogstudier 39. 93-136. https://doi.org/10.7146/nys.v39i39.13534

Fasiolo, Matteo, Raphaël Nedellec, Yannig Goude, Christian Capezza \& Simon N. Wood. 2020. mgcViz. Visualisations for generalized additive models. Version 0.1.6. https://CRAN.R-project.org/package $=$ mgcViz.

Fasiolo, Matteo, Raphaël Nedellec, Yannig Goude \& Simon N. Wood. 2019. Scalable visualization methods for modern generalized additive models. Journal of Computational and Graphical Statistics. https://doi.org/10.1080/10618600.2019.1629942

Fischer-Jørgensen, Eli. 1972. ptk et bdg français en position intervocalique accentuée. In Albert Valdman (ed.), Papers in linguistics and phonetics to the memory of Pierre Delattre (Janua Linguarum 54), 143-200. The Hague \& Paris: Mouton.

https://doi.org/10.1515/9783110803877-014

Fischer-Jørgensen, Eli. 1980. Temporal relations in Danish tautosyllabic CV sequences with stop consonants. Annual Report of the Institute of Phonetics, University of Copenhagen 14. 207-261.

Francis, Alexander L., Valter Ciocca \& Jojo Man Ching Yu. 2003. Accuracy and variability of acoustic measures of voicing onset. Journal of the Acoustical Society of America 113(2). 1025-1032. https://doi.org/10.1121/1.1536169

Gauchat, Louis. 1903. Gibt es Mundartgrenzen? Archiv für das Studium der neueren Sprachen und Litteraturen 111. 365-403.

Gilliéron, Jules \& Edmond Edmont. 1902-1910. Atlas linguistique de la France. Paris: Champion. Goldshtein, Yonatan. 2019. Towards a dialectology of tone in South Jutland. Paper presented at the 10th International Conference on Language Variation in Europe, Fryske Akademy, Leeuwarden. 
Goldshtein, Yonatan \& Liv Moeslund Ahlgreen. Forthcoming. Ideologies of language and place. Negotiations of dialectal authenticity in traditional Danish dialectology. To be published in Journal of Postcolonial Linguistics 4.

Goldshtein, Yonatan \& Rasmus Puggaard. 2019. Overblik over danske dialektoptagelser. Ord \& Sag 39, 18-28

Gooskens, Charlotte. 2005. Traveling time as a predictor of linguistic distance. Dialectologia et Geolinguistica 13. 38-62. https://doi.org/10.1515/dig.2005.2005.13.38

Gósy, Mária. 2001. The VOT of the Hungarian voiceless plosives in words and in spontaneous speech. International Journal of Speech Technology 4. 75-85.

https://doi.org/10.1023/A:1009608900453

Grønnum, Nina. 1998. Illustrations of the IPA. Danish. Journal of the International Phonetic Association 28(1/2). 99-105. https://doi.org/10.1017/So025100300006290

Grønnum, Nina. 2005. Fonetik og fonologi. Almen og dansk. 3rd ed. Copenhagen: Akademisk Forlag.

Gudiksen, Asgerd \& Henrik Hovmark. 2008. Båndoptagelser som kilde til Ømålsordbogen. Nordiske Studier i Leksikografi 9. 173-182.

Hansen, Aage. 1971. Den lydlige udvikling i dansk. Fra ca. 1300 til nutiden II: Konsonantismen. Copenhagen: G.E.C. Gad.

Hansen, Inger Schoonderbek. 2008. Jysk Ordbog. Rapport fra en digital ordbog. Nordiske Studier i Leksikografi 9. 209-218.

Hanson, Helen M. 2009. Effects of obstruent consonants on fundamental frequency at vowel onset in English. Journal of the Acoustical Society of America 125(1). 425-441. https://doi.org/10.1121/1.3021306

Hay, Jennifer \& Paul Foulkes. 2016. The evolution of medial /t/ over real and remembered time. Language 92(2). 298-330. https://doi.org/10.1353/lan.2016.0036

Higgins, Maureen B., Ronald Netsell \& Laura Schulte. 1998. Vowel-related differences in laryngeal articulatory and phonatory function. Journal of Speech, Language, and Hearing Research 41. 712-724. https://doi.org/10.1044/jslhr.4104.712

Hovdhaugen, Even, Fred Karlsson, Carol Henriksen \& Bengt Sigurd. 2000. The history of linguistics in the Nordic countries. Helsinki: Societas Scientarum Fennica.

Hovmark, Henrik. 2006. Ømålsordbogen mellem synkroni og diakroni. LexicoNordika 13. 129-145.

Hullebus, Marc A., Stephen J. Tobin \& Adamantios I. Gafos. 2018. Speaker-specific structure in German voiceless stop voice onset times. Proceedings of Interspeech, 1403-1407. Hyderabad: International Speech Communication Association.

https://doi.org/10.21437/Interspeech.2018-2288

Jensen, J. M. 1902. Et vendelbomåls lyd-og formloere. Copenhagen: H.H. Thieles Bogtrykkeri.

$\mathrm{JO}=$ Jysk Ordbog. Edited by the Peter Skautrup Center for Jutlandic Dialect Research, Aarhus University. https://jyskordbog.dk.

Keshet, Joseph, Morgan Sonderegger \& T. Knowles. 2014. AutoVOT. A tool for automatic measurement of voice onset time using discriminative structured prediction. Version 0.91 . https:// github.com/mlml/autovot.

Kirby, James P. \& D. Robert Ladd. 2016. Effects of obstruent voicing on vowel F0. Evidence from "true voicing" languages. Journal of the Acoustical Society of America 140(4). 2400-2411. https://doi.org/10.1121/1.4962445 
Klatt, Dennis H. 1975. Voice onset time, frication, and aspiration in word-initial consonant clusters. Journal of Speech and Hearing Research 18. 686-706. https://doi.org/10.1044/jshr.1804.686

Kraehenmann, Astrid. 2001. Swiss German stops. Geminates all over the word. Phonology 18. 109-145. https://doi.org/10.1017/So952675701004031

Kristiansen, Tore. 1990. Udtalenormering i skolen. Skitse af en ideologisk bastion. Copenhagen: Gyldendal.

Kristiansen, Tore. 1998. The role of standard ideology in the disappearance of the traditional Danish dialects. Folia Linguistica 32(1/2). 115-129. https://doi.org/10.1515/flin.1998.32.1-2.115

Kristiansen, Tore. 2003a. Danish. In Ana Deumert \& Wim Vandenbussche (eds.), Germanic standardizations. Past to present (Impact: Studies in Language and Society 18), 69-91. Amsterdam \& Philadelphia: John Benjamins. https://doi.org/10.1075/impact.18.04kri

Kristiansen, Tore. 2003b. Language attitudes and language politics in Denmark. International Journal of the Sociology of Language 159. 57-71. https://doi.org/10.1515/ijsl.2003.009

Labov, William. 1963. The social motivation of a sound change. Word 19(3). 273-309. https://doi.org/10.1080/00437956.1963.11659799

Ladd, D. Robert. 2011. Phonetics in phonology. In John Goldsmith, Jason Riggle \& Alan C. L. Yu (eds.), The handbook of phonological theory (Blackwell Handbooks in Linguistics), 348-373. 2nd ed. Chichester: Wiley-Blackwell. https://doi.org/10.1002/9781444343069.ch11

Lisker, Leigh \& Arthur S. Abramson. 1964. A cross-language study of voicing in initial stops. Acoustical measurements. Word 20. 384-422. https://doi.org/10.1080/00437956.1964.11659830

Lisker, Leigh \& Arthur S. Abramson. 1967. Some effects of context on voice onset time in English stops. Language and Speech 10(1). 10-28. https://doi.org/10.1177/002383096701000101

Maegaard, Marie \& Malene Monka. 2019. Patterns of dialect use. Language standardization at different rates. In Marie Maegaard, Malene Monka, Kristine Køhler Mortensen \& Andreas Candefors Stæhr (eds.), Standardization as sociolinguistic change. A transversal study of three traditional dialect areas (Routledge Studies in Language Change), 27-46. London \& New York: Routledge. https://doi.org/10.4324/9780429467486-2

Matthiessen, Christian Wichmann. 1985. Danske byers folketal 1801-1981 (Statistiske Undersøgelser 42). Copenhagen: Danmarks Statistik.

Meulman, Nienke, Martijn Wieling, Simone A. Sprenger, Laurie A. Stowe \& Monika S. Schmid. 2015. Age effects in L2 grammar processing as revealed by ERPs and how (not) to study them. Plos One 10(12). https://doi.org/10.1371/journal.pone.0143328

Möbius, Bernd. 2004. Corpus-based investigations on the phonetics of consonant voicing. Folia Linguistica 38(1/2). 5-26. https://doi.org/10.1515/flin.2004.38.1-2.5

Monka, Malene. 2019. Southern Jutland. Language ideology as a means to slow down dialect leveling. In Marie Maegaard, Malene Monka, Kristine Køhler Mortensen \& Andreas Candefors Stæhr (eds.), Standardization as sociolinguistic change. A transversal study of three traditional dialect areas (Routledge Studies in Language Change), 47-89. London \& New York: Routledge. https://doi.org/10.4324/9780429467486-3

Monka, Malene \& Henrik Hovmark. 2016. Sprogbrug blandt unge i Bylderup anno 2015. Danske Talesprog 16. 73-114.

Mortensen, Johannes \& John Tøndering. 2013. The effect of vowel height on voice onset time in stop consonants in CV sequences in spontaneous Danish. Proceedings of Fonetik 2013. The XXVIth annual phonetics meeting, 49-52. Linköping University. 
Neiman, Gary S., Richard J. Klich \& Elaine M. Shuey. 1983. Voice onset time in young and 70-year-old women. Journal of Speech and Hearing Research 26. 118-123. https://doi.org/10.1044/jshr.2601.118

Nerbonne, John \& Wilbert Heeringa. 2007. Geographic distributions of linguistic variation reflect dynamics of differentiation. In Sam Featherston \& Wolfgang Sternefeld (eds.), Roots. Linguistics in search of its evidential base (Studies in Generative Grammar 96), 267-297. Berlin \& New York: Mouton de Gruyter. https://doi.org/10.1515/9783110198621.267

Nixon, Jessie S., Jacolien van Rij, Peggy Mok, R. Harald Baayen \& Yiya Chen. 2016. The temporal dynamics of perceptual uncertainty. Eye movement evidence from Cantonese segment and tone perception. Journal of Memory and Language 90. 103-125.

https://doi.org/10.1016/j.jml.2016.03.005

Paris, Gaston. 1888. Les parlers de France. Revue des patois gallo-romans 2. 161-175.

Pedersen, Inge Lise. 2003. Traditional dialects of Danish and the de-dialectalization 1900-2000. International Journal of the Sociology of Language 159. 9-28. https://doi.org/10.1515/ijsl.2003.012

Pedersen, Karen Margrethe. 1983. Om transskription af båndoptagelser og anvendelse af teksterne til leksikografiske og syntaktiske undersøgelser. Et EDB-projekt. Folkmålsstudier 28. 131-138.

Puggaard, Rasmus. 2018. Realizations of /t/ in Jutlandic dialects of Danish. Linguistica Lettica 26, 368-393.

Puggaard, Rasmus. 2019. Flexibility of frequent clause openers in talk-in-interaction. The Danish front fields det "it, that" and så "then." Nordic Journal of Linguistics 42(3), 291-327. https://doi.org/10.1017/S0332586519000088

Puggaard, Rasmus. 2020. Replication data, metadata, and scripts for study of regional variation in VOT of Jutlandic varieties of Danish. DataverseNL. https://doi.org/10.34894/JHN1Q7

Puggaard, Rasmus \& Yonatan Goldshtein. 2020. Realization and representation of plosives in Jutlandic varieties of Danish. Variation in phonetics predicts variation in phonology. Paper presented at Laboratory Phonology 17, University of British Columbia, Vancouver. https:// youtu.be/u8ZVkTOBzt4.

R Core Team. 2020. R. A language and environment for statistical computing. Version 4.0.0. https://www.R-project.org/.

Ryalls, Jack, Marni Simon \& Jerry Thomason. 2004. Voice onset time production in older Caucasian- and African-Americans. Journal of Multilingual Communication Disorders 2(1). 61-67. https://doi.org/10.1080/1476967031000090980

Ryalls, John, Alison Zipprer \& Penelope Baldauff. 1997. A preliminary investigation of the effects of gender and race on voice onset time. Journal of Speech, Language, and Hearing Research 40. 642-645. https://doi.org/10.1044/jslhr.4003.642

Schachtenhaufen, Ruben. 2010. Looking for lost syllables in Danish spontaneous speech. In Peter Juel Henrichsen (ed.), Linguistic theory and raw sound (Copenhagen Studies in Language 40), 61-85. Frederiksberg: Samfundslitteratur.

Scheuer, Jann, Anne Larsen, Marie Maegaard, Malene Monka \& Kristine Køhler Mortensen. 2019. Language ideologies. A key to understanding language standardization. In Marie Maegaard, Malene Monka, Kristine Køhler Mortensen \& Andreas Candefors Stæhr (eds.), Standardization as sociolinguistic change. A transversal study of three traditional dialect areas (Routledge Studies in Language Change), 189-218. London \& New York: Routledge. https://doi.org/10.4324/9780429467486-8 
Schouten, M. E. H. \& Arjan van Hessen. 1992. Modeling phoneme perception. I: Categorical perception. Journal of the Acoustical Society of America 92(4). 1841-1855. https://doi.org/10.1121/1.403841

Séguy, Jean. 1973. La dialectométrie dans l'Atlas linguistique de Gascogne. Revue de Linguistique Romane 37(145). 1-24.

Simos, Panagiotis G., Randy L. Diehl, Joshua I. Breier, Michelle R. Molis, George Zouridakis \& Andrew C. Papanicolaou. 1998. MEG correlates of categorical perception of a voice onset time continuum in humans. Cognitive Brain Research 7. 215-219. https://doi.org/10.1016/So926-6410(98)0o037-8

Skautrup, Peter. 1930. Hardiske mål 1. Copenhagen: Th. Linds Efterfølger.

Skautrup, Peter. 1937. Dialektkriterier og deres værdi. Sprog og kultur 6. 59-80.

Skautrup, Peter. 1952. Sammenhænge i dialektal udvikling. In Jørgen Glahder (ed.), Runer og rids. Festskrift til Lis Jacobsen, 95-103. Copenhagen: Rosenkilde og Bagger.

Skautrup, Peter. 1968. Det danske sprogs historie IV. Fra J.P. Jacobsen til Johs. V. Jensen. Copenhagen: Gyldendal.

Sóskuthy, Márton. 2017. Generalised additive mixed models for dynamic analysis in linguistics. A practical introduction. Unpublished manuscript. https://arxiv.org/abs/1703.05339.

Stuart-Smith, Jane, Morgan Sonderegger, Tamara Rathcke \& Rachel Macdonald. 2015. The private life of stops. VOT in a real-time corpus of spontaneous Glaswegian. Laboratory Phonology 6(3/4). 505-548. https://doi.org/10.1515/lp-2015-0015

Swartz, Bradford L. 1992. Gender difference in voice onset time. Perceptual and Motor Skills 75. 983-992. https://doi.org/10.2466/pms.1992.75.3.983

Thorsen, Peder Kristian. 1912/1927. Den berømteste Dialektgrænse i Danmark. In Jens Byskov \& Marius Kristensen (eds.), Afhandlinger og Breve, vol. 2, 107-135. Copenhagen: Schønbergske Forlag.

Torre, Peter \& Jessica A. Barlow. 2009. Age-related changes in acoustic characteristics of adult speech. Journal of Communication Disorders 42. 324-333.

https://doi.org/10.1016/j.jcomdis.2009.03.001

Trudgill, Peter. 1974. Linguistic change and diffusion. Description and explanation in sociolinguistic dialect geography. Language in Society 2. 215-246.

https://doi.org/10.1017/So047404500004358

van Rij, Jacolien, Martijn Wieling, R. Harald Baayen \& Hedderik van Rijn. 2020. itsadug. Interpreting time series and autocorrelated data using GAMMs. R package version 2.4. https:// CRAN.R-project.org/package=itsadug.

Wenker, Georg \& Ferdinand Wrede. 1895. Der Sprachatlas des deutschen Reichs. Marburg: Elwert.

Wickham, Hadley. 2016. ggplot2. Elegant graphics for data analysis (Use R). New York: Springer. https://doi.org/10.1007/978-0-387-98141-3

Wickham, Hadley, Winston Chang, Lionel Henry, Thomas Lin Pedersen, Kohske Takahashi, Claus Wilke, Kara Woo, Hiroaki Yutani, Dewey Dunnington \& RStudio. 2020b. ggplot2. Create elegant data visualizations using the grammar of graphics. $\mathrm{R}$ package version 3.3.0. https://CRAN.R-project.org/package=ggplot2.

Wickham, Hadley, Romain François, Lionel Henry \& Kirill Müller. 2020a. dplyr. A grammar of data manipulation. R package version 0.8.5. https:/CRAN.R-project.org/package=dplyr.

Wieling, Martijn. 2018. Analyzing dynamic phonetic data using generalized additive mixed modeling. A tutorial focusing on articulatory differences between L1 and L2 speakers of English. Journal of Phonetics 70. 86-116. https://doi.org/10.1016/j.wocn.2018.03.002 
Wieling, Martijn, Simonetta Montemagni, John Nerbonne \& R. Harald Baayen. 2014. Lexical differences between Tuscan dialects and Standard Italian. Accounting for geographic and sociodemographic variation using generalized additive mixed modeling. Language 90(3). 669-692. https://doi.org/10.1353/lan.2014.0064

Wieling, Martijn \& John Nerbonne. 2015. Advances in dialectometry. Annual Review of Linguistics 1. 243-264. https://doi.org/10.1146/annurev-linguist-030514-124930

Wieling, Martijn, John Nerbonne \& R. Harald Baayen. 2011. Quantitative social dialectology. Explaining linguistic variation geographically and socially. Plos One 6(9). https://doi.org/10.1371/journal.pone.0023613

Wieling, Martijn, Fabian Tomaschek, Denis Arnold, Mark Tiede, Franziska Bröker, Samuel Thiele, Simon N. Wood \& R. Harald Baayen. 2016. Investigating dialectal differences using articulography. Journal of Phonetics 59. 122-143. https://doi.org/10.1016/j.wocn.2016.09.004

Wood, Simon N. 2003. Thin plate regression splines. Journal of the Royal Statistical Society B 65(1). 95-114. https://doi.org/10.1111/1467-9868.00374

Wood, Simon N. 2017. Generalized additive models. An introduction with R (Texts in Statistical Science). 2nd ed. Boca Raton: CRC Press. https://doi.org/10.1201/9781315370279

Wood, Simon N. 2019. mgcv. Mixed GAM computation vehicle with automatic smoothness estimation. R package version 1.8-31. https://CRAN.R-project.org/package $=\mathrm{mgcv}$.

Wood, Simon N., Zheyuan Li, Gavin Shaddick \& Nicole H. Augustin. 2017. Generalized additive models for gigadata. Modeling the U.K. Black Smoke network daily data. Journal of the American Statistical Association 112(519). 1199-1210. https://doi.org/10.1080/01621459.2016.1195744

Wrede, Ferdinand. 1919. Zur Entwiklungsgeschichte der deutschen Mundartenforschung. Zeitschrift für Deutsche Mundarten 14. 3-18. 


\title{
CHAPTER 5
}

\section{“Organically German"?}

\section{Changing ideologies of national belonging}

\author{
Janet M. Fuller \\ University of Groningen
}

\begin{abstract}
This chapter examines variation in the situated meanings of the term Biodeutsche(r), a term which has emerged relatively recently as a way to refer to people who are German by descent (i.e., not of migration background). This analysis shows that use of this term reflects competing discourses about the role of ethnicity in national belonging in Germany. While the origin and many uses of the term challenge the validity of ethnicity as a basis for legitimacy in German society, some of the data suggest that it has also been adopted as a supposedly neutral term to describe a segment of the German population, which supports an ethnonational ideology.
\end{abstract}

Keywords: media discourse, German, national identity, biodeutsch

\section{Introduction}

What does it mean in contemporary Germany to "be German", and how is this category linguistically constructed? Germany has been a land of immigration for many decades, and policy changes have shifted the criteria for citizenship to include birthplace and (legal) residence as well as descent. Thus in the official sense, the criteria for being German have changed. Yet there continue to be many competing discourses about German belonging, and these discourses are reproduced in part through the choices of terms used for different social groups.

Previous research has looked at words for the Other, including Migrationshintergrund ('migration background') (Fuller 2018a; Scarvaglieri and Zech. 2013), and the current study builds on this research to examine the use of the term Biodeutsche(r). This study looks at the underlying ideological discourses which are evoked, endorsed and challenged through the different patterns of use of this term. I will gloss this term in English with the phrase 'ethnic German', as this is the term used in discussion about the role of descent in German belonging (see for example Aktürk 2012; Brubaker 2004; Gehring 2016). 
In the following section, I present a brief overview of the concept of ethnicity and how it has played a role in German policies and public discourses related to immigration since World War II. Section 3 will provide a discussion of the discourses of belonging, following by a discussion of the previous research on labels for social groups in Section 4. After describing the methodology in Section 5, Section 6 presents the discussion of the various meanings of Biodeutsche $(r)$ and the ideological implications.

\section{German ethnicity, citizenship and belonging: Concepts and policies}

In this section I will address how the concept of ethnicity is used in this analysis, and how it has, in recent German history, been part of national politics.

\subsection{Ethnicity}

The study of race and ethnicity, concepts integral to this analysis, has focused on the socially constructed nature of these concepts. That is, the categorization of phenotypic differences into discrete groups called "races" is considered to be a cultural process, not a biological reality; physical differences fall on a continuum and not in clearly demarcated categories (Gannon 2016). Thus the existence of racial groups is the result of cultural processes, not natural division, and has often been rooted in colonialism and the need to establish difference (Lin and Kubota 2013).

"Ethnicity" is similarly a cultural construct. It differs from race because it is generally used refer to members of a group that putatively share a common history, culture, customs, and often language, aspects of group identity not inherent to the term race. However, ethnicity also implies shared bloodlines, and thus overlaps with ideas about racial categories. Ethnicity is usually the term linked to national origin, which is the focus here, in contemporary societies as well as academic discussions (Aktürk 2012; Brubaker 2009; Zelinsky 2001). Racial categories, although also sometimes seen as correlating with nations, are more typically associated with larger geographical regions and not in a one-to-one correspondence with countries of origin. I will use the term ethnicity in the rest of this chapter, as this is the term which has been adopted to talk about Germanness in academic discourse and also, in many cases, to discuss the ancestry of groups that are all racially categorized as White (Antonsich 2012; Painter 2010).

Germany is well-known for its history of ethnonational ideology, and citizenship and belonging have historically been expressed in these terms. However, such ideological positionings are never static, and this analysis seeks to understand the 
discourses which circulate about the connection between ethnicity and national identity in contemporary Germany. The view of a connection between ethnicity and national identity has had consequences for citizenship regulations and immigration policy, as well as everyday interactions. The following section will provide a brief historical background about the current situation.

\subsection{Immigration and citizenship}

Following WWII, migration into Germany grew rapidly, especially with the Gastarbeiter 'guest worker' program which invited workers (mostly from southern Europe, former Yugoslavia, and Turkey) to come to work in Germany. Germany has become the second most popular destination for migrants in the world, following the US. In 2019, $15.9 \%$ of the population in Germany were international migrants (United Nations 2019). Statistics from 2018 show that an even higher percentage of the population, 25\%, has a "migration background", defined as someone who was not born with German citizenship or has at least one parent who was not (Statistisches Bundesamt 2019).

In the early days of the guest worker program, it was assumed that the migrant workers would neither stay in Germany nor bring their families, and there were no initial strategies to integrate or include these migrants in German society. Many did in fact stay, but subsequent generations, despite being born and raised in Germany, were not entitled to German citizenship. In contrast, another category of migrants entered the country in large numbers after German reunification in 1990 and were entitled to German citizenship upon arrival: the Spätaussiedler (literally 'late settlers'), who were so-called Volksdeutsche (meaning of German descent, but not with German citizenship) from eastern Europe and, primarily, the former Soviet Union. Thus at this point, citizenship for immigrants was still a privilege for those deemed to have German blood (see Fuller 2019 for a more detailed discussion).

It was not until the 1990s that there were changes in naturalization policies to make acquiring German citizenship for migrants and their descendants easier. Even more significantly, in 2000 changes were made to citizenship policy to make those born and raised in Germany eligible for citizenship without the naturalization process, with some caveats (Ersanilli and Koopmans 2010). Although initially those gaining citizenship based on birthplace were not allowed dual citizenship, this restriction was lifted in 2014.

These changes in policy did not happen in an ideological vacuum, of course, and are also intertwined with ideas about not just the legalities of citizenship but the emotional connections to German belonging. These underlying discourses will be addressed in the next section. 


\section{Discourses of belonging}

This analysis encompasses social constructionist and critical perspectives, looking at the ideological positionings which are produced through the use of particular terms to reference social groups. An underlying assumption is that language plays a role in the construction of social reality and thus the words that we use to label social categories represent a particular perspective which is not neutral but constitutive of social meaning (Fairclough 2009; Wodak 2011). Inherent in this process is the possibility of social change; that is, through societal discourses we can change how particular social categories are characterized. The meanings of terms are not fixed but constructed through use. Here, I focus on how the term Biodeutsche( $r$ ) functions to produce and reproduce social categories related to national belonging (van Dijk 2018, Wodak et al. 2009).

Yuval-Davis (2011) notes that everyday practices of belonging include multiple voices and challenges to hegemonic ideologies which allow for heterogeneity within a group; that is, an intersectional perspective on belonging is what is needed. This perspective is adopted here; in what ways does Biodeutsche $(r)$ bring to life the reality of intersectional identities? I examine the multiple meanings of this term based on its usage and how traditional understandings of Germanness are both challenged and naturalized. While this term came to life to challenge ethnonational discourses, we see that it has also been co-opted to reinforce ideas about the primacy of descent in national belonging.

\subsection{Discourses of ethnonational ideology}

The term belonging has been defined in different ways; in this research, it is used to address how the personal emotions of attachment to place are represented in societal discourse (see Antonsich 2010). National belonging is continuously reproduced through texts and talk which establish who is included in and excluded from national groups (Billig 1995; Bonikowski 2017). Duyvendak (2011) discusses how in Europe, discourses about "feeling at home" often involve nostalgia for (putative) past ethnic homogeneity of the nation. This is a central part of one discourse which will be addressed in this analysis, the discourse of ethnonational ideology.

Yet the potential vagueness about how to define ethnicity, and specifically what it means to be "ethnic German", complicates the discussion. Ceuppens and Geschiere (2005) note the upsurge in the focus on "autochthony", a term from Greek which refers to "self" and "soil" - but again, the claim is vague. How many generations back does the claim to being from a particular plot of land need to go? And given shifting borders, what soil counts as German soil? The specific terms 
"autochthone" and "allochthone" have not formed a significant part of the discourses of belonging in Germany, but the concepts nonetheless provide a focus on the issues at stake. As the dichotomy of Menschen mit Migrationshintergrund ('people with migrant background') and Biodeutsche illustrates, descent continues to be a noteworthy aspect of social categorization.

The term ethnonational discourse is used here to talk about how an essentialist category of "German" is constructed which includes descent as a primary focus (Fuller 2018a, 2019, Metzger and Özvatan 2020, Özvatan 2020; Römhild 1999). The Germanness of those seen as descendants of a homogeneous folk linked to Germany is not questioned within this discourse, and those who have other backgrounds do not belong to this category. While they may be integrated into German society, they are still labelled as "other" (e.g., Menschen mit Migrationishintergrund, Passdeutsche). ${ }^{1}$ Integration, as will be discussed in the next section, is desirable and ethnic Germans provide the model of Germanness. However, integration does not make one a "true" or "pure" German within this discourse, and there are privileges granted only to those who are considered German by descent.

\subsection{Integration and belonging: Discourses of exclusion and inclusion}

One manifestation of the discourse about German belonging can be seen in the perpetuation, in the late 1990s and early 2000s, of what has been called the Leitkultur 'guiding culture' concept. Those who support this idea hold that there is a dominant German culture which must be preserved and into which migrants must integrate (Manz 2004; Pautz 2005). While this term has not remained central in the discourse about German integration, it was resurrected in 2018 in a speech by the German Minister of the Interior de Maizière outlining the key elements of a German 'guiding culture' (Fuller 2018a). But even when this term was not used, the issue of diversity in German society and what cultural practices are considered German, or acceptable in German society, has always been integral to the discourse about migration and migration background people in Germany.

Thus, a great deal of the discourse about migration is about integration, although this was not a focus of policy until about 50 years after migration to Germany in large numbers began. In 2007 German Chancellor Merkel introduced a National Integration Plan to provide a federal framework for the implementation of integration programs. A primary focus of this was language learning (Stevenson

1. "Passport German" is a derogatory term used for people of migration background to indicate that while they may have a German passport, they are not legitimately German (see Feustel et al 2019) 
and Schanze 2009), although other aspects of integration are also addressed in integration courses. ${ }^{2}$

There are many indications that in addition to these changes in policy regarding migrants, ideological changes about what it means to be German have also occurred; that is, there are competing discourses with the ethnonational discourse I mention above. One discourse which will be discussed here is what I will call a discourse of inclusion, which maintains that German belonging is based on linguistic, social, and cultural practices. Williams (2014), in her analysis of the discursive scripts produced by political elites from 2000-2010, notes a shift away from an ethnonational understanding of German identity toward more liberal attitudes about immigration and integration. While she notes that there continue to be debates about integration and the Leitkultur, both policy and discourses have shifted dramatically. Among the general population there have also been clear changes (Fuller 2019), but there continue to be competing discourses. Research by Williams (2013) shows that there are different ideas about what constitutes Germanness and citizenship within the migrant background population as well as within the majority. Wilpert (2013: 125-126) notes that for many people with migrant background, citizenship is viewed pragmatically, as a means to a more secure legal status; and for the majority of the population it not has given rise to more acceptance, but rather to more discourse about the inability of Muslims to integrate. Thus, while access to citizenship insures some rights, it does not guarantee acceptance and belonging. To the contrary, citizenship not based on descent opens up an opportunity for the division of German citizens into categories of those who truly belong and those who do not.

One concept which has been used to talk about group belonging is "enoughness" (Blommaert and Varis 2015), that is, the concept that in order to be accepted as a member of a group or representative of a certain category, one must exhibit a certain number of key characteristics. This authenticity is something which is constantly being negotiated and what constitutes enoughness may change - not just over time, but also from one situation to another. In the case of German identity, we have seen that both legal criteria for citizenship and attitudes have changes somewhat since 2000, and are still in flux across interactions.

Thus, many Germans (in particular, those with migration background) must continually negotiate their belonging, and may often be positioned as the unintegrated Other. The process of Othering is a discursive process; through questions such as "Where are you from?" (Hatoss 2012) individuals are positioned as the Other, not belonging in the local space. Labels such as those discussed in this

2. see https://www.make-it-in-germany.com/de/leben-in-deutschland/integration/integrations kurse/ for more information 
research are a prime resource for Othering, because the existence of a named category contributes to its sense of legitimacy. Of course, one can still dispute that a label is appropriate, and as we will see in these data that is in some cases exactly what occurs.

Thus, exactly what set of characteristics are "enough" to make someone German is neither fixed nor finite, and determining which traits are essential is the negotiation of ethnic group membership. For those who adhere to an ethnonational ideology, descent - belonging by blood to the German people - is a key element in how Germanness has been defined (Ditlmann et al. 2011). This is a discourse of exclusion. For those who consider being German to be based on ethnicity, descent is a criterion which trumps all others; it cannot be compensated for by any amount of linguistic or social integration.

However, it should be noted that explicit reference to defining "German" in terms of blood and not cultural background has been shown to be dispreferred in many contemporary contexts, especially by young people (Fuller 2019, Moffit et al. 2018). Speaking German is often cited as part of belonging, but research has shown that language is often a necessary but not sufficient criterion; other social and cultural practices are often cited in the reproduction of inclusive ideologies, included economic participation and adhering to laws (Fuller 2019).

While potentially more inclusive, such discourses may also serve to exclude. In particular, when national origin or religion is perceived as determining cultural practices, this sets up people of certain backgrounds as unable to belong. In particular, in some discourses about integration, doing anything associated with Islam makes a person automatically not German, thus making integration and authentic German identity for Muslims by definition impossible (Fouratan et al 2014, Fuller 2018a, 2019; Holtz et al. 2013, Moffit et al. 2018).

\subsection{Post-national discourse}

Another discourse about German belonging is what has been called a post-national discourse, which focuses on how, with increased migration and diversity, nationality ceases to be a major focal point for self-identification (Wodak 2017). Specific to this analysis, instead of citing other criteria for Germanness, such as cultural behaviors or legal status, this discourse focuses on other aspects of identity as more important. For instance, Ezell et al.'s (2003) study of German university students shows that they tend toward a post-national identification, where Europeanness and transnational values such as human rights and social equality for all are stressed.

However, as Wodak (2017) argues, in many cases increased migration and diversity has created a backlash of ethnonational ideologies. Further, Krzyzanowski 
(2010) has noted that while discourses and policies related to European identities may contribute to unity among EU citizens, it provides opportunity for both structural and discursive exclusion of migrants from outside the EU. Thus this discourse is often disputed. It is this presence of competing ideologies - ethnonationalist, inclusive, exclusive and post-nationalist - that we will address in this following analysis.

\section{The term Biodeutsche(r)}

In this analysis, I will look at the negotiating of belonging through the use of terms to denote different segments of the population in Germany. This analysis focuses on implicit meaning construction, looking at the underlying ideologies in the discourse instead of explicit discussion of the criteria for being German. However, as we will see, one significant aspect of the use of the term Biodeutsche $(r)$ is that there is a lot of meta-commentary surrounding it.

Given the above-mentioned finding that many people avoid naming descent as a criteria for being German, it is of particular interest that the term I will address, Biodeutsche( $r$ ), refers to exactly this criterion, and its use in these data have increased rapidly since 2015. Thus the use of this term brings into focus an attitude which is considered distasteful by some, because the development of this term calls attention to an ethnonational ideology. The complexity of these competing discourses surrounding the role of descent in determining belonging will be addressed in the subsequent analysis section.

Recent research on terms used to talk about portions of the German population show that the words for the Other serve not merely to describe but primarily to exclude. A study by Lutter (2016) investigates the changes in terminology over the years, from Gastarbeiter 'guest worker' to Ausländer 'foreigner' to the current term Menschen mit Migrationshintergrund 'people with migration background', and shows how these changes in terminology reflect changes in the status of the people denoted, but did not alter the fact that these terms served to distinguish these residents or citizens from "normal" Germans. Similar conclusions are drawn by Scarvaglieri and Zech (2013) in their corpus study of the use of the term Migrationshintergrund 'migration background', which is used to create a category of those who are not, and cannot be, authentically German.

There has been little work done on the terms used to describe Germans who do not have migration background. Indeed, these terms are often not commonly used in everyday talk. As the unmarked category in German society, Germans without migration background have been less likely, until recently, to be labelled 
or to have their social characteristics discussed in mainstream discourse. Unlike the term Migrationshintergrund, which is an official term which has been taken up in (some) everyday language use, Biodeutsche(r) has no official standing and its origin is credited to a cabaret artist and an early use by the Green Party politician Cem Özdemir is described as a joking way to refer to Germans without migration background (Goldmann 2017). The goal of the term is described as making visible the privilege granted to those who are usually not labelled. In a study looking at the discussion of crime in contemporary German novels, Titarenko (2019: 34) states baldly that the term Biodeutsch has emerged "as a result of the tense relationship between refugees and local people". Fuller (2019) notes that this term reflects a focus on ethnicity as the criterion for German belonging, but is remarkable in that it emerged initially as a means of mocking the majority group, and was then adopted by this group to refer to themselves. As I will argue below, the term Biodeutsche( $r$ ) is significant because of this development and also because its current use shows great variation and competing social meanings.

\section{Methodology: Media data}

Discourses about immigration and integration are reproduced in the media, meaning that they both represent and shape ideologies about national belonging. This analysis represents an exploratory examination of how the term Biodeutsche $(r)$ is used in the press, and what societal discourses are represented in its use.

The data for this research were collected through a Nexis Uni search for the term Biodeutsch carried out in the summer of 2019, resulting in a corpus with 299 articles which used the term. The search was limited to German-language articles in German newspapers. This analysis does not look at how this term is part of the socio-political profile of individual newspapers, but rather provides a broader, more general view of the use of this terms in the press. Duplicate articles and adjectival uses of the word were eliminated; thus the numbers discussed here represent only articles in which this word was used as a noun. The uses were coded in terms of categories of meaning which emerged from the data. The counts given for each term are of the number of newspaper articles in which these terms appeared, as there were no instances of different meanings of the word occurring within a single article.

The term Biodeutsche( $r$ ) first appears in this corpus in 2008, when there are two articles which use the term. It occurs infrequently in these newspapers until the mid-2010s, when its use suddenly skyrockets, as can be seen in Figure 1. Because these data were collected before the end of 2019, the number for that year is not included. It must be noted that these numbers are simply a raw count of how many 
articles used the term; because the corpus was collected by a search for the term, the data cannot be presented as occurrences per number of printed words. Thus this graph provides us with only a very simple fact: this term has become, since 2015, a common way of denoting a group of people. The question under investigation is, what ideologies about German belonging are reproduced through these uses?

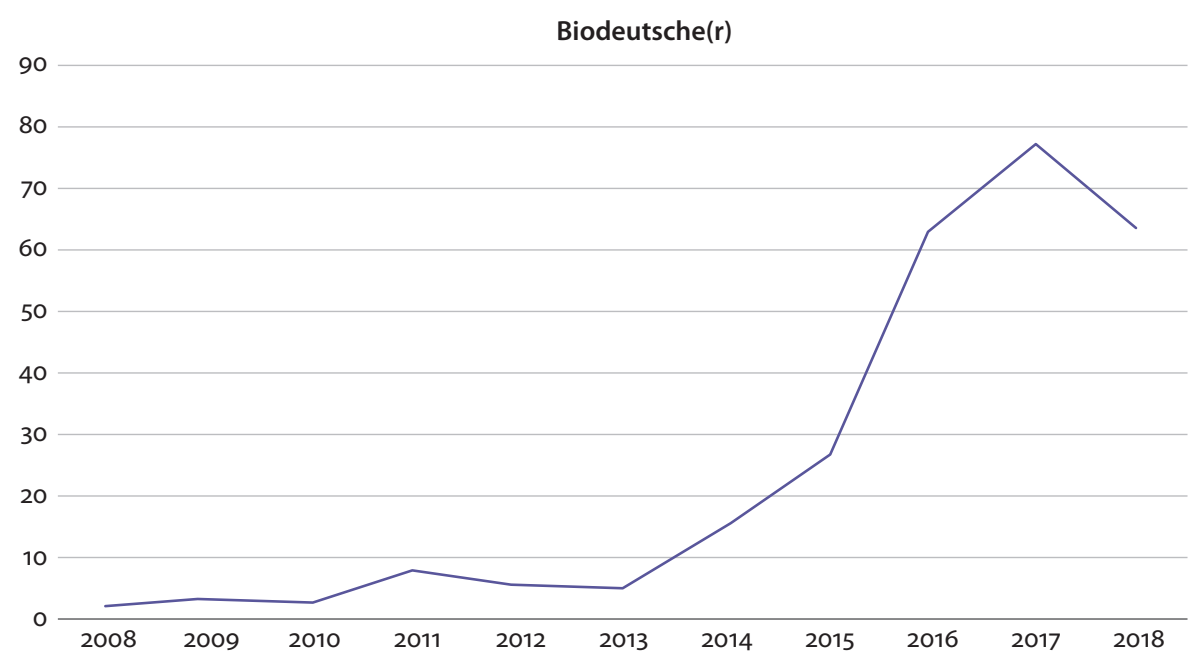

Figure 1. Trajectory of the use of Biodeutsche(r)

\section{Overview of term and its meanings}

There were 299 articles in this dataset which used the term Biodeutsche(r) as a noun. Categories of meaning were not pre-determined but emerged through the analysis of the data with the focus on ethnonational versus inclusive ideologies about belonging in Germany. The result of this was four social meanings, which could be further divided into two discourses: an ethnonational discourse, and a counter discourse which reveals a critical stance toward the validity of ethnic criteria for categorization of members of German society.

Within the examples which showed a critical stance, the first category is the use of this term to denote members of a privileged group. This clearly builds on the original intent of this term, to make privilege explicit. These examples show a recognition of inequality of experience based on whether one is categorized as having migrant background or falling into the unmarked category of Biodeutsch. In most of these examples, there is an implied if not explicit criticism of this inequality and the inherent discrimination involved. The second type of use of the term within the 
counter discourse examples goes a step further, and in these instances the validity of the term is openly questioned. These two types of usage work against ethnonational ideologies about belonging in Germany.

In contrast to these two categories of meaning, there are two additional categories which do other ideological work. There are six instances of claims of reverse discrimination, that is, that it is Biodeutsche(r), and not those of migrant background, who experience prejudice in Germany society. These comments represent the acceptance of this term and thus fall into line with the last category, which are examples in which the term Biodeutsche( $r$ ) is used in a putatively neutral way to refer to what is treated as an objective social category. The distribution of these meanings can be seen in Figure 2.

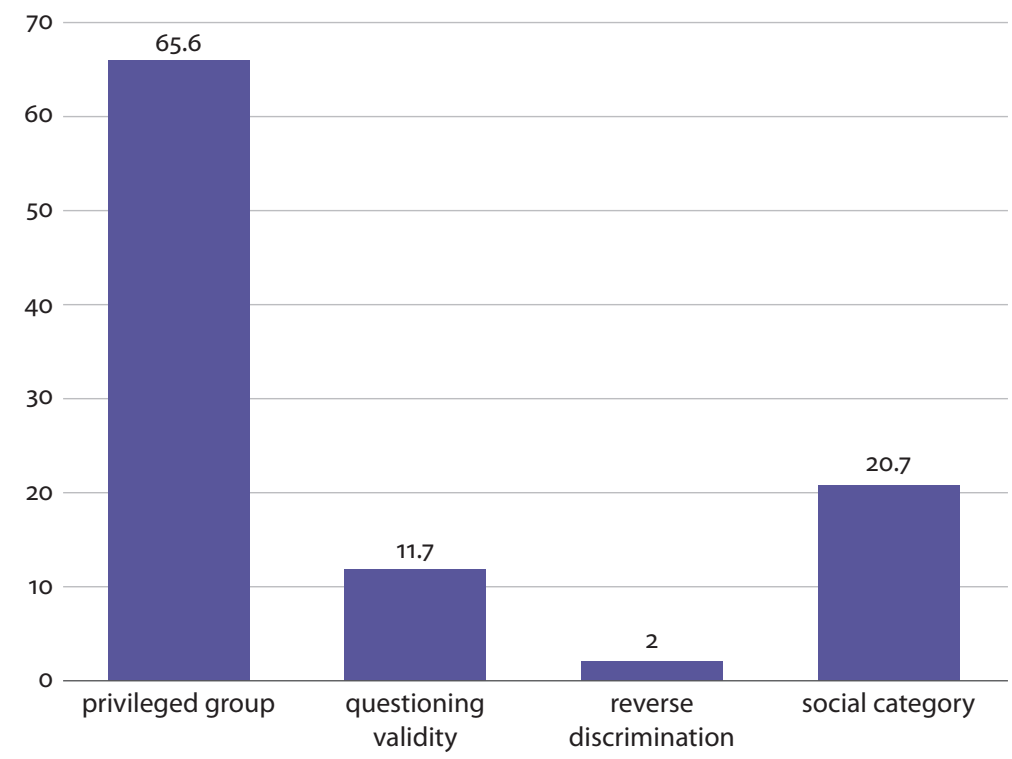

Figure 2. Percentages of categories of meaning for Biodeutsche $(r)(n=299)$

\subsection{Biodeutsche(r): Challenging ethnonational ideology}

As discussed above, Biodeutsche(r) appears to have begun its life with the goal of mocking entitlement in Germany society based on descent. Thus both of the first two uses of the term in the categories of referencing a privileged group and questioning the validity of categorization through ethnicity fit with this original stance. As can be seen in Figure 2, the most common use in these data $(n=196,65.6 \%)$ was to refer to a privileged group in society. 
In Example (1), we see an explicit reference to and critique of this privilege in the last lines. This example is part of an article in which the then state integration secretary Zülfiye Kaykin, a person with migration background, has been criticized for pursuing integration strategies that putatively are common practice among politicians without migration background; thus the critic here is the there are different standards for Biodeutsche than for people with migration background.

(1) Müsste Frau Kaykin aber den Hut nehmen wegen einer Integrationsstrategie, die auch von den meisten Integrationspolitikern ohne türkische Wurzeln verfolgt wird, wäre das Echo in der Migrantengemeinde wiederum absehbar: Was „Biodeutsche” dürfen, darf eine Kaykin noch lange nicht. Wer kann das wollen?

(Die Welt am Sonntag, November 6, 2011) 'If Ms. Kaykin has to quit because of an integration strategy that is also pursued by most integration politicians without Turkish roots, the echo in the migrant community would again be foreseeable: What "Biodeusche" are allowed to do, is far from allowed a Kaykin. Who could want that?'

The same problematization of the people with migrant backgrounds being penalized for the same actions that can be done without consequences by Biodeutsche can be seen in Example (2), in which there is reference to the "right" of Biodeutsche to loiter or hang out in the park, with the implication that if Africans do this in Berlin, this will be seen as engaging in suspicious activity. This example is illustrative of the ambiguity of the social work which this term does in such examples. Although it reproduces the category of ethnic Germans, it also notes the inherent discrimination in uncritical acceptance of this social category as meaningful in terms of cultural behavior.

(2) Im nahen Görlitzer Park versucht man seit einiger Zeit schon die Interessen der verschiedenen Stadtbewohner unter einen Hut zu kriegen, was in der Frage gipfeln kann, ob Afrikaner genauso wie Biodeutsche das Recht aufs Rumlungern im Park haben.

(taz, die tageszeitung, 5 July 2014) 'In nearby Görlitzer Park, attempts have been made for some time to reconcile the interests of the various city dwellers, which can culminate in the question of whether Africans, like Biodeutsche, have the right to loiter in the park.'

A stronger challenge to ethnonational ideologies is found in the second category, which contains examples which challenge the legitimacy of categorizing people according to descent. These examples comprise only $11.7 \%(n=35)$ of the total uses, but they are significant because they are criticisms of the term itself, not simply of discrimination against people of migration background. In some cases, this critique is very explicit and is the focus of the text, as show in (3) and (4). In (3), we see 
mention of Biodeutscher as a nomination for the Unwort des Jahres (literally, the 'unword of the year', meaning 'worst word of the year') in 2016, a clear condemnation of the use of this word. In (4) we see an excerpt of an opinion piece which directly questions whether the word Biodetuscher should be used. The article reports on the critique of this word by the German president Frank-Walter Steinmeier, who said, in an event where he had invited people of Turkish background, Es gibt keine halben oder ganzen, es gibt keine Bio- oder Passdeutschen ('There are not halves or whole, there are no bio- or passport Germans'). In the article, this is referred to as a Plädoyer gegen Deutsche erster oder zweiter Klasse ('plea again [the concept of] first and second class Germans'). The article goes on to spell out their critique of this word, linking it to Nazi ideals.

(3) ... Für das "Unwort des Jahres 2016" sind bisher Wörter wie "Biodeutscher", "Flüchtlingsobergrenze" oder "Umvolkung" als Vorschläge eingereicht worden,

(Solinter Morgenpost, 27 October 2016)

"For the worst word of the year 2016 the words "Biodeutscher", "refugee upper limit" and "ethnic replacement" ${ }^{3}$ have been submitted as suggestions.'

(4) Fangen wir bei Steinmeiers Erwähnung des "Biodeutschen" an. Es ist tatsächlich ein dummes Wort, weil es scheinbar ironisch mit dem Label "Bio" spielt, sich jedoch nur lässig verdruckst am Rande des eigentlich abgelehnten Rassismus bewegt. "Biodeutsch" impliziert die Vorstellung einer von genetischen Veränderungen "reinen" deutschen Abstammung. Die Nazis hätten dazu gesagt: das Ideal vom "arischem Blut".

(Der Tagesspiegel 28 August 2018) 'Let's start with Steinmeier's mention of the "Biodeutschen". It is actually a stupid word, because it seems to play ironically with the label "Bio", but is actually only borders on a racism which has been rejected. "Biodeutsch" implies the idea of a "pure" German descent from genetic changes. The Nazis would have said: the ideal of "Aryan blood".

Finally, in (5) we see another newspaper noting that this word appears frequently, but mostly in the context of questioning whether it is a good word. The tageszeitung, unlike the writer for the Tagespiegel in the last example, does not make a definitive conclusion, but illustrates that the meta-discourse about this word is more the norm than the exception.

3. While the details of this term are beyond the scope of this analysis, it is a term that is focused on fear of migrants taking over Germany; for more commentary on this in the media, see https:// en.wikipedia.org/wiki/Umvolkung. 
(5) In einem unterhaltsamen Text über das Deutschsein schreibt Autor Daniel Haas: Ich meine die richtig, richtig Deutschen, Biodeutsche sagt die taz, glaube ich, dazu....

Biodeutsch sagt also die taz? Tatsächlich? Tatsächlich! Der Blick ins Archiv verrät: Alle paar Wochen taucht das Wort mal in einem Text auf. Allerdings meistens genau deshalb, weil sich jemand fragt, ob es eigentlich ein gutes Wort ist. Ist es ein gutes Wort? Die taz sagt dazu: Wir wissen es nicht.

(taz, die tageszeitung 16 August 2018)

'In an entertaining text about being German, author Daniel Haas writes: I mean the proper, proper Germans, Biodeutsche, as the taz refers to them I think.... So bio-German says the taz? Indeed? Indeed! A look at the archive reveals that the word appears in a text every few weeks. However, mostly precisely because someone wonders whether it is actually a good word. Is it a good word? The taz says: We don't know'

There are further examples of this which are less direct and explicit in their critique of this term. In (6), we see an example where the ability to speak German without an accent - implicitly, an index of belonging in Germany - is found in someone with a migration background. This challenges the idea that those who are not Biodeutsch do not share important cultural practices, such as speaking German natively, with Biodeutsche, and potentially questions whether being or not being biodeutsch is a valid category. In (7), loyalty to German sovereignty, and not ethnicity, is framed as the important criterion for belonging, again raising the question of what the social significane is of the category of Biodeutsche(r).

(6) Özgür "Ötze" Cebe ist kein "Biodeutscher", spricht aber akzentfreies Deutsch.

(Kölnische Rundschau, 23 Oct0ber 2015) 'Özgür Ötze Cebe is not a Biodeutscher, but speaks German without an accent'

(7) Ein Xavier Naidoo mit Migrationshintergrund, der zu Deutschland steht und seine Souveränität verteidigt, gehört hundert Mal mehr zum deutschen Volk als die Biodeutsche Claudia Roth, die jeden Tag schlecht über Deutschland redet!

(Berliner Zeitung, Oct. 11, 2014)

'A Xavier Naidoo with migration background, who stands by Germany and defends its sovereignty, is a hundred times more German than the Biodeutsche Claudia Roth, who speaks badly about Germany every day!'

In addition to these rather straightforward commentaries on the term Biodeutsche(r), there are many instances of this term used in a playful, humorous key. One function of humor is cultural critique (Driessen 2015); the topics of humor are never randomly chosen but are issues of social relevance in the time and place where the joke is made (Kuipers 2008). Relevant for this analysis is the role of humor in 
creating a focus on cultural assumptions to put them under scrutiny (Gilbert 2004; Procházka 2019).

In this case, mocking the term Biodeutsche(r) provides the opportunity to address the basic understanding, and even the reason for the existence, of this term. Joking about what something is called is one way of questioning the existing power structures. Further, humor can be used to mock holders of certain views. Rossing (2012) discusses how Stephen Colbert uses humor to mock those who claim to live in a postracial society; similarly, humor in this study is used to point out how the term Biodeutsche $(r)$ is an indication of the lack of a postnational ideology.

One way in which this term is mocked is by drawing on the use of bio in German to mean "organic", especially for food; this is a classic type of linguistic humor, a pun, which relies on the different meanings of this morpheme (Attardo 2008). This occurs in some of the articles which include a discussion of the meaning of the term, as in (8), as well in instances where social categories are discussed, as in (9). The example in (8) begins with a word play and ends with pointed sarcasm indicating how stupid the writer finds this term; similarly, in (9), the cabaret artist Özgür Cebe jokingly draws a parallel between organically grown or genetically modified produce and ethnic or migration background Germans to focus on the absurdity of this distinction for human beings.

(8) Sind Biodeutsche so etwas wie Biokartoffeln? Auf besonderer Scholle gewachsen? Ist "biodeutsch" dann eine Art Gütesiegel? Im Gegensatz zu normalen Deutschen, die an die Käfighaltung gewöhnt sind? Oder hat nur jemand in eurer Biohirnmasse zulange herumgerührt? Ach deshalb! （taz, die tageszeitung, 2 May 2005) 'Are Biodeutsche something like organic potatoes? Grown on a special farmland? Is biodeutsch then a kind of seal of approval? In contrast to normal Germans, who are used to being kept in cages? Or has someone been stirring around too long in your bio-brain mass? Oh, that's why!

(9) (From an interview with cabaret artist Özgür Cebe) "Born in the BRD" [name of his program] ist ein Bekenntnis zu diesem Land. Ich gelte ja nicht als "Biodeutscher", sondern wohl eher als "Monsantodeutscher". Trotzdem bin ich aber nun mal Deutscher. (Stuttgarter Zeitung, 15 April 2017) "'Born in the Federal Republic of Germany" is a profession of loyalty to this country. I don't count as a "Biodeutscher", but rather as a "Monsantodeutscher". Nevertheless I am German.

The mocking tone which accompanies the use of the term Biodeutsche $(r)$ is not only found in jokes about organic food; there are also frequent comments which seem to be intended to amuse which do not mock the form of the term but the meaning. These examples imply that the distinction between ethnic Germans and those with 
migration background is irrelevant. In (10), reference is made to a German politician who is known for a book about how Germany is being ruined by unintegrated immigrants; here the writer counters this with a claim that the people in their city with migration background are integrated because they are just as unhappy as the Biodeutschen, thus making a mockery of the concept of integration.

(10) Sarrazin hat nicht recht, die Menschen mit Migrationshintergrund in unserer Stadt sind voll integriert. Sie sind genauso mies gelaunt wie die Biodeutschen.

(taz, die tageszeitung, 11 April 2012)

'Sarrazin was wrong, people with migration background in our city are fully integrated. They are just as grumpy as the Biodeutschen.'

In (11), the topic is football, a domain in which there has been a great deal of discussion about players with migration background (Fuller 2018b; Gehring 2016). In this example, the writer translates the euphemism deutsch im klassischen Sinne 'German in the classic sense' with Biodeutsche(r), and also attributes this remark to a right-wing politician who is given the fictitious title of "Director of the Genetics Department". The clear implication here is that the focus on the ethnicity of the players is discrimination. The ridiculousness and irrelevance of ethnicity is emphasized as the writer goes on to ask if one cheers more loudly for an "ethnic German goal", and if this triggers nostalgia for the days when the players all had stereotypically German names. This use of Biodeutsche, both as a noun and an adjective, clearly seeks to portray concerns about ethnicity as not only distasteful but ludicrous.

(11) Kann es etwa sein, dass die nationale Bewegung die EM schlicht boykottiert, weil die Nationalelf, wie ihr Abteilungsleiter Genetik, Alexander Gauland, bemängelte, "nicht mehr deutsch im klassischen Sinne" ist, was auf Deutsch übrigens heißt, dass ihm zu wenig Biodeutsche mitspielen?... Mich würde etwa interessieren, ob man als völkischer Deutscher bei einem biodeutschen Tor, beispielsweise von Bastian Schweinsteiger, doppelt so laut schreit wie bei einem Mustafi- oder Özil-Tor. ... Im frenetischen Jubel über das Tor des in jeder Hinsicht weißen Mannes Schweinsteiger dürfte jedenfalls auch Sehnsucht nach jener Zeit gesteckt haben, als Nationalteams noch nicht "La Mannschaft" hießen und ausschließlich aus Sepps, Bertis, Ullis, Horsts, Rudis und Karlheinzen bestanden.

(Der Spiegel, 18 June 2016)

'Could it be that the national movement is simply boycotting the European Championship because the national team, as its Director of Genetics, Alexander Gauland, criticized, is "no longer German in the classical sense", which in German means, by the way, that not enough Biodeutsche are playing ... I would be interested to know whether you cheer twice as loud as a nationalist German at a biodeutsch goal by, for example, Bastian Schweinsteiger, than at a goal by 


\begin{abstract}
Mustafi or Özil. ... In the frenetic jubilation over the goal of the by all standards white man Schweinsteiger there would also have been longing for that time when national teams were not yet "La team" and consisted only of Sepps, Bertis, Ullis, Horsts, Rudis and Karlheinzes.'
\end{abstract}

These examples, which span the entire period of use of this term, follow in the spirit of the origins of the term: it was coined to mock those it named, used ironically to make fun of the idea that blood was more important than culture. In these usages, this term calls attention to the wrongness of what it names. As noted in the above-mentioned Spiegel article from 2017: Die abschließende Antwort auf die Existenzfrage aller "Biodeutschen" lautet deshalb: Euch gibt es nicht. Diskriminierung, weil sich Menschen für "biodeutsch" halten, leider schon. ("The final answer to the question of the existence of all "Biodeutschen" is therefore: You do not exist. Discrimination because people consider themselves "biodeutsch" unfortunately does.) In the next section, we will discuss the uses of this term which support an ethnonational ideology and thus are part of this discrimination.

\title{
6.2 Missing the joke: Reclaiming Biodeutsche(r)
}

Reclaiming a term means to take what has been intended as an insult and to embrace it as a marker of ingroup solidarity. This has arguably occurred with the term "queer", both within and outside of academic circles (McConnel-Ginet 2002; Rand 2014); instead of indexing a negative social category, it is adopted as a positive term to describe the self. Usually, of course, this process occurs when a word is used as a slur to refer to a minority group; with Biodeutsche(r), there is the added twist of this term being used to mock the majority group, or at least certain ideologies associated with members of that group. The reclaiming of this term is evidenced in the use for the self, as noted in Fuller (2019: 184). (This self-reference is also, for what it's worth, part of the description of the term on Wikipedia; see https:// de.wikipedia.org/wiki/Biodeutsch.)

While the above examples are a counter narrative which critiques a social hierarchy which privileges ethnic Germans, the examples of ethnonational discourse either refute this privilege or ignore it. One small group of uses claim reverse discrimination, that is, oppression of members of the majority group (i.e., Biodeutsche). Of the six instances (2\%) which have this meaning in these data, four, as in (10), discuss the term itself as derogatory and its use as discrimination against ethnic Germans, claiming that this is a growing trend in German society. The other two claim other types of discrimination against ethnic Germans in German society, such as that ethnic Germans are considered racist for social commentary that is accepted from those with migration background. While this use of the term locates 
the problem of discrimination as working against the ethnic majority, it nonetheless portrays ethnic stereotyping as discrimination.

(12) Populäre Schmähbegriffe sind der "Biodeutsche" und Variationen aus "Alman" und "Kartoffel". Vor allem die "TAZ", die sonst jede Diskriminierung geisselt, liebt dieses Vokabular. "Kartoffeln" seien "ignorant, geschichtsverdrossen und besserwisserisch", schrieb eine Kolumnistin im vergangenen Herbst. Der Text war kein Ausrutscher.

(Neue Zürcher Zeitung (Internationale Ausgabe), 20 July 2018) 'Popular insulting terms are the "Biodeutsche" and variations from "Alman"4 and "potato". Above all, the "TAZ", which otherwise disparages all discrimination, loves this vocabulary. "Potatoes" are "ignorant, history-obsessed and know-itall," a columnist wrote last autumn. The text was not a single occurrence.'

The final type of use ignores ideas of privilege and discrimination altogether; these examples occur in these data only since 2014, and thus represent a shift in stance toward this term. In these 35 usages (11.7\%), the term was used to denote a social category, usually in combination with other named social categories, as in (13). Used in this way, as part of a list of social groups, it is portrayed as a neutral term which simply denotes a group in society determined by objective criteria, such as age group. Being an ethnic German is simply one category within a diverse society and the criteria for belonging are accepted as clear and concrete. It is this use, I argue, which is the most socially dangerous as it naturalizes the category of "ethnic German". These uses normalize this division as a factual aspect of diversity in Germany as opposed to a socially constructed social category. In both (13) and (14), the writers are trying to describe population diversity, and contrast Biodeutsche( $r$ ) with immigrant/migrants.

(13) Das Publikum ist gemischt, es geht bei 15 los, aber auch 50-Jährige kommen, Einwandererkinder, Biodeutsche. Sie spricht Jungs an wie Mädchen....

(Die Zeit, 13 March 2014)

'The audience is mixed, it starts at 15 but 50 -year-olds also come. Immigrant children, Biodeutsche. She appeals to boys as well as girls'

(14) ....Männer und Frauen, Reiche und Arme, Rechte, Linke, Pazifisten und Nichtpazifisten, Migranten und Biodeutsche, Ungläubige und Gläubige welcher Religion auch immer.

(Frankfurter Rundschau 28 January 2015) '...men and women, rich and poor, right, left, pacifists and non-pacifists, migration and Biodeutsche, non-believers and believers of whatever religion.'

4. This is the word for 'German' in Turkish. 
These examples do not assign characteristics to Biodeutschen - or members of other groups - but there are some instances where this term is not only used as if it is an accepted term which denotes an objective category, but also serves to construct the Other. In (15), although there is an explicit claim that descent (i.e., being a Biodeutscher) is not necessary to belong in Germany, there is nonetheless a clear contrast made: the Biodeutscher, who belong, and the Muslim, who must prove his patriotism.

(15) Sinnvoll allerdings bleibt die Frage: Wollen die Muslime zu Deutschland gehören? Wer sie bejaht, der muss nicht Biodeutscher sein oder sich nur noch von Eisbein und Sauerkraut ernähren. Er muss Verfassungspatriot werden, muss gleichsam das Grundgesetz neben dem Koran auf dem Nachttisch liegen haben.

(Bilanz.de, 28 November 2018)

'However, the question remains: Do Muslims want to belong to Germany? Whoever answers in the affirmative does not have to be a Biodeutscher or eat only ham hock and sauerkraut. They must become constitutional patriots, must have as it were the Constitution next to the Koran on the bedside table'

The category of Biodeutsche is also constructed, in a few instances, with reference to cultural knowledge - that is, the lack of knowledge about things which are not German. One example discusses how a Biodeutscher would not know what the Zuckerfest is (literally 'sugar festival', the German term for the celebration at the end of Ramadan; in Turkish this festival is called Seker Bayrami, in Arabic Eid al-Fitr). In another example, a comment is made that arabesque music is being played, which is described as unfamiliar to most Biodeutsche.

Thus the category of Biodeutsche as being knowledgeable about German cultural practices is implied, and there is implicit construction of the Other, the non-Biodeutsche, who participate in foreign cultural practices.

\section{Discussion and conclusion}

As this is a preliminary overview of a term which has not been previously studied, there are a number of limitations to this research. This analysis only shows us the public faces of these terms, but not the ways they are used in other contexts: in verbal communication, or in unmoderated online fora, unedited tweets, chats or personal messages. Further, another aspect of variation within the corpus which is not addressed is the different newspapers and also different types of articles within a newspaper; certainly patterns would emerge dependent on the intended readership of the press and the section of the newspaper. This a very fertile avenue for future 
research, as the use of the term in different venues is part of the construction of the identity of the newspaper as well as part of a broader ideological development in society, but alas beyond the scope of this analysis.

However, we do gain some insights into the competing discourses about Germanness through looking at this overview of the use of these terms in newspaper data. First, the origin of the term as intended to mock certain stances about German belonging can be seen in the presence of this type of use throughout the data. The term is primarily used to call out privilege and challenge the relevance of ethnicity as an important criteria in social categories in German society.

The data after 2014 show the development of other uses of this term, namely as a simple reference, which entails the acceptance of ethnicity as an important features when describing people in Germany. This reproduced an ethnonational ideology. It is important to note that such usages are in the minority in these data, however, and the vast majority of the uses mark this term as problematic, ridiculous, or at least a word for which the meaning must be negotiated. It is used to directly critique discrimination in German society as well as implicitly mock the focus on ethnicity as an important aspect of German identity.

In short, what this analysis shows is variation in the uses of this term which is linked to competing discourses. There has been some normalization of the term Biodeutsche(r), in the sense that it has been adopted for use by some as if this social category needs no explanation. However, the need to use the term - and the use has skyrocketed in the past five years - is a sign of the need to depict and challenge ethnonational ideologies, and this is done in various ways. There are direct challenges to the word as well as joking uses. While in some cases it is the ethnic Germans themselves who are made fun of, overwhelmingly it is the idea that ethnic Germans are more legitimately German which is held up for ridicule. The question that remains is whether future uses will expand on the supposedly neutral use of the term Biodeutsche( $r$ ), or if the mocking tone is evidence of a challenge to ethnonational ideologies will persevere.

\section{Acknowledgements}

I would like to thank the editors of this book and book series, and two anonymous reviewers, for their helpful feedback on previous versions of this chapter. 


\section{References}

Antonsich, M. 2010. Searching for belonging-an analytical framework. Geography Compass, 4(6), 644-659.

Antonsich, Marco. 2012. Exploring the demands of assimilation among white ethnic majorities in Western Europe. Journal of Ethnic and Migration Studies 38. 59-76. https://doi.org/10.1080/1369183X.2012.640015

Attardo, Salvatore. 2008. A primer for the linguistics of humor. The Primer of Humor Research 8. 101-155. https://doi.org/10.1515/9783110198492.101

Aktürk, Şener. 2012. Regimes of ethnicity and nationhood in Germany, Russia, and Turkey. Cambridge University Press. https://doi.org/10.1017/CBO9781139108898

Billig, Michael. 1995. Banal nationalism. London: Sage.

Blommaert, J., \& Varis, P. 2015. Enoughness, accent and light communities: Essays on contemporary identities. Tilburg Papers in Culture Studies, 139, 1-72.

Bonikowski, Bart. 2017. Nationhood as cultural repertoire: Collective identities and political attitudes in France and Germany. In Skey, M., \& Antonsich, M. (eds.), Everyday nationhood: Theorising culture, identity and belonging after banal nationalism, 147-174. London: Palgrave Macmillan. https://doi.org/10.1057/978-1-137-57098-7_8

Brubaker, Rogers. 2004. Ethnicity without groups. Cambridge, MA: Harvard University Press. https://doi.org/10.1017/CBO9780511489235.004

Brubaker, Rogers. 2009. Ethnicity, race, and nationalism. Annual Review of Sociology 35. 21-42. https://doi.org/10.1146/annurev-soc-070308-115916

Ceuppens, B., \& Geschiere, P. 2005. Autochthony: local or global? New modes in the struggle over citizenship and belonging in Africa and Europe. Annu. Rev. Anthropol., 34, 385-407. https://doi.org/10.1515/9783110198492.543

Dijk, Teun van. 2018. Discourse and migration. In Ricard Zapata-Barrero \& Evren Yalaz (eds.), Qualitative research in European migration studies, 227-245. Cham: Springer Open. https://doi.org/10.1007/978-3-319-76861-8_13

Ditlmann, Ruth K., Valerie Purdie-Vaughns \& Richard P. Eibach. 2011. Heritage- and ideology-based national identities and their implications for immigrant citizen relations in the United States and in Germany. International Journal of Intercultural Relations 35. 395-405. https://doi.org/10.1016/j.ijintrel.2010.07.002

Driessen, H. G. G. M. 2015. Humor, Anthropology of. In J. D. Wright (ed.), International encyclopedia of the social \& behavioral sciences, 416-419. 2nd edn. New York: Elsevier. https://doi.org/10.1016/B978-0-08-097086-8.12097-5

Duyvendak, Jan. 2011. The politics of home: Belonging and nostalgia in Europe and the United States. Berlin: Springer. https://doi.org/10.1057/9780230305076

Ersanilli, Evelyn \& Ruud Koopmans. 2010. Rewarding integration? Citizenship regulations and the socio-cultural integration of immigrants in the Netherlands, France and Germany. Journal of Ethnic and Migration Studies 36. 773-791. https://doi.org/10.1080/13691831003764318

Ezell, E. D., Seeleib-Kaiser, M., \& Tiryakian, E. A. 2003. National identity issues in the new German elites: A study of German university students. International journal of comparative sociology, 44(4), 280-308.

Fairclough, Norman. 2009. A dialectical-relational approach to critical discourse analysis in social research. In Ruth Wodak and Michael Meyer (eds.), Methods of critical discourse analysis, 162-86. 2nd edn. London: Sage. 
Feustel, Robert, Nancy Grochol \& Tobias Pruwer. 2019. Worterbuch des besorgten Burgers. Mainz: Ventil Verlag.

Foroutan, Naika, Coskun Canan, Sina Arnold, Benjamin Schwarze, Steffen Beigang \& Dorina Kalkum. 2014. Deutschland postmigrantisch I: Gesellschaft, Religion, Identität. https:// www.projekte.hu-berlin.de/de/junited/deutschland-postmigrantisch

Fuller, Janet M. 2018a. Immigration, integration and Leitkultur in German newspapers: Competing discourses about national belonging. Studii de Lingvistica 8(2). 175-190.

Fuller, Janet M. 2018b. Discourses of national belonging in Germany: Twitter data and the 2018 World Cup. Paper presented at the Language and Belonging Workshop, 5 October 2018, Amsterdam, The Netherlands.

Fuller, Janet M. 2019. Discourses of immigration and integration in German newspaper comments. In Andreas Musolff and Lorella Viola (eds.), Migration and media: Discourses about identities in crisis, 317-338. Amsterdam: John Benjamins Publishing Company. https://doi.org/10.1075/dapsac.81.14ful

Gilbert, Joanne R. 2004. Performing marginality: Humor, gender, and cultural critique. Detroit, MI: Wayne State University Press.

Gannon, Megan. 2016. Race is a social construct, scientists argue. Scientific American 5. https:// www.scientificamerican.com/article/race-is-a-social-construct-scientists-argue/

Gehring, Jacqueline. 2016. Race, ethnicity and German identity: A media analysis of the 2010 world cup men's national soccer team. Ethnic and Racial Studies 39. 1962-1980. https://doi.org/10.1080/01419870.2016.1148823

Goldmann, Fabian. 2017. Ist biodeutsch nur ein anderes Wort für Arier? Was hinter dem neuen Wort steckt. Spiegel Panorama, 6 June 2017. https://www.spiegel.de/panorama/biodeutschwer-benutzt-den-begriff-und-was-bedeutet-er-a-00000000-0003-0001-0000-000001410970

Hatoss, Anikó. 2012. Where are you from? Identity construction and experiences of 'othering' in the narratives of Sudanese refugee-background Australians. Discourse \& Society 23. 47-68. https://doi.org/10.1177/09579265114

Holtz, Peter, Janine Dahinden \& Wolfgang Wagner. 2013. German Muslims and the 'integration debate': Negotiating identities in the face of discrimination. Integrative Psychological \& Behavioral Science 47. 231-248. https://doi.org/10.1007/s12124-012-9227-6

Krzyżanowski, Michal. 2010. The discursive construction of European identities: A multi-level approach to discourse and identity in the transforming European Union (Sprache im Kontext 35). Frankfurt: Peter Lang.

Kuipers, Giselinde. 2008. The sociology of humor. In V. Raskin (ed.), The primer of humor research, 361-398. Berlin: Walter de Gruyter. https://doi.org/10.1515/9783110198492.361

Lin, Angel \& Ryuko Kubota. 2013. Discourse and race. In K. Hyland \& B. Paltridge (eds.), The Bloomsbury companion to discourse analysis, 277-290. London: Bloomsbury Academic.

Lutter, Andreas. 2016. Jenseits von Assimilation und Multikultur? Herausforderungen migrationspolitischer Bildung in Deutschland. Linguistik Online 79. 127-137. https://doi.org/10.13092/lo.79.3338

Manz, Stefan. 2004. Constructing a normative national identity: The Leitkultur debate in Germany, 2000/2001. Journal of Multilingual and Multicultural Development 25. 481-496. https://doi.org/10.1080/01434630408668920

McConnell-Ginet, Sally. 2002. Queering semantics: Definitional struggles. In Kathryn Campbell-Kibler (ed.), Language and sexuality: Contesting meaning in theory and practice, 137-60. Stanford: CSLI. 
Metzger, Stefan \& Özgür Özvatan. 2020. Games of belonging: Football, boundaries and politics between Germany and Turkey. Nationalities Papers 48(4). 737-751.

https://doi.org/10.1017/nps.2019.4

Moffitt, U., Juang, L. P., \& Syed, M. 2018. Being both German and Other: Narratives of contested national identity among white and Turkish German young adults. British Journal of Social Psychology, 57(4), 878-896.

Özvatan, Özgür. 2020. The Great Secession: Ethno-national rebirth and the politics of Turkish-German belonging. Social Inclusion 8(1). 285-299. https://doi.org/10.17645/si.v8i1.2437

Painter, Nell Irvin. 2010. The history of white people. New York: WW Norton \& Company.

Pautz, Hartwig. 2005. The politics of identity in Germany: The Leitkultur debate. Race \& Class 46. 39-52. https://doi.org/10.1177/0306396805052517

Procházka, Ondřej. 2019. Chronotopic representations as an effect of individuation: The case of the European migrant crisis. Language in Society 48. 1-27.

https://doi.org/10.1017/So047404519000812

Rand, Erin J. 2014. Reclaiming queer: Activist and academic rhetorics of resistance. Tuscaloosa: University of Alabama Press.

Römhild, Regina. 1999. Home-made cleavages: Ethnonational discourse, diasporization, and the politics of Germanness. Anthropological Journal on European Cultures 8(1). 99-120.

Scarvaglieri, Claudio \& Claudia Zech. 2013. "Ganz normale Jugendliche, allerdings meist mit Migrationshintergrund": Eine funktional-semantische Analyse von Migrationshintergrund. Zeitschrift für Angewandte Linguistik 58. 201-227. https://doi.org/10.1515/zfal-2013-0008

Statistisches Bundesamt. 2019. Bevölkerung: Migration und Integration. https://www.destatis. de/DE/Themen/Gesellschaft-Umwelt/Bevoelkerung/Migration-Integration/_inhalt.html

Stevenson, Patrick \& Livia Schanze. 2009. Language, migration and citizenship in Germany: Discourses on integration and belonging. In Guus Extra, Massimiliano Spotti \& Piet Van Avermaet (eds.), Language testing, migration and citizenship: Cross-national perspectives on integration regimes, 87-106. London: Continuum.

United Nations. 2019. International migrant stock 2019. https://www.un.org/en/development/ desa/population/migration/data/estimates2/estimates19.asp

Titarenko, Maiia. 2019. Verbalized social statuses of a person in the linguocultural space "crime" of modern Germany. Journal of Applied Linguistic and Intercultural Studies 2. 26-36.

Williams, Daniel. 2013. Germanness or rights? Second generation young adults and citizenship in contemporary Germany. German Politics and Society 31. 30-48.

https://doi.org/10.3167/gps.2013.310204

Williams, Helen. 2014. Changing the national narrative: Evolution in citizenship and integration in Germany, 2000-10. Journal of Contemporary History 49. 54-74.

https://doi.org/10.1177/0022009413505658

Wilpert, Czarina. 2013. Identity issues in the history of the postwar migration from Turkey to Germany. German Politics and Society 31. 108-113. https://doi.org/10.3167/gps.2013.310209

Wodak, Ruth, Rudolf de Cillia, Martin Reisigl, Ruth Rodger \& Karin Liebhart (eds.). 2009. The discursive construction of national identity. In The discursive construction of national identity, 7-48. Edinburgh: Edinburgh University Press.

Wodak, Ruth. 2011. Critical linguistics and critical discourse analysis. In Jan Zienkowski, Jan-Ola Östman \& Jef Verschueren (eds.), Discursive pragmatics, 50-69. Amsterdam: Benjamins. https://doi.org/10.1075/hoph.8.04wod 
Wodak, Ruth. 2017. Discourses about nationalism. In John Flowerdew \& John E. Richardson (eds.) Routledge Handbook of Critical Discourse Analysis, 403-420. London: Routledge. https://doi.org/10.4324/9781315739342.ch27

Yuval-Davis, Nira. 2011. The politics of belonging: Intersectional contestations. London: Sage. https://doi.org/10.4135/9781446251041

Zelinsky, Wilbur. 2001. The enigma of ethnicity: Another American dilemma. Iowa City, IA: University of Iowa Press. https://doi.org/10.2307/j.ctt2oq1wrp.9 


\title{
Exploring an approach for modelling lectal coherence
}

\author{
Karen V. Beaman \\ Queen Mary University of London / Eberhard Karls Universität Tübingen
}

\begin{abstract}
This paper presents an exploratory approach for modelling and measuring the concept of lectal coherence - the logical unity of idiolects, dialects, sociolects, regiolects, etc. - and how coherence can shape variation and foster or constrain language change. Twelve phonological and morpho-syntactic features of Central Swabian, a variety of German spoken in the southwestern part of the country, exemplify differences in lectal coherence across two communities (Stuttgart and Schwäbisch Gmünd) and two points in time (1982 and 2017). Following the traditional quantitative variationist approach pioneered by Labov (1963), coupled with Guttman-like (1944) implicational scaling, and drawing on concepts from the order and LATTICE theory of mathematics (Partee, Ter Meulen, and Wall 1993), the proposed model brings together three views of coherence - covariation, implicational scaling, and LATTICE theory - to demonstrate a holistic approach to the study of linguistic coherence and its influence on language change. The research question this investigation explores is: does lectal coherence enable or inhibit linguistic change? The hypothesis tested in this study is that more coherent lects are less vulnerable to change and convergence while less coherent lects are more susceptible.
\end{abstract}

Keywords: sociolinguistics, language variation and change, linguistic coherence, dialects, quantitative models, longitudinal studies, lifespan change, Swabian, German

\section{Introduction}

Fifty years ago, Weinreich, Labov, and Herzog (1968: 188) observed that "idiolects do not provide the basis for self-contained or internally consistent grammars," rather it is the grammar of the speech community, governed by social factors, which reflects regularity and coherence and where linguistic change occurs. Hence, one approach to explaining the regularity of linguistic variation and orderly heterogeneity is the notion of coherence. According to Guy \& Hinskens (2016), the concept of orderly 
heterogeneity implies that "speech communities are sociolinguistically coherent .... [meaning that] the community should collectively behave in parallel: variants (or rates of use of variants) that index a given style, status, or a social characteristic should co-occur" (Guy \& Hinskens 2016: 2). These authors claim that "to the extent that linguistic variables systematically co-vary, they can be characterized as displaying coherence" (Guy \& Hinskens 2016: 1).

Co-variation is one method for determining coherence; however, another approach utilises Guttman (1944) "scalogram analysis" to identify the underlying, orderly structure of the variation revealing implicational-like patterns (Bickerton 1973; DeCamp 1968; Fasold 1970; Greenberg 1963; Rickford 2001). A recent variation analysis using implicational scaling techniques is Ghyselen \& Van Keymeulen's (2016) study of the Belgian dialect of Tussentaal. These researchers found that, as a result of dialect loss, destandardisation, and demotisation, the dialect-standard constellation in Flanders has transformed from a diglossic into a largely diaglossic repertoire. They argue that Tussentaal "is not just a random idiolectal mix of dialect features, but that it is structured by implicational principles shared across the speech community" (Ghyselen \& Van Keymeulen 2016: 15). In fact, "speakers do not randomly mix dialect features when speaking Tussentaal; clear patterns were found whereby the presence of one dialect feature automatically implies the presence of other features" (Ghyselen \& Van Keymeulen 2016: 14).

Auer's (1997) concept of "co-occurrence restrictions" advocates a similar method for categorising repertoires and partitioning them "along continua of standard-dialect realizations" (Auer 1997: 95). He maintains that tight, bi-directional co-occurrence restrictions (i.e., strong coherence) dichotomise lects while loose, uni-directional ones (i.e., weak coherence) promote greater variation which can stimulate language change (cf. Auer's 'intermediate forms'). Remarking on the role of social factors, Auer adds, "it seems that given the appropriate social backing, any co-occurrence restriction may be turned upside down" (Auer 1997: 95). An overall concern with linear scaling, whether bi-directional or uni-directional, is in its strictness and inability to account for inherent linguistic variation or the influence of social factors. Hence, the challenge for the current study in characterising linguistic coherence is to generalise the concept of an implicational structure to one more representative of 'the linguistic situation' and more inclusive of the myriad factors influencing orderly heterogeneity.

Yet another approach employed by some researchers to uncover patterns of coherence across several variables is cluster analysis (Hinskens 2020; Horvath and Sankoff 1987; Meyerhoff and Klaere 2017; Wieling and Nerbonne 2011). One of the earliest such studies was carried out by Horvath and Sankoff (1987) who investigated variation in four vowels in Sydney Australia using principal components analysis (PCA), a data reduction method that determines similarities between groups 
based solely on linguistic criteria. More recently, Meyerhoff and Klaere (2017) used constrained correspondence analysis (CCA), which incorporates researcher designated constraints (e.g., "village membership") to guide the aggregation algorithms (a semi-supervised method in contrast to the unsupervised PCA method). Hinskens (2020) combined both correlational (factor analysis) and distance-based measures (cluster analysis) to investigate the relative vulnerability of features in two different groups of Dutch dialects. All of these approaches found greater or lesser degrees of coherence, based on the number and the nature of the linguistic variables and social factors analysed.

The aim of this paper is two-fold: (1) to explore a new theoretical method for modelling and measuring linguistic coherence across different linguistic varieties and (2) to test the proposed model by analysing coherence across 12 linguistic variables in Swabian, a dialect spoken in southwestern Germany. A major assumption underlying this research is the implicational nature of language variation and change; specifically, greater lectal coherence implies that changes in one variant trigger changes in another variant such that multiple related variables co-occur within a unified variety. The overall hypothesis of this study is that more coherent lects are more resistant to change, while less coherent lects are more vulnerable to change, paralleling Milroy's (1987) findings that the most closed social networks are the most resistant to innovations. To test this hypothesis, a new methodological construct based on variable frequency analysis, implicational scaling, and LATTICE theory is explored, which I call the Lectal Lattice. ${ }^{1}$

\section{Data and methods}

This section describes the data and methods employed in this investigation, covering the speech communities, data collection and preparation, the dependent linguistic variables, and the extra-linguistic predictors.

\subsection{Speech communities}

This research investigates a variety of German, Central Swabian or Schwäbisch, a group of High German dialects belonging to the Alemannic family, which is spoken by just over 800,000 people or one percent of the German population (see Figure 1). Two communities were selected for this research: the large international

1. The author wishes to thank James Garrett for suggesting the LATTICE concept to represent lectal coherence and for developing the R script to depict it. Of course, any deficiencies in the model are entirely my own responsibility. 

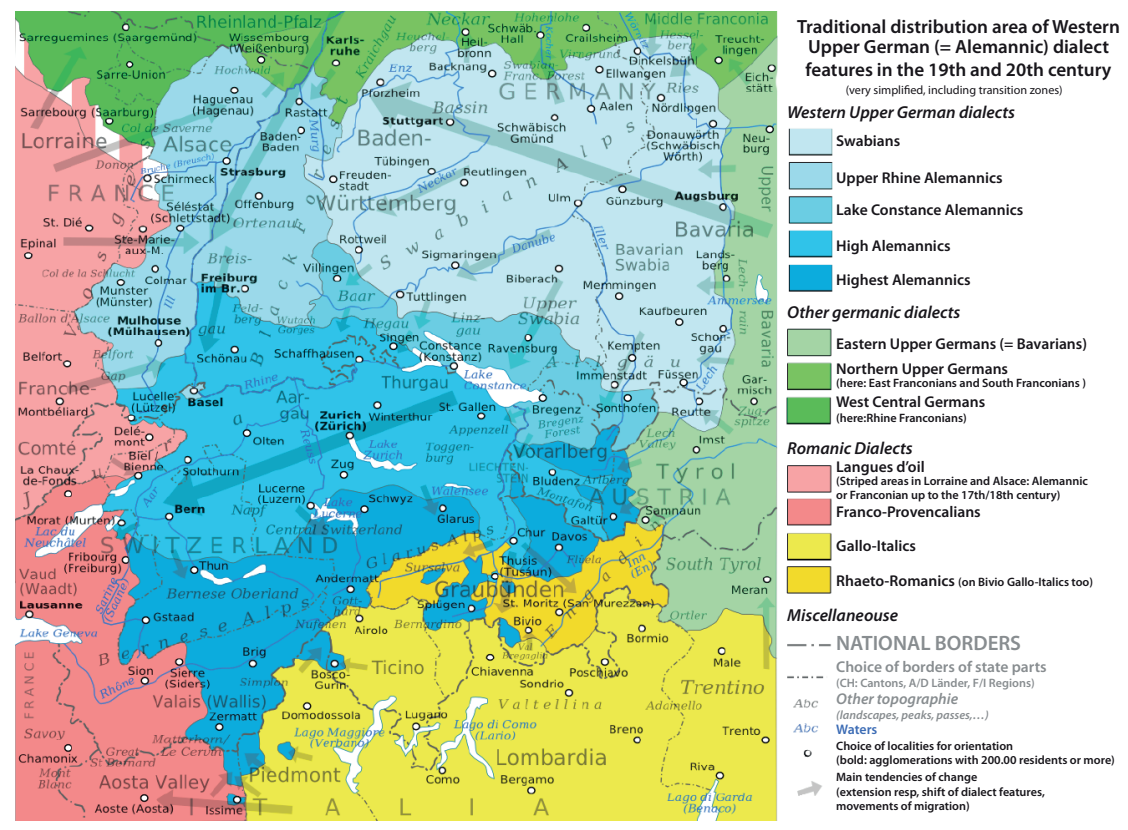

Figure 1. Map of the Swabian and Alemannic Dialect families ${ }^{2}$

city of Stuttgart and its surrounding suburbs and the mid-sized town of Schwäbisch Gmünd and the neighbouring rural villages. Stuttgart, a large urban area with over one million inhabitants, is the heart of Swabia and home to many well-known global firms, including Daimler-Mercedes-Benz, Porsche, Bosch, and Siemens. With 60,000 inhabitants, Schwäbisch Gmünd lies 100 kilometres east of Stuttgart. A typical mid-sized German town, Gmiind [gmy:nd], as it is called by the locals, is surrounded by small rural villages with $77 \%$ of the land dedicated to woodland and agriculture. ${ }^{3}$

Attitudes toward Swabian vary: it is either loved or loathed. It is highly stigmatised by some and adored by others, as these two quotations from native Swabians show:

2. Permission is granted to copy, distribute and modify this document under the terms of the GNU Free Documentation License, Version 1.2 or any later version published by the Free Software Foundation; with no Invariant Sections, no Front-Cover Texts, and no Back-Cover Texts. A copy of the license is included in the section entitled GNU Free Documentation License. https:// commons.wikimedia.org/w/index.php? curid=11150876.

3. Drawn from: http://www.schwaebisch-gmuend.de/.Viewed on 22-jan-2020. 
(1) wenn i Urschwâbe hör, also die mã gar ned versteht, des denkt mã immer, des isch e Fremdsprache ja, ... muss mã halt manchmal de Kopf schüttle, aber so find i des ... kôi schlimme Sprâch ... i find e Dialekt isch nie schlecht

'if I hear really old-Swabian, that you can't even understand, then you always think, that's a foreign language, yeah, ... sometimes you just have to shake your head, but I don't think it's a bad language ... I think a dialect is never bad.'

(Bertha 1982)

(2) meine Kinder schämen sich sogar heutzutage Schwäbisch, also die verbinden Schwäbisch mit irgendwas, was sie nicht möchten.... dieser dörfliche Zusammenhalt stoßen die eher ab.

'nowadays my children are actually ashamed of Swabian, well they associate Swabian with something they don't like.... they are more likely to reject this village solidarity'

(Helmut 2017)

\subsection{Swabian corpus}

The data for this study are drawn from a real-time panel study of 20 native Central Swabian speakers, first recorded 1982 and then re-interviewed between 2017-2018. Table 1 provides the breakdown by speaker demographics. High and low education was measured by the speakers' completion of their Abitur, 'German college preparatory exam'. All speakers were of a similar socio-economic status, quasi upper-middle class.

Table 1. Panel study corpus - speaker demographics

\begin{tabular}{|c|c|c|c|c|c|c|c|}
\hline \multirow{2}{*}{$\begin{array}{l}\text { Study } \\
\text { year }\end{array}$} & \multirow[t]{2}{*}{ Age groups } & \multirow[t]{2}{*}{ Sex } & \multicolumn{2}{|c|}{ Stuttgart } & \multicolumn{2}{|c|}{ Schwäbisch Gmünd } & \multirow[t]{2}{*}{ Total } \\
\hline & & & Hi edu & Lo edu & Hi edu & Lo edu & \\
\hline \multirow[t]{2}{*}{1982} & Group A: ages $30-60$ & M & 0 & 0 & 0 & 1 & 1 \\
\hline & Born 1922-1952 & $\mathrm{W}$ & 0 & 1 & 0 & 2 & 3 \\
\hline \multirow[t]{2}{*}{1982} & Group B: ages 18-29 & M & 4 & 0 & 6 & 0 & 10 \\
\hline & Born 1953-1964 & $\mathrm{W}$ & 1 & 1 & 3 & 1 & 6 \\
\hline \multirow[t]{2}{*}{2017} & Group C: ages $61-88$ & $\mathrm{M}$ & 0 & 0 & 0 & 1 & 1 \\
\hline & Born 1929-1956 & $\mathrm{W}$ & 0 & 1 & 0 & 2 & 3 \\
\hline \multirow[t]{2}{*}{2017} & Group D: ages $30-60$ & M & 4 & 0 & 6 & 0 & 10 \\
\hline & Born 1957-1987 & $\mathrm{W}$ & 1 & 1 & 3 & 1 & 6 \\
\hline \multicolumn{2}{|c|}{ Subtotal } & & 10 & 4 & 18 & 8 & \\
\hline \multicolumn{2}{|l|}{ Total } & & \multicolumn{2}{|c|}{14} & \multicolumn{2}{|c|}{26} & 40 \\
\hline
\end{tabular}

The data collection methods followed the Labovian sociolinguistic paradigm, consisting of semi-structured sociolinguistic interviews, conducted by native Swabian speakers with the primary investigator in attendance in the role of friend-of-a-friend 
(Milroy and Milroy 1985). To increase compatibility across years, the same survey instrument and interviewing techniques were used in both 1982 and 2017, covering questions about the speaker's childhood, games, friends, hobbies, local festivals and activities, and attitudes toward the Swabian language.

Transcriptions were completed in ELAN (Wittenburg et al. 2006) by native German speakers, students at the University of Tübingen. A standard orthography was developed for easily and distinctly transcribing the Swabian dialect forms. All transcripts were validated by a second transcriber and verified by the principal investigator to ensure standards were followed and to neutralise any potential transcriber bias. The dataset consists of 40 interviews (20 from 1982 and 20 from 2017), comprising 43 hours for a total of 162,964 words, 72,550 in 1982 and 90,414 in 2017 (the interviews were slightly longer in 2017 and in Schwäbisch Gmünd).

\subsection{Linguistic variables}

The dependent variables investigated in this study are 12 Swabian dialect features six phonological and six morphosyntactic - all highly representative of the rich palette of features available to the Swabian speaker (see Table 2). All variables were coded for a binary distinction between the dialect variant and the standard German variant. In the present study of lectal coherence, no conditioning factors have been considered. A brief description of each follows.

1. Rounding of diphthong of MHG /ei/ origin (AIS1) is a stereotypical feature of Swabian, hence standard German forms such as klein [klain] 'small' and allein [alarn] 'alone' are realised as glôi [glıI] and allôi [alır] in Swabian.

2. Nasalisation of /a/ before / $\mathbf{n} /(\mathrm{ANN})$ is a traditional feature of Swabian, hence words such as man kann [man kan] 'one can' and Anfang [anfan] 'beginning' are realised as mã kã [mã kã] and Ãfang [ãfan] in Swabian.

3. Unrounding of the front vowel/ö/ (FRV1) is typical in Swabian, so that standard German words such as möglich [mø:klıç] 'possible' and schön [jø:n] 'beautiful' are realised as meeglich [me:gliç] and schee [ $\varepsilon$ : ] in Swabian.

4. Unrounding of the front vowel/ü/ (FRV3) is typical in Swabian, so that standard German forms such as Küche [ky:çə] 'kitchen' and Gmünd [gy:munt] are realised as Kiiche [kırçə] and Gmiind [grsmund].

5. Lowering of long /e:/ (LEO) is a regional dialect feature, so that standard German forms such as lesen 'read' [le:zn] and Lehrer 'teacher' [le:se] are pronounced as lääse [læss] and Läährer [læ:ьe] in Swabian.

6. Palatalisation of /st/ in syllable-coda position (STP) is a highly productive feature of Swabian and the Alemannic dialects, hence words such as machst [maxst] 'you do/make' and nächst [nezçst] 'next' are realised as machscht [max]] and nächsht [nє:ç]] in Swabian. 
Table 2. Swabian linguistic variables under investigation (dialect variant shown in bold)

\begin{tabular}{|c|c|c|c|}
\hline Code & Name & SWG $\sim$ STD & Swabian examples \\
\hline & \multicolumn{3}{|l|}{ Phonological variables } \\
\hline AIS1 & MHG /ei/ Diphthong & {$[\mathrm{OI}] \sim[\mathrm{aI}]$} & $\begin{array}{l}\text { mã brauchd da kôi Flôisch dazue } \\
\text { 'you don't need any meat with it' }\end{array}$ \\
\hline$\overline{\mathrm{ANN}}$ & Nasal 'a' before 'n' & {$[\tilde{\mathbf{a}}] \sim[\mathrm{an}]$} & $\begin{array}{l}\text { mã kã es mit em normale [Mehl] mache } \\
\text { 'you can make it with a normal [flour]' }\end{array}$ \\
\hline FRV1 & $\begin{array}{l}\text { Unrounded Front } \\
\text { Vowel }\end{array}$ & {$[\varepsilon] \sim[\varnothing]$} & $\begin{array}{l}\text { so guet wie meeglich probier es } \\
\text { 'as good as possible [I] try it' }\end{array}$ \\
\hline$\overline{\text { FRV3 }}$ & $\begin{array}{l}\text { Unrounded Front } \\
\text { Vowel }\end{array}$ & {$[\mathbf{I \partial}] \sim[\mathrm{y}]$} & $\begin{array}{l}\text { dann ist d Kieche explodiert } \\
\text { 'then the kitchen exploded' }\end{array}$ \\
\hline$\overline{\mathrm{LEO}}$ & Lower Long Vowel & {$[\boldsymbol{\varepsilon}:] \sim[\mathrm{e}]$} & $\begin{array}{l}\text { dâ e baar Jâhr lääbe } \\
\text { 'live a few years there' }\end{array}$ \\
\hline \multirow[t]{2}{*}{ STPA } & Palatal Coda -st & {$\left[\int \mathrm{t}\right] \sim[\mathrm{st}]$} & $\begin{array}{l}\text { da darfsch ja bloß hundertdreißig fahre } \\
\text { in Italien } \\
\text { 'then you're only allowed to drive } 130 \text { in } \\
\text { Italy' }\end{array}$ \\
\hline & \multicolumn{3}{|c|}{ Morphosyntactic variables } \\
\hline EDP & Plural Verb Inflection & {$[\partial \mathrm{d}] \sim[\partial \mathrm{n}]$} & $\begin{array}{l}\text { die finded es wichtich } \\
\text { 'they think it important' }\end{array}$ \\
\hline IRV1 & Irregular Verb & [gangə] [ge:ən] & $\begin{array}{l}\text { willsch du an Telefon gange } \\
\text { 'do you want to answer the telephone' }\end{array}$ \\
\hline IRV3 & Irregular Verb & [hen] $\sim$ [ha:bən] & $\begin{array}{l}\text { mr hen e aldes Haus khet } \\
\text { 'we have had an old house' }\end{array}$ \\
\hline$\overline{\mathrm{PVB}}$ & $\begin{array}{l}\text { Periphrastic } \\
\text { Subjunctive }\end{array}$ & [dædə] [vуьdə] & $\begin{array}{l}\text { es dääd beeinflusse } \\
\text { 'it should influence' }\end{array}$ \\
\hline SAF1 & Diminutive Suffix & [lə] [çən/laInn] & $\begin{array}{l}\text { dass er en Mädle mâg un se ihn mâg } \\
\text { 'that he likes a girl and she likes him' }\end{array}$ \\
\hline SAF5 & Past Participle Prefix & $\emptyset \sim$ [gə] & $\begin{array}{l}\text { un hen hier e Haus [ge]baut } \\
\text { 'and they have built a house here' }\end{array}$ \\
\hline
\end{tabular}

7. Present tense plural verb inflexion (EDP) -en in standard German (for 1st, 2nd, and 3rd person plural) is realised as -ed in Swabian, so that standard forms such as sie finden 'they find' and wir gehen 'we go' are realised as sie finded and mer ganged in Swabian.

8. Verb gehen 'go' (IRV1) has an irregular conjugation in Swabian, hence forms such as ich gehe 'I go' and weitergeht 'continue' are realised as $i$ gang and wêitergâht. 
9. Verb haben 'have' (IRV3) has an irregular conjugation in Swabian, for example, the past participial has different realisations, ghet, ghed, khet, or khed in Swabian versus gehabt 'had' in standard German.

10. Periphrastic subjunctive tun 'do/make' (PVB) is typical in Swabian, so forms such as er dääd lache 'he would laugh' and es dääd beeinflusse 'it would influence' in Swabian vary with the standard German periphrastic subjunctive using werden 'to become', er würde lachen and es würde beeinflussen.

11. Diminutive suffix -le (SAF1) is highly productive and varies with the standard German suffix -chen (or the older suffix -lein). Hence, forms such as Mädle 'little girl', Tellerle 'little plate', and Unterschiedle 'small difference' vary with standard German forms Mädchen, Tellerlein, and klein Unterschied.

12. Past participle prefix -ge (SAF5) is typically dropped in Swabian, hence forms such as hen kriegt 'have received' and isch umzoge 'has moved' vary with the standard German constructions haben gekriegt and ist umgezogen.

Strict adherence to the principle of accountability was ensured through the use of a bespoke Swabian-German Lexicon (SGL), compiled from all words in the 40 transcripts which contained tokens (either Swabian or standard German) of one of the 12 features under investigation. False starts and repetitions were excluded. In total, 50,875 tokens for the 12 linguistic variables were extracted, 21,714 from 1982 and 29,161 from 2017, with an average of over 1,000 tokens per speaker in 1982 and over 1,400 tokens per speaker in 2017.

\subsection{Extra-linguistic predictors}

Due to space limitations, only two extra-linguistic factors are considered in the current study: (1) two recording years (1982 and 2017) and (2) two communities (Stuttgart and Schwäbisch Gmünd). Additional social factors influencing the Swabian dialect situation have been reported on elsewhere (Baayen, Beaman, and Ramscar 2021; Beaman 2020, 2021; Beaman and Tomaschek 2021). 


\section{Analysis and results}

The analysis and results begin with an overview of the changing dialect situation in Swabia with respect to the 12 linguistic variables under investigation. Next, the Lectal Lattice is described and its construction explained, followed by an examination into the linguistic coherence in the two communities across the two recording periods. Finally, the differences and advantages of the Lectal Lattice over other data reduction methods and graphical representations are discussed.

\subsection{Linguistic variables}

Table 3 shows the results of a generalised linear regression model (generated by the $\mathrm{R}$ predict function using the glmer function in the package lme4 version 1.1-21), which modelled the frequency of the dialect variant versus the standard variant for each of the 12 linguistic variables, considering the two recording periods, two communities, two sexes, and Swabian orientation as fixed effects and speaker and interviewer as random effects (see Beaman $(2020,2021)$ for further information). The phonological variables are on the left and the morphosyntactic ones on the right, sorted by decreasing probability of occurrence in 1982. The "prob" column shows the probabilities of the non-standard variant, the "diff" column shows the difference in usage between 1982 and 2017, and the "sig" column shows the significance level. A couple of interesting patterns can be observed in data. First, as is quickly apparent, all variables indicate highly significant attrition across the two recording periods ( $\operatorname{sig}=$ " “***” for $p<.001$ ), demonstrating that considerable dialect levelling is occurring in Swabian (see Beaman (2020) for further information on dialect levelling in Swabian). Second, with the exception of the two Swabian affixes ('-le' and ' $g e-$ '), the morphosyntactic variables have receded more than the phonological ones; these two features have receded to a similar degree as the phonological ones. Future research on the diminutive suffix (-le) may reveal this variable to be lexical rather than morphological, while dropping of the past participle prefix ( $g e-$ ) may be a case of phonological reduction rather than a morphological distinction. Third, some variables have receded significantly more than others, in particular, IRV1, use of the irregular verb [gange] versus standard [gehe], while others, such as, STP, palatalisation of coda [ $\mathrm{t}$ ] versus [st], retain a fairly high level of usage. The reasons for this lie largely in the levels of saliency ("overt speaker awareness") and stigma associated with the variables (see Beaman 2020 for a detailed discussion on the change in the individual variables). 
Table 3. Swabian linguistic variable predictions by recording year and variable type, generated by the $\mathrm{R}$ predict function based on the results of a logistic regression model with glmer (from Beaman 2021, Table 5). All differences are significant at the $p<0.001$ level

\begin{tabular}{|c|c|c|c|c|c|c|c|c|c|c|c|c|}
\hline \multicolumn{6}{|c|}{ Phonological variables } & \multicolumn{7}{|c|}{ Morphosyntactic variables } \\
\hline Variab & e Year & n & Lodds & Prob & Diff Sig & Variable & Year & n & Lodds & Prob & Diff & Sig \\
\hline$P$ & 1982 & 4,761 & 1.021 & $73.5 \%$ & -14 & EDP & 1982 & 628 & 3.377 & $96.7 \%$ & $3 \%$ & $* * *$ \\
\hline$s t \sim \int t$ & 20175 & 5,716 & 0.353 & $58.7 \%$ & & ən $\sim \mathrm{d}$ & 2017 & 954 & 0.380 & $59.4 \%$ & & \\
\hline ANN & 19822 & 2,717 & -0.357 & $41.2 \%$ & $-16.6 \%{ }^{* * *}$ & PVB & 1982 & 122 & 0.772 & $68.4 \%$ & $-31.1 \%$ & $* * *$ \\
\hline an ã & 20173 & 3,027 & -1.125 & $24.5 \%$ & & 'tun' & 2017 & 181 & -0.518 & $37.3 \%$ & & \\
\hline FRV3 & 1982 & 1,747 & -0.709 & $33.0 \%$ & * & IRV1 & 1982 & 266 & 0.752 & $68.0 \%$ & $51.4 \%$ & $* * *$ \\
\hline $\mathrm{y} \sim \mathrm{I}$ & 20172 & 2,692 & -1.559 & $17.4 \%$ & & ganə & 2017 & 418 & -1.616 & $16.6 \%$ & & \\
\hline LEO & 1982 & 1,827 & -0.787 & $31.3 \%$ & $-10.9 \% * * *$ & IRV3 & 1982 & 1022 & 0.295 & $57.3 \%$ & $-35.5 \%$ & $* * *$ \\
\hline $\mathrm{e} \sim æ$ & 20173 & 3,291 & -1.365 & $20.4 \%$ & & hen & 2017 & 1843 & -1.276 & $21.8 \%$ & & \\
\hline FRV1 & 1982 & 1,365 & -1.074 & $25.5 \%$ & $-13.1 \% * * *$ & SAF1 & 1982 & 1707 & -1.110 & $24.8 \%$ & $-12.9 \%$ & $* * *$ \\
\hline$\varnothing \sim \mathrm{e}$ & 2017 & 1,401 & -1.962 & $12.3 \%$ & & - lə & 2017 & 2277 & -1.997 & $12.0 \%$ & & \\
\hline AIS1 & 19823 & 3,914 & -1.585 & $17.0 \%$ & $-9.2 \%{ }^{* * *}$ & SAF5 & 1982 & 1638 & -1.218 & $22.8 \%$ & $-11.1 \%$ & $* * *$ \\
\hline aI $\sim$ I & 2017 & 4,975 & -2.472 & $7.8 \%$ & & gə $\phi$ & 2017 & 2386 & -2.018 & $11.7 \%$ & & \\
\hline
\end{tabular}

\subsection{Dialect change in Swabia}

Figure 2 depicts the changing dialect situation in Swabia through the analysis of 12 linguistic variables using Principal Components Analysis (PCA) (prcomp function in package stats, version 3.5.3), a data reduction method which has been used by many sociolinguists as a heuristic to group speakers based solely on their linguistic behaviour (Horvath and Sankoff 1987). PCA reduces the dimensionality of multivariate data to a small set of derived factors (i.e., principal components), each representing a summarisation of the linguistic features that co-occur with high frequency. Two PCAs were conducted, one for the proportion of usage of the dialect variant for the six phonological variables and one for the proportion of usage of the dialect variant for the six morphosyntactic variables. In Figure 2, PC1 for the phonological variables is plotted on the horizontal axis (explaining $69.5 \%$ of the variation) and $\mathrm{PC} 1$ for the morphosyntactic variables on the vertical axis (explaining $78.1 \%$ of the variation). The upper right corner approximates $100 \%$ usage of all dialect variants, while the lower left corner verges toward $100 \%$ usage of the standard German variants. Plus signs mark each speaker's dialect usage in 1982, and dots denote each speaker's usage in 2017. With two exceptions, all speakers have experienced dialect attrition as can be seen by the overall trend with the plus signs (1982) at the top of the graph (indicating greater dialect usage) and the dots (2017) at the bottom of the graph (revealing greater standard usage). 
The dotted ellipse at the top of Figure 2 (drawn at two standard deviations from the mean of the group) encircles the speakers from Schwäbisch Gmünd in 1982. The small, compact nature of this ellipse indicates that there was considerable homogeneity among the speakers in 1982, at least with regard to the use of these 12 dialect variants. The dashed ellipse in the middle of Figure 2 encircles all speakers in 1982, signalling a stronger tendency toward the standard variants when the speakers from the urban centre of Stuttgart are combined with those of Schwäbisch Gmünd. Finally, the longest ellipse encircles all speakers in 2017, highlighting two key findings: (1) the Swabian dialect has moved closer to the standard language in 2017 than it was in 1982, as seen by the placement of the pluses (in the upper right) and the dots (in the lower left), and (2) there is noticeably greater diversity in dialect and standard usage in 2017 than there was 1982 (as demonstrated by the size of the 2017 ellipse). Drawing from my own ethnographic observations from over five years living in the region, in 1982 both communities exhibited many, dense, multiplex social relationships, whereas by 2017 , community ties had weakened and social connections had become considerably more dispersed, particularly in Stuttgart. In fact, many of the Stuttgart speakers, who were all close friends in 1982 , had completely lost contact with one another by 2017 , requiring considerable detective work on my part as the principal investigator to locate these individuals to re-interview them.

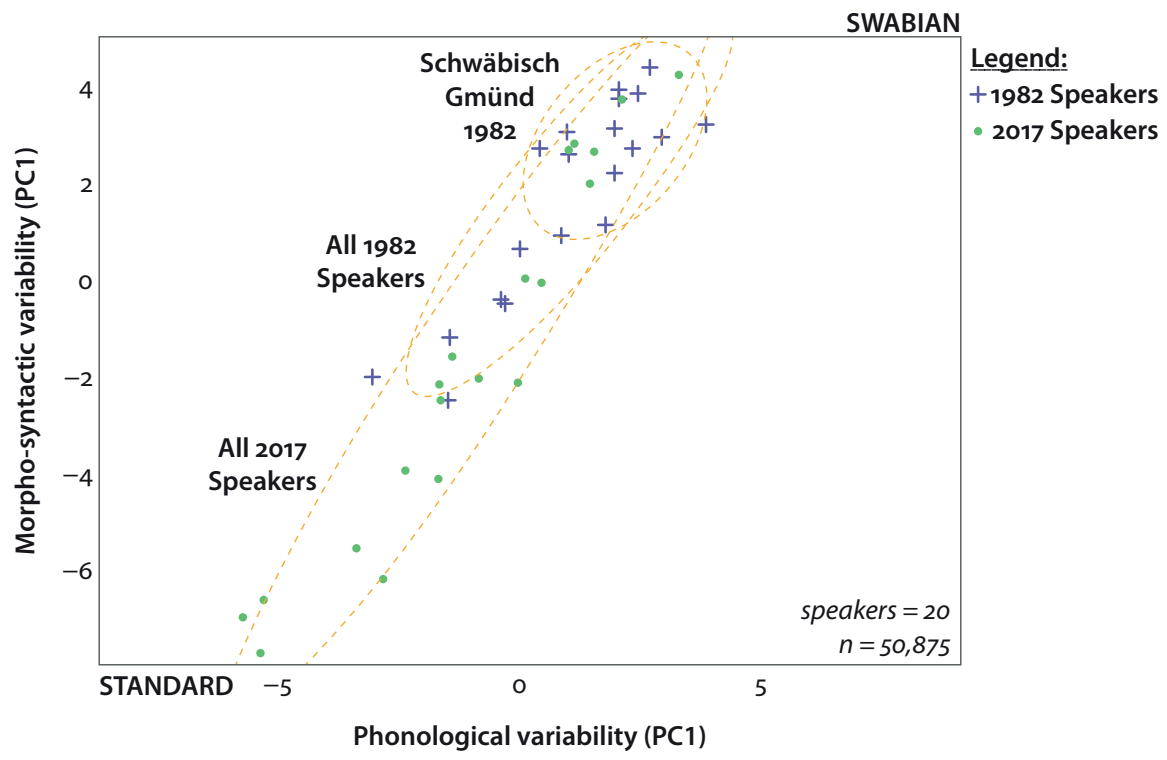

Figure 2. Change in Swabian dialect usage for 12 linguistic variables for two communities over a 35-year time span: Plus signs represent speakers' proportion of dialect usage in 1982 and dots their dialect usage in 2017 


\subsection{Lectal coherence}

The theoretical question this paper seeks to address is to what extent do varying lects reflect coherence and what do differing levels of coherence tell us about linguistic change. By measuring the level of coherence in an individual lect (e.g., the 1982 speakers, the 2017 Stuttgart speakers), we can compare it with another lect and thereby examine the impact that coherence has on language variation and change.

\section{Lattices}

To depict and measure lectal coherence, this paper draws on the concept of a LATTICE, a construct from the order theory of mathematics and universal algebra (Partee, Ter Meulen, and Wall 1993, Chapter 11). Linguists have used LATTiCEs in phonology, syntax, semantics, neurolinguistics and computational linguistics, but not yet in sociolinguistics or variation studies. A LATTICE is an abstract structure that uses binary relations to examine the hierarchical or implicational relationships within a given set of elements. It consists of a PARTIALLY ORDERED SET, called a POSET, in which an order relation $(\leq)$ exists between some of the elements in the set. A LATTICE generalises the data from a straight line (such as $\mathrm{x}$ implies $\mathrm{y}$ implies $\mathrm{z}$ ) to a multi-dimensional picture, which can be depicted by a Hasse diagram, as illustrated in Figure 3. In a Hasse diagram, the elements of the POSET are represented as nodes and the order relations between the elements are represented as links between the nodes.

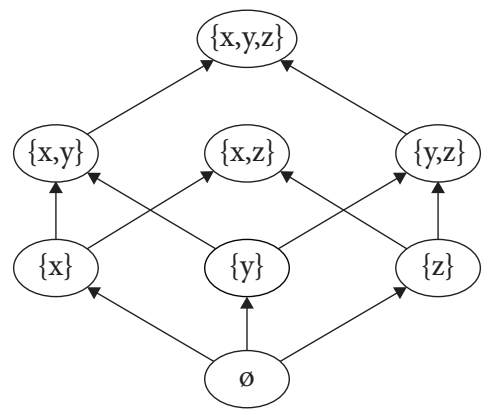

Figure 3. Lattice demonstrating sets and subsets, visualised as a Hasse diagram

To somewhat overgeneralise in the interest of brevity, every two elements in a LATTICE have a least upper bound, called a JOIN, and a greatest lower bound, called a MEET. The relationship between the elements depicted in Figure 3 is one of inclusion: for any two elements, you can move up the LATTICE to find an element that is included by both (the JOIN) or step down the LATTICE to find an element that is included by both (the MEET). LATTICES exhibit the principle of DUALITY, which means that they function equally in both directions - top-down or bottom-up. 
Thus, in turning a LATTICE upside down, the MEETs become JOINS, and the JOINS become meEts (see Partee, Ter Meulen, and Wall (1993), Chapter 11, for details on the construction and interpretation of LATTICES).

It is important to note that POSETS can represent elements at many different levels. The Lectal Lattice comprises two types: (1) POSETS in which the elements are individual linguistic variables, which are then aggregated into an idiolect for a single speaker (as illustrated in subsequent Figures 4 and 5), and (2) POSETs in which the elements are the idiolects of individual speakers which can then be aggregated into different linguistic varieties, such as dialects, regiolects, sociolects (as illustrated in Figures 6 and 7).

\section{Pairwise comparisons}

Borrowing from these theoretical concepts, a Lectal Lattice can be constructed to depict the hierarchical and implicational relationships among the variables in a lect, which can then be visualised as Hasse diagram. The first step in developing a Lectal Lattice is to create post hoc PAIRWISE COMPARISONs for each speakers' set of linguistic variables, arranged in two-by-two contingency tables. Figure 4 illustrates an example POSET for speaker Angela in 1982. The 12 linguistic variables (AIS1 through STP) generate a POSET of 144 pairs of variables. Using the Suissa \& Shuster Exact test with the Holm-Bonferroni method (Holm 1979), each pair of variables is tested to determine whether there is a significant difference in frequency of usage (i.e., proportion of non-standard variant divided by the total variants for the feature). When a statistically significant difference is found $(p<0.05)$ (specifically, when the variable in the row is lower than the variable in the column maintaining the implicational order) the pair is assigned a 1 , otherwise a 0 is assigned. In a POSET every pair of variables need not be related significantly for the pattern to be valid, allowing for uncertainties or inadequacies or unknowns in the dataset, which of course is common with sociolinguistic data.

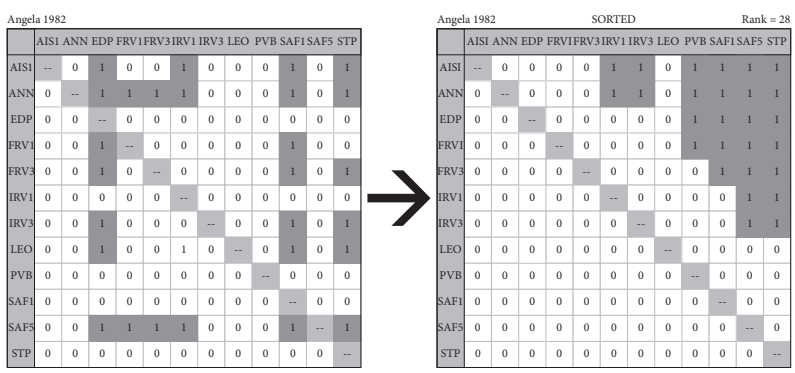

Figure 4. One speaker's POSET illustrating pairwise comparisons for 12 linguistic variables. $0=$ non-significant pair and $1=$ significant pair based on Suissa \& Shuster (1985) Exact test $(p<0.05)$ using the Holm-Bonferroni method 
The speakers' POSETS are then sorted first by significant pairs and then according to the frequency of the dialect variant, generating a new sorted POSET as exemplified on the right in Figure 4. The sorted POSETS are RANKED by summing the significant pairwise comparisons. In Figure 4, Angela in 1982 has a RANK of 28 because there are 28 significant pairwise comparisons in the 12 linguistic variables under investigation. RANK allows us to calculate the DISTANCE between two different lects (two idiolects in this example), a value that denotes the number of pairs that would have to change for the two lects to be identical.

In the next step, neighbouring POSETs, i.e., those that are most similar, are mathematically JOINED; specifically, all neighbours lying at the same minimum DISTANCE are joined one by one. Figure 5 demonstrates Angela's 1982 POSET being joined with Markus' 1982 POSET, to create a new POSET which will become NODE ${ }^{4}$ 101 in the 1982 LATTICE. In this example, there are six joined pairs, indicated in dark grey, which is the mathematical DISTANCE between Angela and Markus' lects. To build the LATTICE, all POSETS are connected with their nearest neighbours and joined into new POSETS. It's POSETS within POSETS - or "turtles all the way down" and up, of course, to maintain the DUALITY of the LATTICE.
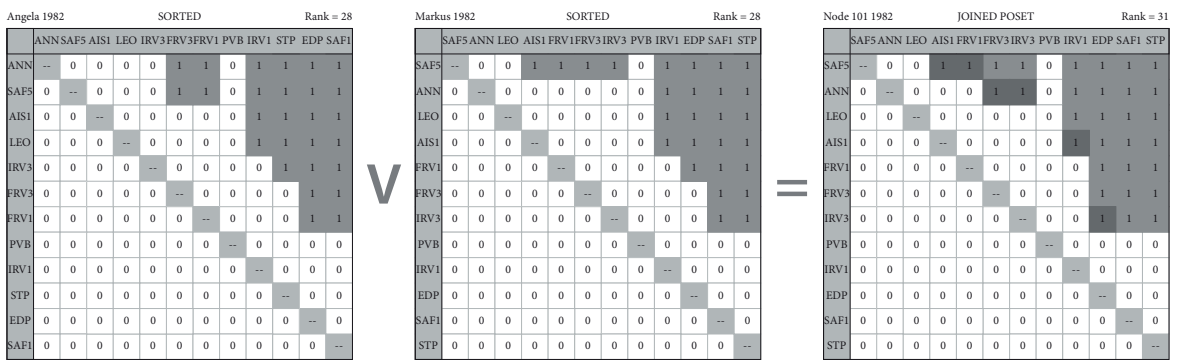

Figure 5. Joining POSETS with nearest neighbours based on DISTANCE to create NODES in the lattice. $0=$ non-significant pair and $1=$ significant pair based on Suissa $\&$ Shuster (1985) Exact test $(p<.05)$ using the Holm-Bonferroni method. Dark grey cells highlight pairs joined in creating the new POSET

\section{The Lectal Lattice}

Figure 6 presents an exemplary Lectal Lattice for the 20 Swabian speakers in 1982. The vertical axis represents the RANK, and the horizontal axis represents the FILE, i.e., the left-to-right right line-up of the individual lects based on the first principal component. The LATTICE was created with standard R functions, including plot, points, lines and text. It is a SEMI-LATtice because it does not display all of the

4. Node numbers are arbitrary, assigned sequentially, used to uniquely identify the different nodes in the LATTICE. 


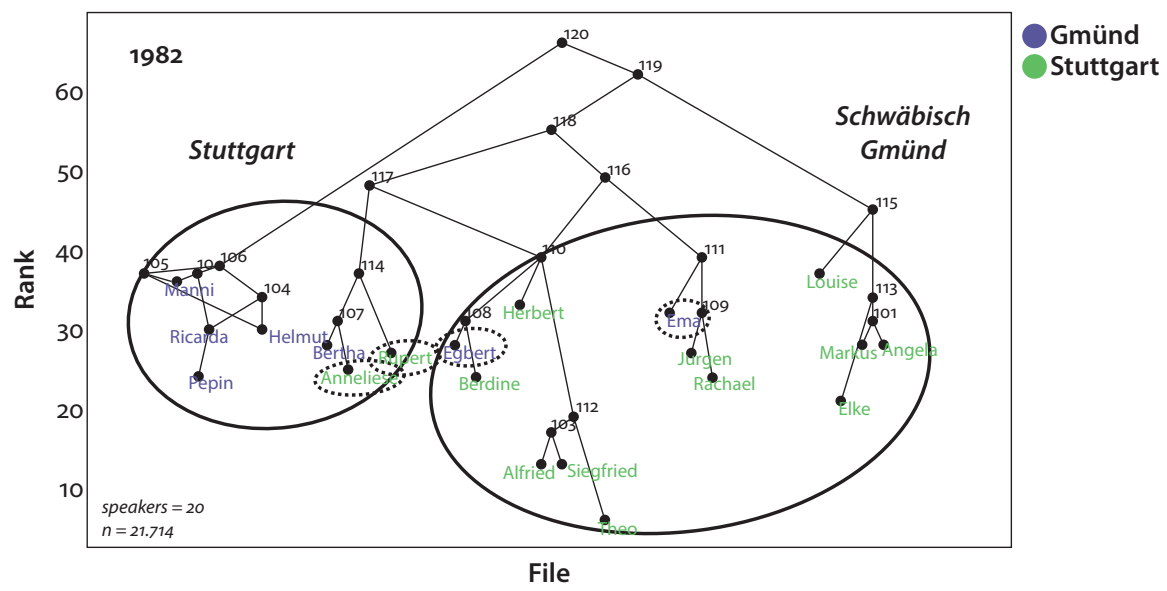

Figure 6. Lectal Lattice for 20 Panel speakers in Stuttgart and Schwäbisch Gmünd in 1982

points in the LATTICE, rather only the significant ones, which greatly simplifies visualisation by eliminating redundant and irrelevant information.

Each point in the Lectal Lattice represents a lect, either a single idiolect or a group of lects that have been joined, such as a dialect, a sociolect, a regiolect, or even a particular style, stance, or register. The points for each speaker's idiolect form the foundation of the LATTICE, which are labelled in Figure 6 with the speakers' pseudonyms. On the far right in Figure 6, NODE 101 from Figure 5 is visible showing the JoIn of Angela and Markus' lects.

From this picture, we can easily see that the speakers fall into two fairly distinct groups, the speakers from Stuttgart on the left and the speakers from Schwäbisch Gmünd on the right, with only a few exceptions or outliers, which can be explained (shown in dotted circles). Rupert and Anneliese from Schwäbisch Gmünd are grouped with the more standardised supra-regional lect of Stuttgart. These two speakers are a few years older and have a higher level of education than the other speakers from Schwäbisch Gmünd (both were studying to be doctors in 1982, one a $\mathrm{PhD}$, the other an $\mathrm{MD}$ ), which may explain why they use more standardised forms than their cohorts. Ema from Stuttgart is grouped with the more conservative dialect speakers in Schwäbisch Gmünd. She is one of the oldest speakers, hence her dialect usage reflects a greater number of traditional Swabian forms which is more in line with speakers from Schwäbisch Gmünd.

Turning to 2017, Figure 7 presents an exemplary Lectal Lattice for the same 20 panel speakers 35 years later. On the right side of the graphic, we see some preservation of the conservative Schwäbisch Gmünd lect; however, on the left, we now see a very different picture. Over the 35-year timespan of this study, some speakers from Schwäbisch Gmünd have "fused" with speakers from Stuttgart, moving in 


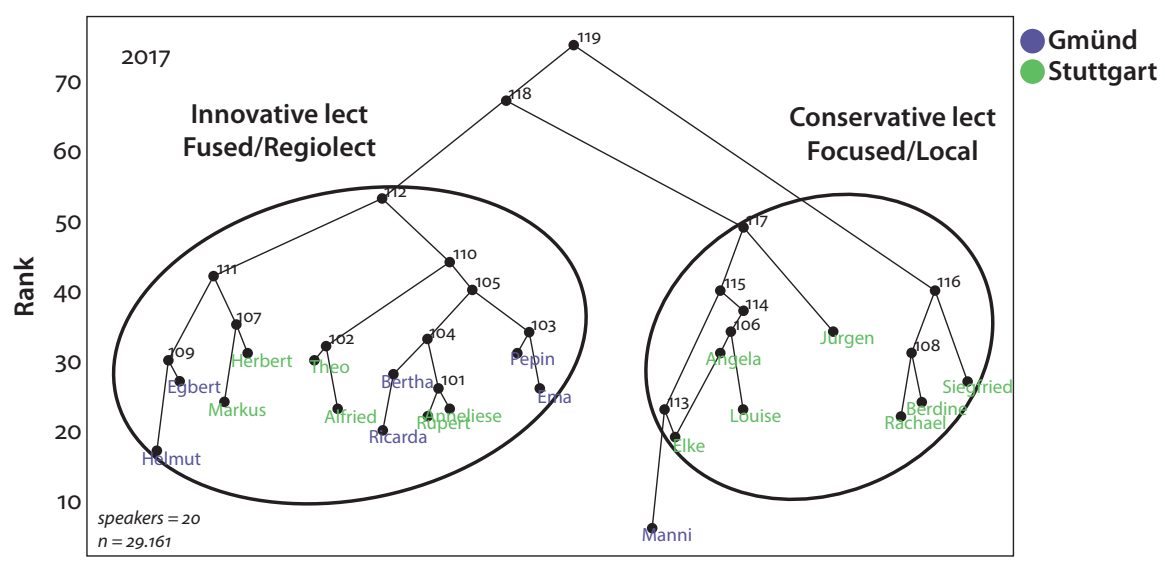

File

Figure 7. Lectal Lattice for 20 Panel speakers in Stuttgart and Schwäbisch Gmünd in 2017

the direction of greater standardisation, a supralocal lect or regiolect, a lect that is not necessarily geographically situated, rather one that is linguistically closer to the standard language (Britain 2010). This finding further demonstrates that the Swabian dialect is undergoing levelling, changing from a geographical or horizontal variety to a sociolectal or vertical variety, as a result of the extensive social and demographic changes taking place in contemporary German society (Auer 2005).

However, Figure 7 reveals that more than half of the Schwäbisch Gmünd speakers have retained their conservative dialect features over the years. Other research has established that dialect attrition and retention is highly influenced by speakers' notions of local orientation (cf. Ortsloyalität 'place loyalty' (Mattheier 1987)) and interlocutor accommodation (Auer and Hinskens 2005; Hinskens, Auer, and Kerswill 2005; Trudgill 1986), a phenomenon reported on elsewhere (Beaman 2020, 2021). Many of the speakers who have moved away from the conservative lect to the fused regiolect are those who live and work regularly with speakers from other dialect groups (cf. Ammon 1973), such as Markus and Rupert who both travel extensively across Germany for their work. Speakers who have retained the conservative dialect, such as Angela and Siegfried, maintain the strongest local orientation to Swabia over their lifespan (Baayen, Beaman, and Ramscar 2021; Beaman 2020; Beaman and Tomaschek 2021).

\section{PCA and the Lattice}

To illustrate the differences and advantages of the Lectal Lattice, Figure 8 presents the results of a Principal Component Analysis (PCA) for the 20 Swabian panel speakers. 1982 is on the left, 2017 is on the right, PC1 is on the horizontal axis, and PC2 on the vertical axis. In 1982, PC1 and PC2 together account for $62 \%$ of 

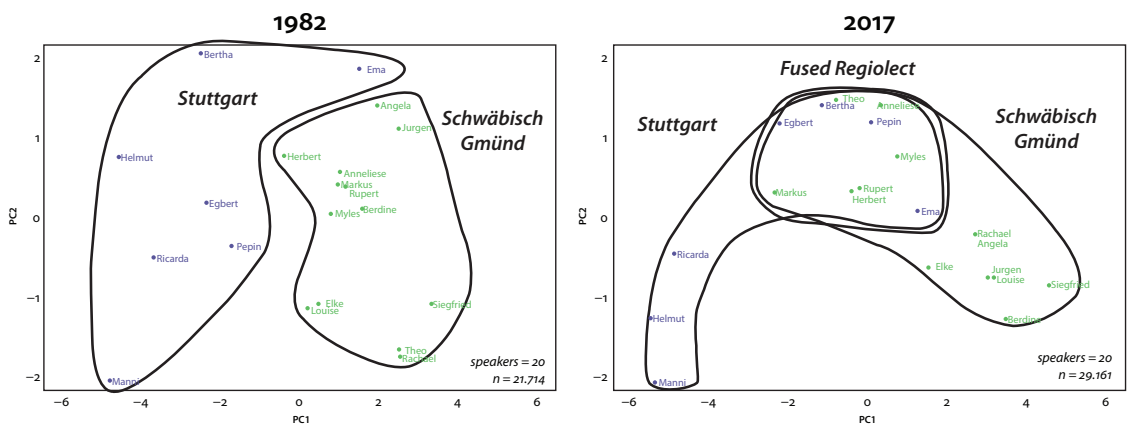

Figure 8. Principal Components Analysis (PCA) depicting distinct Stuttgart and Schwäbisch Gmünd lects in 1982 and the fusing of lects in 2017

the variation, and in 2017 PC1 and PC2 together account for $82 \%$ of the variation. Not surprisingly, the PCA results are quite similar to the Lectal Lattice, albeit with a different graphical representation. In 1982, we again see two very distinct lects, Stuttgart speakers on the left and Schwäbisch Gmünd speakers on the right. The PCA for 2017 also depicts a changing picture of the dialect situation in Swabia. We can still delineate the Stuttgart and Schwäbisch Gmünd groups; however, we see a fusing of the two lects in the middle of the graph. The PCA in Figure 8 corroborates the findings from the Lectal Lattice in Figure 7, both of which reveal greater diversity among the Swabian speakers in 2017 than in 1982.

Both PCA and the Lectal Lattice are data reduction methods that unveil significant groupings of speakers based on linguistic factors alone. One advantage of the Lectal Lattice over PCA is in the graphical display: the hierarchical depiction of related lects exposes the underlying relationships between lects without the researcher having to run multiple PCA models and manually compare and contrast the results. Another important advantage of the Lectal Lattice over PCA is in the calculation of the distance between lects: with principal components, distance is calculated based only on the frequencies of the variables; with the Lectal Lattice, distance is determined based on both the frequencies and the implicational order of the variables. However, the greatest advantage of the Lectal Lattice over PCA and other data reduction methods is the ability to calculate, measure and compare how closely different lects and groups of lects cohere, as explained in the following section.

\section{Implicational coherence}

The motivation behind the Lectal Lattice is the development of a method to evaluate the coherence of lects, that is, how tightly (or loosely) multiple variables co-occur within a given lect. With a quantifiable, objective measure of coherence, we can test the overall hypothesis of this research that more coherent lects are more resistant to 
change, while less coherent lects are more vulnerable to change. The POSETs in the Lectal Lattice provide a method for quantitatively assessing the level of coherence in any given lect by measuring the number of significant pairwise comparisons that follow the implicational pattern. Quite simply, implicational coherence is calculated by summing the 1's above the diagonal (i.e., significant pairs based on Suissa \& Shuster (1985) Exact test $(p<.05)$ using the Holm-Bonferroni method, as shown in Figure 4), subtracting the 1's below the diagonal (i.e., those deviating from the pattern), and then dividing by the total number of significant pairs in the POSET. The following formula describes the calculation for implicational coherence (IC):

$$
I C=\frac{\sum_{i=1}^{n} x_{i}^{w}-\sum_{i=1}^{n} x_{i}^{\beta}}{\sum_{i=1}^{n} x^{i}}
$$

To illustrate how the IC formula works, Figure 9 shows the POSETs for the top-most nodes from the Lectal Lattices in 1982 (NODE 120 from Figure 6) and 2017 (NODE 119 from Figure 7). Following the IC formula, in 1982 there are 60 significant pairwise comparisons above the diagonal and 6 below the diagonal, $(60-6) /$ $66=.818$, signifying a highly coherent lect in 1982 at $82 \%$. However, the POSET for the top-most node in 2017 reveals double the number of deviants (12 versus 6) and hence an implicational coherence of only $68 \%$. While the current sample size is quite small for tests of statistical significance, a common problem in panel study research (Cukor-Avila and Bailey 2017), a two tailed z-test shows this difference in coherence between the 1982 lect and the 2017 lect to be significant (z-value $=5.83$; $p<.001 ; n=78)$.

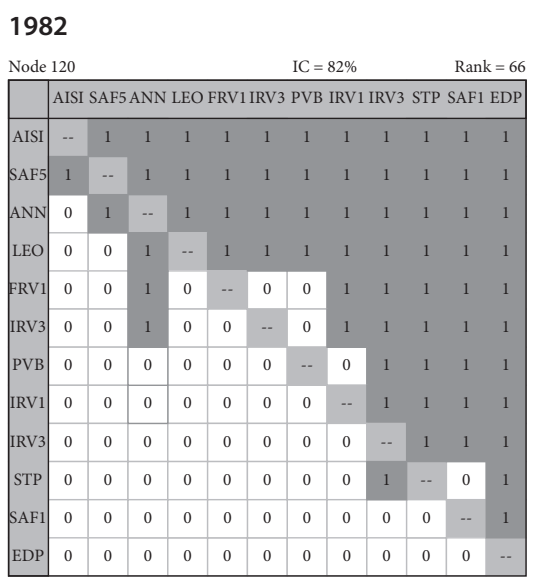

\section{7}

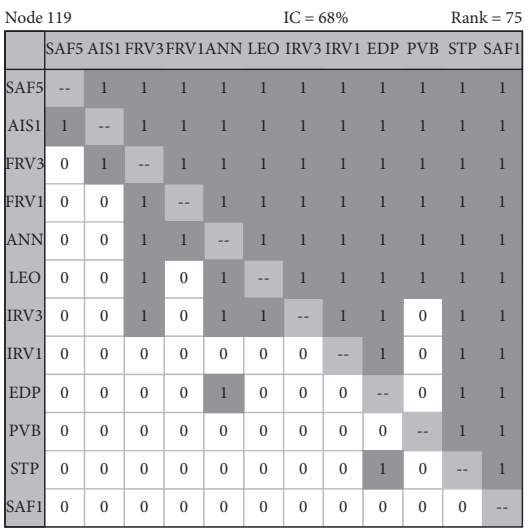

Figure 9. POSETS with pairwise comparisons for 12 variables for the top-most nodes in the 1982 and 2017 Lectal Lattices, demonstrating implicational coherence percentages 
Figure 10 presents the Lectal Lattices from 1982 and 2017 with the implicational coherence percentages displayed for each node. It is interesting to note that all NODES in the 2017 lattice indicate lower levels of coherence than the NODES in the 1982 lattice, demonstrating the pervasive breakdown in the coherence of the Swabian dialect over the last 35 years. In comparing the implicational coherence indices with the results from the previous PCA, PC1 yields an $R^{2}$ value of .165, while IC shows a $R^{2}$ value of .196 , demonstrating that the notion of implicational coherence does a better job of explaining the variance in the data.

a.

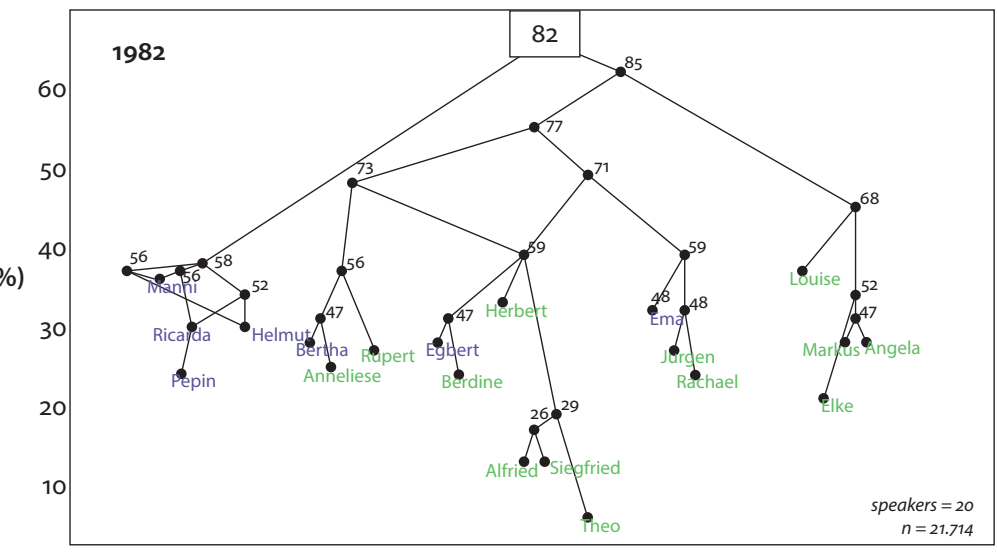

Gmünd

Stuttgart

b.

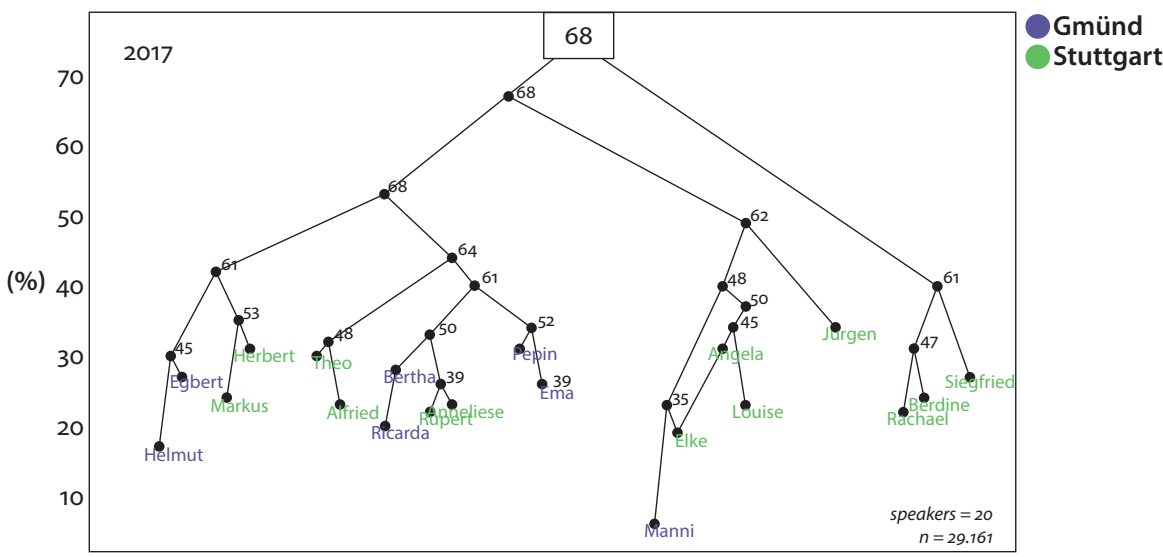

Figure 10. Lectal Lattices for 20 Swabian Panel speakers in 1982 and in 2017 displaying implicational coherence for each node in the lattice 
It is worth noting that an implicational scale can be drawn for any POSET using traditional notation to show the patterning of the variables for that lect. For example, the following implicational scale describes the Swabian variety spoken in 1982 (Node 120), both the main pattern and the deviant pattern (see Section 2.3 for a description of the variable labels):

$$
\begin{aligned}
& \text { AIS } 1<\text { SAF5 }<\text { ANN }<\text { LEO }<\left\{\begin{array}{l}
\text { FRV1 } \\
\text { FRV3 }
\end{array}\right\}<\left\{\begin{array}{c}
\text { PVB } \\
\text { IRV } 1
\end{array}\right\}<\text { IRV } 3<\text { EDP } 1 \\
& \text { AIS } 1>\text { SAF5 }>\left\{\begin{array}{l}
\text { ANN } \\
\text { FRV } 1 \\
\text { FRV3 }
\end{array}\right\}>\text { STP }
\end{aligned}
$$

An example helps to explain the interpretation of this implicational scale: if, for example, a speaker uses the Swabian variant for ANN (Nasalisation of /a/ before $/ \mathrm{n} /$ ), by implication that speaker is also likely to use the Swabian variants to the left in the scale (i.e., SAF5 and AIS1), however not necessarily the variants to the right. Note that the curly brackets denote variables that do not have an implicational relationship with each other (e.g., the two front rounded vowels, FRV1 and FRV3 or PVB and IRV1), rather these groups of variables pattern in the same way. The second row in an implicational scale describes a deviant pattern of variable usage which is valid for some subset of speakers. For these speakers, use of ANN implies use of STP and optionally FRV1 and FRV3 but not necessarily the variants to the left, SAF5 and AIS1 (see Rickford (2001) for further discussion on the interpretation of implicational scales). In short, the Lectal Lattice is based on implicational patterns derived from the ordering between variables, as well as on the frequency of the variables in deriving the order. It addresses several major problems with traditional implicational scaling, most importantly, by not being as strict and thereby allowing for variation in the variable pairings and by factoring in the effect of deviants rather than ignoring them.

\section{Coherence and language change}

At the core of this research is the question of whether lectal coherence enables or inhibits linguistic change. As previously stated, the main hypothesis of this investigation is that more coherent lects are less vulnerable to change and convergence while less coherent lects are more susceptible to change. To test this hypothesis and validate the new method proposed in this paper, separate Lectal Lattices were built for each community by recording year (see Figure 11). Most notable is the considerably lower level of coherence in Stuttgart (59\% and 61\%) than in Schwäbisch Gmünd (80\% and 77\%) for both recording periods. Other research has shown that the extensive dialect levelling occurring in Swabian, is predominately situated in 
the large urban centre of Stuttgart (Auer 2005; Beaman 2020, 2021). Using Van Hofwegen and Wolfram's (2010) "Dialect Density Measure", a token-based approach that calculates the proportion of dialect variants across all possible variants for the 12 dialect features in this investigation (Beaman 2020, 2021), dialect density has declined considerably more in Stuttgart (from $41.0 \%$ in 1982 to $18.2 \%$ in 2017, $n=16,482$ ) than in Schwäbisch Gmünd (from 54.3\% in 1982 to $40.9 \%$ in 2017, $n=25,220$ ). These findings provide support for the hypothesis that the less coherent dialect of Stuttgart is more susceptible to change than the more coherent dialect of Schwäbisch Gmünd. The supposition underlying this premise is that strong coherence binds linguistic variables together making them more resistant to outside influences (e.g., "change-from-above"), much like the strong social ties in closed social networks resist outside innovation (Milroy 1987).

a.

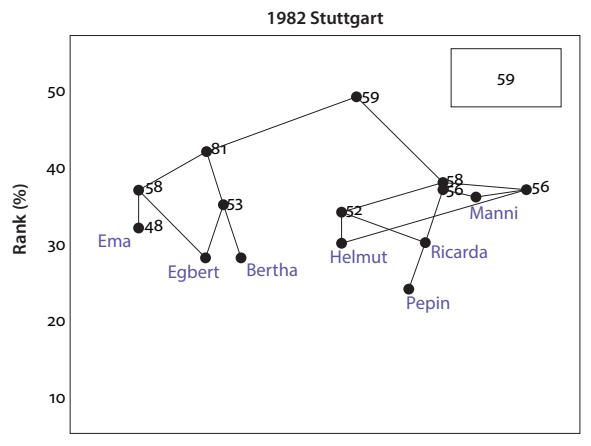

c.

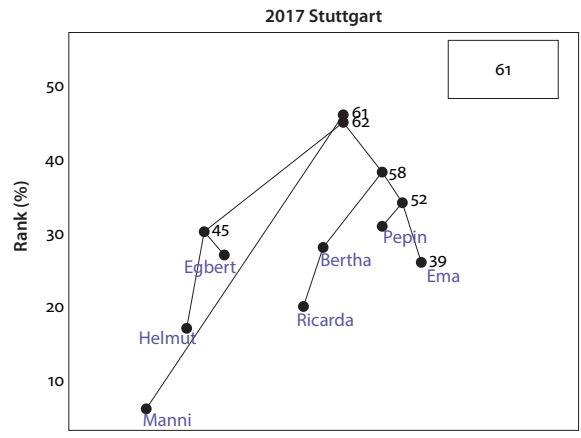

b.

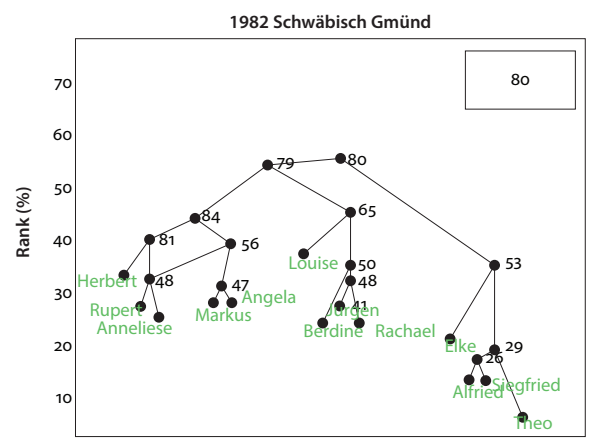

d.

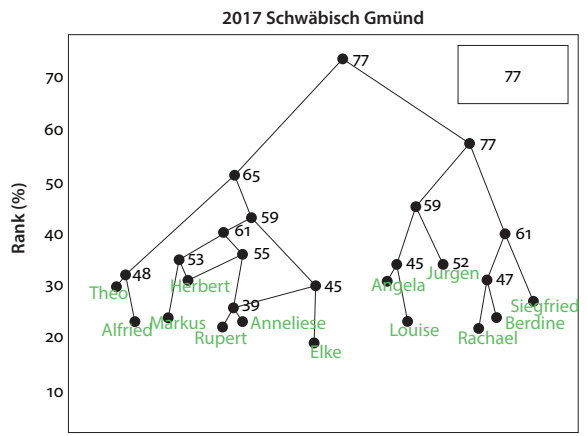

Figure 11. Individual Lectal Lattices for Stuttgart and Schwäbisch Gmünd in 1982 and in 2017 showing change in implicational coherence in real-time 


\section{Limitations and future opportunities}

This paper has presented an exploratory model into a potential new method for measuring, visualising, and comparing coherence across lects; however, it is not without some limitations. Future refinement of the Lectal Lattice should consider the following opportunities:

1. Structure and shape of the graphs: the structure and shape of the Lectal Lattice, particularly with respect to the horizontal axis (based on PC1) is arbitrary. Future refinement should consider a method for comparing the generated graphs to an MDS (multidimensional scaling) analysis to enhance the structure of the graphs and provide better visualisation of the differences.

2. Proportion of idiolects sharing the same pattern: currently the Lectal Lattice is built from significant patterns that occur in a least one idiolect in the lect, meaning that all pairwise comparisons are treated equally. Future development should take into account the frequency of occurrence of each pattern, i.e., the proportion of speakers with the same pattern, and weight the calculation of rank and implicational coherence based on the number of speakers exhibiting each pattern.

3. Variables with very low or very high token counts: the current implementation does not account for variables with very high or very low token counts. While none of the 12 variables in the current study are skewed in this way, this situation needs to be considered when expanding the Lectal Lattice to other datasets.

4. Positioning of the ellipses depicting similar lects: currently the positioning of the ellipses encircling similar lects is a manual process made by an informed researcher. An expanded implementation of the Lectal Lattice could include additional researcher-defined criteria about the speakers and the variables to assist in identifying and depicting similar lects.

5. Additional intra- and extra-linguistic predictors: the current study has considered only recording year and community as predictors of lectal coherence. Additional social predictors, such as speakers' gender, age, identity and so on, as well as sociolinguistic predictors, such as the stigma/prestige, and other aspects of the variables, such as saliency and dialect variety, can be incorporated into the model to uncover more nuanced aspects of lectal coherence.

6. Additional communities and variables: the current study has tested only two implementations of the Lectal Lattice based on 12 variables and 20 speakers from 35-year panel study (1982 and 2017). Further exploration should consider additional communities, time slices and variables in order to provide a deeper analysis of the relationships and coherence between variables in a lect (see Beaman 2020 for an extension of the Lectal Lattice to an apparent-time study). 
7. Larger dataset: a common problem with panel study datasets is the small token count making it difficult to conduct rigorous tests of statistical significance. An opportunity for future research is to test the concept of the Lectal Lattice against larger and more complex datasets to assess its explanatory power and determine its robustness.

\section{Conclusion}

Early in the variationist paradigm, Fasold (1970) argued that the combination of frequency analysis and implicational scaling leads to more revealing insights than either approach can individually (Fasold 1970: 562). Using a new mathematical construct borrowed from LATTICE theory, this paper advances Fasold's claim by exploring a method for combining statistically significant differences in the proportion of dialect use with implicational scaling techniques to measure the levels of coherence in differing lects. The Lectal Lattice introduced in the paper supports the investigation of the relationship between lectal coherence and linguistic variation and change. By measuring levels of implicational coherence between the variables in a lect, the Lectal Lattice provides an approach for predicting which lects may be more susceptible to variation and change and which may be more resistant.

The Lectal Lattice offers several benefits over other methods in identifying unified lects and assessing coherence. First, it provides superior explanatory value over principal components by exposing the significant relationships between variables based on pairwise comparisons. Second, rather than a single linear chain, such as with an implicational scale, the Lectal Lattice is multidimensional, rendering a single visualisation that reveals the logical groupings and hierarchical ordering of similar lects. Third, LATTICE methodology with its variable POSETS proposes an independent statistical method for calculating the level of coherence of different lects. Fourth, the Lectal Lattice offers a method for testing the hypothesis of this investigation that less coherent lects are more vulnerable to change by providing a means to compare the variation in the structural relationships between variables across different lects. Indeed, the findings from this preliminary investigation reveal Stuttgart to be the less coherent lect and hence the one more open to change, which was verified by a steep reduction in dialect density (23\%) over the 35-year time-span of this study. 
Finally, LATTICE theory supports Weinreich, Labov, and Herzog (1968) that coherence or "orderly heterogeneity" is found in the aggregate grammar of the speech community rather than in the individual, reinforcing the widely-held premise that individuals in a community behave in parallel, reflecting regularity and coherence. As Figures 10 and 11 reveal, coherence across the lifespan of these Swabian speakers has diminished over time. The Swabian of 2017 is less coherent than the Swabian of 1982, particularly in the urban centre of Stuttgart, suggesting that modern Swabian remains highly vulnerable to ongoing change with continued levelling and convergence to standard German the most likely outcome.

\section{Acknowledgements}

I wish to thank the following people for their review and feedback on earlier versions of this paper: Jenny Cheshire, Greg Guy, Frans Hinskens, and Dirk Speelman, as well as the audience from ICLaVE|10 at Fryske Akademy in Leeuwarden where I first presented this research. Any deficiencies remaining are of course my own.

\section{References}

Ammon, Ulrich. 1973. Dialekt und Einheitssprache in ihrer sozialen Verflechtung: Eine empirische Untersuchung zu einem vernachlässigten Aspekt von Sprache und sozialer Ungleichheit. (Beltz-Monographie, Pragmalinguistik 3). Weinheim \& Basel: Beltz.

Auer, Peter. 1997. Co-occurrence restrictions between linguistic variables: A case for social dialectology, phonological theory and variation studies. In Frans Hinskens, Roeland van Hout \& W. Leo Wetzels (eds.), Variation, change, and phonological theory, 69-100. Amsterdam: John Benjamins. https://doi.org/10.1075/cilt.146.05aue

Auer, Peter. 2005. Europe's sociolinguistic unity, or: A typology of European dialect/standard constellations. In Nicole Delbecque, Johan van der Auwera \& Dirk Geeraerts (eds.), Perspectives on variation: Sociolinguistic, historical, comparative, 7-42. Berlin: Mouton de Gruyter. https://doi.org/10.1515/9783110909579.7

Auer, Peter \& Frans Hinskens. 2005. The role of interpersonal accommodation in a theory of language change. In Peter Auer, Frans Hinskens \& Paul Kerswill (eds.), Dialect change: Convergence and divergence in European languages, 335-357. Cambridge: Cambridge University Press. https://doi.org/10.1017/CBO9780511486623.015

Baayen, R. Harald, Karen V. Beaman \& Michael Ramscar. Forthcoming 2021. Deconfounding the effects of competition and attrition on dialect across the lifespan: A panel study investigation. In Karen V. Beaman \& Isabelle Buchstaller (eds.), Language variation and language change across the lifespan: Theoretical and empirical perspectives from panel studies. New York: Routledge.

Beaman, Karen V. 2020. Coherence in real- and apparent-time: A sociolinguistic study of Swabian. Queen Mary University of London: Unpublished PhD Thesis. 
Beaman, Karen V. 2021. Identity and mobility in linguistic change across the lifespan: The case of Swabian German. In Arne Ziegler, Stefanie Edler, Nina Kleczkowski \& Georg Oberdorfe (eds.), Urban matters: Current approaches of international sociolinguistic research (Studies in Language Variation). Amsterdam: John Benjamins.

Beaman, Karen V. \& Fabian Tomaschek. 2021. Loss of historical phonetic contrast across the lifespan: Articulatory, lexical, and social effects on sound change in Swabian. In Karen V. Beaman \& Isabelle Buchstaller (eds.), Language variation and language change across the lifespan: Theoretical and empirical perspectives from panel studies. New York: Routledge.

Bickerton, Derek. 1973. The nature of a creole continuum. Language 49(3). 640-669. https://doi.org/10.2307/412355

Britain, David. 2010. Supralocal regional dialect levelling. In Carmen Llamas \& Dominic Watt (eds.), Language and identities, 193-204. Edinburgh: Edinburgh University Press.

Cukor-Avila, Patricia \& Guy Bailey. 2017. The effect of small Ns and gaps in contact on panel survey data. In Suzanne Evans Wagner \& Isabelle Buchstaller (eds.), Panel studies of variation and change, 181-212. New York: Routledge. https://doi.org/10.4324/9781315696591-8

DeCamp, David. 1968. Toward a generative analysis of a post-creole speech continuum. In Dell Hymes (ed.), Pidginization and creolization of languages, 349-70. Cambridge: Cambridge University Press.

Fasold, Ralph W. 1970. Two models of socially significant linguistic variation. Language 46(3). 551-563. https://doi.org/10.2307/412306

Ghyselen, Anne-Sophie \& Jacques Van Keymeulen. 2016. Implicational scales in colloquial Belgian Dutch. Dialectologia et Geolinguistica 24. 1-17. https://doi.org/10.1515/dialect-2016-0004

Greenberg, Joseph H. 1963. Some universals of grammar with particular reference to the order of meaningful elements. In Joseph H. Greenberg (ed.), Universals of language, 73-113. London: MIT Press.

Guttman, Louis. 1944. A basis for scaling qualitative data. American Sociological Review 9(2). 139-150. https://doi.org/10.2307/2086306

Guy, Gregory R. \& Frans Hinskens. 2016. Linguistic coherence: Systems, repertoires and speech communities. Lingua 172-173. 1-9. https://doi.org/10.1016/j.lingua.2016.01.001

Hinskens, Frans. 2020. Surviving Limburg and Hollandic dialect features and what they have in common. In Massimo Cerruti \& Stavroula Tsiplakou (eds.), Intermediate language varieties: Koinai and regional standards in Europe, 55-77. John Benjamins.

https://doi.org/10.1075/silv.24.03hin

Hinskens, Frans, Peter Auer \& Paul Kerswill. 2005. The study of dialect convergence and divergence: Conceptual and methodological considerations. In Peter Auer, Frans Hinskens \& Paul Kerswill (eds.), Dialect change: Convergence and divergence in European languages, 1-50. Cambridge: Cambridge University Press. https://doi.org/10.1017/CBO9780511486623.003

Van Hofwegen, Janneke \& Walt Wolfram. 2010. Coming of age in African American English: A longitudinal study. Journal of Sociolinguistics 14(4). 427-455.

https://doi.org/10.1111/j.1467-9841.2010.00452.x

Holm, Sture. 1979. A simple sequentially rejective multiple test procedure. Scandinavian Journal of Statistics 6(2). 65-70. http://www.jstor.org/stable/10.2307/4615733

Horvath, Barbara M. \& David Sankoff. 1987. Delimiting the Sydney speech community. Language in Society 16(2). 179-204. https://doi.org/10.1017/So047404500012252

Labov, William. 1963. The social motivation of a sound change. Word 19(3). 273-309.

https://doi.org/10.1080/00437956.1963.11659799 
Mattheier, Klaus J. 1987. Variabilität zwischen Dialekt und Standardsprache. Zeitschrift für Germanistik 8(5). 544-558.

Meyerhoff, Miriam \& Steffen Klaere. 2017. A case for clustering speakers and linguistic variables: Big issues with smaller samples in language variation. In Isabelle Buchstaller \& Beat Siebenhaar (eds.), Language Variation - European Perspectives VI (Studies in Language Variation VI), 23-46. John Benjamins. https://doi.org/10.1075/silv.19

Milroy, James \& Lesley Milroy. 1985. Linguistic change, social network and speaker innovation. Journal of Linguistics 21(2). 339-384. https://doi.org/10.1017/So022226700010306

Milroy, Lesley. 1987. Language and social networks. 2nd edn. Oxford: Basil-Blackwell.

Partee, Barbara H., Alice G. ter Meulen \& Robert E. Wall. 1993. Mathematical methods in linguistics. Dordrecht: Kluwer Academic Publishers. https://doi.org/10.1007/978-94-009-2213-6

Rickford, John R. 2001. Implicational scales. In J. K. Chambers, Peter Trudgill \& Natalie SchillingEstes (eds.), The handbook of language variation and change, 142-167. Malden MA: Blackwell Publishing.

Trudgill, Peter. 1986. Dialects in contact. Oxford: Blackwell Publishing.

Weinreich, Uriel, William Labov \& Marvin I. Herzog. 1968. Empirical foundations for a theory of language change. In Winfred Lehmann \& Yakou Malkiel (eds.), Directions for Historical Linguistics, 95-188. Austin: University of Texas.

Wieling, Martijn \& John Nerbonne. 2011. Bipartite spectral graph partitioning for clustering dialect varieties and detecting their linguistic features. Computer Speech and Language 25(3). 700-715. https://doi.org/10.1016/j.csl.2010.05.004

Wittenburg, Peter, Hennie Brugman, Albert Russel, Alex Klassmann \& Han Sloetjes. 2006. ELAN: A professional framework for multimodality research. Proceedings of the Fifth International Conference on Language Resources and Evaluation (LREC'06), 1556-1559. Nijmegen: Max Planck Institute for Psycholinguistics, The Language Archive. 


\title{
CHAPTER 7
}

\section{"I'm dead posh in school"}

\section{Attitudes and linguistic behaviour of Merseyside adolescents}

\author{
Rachel Byrne \\ University of Liverpool
}

\begin{abstract}
Liverpool English, or "Scouse", is a dialect often used by speakers in Merseyside. This study involves the use of word-list elicitation and semi-structured group interviews with adolescents from two schools in Merseyside: one in Liverpool, and one on the Wirral. Analysis of the elicited vowels of the SQUARE and NURSE lexical sets shows that Wirral speakers orient themselves to Liverpool pronunciations to an extent, using NURSE fronting in unexpected ways to achieve varying linguistic and social goals. The qualitative data shows that Merseyside speakers are highly aware of the social markedness of Scouse, with Wirral speakers using Liverpool forms to identify themselves as local Merseyside speakers, but not "Scousers". Participants from both schools intentionally engage in style-shifting of local dialect in order to construct unique identities for themselves. ${ }^{1}$
\end{abstract}

Keywords: dialect, accent, identity, style-shifting, sociolinguistics, variation, change, indexicality, enregisterment

\section{Introduction}

Liverpool English, commonly known as "Scouse", is the dialect used by many speakers in Liverpool and the wider Merseyside area of North-West England. The Liverpool accent "is limited to the city itself, to urban areas adjoining it, and to towns facing it across the River Mersey" (Hughes et al. 2012: 112). Scouse has a highly distinctive phonology, as well as a large localised vocabulary (Crowley 2017). Phonologically, the most recognisable features of Scouse include "TH-stopping, non-rhoticity, the absence of contrast in the SQUARE and NURSE lexical sets and

1. Parts of this paper formed part of my MRes thesis; see Byrne (2018) for a full account of this study. 
Liverpool lenition" (Honeybone 2007: 107). In particular, these merged SQUARE and NURSE lexical sets are typically fronted in Liverpool English (Watson and Clark 2013). The degree of fronting of these lexical sets by Merseyside speakers is the focus of the current study. I also consider the interaction of Scouse phonology with speaker identity and attitudes towards Liverpool dialect. As an urban variety of English, Scouse is often associated with working-class speech (Grant and Grey 2007), and in perceptual dialectology studies it has frequently been assessed negatively in categories such as "social attractiveness" and "prestige" (Coupland and Bishop 2007; Montgomery 2012). By looking at Scouse in this way, I address the question of how attitudes towards Scouse impact upon the way speakers present themselves within their own localities in Merseyside. The data has been collected from two different geographical regions in Merseyside, following Newbrook (1999), who asserts that the Scouse dialect area is expanding into Liverpool's hinterlands. Data was collected from one school within the Liverpool area, and a grammar school on the Wirral; this is a region of Merseyside that is less than ten miles away from the Liverpool school, but separated geographically by the River Mersey that runs between them. The participants in the study are from predominantly middle-class areas of Liverpool and Merseyside.

Collecting data from these different areas allows us to consider the relationship between attitudes and linguistic behaviour of speakers from regions which, despite being relatively geographically close, are impacted by differing social, geographical and cultural factors.

\section{Merseyside English}

Linguistically, Liverpool is a highly recognisable and unique area (Montgomery 2012). Although Liverpool shares elements of its dialect with other regions, for example the lack of a split between FOOT and STRUT vowels which is consistent with other Northern areas, it also has unique features including "Liverpool lenition", where / $t, d, k$ / can be fricativised, and the SQUARE NURSE merger (Honeybone 2007: 107). Notably, the merged SQUARE and NURSE lexical sets are pronounced as a mid front vowel $\left[\varepsilon^{2}\right]$ in Liverpool English, rather than the mid central vowel realisation of NURSE [3:] and diphthong approximating pronunciation of SQUARE [Eə] used in Standard British English (Watson and Clark 2013: 298). In other varieties of Northern British English, the "SQUARE vowel can also be realised as a mid front monophthong" (ibid.). Watson and Clark (2013) also observed that fronted realisations of NURSE were found to be particularly salient, where Merseyside speakers perceived $[\varepsilon:]$ to be marked. In particular, they found that their participants did 
not respond to hearing central NURSE pronunciations, while they often reacted to fronted NURSE pronunciations (ibid).

Liverpool English is also distinct in that it has often proven to be resistant to dialect levelling. Beal (2010) observed that Merseyside adolescents engage in unique linguistic behaviours, including resisting dialect levelling with regard to T-glottalling. She says that "young Liverpudlians are behaving differently from their contemporaries in other towns and cities because they have such a strong sense of local identity", and there is "no incentive" for them to adopt it when ' $t>h$ ' carries sociolinguistic meaning as glottalisation in Liverpool (2010: 85). The current research therefore considers the extent of the impact that such perceptions of identity has upon young speakers' realisations of SQUARE and NURSE.

As well as resisting linguistic change from other regions, Scouse linguistic features have been shown to be diffusing outside of Liverpool. Newbrook (1999: 91) noted that a process of dialect levelling has led to a direction of linguistic change on the Wirral that is moving towards "Liverpool/Birkenhead" usage, rather than diverging away from it. This has relevant social implications due to the fact that the Wirral is both "middle-class in character", displaying "larger proportions of higher-prestige usage" than in Liverpool, whilst simultaneously containing "large numbers of working class speakers with strong local accents of various kinds" (1999: 91). Newbrook's stance that Liverpool and Birkenhead (one of the Wirral towns closest to Liverpool) are linguistically similar reinforces the idea that speech production in Liverpool and on the Wirral is often comparable. Yet it is important to note that Birkenhead, like Liverpool, is demographically more working-class than other areas of Wirral. The current study focuses on more middle-class areas in both regions, where the relationship between Liverpool and Wirral perceptions and linguistic behaviour is less widely documented.

Given that Liverpool English is often negatively assessed in perceptual dialectology studies due to its working-class connotations (Montgomery 2012; Grant and Grey 2007), the idea that some Wirral speakers are converging their speech towards Liverpool English, rather than away from it, is arguably unexpected. However, Newbrook argues that "future developments are likely to involve the continuation" of linguistic assimilation towards Liverpool English on the Wirral (1999: 105).

The distinct linguistic behaviour of Liverpool and Merseyside speakers is evidently influenced by speaker attitudes, which has been demonstrated by previous research in the wider Merseyside area. West (2015) found that the extent of linguistic convergence towards Liverpool English in regions on the Merseyside/Lancashire border is often linked to speaker perceptions of Scouse. She noted that in Southport, where speakers held more negative perceptions of Scouse, speakers maintained a distance from Scouse features in their language usage; meanwhile, speakers from 
Ormskirk, ${ }^{2}$ who held more positive attitudes towards Scouse, were converging towards Liverpool features. Her findings were particularly relevant with regard to the SQUARE and NURSE lexical sets, where "younger Ormskirk speakers' positive assessments of Liverpool and Scouse are correlated with their raised production of NURSE" (2015: 337). Furthermore, West noted that it was younger females who were leading the change towards "a more fronted, Scouse-like pronunciation of NURSE, with a minimum of $60 \%$ (6 out of 10) of NURSE free speech forms fronting and raising towards SQUARE" (2015: 338).

\subsection{Indexicality and enregisterment}

When considering the relationship between linguistic behaviour and speaker attitudes, I will be applying the concepts of indexicality and enregisterment. Indexicality involves the linking of micro-social and macro-social linguistic concepts, as outlined by Silverstein (2003). There are three orders of indexicality: the first order involves correlating a "particular linguistic form and social category", observable by outsiders rather than the speaker themselves (Beal and Cooper 2015: 27). Second-order indexicality involves speakers noticing the links between linguistic features and social categories, whilst third-order indexicality involves forms linked with particular categories becoming "the subject of overt comment" (Beal and Cooper 2015: 27). Related to this is the concept of enregisterment, which Agha (2007: 81) defines as "processes and practices whereby performable signs become recognized (and regrouped) as belonging to distinct, differentially valorized semiotic registers by a population". When language becomes enregistered, "a linguistic repertoire becomes differentiable within a language as a socially recognised register", where the social status of a speaker is "linked to a specific scheme of cultural values" (Agha 2003: 231). In an analysis of Pittsburghese, Johnstone (2013) described how enregisterment according to multiple schemas can evoke a Pittsburghese identity. For example, "a feature that evokes (and helps construct) a Pittsburgh persona may also evoke (and help construct) a working-class persona, or it may evoke both, thus serving to overlay and align Pittsburgh and working-class identities" (2013: 225). When speakers were aware of the social salience of particular features, Johnstone, Andrus and Danielson (2006) found that speakers drew upon particular features of Pittsburghese in different speech contexts; for example, the monophthongization of the diphthong / aw/ is more likely to occur in the speech of working-class Pittsburgh males than

2. Southport is located on the Merseyside side of the border, 19 miles from Liverpool, whilst Ormskirk is in Lancashire, 14 miles north of Liverpool. 
other people. Due to these social factors being indexically linked with use of this linguistic feature, Johnstone et al. concluded that speakers who use /aw/ "may use it less when they are trying harder to sound educated or cosmopolitan, or more when they are trying harder to sound like working-class men or like other Pittsburghers" (2006: 83). The notion that speakers engage in style-shifting due to social factors being indexically linked to the use of linguistic variables is also applicable to the current situation in Merseyside with Scouse.

\section{Methodology}

The participants in this study are adolescents, since the attitudes of speakers in this age category have a particularly significant impact upon their linguistic production. Also, adolescents are often considered to be the primary facilitators of linguistic change (Watson 2007). Data was elicited from 27 students across two schools. One school is an all-girls grammar school based on the Wirral; the other is a co-educational school in Liverpool. Following previous research into linguistic behaviour and identity construction (Llamas 2007; Burbano-Elizando 2010; West 2015), data was collected via a mixed-method approach. First, participants read from a list of 25 words on a one-on-one basis, so that specific phonological tokens could be collected from a careful speech context. This was carried out in the school classrooms with only the researcher, individual student, and class teacher present for ethical reasons. Whilst it must be acknowledged this has might have had the potential to influence elicitation due to the Observers' Paradox (Labov 1972), the teacher was not an active participant and was engaged in their own work whilst the word list elicitation activity took place. The results of this paper focus on the two words from this list, fair and first, which represented the SQUARE and NURSE lexical sets. Next, I conducted semi-structured group interviews to obtain attitudinal data. I held two interviews in the Wirral school, with one group consisting of seven participants, three of whom were aged between 16 and 17 years old, and four of whom were aged between 13 and 14 years old. The second interview group consisted of six participants: four aged between 15 and 16, one aged between 12 and 13, and one aged between 16 and 17 years old. All of the students in the Wirral school are female. In the Liverpool school, I interviewed all fourteen participants together. All of the participants were from the same English class and aged between 16 and 17 years old. Eight of these students were female, and six were male. Each interview lasted between 20 and 30 minutes and was audio-recorded using a Zoom H4n recorder. The tokens discussed in the quantitative results were manually extracted using Praat (Boersma \& Weenink 2017), and measurements for F1 and 
F2 were taken for SQUARE and NURSE words. There were 54 tokens analysed, one for the elicitation of SQUARE and one for NURSE by each individual. The data was normalised using the NORM Vowel Normalization and Plotting Suite (Kendall and Thomas 2007), following the method described in Labov et al. (2006: 39-40).

\section{Results}

\subsection{Quantitative data}

The quantitative results primarily focus on the extent of fronting used in the SQUARE and NURSE lexical sets. Previous research has shown that fronting, of NURSE in particular, is salient both linguistically and perceptually (Watson and Clark 2013; West 2015). For this reason, and due to the fact that vowel raising was not found to be statistically significant in the results, I focus only on fronting in this analysis.

Figure 1 shows that, there is a high degree of overlap in F2 values in the Liverpool school, supporting results from Watson and Clark (2013).

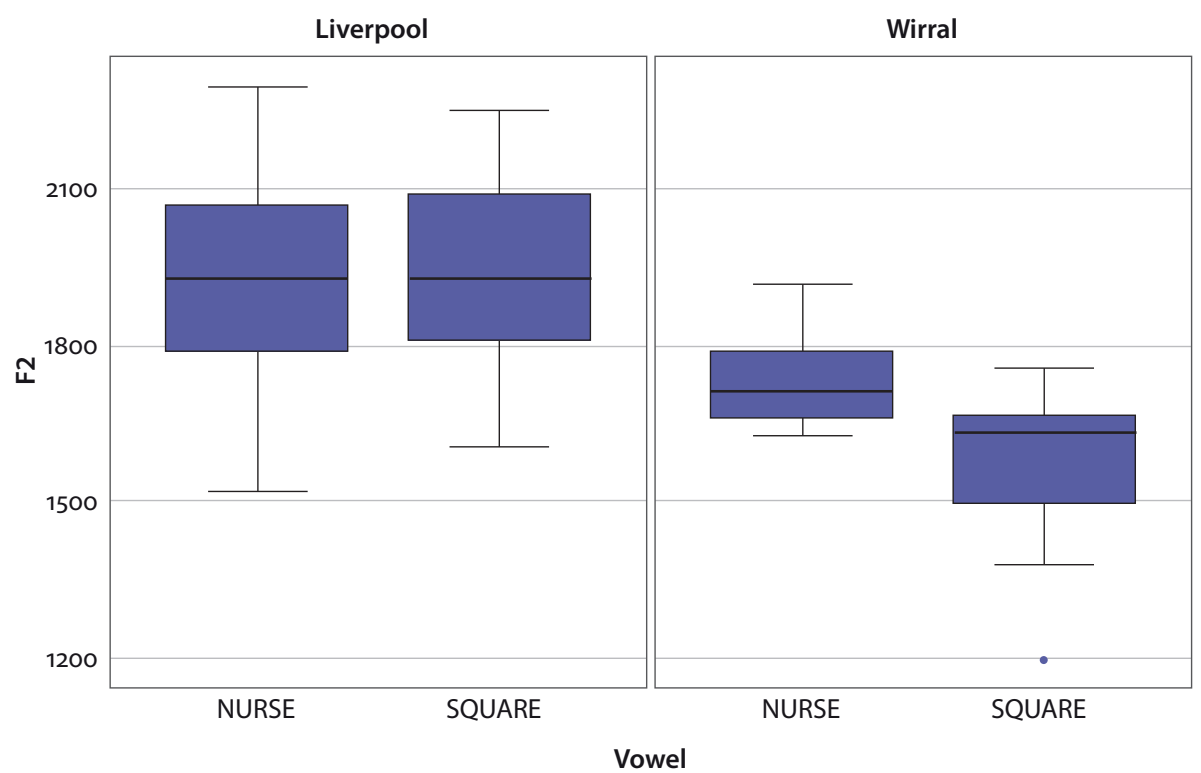

Figure 1. Boxplot of F2 values of SQUARE and NURSE, split up by school 
For the Wirral speakers, realisations of the vowels in SQUARE and NURSE are not completely distinct. The overall lack of overlap seen in the Wirral results is particularly evident in comparison to the Liverpool data where the merger is clearly shown. The data shows that these Wirral speakers are not following anticipated trends in the way that they use NURSE fronting, as speakers are fronting NURSE, the more backed vowel of the lexical set, more than SQUARE in the word-list exercise.

Using t-tests in R, I analysed the F2 data (Table 1).

Table 1. Paired t-test of F2 SQUARE NURSE results for both schools

\begin{tabular}{lccc}
\hline Test & $\mathbf{t}$ & $\mathrm{df}$ & $\mathrm{p}$ \\
\hline Wirral school & -3.010 & 20.189 & 0.007 \\
Liverpool school & -0.064 & 25.560 & 0.950 \\
\hline
\end{tabular}

We can observe from the t-tests that the difference between SQUARE and NURSE in the Wirral school has a statistically significant p-value, whilst the distinction is not significant for the Liverpool speakers. The statistical significance of the Wirral fronting results is emphasised by the commentary the participants make during the interviews which will be discussed in 4.2 , which indicates that they are overtly aware of salient features of Scouse, including SQUARE and NURSE fronting. This indicates that the use of NURSE fronting by Wirral speakers is above their level of conscious awareness, and as such, has the potential to "become available for social work" including style-shifting (Johnstone et al. 2006: 82).

These findings are particularly unexpected when we consider the context of this data, which was collected in an educational setting in a middle-class area. Juskan established in his data that "middle-class speakers have lower F2 values than their working class counterparts", which was "not surprising because it means that middle-class speakers use less Scouse variants than working-class Liverpudlians, which is true for both female... and male subjects" (2018: 123). However, the Wirral speakers' fronting of NURSE shows that they are engaging with Liverpool English, despite maintaining some distinction between themselves and Liverpool speakers by not fully merging the SQUARE and NURSE lexical sets. Whilst the data shows that Wirral speakers are diverging from the trends to some extent, they also support results such as those of West (2015: 338), where younger Ormskirk speakers, who viewed Liverpool and Scouse positively, were leading changes towards "a more fronted, Scouse-like pronunciation of NURSE", particularly in free speech forms. It should be noted, however, that the results of this study are from word list data rather than free speech forms, where participants were in a careful, not spontaneous, speech context. It appears that a major social shift has taken place amongst 
adolescents in this area in recent years, where middle-class adolescents in a grammar school setting are now engaging in a highly socially marked practice that is strongly associated with Scouse (Watson and Clark 2013), even in careful speech.

I also tested for gender significance in the results, as shown in Table 2.

Table 2. Paired t-test for gender significance of F2 values, first comparing males to females from both the Liverpool and the Wirral school, then males and females from the Liverpool school only

\begin{tabular}{lccc}
\hline Test & $\mathrm{t}$ & $\mathrm{df}$ & $\mathrm{p}$ \\
\hline Both schools & -0.291 & 31.188 & 0.773 \\
Liverpool school & -4.398 & 25.280 & $<0.001$ \\
\hline
\end{tabular}

The results of the t-test in Table 2 indicate that gender is not significant when we compare the male speakers with female speakers from both schools. Because the Wirral school is an only-girls school, it was not possible to test for gender significance here. Gender also proved not to be significant when comparing the results of females from both schools. When the test was conducted for speakers in the Liverpool school only, gender does prove to be statistically significant. This gender variation is not necessarily unexpected, and has been found in other studies of adolescents including that of Eckert (1989: 245), who found that "gender has a variety of effects on variables".

Although gender is quantitatively significant, unlike the results for SQUARE and NURSE fronting in Table 1, the speakers do not explicitly mention gender during the interviews. Swann (2002: 52) addresses such instances where gender is not made relevant by participants, summarising an argument by Schegloff (1997) that "any aspects of context that are seen to be relevant to an interaction (including the social characteristics of participants/speakers) should derive from the orientations of the participants/speakers themselves, and not from those of the analyst". I am analysing my data from a "third wave" perspective, where variation is viewed "as a reflection of social identities and categories to the linguistic practice in which speakers place themselves in the social landscape through stylistic practice" (Eckert 2012: 94). As such, I will now turn to a discussion of those social variables that speakers deem to be salient during the interviews, and how these relate to their linguistic behaviour.

\subsection{Perceptions of Scouse: Linguistic features}

To understand why the students use SQUARE and NURSE in the ways that they do, we must consider the social and perceptual functions that Scouse serves for them. In both schools, participants were overtly aware that NURSE was often more fronted by Liverpool English speakers. When asked which linguistic features they would 
describe as "Scouse", students in the Wirral school commented that the discourse marker erm [3:m] would be pronounced more like [ $\varepsilon: \mathrm{m}]$ in Scouse. Similarly, Liverpool students used the example of the word Mersey being pronounced more like [me:zi] than [mз:zi] by Liverpool English speakers, and that they recognised this as sounding "Scouse". The perception of this feature being linked to Scouse by students from both schools indicates that for these adolescents, fronted NURSE forms are socially marked and index a Scouse identity. An analysis of SQUARE and NURSE realisations by Newbrook showed "surprisingly low salience" by Wirral speakers, with "little reference... made to them in discussion" (1999: 95). The reason given for this was that "the rather strong middle-class tendency to preserve the RP contrast makes this issue less salient than elsewhere in Merseyside" (1999: 95). The results from the current study indicate that a major change has occurred in the Wirral both linguistically and socially since these conclusions were drawn, as NURSE fronting is indeed a salient phonological feature according to speakers from both the Wirral and Liverpool. Wirral students in middle class areas are no longer relating their pronunciations to RP as in Newbrook's analysis, but moving more towards Liverpool forms. As well as NURSE fronting, extracts 1 to 3 demonstrate other features that Wirral participants felt to be indicative of a Scouse dialect:

(1) it's not posh but it's like we pronounce our ts more than like Scousers do and like enunciate some of the words more

(2) The $r$ s of Scouse people are sometimes a bit like I don't know how. I can't like do it but I don't know. do you know what I mean like imagine someone saying Steven Gerrard you can imagine the Gerrard bit like the double $r$

(3) There's a lot of slang as well like if you watch like Eastenders or any of them and they're like they use slang that's quite similar to like Scouse

In Extract 1 speakers comment on $t$-lenition, with the reference to pronouncing [ $t$ ] "more than like Scousers do", and in Extract 2 we see a description of a trilled [r], which was recorded by Cheshire and Edwards (1991: 229) as a feature of Liverpool English. Indeed, Cheshire and Edwards (ibid.) discuss a comment from an interview informant who describes "Scouse" pronunciation of $[r]$ in a very similar manner to that shown in Extract 2. Their informant states "when I start to speak like a Scouser. I say married as if there's about $7 \mathrm{rs}$ in it - marrrrrried", which is analogous to the description of "double the r" mentioned above, suggesting that the same pronunciation is being described. In Extract 3 we see a perception of informality or slang being described as part of what they believe constitutes Scouse language, reflecting salient features highlighted in previous research into Liverpool English (e.g. Honeybone 2007). When the Wirral speakers were asked how they would describe their own accent, responses included: 
(4) A Wirral accent

(5) I wouldn't say it's Scouse

(6) I don't feel like it's really an accent. It's just like there

(7) It's good it's just normal

(8) It's not that strong I don't think it's that strong compared to Liverpool

Although one student described their way of speaking as "a Wirral accent", the students in comments 6 and 7 argued that they did not have a distinct accent at all, whilst extracts 5 and 8 suggest that the main notable feature of a Wirral accent is that it is not a Scouse, or Liverpool, variety. The perceptions of Wirral speakers emulate Jansen's (2013: 209) observations of Carlisle English speakers:

Carlisle English (henceforth CE) speakers are almost always identified as Scottish English or Newcastle English speakers. At the same time, they insist that their dialect is different from Newcastle English, let alone Scottish English. Yet when asked about their dialect the majority of CE speakers cannot name any phonological or morphosyntactic features.

Similarly, on the Wirral, speakers believe that their way of speaking is different to Liverpool English, yet Wirral features are not deemed salient enough for there to be a definable "Wirral" dialect with distinct linguistic forms.

\subsection{Perceptions of Scouse identity}

For many of the informants in this study, both in Liverpool and Wirral, a Scouse identity is perceived to be fixed and inflexible, with certain categories that must be fulfilled in order for somebody to authentically identify as a "Scouser". In fact, students from both schools commented that using Scouse linguistic features is not enough to evoke a Scouse identity. One Liverpool student argued that Scouse identity depends on multiple variables:

(9) How strong your accent is, the colour of your bin, whereabouts you're from

For context, in Liverpool, residents use purple bins for refuse waste, which is a different colour from the bins used at homes outside of the area (such as Wirral). As such this is considered by some as a marker of being a Liverpudlian, and therefore a "Scouser". Another student from the Liverpool school argued that somebody could only be defined as a Scouser if they were born in Liverpool. When another student responded to this, asking whether they would be considered to be a "Scouser", despite not being born in Liverpool but having lived there since the age of two 
years old, the student responded that "I wouldn't personally class you as a Scouser because you weren't born here". The responses illustrate that for Liverpool speakers, "Scouseness" depends on much more than linguistic behaviour. These adolescents show that they view "Scouse" identity as static, requiring the fulfilment of particular social requirements that cannot be controlled by the individual, for example their place of birth. For Wirral speakers, there was a distinct awareness of such views, meaning that they had clear ideas as to what a Scouse identity might be, but it was not one that they related to themselves. In particular, the students in extracts 10, 11 and 12 emphasise that they are often assigned a "Scouse" identity by non-local speakers, but this was not an identity that they chose to orient to:

(10) I feel like we don't really notice it. But when you go away people are like oh my God you're so Scouse and it's like no

(11) I feel like older generations though like if someone said you sound Scouse from like down South or whatever or where someone else is from like yeah you would think they would be more like protective over the Wirral accent and they're like no we're on the other side of the water sort of thing like they don't really wanna be compared to a Scouse accent

(12) I think it's odd because I don't think we do sound Scouse it's like completely like yeah it's like saying we sound like Australian or something 'cause we really don't

We can observe from the responses of the Wirral participants that although they are aware that their linguistic behaviour can lead to them being identified as Merseyside speakers, they explicitly deny any association with being a "Scouser", to the point that the participant in comment 12 feels that their dialect being described as "Scouse" is as applicable to them as being described as "Australian". This is not to say that the Wirral speakers are distancing themselves due to having negative perceptions of Liverpool, as comment 13 shows:

(13) I don't know I feel like it depends who it comes from if it comes from someone who doesn't live round here and they're like ooh are you from Liverpool it doesn't make you like proud but it's like ooh yeah that's where I'm from I'm from near there

This student highlights the positive associations that several Wirral speakers held towards having a local identity, and being recognisable as a Merseyside speaker, though not a Liverpudlian. For Wirral adolescents there seems to be a sense of pride at being identified as belonging to the Merseyside geographic region. However, they are anxious for this local identity not to be confused with a specifically "Scouse" 
identity. This is partly due to their awareness of social stereotypes enregistered by the use of Scouse features, as illustrated in comments 14 and 15. Although this is not the only contributing factor: it is also in large part due to an awareness of the connotations of inauthenticity that are related to non-Liverpudlians identifying as Scouse, which I discuss in Section 4.4.

(14) There's like the stereotypical views of like uneducated and stuff around the accent

(15) People can think it's quite chavvy

These students demonstrate that even on the Wirral, where speakers have a connection with and understanding of Liverpool, they are exceedingly aware of the negative stereotypes associated with Scouse. The students suggest that they do not necessarily believe these stereotypes themselves (or at least they are reluctant to admit it if these are personal views), stating "people can think..." or "there's like the stereotypical views of..." These comments reinforce the Wirral speakers' awareness of such negative associations of Scouse that have been highlighted in other works (Coupland and Bishop 2007; Grant and Grey 2007) where Scouse is linked to being working class, or in this case, linked to ideas of being "uneducated" or "chavvy". (The adjective chavvy originates from the slang term chav, which is defined as "a young person of a type characterized by brash and loutish behaviour and the wearing of designer-style clothes (esp. sportswear); usually with connotations of low social status" (OED 2020)). The Wirral students' understanding of the use of Scouse indexing such stereotypes is arguably an important contributor as to why they distance themselves from being related to the identity of a Scouser, despite acknowledging that are linguistically similar.

\section{4 (In)authenticity and covert prestige}

Another significant reason why Wirral speakers behave in this way is due to connotations of inauthenticity associated with non-Liverpudlians using Scouse features:

(16) I feel like people say it's plazzy Scouse

(17) Even though we're not trying to be Scouse people make out like you're trying to be someone that you're not and trying to (.) speak (.) you know like you're copying someone

Plazzy is defined in The Liverpool English Dictionary as "plastic; false, imitation, second-rate" (Crowley 2017: 181). These comments reinforce why the Wirral speakers were so reluctant to socially identify as Scousers. Issues of inauthenticity are 
echoed by the Liverpool students, who suggested that if a speaker from outside of Liverpool used Scouse dialect, this would mean that the person would be defined as a "wool", a similar term to "plastic Scouser". Wool is defined by Crowley as "someone who lives outside Liverpool i.e. St. Helens, Skelmersdale, Prescot, ${ }^{3}$ the Wirral, etc. and therefore not strictly a true Scouser" (2017: 247). In Liverpool, one student described a "wool" as:

(18) Someone who tries to be Scouse but like the Wirral I don't think you [the researcher] sound very Scouse so I wouldn't really class you as a wool. But someone from Runcorn or Skelmersdale comes over sounding really Scouse like no. You're not

This response echoes those of the Wirral students, in that it is partly the intention of the speaker that determines whether they will be considered to be a false Scouser or not; that is, if somebody "tries to be" Scouse, this will be viewed more negatively than a speaker just sounding Scouse in their language. I believe that this is due to the perceived difference between sharing linguistic forms compared to a speaker trying to replicate a "Scouse" identity, and therefore social practices associated with Scouse. As the data shows, the conditions that a speaker must adhere to in order to be considered to be a "Scouser" are, according to these Liverpool adolescents, very strict; as such, somebody trying to replicate a Liverpool identity without fitting into these categories can lead to them quickly being defined as inauthentic. Although the Merseyside students have shown awareness of the negative social stereotypes indexed by Scouse, it seems that there is simultaneously an in-group status that Liverpool speakers achieve by both using Scouse language and fulfilling the relevant social categories. Identifying as a Scouser is covertly prestigious for these Liverpool speakers, and "outsiders" who attempt to imitate a Scouse identity through either using "very Scouse" language or "trying to be" Scouse are derided. These findings reflect the results of Cooper (2019: 76), where some informants perceived the use of local (Sheffield) dialect features as symbolising an authentic local identity, whilst speakers from nearby Barnsley were identified as "outsiders". Moreover, "the main defining factor between these two identities is the perception that Sheffield and Barnsley have different accents to each other, which in turn indexes that Barnsley is distinct from Sheffield" (ibid). Something comparable is happening in Merseyside, with Wirral speakers engaging in a similar level of NURSE fronting to Liverpudlians,

3. St. Helens is 14.8 miles from Liverpool City Centre, Skelmersdale is approximately 16 miles away, and Prescot is just under 9 miles away. The average annual household income in these areas is $£ 21,800$, $£ 20,700$, and $£ 19,900$ respectively. Liverpool Pier Head average household income is $£ 22,900$. Data from the Office for National Statistics (ONS 2020). 
whilst students from both areas perceive themselves to use "Scouse" very differently from each other. The Liverpool informants perceive the use of Scouse to symbolise authenticity and group solidarity, viewing the utilisation of these features by "outsiders" negatively.

\subsection{Style-shifting and perceptions of class}

In the Wirral school, perceptions of when using Scouse dialect was appropriate varied, primarily depending on the relationships that the students held with their interlocutors:

(19) I'm dead posh in school but like at home with my Mum 'cause my Mum's from Liverpool I go quite Scouse

(20) My family are. Well they're not Scouse they're not posh they're like normal. They like try and be posh [laughs] so they sound like dead posh to me compared to like some people in school so it's like a different environment I think like my voice goes lower and more scouse I think in school whereas at home I think it's like a bit different

(21) I feel like though if I said some things to my parents that I said to my friends they wouldn't like actually know what that word means they'd be like what does that mean... I just talk different to my friends when I talk. With the same accent but I think I change the words sometimes... for example you wouldn't say to your parents he was bevvied... but you'd say he was drunk. But you'd say to your friends probably he was bevvied

For Wirral adolescents, their use of style-shifting does not only depend upon their own perceptions of Scouse, but the way that they believe they might be perceived by others by using it. For example, the student in comment 20 considers their family to be "posh", and reports speaking "more Scouse" in school rather than at home. Meanwhile the student in comment 19, whose parents are or were local to Liverpool, felt more comfortable using Scouse at home than in school. The results support Johnstone's investigation of Pittsburghese (2013), where in the current study, Scouse is enregistered to mean a "not posh", or working-class identity. In some cases, such as comment 21, the students evoke the informal, not "posh" connotations enregistered by Scouse in order to build up covert prestige amongst friends. For them, Scouse is a repertoire that they draw upon to build relationships with others. The working-class identities indexed by the use of Scouse are emphasised by the Liverpool students: 
(22) With a lot of regional accents like it tends to be like potentially like more working class erm. I don't mean just for Scouse I mean like with a lot of regional accents sort of like it tends to be thicker like and I think I think like Childwall and like you know it's not necessarily it's quite like a it's not posh but it's like a very middle class area so I think it's like probably less strong here I would say maybe like Kensington or Toxteth

Childwall especially doesn't have a strong Scouse accent

It appears that the Liverpool students are positive about Scouse because they perceive their form of Scouse to be more middle-class, and therefore more prestigious. In particular, they differentiate themselves from less affluent areas such as Kensington or Toxteth, where a "stronger" Scouse accent indexes a working-class status. To some extent, the Liverpool students show a similar understanding of Scouse dialect as the Wirral speakers; that is, that stronger Scouse accents mean "more working class" and "not posh" respectively. The difference is that the Liverpool speakers are confident in their identity as Scousers, even more so because they perceive themselves to be "middle class" Liverpudlians who are "less Scouse" than those in other areas of Liverpool. The Wirral adolescents are also aware of their middle-class status, and therefore report to only draw upon Scouse in situations where they feel it is covertly prestigious, or they are trying to be informal. However, we know from the quantitative data that the Wirral speakers are engaging with Scouse even in careful speech contexts, although not to the same degree as the Liverpool students. This suggests that to some extent, Liverpool English is diffusing to middle class areas of the Wirral, supporting Beal (2010) and Newbrook (1999). Despite this, and even though the Liverpool students are proud of their Scouse identity, they are simultaneously conscious of the negative social qualities indexed by it:

(24) I went for my job interview when like I just before I started work obviously and I honestly like made my accent a lot less Scouse when I went for it but now that I'm more comfortable... I'll speak a lot more Scouse when I'm in work. Like I'll just speak the way I normally would but I did like tone it down a lot when I first started but I work in Birkenhead so it's not in Liverpool so that might be a reason for it

Like the Wirral students, the Liverpool speakers also style-shift Scouse, avoiding drawing upon a Scouse repertoire in more formal situations where they wish to present themselves positively. The motivations for style-shifting of Scouse shown here by Liverpool and Wirral students emphasise Coupland's assertion that dialect varieties are "particularly well configured for stylized performance because they do generally constitute known repertoires with known socio-cultural and personal associations - such as high/low socio-economic status" (2001: 350). 


\subsection{Impact of attitudes upon SQUARE and NURSE production}

The Wirral students were highly cognisant of defining themselves in relation to Liverpool and Scouse, with a Wirral dialect or identity being secondary to this. Meanwhile, the Liverpool students were assured of their Scouse identities, and their only comments in relation to Wirral speakers (and people from other peripheral Merseyside regions) were that they viewed them as inauthentic outsiders. Such negotiations of identity are not surprising, with Wirral speakers being on the periphery of Liverpool geographically, linguistically and socially. In an investigation of tag question usage by girls at Midlan High School, Moore (2010: 132) noted that one of her participant's "marginal participation in the Townie CofP [community of practice] made her more aware of identity issues than her Popular peers, whose distance from the new CofP made it impinge less dramatically upon their sense of self". Whilst the current research is talking more widely, with the students in different regions of Merseyside rather than the same school, the Wirral adolescents do appear to be drawing upon similar ideologies. That is, as Wirral speakers interact with Liverpool due to living so close by, they are hyper-aware of their identity being directly in relation to Liverpool, rather than relating to a salient "Wirral" identity. The quantitative data shows that Wirral speakers are phonologically orienting themselves towards Liverpool English through NURSE fronting, which is a socially salient feature that indexes being "Scouse". This is particularly significant in relation to Juskan (2018), whose middle-class informants had lower F2 values than their working class counterparts. Here, middle class Wirral adolescents produce F2 NURSE on a level comparable with Liverpool speakers, highlighting a linguistic and social shift towards aspects of Scouse. These findings support Newbrook's assertion (1999) that assimilation towards Liverpool English would continue on the Wirral. Additionally, the female adolescents engaging with NURSE fronting here reflect West's Merseyside data (2015), where younger females are leading the convergence towards Liverpool English. However, unlike the Liverpool speakers, the Wirral students maintain a distinction between SQUARE and NURSE, and do not go so far as to fully merge them. This indicates that Wirral adolescents are specifically using NURSE fronting as a part of a covertly prestigious repertoire, primarily when amongst school friends or in situations that they perceive to be informal. Meanwhile, the Liverpool informants are comfortable in their Scouse identity, which is reflected in the way in which they engage with both fronting and merging of the SQUARE NURSE lexical sets. For them Scouse brings about a sense of pride due to indexing in-group status. Even so, students from both schools showed that they were grappling with social issues related to Scouse, style-shifting away from it in contexts where they feel they might be judged negatively for using it. 


\section{Conclusions}

This data shows that NURSE fronting remains salient both linguistically and perceptually in the minds of both Liverpool and Wirral speakers. In particular, Wirral students' use of NURSE fronting is above their level of consciousness, which is especially highlighted when taking the careful speech context into account. The results demonstrate the complexities of the relationship between linguistic behaviour and the identities that the speakers present. Although Wirral speakers are aware of salient Scouse features, and use NURSE fronting in particular contexts, they are simultaneously mindful of their out-group status with regard to a Scouse identity. For them, Scouse is used as a linguistic resource that is drawn upon to symbolise covert prestige and informality, rather than to define themselves as "Scousers".

\section{References}

Agha, Asif. 2003. The social life of cultural value. Language and Communication 23. 231-273. https://doi.org/10.1016/S0271-5309(03)00012-o

Agha, Asif. 2007. Language and social relations. Cambridge: Cambridge University Press.

Beal, Joan. 2010. An introduction to regional Englishes: Dialect variation in England. Edinburgh: Edinburgh University Press.

Beal, Joan \& Paul Cooper. 2015. The enregisterment of Northern English. In Raymond Hickey (ed.), Researching Northern English. Amsterdam: John Benjamins Publishing Company. https://doi.org/10.1075/veaw.955.02bea

Boersma, Paul \& David Weenink. 2017. Praat: Doing phonetics by computer [Computer program]. Version 6.1.05. http://www.praat.org/. (16 October, 2019.)

Burbano-Elizando, Lourdes. 2010. Language variation and identity in Sunderland. University of Sheffield: $\mathrm{PhD}$ thesis.

Byrne, Rachel. 2018. Investigating the language attitudes and linguistic behaviour of adolescents in Merseyside towards Liverpool English. University of Liverpool: Master of Research thesis [Unpublished].

Cheshire, Jenny \& Viv Edwards. 1991. Schoolchildren as sociolinguistic researchers. Linguistics and Education 3. 225-249. https://doi.org/10.1016/0898-5898(91)90009-8

Cooper, Paul. 2019. The enregisterment of "Barnsley" dialect: Vowel fronting and being 'broad' in Yorkshire dialects. Language and Communication 64. 68-80.

https://doi.org/10.1016/j.langcom.2018.10.001

Coupland, Nikolas. 2001. Dialect stylization in radio talk. Language in Society 30(3). 345-375. https://doi.org/10.1017/So047404501003013

Coupland, Nikolas \& Hywel Bishop. 2007. Ideologised values for British accents. Journal of Sociolinguistics 11. 74-103. https://doi.org/10.1111/.j.1467-9841.2007.00311.x

Crowley, Tony. 2017. The Liverpool English dictionary: A record of the language of Liverpool 18502015. Liverpool: Liverpool University Press. https://doi.org/10.2307/j.ctt21pxj66 
Eckert, Penelope. 1989. The whole woman: Sex and gender differences in variation. Language Variation and Change 1(3). 245-267. https://doi.org/10.1017/S095439450000017X

Eckert, Penelope. 2012. Three waves of variation study: The emergence of meaning in the study of sociolinguistic variation. Annual Review of Anthropology 41(1). 87-100.

https://doi.org/10.1146/annurev-anthro-092611-145828

Grant, Anthony \& Clive Grey (eds.). 2007. The Mersey sound: Liverpool's language, people and places. Ormskirk: Open House Press.

Honeybone, Patrick. 2007. New-dialect formation in nineteenth century Liverpool: A brief history of Scouse. In Anthony Grant \& Clive Grey (eds.), The Mersey sound: Liverpool's language, people and places, 106-140. Liverpool: Open House Press.

Hughes, Arthur, Peter Trudgill \& Dominic Watt. 2012. English accents \& dialects: An introduction to social and regional varieties of English in the British Isles. London: Hodder Education.

Jansen, Sandra. 2013. 'I don't sound like a Geordie!' Phonological and morphosyntactic features of Carlisle English. In Nils-Lennart Johannesson, Gunnel Melchers \& Beyza Björkman (eds.), Of butterflies and birds, of dialects and genres: Essays in honour of Philip Shaw, 209-224. Stockholm: Acta Universitatis Stockholmiensis.

Johnstone, Barbara, Jennifer Andrus \& Andrew E. Danielson. 2006. Mobility, indexicality, and the enregisterment of Pittsburghese. Journal of English Linguistics 34(2). 77-104. https://doi.org/10.1177/0075424206290692

Johnstone, Barbara. 2013. Speaking Pittsburghese: The story of a dialect. New York: Oxford University Press. https://doi.org/10.1093/acprof:0so/9780199945689.001.0001

Juskan, Marten. 2018. Sound change, priming, salience: producing and perceiving variation in Liverpool English (Language Variation 3). Berlin: Language Science Press.

Kendall, Tyler \& Erik R. Thomas. 2007. NORM: The vowel normalization and plotting suite. http://lingtools.uoregon.edu/norm/about_norm1.php. (17 September, 2019.)

Llamas, Carmen. 2007. A place between places: Language and identities in a border town. Language in Society 36(4). 579-604. https://doi.org/10.1017/So047404507070455

Labov, William. 1972. Sociolinguistic Patterns. Oxford: Blackwell.

Labov, William, Ash, Sharon \& Boberg, Charles. 2006. The atlas of North American English: Phonetics, phonology and sound change. Berlin/Boston: Mouton De Gruyter.

Montgomery, Chris. 2012. Mapping the perceptions of non-linguistics in Northern England. In Sandra Hansen, Christian Schwarz, Philipp Stoeckle \& Tobias Streck (eds.), Dialectological and folk dialectological concepts of space: Current methods and perspectives in sociolinguistic research on dialect change, 164-179. Berlin \& Boston: De Gruyter.

https://doi.org/10.1515/9783110229127.164

Moore, Emma. 2010. Communities of practice and peripherality. In Carmen Llamas \& Dominic Watt (eds.), Language and Identities, 123-133. Edinburgh: Edinburgh University Press.

Newbrook, Mark. 1999. West Wirral: Norms, self-reports and usage. In Paul Foulkes \& Gerard Docherty (eds.), Urban voices: Accent studies in the British Isles, 90-106. New York: Arnold.

Office for National Statistics. 2020. Income estimates for small areas, England and Wales: financial year ending 2018. https://www.ons.gov.uk/peoplepopulationandcommunity/personalandhouseholdfinances/incomeandwealth/bulletins/smallareamodelbasedincomeestimates/ financialyearending2018. (5th June, 2020.)

Oxford English Dictionary Online. “chav, n.”. 2020. Oxford: Oxford University Press. https:// www.oed.com/view/Entry/264253?redirectedFrom=chav\&. (May 20, 2020.) 
RStudio Team. 2020. RStudio: Integrated development environment for R. RStudio, PBC., Boston, MA. http://www.rstudio.com/. (20 July, 2020.)

Schegloff, Emanuel A. 1997. Whose text? Whose context?. Discourse and Society 8 (2): 165-187. Silverstein, Michael. 2003. Indexical order and the dialectics of sociolinguistic life. Language and Communication 23. 193-229. https://doi.org/10.1016/So271-5309(03)00013-2

Swann, Joan. 2002. Yes, but is it gender?. In Lia Litosseliti \& Jane Sunderland (eds.), Gender identity and discourse analysis, 43-67. Amsterdam: John Benjamins Publishing Company. https://doi.org/10.1075/dapsac.2.03swa

Watson, Kevin. 2007. Is Scouse getting Scouser? Phonological change in contemporary Liverpool English. In Anthony Grant \& Clive Grey (eds), The Mersey sound: Liverpool's language, people and places, 215-241. Ormskirk: Open House Press.

Watson, Kevin \& Clark, Lynn. 2013. How salient is the NURSE SQUARE merger? English Language and Linguistics 17(2). 297-323. https://doi.org/10.1017/S136067431300004X

West, Helen. 2015. Language attitudes and divergence on the Merseyside/Lancashire border. In Raymond Hickey (ed.). Researching Northern English, 317-341. Amsterdam: John Benjamins Publishing Company. https://doi.org/10.1075/veaw.955.14wes 



\title{
CHAPTER 8
}

\section{Benim}

\section{A new pronoun in Swedish}

\author{
Nathan J. Young \\ Centre for Research on Bilingualism at Stockholm University
}

\begin{abstract}
A new first-person pronoun has emerged in the vernacular of Stockholm Swedish. A loan from Turkish, benim is indexically self-aggrandizing and a feature of the male genderlect of Stockholm's racialized proletariat. It is also typologically unusual by virtue of being a loanword in an abstract functional role, namely, a pronoun. I detail several factors that, in concert, allowed benim to enter into Swedish first as a naked prototype, then as a reanalysis of dissociative third-person constructions, and finally, as a productive first-person personal pronoun. I conclude further that the actuation of these factors was the unique social ecology of class and racial exclusion, which are generally known to drive symbolic status-moves among the subordinated.
\end{abstract}

Keywords: contact linguistics, constructionalization, grammaticalization, multiethnolects, pronouns, Rinkeby Swedish, Stockholm Swedish

\section{Introduction}

Benim, a loan from Turkish, has recently emerged as a first-person ego-honorific pronoun in Stockholm's multiethnolect, exemplified in (1)

(1) benim gjorde brott innan benim fick mustasch I did crimes before I got moustache 'I've been breaking the law before I even had a moustache'

(Z.e \& Jiggz 2018, time 2:36)

This chapter will offer an account of benim that includes its syntactic and socioindexical use. I will also offer a proposal about its evolutionary emergence into Stockholm Swedish, which is is of particular theoretical importance to contact sociolinguistics and construction grammar. As it pertains to contact linguistics, functional words are rarely borrowed in contact scenarios (Hock 2009: 381-385), 
and I argue that a unique concert of external and internal factors brought about the emergence of this unusual linguistic phenomenon. As it pertains to construction grammar, I draw on Traugott (2015) to argue that the emergence of benim as a productive pronoun depended on a chain of matched constructions, each of which was an incrementally divergent iteration of its cognitively-anchored predecessor.

\subsection{Stockholm: Europe’s first-documented multiethnolect}

Rinkeby Swedish is generally recognized as Europe's earliest-known and Scandinavia's first multiethnolect (Kotsinas 1988a). The linguistic situation in Stockholm is matched by a parallel linguistic development that is ongoing across Europe, referred to by Clyne (2000) as multiethnolects and by Rampton (2011) as contemporary urban vernaculars. Rampton (2011) describes these linguistic developments as Europe-specific late-modern phenomena with the following three properties: (1) they emerged in urban neighborhoods shaped by immigration and class stratification; (2) they are connected-but-distinct from migrant languages, the traditional working-class variety, and the standard variety; (3) they are widely known and represented in media and popular culture. Stockholm's multiethnolect matches his description quite closely - it first emerged in the working-class migrant housing projects of Rinkeby and Flemingsberg; it has features from both migrant languages and the indigenous working-class variety Ekensnack; it is widely represented in the media, the most prominent genre of which is hip hop. The data from this study come from a corpus of Swedish hip hop, which I will detail more closely in Section 3.

It is useful to conceptualize this linguistic development as a uniquely late-modern phenomenon. This is because, along with neoliberalization and the rise of social inequality, one of the signature features of late-modernity in Europe is the racialization of the social-class hierarchy (Hesse 2007; Lee 2010; Lentin 2008; Lentin \& Titley 2011). As the speech of the children of non-Western migrants continues to focus into coherent varieties, it is becoming more apparent that we are witnessing the emergence of racialized working-class sociolects. For example, Cornips and de Rooij (2013) have proposed that straattaal in Rotterdam has come to index anti- or "non-mainstream social categories and practices" in a binary hierarchy (Cornips \& de Rooij 2013: 138-139) that, in my view, closely resembles a racialization process. The binary hierarchy erases heritage ethnicities like Moroccan, Surinamese, and Antillean and encapsulates them all within a single category called allochthon (Greek: other land) that is subordinate to the Dutch autochthon population (Greek: same land). 
Likewise in Stockholm, the notion of "second-generation immigrants" ignores the relatively large Nordic and Western European diaspora in the city, the children of whom are also technically second-generation immigrants. This is one reason why Hübinette, Hörnfeldt, Farahani and Rosales (2012) have proposed taking a Critical Race Theoretical perspective to any contemporary discussion of immigrants or their descendants. They argue that immigrant (Swedish: invandrare) is actually just a racialized euphemism for what Mulinari and Neergaard (2004) have referred to as Sweden's racialized working class. This demographic subgroup has developed its own linguistic variety after more than 40 years of social exclusion and relegated suburban enclosure.

In this sense, the term multiethnolect inadequately addresses the racializing aspect of this process. Rather than being the variable "lect" of multiple ethnicities, it is the focused "lect" of a proletariat for whom ethnic differences have been erased. In other words, the blanket exclusion that non-white (phenotypically marked) ethnicities face from the majority white population has enacted an enclosure upon all types of otherwise heterogeneous ethnicities, which in turn has resulted in extensive cross-cultural contact and extensive linguistic focusing within that enclosure. Cheshire, Kerswill, Fox and Torgersen (2011: 157) take a similar position when they call Multicultural London English "ethnically neutral", proposing that the ethnic makeup of individual speakers has no bearing on which features they use; the defining factor is that they are not part of the white majority. ${ }^{1}$

It is not the first time that transformative demographic change - and the new stratifications born out of this change - has incubated new varieties. During their respective industrial revolutions, European cities witnessed the emergence of coherent working-class varieties such as London's Cockney and Birmingham's Brummie. Due to this explosive population growth, some linguists have proposed that the traditional working-class varieties of these cities emerged from a koinéization process whereby exogenous forms swamped the local variety (Honeybone 2007; Johnston 2015; Kerswill 2018). Kotsinas (1988b) has similarly proposed that Stockholm's industrial-era working-class variety Ekensnack (a.k.a. Lågstockholmska 'Low Stockholmian') developed in a similar fashion. She takes the position, in fact, that the evolution of Ekensnack and Stockholm's multiethnolect are part and parcel of the same process.

1. Note, however, that Wiese (2009: 784) might disagree with this claim. She has argued that speakers from the majority-German population are active participants in the development and spread of Kiezdeutsch. Most of the literature, however, depicts majority-group speakers as the exception (Auer 2003; Cheshire et al. 2011; Nortier \& Dorleijn 2008). 
In both cases is slang an important part of the variety, and in both cases words are borrowed from various substrate languages; in the case of Ekensnack from Romani, Månsing, ${ }^{2}$ and various dialects; in the case of Rinkeby Swedish from Romani, Turkish, Greek, etc., in other words the minority languages in Rinkeby.

(Kotsinas 1988b: 145, my translation)

Naturally, the same processes of racialization were not as strong during the Industrial Revolution, since the Romani population was only a subset of the Industrial proletariat, but the parallels are clear. This is especially the case if one considers racialization as an additive vehicle to social class for the exclusion and enclosure of a sub-population. In Section 8 of this paper, I show that benim and its contemporary use has a striking similarity to the first-person honorific pronoun mandrom - a loan from Swedish Romani - that was widely used in Low Stockholmian at the turn of the Twentieth Century. I argue that the enclosures rendered by class and racial subordination likely actuated the emergence of indexically-rich lexemes like benim.

\subsection{Slang and symbolic distinction}

As Kotsinas (1988b) illustrates above, the conceptualization of Rinkeby Swedish within the paradigm of Low Stockholmian is an epistemological strategy that allows us to focus less on group second-language acquisition and more on the mechanics of hegemony and marginalization. Through this lens, I see the appropriation of foreign lexical matter as a symbolic means of distinction and even opposition - not unlike the mundane monolingual innovations that have engaged the variationist enterprise for so long in cities like Detroit (Eckert 2000), Martha’s Vineyard (Labov 1963), New York (Labov 1966), Philadelphia (Labov 2001), and so on.

Certainly, the dynamics of immigration are a key factor to the emergence of these features, but I would argue that their appropriation is accelerated - and perhaps even actualized - by the external forces of racialized subordination and class exclusion. Just as young Chilmark fisherman appropriated an existing feature in the speech community in reaction to the threat of mainland tourists (Labov 1963), young racialized working-class Stockholmers have appropriated pre-existing linguistic matter in reaction to the threat of race and class exclusion.

Cheshire (2013) offers a similar perspective in her explanation for the use and development of man - the recent first-person pronoun that has developed in London's multiethnolect. In addition to the flexibility afforded the pronoun by means of group second-language acquisition (man originates from Jamaican

2. Månsing was the language spoken by the knallers - nomadic merchants from Westrogothia who roamed Central and Southern Sweden between the 16th and 19th Centuries (Bergman 1931). 
creole), the unique ecology of London street life renders the need for a pronoun that indexes in-group membership (2013:621) and high-involvement narratives about conflict (2013: 622).

Whether the feature is "originally foreign" or not is less important than the fact that external threats actuate a socio-symbolic gap that must be satiated by oppositional practice, and the material for such practice must be readily available in the feature pool. The loanword benim is emblematic of this because, while Turkish, it has never been mentioned in the otherwise rich literature on slang during the height of Turkish migration in Sweden in the 1980s (Kotsinas 1988a, 1994, 2001). Therefore, its emergence cannot be understood as part of some sort of mechanical contact-driven process. Its first mention is in a slang dictionary from 2004 (Kotsinas \& Doggelito 2004) - well within the late-modern era and long after Turks had been outnumbered by other migrant groups - and its first discussion in the academic literature was in 2018 (Young 2018).

\section{Research aims}

I wish to address five research aims: (1) In Section 4, I will account for the syntactic use of benim; (2) In Section 5, I will describe its socio-pragmatic meaning; (3) In Section 6, I will construct a social profile of its users; and (4) in Section 7, I will offer a hypothesis rooted in grammatical constructionalization (Goldberg 2006; Traugott 2015) on how the pronoun emerged into vernacular Swedish. A fifth and final aim of this article, presented in Section 8, is to shed light on the actuation problem (Labov 2001: 466) of benim by contextualizing it within the history of Lågstockholmska and mandrom, the first-person honorific pronoun used in that variety 100 years earlier.

\section{Data: A corpus of Stockholmian hip hop}

Data come from a corpus of 923 Swedish hip hop songs that were released between 2012 and 2019. The songs are authored by 93 artists who hail from Greater Stockholm. ${ }^{3}$

Although the entirety of the data for this analysis comes from Stockholmian hip hop, this paper is not about the genre of hip hop, per se. Rather, hip hop is the domain within which I access the more flamboyant styles of Stockholm's

3. NB that I include Västerås and Uppsala as part of the extended metropolitan area of Stockholm. 
contemporary vernacular. Therefore, the premise of this article is that the material is representative of the city's current vernacular speech. Much like the case in neighboring Denmark (Stæhr \& Madsen 2017), Germany (Androutsopoulous 2000, 2009), and Norway (Cutler \& Røyneland 2015; Opsahl \& Røyneland 2016), the link between Swedish hip hop and Stockholm's multiethnolect (locally known as Suburban Swedish) is well-established. The first dictionary of "suburban slang", for example, was co-authored by Dogge Doggelito, a member of the hip hop group Latin Kings (Kotsinas \& Doggelito 2004). Two members of Latin Kings later established Red Line Records, to which a number of the rappers analyzed here are (or have been) signed. These include Dani M, Gee Dixon, Jacco, Labyrint, Linda Pira, and STOR.

Behschnitt (2013: 194) has described Stockholmian hip hop "as a collective symbol of suburban youth culture and as mediator of multi-ethnic youth language to a broader public". Smalley (2015: 267), in her dissertation on contemporary urban vernacular (CUV) in Stockholmian hip hop, found that "rappers play a key role in the representation of CUVs to a wider audience, codifying and thereby recording the sounds and words that make up these varieties". Further, Jonsson, Franzén and Milani (2020: 6-9) investigated how Stockholmian rapper Fille (also analyzed in the present corpus) is presented as an "exemplary" speaker of Rinkeby Swedish when he establishes a "slang school" in the Swedish reality television program So much better. The placement of his linguistic authority within a humorous event constitutes one of several "facets of the characterological persona that this contemporary urban vernacular brings into being” (Jonsson, Franzén \& Milani 2020: 2).

The corpus contains 402,800 words. Of its 93 artists, 25 (27\%) are women and $68(73 \%)$ are men. While I do not have access to the ages of all the artists, the artist I estimate as the oldest, Abidaz, was 39 during his last record release. The artist I estimate to be the youngest, Jireel, was 15 during his earliest record release. Benim occurs 512 times in the corpus. An overview of the data analyzed is provided in Table 1.

Table 1. Overview of the data material

\begin{tabular}{lrr}
\hline & All \\
\hline Artists & 93 & \\
Words & 402,800 & \\
Total number of first-person pronouns & 18,006 & \\
benim & 512 & $(2.8 \%)$ \\
\hline
\end{tabular}




\section{Syntactic use of benim}

Table 2 shows the distribution of the grammatical role of benim in the corpus. Benim appears more often as a grammatical subject, which, importantly, is NOT a reflection of the higher frequency of subject forms in speech. The actual portion of subject forms of benim $(n=440)$ as a percentage of all 13,999 subject forms is $3.1 \%$, which is higher than the portion of oblique forms of benim $(n=62)$ as a percentage of all 3,980 oblique forms (1.6\%). This, in turn, is higher than the portion of possessive benims $(n=10)$ as a percentage of all 4,609 possessive forms $(0.2 \%)$. A full breakdown of the distribution of syntactic usage is provided in Table 2.

Table 2. Grammatical role of benim

\begin{tabular}{lccc}
\hline & Standard + benim & benim & Percentage \\
\hline subject (benim) & 13,999 & 440 & $3.1 \%$ \\
object (benim) & 3,980 & 62 & $1.6 \%$ \\
possessive (benims) & 4,609 & 10 & $0.2 \%$ \\
\hline
\end{tabular}

An example of the typical subject pronoun was provided above in (1). Examples of object/oblique and possessive forms are provided in (2) and (3), respectively.

(2) $d u$ har benim $i$ din mun You have me in your mouth

'You gossip about me all the time'

(Yasin Byn 2015, time 1:13)

(3) benims nia, den e ej latch

My niner it is not nice

'My niner is not nice'

(Joel Fungz, Ibbe, Chris o Fada, Michel Dida \& Ille FreeWay 2018, time 1:03)

Curiously, the subject form of benim occurs in two types of constructions. The first construction $(n=378)$ consists of benim as the simple standalone first-person pronoun exemplified in (1). The second construction $(n=62)$ consists of benim as a left-dislocated topic followed by the third-person pronoun han 'he', ${ }^{4}$ exemplified in $(4 a, b)$.

(4) a. benim han e honcho

I he is honcho

'I'm the head honcho'

(Pyramids, Jireel, Pato Pooh \& Lamix 2017, time 1:36)

4. There is only one example of benim hon 'benim she' in the corpus (Showit 2018). 

b. benim han e boss; jag ska dö som en man I he is boss I will die like a man 'I'm the boss; I will die like a man'

(Jireel 2016, time 1:27)

As can be seen in $(4 \mathrm{a}, \mathrm{b})$, the third-person personal pronoun refers to the speaker. I refer to this as the "benim han construction". Such use of what Horn (2008) refers to as "the dissociative third person" is a rhetorical strategy that literary scholars have entitled illeisms (Horn 2008: 175). Illeisms are more often than not associated with male athletes and politicians who wish to signal bravado (Zwicky 2007). A famous example comes from the American basketballer LeBron James who, when asked in 2010 about his decision to join the Miami Heat, replied "I wanted to do, um, what was best, um you know, for LeBron James and what LeBron James is gonna do to make him happy." When US President Trump was asked about Russian interference in the presidential election, he responded "Nobody's been tougher on Russia than Donald Trump".

Such illeist uses of proper names and third-person pronouns occur in the present corpus as well, illustrated in (5) where the rapper Z.e left-dislocates his own name and inserts the third-person pronoun han 'he' as the grammatical subject. This construction offers an important clue for how benim found its way from Turkish into the Swedish grammar. It constitutes a core component of my hypothesis on the evolution of benim in Section 7.

(5) Ainajag, och Z.e han rattar den

Police chase, and Z.e he(I) steer it

'Police chase, and Z.e(I) is(am) driving'

(Z.e 2016, time 2:10)

\section{Socio-indexical pragmatics of benim}

Benim has a self-aggrandizing indexicality. In other words, it elevates the speaker, which can result in the deprecation of the interlocutor. Hip hop is by its very nature self-aggrandizing and other-deprecatory. Therefore, it is easy to fall into the false-positive trap of qualitatively assessing benim as self-aggrandizing based on its pragmatic occurrence alone. To avoid this trap, I tested whether benim actually occurred more often in self-aggrandizing phrases than the standard form jag 'I'. I coded the 440 subject exemplars of benim for self-aggrandizement, and I coded a randomized sample of 1,000 standard subject exemplars of jag.

Sentences that I evaluate as self-aggrandizing include those with simple predicates like "benim är kung" 'I am king' or more complex boasts like "varför rulla fattig, jag gör para om jag kan” 'why roll poor, I make money when I can'. In the 
latter construction, for example, "I make money when I can" is made into a boast by its antecedent "why roll poor".

Table 3 shows the raw count and percentage of the 440 benim-subject exemplars that were coded as self-aggrandizing in comparison to the random sample of 1,000 jag-subject exemplars that were coded as self-aggrandizing. Of the 440 benim-subject exemplars, 288 (66\%) occur in self-aggrandizing semantic conditions. The remainder occur in other types of semantic conditions. Of the 1,000 jag exemplars, 242 (24\%) occur in self-aggrandizing semantic conditions. This leads me to conclude that benim carries socio-indexical connotations of self-aggrandizement.

Table 3. The distribution of subject-form 'benim' and standard 'jag' in self-aggrandizing phrases

\begin{tabular}{lcccc}
\hline & \multicolumn{2}{c}{$\boldsymbol{b e n i m}(n=440)$} & \multicolumn{2}{c}{ jag $(n=1,000)$} \\
\hline self-aggrandizing lines & 288 & $66 \%$ & 242 & $24 \%$ \\
other lines (e.g., sentimental) & 151 & $34 \%$ & 758 & $76 \%$ \\
\hline
\end{tabular}

Where jag seems to occur more often is in complications to the narrative and in moments of sentiment. Examples of complications are "minns tiden jag var solo" 'I remember the time I was solo' and "det krävdes att jag tog en överdos" 'it took me having to overdose'. Examples of sentiment are "jag tänker på min mamma, pappa, syster och min bror" 'I think about my mother, father, sister and brother' and "I die for you" 'jag dör för dig'.

To summarize, I interpret the distribution in Table 3 to mean that benim further aggrandizes the speaker beyond the already-aggrandizing trappings of hip-hop subjectivity. This is why I refer to benim as "ego-honorific".

\section{Social profile of benim users}

\subsection{Ethnic and national heritage}

While I do not have information on all of the rappers' ethnic background (or national origin), I do have it for 35 of them. The information becomes sporadically available in interviews or, occasionally, in the lyrics of their songs. Where the ethnic information was available, I coded for ethnicity (e.g., Wolof). Where only national origin was available, I coded for this instead (e.g., Gambian). Of the 35 rappers for which I have heritage information, 20 of them use benim in their lyrics, totaling 268 of the 512 total benim exemplars. Their names, ethnicities, and number of benim usages are provided in Table 4 . 
Although the data in Table 4 constitute a mere sub-sample of the larger analysis, it becomes clear, nonetheless, that "rights" to benim have ethnically leveled. We do not see the sort of Black/Asian divide like we witnessed in the UK in the 1990s (Rampton 1995). None of the rappers here are Turkish; rather, a wide range of ethnic and national heritages are represented. This provides evidence and support for using the term multiethnolect in the Swedish context, given that a Turkish loan is so readily used by speakers who lack any shared ethnic affiliation. While this may intuitively not be very surprising, rarely has the literature on European multiethnolects actually tracked the use of specific heritage-language lexical matter according to the heritage nationalities or linguistic background of the speakers.

Table 4. Ethnic/national heritage of the rappers that use benim

\begin{tabular}{llc}
\hline Rapper & Ethnic/national heritage & Usages of benim \\
\hline 1.Cuz & Somali & 1 \\
Abidaz & Eritrean & 7 \\
Aki & African American/Finnish & 2 \\
Antwan & Assyrian & 9 \\
Dani M & Venezuelan/Finnish & 10 \\
Denz & Eritrean & 28 \\
Dree Low & Somali & 26 \\
Erik Lundin & Swedish/Gambian & 6 \\
Gee Dixon & Gambian & 14 \\
Ibbe & Sierra Leonean & 4 \\
Ille Freeway & Somali & 7 \\
Ivory & Ivorian & 5 \\
Jireel & Angolan & 17 \\
Lamix & Gambian & 28 \\
Linda Pira & Swedish/Colombian & 1 \\
Pato Pooh & Chilean & 19 \\
Patryk & Romani & 9 \\
Showit & Eritrean & 2 \\
Yasin Byn & Somali & 17 \\
Z.e & Polish & 56 \\
& Total & 268 \\
\hline
\end{tabular}




\subsection{Social class}

Anecdotally, Swedish hip hop is known to originate from working-class multiethnic neighborhoods. Since I have not conducted interviews with any rapper, ${ }^{5}$ I do not have specific social-class metrics for them. I do, however, have information on the home neighborhoods for 34 of the rappers, 20 of whom produce benim in their lyrics, totaling 248 of the 512 total benim exemplars. I harvested the regional data on median monthly income and the percentage of unemployed residents for their respective neighborhoods from the most recent statistical data available from municipal reports, dating between 2016 and 2018. The rappers' names, neighborhood, neighborhood median monthly income, neighborhood unemployment, and number of benim usages are catalogued in Table 5.

Table 5. Neighborhood and socioeconomic profile of the rappers that use benim. Neighborhoods where the monthly median income is less than and unemployment is higher than the city average are marked with an asterisk

\begin{tabular}{|c|c|c|c|c|c|}
\hline & Rapper & Neighborhood & $\begin{array}{c}\text { Neighborhood } \\
\text { monthly income } €\end{array}$ & $\begin{array}{c}\text { Neighborhood } \\
\text { unemployed residents \% }\end{array}$ & $\begin{array}{l}\text { Usages } \\
\text { of benim }\end{array}$ \\
\hline * & 1.cuz & Hässelby & 1,895 & 6.1 & 1 \\
\hline * & Abidaz & Hagalund & 2,156 & $\mathrm{n} / \mathrm{a}$ & 7 \\
\hline * & Adel & Akalla & 1,961 & 5.2 & 1 \\
\hline * & Aki & Gottsunda & 1,745 & 6.5 & 2 \\
\hline & Alex Ceesay & Stocksund & 4,203 & $\mathrm{n} / \mathrm{a}$ & 31 \\
\hline * & Ambessa & Fittja & 1,588 & 7.0 & 1 \\
\hline * & Antwan & Råby & 1,610 & 7.0 & 9 \\
\hline * & BLB & Husby & 1,683 & 7.1 & 2 \\
\hline * & Dani M & Stenhagen & 2,117 & 3.8 & 10 \\
\hline * & $\operatorname{Den} z$ & Rissne & 2,052 & $\mathrm{n} / \mathrm{a}$ & 28 \\
\hline * & Dree Low & Husby & 1,683 & 7.1 & 26 \\
\hline & Erik Lundin & Bromsten & 2,586 & 3.9 & 6 \\
\hline * & Ibbe & Rågsved & 1,859 & 6.0 & 4 \\
\hline * & Ivory & Vällingby & 2,279 & 4.2 & 5 \\
\hline * & Jireel & Rågsved & 1,859 & 6.0 & 17 \\
\hline & Macky & Dalen & 2,812 & 2.0 & 11 \\
\hline * & Pato Pooh & Rinkeby & 1,458 & 8.8 & 19 \\
\hline * & Rami & Storvreten & 1,815 & 7.2 & 1 \\
\hline * & Sinan & Tureberg & 1,470 & $\mathrm{n} / \mathrm{a}$ & 11 \\
\hline * & Z.e & Tensta & 1,581 & 8.2 & 56 \\
\hline \multirow{2}{*}{\multicolumn{3}{|c|}{ Stockholm average }} & 2,520 & 2.9 & \\
\hline & & & & Total usages: & 248 \\
\hline
\end{tabular}

5. Rapper Pato Pooh was kind enough to review this article for content and accuracy via email, but he has not participated in any interview with me. 
Seventeen of the 20 rappers hail from neighborhoods that have a median monthly income below the city average of $€ 2520$, and 18 of the rappers hail from neighborhoods that have an unemployment rate above the city average of $2.9 \%$. Eleven of the rappers hail from neighborhoods that are widely known as particularly marginal: Akalla, Fittja, Gottsunda, Husby, Råby, Rågsved, Rinkeby, and Tensta. This is also reflected in the income data; these are all neighborhoods with median incomes below $€ 2000$ per month. ${ }^{6}$

What this analysis shows is the connection between the hip-hop corpus, the actual neighborhoods where Swedish multiethnolect is known to be the prevailing variety, and the status of these neighborhoods as socioeconomically peripheral.

It is also worth pointing out that the two highest users of benim stand out from the remaining group in an important way. Alex Ceesay from Stocksund has 31 uses, and Z.e from Tensta has 56 uses. Alex Ceesay stands out because he is from a traditionally affluent neighborhood, and Z.e stands out because he is the "whitest" of all the rappers in the corpus. While certainly a tricky term, "white" is defined here as the Swedish ideal described by Hübinette et al. (2012: 60). We cannot ignore the possibility that Ceesay's home neighborhood and Z.e's complexion might have roused challenges to their legitimacy at different points throughout their lives. One can imagine that experiencing such challenges might drive either rapper to use more slang overall or, specifically, to co-opt benim's other-deprecatory power to dissuade any such unwelcome challenges. Crucially, I am not myself proposing that they lack legitimacy; rather, I am proposing that reductive understandings of race and class in Stockholm can result in the erasure of Ceesay's and Z.e's very real lived experiences. One potential tool to fight that erasure can be the use of symbolic resources like benim.

\subsection{Gender}

The corpus contains 402,800 words and 93 artists, of whom 25 (27\%) are women and 68 (73\%) are men. The word count, however, is not similarly distributed. Female rappers contribute 67,582 (17\%) words, and male rappers contribute 335,218 (83\%) words. The gender distribution of benim, however, is quite different. Women are heavily underrepresented, contributing only 10 exemplars (2\%) of the 512 total exemplars of benim. This is broken down in Table 6.

6. Some readers may find these numbers insufficiently "marginal". It is important to note that Sweden ranks 8 on the OECD human development index and has no ghettos according to Wacquant's (2004) contemporary definition of the term. 
Table 6. Distribution of benim by gender; the distribution of words and total first-person pronouns (benim, benims, jag, mig, min, mitt, mina) by gender

\begin{tabular}{lrrrrr}
\hline & \multicolumn{2}{c}{ Men } & \multicolumn{2}{c}{ Women } & All \\
\hline Artists & 68 & $73 \%$ & 25 & $27 \%$ & 93 \\
Words & 335,218 & $83 \%$ & 67,582 & $17 \%$ & 402,800 \\
Total first-person & 14,352 & $80 \%$ & 3,654 & $20 \%$ & 18,006 \\
benim & 502 & $98 \%$ & 10 & $2 \%$ & 512 \\
\hline
\end{tabular}

What is key here is that female rappers do NOT produce significantly fewer self-aggrandizing lines than men. Table 7 shows that in the subsample of 1,000 lyrics with jag as the subject (instead of benim), $20 \%$ of the lines produced by women are self-aggrandizing and $25 \%$ of the lines produced by men are self-aggrandizing. It can therefore not be said that the absence of benim among women is due to the fact that their lyrics are less boastful. Rather, a more probably conclusion is that benim is part of Stockholm's male genderlect.

Table 7. Gender distribution of self-aggrandizing lines (i.e., phrases) in 1000 randomly-selected lines that have standard jag 'I' as the subject

\begin{tabular}{llllll}
\hline & \multicolumn{2}{c}{ Men } & & \multicolumn{2}{c}{ Women } \\
\cline { 2 - 3 } \cline { 5 - 6 } & \multicolumn{2}{c}{$j a g(n=823)$} & & & \multicolumn{2}{c}{ jag $(n=177)$} \\
\hline self-aggrandizing lines & 204 & $25 \%$ & & 35 & $20 \%$ \\
other lines (e.g., sentimental) & 619 & $75 \%$ & & 142 & $80 \%$ \\
\hline
\end{tabular}

This is not to say that the findings on self-aggrandizement in Section 5 are unimportant to the findings here. Quite the contrary, I would argue that the self-aggrandizing indexicality of benim has enabled it to take on a masculine indexicality because boasting is accepted and even encouraged for men while being frowned upon for women. Eckert's (2008) exposé on the indexical field offers helpful insight as to how the indexicality of benim might evolve. Indexical meanings are highly underspecified and are linked by means of "ideological connections" (2008: 454). This is how the aspiration of / $\mathrm{t} /$ can take on a wide range of socio-indexical meanings from "nerd girl" to "gay diva" to "schoolteacher". Those three personas are linked to stances such as "articulate", "prissy", and "effortful", which themselves are also ideologically linked to one another (Eckert 2008: 469). In other words, someone seen as prissy is more likely to be perceived as articulate than as inarticulate and is more likely to be perceived as effortful than as sloppy. By means of these indexical chains do new indexical constructions emerge.

Returning to the data on benim, male and female rappers may be equally self-aggrandizing in their lyrical content, but the ideological connection between 
the construction of masculinity and boastful stances will be stronger due to pre-existing gender ideologies, ideologies of which may keep female speakers from using benim too extensively.

Miyazaki (2004) found similar gendered results in girls' and boys' use of ore, a Japanese other-deprecatory first-person pronoun that bears considerable resemblance to benim.

Girls' masculine pronoun use, for instance, was at times well received but at other times dismissed as crazy. A boy's feminine first-person pronoun use was ridiculed and sometimes severely punished. Girls and boys continually have to negotiate their speech and identity in a complex field of gender and power.

(Miyazaki 2004: 265)

While the distribution of ore production was gendered just like benim, stances of dominance and submission appeared also to be important because those stances are connected to the prevailing conceptualization of gender roles. Since the female use of benim is exceptionally rare and may at times be negatively sanctioned, the ten occurrences by female rappers may be received by listeners as especially boastful. Without a perceptual experiment, this is impossible to ascertain, but Miyazaki's and Eckert's work would imply so.

\section{The evolution of benim: A hypothesis}

It is so rare that a new pronoun emerges in a variety that we know very little about the process (cf. Cheshire 2013). In fact, functional words are not often borrowed into a recipient language; rather, content words dominate at a much higher rate (Field 2002; Haspelmath 2008; Haugen 1950; Hock 2009; Muysken 1981; van Hout \& Muysken 1994; Whitney 1881). According to Hock (2009: 381-385), in the rare event that the donor lexeme is functional, it is first typically stripped of its functional role and nominalized. An example of this is the borrowing of the AAVE verb to mack - which means to court or seduce - into Swedish. The Swedish loan is göra mack, which translates literally as 'do/make mack'. Mack here is stripped of its functional role, nominalized, and affixed to the "all-purpose verb" göra 'do/make'.

I hypothesize here that the Turkish pronoun benim was similarly stripped of its grammatical function, nominalized, and then affixed into the illeist construction benim han that I exemplified in $(4 \mathrm{a}, \mathrm{b})$. This construction was enabled by the Nordic tendency to routinely left-dislocate semantic subjects and produce a personal pronoun as the grammatical subject. The benim han construction then entered into the community grammar as an exemplar that later enabled benim to undergo reanalysis and become the free-standing productive first-person pronoun that it is today. In the following sections, I detail each step. 
Turks were one of the largest migrant groups in Rinkeby and Flemingsberg, the two original birthplaces of Rinkeby Swedish (Kotsinas 1988a: 266). Turkish is also the donor language of many of the most-commonly used slang words in Stockholm's multiethnolect (Young 2018).

A dictionary will simply define benim as the Turkish genitive form 'my' of the first-person pronoun ben, which means 'I'. Below is a sample declension of the pronoun in Turkish.

$\begin{array}{lll}\text { Turkish NOMINATIVE } & \text { ben } & \text { I } \\ \text { Turkish GENITIVE } & \text { benim } & \text { of me/my/mine } \\ \text { Turkish DATIVE } & \text { bana } & \text { to me } \\ \text { Turkish ACCusAtive } & \text { benime } & \text { me }\end{array}$

The actual usage, however, is more complicated than what a typical dictionary implies. First, Turkish is an agglutinative language, and the unmarked way to indicate first-person possession is with the morpheme $-m$. This means that the routine way to indicate that a car, araba in Turkish, belongs to me is to say arabam. It is only in instances of emphasis that benim would be added, rendering arabam benim. Second, benim is the form used in exclamatives. For example, if one's mother were to knock on the door and one was to ask "who is it?", her response would be "benim!", which translates pragmatically into English as "it's me!". If one were to play peekaboo with a Turkish baby, it is commonplace to exclaim "benim!" at the moment one's hands open to reveal one's face.

What all of these usages have in common is salience. It may not necessarily be the case that benim is frequent in Turkish, but when it does occur, it is in salient instances. Cheshire, Kerswill, Fox and Torgersen (2011) point out that while frequency is important for selection from the feature pool (Mufwene 2001), salience may also play a key role behind why certain features dominate over other potential donor features. This would explain why benim - not ben - prevailed.

\subsection{Left dislocation in the Nordic languages}

According to Johannessen (2014), left-dislocation of subjects is commonplace in the Nordic languages, exemplified in (6).

(6) Johan han e bra komisk ibland. Johan he is good comic sometimes 'Johan is very comic sometimes.' 
Whereas (6) would take a marked topicalized meaning in English or German, it is unmarked in Danish, Norwegian, and Swedish. In the corpus examined for this article, examples of left-dislocated subjects abound, such as in (7a, b) and (8). Example (3) also happens to contain one as well (...nia, den...).

(7) a. När vi är på klubben par dom blir ex

When we are on the club couples they become exes

'When we are at the club couples become exes.' (Adel 2018, time 1:10))

b. Dom hinner inte ikapp, nej; araban den ax

They catch not up no the car it speeds

'They can't catch up, no; the car is speeding.'

(Macky \& Thrife 2017, time 1:01)

(8) Ainajag, och Z.e han rattar den

Police chase, and Z.e he(I) steer it

'Police chase, and Z.e(I) is(am) driving'

(Z.e 2016, time 2:11)

\subsection{Benim as a left-dislocated noun in an illeist construction}

While (6) and (7a, b) are semantically similar, (8) is semantically mismatched because it is speaker-referential, enabled by means of the dissociative third-person illeist Z.e han 'Z.e he'. It is, however, matched in terms of construction, and if we examine the double subject construction within the theoretical lens of construction acquisition, then a clear evolutionary pathway is revealed. I propose here that the Johan han construction in (6) opened the pathway for the illeist Z.e han construction in (8), which, in turn, opened a pathway for the benim han construction in (9a, b).

(9) a. benim han e honcho

I he is honcho

'I'm the head honcho'

(Pyramids, Jireel, Pato Pooh, \& Lamix 2017, time 1:36)

b. benim han e boss; jag ska dö som en man

I he is boss I will die like a man

'I'm the boss; I will die like a man'

(Jireel 2016, time 1:27)

According to Goldberg (2006: 89), certain constructions dominate in the acquisition of grammar because they "involve a type of cognitive anchoring where a high-frequency type of example acts as an anchor, i.e. a salient standard of comparison". When new lexical material is introduced, a series of analyses will be conducted based on its form-meaning constellation. Benim is both disyllabic and speaker-referential, and the only other examples of disyllabic speaker-referential lexemes in Swedish are proper names (all pronouns are monosyllabic), and this is 
especially the case when a lexeme is phonotactically foreign like -nim. Since proper names often occur in double-subject constructions like Johan han or Z.e han, it is plausible that the entry of benim into the grammar would be facilitated by the anchoring role of such constructions. If we refer back to Hock's (2009) argument that functional loans are grammatically stripped and nominalized, then it is all the more plausible that benim would have entered as a naked prototype and more vulnerable to analogization. Furthermore, the lingering self-referential semantics of benim would serve to further cement the rhetorical function of the dissociative third-person construction.

\subsection{Grammatical constructionalization of 'benim han e' to 'benim'}

The benim han construction almost always occurs with a copula; specifically, in 58 out of its 62 occurrences. What this implies is that the benim han construction may have spread by means of the fixed-form exemplar benim han e 'benim he is'. Later, its wide circulation would have permitted successive speakers to reanalyze it and repurpose benim for the wider grammatical usage seen in (10), (11), and (12).

(10) benim gjorde brott innan benim fick mustasch I did crimes before I got moustache

'I've been breaking the law before I even had a moustache'

(Z.e \& Jiggz 2018, time 2:36)

(11) $d u$ har benim $i$ din mun

You have me in your mouth

'You gossip about me all the time'

(Yasin Byn 2015, time 1:13)

(12) benims nia, den e ej latch

My niner it is not nice

'My niner is not nice'

(Joel Fungz, Ibbe, Chris o Fada, Michel Dida \& Ille FreeWay 2018, time 1:03)

According to Traugott (2015), this process is referred to as grammatical constructionalization by which a form new -meaning new pairing is forged "through a sequence of small-step reanalyses of both form and meaning" (2015: 54). This implies that benim is not merely an innovation; rather, it is a type-change in "degree of schematicity, productivity, and compositionality" (2015: 55) that involves the following process:

Language-users loosely associate an implicature or "invited inference" from a construct with the semantics of an existing construction in the constructional network, preferring to use parts of the construct in a particular distributional niche, or repeating part of a construct as a chunk.

(Traugott 2015: 55) 
Therefore, it can be concluded that a complex interaction of socio-pragmatics (the dissociative third-person), de-grammaticalization (nominalized benim), and construction grammaticalization have facilitated an iterative chain of constructions that birthed a new personal pronoun. ${ }^{7}$

\subsection{Summarizing the proposed evolutionary trajectory of 'benim'}

The constructional network I propose is that stage 1, the left-dislocation construction of proper names like Johan han, facilitated stage 2, the illeist Z.e han, which facilitated stage 3 , the left-dislocation of the de-grammaticalized benim to benim han. Two elements that are of utmost importance to the latter stage are the fact that the surface form of benim increases the chance of proper-name matching in Swedish constructions (and the fact that speaker-referential meaning can be maintained through dissociative third-person illeisms). Stage 3 served then as an anchor point for a final reanalysis in stage 4 whereby benim became a free-standing productive pronoun, and this may have been facilitated by the fixed-form exemplar benim han e.

Figure 1 contains a flowchart of how, in more detail, benim might have entered from Turkish into Swedish and become a productive first-person ego-honorific pronoun in the contemporary vernacular. In the late 1970s and 1980s, as Turkish migrants began concentrating in Rinkeby and Flemingsberg, the word would occur in infrequent, albeit salient, moments. With time, second-language learners and young acquirers of Swedish would continue to use benim in an exclamatory way. This, combined with the imperfect acquisition of Turkish, would have facilitated the grammatical stripping of benim.

As I outlined earlier, illeisms are a common rhetorical strategy for speakers wishing to signal bravado. At the same time, an unmarked feature in spoken Swedish is the left-dislocation of the semantic subject and the insertion of a third-person personal pronoun to take on the role of grammatical subject. This would have provided the opportunity for younger speakers - speakers who are closer to or within the Critical Period of Language Acquisition - to reanalogize benim by inserting it into dissociative third-person left-dislocated subject phrases. The innovative construction could have begun with the simple copula construction benim han e benim he is'. This fixed form exemplar would have been readily available for duplication because, as an exemplar, it makes fewer cognitive demands.

7. It is important to point out that constructions as in $(9 \mathrm{a}, \mathrm{b})$ do not occur with the first-person pronoun jag ( ${ }^{\star}$ benim jag). Constructions like (8) do not occur with jag either ( ${ }^{\star} Z . e$ jag), and neither do constructions like "^benim jag". 


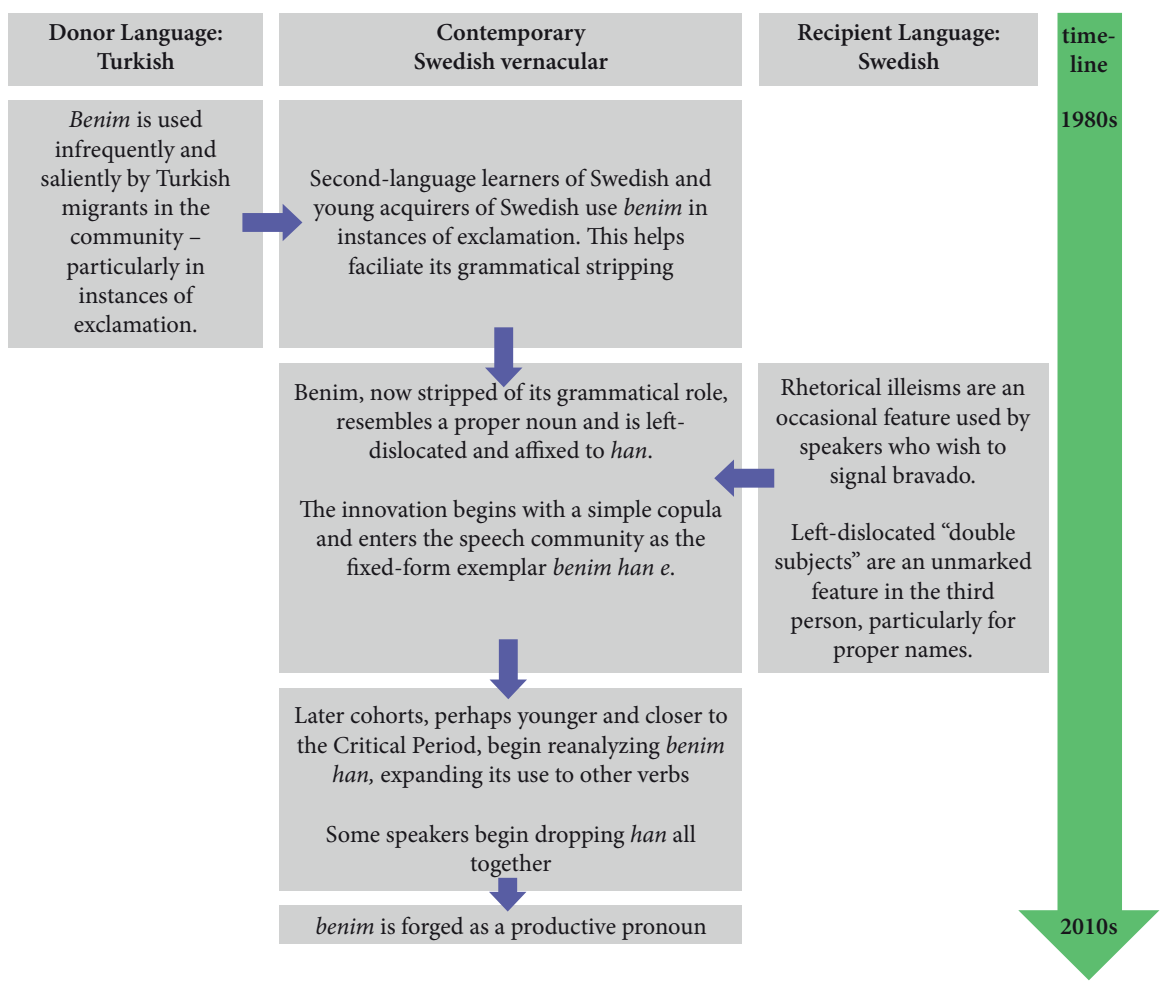

Figure 1. Proposed evolutionary history of benim in the Swedish vernacular

Later cohorts, at some point in the 2000s or 2010s - perhaps also younger and closer to or within the Critical Period of Language Acquisition - would have grammatically reconstructionalized this exemplar. This would have facilitated using benim han with more verbs than just the copula, and it would have facilitated the dropping of the dissociative han all together, rendering the productive pronoun benim.

\section{Benim in historical context}

Although I have offered a hypothesis on how benim came to be despite the labyrinthine constraints of Swedish grammar, the impetus for the change remains to be accounted for. Labov (2001) reminds us that investigations of linguistic variation throughout the world share a common theoretical puzzle: the Actuation Problem.

There remains, as always, the Actuation Problem. Why here and now? The beginnings of change are as mysterious as ever. Why not here and not now?

(Labov 2001: 466) 
As it pertains to Stockholm, one can imagine the popular narrative surrounding benim as a male genderlectal word. I recently heard "well it comes from the male chauvinistic tendencies of men from the Middle East!". Aside from the obvious fact that Turkey is not in the Middle East, the picture is of course more nuanced than that. Certainly, the language-contact ecologies within Stockholm's multiethnic suburbs have coalesced with a particularly flamboyant expression of masculinity to render particular lexical outputs. The ego-honorific benim accompanies a large lexical inventory for sex and women, stemming from Turkish, Arabic and Romani.

However, if we are to take a more critical eye to the actuation problem, we ought to look further back in history, for this is not the first time a first-person honorific has circulated in Swedish. During the Industrial Revolution when Lågstockholmska 'Low Stockholmian' was the infamous variety of Stockholm's criminal underworld and lower working class, the ego-honorific mandrom played a similar syntactic and socio-indexical role as benim does today. Examples of its use are provided in $(13 a, b)$.

$$
\begin{aligned}
& \text { a. Mandrom ha studera live jävlitt skarpt } \\
& \text { I have studied life damned sharply } \\
& \text { 'I have studied life pretty damn closely' } \\
& \text { b. De e mandroms tjejja! } \\
& \text { That is my girl } \\
& \text { 'That's my girl!' }
\end{aligned}
$$

Mandrom comes from the Swedish Romani first-person pronoun mande and its variants mander and mandro (Bergman 1931: 28; Lindell, Thorbjörnsson-Djerf \& Carling 2008: 36), the latter of which is a fossilization of the Common Romani first-person possessive mundro (Carling 2005: 91). The evolutionary journey of the pronoun from Common Romani (as described by Matras 2002: 100) to Swedish Romani to Low Stockholmian is illustrated in Table 8.

Table 8. The evolutionary journey of mandrom

\begin{tabular}{llll}
\hline & Common Romani & Swedish Romani & Low Stockholmian \\
\hline SUBJECT & me & mande/mander/mandro & mandrom \\
POSSESSIVE & mindro/mundro & mandros & mandroms \\
OBLIQUE & man-SUFFIX & mande/miro & mandrom \\
\hline
\end{tabular}

I draw mandrom into the discussion to explicitly draw parallels between the Industrial Revolution and our current era, late modernity. Both are epochs defined by rapid social change and intense social stratification. Aside from the relatively 
short "Golden Era" of Swedish social democracy (1930s-1980s; Therborn 1998), Sweden and its capital, Stockholm, have always been socially stratified. Liquor purchases were rationed according to social class until 1954 (Centre for Business History 2019), women gained the right to vote long before social-welfare recipients (1919 versus 1945), and the middle classes avoided public schools until after World War II (Sandin 2003: 60-61).

As industrialization began to partition the citizenry according to their relationship to production, Stockholm, itself situated within a dense archipelago, saw its social classes assemble on different islands. Figure 2 contains a map of the city in year 1841 . The brown shading indicates the developed parts of the city, blue shading indicates water, and green indicates farmland and forests. The central island is the historic medieval city Gamla Stan (previously known as Stadsholmen), and Södermalm to the south is where the new industrial working class was confined. The growing middle class spread to Norrmalm in the North. Since then, the city's population has grown to fill the full map, but the social classes today continue to be separated by water and forests. These symbolic and physical enclosures contributed to the emergence and maintenance of Lågstockholmska, its many inputs from Swedish Romani and Månsing (Lagerström 2004), the eventual development Ekensnack during the Industrial Revolution (Kotsinas 1988c; Thesleff 1912), and the development of Swedish multiethnolect during late modernity.

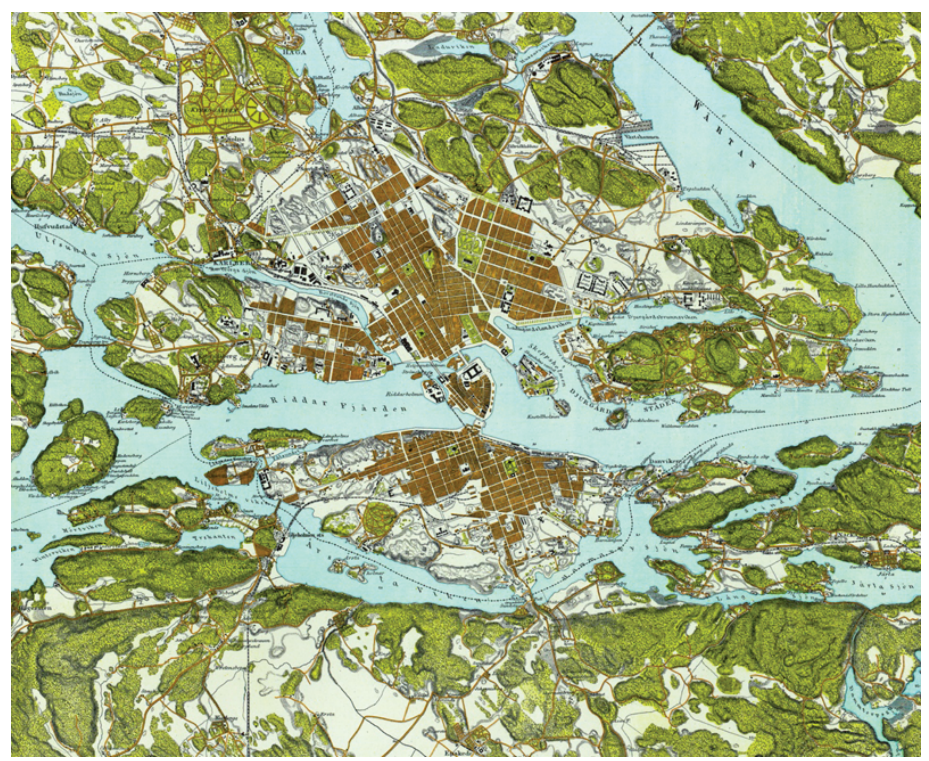

Figure 2. Stockholm in 1841 (Topografiska corpsen 1861) 
The tie between Stockholm's Industrial Revolution then and late modernity now is that both periods were marked by stratification and the rapid inflow of labor migrants. In the former era, migrants arrived from the surrounding provinces; in the latter, migrants arrived from non-Western countries. According to Labov (2001), the valorization of oppositional practices in marginalized communities whether minority or working-class or both - incubates linguistic innovation. This process is known as the Nonconformity Principle (Labov 2001: 516), and the coinage of mandrom and benim can be seen as examples of this.

But it is not just the opposition to norms that may have actuated these new slang terms; it may also be the need for symbolic currency when material currency is lacking. As structural factors like segregation, racism, and income inequality render the hegemonic order more salient to those who are not part of it, so too will there be pressure for the subordinated group to duplicate the hierarchy within itself. Irvine and Gal (2000) refer to this as fractal recursivity.

Fractal recursivity involves the projection of an opposition, salient at some level of relationship, onto some other level. [...] Thus the dichotomizing and partitioning process that was involved in some understood opposition (between groups or linguistic varieties, for example) recurs at other levels, creating either subcategories on each side of a contrast....

(Irvine \& Gal 2000: 403)

I believe that as Stockholm became more heavily hierarchical, twice in modern history, its subordinated groups were increasingly motivated to create their own internal hierarchies as a way of both duplicating the superstructure - as Irvine and Gal propose - and as a way to divide up the ever-shrinking availability of material resources. Such circumstances render an ecology ripe for indexicals like benim and mandrom that can be used in rhetorical strategy to assert the speaker and deprecate the interlocutor.

\section{Conclusion}

I have offered a descriptive account of benim and have sought clues in the data to explain how it emerged into the Swedish vernacular grammar. The word is a first-person ego-honorific pronoun that projects aggrandizement onto the speaker and is part of the male genderlect of Stockholm's racialized proletariat. Aside from its clear local relevance to the Swedish research community, benim is theoretically relevant to the field of contact sociolinguistics by virtue of being a loanword in a highly abstract functional role. It is also of relevance to students of grammatical constructionalization who might wish to examine such a process within an ecology characterized by social stratification and superdiversity. 
I have proposed here that this unique and special emergence of benim was made possible by the concert of four factors: (1) the initial salience of benim usages in Turkish; (2) the availability of dissociative third-person "illeisms" in vernacular performances of bravado; (3) the unique typological feature of left-dislocated "double subjects" in Swedish; and (4) the surface form of benim resembling a proper noun within Swedish phonotactics. I claim further that the contemporaneous actuation of these four factors has been emergent class and racial exclusion, which has urgently expanded the need for oppositional practice - a gap which benim has helped satiate. The pronoun's other-deprecatory function also enables the reproduction of hegemony within the community at a fractal level, operating as one of many symbolic resources.

\section{Acknowledgements}

I wish to thank Devyani Sharma, Erez Levon, David Adger, Jenny Cheshire and Olle Josephson for the helpful and generous feedback that led to this final analysis. I am also grateful for the four anonymous reviewers who dedicated so much time and effort to ensure that this work might meet the rigor of our discipline. Thanks also to Pato Pooh who graciously provided me with a much-needed insider perspective. I am of course responsible for all remaining shortcomings.

\section{References}

Auer, Peter. 2003. “Türkenslang”: Ein jugendsprachlicher Ethnolekt des Deutschen und seine Transformationen. In Annelies Häcki-Buhofer (ed.), Spracherwerb und Lebensalter. Kolloquium anlässlich des 60. Geburtstags von Harald Burger, 255-264. Tübingen: Francke.

Behschnitt, Wolfgang. 2013. The rhythm of hip hop: Multi-ethnic slang in Swedish literature after 2000. In Wolfgang Behschnitt, Sarah De Mul \& Liesbeth Minnaard (eds.), Literature, Language, and Multiculturalism in Scandinavia and the Low Countries (Textxet: Studies in Comparative Literature 71), 175-195. Leiden: Brill. https://doi.org/10.1163/9789401209854_0o9

Bergman, Gösta. 1931. Rotvälska: Rommani, månsing, förbrytarspråk och slang. Stockholm: Wahlström \& Widstrand.

Bergman, Gösta. 1964. Slang och hemliga språk. Stockholm: Prisma.

Carling, Gerd. 2005. Romani i svenskan: Storstadsslang och standardspråk. Stockholm: Carlssons Bokförlag.

Centre for Business History. 2019. Åren med den omstridda motboken [webpage]. http://www. systembolagethistoria.se/teman/ursprunget/aren-med-den-omstridda-motboken/

Cheshire, Jenny. 2013. Grammaticalisation in social context: The emergence of a new English pronoun. Journal of Sociolinguistics 17(5), 608-633. https://doi.org/10.1111/josl.12053

Cheshire, Jenny, Paul Kerswill, Sue Fox \& Eivind Torgersen. 2011. Contact, the feature pool and the speech community: The emergence of Multicultural London English. Journal of Sociolinguistics 15(2), 151-196. https://doi.org/10.1111/j.1467-9841.2011.00478.x 
Clyne, Michael. 2000. Lingua franca and ethnolects in Europe and beyond. Sociolinguistica 14. 83-89. https://doi.org/10.1515/9783110245196.83

Cornips, Leonie \& Vincent de Rooij. 2013. Selfing and othering through categories of race, place, and language among minority youths in Rotterdam, The Netherlands. In Ingrid Gogolin, Peter Siemund, Monika Edith Schulz \& Julia Davydova (eds.), Multilingualism and language diversity in urban areas (Acquisition, Identities, Space, Education 1), 129-164. Amsterdam: John Benjamins. https://doi.org/10.1075/hsld.1.o7cor

Cutler, Cecelia \& Unn Røyneland. 2015. Where the fuck am I from? Hip-hop youth and the (re) negotiation of language and identity in Norway and the US. In Jacomine Nortier (ed.), Language, youth and identity in the 21st century: Linguistic practices across urban spaces, 139163. Cambridge: Cambridge University Press. https://doi.org/10.1017/CBO9781139061896.010 Eckert, Penelope. 2000. Language variation as social practice: The linguistic construction of identity in Belten High. Oxford: Wiley-Blackwell.

Eckert, Penelope. 2008. Variation and the indexical field. Journal of Sociolinguistics 12(4), 453-476. https://doi.org/10.1111/j.1467-9841.2008.00374.x

Field, Fredric W. 2002. Linguistic Borrowing in Bilingual Contexts, Vol. 62. Amsterdam, Philadelphia: John Benjamins Publishing. https://doi.org/10.1075/slcs.62

Goldberg, Adele E. 2006. Constructions at work: The nature of generalization in language. Oxford: Oxford University Press on Demand.

Haspelmath, Martin. 2008. Loanword typology: Steps toward a systematic cross-linguistic study of lexical borrowability. In Thomas Stolz, Dik Bakker \& Rosa Salas Palomo (eds.), Aspects of language contact: New theoretical, methodological and empirical findings with special focus on romancisation processes (Empirical Approaches to Language Typology [EALT] 35), 43-62. Berlin: Mouton de Gruyter. https://doi.org/10.1515/9783110206043.43

Haugen, Einar. 1950. The analysis of linguistic borrowing. Language 26(2), 210-231. https://doi.org/10.2307/410058

Hesse, Barnor. 2007. Racialized modernity: An analytics of white mythologies. Ethnic and Racial Studies 30(4), 643-663. https://doi.org/10.1080/01419870701356064

Hock, Hans H. 2009. Principles of historical linguistics. Berlin: Walter de Gruyter.

Honeybone, Patrick. 2007. New-dialect formation in nineteenth century Liverpool: A brief history of Scouse. In Anthony Grant \& Clive Grey (eds.) The Mersey sound: Liverpool's language, people and places, 106-140. Liverpool: Open House Press.

Horn, Laurence R. 2008. "I love me some him": The landscape of non-argument datives. In Olivier Bonami \& Patricia Cabredo Hofherr (eds.), Empirical Issues in Syntax and Semantics 7: Papers from CSSP 2007, 169-192. Paris: CSSP.

Hout, Roeland van \& Pieter Muysken. 1994. Modeling lexical borrowability. Language Variation and Change 6(1). 39-62. https://doi.org/10.1017/So954394500001575

Hübinette, Tobias, Helena Hörnfeldt, Fataneh Farahani \& René L. Rosales. (2012). Om ras och vithet i det samtida Sverige. In Tobias Hübinette, Helena Hörnfeldt, Fataneh Farahani \& René L. Rosales (eds.), Om ras och vithet i det samtida Sverige, 11-36. Stockholm: Mångkulturellt Centrum.

Irvine, Judith T. \& Susan Gal. 2000. Language ideology and linguistic differentiation. In Paul V. Kroskrity (ed.), Regimes of language: Ideologies, polities, and identities, 35-84. Oxford: James Currey Publishers.

Johannessen, Janne B. 2014. Left dislocation in main and subordinate clauses. Nordic Atlas of Language Structures 1(1). 8-15. 
Johnston, Paul A. 2015. Vowel system restructuring in the West Midlands of England. In Michael Adams, Laurel J. Brinton \& R. D. Fulk (eds.), Evidence and method in histories of English (Studies in the History of the English Language VI), 183-200. Berlin \& Munich \& Boston: Walter de Gruyter GmbH. https://doi.org/10.1515/9783110345957.183

Jonsson, Rickard, Anna G. Franzén \& Tommaso M. Milani. 2020. Making the threatening other laughable: Ambiguous performances of urban vernaculars in Swedish media. Language \& Communication 71. 1-15. https://doi.org/10.1016/j.langcom.2019.11.001

Kerswill, Paul. 2018. Dialect formation and dialect change in the Industrial Revolution: British vernacular English in the nineteenth century. In Laura Wright (ed.), Southern English Varieties Then and Now (Topics in English Linguistics [TiEL] 100), 8-38. https://doi.org/10.1515/9783110577549-002

Koch, Martin. 1916. Guds vackra värld: En historia om rätt och orätt. Del 3. Stockholm: Albert Bonnier.

Kotsinas, Ulla-Britt. 1988a. Rinkebysvenska - en dialekt? In Per Linell, Viveka Adelswärd, Torbjörn Nilsson \& Per A. Pettersson (eds.), Svenskans beskrivning 16, Vol. 1, 264-278. Linköping: Tema Kommunikation.

Kotsinas, Ulla-Britt. 1988b. Stockholmsspråk i förändring. In Gertrud Pettersson (ed.), Studier i svensk språkhistoria, 133-147. Lund: Lund University Press.

Kotsinas, Ulla-Britt. 1994. Ungdomspråk (Ord och stil 25). Stockholm: Hallgren \& Fallgren.

Kotsinas, Ulla-Britt. 2001. Lever Ekenssnacket? Om äldre och nyare Stockholmsslang. Uppsala: Kungliga Gustav Adolfs Akademien för svensk folkkultur.

Kotsinas, Ulla-Britt, \& Dogge Doggelito. 2004. Förortsslang. Stockholm: Norstedts Akademiska Förlag.

Labov, William. 1966. The Social Stratification of English in New York City. Washington, D.C.: Center for Applied Linguistics.

Labov, William. 1963. The social motivation of a sound change. Word 19(3). 273-309. https://doi.org/10.1080/00437956.1963.11659799

Labov, William. 2001. Principles of linguistic change, Volume 2: Social factors. Oxford: Blackwell. Lagerström, Sven H. G. 2004. Månsing: Knallernas hemliga språk. Borås: Jonito Förlag.

Lee, Raymond L. M. 2010. On the margins of belonging: Confronting cosmopolitanism in the late modern age. Journal of Sociology 46(2). 169-186. https://doi.org/10.1177/1440783309355064

Lentin, Alana. 2008. Europe and the Silence about Race. European Journal of Social Theory 11(4). 487-503. https://doi.org/10.1177/1368431008097008

Lentin, Alana \& Gavan Titley. 2011. The crises of multiculturalism: Racism in a neoliberal age. London, New York: Zed Books.

Lindell, Lenny, Kenth Thorbjörnsson-Djerf \& Gerd Carling. 2008. Ordbok över svensk romani: Resandefolkets språk och sånger. Stockholm: Podium.

Matras, Yaron. 2002. Romani: A linguistic introduction. Cambridge: Cambridge University Press. https://doi.org/10.1017/CBO9780511486791

Miyazaki, Ayumi. 2004. Japanese junior high school girls' and boys' first-person pronoun use and their social world. In Shigeko Okamoto \& Janet S. Shibamoto-Smith (eds.), Japanese language, gender, and ideology: Cultural models and real people, 256-274. New York: Oxford University Press.

Mufwene, Salikoko. S. 2001. The ecology of language evolution. Cambridge: Cambridge University Press. https://doi.org/10.1017/CBO9780511612862

Mulinari, Diana \& Anders Neergaard. 2004. Den nya svenska arbetarklassen: Facket och de rasifierade arbetarna. Umeå: Borea. 
Muysken, Pieter. 1981. Quechua en Spaans in het Andesgebied. Tijdschrift voor Taal- en Tekstwetenschap 1. 124-138.

Nortier, Jacomine \& Margreet Dorleijn. 2008. A Moroccan accent in Dutch: A sociocultural style restricted to the Moroccan community? International Journal of Bilingualism 12(1-2). 125-142. https://doi.org/10.1177/13670069080120010801

Opsahl, Toril \& Unn Røyneland. 2016. Reality rhymes: Recognition of rap in multicultural Norway. Linguistics and Education 36. 45-54. https://doi.org/10.1016/j.linged.2016.06.003

Rampton, Ben. 1995. Language crossing and the problematisation of ethnicity and socialisation. Pragmatics 5(4). 485-513. https://doi.org/10.1075/prag.5.4.04ram

Rampton, Ben. 2011. From 'multi-ethnic adolescent heteroglossia' to 'contemporary urban vernaculars'. Language \& Communication 31(4). 276-294.

https://doi.org/10.1016/j.langcom.2011.01.001

Sandin, Bengt. 2003. Skolan, barnen och samhället i ett historiskt perspektiv. In Staffan Selander (ed.), Kobran, nallen och majjen: Tradition och förnyelse i svensk skola och skolforskning, 55-69. Stockholm: Liber.

Smalley, Nichola. 2015. Contemporary urban vernaculars in rap, literature and in translation in Sweden and the UK. London, UK: University College London: Ph.D. thesis.

Stæhr, Andreas \& Lian M. Madsen. 2017. 'Ghetto language' in Danish mainstream rap. Language \& Communication 52.60-73. https://doi.org/10.1016/j.langcom.2016.08.006

Therborn, Göran. 1998. A unique chapter in the history of democracy: The Swedish social democrats. In Klaus Misgeld, Karl Molin \& Klas Åmark (eds.), Creating Social Democracy, 1-34. University Park, PA: Penn State University Press.

Thesleff, Arthur. 1912. Stockholms forbrytarspråk och lägre slang, 1910-1912. Stockholm: Albert Bonniers Förlag.

Topografiska Corpsen. 1861. Trakten omkring Stockholm i IX blad. Stockholm: Stockholms Stadsarkiv.

Traugott, Elizabeth C. 2015. Toward a coherent account of grammatical constructionalization. In Lotte Sommerer, Spike Gildea, Jóhanna Barðdal \& Elena Smirnova (eds.), Diachronic construction grammar, 51-80. Amsterdam \& Philadelphia: John Benjamins Publishing Company. https://doi.org/10.1075/cal.18.02tra

Wacquant, Loïc. 2004. What is a ghetto? Constructing a sociological concept [pre-published proof]. In Niel J. Smelser \& Paul B. Baltes (eds.), International encyclopedia of the social \& behavioral sciences. London: Pergamon Press. https://citeseerx.ist.psu.edu/viewdoc/ download?doi=10.1.1.572.465\&rep=rep1\&type $=$ pdf

Whitney, William D. 1881. On mixture in language. Transactions of the American Philological Association 12. 5-26. https://doi.org/10.2307/2935666

Young, Nathan. 2018. 'Copycats, ja dom shouf': Using hip hop to compare lexical replications in Danish and Swedish multiethnolects. University of Pennsylvania Working Papers in Linguistics 24(2). 174-184.

Zwicky, Arnold. 2007. Illeism and its Relatives. Unpublished paper retrieved from http://itre.cis. upenn.edu/ myl/languagelog/archives/004762.html 


\section{Discography}

Adel. 2018, January. Choklad [Chocolate] [music video]. Fivestar Records and Virgin Miri. Retrieved from https://www.youtube.com/watch? $=\mathrm{q} 4 \mathrm{DpscNK} 28 \mathrm{I}$

Jireel. 2016, September. Cataleya [music video]. Retrieved from https://www.youtube.com/ watch?v=k_nTibAFxk0

Joel Fungz, Ibbe, Chris o Fada, Michel Dida \& Ille FreeWay. 2018, March. Nia Remix [Niner Remix] [music video]. Retrieved from https://www.youtube.com/watch?v=7wOyv1LeS88

Macky \& Thrife. 2017, August. Foten pågasen [Foot on the gas] [music video]. Retrieved from https://www.youtube.com/watch?v=BpJTBaDcqss

Pyramids, Jireel, Pato Pooh \& Lamix. 2017], June. Jet Jet [music video]. Retrieved from https:// www.youtube.com/watch?v=D8wrErl5BYE

Showit. 2018, July. Main Chick [music video]. Retrieved from https://www.youtube.com/ watch?v=TAlxWPTtT-c

Yasin Byn. 2015, June. Vart än jag går [Wherever I go] [music video]. Retrieved from https:// www.youtube.com/watch?v=HZ4rcpktB30

Z.e. 2016, May. Trampar nu på deras tår [Stepping now on their toes] [music video]. Retrieved from https://www.youtube.com/watch?v=j03iXDWbs4E

Z.e, \& Jiggz. 2018, November. Sverige vet [Sweden knows] [music video]. Retrieved from https:// youtu.be/P1K4wfpVVRM 



\title{
Identification of clusters of lexical areas using geographical factors
}

\section{A case study in the Occitan language area}

\author{
Clément Chagnaud ${ }^{1}$, Guylaine Brun-Trigaud ${ }^{2}$ \\ and Philippe Garat ${ }^{1}$ \\ ${ }^{1}$ Université Grenoble Alpes / ${ }^{2}$ Université Côte d'Azur
}

\begin{abstract}
We propose a multidimensional statistical analysis procedure using projection and clustering methods in order to identify coherent clusters in a set of lexical areas. The methodology includes a geographical factor, such as administrative divisions or land cover features, to help the identification of clusters. By applying this method on data from the Occitan language area in the south of France, we are able to identify new spatial patterns and lexical boundaries that do not match traditional dialect boundaries. Our method helps to suggest possible explanations for these new patterns.
\end{abstract}

Keywords: geolinguistics, clustering, geovisualisation, statistics, digital humanities, Occitan language

\section{Context}

Dialectologists are interested in the study of linguistic features of spoken varieties such as local dialects. These linguistic features can be of different nature (phonetic, morphosyntactic, lexical, semantic or prosodic) and can change over time and space in a given geographic area (Chambers \& Trudgill 1998).

Geolinguistics studies the geographical distribution of these linguistic features and focuses particularly on the spatial synchronism between them. To reach this scope, geolinguists need to find the geographical boundaries delimiting the presence of each linguistic featureor isoglosses, are calculated from data collected during very large fieldwork projects. The phonetic and lexical variants of a linguistic variable are thus investigated and sampled at numerous locations (survey points) in the territory under investigation. The raw datasets are compiled into linguistic atlases such as the iconic Atlas Linguistique de la France (Gilliéron \& Edmont, 1902-1910) 
or many other regional atlases. These resources are sets of maps recording variation in speech (Boberg et al., 2018). As an example, Figure 1 displays the lexical variants of chêne 'oak tree' from the THESOC ${ }^{1}$ database covering the Occitan language area in the south of France. This isogloss map has been produced using spatial interpolation methods for qualitative data (Chagnaud et al., 2017).

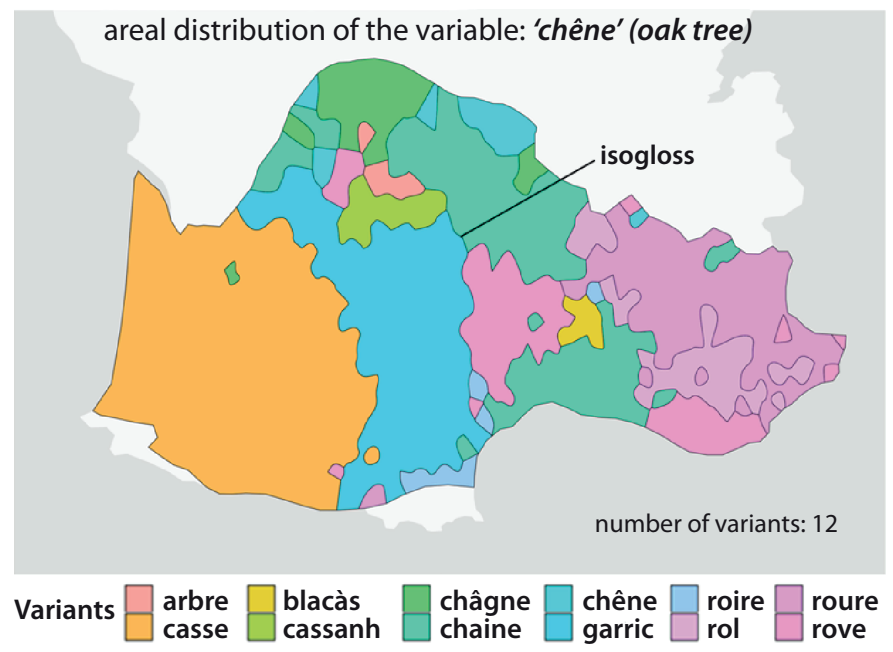

Figure 1. Areal distribution of the lexical variants of chêne 'oak tree' in the Occitan language area. The data are extracted from THESOC

Using such isogloss-based analyses, one can study the dispersal areas representing the geographical distribution of linguistic features. The joint analysis of multiple dispersal areas will reveal the synchronism (at a given time) between linguistic phenomena (Lafkioui 2015). By performing empirical analyses of a wide corpus of maps, geolinguists such as Léonard (2001) and Brun-Trigaud et al. (2005) have been able to identify the existence of spatial patterns, specific regions in which many variants co-occur, by grouping the dispersal areas that are visually similar in location and shape (an example is given in Figure 2). These typological analyses have also revealed that a number of linguistic phenomena do not match the structures of traditional dialect boundaries (Brun-Trigaud \& Malfatto 2013).

These typological analyses were first performed in an intuitive way, with the intention to explain linguistic phenomena by socio-historical or geographical factors (Saussure 1971; Dalbera 2013), but they have since been corroborated by statistical clustering methods applied to a corpus of several hundreds of maps and using a dialectometric approach (Brun-Trigaud et al., 2020). Using for instance the

1. http://thesaurus.unice.fr/index.html 

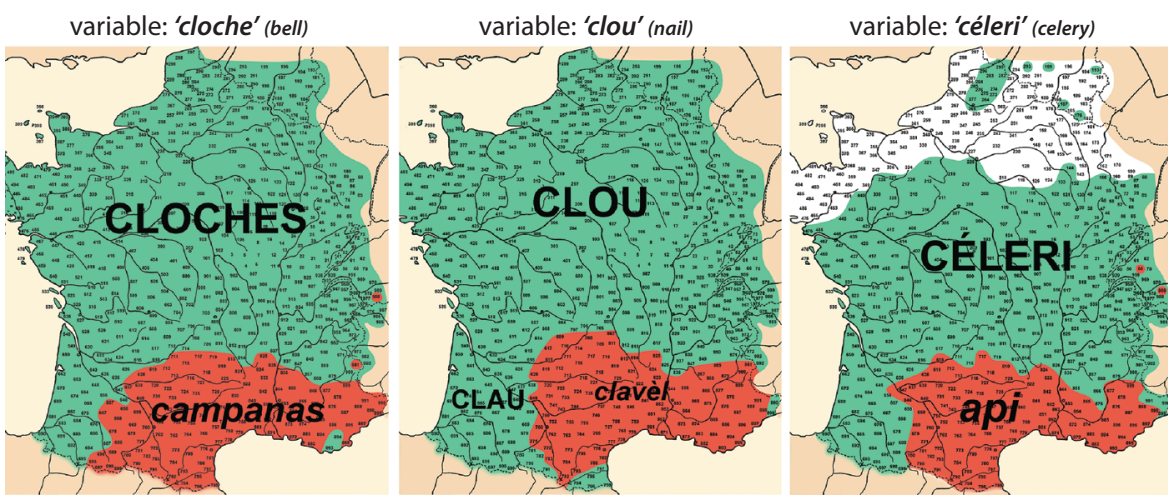

Figure 2. The dispersal areas of campanas, clavel and api (in red) are considered as a recurrent spatial pattern. Interpreted maps from the Atlas Linguistique de la France from Brun-Trigaud et al. (2005)

Levenshtein distance (Miller et al., 2009) it is possible to establish a quantitative linguistic distance between survey points (Heeringa 2004); these distances are then clustered with traditional clustering methods (hierarchical clustering analysis, fuzzy clustering, etc.) (Everitt et al., 2011). A handful of software tools, such as Gabmap ${ }^{2}$ (Nerbonne et al., 2011; Leinonen et al. 2016), have implemented the dialectometric approach, and allow the production of map representations of linguistically homogeneous areas (Figure 3).

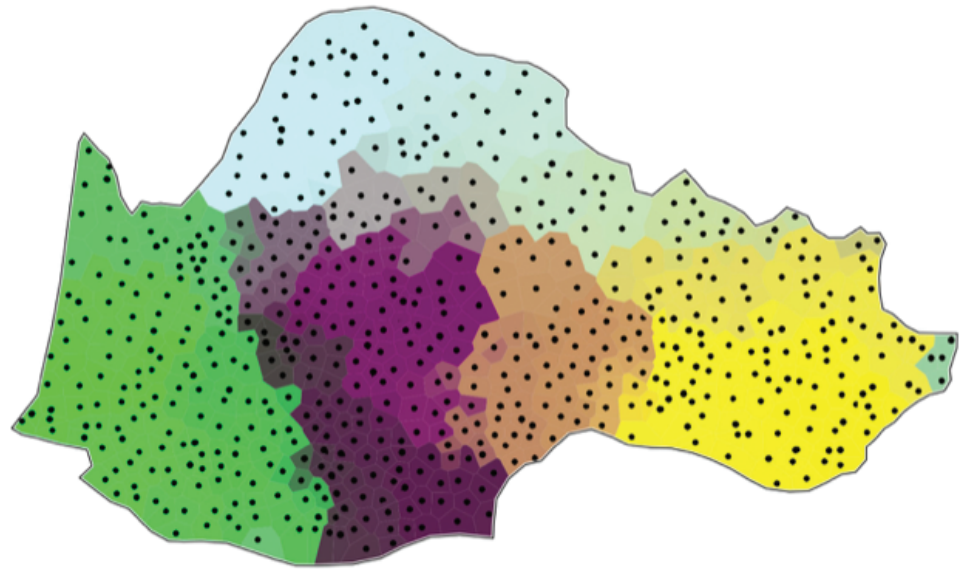

Figure 3. Fuzzy cluster map produced with Gabmap with raw data from the THESOC. The black dots are the survey points and the colors represent the clusters computed with a dialectometric approach 
The statistical clustering methods have generally proved useful in finding spatial structures similar to the empirically determined typologies (Brun-Trigaud 2012). However, they do not analyse the dispersal areas but rather the survey points from which these areas are computed. In addition, neither geolinguists' visual analysis nor the statistical dialectometric approach can so far study the links between the identified spatial patterns and other types of contextual data (geographical, geo-historical or socio-economic features) likely to be explanatory factors.

In this context, we propose a new spatial analysis taking the dispersal areas of the corpus of maps as statistical objects to be clustered according to their spatial similarities. We aim to identify coherent clusters containing dispersal areas with spatial co-occurrences. The difficulty lies in the fact that the dispersal areas are very heterogeneous in size and shape, i.e., their boundaries are never the same. To understand the complex spatial structures, our approach is based on the integration of a geographical factor and the measure of its clustering power on these structures. At this stage, the geographical factor that we are talking about is a division (partition) of the studied region into several geographical entities. The method is innovative in that it allows us to cross-reference spatial data from different sources and platforms in order to find connections between linguistic phenomena and geographical, historical or sociological realities.

The following sections give a stepwise description of our clustering method and its implementation. We illustrate the method through a case study of geolinguistic data from the Occitan language area.

\section{Method}

We aim to classify a heterogeneous set of dispersal areas into coherent clusters by integrating a geographical division as a grouping factor. We hypothesize that a geographical factor such as the watershed limits or the boundaries of former provinces can have an influence on the spatial diffusion of linguistic features over time. The dispersal areas are in the form of geographical surface entities initially represented in the two-dimensional space of a map.

Classifying these objects requires comparing them with each other. In order to do so we must be able to characterize them quantitatively according to common spatial criteria. We transform dispersal areas into abstract points in a multi-dimensional representation space specific to the chosen geographical factor.

Our corpus of dispersal areas then becomes a set of points in a representation space that can now be clustered. We propose to rely on two unsupervised classification methods: the Hierarchical Clustering Analysis (HCA) and the centroid-based algorithm called $k$-means. 
The steps of our method are: (i) creating an adapted representation space, (ii) projecting the objects in this representation space, and (iii) applying the clustering algorithm.

\subsection{Representation space}

In order to create a representation space, we first discretize the studied domain into $n$ hexagonal spatial units (the mesh size depends on the chosen level of discretization). This gives us an initial representation space $E$ (of dimension $n$ ) where any dispersal area is discretized as $n$ surface coordinates: the $i$ th coordinate is the part of the surface occupied in mesh number $i$. Clustering in such $n$-dimensional space would not be very effective because the objects would be too dispersed (curse of the dimension).

We then build a smaller representation space $F$ of dimension $p<n$. The dimension $p$ must be reasonably small in order to ensure an effective clustering thereafter. We use the geographical factor to build this space $F$, by proceeding as follows:

1. We first calculate the so-called matrix of areas, designated by $A$, by crossing all spatial units with all regions of the geographical factor: the cell $(i, j)$ of matrix $A$ contains the intersection area between the $i$ th spatial unit and the $j$ th region of the geographical factor (Figure $4 \mathrm{a}$ ). Therefore, the matrix $A$ has the dimensions $n \times p$. We can get the profile of each spatial unit with respect to the chosen geographical factor by calculating the row-wise percentages of $A$. Similarly, we can express the profile of each region of the geographical factor with respect to the spatial units by calculating the column-wise percentages of matrix $A$.

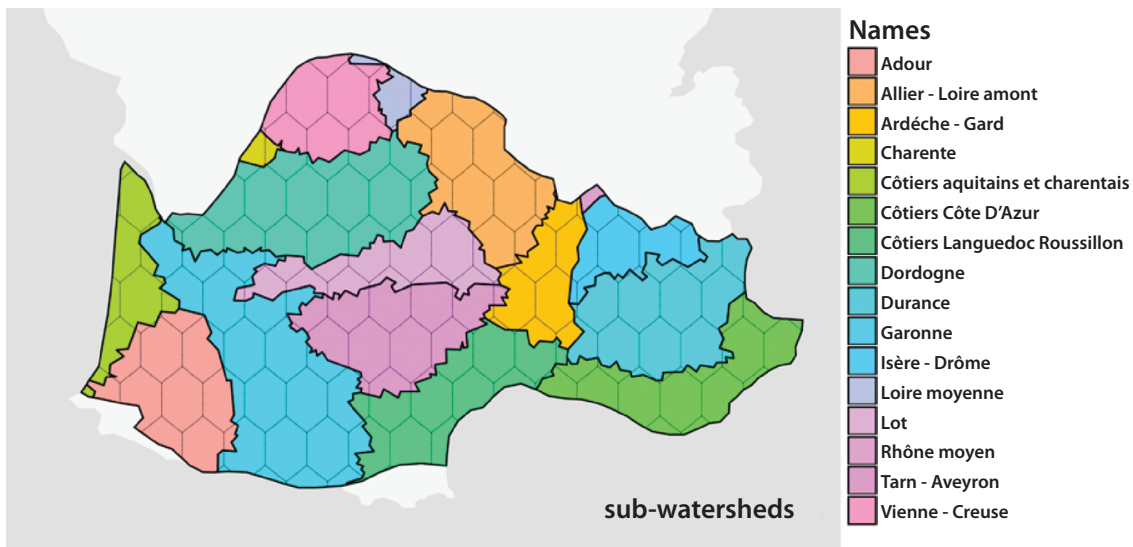

Figure 4a. Correspondence analysis: Superposition of the regions in the geographical factor (here: sub-watersheds) and the hexagonal mesh 
2. We then run a correspondence analysis (CA) (Rencher 2002) on matrix A. This method is a multidimensional statistical analysis which effectively represents the spatial units as a set of $n$ points in the representation space $F$ (Figure $4 b$ ).

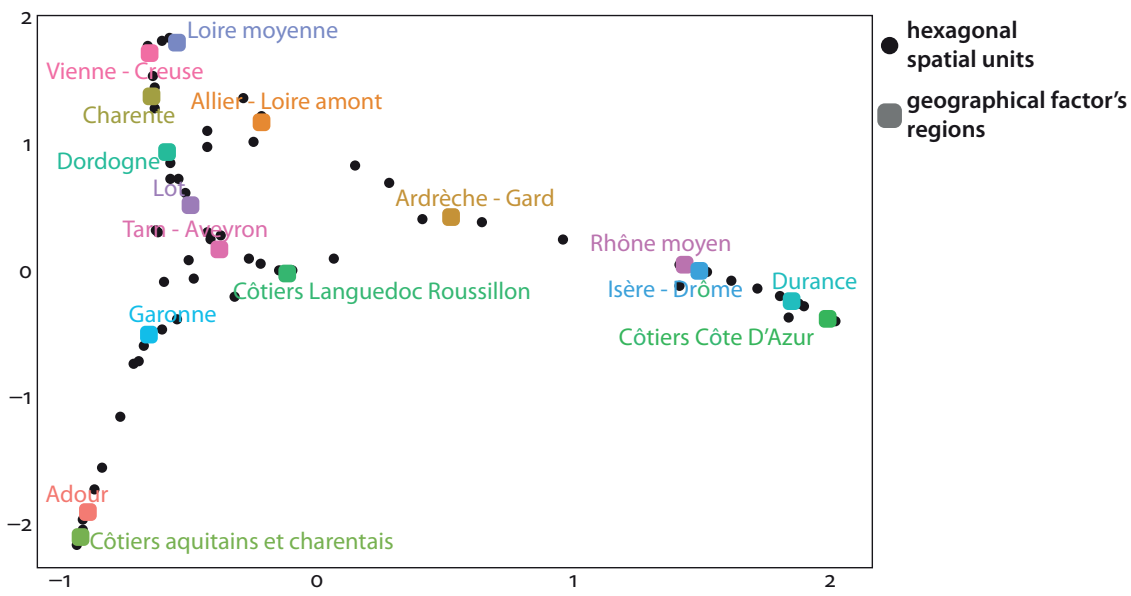

Figure $4 \mathrm{~b}$. Correspondence analysis: Simultaneous representation (semi-barycentric) of the $p$ regions of the geographical factor and the $n$ hexagonal spatial units, according to the first two factorial axes

\subsection{Barycentric projection}

The $n$ spatial units are then placed in a representation space $F$ of dimension $p$, specific to the chosen geographical factor. We now project the $N$ dispersal areas in this same space: in the same way as described in Section 2.1, we calculate a second matrix of areas, designated $A^{\prime}$, of dimension $N \times p$. The cell $(k, i)$ of matrix $A^{\prime}$ contains the area of the intersection between the $k$ th dispersal area and the $i$ th spatial unit. The row-wise percentages of this matrix are then calculated to obtain the profile of each dispersal area according to spatial units (Figure 5a). We use these profiles to project the dispersal areas in the representation space as barycentres of the specific spatial units that each one occupies (Figure 5b). 


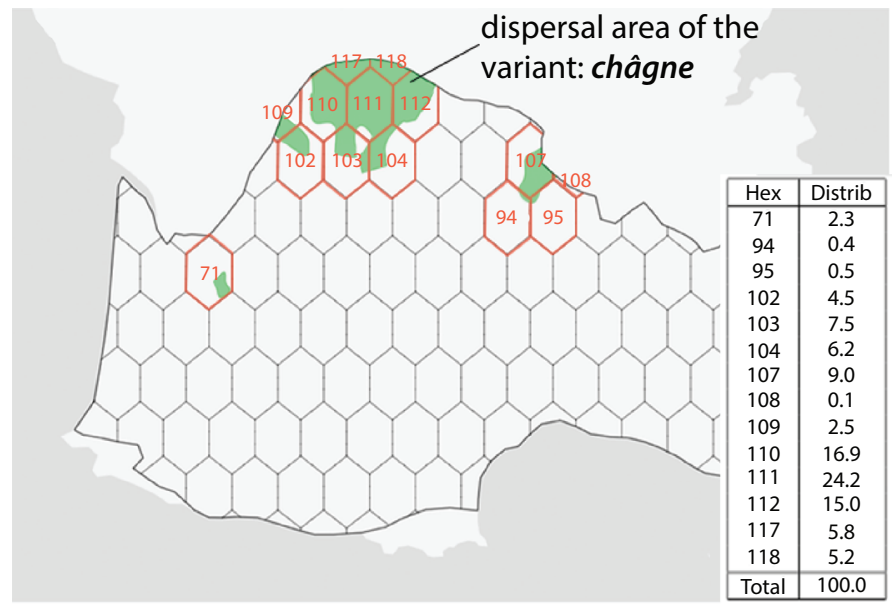

a. The lexical variant châgne for chêne 'oak' (in green) occupies fourteen spatial units (in red) in the geographic space

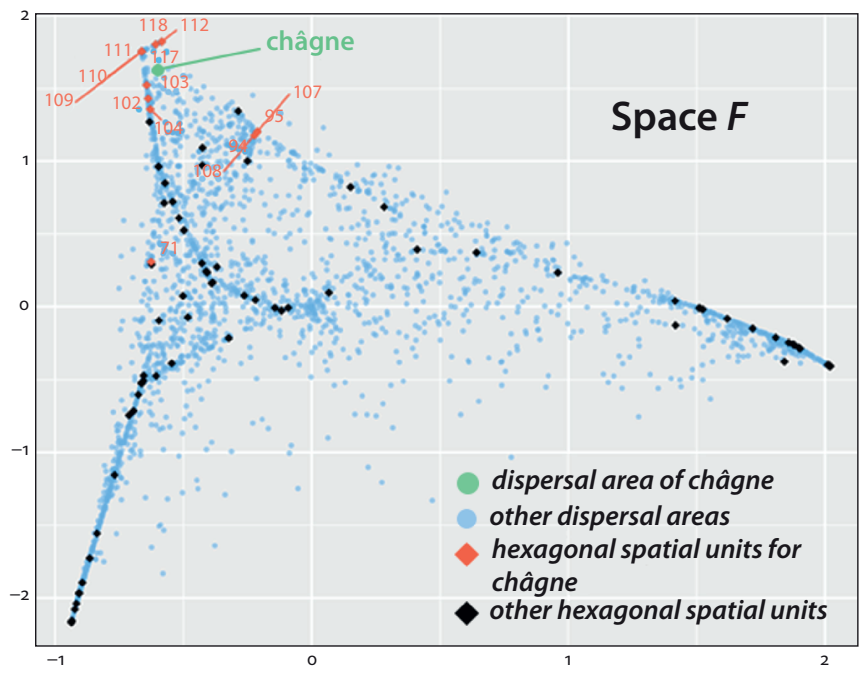

b. The representation space $F$ is shown according to its first two factorial axes: dispersal areas are represented by blue dots located at the barycentre of the spatial units (black dots)

Figure 5. Barycentric projection of the dispersal areas 


\subsection{Clustering}

The last step of our analysis is a supervised clustering procedure of the points representing the dispersal areas in the representation space $F$. Several possibilities exist given the large number of methods available in the literature (Everitt et al., 2011). We have chosen to use a Hierarchical Clustering Analysis (HCA) algorithm with different aggregation criteria such as Ward's minimum variance, single link, complete link, and average distance. The dendrogram produced by the clustering procedure can be trimmed (pruned) at any level, according to the desired number of clusters. The clusters can be consolidated by means of a $k$-means algorithm with starting points initialized with the centroids of the classes established previously by the HCA (Nakache \& Confais 2004).

In order to measure the clustering power of the geographical factor, we propose two indicators $\left(R_{E}^{2}\right.$ and $\left.R_{F}^{2}\right)$ which represent the ratio of between-cluster variance over the total variance, when data are represented in the spaces $E$ and $F$, respectively. The closer these indicators are to 1 , the more compact the clusters are, which means that the clustering is efficient. It is thus possible for users to compare different geographical factors and establish which ones best explain the linguistic variation found in their dataset.

\section{Implementation of the method}

The method described above has been implemented in an exploratory geographic data analysis environment developed in $\mathrm{R}$ (including packages such as FactoMineR and R shiny, among others). It offers the user the possibility to explore the clustering process by interactively modifying the clustering parameters and then visualizing the results (carto)graphically. Since visualization and clustering are dynamically linked, the user can explore each cluster in order to examine the elements it contains and understand the clustering results.

\subsection{Visual exploration}

The cartographic representation serves to highlight the concentration profile of the generated clusters. Given a cluster and the set of its dispersal areas, we identify the zones covered locally by one, two or $n$ dispersal areas. An index (or concentration score) $n / N_{\max }$ is then computed, where $N_{\max }$ is the largest number of overlapping dispersal areas identified for this cluster. The closer to 1 the $n / N_{\text {max }}$ value is, the higher the concentration of areas at the $n$th zone. This visualization allows the user to identify the epicentre of the cluster which can be interpreted as the geographical origin of the diffusion of a phenomenon (see Figure 6). 


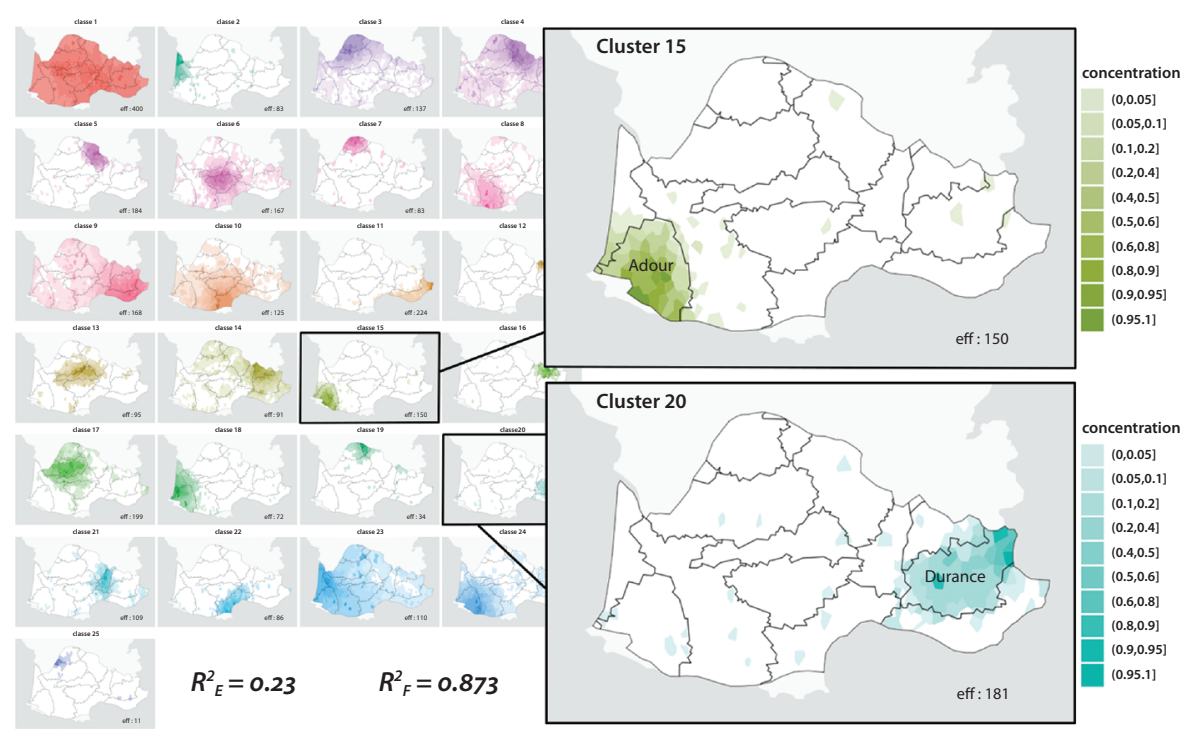

Figure 6. Unsupervised classification into 25 clusters, using the geographical factor of 'sub-watersheds'. The clusters are aggregated with Ward's criterion and consolidated with the k-means algorithm

Each cluster can further be explored through an analysis of the geographical (contour, spatial extent, location) and thematic features of the dispersal areas that compose it. The geographical analysis aims to identify the most representative dispersal area of the cluster (the paragon) in relation to the concentration profile. The other members of the cluster are sorted in descending order of representativeness.

\subsection{Cluster characterization}

In order to better characterize each cluster, we carry out a thematic analysis using illustrative variables: the distribution of the themes and sub-themes in each cluster is compared to their distribution in the entire corpus. Radar diagrams graphically show the difference between cluster distribution and corpus distribution. In order to obtain a good overview of the clusters showing a large discrepancy with the full corpus, each theme of the radar must be read individually. We computed the biggest difference of each themeacross all clusters and we set this value as the maximum value of the radial scale. Two examples of radar charts are presented in Figures 7 and 10. 


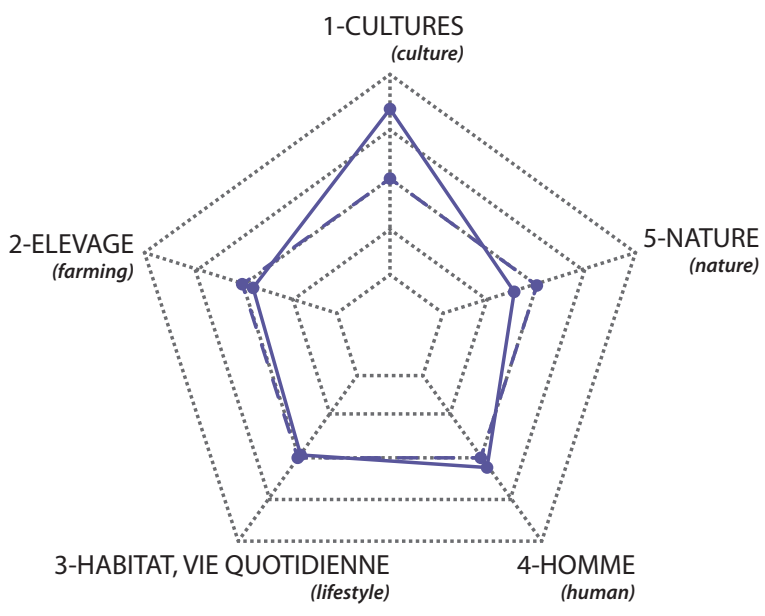

Figure 7. Thematic analysis of cluster 15 (Adour) using a five-item thematic variable: Frequency table and radar chart. In the radar chart, the dashed line represents the mean profile and the plain line represents the cluster profile

\begin{tabular}{|c|c|c|c|c|c|}
\hline \multicolumn{6}{|c|}{ Cluster 15} \\
\hline Themes & $\begin{array}{c}\text { Cluster } \\
\text { frequencies }\end{array}$ & $\begin{array}{c}\text { Total } \\
\text { frequencies }\end{array}$ & $\begin{array}{c}\text { Cluster } \\
\text { percentage }\end{array}$ & $\begin{array}{c}\text { Total } \\
\text { percentage }\end{array}$ & Gap \\
\hline 1-CULTURES (culture) & 35 & 527 & 23.33 & 15.33 & 8.00 \\
\hline 2-ELEVAGE (farming) & 25 & 670 & 16.67 & 19.49 & -2.83 \\
\hline $\begin{array}{l}\text { 3-HABITAT,VIEQUOTIDIENNE } \\
\text { (lifestyle) }\end{array}$ & 41 & 956 & 27.33 & 27.81 & -0.48 \\
\hline 4-НОмме(human) & 17 & 344 & 11.33 & 10.01 & 1.32 \\
\hline 5-NATURE (nature) & 32 & 940 & 21.33 & 27.35 & -6.02 \\
\hline
\end{tabular}

\section{Case study: Occitan}

We applied our clustering method to a corpus of 235 geolinguistic maps from the Thesaurus Occitan (THESOC; Dalbera et al., 2012) which includes all the regional linguistic atlases of the Occitan language area in France, totaling 645 survey points in this region. For each of the lexical variables, the dispersal areas of the variants were computed using interpolation methods applied to qualitative data (Chagnaud et al., 2017). This resulted in a corpus of $N=3437$ dispersal areas (in our case lexical areas), for which spatial co-occurrences and associations with geographical factors must be identified by our clustering method. 
We applied different types of geographical factors to our case studies: environmental boundaries such as sub-watersheds (the drainage basins of sixteen main rivers and their tributaries) or hydro-ecoregions ${ }^{3}$ (a geographical typology of France into 22 homogeneous regions), administrative divisions (departments) or ancient historical districts (Generalitiesof pre-Revolution France under the Ancien Regime, or Provinces of Gaul in 450 AD).

When applying the various geographical factors to the lexical dataset described above, we decided to set the number of clusters at a fixed value of $k=25$ clusters. Choosing the appropriate number of clusters always remains a difficult task, but owing to the size of our dataset $(N=3437)$ we found that a 25 -cluster classification was reasonable for meaningful linguistic analyses.

When using the geographical factor of 'sub-watersheds' (Figure 6), some regions clearly attract local clusters containing region-specific variants: cluster 8 (150 variants) matches with the Adour region, cluster 20 (181 variants) with the Durance, cluster 11 (244 variants) with the Côte d'Azur or cluster 8 (up to 330 variants) with the Garonne region. Even if cases of perfect spatial coherence between a geographic region and a lexical area are quite rare, it is nevertheless possible to find some good matches. This is the case for trauc (a variant of chatière 'cat flap') which we identify as the paragon of cluster 8 and which matches quite well with the Garonne region (Figure 8). For the thematic characterization of the clusters, we used a thematic variable with five items (culture, farming, lifestyle, human, nature). These items can be more or less involved in the computed clusters. For example, the radar chart in Figure 7 shows that cluster 15 (which includes the region-specific variants of the Adour basin) mainly contains variants related to the theme of cultural practices.

We should point out that the structure of the geographical factor plays a role in the relevance of results: a model with very large regions (such as the Provinces of Gaul) or, on the contrary, with small intricate regions such as the hydro-ecoregions, gives results that are quite difficult to analyze. This probably means that some geographical factors are not relevant for the typology of the lexical areas of our corpus. For comparative purposes, Table 1 gives the values of the indicators $R_{E}^{2}$ and $R_{F}^{2}$ for the five geographical factors under identical clustering settings ( $k=25$ clusters, Ward's aggregation criterion, k-means consolidation). It is clear that the five geographical factors used in our study do not yield identical clusters. The indicator $R_{E}^{2}$ suggests that the compactness of the 25 clusters is strongest when the clustering procedure is driven by departments. The indicator $R_{F}^{2}$ reveals the efficiency of clustering, but remains more complicated to interpret: it measures the compactness

3. https://www.irstea.fr/fr/les-hydroecoregions-de-france-metropolitaine 


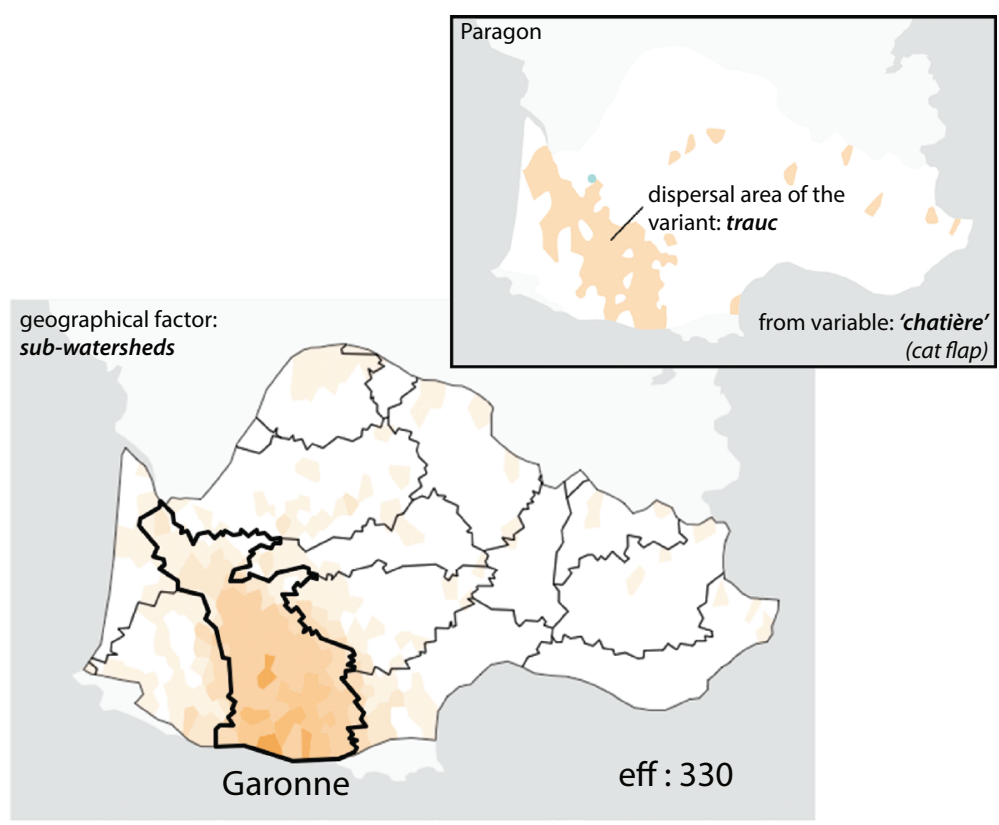

Figure 8. Clustering analysis using the geographical factor of 'sub-watersheds'. Focus on the Garonne basin and the 330 lexical variants of cluster 8. Paragon: The lexical area of trauc, a variant of chatière 'cat flap'

of the clusters within dimensionally different spaces of representation. As such the values are not comparable from one case to the other, except if the dimension $p$ remains equal. We continue to investigate how to adequately compare $R_{F}^{2}$ values.

Among the two historical geographical factors, the Generalities pre-1789 and the Provinces of Gaul in $450 \mathrm{AD}$, the former performs better than the latter. Some of the generalities attracted a significant number of region-specific variants: for example, the Rouergue region matches with cluster 6 (containing 93 variants); in particular we observe a very good match between this region and the dispersal area of rita (a variant of cane 'female duck') which is the paragon of this cluster (Figure 9).

Table 1. Comparison of the 'clustering power' of the five geographical factors

\begin{tabular}{lcc}
\hline Geographical factor & $R_{E}^{2}$ & $R_{F}^{2}$ \\
\hline None & - & 0.374 \\
Departments & 0.308 & 0.722 \\
Generalities pre-1789 & 0.233 & 0.900 \\
Provinces of Gaul in 450 AD & 0.191 & 0.950 \\
Sub-watersheds & 0.230 & 0.873 \\
Hydro-ecoregions & 0.222 & 0.897 \\
\hline
\end{tabular}




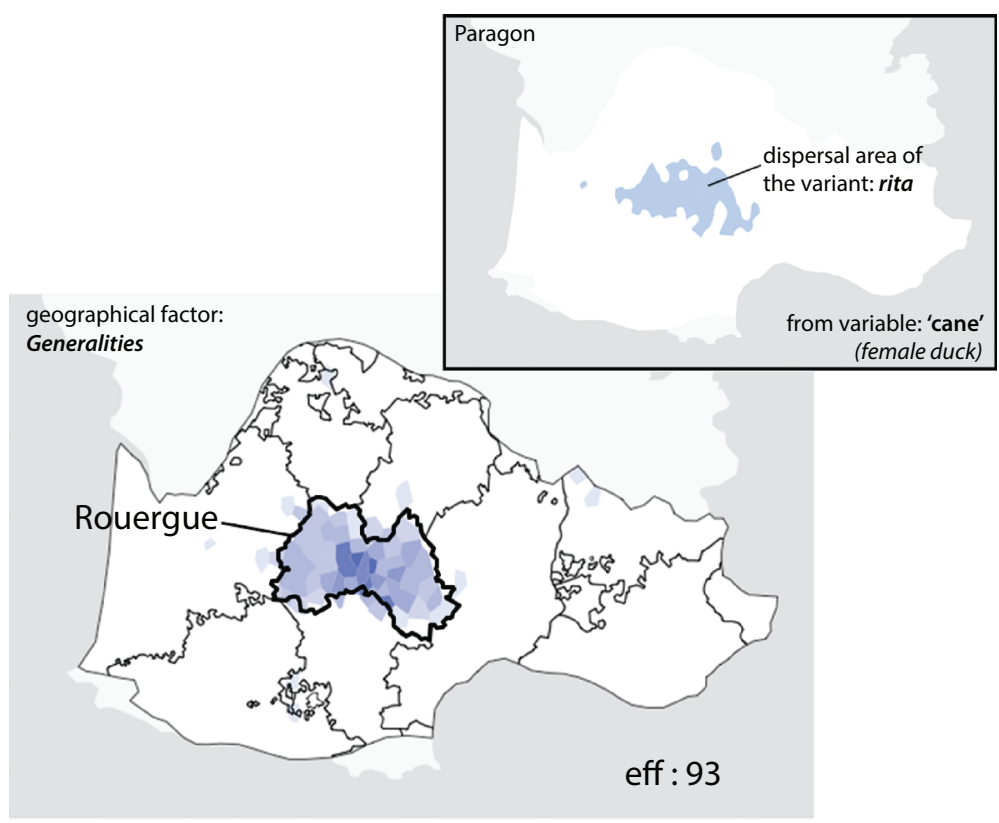

Figure 9. Clustering analysis using the 'Generalities' geographical factor. Focus on the Rouergue region and the 93 variants of cluster 6 Paragon: 'rita' lexical area, from notion 'cane' - 'female duck'.

The radar chart in Figure 10 displays the frequency analysis of cluster 6, using a 17 -item thematic variable. It shows the relatively important place occupied by barn animals (hens, ducks, etc.) in the cluster, alongside other themes such as landform or human body parts. These thematic indications can guide the researcher on the importance of certain lexical features that may be useful for their analyses.

However, the most surprising results are obtained when we use the modern administrative division of France, the departments, as a geographical factor. This division is quite recent (even though it was first set up in 1790) so we assumed that it had little relationship with local dialects. However, performing a clustering analysis into $k=50$ clusters, more than half of the 31 departments included in the Occitan language area quite clearly match many lexical clusters. For example, the Alpes-Maritimes or the Hautes-Pyrénées contain some areas that do not exist elsewhere in the Occitan domain.

As was the case for the geographical factor of 'sub-watersheds', some lexical areas are even a perfect match with the shape of the department, such as the dispersal area of pastenada, a variant of carotte 'carrot' in the department of Puy-de-Dôme (Figure 11). 


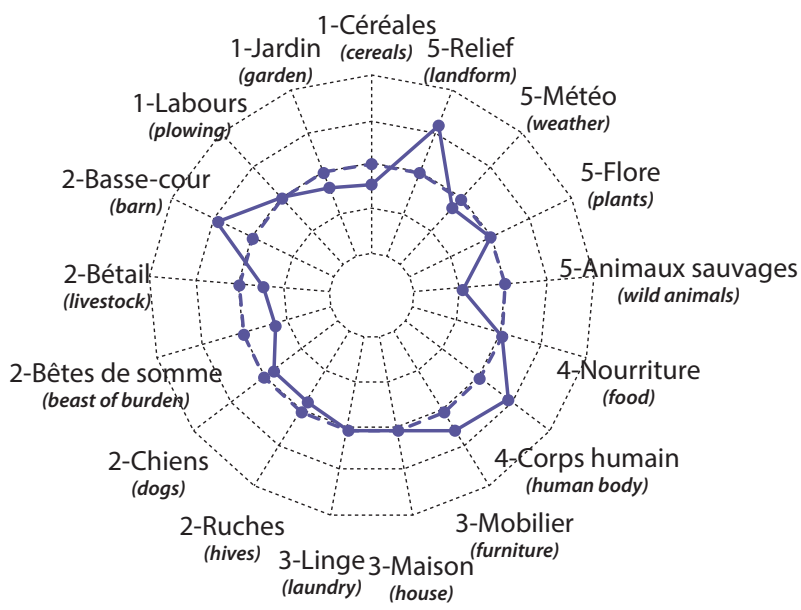

Figure 10. Thematic analysis for cluster 6 (Rouergue) over seventeen themes: Frequency table and radar chart. In the radar chart, the dashed line represents the mean profile and the plain line represents the cluster profile

\begin{tabular}{|c|c|c|c|c|c|}
\hline \multicolumn{6}{|c|}{ Cluster 6} \\
\hline Sub-themes & $\begin{array}{c}\text { Cluster } \\
\text { frequencies }\end{array}$ & $\begin{array}{c}\text { Total } \\
\text { frequencies }\end{array}$ & $\begin{array}{c}\text { Cluster } \\
\text { percentage }\end{array}$ & Total & $\begin{array}{c}\text { Gap } \\
\text { percentage }\end{array}$ \\
\hline 1-Céréales (cereals) & 3 & 217 & 3.23 & 6.31 & -3.09 \\
\hline 1-Jardin (garden) & 4 & 203 & 4.30 & 5.91 & -1.61 \\
\hline 1-Labours (plowing) & 3 & 107 & 3.23 & 3.11 & 0.11 \\
\hline 2-Basse-cour (barn) & 6 & 104 & 6.45 & 3.03 & 3.43 \\
\hline 2-Bétail (livestock) & 7 & 399 & 7.53 & 11.61 & -4.08 \\
\hline $\begin{array}{l}\text { 2-Bêtes de somme } \\
\text { (beast of burden) }\end{array}$ & 0 & 37 & 0.00 & 1.08 & -1.08 \\
\hline 2-Chiens (dogs) & 1 & 52 & 1.08 & 1.51 & -0.44 \\
\hline 2-Ruches (hive) & 1 & 78 & 1.08 & 2.27 & -1.19 \\
\hline 3-Linge (laundry) & 4 & 148 & 4.30 & 4.31 & -0.01 \\
\hline 3-Maison (house) & 9 & 317 & 9.68 & 9.22 & 0.45 \\
\hline 3-Mobilier (furniture) & 19 & 491 & 20.43 & 14.29 & 6.14 \\
\hline $\begin{array}{l}\text { 4-Corps humain } \\
\text { (human body) }\end{array}$ & 8 & 171 & 8.60 & 4.98 & 3.63 \\
\hline 4-Nourriture (food) & 5 & 173 & 5.38 & 5.03 & 0.34 \\
\hline $\begin{array}{l}\text { 5-Animaux sauvages } \\
\quad \text { (wild animals) }\end{array}$ & 5 & 356 & 5.38 & 10.36 & -4.98 \\
\hline 5-Flore (plants) & 6 & 252 & 6.45 & 7.33 & -0.88 \\
\hline 5-Météo (weather) & 4 & 213 & 4.30 & 6.20 & -1.90 \\
\hline 5-Relief (landform) & 8 & 119 & 8.60 & 3.46 & 5.14 \\
\hline
\end{tabular}




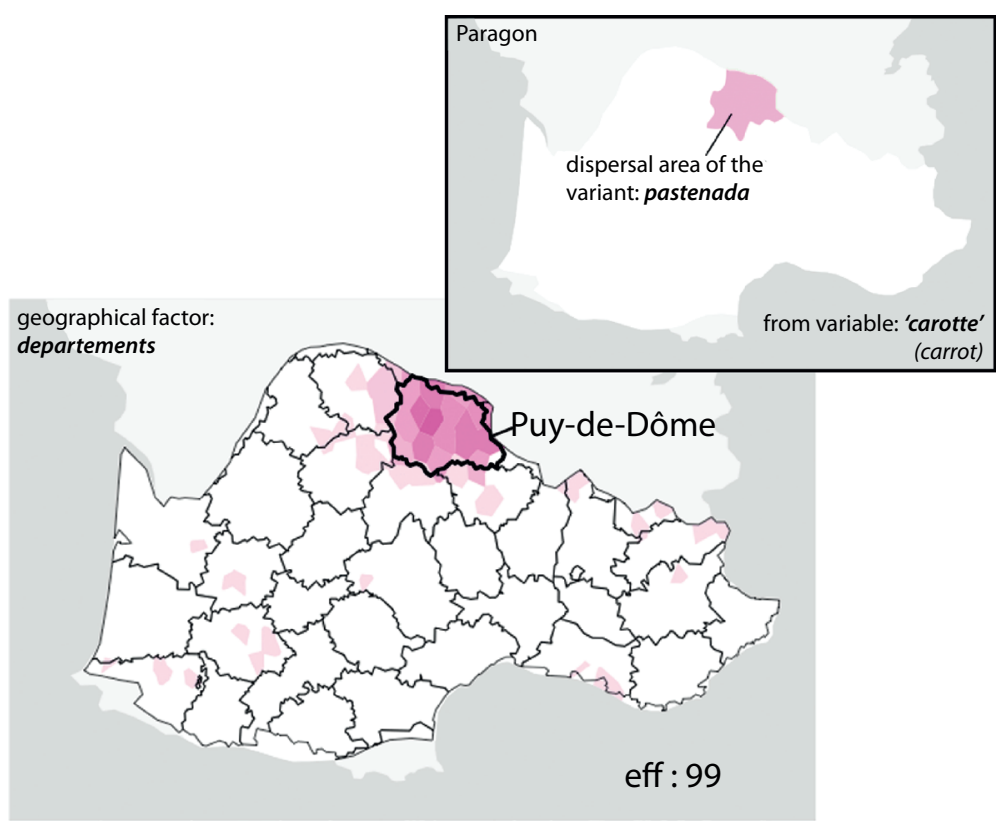

Figure 11. Cluster analysis after a 50 clusters classification with departments' geographical factor; Ward's aggregation method; k-means consolidation. Focus on Puy-de-Dôme region. Paragon: 'Pastenada' area from variable 'carotte'

On the other hand, some departments do not seem to cluster any areas, such as HauteGaronne, Aveyron or Tarn-et-Garonne. This observation might be explained by the historical evolution of the departments. The department of Tarn-et-Garonne was formed in 1808 from part of the territories of the older departments of Haute-Garonne and Aveyron. The fact that some lexical areas match with original department boundaries, and mismatch with more recent boundary changes, may indicate that the departments were originally set up based on territorial and perhaps linguistic consistency.

Overall, we can observe that a geographical factor with a fine but still geographically coherent division can produce interesting results that open perspectives on what might have shaped the spatial dispersion of local dialects. At this stage, we are merely exploring the possibilities offered by this clustering method, but nevertheless we can already identify some interesting perspectives. 


\section{Conclusion}

Using a method for classifying geographical surface objects representing the dispersal areas of geolinguistic phenomena, we have been able to identify spatial co-occurrences and create coherent clusters in a corpus of thousands of lexical entries. This method, implemented with an exploratory geographical data analysis approach, offers the opportunity to more easily identify the links between linguistic phenomena and geographical or historical factors. The strength of these links is quantified using the indicators $R_{E}^{2}$ and $R_{F}^{2}$. However, further work is needed to adjust these indicators to take into account the number $p$ of regions in the geographical factors used. Also, it would be interesting to allow linguists to select (as paragons) specific lexical areas from the corpus, and use them to cluster other areas of the corpus. Questioning and affirming the validity of the clusters remains the responsibility of these specialists, but our goal is to complete our method with a number of metrics that may help this decision process.

\section{Bibliography}

Boberg, Charles, John Nerbonne \& Dominic Watt (eds.). 2018. The Handbook of Dialectology. UK \& USA: John Wiley \& Sons, Inc.

Brun-Trigaud, Guylaine, Yves Le Berre \& Jean Le Dû. 2005. Lectures de l'Atlas Linguistique de la France de J. Gilléron et E. Edmont: Du temps dans l'espace. Paris: CTHS.

Brun-Trigaud, Guylaine. 2012. Essai de typologie des aires lexicales dans l'Atlas Linguistique du Centre. Annales de Normandie 62(2). 77-93.

Brun-Trigaud, Guylaine \& Albert Malfatto. 2013. Limites dialectales vs limites lexicales dans le domaine occitan: Un impossible accord? In Ernestina Carrilho, Catarina Magro \& Xosé Afonso Álvarez Perez (eds.), Current Approaches to Limits and Areas in Dialectology, 293310. Cambridge Scholars Publishers.

Brun-Trigaud, Guylaine, Albert Malfatto \& Maguelone Sauzet. 2020. Essai de typologie des aires lexicales occitanes: Regards dialectométriques. Fidélités et dissidences: 12e Congrès de l'Association Internationale d'Etudes Occitanes. 169-179.

Chagnaud, Clement, Philipe Garat, Paule-Annick Davoine, Elisabetta Carpitelli \& Axel Vincent. 2017. Shinydialect: A cartographic tool for spatial interpolation of geolinguistic data. 1st ACM SIGSPATIAL workshop on Geospatial Humanities, 23-30. ACM. https://doi.org/10.1145/3149858.3149864

Chambers, J. K. \& Peter Trudgill. 1998. Dialectology (Cambridge Textbooks in Linguistics). 2nd edn. Cambridge: Cambridge University Press. https://doi.org/10.1017/CBO9780511805103

Dalbera, Jean-Philippe, Jean-Claude Ranucci, Pierre-Aurélien Georges, Michèle Oliviéri \& Guylaine Brun-Trigaud. 2012. La base de données linguistique occitane Thesoc: Trésor patrimonial et instrument de recherche scientifique. Estudis Romànis 34. 367-387.

https://doi.org/10.2436/20.2500.01.108 
Dalbera, Jean-Philippe. 2013. La trajectoire de la dialectologie au sein des sciences du langage: De la reconstruction des systèmes dialectaux à la sémantique lexicale et à l'étymologie. Corpus 12. 173-200. https://doi.org/10.4000/corpus.2390

Everitt, Brian S., Sabine Landau, Morven Leese \& Daniel Stahl. 2011. Cluster Analysis. 5th edn. United Kingdom: John Wiley. https://doi.org/10.1002/9780470977811

Gilliéron, Jules \& Edmond Edmont. 1902-1910. Atlas Linguistique de la France. Paris: Champion. Heeringa, Wilbert Jan. 2004. Measuring dialect pronunciation differences using levenshtein distance. University of Groningen: Ph.D. thesis.

Lafkioui, Mena B. (2015). Méthodologie de recherche en géolinguistique. Corpus 14. 139-164. https://doi.org/10.400o/corpus.2658

Leinonen, Therese, Çağrı Çoltekin \& John Nerbonne. 2016. Using Gabmap. Lingua 178. 71-83. https://doi.org/10.1016/j.lingua.2015.02.004

Léonard, Jean-Léo. 2001. Aréologie dialectale et modularité des réseaux dialectaux: Étagement spatial et structural des processus (morpho)phonologiques dans le réseau dialectal basque. XVe Congrès international de l'Académie basque, 17-19 septembre 2001, 141-168.

Miller, Frederic P., Agnes F. Vandome \& John McBrewster. 2009. Levenshtein distance: Information theory, computer science, string (computer science), string metric, damerau- levenshtein distance, spell checker, hamming distance. Orlando: Alpha Press.

Nakache, Jean-Pierre \& Josiane Confais. 2004. Approche pragmatique de la classification: Arbres hiérarchiques, partitionnements. Paris: Technip.

Nerbonne, John, Rinke Colen, Charlotte Gooskens, Peter Kleiweg \& Therese Leinonen. 2011. Gabmap: A web application for dialectology. Dialectologia Special Issue II. 65-89.

Rencher, Alvin C. 2002. Methods of multivariate analysis. 2 edn. Hoboken, NJ, USA: Wiley-Interscience. https://doi.org/10.1002/0471271357

Saussure, Ferdinand de. 1971. Cours de linguistique générale. Paris: Payot. 



\title{
(Il)literacy and language change
}

\section{Non-standard relative constructions in historical Basque}

\author{
Dorota Krajewska and Eneko Zuloaga \\ University of the Basque Country UPV/EHU
}

\begin{abstract}
In this paper we examine a corpus of sixteenth- to nineteenth-century Basque private letters and administration documents from a historical sociolinguistic point of view. Because of the diglossic situation, such texts are rare but valuable in the historical corpus of Basque. In particular, we analyse relative clauses with the pronoun zein 'which'. The construction was borrowed from Romance by highly literate bilinguals, but then spread, especially through formulaic language, to less literate writers too. We focus on the development of non-standard variants of this relative clause, which are common in our corpus, but not found in printed literary texts. We argue that the sociolinguistic context was crucial in the emergence, spread and syntactic change of the relative construction.
\end{abstract}

Keywords: historical sociolinguistics, syntax, relative clauses, literacy, Basque

\section{Introduction}

In this paper we adopt the viewpoint of historical sociolinguistics to reflect on Basque writing, written language, and syntactic change under language contact. Our analysis is based on a corpus of sixteenth- to nineteenth-century Basque letters and administrative documents. Processes described here have parallels in other European languages, but the Basque case offers the opportunity to observe them in a particularly interesting diglossic context, where a prestigious and standardised language (French or Spanish) was the usual means of written communication, and another language (Basque) had not yet developed a standard.

We focus on relative clauses (RC), which are complex constructions, typical of higher registers, and prone to cause problems for not-so-proficient writers. The most common relativisation strategy in modern Basque and in most historical sources is prenominal, and differs from relative clauses found in the surrounding 
Romance languages. However, through contact Basque innovated a construction with the pronoun zein 'which', which is the object of our study. Being considered an uninteresting calque, it has received little attention, and its use outside the "canonical" sources (such as printed books) has not been studied. We show that the relative pronoun zein is common in our corpus and that it became a feature of written registers. Moreover, we propose that several non-standard variants of the construction demonstrate that the diffusion of syntactic change happened in written interactions between writers, for example, by means of exchanges of letters, and mainly through formulaic language.

The paper is structured as follows. Section 2 introduces relativisation strategies in Basque and Romance. Section 3 describes the sociolinguistic situation of Basque before the twentieth century and the influence it had on writing. Section 4 presents our corpus study. Section 5 provides an explanation of the syntactic changes observed in the corpus and compares them to phenomena attested in other European languages.

\section{Basque and Romance relativisation strategies}

Basque has several finite relative constructions, which differ in the following features (De Rijk 1972; Oyharçabal 1987; Oyharçabal 2003; Krajewska 2017) (see Table 1):
a. embedded vs. appositive RC
b. position of the RC: postnominal vs. prenominal
c. treatment of the relativised noun: gap vs. pronoun
d. choice of subordinator: -en, bait- or both

We thus have prenominal (1), postnominal (2), appositive (3), and zein relatives (4), illustrated below with examples from classical Basque sources:

(1) [gizon-ek erran dukeite-n] hitz alfer guzi-a-z man-DEF.ERG.PL say AUX.3PL>3SG-SUB word vain all-DEF-INS 'all the vain words man can say'

(Leizarraga, 1571)

(2) arbore [fruktu on-ik egi-ten ez-tu-en guzi-a] tree fruit good-PART make-IPFV NEG-AUX.3sG $>3$ SG-SUB all-DEF.ABS 'every tree which does not produce good fruit'

(Leizarraga, 1571)

(3) zuhaitz alferr-a [fruitu-rik iasai-ten ez-tu-en-a] tree lazy-DEF.ABS fruit-PART give-IPFV NEG-AUX.3SG $>3$ SG-SUB-DEF.ABS 'a lazy tree which does not give fruit'

(Axular, 1643) 
(4) gizon zuhur bat-en pare [zeiñ-ek bastitu bai-duke bere man wise one-GEN like which-INDEF.ERG build SUB-AUX.3SG $>3$ SG his etxe-a harri-a-ren gaiñean]

house-DEF.ABS rock-DEF-GEN on

'like a man who built his house on the rock'

(Haraneder, 1740)

Table 1. Features of Basque RCs

\begin{tabular}{lcccc}
\hline Feature & Prenominal & Postnominal & Appositive & zein \\
\hline Embedded & + & + & - & - \\
Relative left to the head & + & - & - & - \\
Gapping & + & + & + & - \\
Subordinator & $-e n$ & $-e n$ & $-e n$ & - en $/$ bait- \\
\hline
\end{tabular}

The prenominal construction, the least marked one, differs from Romance relative clauses. Broadly speaking, Romance languages employ relative pronouns (relativisers which can express semantic features) or uninflected particles usually identical to complementisers (Stark 2016). In non-standard varieties, particles are more widespread: pronouns which inflect in the standard variety may not inflect, and uninflected particles may relativise more arguments (Blanche-Benveniste 1990; Giacalone Ramat 2008; Murelli 2011; Cerruti 2016; Stark 2016). For example, in restrictive clauses Standard French uses the complementiser que (object relatives), qui (subject relatives), and invariant dont (possessives (5a)). With prepositions, inflected lequel (5a), invariant qui and quoi are used (Stark 2016: 1031). In non-restrictive clauses, lequel can relativise subjects and, less frequently, objects (Stark 2016: 1032). In non-standard French, que relativises more syntactic positions (5b) (see, among others, Guiraud 1966; Auger 1995; Stark 2016).

(5) a. le livre dont/duquel je t'ai parlé the book whose/of.the.which I you=have talked

'the book that I have talked to you about' (Stark 2016: 1030) (French)

b. le livre que je t'ai parlé

the book that I you=have talked

'the book that I have talked to you about'

(Stark 2016: 1030) (Colloquial French)

The syntax of the Basque zein RC (4) resembles the Romance counterparts, especially structures with lequel in French or (el) cual in Spanish. The relativised constituent is pronominalised, usually with zein 'which' (non 'where' and noiz 'when' are also common, and nor 'who' and zer 'what' are attested, but scarce). The pronoun takes the case required by the syntax of the subordinate clause. Unlike in Romance, in Basque the verb in the subordinate clause is usually marked with one of the 
subordinators (-en or bait-), and the subordination is doubly marked (with the subordinator and the relative pronoun).

Attested since the earliest texts, the zein RC was frequent until the nineteenth century: taking into account prenominal, postnominal, appositive and zein relatives, it accounts for $20-30 \%$ of relatives in many texts, especially in translations, catechisms, and, in general, production heavily influenced by Romance models (Krajewska 2017). In the nineteenth century the frequency of the zein RC dropped. Nowadays it is not employed in informal registers, but occasionally appears in formal writing or translations. This decline can be linked to a rise in linguistic awareness and linguistic purism. The construction was first explicitly rejected in Azkue's grammar (1891) as a calque from Romance. This view is repeated in many twentieth-century prescriptive dictionaries and grammars (Azkue 1969 [19051906]; Azkue 1923-1925; Lafitte 1991 [1944]).

\section{Writing in Basque before the twentieth century}

\subsection{The historical sociolinguistics of Basque}

Since the Middle Ages, Basque has coexisted with Latin and Romance languages in a diglossic situation (Ferguson 1959; Fishman 1972). Following Madariaga (2014: 734-35), in $160078 \%$ of the inhabitants of the Basque Country were Basque speakers. This proportion decreased to $69 \%$ in 1800 and to $52 \%$ in 1868 . Basque has also lost large geographical areas and urban space due to industrialization processes, population movements, and repression. Basque became an official language in the Basque Autonomous Community and parts of Navarre (Spain) in 1979 and 1982, but it lacks official status in the Basque-speaking territories in France.

Despite being the language of the majority of the population, Basque was rarely used in official spheres until the late twentieth century. Since the fifteenth century, diglossia is reflected for example in legal proceedings where witnesses' testimonies are often given in Basque, even though the rest is written in Romance. Noblemen only wrote Basque for private purposes, for instance in letters sent to family members, or sometimes in literary drafts.

The standardisation of Basque, understood as a development of a common standard accepted by the speakers, began in 1964 (Amorrortu 2003; Salaburu 2018; Zuazo 2019). Before the twentieth century, there were attempts to create partial standards for some dialects. In the Northern Basque Country, a Classical Labourdin literary dialect developed in the seventeenth century through the publication of religious literature. The most important codification effort in the Southern Basque 
Country was the work of Larramendi, with an "apology of Basque" (1728), the first published grammar of Basque (1729) and the first Basque dictionary (1745). The common trait of all the pre-twentieth-century codification endeavours was that their influence was limited to learned authors. For example, the impact of Larramendi is clear in the literature produced in the western and central Basque dialects, but it did not affect the writings of lay people (Urgell 2018).

\subsection{Literacy and biliteracy}

In the Basque Country, as elsewhere in Europe, alphabetisation was more common in urban areas, higher social strata and among men, and less common in rural areas, lower social strata, and among women (Elosegi 2019).

For the Southern Basque Country, first official registers of literacy come from the second half of the nineteenth century: in $187738 \%$ of inhabitants of Álava were literate, and around 54\% in Bizkaia, Gipuzkoa and Navarre (Dávila, Eizagirre \& Fernández 1994). In the Northern Basque Country, marriage signatures analysed by Elosegi (2019) show that in Labourd in the mid-eighteenth century $11 \%$ of women and $33 \%$ of men could sign (though there were differences between areas, with more literates in cities). Illiteracy rates were lower in France than in Spain: France achieved generalised literacy by the end of the nineteenth century, and Spain only in the mid-twentieth (Lyons 2012: 10).

The authors of texts we examine here were Basque-Romance bilinguals, though the level of knowledge of Romance varied. This brings us to the issue of biliteracy, and the way it was acquired. Schooling in Basque was limited. Before the twentieth century it only existed - to a limited extent - in the Northern Basque Country. Petites écoles, basic level schools, are documented there since the seventeenth century (Oyharçabal 1999), although we do not know what proportion of the population could access them. Their goal was to propagate the Catholic faith, mainly through memorising the catechism, and reading and writing were subordinate to that objective (Chartier, Julia \& Compère 1976; Carter 2011). Reading was taught earlier than writing, and some people could only read, especially those who left school early to work (Grosperrin 1984; Chartier 1997). Thus, those who attended these schools might have had basic writing skills, but not necessarily enough to compose, for example, a letter, which was a specialised skill, as observed by Lyons (2014: 256). As Basque schooling was non-existent apart from the petites écoles, authors of texts in our corpus were most probably schooled in the dominant language (Latin or Romance), and not taught to write Basque. The outcome is that they had to exploit the knowledge about writing in one language to write in another. 


\section{Zein RCs in administrative texts and letters}

\subsection{Non-canonical texts in Basque historical corpus}

Mounole and Lakarra (2018: 358) describe the corpus of historical Basque as small, asymmetric (no attestations for some varieties until after 1850) and homogeneous (mostly religious texts). This is an effect of diglossia: until the last decades of the twentieth century the members of higher social strata wrote almost only in Latin or Romance (Castilian, Occitan or French), depending on the period and the territory. Basque was mostly employed in writing to spread Christian ideas to monolingual people, and that explains why religious works prevail. Sarasola (1975: 109) counted 101 original Basque books, mostly about religion, between 1545 and 1900 (194 when also including translated books, and 588 when adding re-editions). Nevertheless, there are exceptions, such as oral materials transcribed by historians, private letters, and administrative documents.

For this study we have analysed all sixteenth- to nineteenth-century Basque texts available from the following genres: administrative letters and documents, notaries' texts, and private letters. Such texts can be considered "non-canonical" in the history of Basque, as opposed to "canonical" sources: printed texts, usually treating with religion. Canonical texts, extensively studied with reference to relativization strategies (e.g. in Krajewska 2017), will be used here as a basis for comparison, and the grammar used in those texts will be considered standard. The goal is to analyse the variation across textual genres, and to identify differences between canonical and non-canonical sources. This issue has not been the focus of Basque linguistics, which, because of the scarcity of texts, tends to analyse all sources together without considering the genre.

Preserved fifteenth- to eighteenth-century correspondence in Basque comprises only around 23,000 words (Padilla-Moyano 2015). Of these, 15,000 pertain to private letters. The biggest part (around 9,000 words) comes from fifty missives sent in 1757 on the ship Le Dauphin from Labourd to Louisbourg (Canada) (Lamikiz, Padilla-Moyano \& Videgain 2015). Since many were signed by members of the lower social strata, Padilla-Moyano (2015) proposed that a significant proportion of the Labourdin society, including women, was literate. However, Elosegi (2019), after analysing church registers and notarial documents, concluded that most letters were written by intermediaries. Among the 42 senders he could identify, only ten (seven men and three women) were literate and they belonged to upper or upper-middle social classes. Delegated writing was the usual way through which illiterate or semi-literate people could access writing until literacy became universal (Lyons 2014). Lyons (2014) lists three categories of intermediaries: the professional 
writer, the local notable (such as a cleric or a schoolteacher) and a family member or friend. Data from the Le Dauphin letters suggest that the latter two categories were involved (Padilla-Moyano 2015; Elosegi 2019).

Administrative documents were scarce before 1900. Trebiño (2001) gathered 79 texts (including letters) from between 1616 and 1935. Among them we find municipal laws, requests, or notifications. Many were translated from Romance and signed by civil servants of different ranks: mayors, secretaries, clerks, commissioners, or accountants. Even though we have little information about authors, it is unlikely that a monolingual Basque speaker could work in administration, as the language normally used in administration was Spanish or French.

Finally, Elosegi (2018) discovered Basque writings by eight notaries from Labourd (France), among whom Martin Harismendy stands out with 164 pages (11,200 words) in Basque. However, Harismendy's Basque documents represent a small proportion of his production of 13,167 pages.

Thus, in this paper we analyse texts which, because of the diglossic situation, are exceptional in the historical corpus of Basque. We have explained why the sociolinguistic context did not favour their production, but it is in order to reflect on why there were exceptions:

a. Basque could be used for personal reasons (for instance, between two native Basque mayors who knew each other well).

b. Basque could be a bridge language employed, for example, in correspondence between towns located on opposite sides of the border between France and Spain.

c. The great part of the society was monolingual. Because of that the authorities considered Basque useful to spread their decisions. Courts sometimes prepared interrogatories in Basque for monolinguals.

\subsection{The frequency of zein RCs}

In this section we analyse the outcomes the sociolinguistic situation had on the Basque syntax. We gathered 227 occurrences of the zein RC, from 106 texts. ${ }^{1}$ Of these 18 are administration documents (16 different authors), 13 notaries' text (3 authors), 32 administrative letters (17 authors), and 43 private letters. Table 2 presents the distribution of tokens across text types and centuries. Most examples from private correspondence ( 42 out of 65 ) come from the Le Dauphin collection, where zein relatives appear in 24 out of 50 letters.

1. More texts were analysed, but only those featuring the construction in question are included. 
Table 2. Tokens of the zein RC, split up by genre and century

\begin{tabular}{lccccc}
\hline Century & Adm. doc. & Adm. letters & Notaries & Private letters & Total \\
\hline 16 & 0 & 0 & 0 & 9 & 9 \\
17 & 0 & 33 & 0 & 3 & 36 \\
18 & 22 & 10 & 37 & 48 & 117 \\
19 & 33 & 27 & 0 & 5 & 65 \\
Total & 55 & 70 & 37 & 65 & 227 \\
\hline
\end{tabular}

To assess the frequency of zein RCs we have also extracted all other headed finite relative clauses from the texts. Table 3 shows the frequency of prenominal, postnominal, appositive and zein relatives as well as the overall frequency of relative constructions across text types and in the whole corpus. ${ }^{2}$ Additionally, we compare these figures with a sample of 17 seventeenth-to-nineteenth-century canonical Basque texts: catechisms and other types of religious prose.

Table 3. Normalised frequencies (per 1,000 words) of relative constructions

\begin{tabular}{lcccccc}
\hline Text type & Tokens & \multicolumn{5}{c}{ Frequency (per 1,000 words) } \\
\cline { 3 - 6 } & & Prenom. & Postnom. & Appos. & zein & All RCs \\
\hline Administrative texts & 658 & 11.0 & 1.2 & 1.0 & 7.1 & 20.2 \\
and letters & & & & & & \\
- Adm. documents & 289 & 15.9 & 1.0 & 1.1 & 4.5 & 22.5 \\
- Adm. letters & 160 & 7.6 & 2.2 & 1.0 & 8.5 & 19.2 \\
- Notaries & 95 & 23.2 & 0.9 & 2.8 & 17.1 & 44.0 \\
- Private letters & 114 & 4.3 & 0.5 & 0.4 & 7.0 & 12.4 \\
Religious texts & 3,241 & 7.9 & 0.7 & 1.1 & 2.0 & 11.6 \\
\hline
\end{tabular}

As expected (see Biber 1988), there are differences between text types: the highest rate of relatives per 1,000 words is found in notarial documents (44), followed by administrative documents and letters (around 20). Texts produced by notaries and clerks have more relatives than Basque religious prose has (with about 12 per 1,000 words), and private letters contain a similar number of relative clauses as religious prose.

The proportion of postnominal and appositive constructions does not vary across text types, but there are differences in the use of the zein RC. It accounts for $17 \%$ of all relatives in religious texts. This proportion is similar in administration documents, but higher in private and administration letters ( $56 \%$ and $44 \%$, respectively) and notarial texts (39\%). Consequently, the prenominal construction (the most common in modern language) is less frequent in those texts.

2. As most texts in our corpus are short (300 words on average), the frequencies were calculated per text type (and not per text). 


\subsection{Non-standard variants}

The most interesting aspect of the zein relative construction in our corpus is its non-standard variants, which are not found in canonical sources. They involve a form of the pronoun zein 'which' functioning as an invariable relative particle. Contrary to the standard construction, the pronoun does not take the case corresponding to the relativised argument.

In the most common non-standard variant, the inessive pronoun - usually the indefinite zeinetan and sometimes the definite singular zeinean - relativises all syntactic functions, for example, the absolutive subject:

(6) Iskriba-tzen dauzkitzut bi lerro hauk zu-ri gure write-IPFV AUX.1SG $>3$ PL $<2$ SG two line these you-DAT our osasun-a-ren marka-tze-ko, [zein-etan hanitz on health-DEF-GEN inform-NMLZ-RM which-INDEF.INES very good bai-ta Jainko-a-ri eskerr-ak] suB-be.3SG god-DEF-DAT thank-DEF.ABS.PL

'I am writing these two lines to you to inform you on my health, which, thank God, is very good.' (LeDauphin-45, private letter, 1757)

In other variants we find zeinak, ambiguous between absolutive plural or ergative singular (used to relativise absolutive singular in (7)), or the absolutive definite zeina.

(7) Egorri dinat

bat Lantzekanetu-rekin, bertze-a hire send AUX.1SG $>3 \mathrm{SG}<2 \mathrm{SG}$ one Lantzekanetu-SOC other-DEF.ABS your kusin-a defuntu-ba-rekin, [zen-ak etorri cousin-DEF.ABs dead-DEF-SOC which-DEF.ABS.PL/DEF.ERG come bait-zen Misel-ekin Baiona-rat, gaso-a] SUB-AUX.PST.3SG Misel-soc Bayonne-ADL poor-DEF.ABS 'I have sent you one with Lantzekanetu, and another one with your late cousin, who came with Misel to Bayonne, poor guy.'

(LeDauphin-20, private letter, 1757)

There are also clauses that we label as "non-relative" because what looks like a subordinate relative does not modify anything. For example, in (8), as the translation shows, the syntax is rather odd: if 'in which' refers to the letter, a part of the sentence is missing (we would expect 'in which we wrote that...'). 
(8) Marka-tzen darotazu ez-tuzu-la Qanigon-ekin write-IPFV AUX.2SG $>3$ SG $<1$ SG NEG-AUX.2SG $>3$ SG-COMPL Qanigon-SOC izatu letra-rik, bainan egin gintuben, [zein-etan have letter-PART but make AUX.PST.1PL $>3$ SG which-INDEF.INES aizpa Nana Miarritz-en bai-tugu neskato Bodri-rekin] sister Nana Miarritz-INEs sub-have.1PL $>3$ sg maid Bodri-soc 'You write that you haven't got our letters from Qanigon, but we wrote one, in which sister Nana is maid in Biarritz with Bodri.'

(LeDauphin-38, private letter, 1757)

Non-standard variants are most common in private letters, where over $40 \%$ of the examples are of this kind (Table 4).

Table 4. Non-standard zein relative clauses in different text types

\begin{tabular}{lcc}
\hline Text type & Tokens of $z$ zein RC & Non-standard variants (\%) \\
\hline Adm. doc. & 55 & 20.0 \\
Notaries & 37 & 18.9 \\
Adm. letters & 70 & 7.1 \\
Private letters & 65 & 43.1 \\
\hline
\end{tabular}

Table 5 presents occurrences of each variant (including the non-relative), and the number of sources in which it appears. The variant with zeinetan is the most widespread non-standard option.

Table 5. Frequencies of variants of zein relative

\begin{tabular}{lcc}
\hline Zein RC type & Tokens & Texts \\
\hline Standard & 176 & 88 \\
Non-standard zeinetan & 28 & 22 \\
Non-standard zeina/zeinak & 15 & 8 \\
Non-relative & 8 & 4 \\
\hline
\end{tabular}

The frequency of non-standard relatives seems highest in the eighteenth century, and it decreases in the nineteenth century. This might reflect an increase in literacy and knowledge of Romance languages, which would cause using the standard zein relative. Non-standard variants were unsuccessful innovations: they are not attested in the twentieth century. ${ }^{3}$

3. However, in modern written Basque there is a non-standard relative construction with the invariant particle non 'where', which seems not unlike the variant with zeinetan, but its development and use require further study. 


\subsection{Zein relatives and formulaic language}

Zein relatives in our corpus are often found in epistolary formulae, which are defined by Wray (2005: 9) as "a sequence, continuous or discontinuous, of words or other elements, which is, or appears to be, prefabricated: that is, stored and retrieved whole from memory at the time of use, rather than being subject to generation or analysis by the language grammar".

Following the classification by Wray (2005) and Rutten and Van der Wal (2012), two classes are relevant here: text-constitutive (e.g. letter openings) and intersubjective formulae (e.g. greetings or expressions of health). In a small corpus such as ours it is difficult to decide what counts as a formula. We thus only include two classes frequent in the data: (a) letter openings ("I have received your letter in which ..." and its variations, see Example (9)), and (b) the expression of the sender's health and hope that the receiver is alright ("we have health, which we hope you also have", "I want to let you know about my health, which is good" and similar phrases, Example (10)).

(9) Rezebitu dut atzo $z u-k$ eskribatu karta, receive AUX.1SG>3sG yesterday you-ERG write letter [zoin-tan erra-ten bai-tuzu jente paubri-ak which-INDEF.INES SAy-IPFV SUB-AUX.2sG $>3$ sG people poor-DEF.ABS.PL dire-la zu-ri eska-tzen dute-n-ak be.3PL-COMPL you-DAT ask-IPFV AUX.3PL $>3$ SG-SUB-DEF.ABS.PL gastu-ak] payment-DEF.ABS.PL

'Yesterday I received the letter you wrote, in which you say that it is the poor people that asks you for money.' (administration letter, 1817; Camino (2012))

(10) Osasun dugu Janko-a-ri esker, [zein-etan dezira-tzen health have.1PL $>3$ SG god-DEF-DAT thank which-INDEF.INES wish-IPFV bai-kinduke zuri-a hala ba-litz] SUB-AUX.POT.1PL>3SG your-DEF.ABS so COND-be.HYP.3sG 'We have health, thank God, which we wish you also have.'

(LeDauphin-46, private letter, 1757)

Table 6 shows that there is a correlation between the frequency of occurrence in a formula and letter type, on one hand, and type of relative, on the other hand. In private letters relatives appear more frequently in formulae than in administration letters. In Le Dauphin collection, this proportion is even higher (39\%). Non-standard relatives are also more common as part of a formula than the standard construction. 
Table 6. Relative clauses in formulae according to the text type and construction

\begin{tabular}{llcc}
\hline Context & & Tokens & Formulae \\
\hline Letter type & Administrative & 70 & $12.9 \%$ \\
& Private & 65 & $29.2 \%$ \\
Relative clause type & Standard & 102 & $14.7 \%$ \\
& Non-standard & 33 & $39.4 \%$ \\
\hline
\end{tabular}

\section{Discussion}

In this paper we focus on texts written in Basque despite the adverse diglossic situation. Their authors usually belonged to upper social strata and were taught how to write in Romance. Thus, literacy in Basque depended on literacy in another language. This fact is patent in spelling: for instance, writers often struggled to render Basque sibilants using Romance systems, which have fewer sibilant phonemes. Here we explore the consequences it had on syntax.

Writing does not usually happen in void and knowing how to write is not limited to the command of the code. It also presupposes knowledge related to different aspects of writing, such as genre knowledge and knowledge related to the social context of writing (Beaufort \& Iñesta 2014). For example, writing a letter requires understanding of the conventions ruling this type of texts and of how the given community usually writes them, as well as what is thought to be correct and what not. Genres can in fact be understood as "socially and culturally patterned ways of engaging in activity" (Lillis 2013: 70).

As regards genres analysed here, in terms of Koch and Oesterreicher (2012 [1985]), private letters are closer to the language of immediacy, and formal documents produced by different institutions are examples of language of distance: they constitute a monologue, there is distance between the partners, and topics are fixed. Administrative correspondence falls somewhere in between. Nevertheless, the texts in our corpus were written before the language was standardised, and as a result they exhibit dialectal features and characteristics described for the language of immediacy by Koch \& Oesterreicher (2012 [1985]: 454-455): congruence errors, problems with segmentation, low type-token ratio, overall lexical poverty, hesitation phenomena or markers of correction. Moreover, features of illiterate writing (see Montgomery 1995) are common: problems with spelling and word division or missing punctuation marks. This is because those texts were written in Basque by people who were literate in Romance. In a complex sociolinguistic environment, they could not rely on a fully standardised language and had to use a dialectal variety. Nevertheless, they looked for models to construct their writings. 
Bilinguals could resort to norms of other languages. For instance, when a clerk prepared a Basque document, he could translate from Spanish or French the typical phrases of administrative language, and, in general, try to copy the style of the text. The same holds for other conventions, for example the use of epistolary formulae.

Writers also treated Basque texts as models. For this to be possible, though, a certain tradition of Basque writing had to exist in the social environment. For instance, when composing a letter, the writer could reuse fragments of Basque letters, provided he had access to any. In general, learning of correspondence-writing conventions usually happened in practice: by reading or listening to letters and then imitation (see van der Wal \& Rutten 2013 and references therein). This explains the similarity between texts written by different people.

The zein relative construction is thought to have developed in Basque due to language contact (Lafitte 1991 [1944]; Haase 1992; Trask 1998). This might be a change from above spreading in writing from more literate bilinguals (usually belonging to higher social classes) to less proficient ones. Similar explanations have been proposed for changes in relativisation strategies in a number of languages (Romaine 1982; Rissanen 1999; Rutten \& van der Wal 2014, among others). In Basque, this change could happen through imitating the Romance style, for instance, through importing epistolary formulae, when writing a text belonging to a genre not-so-entrenched in Basque. We will develop this idea in what follows.

(11)-(14) are typical French eighteenth-to-twentieth-centuries letter openings with different types of RCs (with qui, dont and lequel). Example (14) resembles non-standard Basque relatives: apart from a resumptive pronoun elle, the pronoun has the non-standard form (auquel with a preposition instead of laquelle). Branca-Rosoff (1990) lists incorrect relatives among characteristics of letters of early twentieth-century soldiers.

(11) Je répond a ta lettre que nous avons reçu il y a qu' elques jours dont nous avons étés très contents de voir que vous êtes tous en bonne santé

(Bruneton-Governatori \& Moreux 2015: 89)

(12) Je vous aist crist cette Lettre pour vous faire asavoir de mes nousvelle qui sontres bonne dieu mersie

(Martineau 2007: 205)

(13) J'ai reçu hier 20 janvier ta lettre du 17 dans laquelle tu me parles du dessus de piano d'Adèle et où se trouve le petit mot de Jeannette

(Vicari 2018: 14)

(14) J'ai reçu ta longue lettre du 28 auquel elle m'a fait grand plaisir

(Branca-Rosoff 1990: 23)

Thus, formulae containing the zein $\mathrm{RC}$ were used by Basque writers, possibly less experienced, who were in need of prefabricated elements. Imitation was not always perfect, and often it was more like a "broken telephone" transmission, with 
misunderstandings and modifications of the construction. One of the reasons for that could be the limited command of Romance languages, and particularly of formal registers.

Bilingual speakers who used primarily spoken registers of Romance languages might have had problems with relatives in these languages, because they are rare in the spoken language and because Basque and Romance relativisation strategies differ. For English, for instance, Biber (1988) found that per 1,000 words there are on average 2.9 relative clauses in conversations, 4.6 in press reports, and 8.6 in official documents. Additionally, the French and Spanish equivalents of the zein RC - structures with lequel and el cual, respectively - pertain to formal written registers (Guiraud 1966; Auger 1995). With limited exposition to those constructions, bilinguals might not have understood their syntax. Speakers were more likely to be exposed to Romance constructions with invariant particles, which also differ from Basque usual relatives, but are simpler to use, and more common in the spoken language. The resulting non-standard Basque relatives are similar to lequel/el cual relatives because of the pronoun used, but function like Romance relatives with invariant particles.

Formulaic language played a significant role in these processes. As regards the variant with the inessive zeinetan, there is an epistolary formula, in which the inessive argument is relativised (15). Its equivalent is common in other languages (13), and the first step was to translate it into Basque using the standard zein construction:

(15) Recebitu dut çure guthun-a, [çoin-etan escriba-tzen receive AUX.1SG>3SG your letter-DEF.ABS which-INDEF.INES write-IPFV bai-terautaçu nola dezir handi-a ducie-la SUB-AUX.2SG $>3$ SG $<1$ SG how wish big-DEF.ABS have.2PL $>3$ SG-COMPL guci-ec baque eta arcordu hun bat-en eçar-te-ra bi all-DEF.ERG.PL peace and agreement good one-GEN bring-NMLZ-ADL two herri hoyen artian] community these.GEN between

'I have received your letter in which you write me that your greatest wish is to bring peace and good agreement between the two communities.'

(Etxart, administrative letter, 1616-1617)

We think that such formulae - or even this very formula - were the source of the non-standard zeinetan RC. Writers reanalysed the inessive pronoun in a formula (15) as a particle introducing the clause and extended it to situations where another syntactic function is relativised.

This reanalysis could have happened through "recycling" and slight modifications of parts of formulae. This is represented in (16). The first stage is the formula (16a). It is then shortened: from 'in which you write that $X$ ' we arrive at 'in which $\mathrm{X}$ '. This clause is used in a sentence containing a reference to a letter (16b). Even 
though syntactically it cannot function as a RC, semantically it resembles it. We find several such examples in our corpus: the ones we labelled as "non-relative" (see (8) above). In such contexts the pronoun zeinetan loses its locative value and becomes a semantically empty relativiser. Afterwards the construction can be used to modify any noun phrase in any circumstances (16c), as in (17).

(16) a. I have received your letter, [in which you write that X]

b. You write that you haven't got any letters ... [in which X]

c. ... [a noun phrase] [which X]

(17)

$\begin{array}{ll}\text { salutatzen zaituzte aizpa Nanak, [zeinetan } & \text { Miarritzen } \\ \text { greet-IPFV AUX.2PL }>3 \text { SG sister Nana-ERG which-INDEF.INES } & \text { Biarritz-INES } \\ \text { bai-ta neskato] } & \\ \text { sub-be.3SG maid } & \\ \text { 'sister Nana, who is a maid in Biarritz, sends greetings.' }\end{array}$

(LeDauphin-15, private letter, 1757)

Similar scenarios can be proposed for other, less frequent variants. The option with zeina can be linked to the health formula, in which the absolutive form of the pronoun is found:

(18) Bada, ni-k ere satifa-tzen zaitut guri-a-z, [zeñ-a so I-ERG also satisfy-IPFV AUX.1sG $>2$ sG our-DEF-INS which-DEF.ABS bai-tugu haiñitz perfekt-a Jainko-a-ri esker] SUB-have.1PL $>3$ SG very perfect-DEF.ABS god-DEF-DAT thank 'And so, I also inform you on our (health) which, thank God, we have perfect.' (LeDauphin-49, private letter, 1757)

The changes attested in Basque can be considered another example of diaphasic variation in relativisation strategies, common in many European languages, where relative pronouns that are inflected in the standard language are invariant in non-standard varieties.

A particular case of this variation involves locative pronouns as general relativisers. In some languages such relativisers belong to the standard (e.g. pu 'where' in Modern Greek (Murelli 2011: 184)), but elsewhere they are limited to non-standard varieties. For example, wo 'where' can relativise all cases in some German varieties (Romaine 1984; Fleischer 2004). In Romance, something similar happens in non-standard Italian with dove 'where' (Cerruti 2016).

The explanation proposed here for Basque non-standard relative clauses resembles the general scenario in the development of relative particles from locative pronouns proposed by Murelli (2011: 183). According to him, the locative interrogative is first used to relativise locative arguments, but it then becomes an "unspecific connector" linking main and subordinate clauses (which is not a RC syntactically, but there is a shared participant in both clauses). From there it extends to relative 
clauses, relativising first inanimate and then also animate obliques, before extending to other syntactic functions. In Basque texts we also find something similar to the unspecific connector (in "non-relative" examples), though we do not have enough information on the order of extension (oblique to grammatical cases). The data discussed here provide an insight into why such changes can happen and how they can proceed in written language. In Basque, the reason appears to be related to language contact, incomplete bilingualism and inexpert writers' reliance on formulaic language.

Fixed phrases were also important for the development of relative constructions elsewhere, for example in the English wh-relative (Romaine 1982; Rissanen 1999). Bergs (2005: 50) argues that who, whom or whose "do not simply enter the linguistic system as grammatical elements in one big swoop, but which originate as part and parcel of complex formulaic expressions which are then slowly (des-)integrated into the grammar." Non-standard zein relatives also originated as a part of fixed phrases, but eventually became a productive relativisation device (the construction occurs also outside formulaic contexts). Moreover, the non-standard zein eventually spread to writing of people proficient in Romance.

We could also ask why writers used the zein relative construction so often: as compared to Basque religious prose, this construction is more frequent in our corpus, especially in letters and notarial documents. We think that the construction, most probably not employed in informal oral interactions, became a feature associated with written language. Letters are, in general, closer to spoken discourse than many other genres, but they contain elements of more formal registers, too, and reflect people's awareness of writing conventions (Martineau 2007; van der Wal \& Rutten 2016). The use of formulae is a sign of this awareness. More generally, the spread of zein relative into the genres other than literary texts can be seen as an example of the creation of Basque written register. Importantly, with non-standard zein relatives this process seems to have happened in a "natural" way, in exchanges between writers, and not through influence of printed language. The proof of that is that those non-standard relatives are not found in printed Basque books.

\section{Conclusion}

The Basque zein relative clause has been traditionally considered an uninteresting calque from Romance, but the particularities behind this borrowing were not discussed. Having analysed a corpus of genres understudied in Basque linguistics, such as administrative documents and private letters, we have shown that in order to understand how the construction was introduced into the language it is necessary to take into account the sociolinguistic situation and characteristics of textual genres. 
We have reflected on reasons for the emergence and spread of zein relative, the mechanisms that underlie its diffusion to different genres and from more literate to less literate writers. Finally, we have explained the creation of non-standard variants of the construction. Similar processes to those observed in Basque were described for other European languages, but our case study provides an insight into how such processes take place in the context of diglossia and lack of standard variety.

This sociolinguistic situation made people look for models in other languages (specifically, imitating Romance constructions), but also in Basque texts they had access to, such as letters. In this way, the relative construction with the pronoun zein 'which', common in literary texts, spread to administrative or legal language and private letters. In letters, epistolary formulae, partially fixed expressions usually translated from Romance, played a key role in these processes, because a few of them contained the zein relative. In a further development, non-standard relatives (e.g. the variant with inessive pronoun) emerged when, similarly to what occurred in other European languages, writers reanalysed the syntax of formulae with the standard zein relative. We propose that this innovation happened because of the limited command of Romance languages of some writers, who did not understand the syntax of the standard construction. The new relativisation strategy then became productive and spread to other writers. We argue that zein relative, standard and non-standard, eventually became a feature of the emerging Basque written register. The life of the non-standard relative construction, though interesting, was relatively short, as it did not make it into the twentieth century, and the reasons for it appear to be increasing knowledge of Romance languages in the population.

\section{Abbreviations and glossing conventions}

\begin{tabular}{|c|c|c|c|}
\hline ABS & absolutive & INS & instrumental \\
\hline $\mathrm{ADL}$ & adlative & IPFV & imperfective \\
\hline AUX & auxiliary verb & NEG & negation \\
\hline COMPL & complementiser & NMLZ & nominalisation \\
\hline COND & conditional & PART & partitive \\
\hline DAT & dative & PL & plural \\
\hline DEF & definite & POT & potential \\
\hline ERG & ergative & PST & past \\
\hline GEN & genitive & $\mathrm{RM}$ & relational marker \\
\hline HYP & hypothetical & SG & singular \\
\hline INDEF & indefinite & soc & sociative \\
\hline INES & inessive & SUB & subordinator \\
\hline
\end{tabular}

In glosses of finite verbs the sign ">" distinguishes ergative and absolutive arguments and " $<$ " distinguishes dative ones. 


\section{Funding}

The research for the paper was made possible by the grants from the Spanish Ministry of Science and Innovation (FFI2016-76032-P and PGC2018-098995-B-I00). Support given by the research group on historical linguistics (IT1344-19) funded by the Basque Government is also acknowledged.

\section{References}

Amorrortu, Estibaliz. 2003. Basque sociolinguistics: Language, society, and culture. Reno: Center for Basque Studies.

Auger, Julie. 1995. On the history of relative clauses in French and some of its dialects. In Henning Andersen (ed.), Historical linguistics, 1993: Selected papers from the 11th International Conference on Historical Linguistics, 19-32. Amsterdam \& Philadelphia: John Benjamins. https://doi.org/10.1075/cilt.124.03aug

Azkue, Resurrección María. 1891. Euskal izkindea. Bilbao: Astui.

Azkue, Resurrección María. 1923-1925. Morfología vasca. Bilbao: Editorial Vasca.

Azkue, Resurrección María. 1969 [1905-1906]. Diccionario vasco-español-francés. Bilbao: La Gran Enciclopedia Vasca.

Beaufort, Anne \& Anna Iñesta. 2014. Author profiles: Awareness, competence, and skills. In Eva-Maria Jakobs \& Daniel Perrin (eds.), Handbook of writing and text production, 141-158. Berlin: Mouton De Gruyter. https://doi.org/10.1515/9783110220674.141

Bergs, Alexander. 2005. The role of the individual in language change from the point of view of Social Network Analysis. Logos and Language 6. 30-54.

Biber, Douglas. 1988. Variation across speech and writing. Cambridge: Cambridge University Press. https://doi.org/10.1017/CBO9780511621024

Blanche-Benveniste, Claire. 1990. Usages normatifs et non normatifs dans les relatives en français, en espagnol et en portugais. In Johannes Bechert, Giuliano Bernini \& Claude Buridant (eds.), Toward a typology of European languages, 317-335. Berlin: Mouton de Gruyter. https://doi.org/10.1515/9783110863178.317

Branca-Rosoff, Sonia. 1990. Conventions d'écriture dans la correspondance des soldats. Mots 24(1). 21-36. https://doi.org/10.3406/mots.1990.1535

Bruneton-Governatori, Ariane \& Bernard Moreux. 2015. Un modèle épistolaire populaire: Les lettres d'émigrés béarnais. In Daniel Fabre (ed.), Par écrit: Ethnologie des écritures quotidiennes, 79-103. Paris: Éditions de la Maison des sciences de l'homme.

Camino, Iñaki. 2012. Bi testu llabur Aezkoa eta Zuberoako. Garralda (1828) \& Larraine (1817). Fontes Linguae Vasconum 114. 61-72.

Carter, Karen E. 2011. Creating Catholics: catechism and primary education in early modern France. Notre Dame: University of Notre Dame Press.

Cerruti, Massimo. 2016. Changes from below, changes from above. Relative constructions in contemporary Italian. In Massimo Cerruti, Claudia Crocco \& Stefania Marzo (eds.), Towards a new standard: Theoretical and empirical studies on the restandardization of Italian, 62-88. Berlin: Mouton de Gruyter.

Chartier, Roger. 1997. Du livre au lire. Réseaux 1. 271-290.

Chartier, Roger, Dominique Julia \& Marie-Madeleine Compère. 1976. L'éducation en France du XVIe au XVIIIe siècle. Paris: Société d'Éducation d'Enseignement Supérieur. 
Dávila, Pauli, Ana Eizagirre \& Idoia Fernández. 1994. Los procesos de alfabetización y escolarización en Euskal Herria. Cuadernos de Sección. Educación 7. 63-99.

Elosegi, Xabier. 2018. Senpereko eta Lapurdiko euskara XVIII mendean. Senpere: Lapurdi 1609. Elosegi, Xabier. 2019. Le Dauphin: 1757ko gutuneriari buruzko osagarriak eta gogoetak. Bilbao: Euskaltzaindia.

Ferguson, Charles A. 1959. Diglossia. Word 15(2). 325-340.

https://doi.org/10.1080/00437956.1959.11659702

Fishman, Joshua A. 1972. The sociology of language. Rowley: Newbury House.

Fleischer, Jürg. 2004. A typology of relative clauses in German dialects. In Bernd Kortmann (ed.), Dialectology meets typology, 211-243. Berlin: Mouton de Gruyter.

Giacalone Ramat, Anna. 2008. Persistence and renewal in the relative pronoun paradigm: the case of Italian. Folia Linguistica Historica 25(1-2). 115-138. https://doi.org/10.1515/flin.26.1-2.115

Grosperrin, Bernard. 1984. Les petites écoles sous l'Ancien Régime. Rennes: Ouest France.

Guiraud, Pierre. 1966. Le système du relatif en français populaire. Langages 3. 40-48. https://doi.org/10.3406/lgge.1966.2342

Haase, Martin. 1992. Sprachkontakt und Sprachwandel im Baskenland. Hamburg: Helmut Buske. Koch, Peter \& Wulf Oesterreicher. 2012 [1985]. Language of immediacy - language of distance: Orality and literacy from the perspective of language theory and linguistic history. In Claudia Lange, Beatrix Weber \& Göran Wolf (eds.), Communicative spaces. Variation, contact, and change, 441-473. Frankfurt am Main: Peter Lang.

Krajewska, Dorota. 2017. Euskararen sintaxi diakronikorantz: Egitura konplexuak / Towards a historical syntax of Basque: Complex constructions. Vitoria-Gasteiz: UPV/EHU doctoral dissertation. http://hdl.handle.net/10810/26877

Lafitte, Pierre. 1991 [1944]. Grammaire basque. Donostia: Elkar.

Lamikiz, Xabier, Manuel Padilla-Moyano \& Charles Videgain. 2015. Othoi çato etchera. Le Dauphin itsasontziko euskarazko gutunak (1757) - Correspondance basque du corsaire Le Dauphin (1757). Special edition of Lapurdum 2.

Larramendi, Manuel. 1728. De la antigüedad y universalidad del bascuenze en España. Salamanca: Eugenio García de Honorato.

Larramendi, Manuel. 1729. El imposible vencido. Salamanca: Antonio Joseph Villargordo Alcaraz.

Larramendi, Manuel. 1745. Diccionario trilingüe del castellano, vascuence y latín. San Sebastián: Bartolomé Riesgo y Montero.

Lillis, Theresa. 2013. The sociolinguistics of writing. Edinburgh: Edinburgh University Press.

Lyons, Martyn. 2012. The writing culture of ordinary people in Europe, c. 1860-1920. Cambridge: Cambridge University Press. https://doi.org/10.1017/CBO9781139093538

Lyons, Martyn. 2014. The power of the scribe: Delegated writing in Modern Europe. European History Quarterly 44(2). 244-262. https://doi.org/10.1177/0265691414526342

Madariaga, Juan. 2014. Sociedad y lengua vasca en los siglos XVII y XVIII. Bilbao: Euskaltzaindia. Martineau, France. 2007. Variation in Canadian French usage from the 18th to the 19th century. Multilingua 26(2-3). 203-227. https://doi.org/10.1515/MULTI.2007.010

Montgomery, Michael. 1995. The linguistic value of Ulster emigrant letters. Ulster Folklife 41. 26-41. Mounole, Céline \& Joseba A. Lakarra. 2018. Euskara Arkaikoa. In Joakin Gorrotxategi, Iván Igartua \& Joseba A. Lakarra (eds.), Euskararen historia, 345-468. Vitoria-Gasteiz: Eusko Jaurlaritza.

Murelli, Adriano. 2011. Relative constructions in European non-standard varieties. Berlin: Walter de Gruyter. https://doi.org/10.1515/9783110238792

Oyharçabal, Bernard. 1987. Étude descriptive de constructions complexes en basque, propositions relatives, temporelles, conditionelles et consessives. Paris: Université de Paris VII doctoral dissertation. 
Oyharçabal, Bernard. 1999. Euskarazko irakaskintzaren historia ororen eskolen ildotik, iraultzaren frantses garaiko eskola liburuxka bat. Lapurdum 4. 81-105. https://doi.org/10.400o/lapurdum.1545

Oyharçabal, Bernard. 2003. Relatives. In José Ignacio Hualde \& Jon Ortiz de Urbina (eds.), A grammar of Basque, 762-821. Berlin: Walter de Gruyter.

Padilla-Moyano, Manuel. 2015. Le Dauphin itsasontziko gutuneria (1757) edo euskararen historia behetik. Special edition of Lapurdum 2. 45-77.

Rijk, Rudolf Pieter Gerardus de. 1972. Studies in Basque syntax: Relative clauses. Cambridge, Massachusetts: Massachusetts Institute of Technology.

Rissanen, Matti. 1999. Syntax. In Richard M. Hogg \& Roger Lass (eds.), The Cambridge history of the English language, vol. 3, 187-331. Cambridge: Cambridge University Press.

Romaine, Suzanne. 1982. Socio-historical linguistics. Cambridge: Cambridge University Press. https://doi.org/10.1017/CBO9780511720130

Romaine, Suzanne. 1984. Towards a typology of relative-clause formation strategies in Germanic. In Jacek Fisiak (ed.), Historical syntax, 437-470. Berlin: Mouton de Gruyter. https://doi.org/10.1515/9783110824032.437

Rutten, Gijsbert \& Marijke van der Wal. 2012. Functions of epistolary formulae in Dutch letters from the seventeenth and eighteenth centuries. Journal of Historical Pragmatics 13(2). 173-201. https://doi.org/10.1075/jhp.13.2.01rut

Rutten, Gijsbert \& Marijke van der Wal. 2014. Social and constructional diffusion: Relative clauses in seventeenth- and eighteenth-century Dutch. In Ronny Boogaart, Timothy Colleman \& Gijsbert Rutten (eds.), Extending the scope of construction grammar, 181-205. Berlin, New York: Walter de Gruyter.

Salaburu, Pello. 2018. El euskera contemporáneo: el largo camino de la unificación literaria. In Joaquín Gorrochategui, Iván Igartua \& Joseba A. Lakarra (eds.), Historia del euskera, 799-869. Vitoria-Gasteiz: Eusko Jaurlaritza.

Sarasola, Ibon. 1975. Euskal literatura numerotan. San Sebastián: Kriseilu.

Stark, Elisabeth. 2016. Relative clauses. In Adam Ledgeway \& Maiden Martin (eds.), The Oxford guide to the Romance languages, 1029-1040. Oxford: Oxford University Press. https://doi.org/10.1093/acprof:oso/9780199677108.003.0064

Trask, Robert L. 1998. The typological position of Basque: Then and now. Language Sciences 20. 313-24. https://doi.org/10.1016/S0388-0001(98)00006-o

Trebiño, Imanol. 2001. Administrazio zibileko testu historikoak. Vitoria-Gasteiz: IVAP.

Urgell, Blanca. 2018. Lehen Euskara Modernoa. In Joakin Gorrotxategi, Iván Igartua \& Joseba A. Lakarra (eds.), Euskararen historia, 549-657. Vitoria-Gasteiz: Eusko Jaurlaritza.

Vicari, Stefano. 2018. Rituels épistolaires dans les lettres des poilus peu et moins lettrés: Une analyse contrastive. SHS Web of Conferences 46. 06009.

https://doi.org/10.1051/shsconf/20184606009

Wal, Marijke van der \& Gijsbert Rutten. 2013. The practice of letter writing: Skills, models, and Early Modern Dutch manuals. Language \& History 56(1). 18-32.

https://doi.org/10.1179/1759753613Z.00000000014

Wal, Marijke van der \& Gijsbert Rutten. 2016. At the crossroads. Orality and literacy in Early and Late Modern Dutch private letters. In Ann-Catrine Edlund, Timothy G. Ashplant \& Anna Kuismin (eds.), Reading and writing from below: exploring the margins of modernity, 197-214. Umeå: Umeå University.

Wray, Alison. 2005. Formulaic language and the lexicon. Cambridge: Cambridge University Press. Zuazo, Koldo. 2019. Standard Basque and its dialects. London-New York: Routledge. 


\title{
Dialect contact in the vowel system of Mišótika Cappadocian
}

\author{
Nicole Vassalou ${ }^{1,2}$, Dimitris Papazachariou ${ }^{1}$ and Mark Janse ${ }^{2}$ \\ ${ }^{1}$ University of Patras / ${ }^{2}$ Ghent University
}

\begin{abstract}
This study focuses on changes in the vowel system of contemporary Mišótika Cappadocian. It presents an acoustic analysis of the vowels of Mišótika, based on recordings of 16 native speakers from two different Cappadocian communities in Northern Greece. Our analysis shows that the current vowel system diverges from the one attested a century ago. Moreover, there are significant differences between the two Cappadocian speech communities, which are the result of dialect contact under different sociolinguistic conditions. Finally, gender also seems to be a significant sociolinguistic parameter, as male speakers seem to be one step ahead in the process of linguistic change.
\end{abstract}

Keywords: Mišótika, Cappadocian, vowel system, linguistic change, dialect contact, gender

\section{Introduction}

This study examines the vowel system of contemporary Mišótika, which is a variety of Cappadocian Greek. Our research aims to present the linguistic changes that the vowel system of Mišótika has undergone since the forced migration of the Cappadocians under the population exchange between Greece and Turkey in 1923-24, due to dialect contact and negative language attitudes of the locals against Cappadocian newcomers. Our second goal is to analyse the distribution of the vowels in the vowel space, taking into account the impact of the different contact conditions as well as gender.

In particular, we compare the speech of Mišótika speakers from two Cappadocian communities (Neo Agioneri and Xirochori) and analyse the differences between them, taking into consideration mechanisms of language contact and linguistic change (see, e.g., Trudgill 1986; Chambers, Trudgill \& Schilling-Estes 2002; Hickey 2010). We also study the effect of gender (see, e.g., Holmes \& Meyerhoff 2003; 
Coates 2013; Eckert \& McConnell-Ginet 2013), because it was found that the two genders perform different social roles in their communities.

Section 2 contains some basic information about the historical and linguistic background of Cappadocian Greek. In Section 3 we present the research methodology and some information about the communities under investigation. In Section 4 the results of the acoustic analyses of the vowel systems of the two Cappadocian varieties, split up by gender, are presented. In Section 5 we discuss and interpret the observed Cappadocian variation patterns in more detail. Finally, in Section 6 we present the conclusions of this study.

\section{Historical and linguistic background}

Cappadocian was spoken until 1924 in what is now the Central Anatolian Region of present-day Turkey (see Figure 1). It is a Greek-Turkish contact variety, the result of very long-term language contact, and was spoken by Greek Orthodox Christians in Cappadocia until the population exchange between Greece and Turkey in 1923-24. This linguistic variety of Greek origin had been in contact with Turkish for almost nine centuries after the invasion of the Seljuks in the 11th century and the conquest of Byzantine Asia Minor by the Ottoman Turks in the 14th century. The result of this contact is apparent in the Cappadocian lexicon, phonology, morphology and syntax, although the exact impact varies among the different subdialects according to the nature and duration of the contact situation. ${ }^{1}$

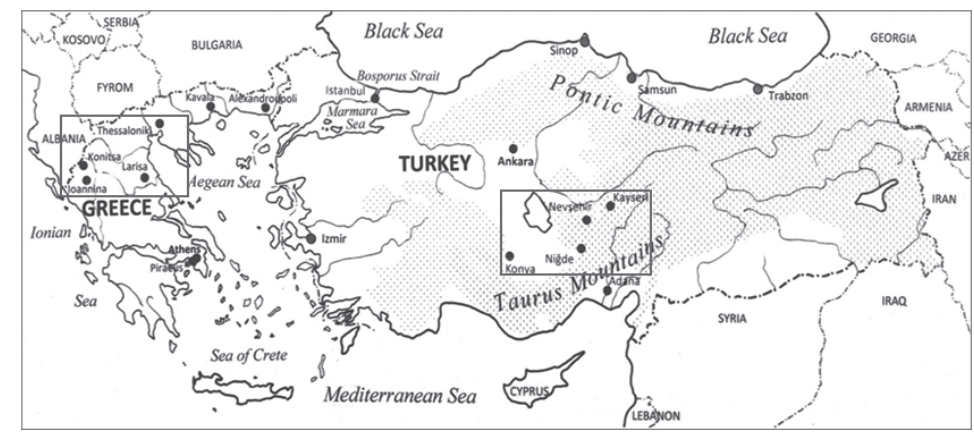

Figure 1. Central Macedonia (Greece) and Cappadocia (Turkey)

1. Cf. Dawkins (1916), Janse (2002, 2008, 2009, 2020a, 2020b), Karatsareas (2011). 
One of the Cappadocian villages was Misti (present-day Konakl1), ${ }^{2}$ a homogeneous town without close contact with Muslim groups (Dawkins 1916: 19). When the Cappadocians were forced to leave their homeland in 1924, the inhabitants of Misti, estimated at around 400 families, were scattered all over Greece and settled in over twenty different villages and towns.

In Greece, Cappadocians settled either in homogeneous villages with other Cappadocian speakers, in mixed villages with other Greek dialect speakers (locals and/or refugees), or in big cities like Athens and Thessaloniki. As a consequence, the Cappadocian refugees and their descendants have been in contact with different varieties of Greek for almost a century, under different sociolinguistic conditions, creating several different versions of contact for the same linguistic system.

The basic research question is whether language contact with Standard Modern Greek (SMG) or other varieties of Modern Greek is gradually leading to the attrition of Mišótika or the creation of a new koine, ${ }^{3}$ i.e., a new variety which includes mixed features from Mišótika, SMG, and/or other Greek dialectal varieties. We should also take account of the pressure that the Cappadocians felt from the Greek locals with whom they were in contact after the population exchange, and the severe stigma that any Turkish characteristics carried for many decades, not just in the language but in other aspects of social behaviour as well.

The arrival of migrants in Greece did not imply the end of their adventures or difficulties. They had to fight hard to defeat hardship, deprivation, and even the hostility of many Greek locals. There is a lot of evidence in various sources and in the recordings for our study as well, which highlight the discrimination and negative languages attitude that Cappadocians suffered in Greece. ${ }^{4}$ The following testimony of a Cappadocian refugee captures the atmosphere they encountered upon coming to Greece: "Mas féran sto Ionanistán. Mia xará ímastan ecí káto. Ecí ímastan jaúriðes c' eðó imaste turkóspori" ['They brought us to Ionanistan [Greece]. We were fine down there. There we were 'infidels' and here we are 'Turkish bastards']. ${ }^{5}$

2. Konaklı is located about $35 \mathrm{~km}$ northeast of Niğde in Niğde Province (see Figure 1).

3. The koineization process results in the creation of a new variety, under the activation of three different linguistic mechanisms, i.e., leveling, simplification and reallocation (cf., e.g., Trudgill 1986; Hinskens 1992).

4. Cf. Mourelos (1982); Harakopoulos (2003), Janse (2008: 123-125; 2018: 300-301; 2020a: 47-48).

5. Granddaughter of Turkish refugees quoting her grandmother in the documentary film "Last Words" by Koert Davids (serious Film 2014, www.seriousfilm.nl/projects/last-words). 
One of the results of this stigmatization is to be found in the linguistic system of the variety, as the Cappadocians were trying to hide the use of their dialect, as well as to assimilate to the new linguistic environment.

As far as the vowel system of the Mišótika dialect is concerned, we have to point out that before the population exchange, the Cappadocian vowel system, including the dialect of Misti, consisted of eight vowels, aligning it with the vowel system of Turkish (Dawkins 1916: 67-68). ${ }^{6}$

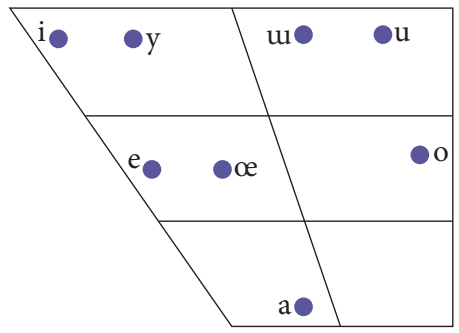

Figure 2. The pre-1924 Cappadocian vowel system

The vowels /i, e, a, o, u/ also existed in other Greek varieties, but /y, œ, w/ were borrowed from Turkish (Dawkins 1916; Janse 2009, 2020b). The vowels /y, œ, w/ appeared mainly in Turkish loanwords, e.g. [ty'tyn] < Turkish tütün "tobacco", [mu'sur] < Turkish misır "corn", whereas their presence in Greek words was rare,

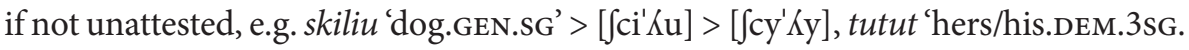
GEN.sG' [tu'tut] > [ty'tyt], ikusen 's/he heard' ['ikusen] > ['iksen] > ['yksen] (Janse 2009: 40f, 2020b: $\$ 6.1 .1){ }^{7}$

Therefore, our research aims to indicate the change that the vowel system of contemporary Mišótika has undergone in the speech of the second-generation Cappadocian descendants, in comparison with the older system (see Figure 2), which Cappadocians used before their settlement in Greece in the 1920s.

6. Dawkins conducted fieldwork in Cappadocia in the years 1909-1911 and is our only source for pre-1924 Mišótika.

7. The very scanty evidence does not allow any speculations about the exact conditions under which $[\mathrm{i}]$ or $[\mathrm{u}]$ could change to $[\mathrm{y}]$ in certain environments. 


\section{Data and methodology}

Our study is an acoustic analysis of the vowels of contemporary Mišótika based on recordings of spontaneous speech of elderly native speakers (male and female), who live in two Cappadocian communities in the administrative region of Central Macedonia (Northern Greece): Neo Agioneri (Kilkis prefecture) and Xirochori (Thessaloniki prefecture) (see Figure 3).

Neo Agioneri is a homogeneous village of Cappadocian origin, populated entirely by descendants from Misti, ${ }^{8}$ where the inhabitants speak exclusively Mišótika among themselves. Xirochori, by contrast, is a mixed village, inhabited not only by Cappadocians but also by speakers of other Greek dialects, specifically Pontians, Thracians and Sarakatsani.

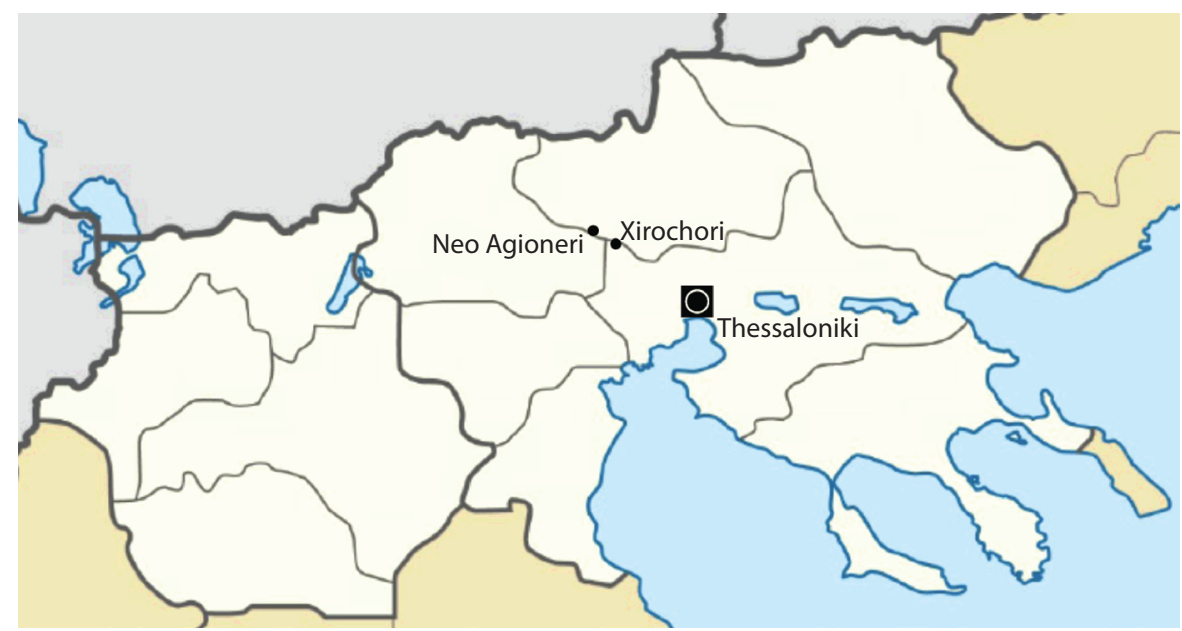

Figure 3. Central Macedonia (Greece) $)^{9}$

Nevertheless, the social organization of the two villages is quite similar, especially in terms of the roles of men and women. According to the informants' narratives, the women constituted a low-contact and stable group, while their only occupation was the care of the household and their children in their daily lives (see Tables 1 and 2).

8. In Neo Agioneri, there are also some inhabitants who are not of Misti origin but they have married people from the village. Nevertheless, in the present study, we excluded such cases and we examined only native speakers.

9. commons.wikimedia.org/wiki/File:West_\%26_Central_Macedonia_Regions_Greece_location_map.svg 
252 Nicole Vassalou, Dimitris Papazachariou and Mark Janse

Table 1. Sociodemographic details of the participants from Neo Agioneri

Women from Neo Agioneri

\begin{tabular}{|c|c|c|}
\hline Participants $^{1}$ & Education & Profession $^{2}$ \\
\hline XO_speaker 1 & junior high school & housewife \\
\hline SP_speaker 2 & junior high school & housewife \\
\hline XG_speaker 3 & primary school & housewife and seamstress \\
\hline PG_speaker 4 & junior high school & housewife \\
\hline \multicolumn{3}{|c|}{ Men from Neo Agioneri } \\
\hline GG_speaker 5 & technical high school & factory worker \\
\hline HX_speaker 6 & junior high school & farmer \\
\hline HP_speaker 7 & junior high school & bus driver \\
\hline KM_speaker 8 & high school & farmer \\
\hline
\end{tabular}

1. The names of participants are presented in a coded way so that their personal data are protected.

2. The majority of women had never been employed as their only occupation was the care of the household and their children, and for this reason, we refer to them as housewives in the profession category.

Table 2. Sociodemographic details of the participants from Xirochori

\section{Women from Xirochori}

\begin{tabular}{|c|c|c|}
\hline Participants & Education & Profession \\
\hline MT_speaker 9 & primary school & housewife \\
\hline GP_speaker 10 & junior high school & housewife \\
\hline KS_speaker 11 & primary school & housewife \\
\hline PS_speaker 12 & junior high school & housewife \\
\hline \multicolumn{3}{|c|}{ Men from Xirochori } \\
\hline KK_speaker 13 & junior high school & farmer \\
\hline GT_speaker 14 & junior high school & carpenter \\
\hline NG_speaker 15 & primary school & butcher \\
\hline GX_speaker 16 & technical high school & factory worker \\
\hline
\end{tabular}

Moreover, their network was limited to contact with the neighbourhood, mainly with women from Misti origin. Constituting a closed community, the women used to speak exclusively Mišótika instead of Modern Greek among themselves in both villages, whereas in Xirochori they spoke Mišótika and SMG, using the dialect in interactions with speakers of the same background, and SMG in contacts with speakers of the other varieties of Greek.

Men, on the other hand, had greater mobility. Most of them often visited other villages and nearby cities, such as Thessaloniki, due to their professional activities (see Tables 1 and 2). As a result, they were forced to accommodate to the various linguistic environments of other varieties and the contact with SMG was clearly 
more pronounced as well. Furthermore, they were more socially active as they were busy with political issues and the organization of the local associations.

When we planned the fieldwork and the data collection, the background of the two Cappadocian communities and the social stigmatization of the dialect were taken into consideration. Therefore, an ethnographic approach was chosen as the most appropriate method in order not to trigger the Observer's Paradox (Labov 1972). However, we strongly believe that the emergence of the Observer's Paradox is not simply due to the presence of the microphone and the recorder, but the result of the communicative settings of the recording and the absence of real social bonds between the fieldworker and the informants (Papazachariou 2006). For this reason, we trained a native male speaker of Mišótika, a core member of both speech communities, to act as our main fieldworker. The fieldworker worked in a public service that served the inhabitants of both villages and thus had close bonds with all the research participants. More specifically, the speakers recorded were members of his family as well as people from his inner circle. By doing so, we managed to mitigate the impact of the alien presence, to create a friendly and daily casual communicative situation and thus to record natural dialectal speech.

Sixteen elderly speakers (age range 65-88) of Mišótika were examined: four women and four men from each village (see Tables 1 and 2). ${ }^{10}$ The participants were selected according to ethnographic criteria. All of them were born in Greece and are second-generation Mišótika speakers. The Mišótika dialect is their first language and the dominant one in their present-day linguistic repertoires, as they had been exposed exclusively to the dialect spoken by their parents and grandparents until they started going to school where they had to accommodate to the use of SMG. Moreover, only native speakers who had lived their whole life in the village under investigation were examined. In other words, only participants who had not moved to another city in Greece or to another country for a long period of time were selected. Our goal was for all research participants from each village to have been exposed to the same linguistic environment throughout their lives under equivalent conditions.

1,000 vowel tokens were collected from each informant, for a total of 16,000 tokens. The Praat phonetic analysis program (Boersma \& Weenink 2019) was used for the transcription, annotation and formant analysis of the data. The data was segmented manually and the formants were measured at the midpoint of each vowel. Subsequently, the results of the formant analysis were normalized and represented, following the Watt \& Fabricius normalization method (Watt \& Fabricius

10. The mean ages of each participant group: women from Neo Agioneri mean $=79$, men from Neo Agioneri mean $=75$, women from Xirochori mean $=80$, men from Xirochori mean $=78$. 
2002), ${ }^{11}$ with the help of Visible Vowels, a web app for the analysis, normalization and visualization of acoustic vowel measurements (Heeringa \& Van de Velde 2018).

Finally, separate repeated-measures MANOVA tests were conducted for each vowel to compare the effect of gender and location on the formant frequency measures (normalized F1 and F2 values) of each vowel, in order to assess the differences between (1) the two Cappadocian communities and (2) men and women.

\section{Results}

In this section, we present the results provided by the measurements of the vowels of female and male speakers of Mišótika from Neo Agioneri and Xirochori and discuss their distribution in the vowel spectrum. The analysis of the speech of women and men from both Cappadocian communities highlighted the distribution of nine vowels according to the F1 and F2 values, the eight vowels that appeared in the pre-1924 Cappadocian system (Dawkins 1916), as well as the vowel [æ], which does not exist either in SMG or in the older Cappadocian system, but is now prominently present in the vowel space of Mišótika. Although the [æ] sound is observed in our data set, its phonological status was unclear at that moment. We will argue below that it functions as a variant of /e/ in the Mišótika system, showing the specific phonological/phonetic contexts that this vowel appears in.

We have to mention that when we refer to the vowel system in the present analysis, we mean the phonetic realizations of the sounds in the system and not phonological units. Therefore, all detected sounds are displayed in the phonetic charts in order for their distribution in the vowel spectrum to be captured.

\subsection{Neo Agioneri}

As the two charts in Figure 4 show, ${ }^{12}$ there are some remarkable gender differences in Neo Agioneri. More specifically, we can discern differences in the distribution of the five vowels [i, e, a, o, u], i.e., the vowels that also exist in SMG, as well as differences in the distribution of the three vowels borrowed from Turkish.

11. The normalization results in the reduction of the individual differences related to the physiological articulation system of every speaker, while at the same time the systematic differences between the vowel systems of the informants are retained.

12. The vertical axis refers to the normalised F1 values, which are the result of Watt \& Fabricius algorithm: F1/ (SxF1). Similarly, the horizontal axis refers to the normalised F2 values, which are derived by the algorithm: F2/ (SxF2). 
It seems that the vowels form a smaller vowel space in the speech of men than that of women, due to the less low realization of [æ] and [a], and the less back realization of [u] and [o] (see Figure 4 and Tables 3 and 4).

\section{Agioneri women}

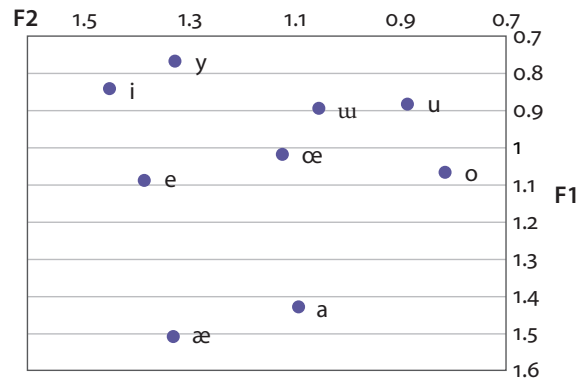

Agioneri men

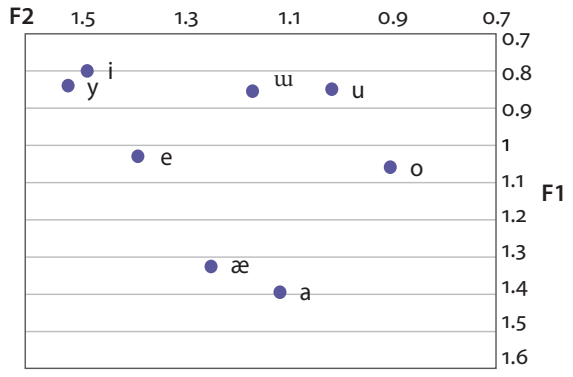

Figure 4. Vowel distribution in Neo Agioneri, split up by gender

The [y, œ, u] old Cappadocian vowels have a low frequency of appearance in our data (see Tables 3-5). This is due to the fact that their distribution in Greek-origin words is rare. These vowels occur mainly in words of Turkish origin, several of which have disappeared and been replaced by Modern Greek equivalents. At the same time, it was observed that in the words in which the vowels [y, œ, u] are still used, they can be replaced by the variants [i], [o] and [u] respectively. To determine the lexical items in which the vowels could appear, we relied on the corpus of words in which Dawkins (1916) and other later scholars (e.g., Kostakis 1977, 1991; Kotsanidis 2006; Fates 2012) attested their occurrence. Therefore, the proportion of use of the $[y, œ, u, æ]$ vowels was calculated according to the instances that the possible lexical items were realized by the research participants (see Table 5).

Table 3. Normalized F1 and F2 values of Neo Agioneri women

\begin{tabular}{lrcc}
\hline Vowels & $\mathrm{N}$ & $\mathrm{F} 1 /(\mathrm{SxF} 1)$ & $\mathrm{F} 2 /(\mathrm{SxF} 2)$ \\
\hline $\mathrm{i}$ & 799 & 0.840 & 1.453 \\
$\mathrm{e}$ & 499 & 1.085 & 1.386 \\
$\mathrm{a}$ & 1,219 & 1.429 & 1.095 \\
$\mathrm{o}$ & 370 & 1.065 & 0.815 \\
$\mathrm{u}$ & 396 & 0.883 & 0.885 \\
$æ$ & 182 & 1.504 & 1.330 \\
$\mathrm{u}$ & 75 & 0.895 & 1.055 \\
$\mathrm{y}$ & 20 & 0.769 & 1.327 \\
$\propto$ & 6 & 1.017 & 1.123 \\
\hline
\end{tabular}


256 Nicole Vassalou, Dimitris Papazachariou and Mark Janse

Table 4. Normalized F1 and F2 values of Neo Agioneri men

\begin{tabular}{lccc}
\hline Vowels & $\mathrm{N}$ & $\mathrm{F} 1 /(\mathrm{SxF} 1)$ & $\mathrm{F} 2 /(\mathrm{SxF} 2)$ \\
\hline $\mathrm{i}$ & 827 & 0.801 & 1.490 \\
$\mathrm{e}$ & 392 & 1.028 & 1.393 \\
$\mathrm{a}$ & 1,247 & 1.393 & 1.118 \\
$\mathrm{o}$ & 349 & 1.059 & 0.904 \\
$\mathrm{u}$ & 450 & 0.847 & 1.018 \\
$æ$ & 120 & 1.321 & 1.253 \\
$\mathrm{w}$ & 46 & 0.857 & 1.170 \\
$\mathrm{y}$ & 7 & 0.840 & 1.529 \\
$\propto$ & - & - & - \\
\hline
\end{tabular}

Table 5. Frequency distribution of [y, œ, u, æ] vowels in Neo Agioneri

\begin{tabular}{llc}
\hline Vowels & Women & Men \\
\hline$[y]$ & $42 \%(20 / 48)$ & $15 \%(7 / 47)$ \\
{$[œ]$} & $60 \%(6 / 10)$ & $0 \%(0 / 0)$ \\
{$[\mathrm{w}]$} & $66 \%(75 / 114)$ & $46 \%(46 / 99)$ \\
{$[æ]$} & $92 \%(182 / 197)$ & $78 \%(120 / 153)$ \\
\hline
\end{tabular}

In particular, [œ] was produced only six times by women while it was not realized by men at all. The proportion of its use was $60 \%$ (see Table 5 ), as it was realized 6 times out of the 10 possible tokens produced by women. [y] appears twenty times in the speech of the female informants but only seven times in the speech of men. Its use in the entire number of instances is $42 \%$ (20 times out of 48 ) in the speech of women, in contrast to the lower rate of $15 \%$ in the speech of men (only 7 times out of the 47 possible lexical incidences).

[u] seems to appear more frequently, albeit in low percentages in relation to the vowels [i, e, a, o, u], as it was detected in 75 tokens in the speech of women and in 46 tokens in the speech of men respectively. Moreover, the instances of [u] in the recordings of women have a $66 \%$ score as far as the lexical incidence is concerned and a $46 \%$ score in the recordings of men, which indicates that the vowel [u] has higher usage rates than the other two old Cappadocian vowels, [y] and [œ].What is particularly interesting is the distribution of the vowel [æ], which occurs in words of both Greek and Turkish origin as a variant of /e/ in specific metrical contexts (e.g., [me'sæl] or [mæ'sæl] < Turkish masal "fairytale"). This vowel was found in 182 of 197 tokens (92\%) in female speech and in 120 of 153 tokens (78\%) in male speech. Based on the charts (see Figure 4), we observe that [æ] is realized in a front and really low position by the female informants, which means that it is a vowel lower than [e] and more front than [a]. Conversely, in the speech of men, it is realized 
in a more central position, and at the same time in a less low position, above the vowel [a], as opposed to its realization by women. In Section 5.1 we provide a more detailed analysis of this vowel.

\subsection{Xirochori}

The vowel system of Xirochori differs from the Neo Agioneri vowel system. First of all, it seems that the distribution of [i, e, a, o, u] creates a smaller vowel space than that of the speakers from Neo Agioneri. At the same time, the men from Xirochori realize a more centralized vowel system than every other group of informants (see Figure 5). Typical examples are the less low realization of [a], and the less back realization of $[\mathrm{u}]$ and $[\mathrm{o}]$.
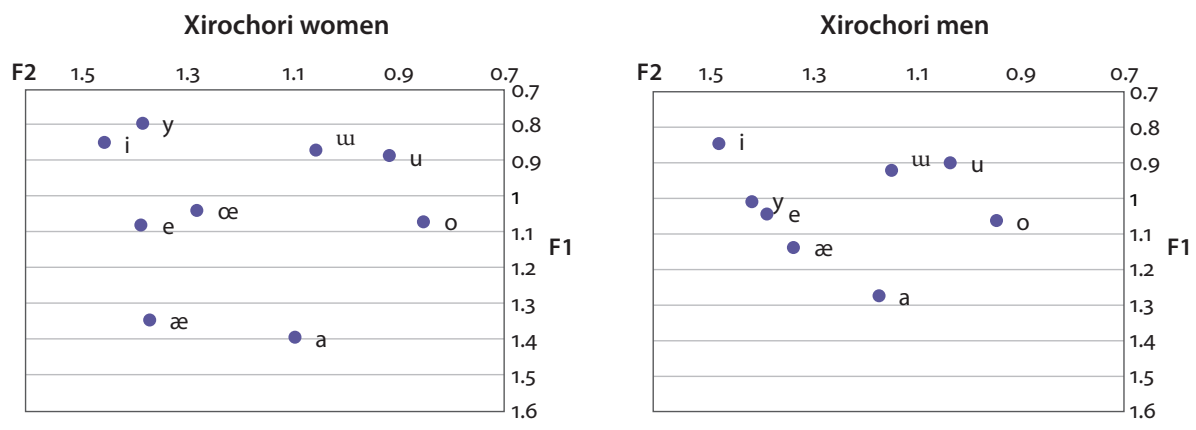

Figure 5. Vowel distribution in Xirochori, split up by gender ${ }^{13}$

As for the three vowels of Turkish origin, the vowel [y] occurs less frequently in the speech of male speakers from Xirochori (see Tables 6-8). In comparison with the 23 tokens $(n=56)$ we found for female speakers, we have only 4 tokens for male speakers $(n=32)$. Its relative frequency is also higher in female $(41 \%)$ than in male speakers (12\%), which is in line with the results for Neo Agioneri (see Table 5). In other words, the vowel [y] presents almost the same drop in the percentage rates of its realization between the two genders in both Cappadocian communities. This is due to the fact that this [y] sound is replaced by a Greek counterpart more often in the speech of men than of women. As for its distribution, we notice that the four instances of the vowel [y] produced by male speakers are realized in a high-mid

13. Some of the vowels in the charts (see Figures $4 \& 5$ ) may look similar. Nevertheless, they are distinct sounds based on the position of the lips, as for example, [y] is a round vowel while [i] or [e] are not. Furthermore, we have to mention that the shift of some of these vowels is due to the fact that the front vowels in SMG are not round, in contrast to the vowel [y] of Turkish origin, while the back vowels are round in SMG, in contrast to [ü] respectively. 
258 Nicole Vassalou, Dimitris Papazachariou and Mark Janse

Table 6. Normalized F1 \& F2 values of Xirochori women

\begin{tabular}{lrcc}
\hline Vowels & $\mathrm{N}$ & $\mathrm{F} 1 / \mathrm{S}(\mathrm{F} 1)$ & $\mathrm{F} 2 / \mathrm{S}(\mathrm{F} 2)$ \\
\hline $\mathrm{i}$ & 916 & 0.849 & 1.461 \\
$\mathrm{e}$ & 511 & 1.083 & 1.389 \\
$\mathrm{a}$ & 1,146 & 1.397 & 1.099 \\
$\mathrm{o}$ & 396 & 1.071 & 0.855 \\
$\mathrm{u}$ & 357 & 0.887 & 0.920 \\
$æ$ & 210 & 1.346 & 1.374 \\
$\mathrm{u}$ & 67 & 0.872 & 1.058 \\
$\mathrm{y}$ & 23 & 0.796 & 1.388 \\
$\propto$ & 12 & 1.039 & 1.284 \\
\hline
\end{tabular}

Table 7. Normalized F1 \& F2 values of Xirochori men

\begin{tabular}{lccc}
\hline Vowels & $\mathrm{N}$ & $\mathrm{F} 1 / \mathrm{S}(\mathrm{F} 1)$ & $\mathrm{F} 2 / \mathrm{S}(\mathrm{F} 2)$ \\
\hline $\mathrm{i}$ & 790 & 0.848 & 1.467 \\
$\mathrm{e}$ & 496 & 1.047 & 1.374 \\
$\mathrm{a}$ & 1,194 & 1.273 & 1.163 \\
$\mathrm{o}$ & 381 & 1.064 & 0.941 \\
$\mathrm{u}$ & 344 & 0.902 & 1.029 \\
$æ$ & 137 & 1.140 & 1.325 \\
$\mathrm{w}$ & 35 & 0.925 & 1.139 \\
$\mathrm{y}$ & 4 & 1.009 & 1.404 \\
$\propto$ & - & - & - \\
\hline
\end{tabular}

Table 8. Frequency distribution of [y, œ, u, æ] vowels in Xirochori

\begin{tabular}{llc}
\hline Vowels & Women & Men \\
\hline$[\mathrm{y}]$ & $41 \%(23 / 56)$ & $12 \%(4 / 32)$ \\
{$[œ]$} & $86 \%(12 / 14)$ & $0 \%(0 / 0)$ \\
{$[\mathrm{w}]$} & $64 \%(67 / 105)$ & $43 \%(35 / 80)$ \\
{$[æ]$} & $87 \%(210 / 241)$ & $78 \%(137 / 174)$ \\
\hline
\end{tabular}

position (close to the vowel [e]), in contrast with the extremely high position of the vowel in the female speakers' speech (above the vowel [i]).

In addition, the vowel [œ] is not realized by Xirochori men. In Xirochori women, it was found 12 times $(n=14)$ (see Table 8$)$, but its pronunciation is different from the Neo Agioneri women (see Figure 4), as it is realized in a more front position than central. As for the vowel [u], it seems that it is realized as a high vowel, but in a less back position (like the vowels $[\mathrm{u}]$ and [o]) in the speech of men in comparison with women. Moreover, its relative frequency is $64 \%$ among 
women, and $43 \%$ among men. The vowel [u] is thus another case of reduced usage of the older Cappadocian vowels in the speech of men from both Cappadocian communities under investigation.

It seems that $[æ]$ is realized in a different position in the vowel space by men and women, and at the same time, its position differs from the equivalent sound produced by the Neo Agioneri speakers. More specifically, the men from Xirochori produced the vowel [æ] in a low-mid position closer to [e]. By contrast, it is realized in a more front and lower position in the speech of women. Finally, it was detected in 137 tokens $(n=174)$ in the speech of men $(78 \%)$, but in 210 tokens $(n=241)$ in women (87\%). Although this vowel also has a low frequency in comparison with the $[i, e, a, o, u]$ vowels that also exist in SMG, it is differentiated from the other three $[y, œ, u]$ vowels, as it is not detected in the older Cappadocian vowel system and it seems to be a new sound (see also Section 5.1). ${ }^{14}$

Overall, the results of the present investigation demonstrate a frequency difference between the vowels that exist in SMG and the vowels that do not. The vowels $[i, e, a, o, u]$ outnumber the other four vowels [æ, y, œ, u] significantly, as we can observe in the frequency distributions in Tables 3-8.

\section{Discussion}

\subsection{The vowels [œ, y, w, æ]}

The old Cappadocian vowels [y, œ, u] have a low frequency in our data in comparison with the vowels [i, e, a, o, u] that also exist in SMG (see Tables 3-8). These vowels occur mainly in Turkish loanwords, several of which have disappeared and been replaced by Greek lexemes. At the same time, we studied the lexical items in which the $[y, œ, u, æ]$ vowels could appear, based on the words that had been detected by Dawkins (1916) and other scholars (e.g., Kostakis 1977, 1991; Kotsanidis 2006; Fates 2012). Our results show that in the words in which the vowels [y, œ, u] are still used, they are sometimes replaced by their Greek equivalents. On the other hand, the vowel $[æ]$ is detected in words of both Greek and Turkish origin and it seems to function as a variant of /e/ in the system of the dialect.

To get more insight in the vowels of Mišótika, we discuss each vowel separately. Firstly, we have found that the mid front rounded vowel [œ] seems to be in the process of extinction, as it is entirely lost in the men's speech whereas it appears in a limited set of words, but quite systematically, in the women's speech from both

14. For more information see Vassalou et al. $(2017,2019)$. 
villages. In 18 out of 24 items [œ] shows up; the six other tokens are realized as the Greek counterpart [o].

(1) [tšœ'žme] or [tšo'žme] < Turkish çeşme "tap"

(2) ['šœmna] or ['šomna] < Medieval Greek $\delta \imath \sigma \omega \mu i \alpha^{\alpha}$ "shoulders"

The high front rounded vowel $[y]$ also seems to be in the process of extinction, as it presents low percentages of realization. It was produced in 54 out of 183 tokens $(30 \%)$ in both speech communities. At the same time, it was found that [y] alternates with $[\mathrm{i}]$ or $[\mathrm{u}]$ in the remaining cases.

(3) [my'syr] or [mi'sir] < Turkish misır "turkey"

(4) [ty'tyn] or [tu'tun] < Turkish tütün "tobacco"

Nevertheless, the vowel $[y]$ was realized more times in the speech of women from both villages (i.e., $42 \%$ rate of use in Neo Agioneri and $41 \%$ in Xirochori), while it is highly reduced in men's speech (i.e., 15\% rate of use in Neo Agioneri and 12\% in Xirochori).

The high back unrounded vowel [u] was produced in 223 out of 398 tokens (56\%) in the speech of all participants, and its appearance is limited to words of Turkish origin. It seems that the words that contain the variant [u] have a relatively higher frequency, in comparison with words that contain the two other vowels of Turkish origin [y] and [œ]. In the remaining possible realization instances, the vowel $[\mathrm{u}]$ is replaced by the Greek counterpart $[\mathrm{u}]$.

(5) [tu'ndur] or [tu'ndur] < Turkish tandur "clay oven"

(6) [pa'mbur] or [pa'mbur] < Turkish vapur, dialectal papur "steamer"

What may be inferred from the above findings is that the realization of the vowels [y, œ, u] of Turkish origin is often optional, and it seems that they have been assimilated to [u], [i] or [o] respectively, because of the language contact with SMG.

However, the female speakers produced higher percentages of the variant [ur] than male speakers. More specifically, its use in the entire number of instances is $66 \%$ in the speech of women from Neo Agioneri and $46 \%$ in men. In Xirochori, it was produced 67 times $(n=105)$ at a rate of $64 \%$ by women, but only 35 times $(n=80)$ at a rate of $43 \%$ by men. These numbers show that the vowel [u] is another case of reduced usage of the old Cappadocian vowels in the speech of men from both Cappadocian communities under investigation.

Focusing on the social characteristics of the participants (see Tables 1 and 2), it was shown that people with lower education (i.e., primary school) had a higher rate of use of the three old Cappadocian vowels [y, œ, u] than those with a higher educational level. It was also observed that housewives used the three variants more 
than any other male profession, something that coincides with the significant differences between the two genders. ${ }^{15}$ This seems to imply that women show a higher usage rate of the words in which the vowels [y, œ, u] of Turkish origin appear. Men, on the other hand, either replace those words with Greek lexemes or realize more frequently the Greek equivalents of the vowels $[y, \propto, m]$ in their speech.

Moreover, [u] is realized as a high vowel, and it is less back in the speech of men than women (repeated-measures MANOVA $F(1,215)=13.042, p<0.001$, $\eta^{2}=0.057$ ), see Figures 4 and 5 . The shift of the vowel [u] is definitely due to the fact that the back vowels in SMG are rounded and not unrounded, as [u].

The low front unrounded vowel [æ] seems to appear systematically in the speech of both villages under investigation and more frequently than any of the other three Cappadocian vowels (i.e., in 649 out of 765 tokens). In Neo Agioneri, this vowel was found in 182 of 197 tokens (92\%) in female speech and in 120 of 153 tokens $(78 \%)$ in male speech. In Xirochori, it was detected in 137 of 174 tokens (78\%) in the speech of men, but in 210 of 241 tokens (87\%) in women.

Moreover, when we studied the segmental and metrical environments (stressed or unstressed, ultimate or other syllables, di- or polysyllabic words, etc.) in which the vowel [æ] occurs, we noticed that it is present in words of both Greek and Turkish origin and appears in specific metrical contexts, mostly as the stressed vowel of an iambic foot in disyllabic words. Sometimes it is also found in the unstressed syllable of an iambic foot, but with the precondition that the same vowel $[æ]$ appears in the stressed syllable of the same foot as well, probably as a result of regressive vowel harmony. ${ }^{16}$

(7) [de'ræ] or [dæ'ræ] < Medieval Greek $\varepsilon \delta \alpha ́ \rho \varepsilon$ "now"

(8) [se'vær] or [sæ'vær] < Turkish sever "time"

It seems that its realization in the unstressed position is optional, and only in the metrical environment described. Therefore, the variant [æ] is assumed to be an additional part in the vowel system, i.e., as a variant of /e/ in particular phonological/ phonetic contexts. The above allophonic function of [æ], as well as its systematic

15. As the present study focuses on the effect of gender on the distribution of each vowel in the vowel space, we will not expand further on the impact of other social factors such as the profession and educational level of the participants.

16. It should be noted that this type of harmony (regressive) is different from the progressive vowel harmony found in Turkish and other Altaic languages, which applies to suffixes (see Archangeli \& Pulleyblank 2007 on different types of harmony). The progressive vowel harmony of the Turkish type is found in Cappadocian as well (Janse 2009: 39f; 2020b: $\$ 6.2 .1 .4 .1$ ). For other examples of regressive vowel harmony, traditionally called regressive vowel assimilation, in Cappadocian see Dawkins (1916: 64f.) and Janse (2020b: $\$ 6.2 .1 .4$ ). 
appearance in the vowel inventory of both villages, reinforces the conclusion that the vowel has a place in the vowel system of Mišótika. Furthermore, it is likely that the constraint of the realization of this vowel in particular metrical environments will be the reason behind its low percentage rates.

Looking at the distribution of [æ] in Figures 4 and 5, it seems that it is realized in different positions in the vowel spaces of men and women, since men realize $[æ]$ in a higher position than women, especially in Xirochori, and at the same time its overall distribution diverges between the speakers from the two villages. This is confirmed by the repeated-measures MANOVA tests (gender: $F(1,581)=41.659$, $p<0.001, \eta^{2}=0.067$; location: $\left.F(1,581)=94.889, p<0.001, \eta^{2}=0.140\right)$.

At the same time, $[æ]$ is not recognized as one of the older Cappadocian vowels. It should be noted that, in his study in 1916, Dawkins did not distinguish this vowel for any of the Cappadocian dialects, including Mišótika. However, the vowel was not unknown to Dawkins, who included it among the "modified vowels" transcribed as $\ddot{a}, \ddot{o}, \ddot{u}$ (1916: 39) and identified it as one of the characteristic vowels of two other Asia Minor Greek dialects, Pharasiot and Pontic (1916: 152-153). What may be inferred from the status of [æ] vowel in present-day Mišótika, is that its origin is a complex issue. From our point of view, there are two hypotheses.

\section{Hypothesis 1}

As the vowel is not recognized as one of the older Cappadocian vowels attested by Dawkins (1916), its adoption by the speakers of Mišotika could be the result of contact in Greece after the migration. ${ }^{17}$ It should be noted that $[æ]$ is also found in Pontic as the result of a phonological operation (/i/ + /a/ $>$ /ia/ $>$ [æ]: /spiti/ + /a/ (plural morpheme) $>/$ spitia/ $>$ ['spitæ] 'houses') (Revithiadou \& Spyropoulos 2009: 41). Moreover, close to Neo Agioneri there is another village, Palio Agioneri, which is populated by Pontic Greek speakers who also settled in Greece in the 1920s. At the same time, Xirochori also had Pontic inhabitants, as mentioned before. Therefore, the close contact of the speakers of the two dialects may have led to the activation of a levelling process of the Cappadocian to the Pontic system. Through this mechanism of change, we can assume that Mišótika speakers adopted the $[æ]$ vowel as it was a salient feature of Pontic. According to this hypothesis, the appearance of [æ] could be the result of contact between the two Cappadocian communities under investigation and their Pontic neighbours. However, Vassalou (forthcoming) shows that the [æ] vowel also appears in other Cappadocian communities that did not have close contact with Pontics in Greece (for example Mandra, near Larissa).

17. According to Newton (1972: 46-49), a low front vowel [æ] appears, in contrast to [a], in the Greek dialects of Thessaly, Macedonia, and Thrace. 


\section{Hypothesis 2}

We believe that the vowel could also have been adopted by the Mišótika speakers when they were still in Cappadocia. Studies on Turkish dialects observed that [æ] sometimes occurs as an allophone of /e/ before coda /m, n, l, r/ (see, e.g., Göksel \& Kerslake 2005: 10). Moreover, the [æ] vowel was attested by Dawkins (1916) in Asia Minor Greek varieties. The question that now arises is why Dawkins did not include $[æ]$ in his description of Cappadocian. One possible explanation is that the [æ] vowel became part of the Cappadocian vowel system due to contact with the local Turkish or even Asia Minor Greek varieties only at the beginning of the 20th century. Thus, during Dawkins' fieldwork, it was at the first stage of its appearance, when the percentages were extremely low and the variant appeared in a few very specific lexical items. We consider the second hypothesis to be the most likely one.

Using the framework of dialect contact, we can observe and interpret the differences between present-day Mišótika and the older system described by Dawkins a century ago. On the one hand, the vowels $[y, \propto, u]$, which occur mainly in words of Turkish origin, have been stigmatized as Turkish variants and are in the process of extinction due to mechanisms of levelling towards a new koine, as Mišótika has been in contact with Modern Greek since the population exchange of the 1920s. There are a lot of testimonies in various sources (see footnote 4 ) indicating the negative language attitude of the Greek locals to Cappadocians due to the Turkish characteristics of their spoken dialect. As a consequence, the low frequency of the three old Cappadocian vowels may be the result of the Cappadocians' attempts to assimilate to the Greek linguistic environment. On the other hand, the vowel [æ] seems to have survived the levelling process and to have been reallocated, evolving a new sociolinguistic function in the new dialect, as a strong indicator of the Mišótika identity.

\subsection{The vowels [i, e, a, o, u]}

As regards the other five vowels of the Mišótika vowel system (i.e., [i, e, a, o, u], which also exist in SMG), comparing the vowel spectra of women and men (see Figures 4 and 5), we could argue that the front vowels [i] and [e] are realized almost in a similar position, although men realize the vowel [e] in a higher position than women. This difference is statistically significant in a repeated-measures MANOVA test $\left([\mathrm{e}]: F(1,1890)=9.184, p=0.002, \eta^{2}=0.005\right)$.

On the other hand, the back vowels $[\mathrm{u}]$ and $[\mathrm{o}]$ present a more centralized distribution in the vowel space of men (i.e., a less back realization), in contrast to the vowel spectrum of women. The repeated measures MANOVA tests show a significant effect of gender for $[\mathrm{u}]\left(F(1,1539)=106.989, p<0.001, \eta^{2}=0.065\right)$ and [o] $\left(F(1,1488)=57.744, p<0.001, \eta^{2}=0.037\right)$. 
For the vowel [a] significant effects of gender $(F(1,4798)=502.415, p<0.001$, $\left.\eta^{2}=0.095\right)$ and location $\left(F(1,4798)=269.363, p<0.001, \eta^{2}=0.053\right)$ are found. In particular, comparing the vowel spectra (see Figures 4 and 5), we observe that men, notably from Xirochori, realize the vowel [a] in a higher and more front position than women. At the same time, its overall distribution diverges between the speakers from the two Cappadocian communities.

It seems that the vowel spectrum of men, especially from Xirochori, is more centralized, occupying smaller vowel space than that of women. Furthermore, the combination of the above findings shows a scaling effect. On the one end, it seems that we have the vowel system of Agioneri women which occupies the biggest spectral space. The vowel systems of Neo Agioneri men and Xirochori women lie somewhere in-between. The vowel system of Xirochori men, which presents the smallest spectral space, is found on the other end of the scale (see Figures 4 and 5).

Taking into consideration the statistical results of repeated-measures MANOVA tests, gender seems to be the most influencing sociolinguistic parameter, as the effect of gender is significant for all vowels, except [i]. Conversely, the effect of location which signifies the differences between the two Cappadocian communities only has a significant effect on two vowels ([a] and [æ]).

The differences between the speech of men and women can be interpreted as a result of different stages of a koineization process of these two gender groups, as male speakers are one step ahead in the linguistic change. This is reinforced by the fact that in men's speech, the mid front rounded [œ] has been lost entirely, the high front rounded [y] is almost eliminated, and the high back unrounded [u] is reduced in frequency. In contrast, in women's speech, [œ] is still produced, albeit rarely, and $[\mathrm{y}]$ and $[\mathrm{w}]$ are attested more frequently. Also, the fact that the overall vowel system of the men is more centralized, occupying a smaller vowel space than that of the women, could be explained as another step towards koineization.

A very reasonable explanation of the different stages of the levelling process in the two genders could be the effect of the contact situations existing in each village in combination with the different social roles of the two genders. As already mentioned, Xirochori is a mixed community, since not only Cappadocians but also speakers of other Greek dialects live there, whereas Neo Agioneri is homogeneous. At the same time, men have greater mobility than women due to their social and professional activities (see Tables 1 and 2). In particular, the profession of the majority of men requires daily social contact and mobility in different villages or even cities, and as a matter of fact, the contact with SMG or other varieties of Greek was clearly more pronounced.

On the other hand, the women constituted a low-contact and stable community. They had never been employed and were occupied only with the care of the 
household and their children. As a result, they did not have great mobility, especially in the earlier days, and were more closely knit with their family and the neighbourhood. We strongly believe that the combination of the above social parameters can lead to the conclusion that men, especially in Xirochori, are ahead in the process of linguistic change to koineization, as a result of dialect contact, whereas women seem to preserve their dialectal features due to fewer opportunities of contact.

\section{Conclusion}

We have shown that the vowel systems of the speakers from the two Cappadocian communities diverge from the older system described by Dawkins (1916). In particular, the analysis of the speech of two Cappadocian communities provides evidence for the existence of the previously unrecorded [+front, -high, -round] vowel [æ], which has appeared in the vowel system of Mišotika. At the same time, the three older vowels [y], [œ] and [u], which do not exist in SMG, are in different stages of reduction and possible loss.

Furthermore, there is evidence that there are differences between the two Cappadocian speech communities, where community structure (homogeneous vs. mixed) and gender roles seem to be significant sociolinguistic parameters influencing the distribution of the vowels in the vowel spectrum. In other words, it appears that the vowel system of the inhabitants of both villages diverges from the older one described by Dawkins, and at the same time, the male speakers are one step ahead in the process of linguistic change in comparison with the women.

To conclude, Mišótika is not a dead variety, at least among elderly speakers. There are people who use it and recognize it as a distinct system as opposed to SMG. Nevertheless, the variety used by present-day native speakers presents essential changes from the variety spoken at the time of the migration of Cappadocians in Greece (1924).

\section{Funding}

This paper is part of the doctoral research of the first author, funded by the General Secretariat for Research and Technology (G.S.R.T. - ГГЕT), the Hellenic Foundation for Research and Innovation (H.F.R.I. - E $\Lambda \mathrm{I} \Delta \mathrm{EK}$ ) and the UGent project 'Asia Minor as a Linguistic Area: Greek-TurkishArmenian Language Contacts in Cappadocia and the Anatolian Substrate' (HERA.15.029). 


\section{References}

Archangeli, Diana \& Douglas Pulleyblank. 2007. Harmony. In Paul de Lacey (ed.), The Cambridge Handbook of Phonology, 353-378. Cambridge: Cambridge University Press. https://doi.org/10.1017/CBO9780511486371.016

Boersma, Paul \& David Weenink. 2019. Praat: Doing phonetics by computer. Version 6.1.03, retrieved 2 May 2019 from http://www.praat.org/

Chambers, Jack K., Peter Trudgill \& Natalie Schilling-Estes (eds.). 2002. The handbook of language variation and change. Oxford: Blackwell.

Coates, Jennifer. 2013. Women, men and language: A sociolinguistic account of gender differences in language. 3rd ed. London: Routledge.

Dawkins, Richard M. 1916. Modern Greek in Asia Minor: A study of the dialects of Silli, Cappadocia and Phárasa with grammar, texts, translations and glossary. Cambridge: Cambridge University Press.

Eckert, Penelope \& Sally McConnell-Ginet. 2013. Language and gender. 2nd ed. Cambridge: Cambridge University Press. https://doi.org/10.1017/CBO9781139245883

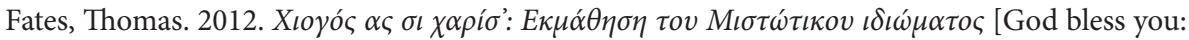
Learning the Mišótika dialect]. Konitsa.

Göksel, Asli \& Celia Kerslake. 2005. Turkish: A comprehensive grammar. London: Routledge.

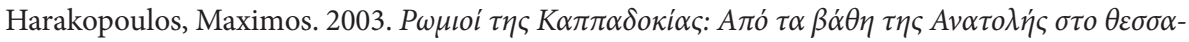

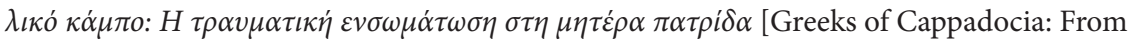
the depths of the East to the Thessalian plain: The traumatic integration into the motherland]. Athens: Ellinika Grammata.

Heeringa, Wilbert \& Hans Van de Velde. 2018. Visible vowels: A tool for the visualization of vowel variation. In Proceedings CLARIN Annual Conference 2018, 8-10 October, Pisa, Italy. CLARIN ERIC.

Hickey, Raymond (ed.). 2010. The handbook of language contact. Wiley-Blackwell. https://doi.org/10.1002/9781444318159

Hinskens, Frans. 1992. Dialect levelling in Limburg: Structural and sociolinguistic aspects. Ph.D. thesis. University of Nijmegen.

Holmes, Janet \& Miriam Meyerhoff (eds.). 2003. The handbook of language and gender. Oxford: Blackwell. https://doi.org/10.1002/9780470756942

Janse, Mark. 2002. Aspects of bilingualism in the history of the Greek language. In James N. Adams, Mark Janse \& Simon Swain (eds.), Bilingualism in Ancient Society, 332-390. Oxford: Oxford University Press. https://doi.org/10.1093/acprof:oso/9780199245062.003.0013

Janse, Mark. 2008. Grieks lichaam, Turkse ziel: Multiculturele symbiose in Cappadocië en de Cappa-docische diaspora [Greek body, Turkish soul. Multicultural symbiosis in Cappadocia and the Cappadocian diaspora]. In Danny Praet (ed.), Us \& Them: Essays over filosofie, politiek, religie en cultuur van de Antieke Oudheid tot Islam in Europa ter ere van Herman De Ley, 107-137. Gent: Academia Press.

Janse, Mark. 2009. Greek-Turkish language contact in Asia Minor. Études Helléniques / Hellenic Studies 17. 37-54.

Janse, Mark. 2018. Christendom en Islam in Ottomaans Cappadocië [Christianity and Islam in Ottoman Cappadocia]. In Danny Praet \& Jan Nelis (eds.), Islam \& Christendom, 289-304. Gent: Academia Press. 


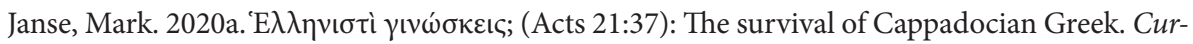
sor $16.41-49$.

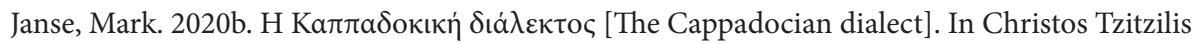

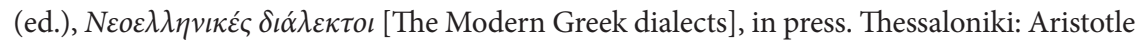
University of Thessaloniki, Institouto Neoellinikon Spoudon (Idryma Manoli Triantafyllidi).

Karatsareas, Petros. 2011. A study of Cappadocian Greek nominal morphology from a diachronic and dialectological perspective. Ph.D. thesis. University of Cambridge.

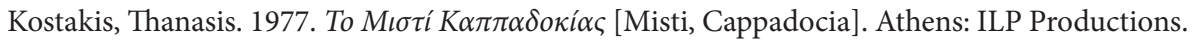

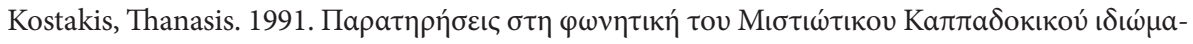

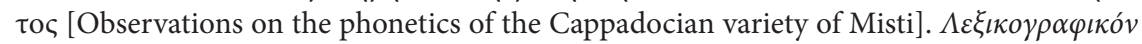
$\Delta \varepsilon \lambda \tau i ́$ v $17.175-188$.

Kotsanidis, Lazaros. 2006. To $\gamma \lambda \omega \sigma \sigma \iota \kappa o ́ ~ \iota \delta i ́ \omega \mu \alpha ~ \tau o v ~ M ı \sigma \tau i ~ K \alpha \pi \pi \alpha \delta o \kappa i ́ \alpha \varsigma$ [The linguistic variety of Misti, Cappadocia]. Kilkis.

Labov, William. 1972. Sociolinguistic patterns. Philadelphia: Pennsylvania University Press.

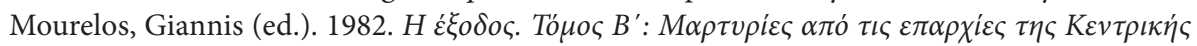

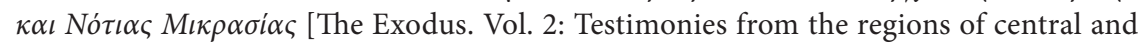
southern Asia Minor]. Athens: Centre for Asia Minor Studies.

Newton, Brian. 1972. The generative interpretation of dialect: A study of Modern Greek phonology. Cambridge: Cambridge University Press.

Papazachariou, Dimitris. 2006. The quantitative study of the lateral variable (l) in the dialect of Patras. In Mark Janse, Brian Joseph \& Aggeliki Ralli (eds.), Proceedings of the Second International Conference on Modern Greek Dialects and Linguistic Theory, 298-313. Mytiline: Patras University Press.

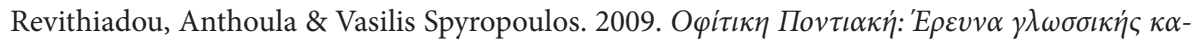

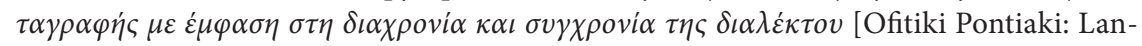
guage recording research with emphasis on the diachrony and synchronicity of the dialect]. Athens: John's Latsis Public Benefit Foundation.

Trudgill, Peter. 1986. Dialects in contact. New York: Blackwell.

Vassalou, Nikoleta. Forthcoming. Mišótika Cappadocian in contact: the consequences of linguistic change on the variety's vowel system. Ph.D. thesis. University of Patras and Ghent University.

Vassalou, Nicole, Dimitris Papazachariou \& Mark Janse. 2017. The vowel system of Mišótika Cappadocian. In Artemis Alexiadou, Jannis Androutsopoulos, Thanasis Georgakopoulos, Alexis Kalokairinos \& Theodossia S. Pavlidou (eds.), Proceedings of the 12th International Conference on Greek Linguistics (2), 1139-1154. Edition Romiosini - CeMoG, Freie Universität, Berlin.

Vassalou, Nicole, Dimitris Papazachariou \& Mark Janse. 2019. Variation in the vowel system of Mišótika Cappadocian: Findings from two refugee villages in Greece. In Maria Chondrogianni, Simon Courtenage, Geoffrey Horrocks, Amalia Arvaniti \& Ianthi Tsimpli (eds.), Proceedings of the 13th International Conference on Greek Linguistics, 276-285. London: University of Westminster.

Watt, Dominic J. \& Anne H. Fabricius. 2002. Evaluation of a technique for improving the mapping of multiple speakers. Leeds Working Papers in Linguistics and Phonetics 9. 159-173. 



\title{
Leaders of language change
}

\section{Macro and micro perspectives}

\author{
Meredith Tamminga \\ University of Pennsylvania
}

\begin{abstract}
Questions about who leads language change have been central to the sociolinguistic literature for decades. More recent work on covariation between simultaneous changes calls into question whether broad, generalized change leadership can exist. Using data from Philadelphia, I show that covariation patterns fluctuate over time. These fluctuations are not random but rather appear to be tied to the overall diachronic shifts in the community. However, I also suggest that predicting individual differences in covarying changes is not as simple as operationalizing the traits that have been captured in qualitative descriptions of particular leaders. I propose that reconciling these results requires distinguishing between individual leadership in Labov's "saccadic" sense and the broader structure of how innovations covary within the community as a whole.
\end{abstract}

Keywords: sound change, English, covariation, coherence, individual differences, leaders

\section{Introduction}

For a language to change, some innovation must spread among the language users that make up a community, leading to questions about how language users take up, drive forward, and pass on innovations. Accordingly, sociolinguists who study language change over time have long been interested in questions about who leads language change. Labov puts it succinctly in his influential study of sound change leaders in Philadelphia: "The basic strategy of this pursuit of the causes of change is to identify the leaders of change in progress; in place of the question 'why?' I have substituted the question 'who?'” (2001: 190). In other words, by investigating the traits and social situation of speakers who are at the front edge of ongoing language changes, we hope to learn something about the general mechanisms and pathways of change. Many results about the spread of language change through communities involve claims about social groups at the forefront of such change; the well-known 
refrain that "young women lead language change" provides a clear example. On the level of particular speakers, the field has seen many rich and in-depth studies of individuals who stand out linguistically in comparison to their peers. Common threads in these accounts are depictions of language change leaders as outgoing, influential, nonconformist, and well-connected (see e.g. Haeri 1991; Milroy 1993; Labov 2001; Denis 2011).

At the same time, there is a distinct thread in the sociolinguistics literature that asks, in Nevalainen, Raumolin-Brunberg, and Mannila's words, "whether there are people who lead several changes at the same time" (2011:26). A typical first pass at addressing this question involves correlating individual speakers' use of multiple ongoing changes, sometimes followed by binning speakers across changes in an attempt to identify individuals or subgroups who might stand out as leaders. In such studies, coherence (to use Guy and Hinskens' (2016) term) can sometimes be observed but is not the norm (Maclagan, Gordon \& Lewis 1999; Nevalainen, Raumolin-Brunberg, and Mannila 2011; Thorburn 2014; Becker 2016; Waters \& Tagliamonte 2017). On the basis of both their own correlational study and their review of the literature, Waters and Tagliamonte conclude that "individuals who are leading one change in a speech community are not necessarily leading other, concurrent changes" (2017: 37). Similarly mixed results are found in studies of covariation between stable sociolinguistic variables or between stable variables and ongoing changes (Labov 2001; Guy 2013; Oushiro 2016). As the coherence literature moves beyond the question of whether speaker-level coherence is or is not a uniform property of speakers within speech communities (it appears it is not) and toward the questions of when and why interspeaker covariation arises, we might also ask what the implications are for our thinking on who leads language change. If multiple changes are taking place simultaneously in the community but are all led by different people, who exactly are the leaders of change and what changes are they leading?

In this paper I take up some questions around the apparent disconnect between these two strands of the sociolinguistic literature. Methodologically, the paper is focused on a covariation study, rather than containing any portraits of identified change leaders. I frame the question of whether covariation patterns are diachronically stable as a macro view on individual differences in the community. I will show that covariation patterns can be stable across time in ways that suggest they reflect real differences between speakers in the community, but also can shift over time in ways that appear to be linked in some way with the diachronic trajectories we observe in aggregate. I will then turn briefly to preliminary results on a more micro question: can we predict the individual differences that we see within the covarying changes? Having observed that the covariation between three Philadelphia vowels (DOWN, GOAT, THOUGHT) has been stable for over a century of speaker 
birth years and is detectable even within a relatively-homogeneous group of young women, I ask whether several individual-differences predictors that are related to commonly-proposed sociolinguistic leadership traits are able to predict who is most and least advanced in this set of changes. I suggest that the null results of this second study point us toward a dissociation between questions of leadership and questions of covariation.

\section{Philadelphia vowel changes}

The simultaneous changes in progress I will investigate in this paper are five vowel changes in Philadelphia English, which I will label using lexical class terms: FACE, PRICE, DOWN, GOAT, and THOUGHT. All five of these vowel classes have been known to be changing since the earliest major sociolinguistic fieldwork done in Philadelphia, the Language Change and Variation (LCV) study conducted by Labov and colleagues between 1973 and 1977. Labov et al. describe that project as having "the aim of determining where in the social system the leaders of change were to be found" (2013: 31), highlighting the historical and continuous centrality of notions of leadership to the sociolinguistic study of language change. The most thorough reporting from this project can be found in Labov (2001). Forty years later, Labov, Rosenfelder, and Fruehwald (2013) find that some of the changes identified by the LCV project have continued in the same direction, but others reversed course sometime in the intervening decade. I will refer to FACE and PRICE, the changes that continue in the direction identified in Labov (2001), as the "continuing changes" and the changes that reflect either a change reversal (DOWN and GOAT) or a withdrawal from an earlier-established stereotype (тноUGнт) as the "reversing changes." A more precise definition of each of these changes is given here:

- FACE: raising and fronting along the front diagonal of the vowel space, only in the allophone with a following consonant in the same word (regardless of syllable or morpheme boundaries (Fruehwald 2013))

- PRICE: raising of the nucleus toward the center of the vowel space, only before voiceless consonants in the same word

- DOWN: originally, raising and fronting of the nucleus; reversal involves lowering and backing of the nucleus toward its earlier low-central target

- GOAT: originally, fronting; reversal involves backing toward its previous mid-back target

- THоUghт: originally, a high, tense, ingliding stereotype; reversal involves lowering toward the low back part of the vowel space (but not merger with LOT, so far) 
There have been several previous investigations of the speaker-level relationships between Philadelphia vowel changes, including these five and other vowel classes. Labov finds large and significant correlations between tense short-a and DOWN, tense short-a and FACE, DOWN and FACE, and GOAT and TоOTH, as well as between several of the vowel changes and /dh/-stopping (2001: 372). Fruehwald (2013) finds correlations between the non-post-coronal back upgliding vowels in the PNC data as a whole, then updates this finding in Fruehwald (2019), where he shows that these correlations survive controlling out broad sociodemographic information while apparent additional correlations between FACE and PRICE do not. Sneller (2015) finds that speakers with the traditional Philadelphian split short-a system (which is being replaced by an entirely different pre-nasal allophony system) also have more traditionally Philadelphian forms of NORTH, GOAT, DOWN, and THOUGHT (but not FACE, NEW, PRICE, or START). In Tamminga (2019), I find that among 66 young white women (from the LLC data I will describe in Section 3), the three reversing changes exhibit significant positive pairwise correlations. I do not find similar correlations between the continuing changes or between continuing and reversing changes.

\section{Data}

This paper draws on two sets of data from Philadelphia English speakers, the first of which is featured in Section 4 and the second of which is the focus of Section 5. The first is the data from 356 speakers in the Philadelphia Neighborhood Corpus of LING 560 Studies (PNC, Labov and Rosenfelder 2011). The speakers were born between 1888 and 1988 and were recorded in sociolinguistic interviews conducted by students from the University of Pennsylvania between 1973 and 2012. The data includes 192 women (of which 157 are white, 16 are African American, 11 are Latina, and eight are of other ethnicities) and 165 men (of which 143 are white, 16 are African American, five are Latino, and one is of another unspecified ethnicity). These speakers were broken down into six birth year spans that have approximately the same number of speakers in each span (rather than each span covering the same size birth year range). The middle spans cover smaller birth year ranges because the speakers are concentrated more heavily in those birth years. Table 1 presents the birth year ranges of these spans and the number of speakers in each.

The second data set is from a more recent project under my own direction called the Cognitive Characteristics of the Leaders of Language Change, which I will abbreviate LLC (for Leaders of Language Change) in this paper. This project is aimed at studying individual differences within a substantially more homogeneous 
Table 1. Participants in each PNC birth year span

\begin{tabular}{lcc}
\hline Span number & Birth years & Speaker N \\
\hline 1 & $1888-1920$ & 63 \\
2 & $1921-1935$ & 63 \\
3 & $1936-1949$ & 69 \\
4 & $1950-1957$ & 56 \\
5 & $1958-1965$ & 55 \\
6 & $1966-1988$ & 51 \\
\hline
\end{tabular}

group: self-identified white women who were born between 1987 and 1999 and grew up in Philadelphia. These speakers were recorded in dyadic conversation between pairs of friends, rather than in sociolinguistic interviews with strangers. The non-linguistic individual differences measures used in Section 5 are available for 56 of the LLC speakers, which is therefore the subset of the LLC data I will use in that section.

Both the PNC and LLC recordings were orthographically transcribed in ELAN and then forced-aligned at the word and phone level using FAVE-align. F1 and F2 vowel measurements (in $\mathrm{Hz}$ ) were taken automatically using FAVE-extract (Rosenfelder et al. 2011). These measurements were then normalized using a within-speaker z-score over all the vowels (equivalent to Lobanov normalization).

For each vowel change, I took a single dimension as the primary "change dimension," following the results in Labov et al. (2013). Measurements along the relevant change dimension will be the dependent variable for each vowel-specific regression model. For the vowels whose change dimension is along the front diagonal of the vowel space, I follow Labov et al. (2013) in using F2-2 ${ }^{\star} \mathrm{F} 1$ as a dimension called diag. I designated one end of the change dimension as the "innovative" direction and oriented the measurements along that dimension, so that higher values reflect a more innovative vowel quality. Because some of the changes reverse direction during the time period covered here, it is not straightforward to choose an innovative direction: for example, for a speaker born in the first part of the 20th century, a fronter GOAT may reflect greater advancement in the fronting change, while for a speaker born in the 1980s, that same front GOAT quality may be seen as conservative with respect to the reversal. I decided to take the community direction from speakers born in the first half of the 20th century as the reference for the orientation of the change dimensions, so that higher values always represent a vowel that is further ahead in the "original" change direction. The directionality of the values will be important for interpreting positive versus negative correlations in the data analysis, so I outline them here: 
- FACE: a higher diag value is a higher/fronter vowel, more advanced in raising/ fronting

- PRICE: a higher -F1 indicates a higher vowel, more advanced in raising

- Down: a higher diag indicates a higher/fronter vowel, more advanced in raising/fronting (but more conservative in the reversal)

- GOAT: a higher F2 indicates a fronter vowel, more advanced in fronting (but more conservative in the reversal)

- тноught: a higher -F1 is a higher vowel, more advanced in raising (but more conservative in the reversal)

Table 2 gives the dependent variables and the per-span token counts for each of the vowel changes.

Table 2. Change direction for each vowel and number of vowel tokens in each birthyear span

\begin{tabular}{lccccccc}
\hline Vowel & Measure & Span 1 & Span 2 & Span 3 & Span 4 & Span 5 & Span 6 \\
\hline FACE & diag & 5,163 & 4,927 & 6,254 & 4,164 & 3,387 & 4,150 \\
PRICE & $-\mathrm{F} 1$ & 2,846 & 3,110 & 4,270 & 3,539 & 3,205 & 6,115 \\
DOWN & diag & 4,363 & 4,341 & 5,636 & 4,126 & 2,921 & 3,690 \\
GOAT & F2 & 2,757 & 2,426 & 2,754 & 1,978 & 1,432 & 2,057 \\
THOUGHT & $-\mathrm{F} 1$ & 4,741 & 4,105 & 5,209 & 3,716 & 2,601 & 3,506 \\
\hline
\end{tabular}

\section{Are covariation patterns stable over time?}

In the first study I present here, I ask whether the change covariation patterns that I identified in Tamminga (2019), which used data from recently-recorded young white Philadelphian women, have characterized the broader Philadelphia speech community over the much longer time course of data that we have available. As a reminder, in that paper I found that the reversing changes were correlated but the continuing changes were not, nor were any reversing-continuing change pairs correlated. 


\subsection{Statistical methods}

For each vowel for each PNC birth year span, I fit a separate linear mixed effects model (LMEM) using the lme4 package in R (Bates et al. 2015). ${ }^{1}$ The models are intended to control the effects of a range of known linguistic predictors of vowel quality plus social group predictors that are not the target of this individual differences investigation. In this respect, the models serve not their more familiar hypothesis-testing function, but rather a simpler data-processing function. The models also include random intercepts for word and speaker. The model fixed-effects predictors are as follows:

- Lexical frequency: z-scored Lg10WF measure from SUBTLEX ${ }_{U S}\left(\right.$ Brysbaert $^{-}$ \& New 2009)

- Vowel duration: z-scored natural log of duration taken from FAVE-extract

- Phonological context: separate predictors for preceding segment identity plus place, manner, and voicing of following segment

- Speaker gender: sum coded (male $=1$, female $=-1)$

- Speaker birth year: $\mathrm{z}$-scored year of birth

- Speaker age: $z$-scored age at time of interview

- Speaker race: treatment coded (white $=0$, non-white $=1$ )

Following Drager \& Hay (2012), I take the by-speaker random intercepts from each model as a measure of how innovative or conservative each speaker is, controlling for the other social and linguistic factors, in comparison to the other speakers from the same birth year cohort in the data. I then correlate the random intercepts across the pairs of vowels within each birth year span. Having previously found that the choice of correlation type does not seem to change the outcome in the interspeaker covariation analysis of the LLC subset from Tamminga (2019), I use Pearson correlations here for their familiarity. I use permutation tests to assess the significance of each correlation. For these tests, each set of paired observations has the dependent variable randomly reshuffled 5000 times. Observed correlations with a more extreme value than $95 \%$ of these permutation trials are reported as statistically significant.

1. Fitting separate models to each vowel and bin subset raises possible issues of non-independence, particularly in light of the study's central result that many of the vowel pairs are not independent. A preferable approach would be to fit a full model that estimates the covariance within the model, but such a model is very large and does not converge. Future work on this topic might consider more complex model fitting options. 


\subsection{Results}

The results of this analysis are shown in Figure 1. The facets separate out the patterns for four different pair types: (a) a pair of continuing changes, (b) three pairs of reversing changes, (c) FACE plus the three reversing changes, and (d) PRICE plus the three reversing changes. The measure on the $y$-axis is the Pearson's $\mathrm{R}$ value of the correlation between the speaker random intercepts from the LMEMs for each of the two vowels in any given pair. The points are filled (colored) if they represent a pairwise correlation that is significant according to the permutation test standard described above, and open (white) if they represent a correlation that is not significant. In all cases where overlap between points makes it difficult to tell whether each separate point is significant, the overlapping points share the same significance status (for example, in span 2 in the "both reversing" facet, the DOWN- GOAT and DOWN- THOUGHT correlations are both significant). The horizontal solid black line indicates a correlation of $R=0$, where there is no apparent linear relationship between speakers' degrees of innovativeness in one change and the other change. Positive values above the black line indicate a positive correlation, meaning that a speaker who is relatively advanced in one change will also be advanced in the other. Negative values below the black line indicate an inverse correlation, meaning that a speaker who is on the innovative end of one change will be more conservative in the other, and vice versa. Recall that being "innovative" or "advanced" here are defined as being further ahead in the change's original direction: higher and fronter along the front diagonal for FACE and DOWN, higher for PRICE and THOUGHT, and fronter for Down. The dotted vertical grey line at span 3 in each facet is included as a visual reference point for the beginning of the change reversals in Down and GOAT, which Labov et al. (2013) pinpoint as occurring in 1940 (span 3 includes speakers born 1936-1949).

In the top facet of the graph, we can see that the two continuing changes, FACE and PRICE, correlate positively beginning in span 3. In the second facet, we see that most of the reversing change pairs show moderately strong positive correlations across every birth year span, with especially strong and stable covariation between the two back upgliding vowels DOwN and GOAT. In the third facet, the broad pattern is that FACE and the reversing changes correlate negatively prior to span 3 and positively after span 3 , although none of these correlations are very large. In the final facet, we see that PRICE and the reversing changes have near-zero or weaker positive correlations before span 3 and then, within each pair, get stronger starting in span 3 .

While there is some complexity to the results shown in Figure 1, it is important not to lose sight of a number of simple points. First, there is quite a lot of covariation overall, which is notable in light of the underwhelming results from the coherence literature as reviewed very briefly in Section 1 as well as in comparison to the 

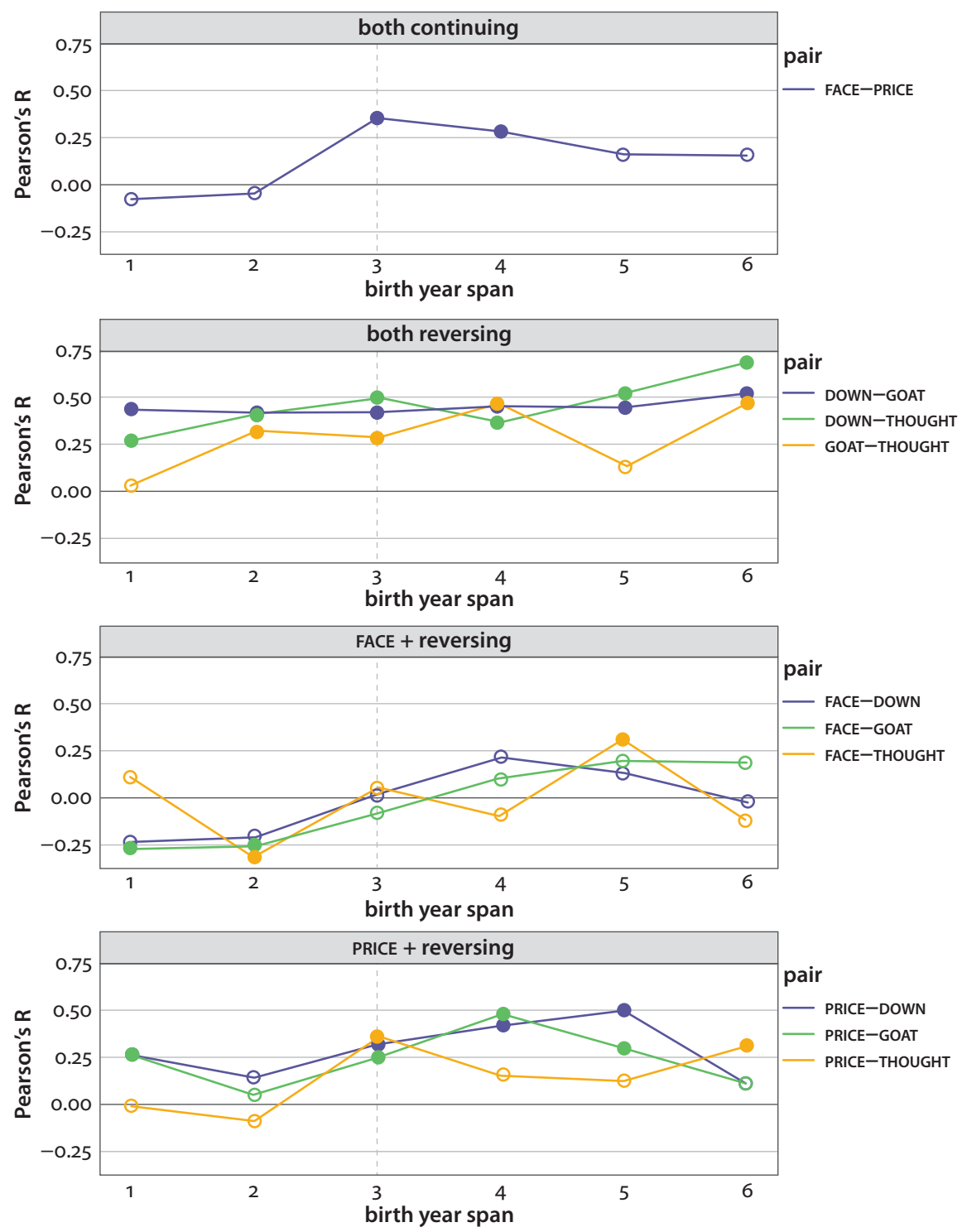

Figure 1. Change over time in interspeaker covariation between five Philadelphia vowels. Filled points indicate significant correlations; empty points indicate non-significant correlations

results from current young women in Tamminga (2019). Second, many of these correlations are repeated in the same direction across birth year spans, increasing our confidence that they reflect true correlations in the community. The covariation patterns between pairs of reversing changes, for example, are apparent for 
almost every birth year span for all three pairs: throughout the twentieth century in Philadelphia, it has been the case that the speakers with higher тноUGHT also have a fronter GOAT and the higher/fronter DOWN. Since World War II, these speakers have also had higher PRICE vowels and, to a lesser extent, higher FACE values.

A slightly more speculative conclusion to draw is that the timing of the shifts in the covariation patterns appears as if it may be related to the timing of the major diachronic reversals documented by Labov et al. (2013). It is of some interest to note that the covariation between FACE and PRICE emerges right around the time of the reversals - even though neither FACE nor PRICE reverses. The shift from negative to positive correlations between FACE and the reversals, as well as the increase in the strength of the positive correlations between PRICE and the reversals, both also seem to revolve around span 3. Although these observations suggest some relationship between the covariation patterns and the overall community diachronic trajectory, the covariation facts cannot simply be "read off" of the aggregate diachronic facts: between the FACE covariation patterns and the PRICE covariation patterns, there is no perspective from which we could conclude that there is a monotonic relationship between the diachronic change directions and the presence and polarity of covariation. We could try to understand the relationship between FACE and the reversing changes as (mostly) consistently negative, if the reversing changes had been oriented toward the community diachronic direction in each span. In other words, if I had decided that the "innovative" direction for the reversing changes in spans 4-6 was the reversal direction (lower THOUGHT, lower/backer DOWN, backer GOAT), the positive correlations seen in these spans would have been negative. However, if I did make that change, it would shift the PRICE results as well: PRICE would go from positively correlated in spans 1-3 to negatively correlated in spans 4-6. Another way of looking at it is that FACE values are consistently negatively correlated with the contemporaneous innovative direction of the reversals (including being 0 when the slope of the change-over-time line is 0 ), while PRICE values are consistently positively correlated with a fixed phonetic value in the reversing vowels. While I do not yet have an explanation to offer for why that should be, I suggest these results motivate continued inquiry into the question of how different changes are related to each other at the speaker level. It appears there is detail in the individual differences that goes beyond what we can learn from aggregate community patterns. In the next section, I ask whether we can predict individual differences within the changes that show the most covariation: the reversing changes. 


\section{Can we predict individual differences within the changes that covary?}

In Tamminga (2019), I found that the pairwise correlations between the reversing changes DOWN, GOAT, and THOUGHT were the only source of significant change covariation within the sample of young women in the LLC data. In the previous section, I showed that, while other correlations were present in earlier generations, the reversal correlations stand out for their strength and stability over the course of the twentieth century, which boosts our confidence that the Tamminga (2019) result is not spurious but reflects real interspeaker relationships between these vowels. In this section, I use data from an overlapping group of participants from the same project as in Tamminga (2019) to ask whether we have any idea what makes some people further ahead and others further behind in DOWN/GOAT/THOUGHT. I use Principal Components Analysis to extract a single reversal dimension, which turns out to be the first principal component, from the speaker random intercepts for all five vowels in these young women's conversational speech data. This effectively reduces the information about the correlations across the five vowels into a single dimension that captures a speakers' degree of participation in the correlated reversing changes. I then ask whether non-linguistic individual differences predictors, collected from these young women in an experimental battery completed after recording of the conversational speech data, can capture any of the variance in the individual speaker values. While the battery included quite a few other measures, here I focus on the measures that were adopted because they putatively tap traits proposed to be associated with change leadership or mechanisms of sound change: extraversion, social network size, and AQ score.

\subsection{The individual differences measures}

The individual differences predictors investigated in this section are measured as follows:

- The Extraversion score from the Big Five Inventory (BFI) (John \& Srivastava 1999). The BFI is a 44-item self-reported measure of the Big-Five personality factors (Goldberg 1992). The Extraversion factor comprises the traits of gregariousness, assertiveness, activity, excitement-seeking, positive emotions (enthusiasm), and warmth.

- Estimated personal degree from a scale-up network estimation survey following McCormick, Salganik, and Zheng (2010), calculated using the networkreporting package in R (Feehand \& Salganik 2014). An individual's degree is the number of people they know. Scale-up methods to estimate individual degrees 
ask participants how many people they know in certain categories (in this case, people with particular first names) and estimates the degree from the known prevalence of those categories in the population (in this case, based on data from the 1990 census).

- The overall score from the Autism-spectrum Quotient (AQ) (Baron-Cohen et al. 2001). The AQ is a self-reported survey of "autistic-like" traits that in this context is probably best understood as a combined personality and cognitive style measure. Higher AQ scores equate to a higher degree of these autistic-like traits.

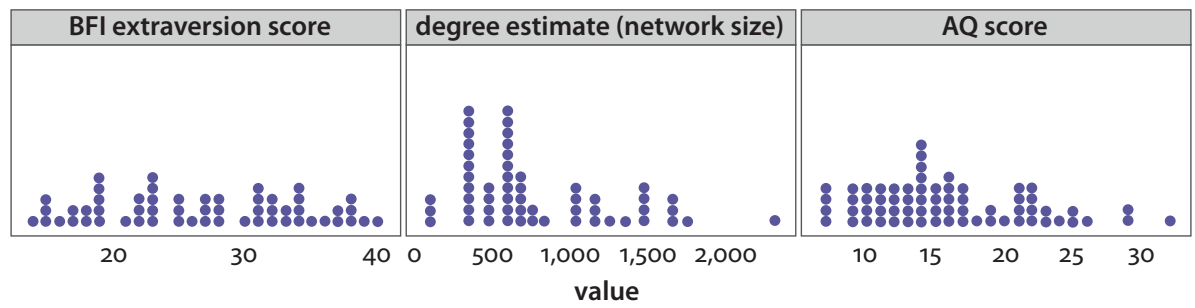

Figure 2. Distribution of participant values for the three individual differences measures

The BFI extraversion measure is included because personality traits relating to outgoingness, gregariousness, connectedness, and personal influence have been recurring themes in the sociolinguistic literature on change leaders (see Haeri 1991; Labov 2001; Denis 2011 inter alia). Similarly, such themes partially motivate the inclusion of the estimated personal degree; network degree is also an interesting candidate predictor in light of a number of recent studies finding that personal social network size influences a range of linguistic behaviors that may be linked to language change (Lev-Ari 2017, 2018a, 2018b, 2018c). The AQ (Autism-spectrum Quotient, Baron-Cohen et al. (2001)) is included here because it has been a leading measure in a line of experimental work on individual differences in phonetic flexibility behaviors, such as phonetic imitation and compensation for coarticulation, that again are often thought to underpin sound change (Stewart \& Ota 2008; Yu et al. 2011; Yu et al. 2013; Yu 2013; Wagner \& Hesson 2014; Kingston et al. 2015). Yu (2013) explicitly links this individual differences literature to sociolinguistic hypotheses about the leaders of language change. While a range of other individual differences measures were collected in the full battery from the LLC project, these three are the most obviously related to our expectations about what might make some speakers especially advanced in their use of changes in progress.

It is worth noting that these measures are significantly correlated with each other. The Pearson's correlation between extraversion and network size is 0.38 
$(p=0.004)$, between extraversion and AQ is $-0.48(p<0.001)$, and between network size and AQ is $-0.27(p=0.04)$. It is intuitively unsurprising that these measures would be related. Presumably a tendency toward extraversion is likely to lead to meeting and getting to know a larger number of people. And many of the items on the AQ survey, especially on its "social" subscale, relate to traits that overlap with extraversion (such as "I am good at social chit-chat," "I enjoy social occasions," and "I enjoy meeting new people"). The weaker correlation between network size and AQ suggests there may be a less direct connection there, perhaps merely their shared correlations with extraversion.

\subsection{Statistical methods}

The dependent measure used in this section is taken from a Principal Components Analysis (PCA) model of speaker random intercepts across the five vowel changes at hand. Models identical to the ones from Section 4 were fit to the data from the 56 LLC participants, and the speaker random intercepts extracted. I then fit a PCA model to the full set of speaker random intercepts for the five vowels using the factoextra package in R (Kassambara \& Mundt 2017). The eigenvectors for the five vowel variables are plotted against the first two components of the PCA in Figure 3. Note that Figure 3 does not represent the full multi-dimensional space in which the observations are distributed: the PCA captures orthogonal dimensions within that space along which the observations cluster, and Figure 3 shows only information about how the two most important dimensions identified by the model relate to the features (i.e. vowels) that went into the model in the first place. We can see from this figure that the first principal component, which captures $37.5 \%$ of the variance in the data, is most highly correlated with DOWN and THOUGHT (their loadings on the component are $32 \%$ and $30 \%$ respectively), and while GOAT is not that much more strongly correlated with the component than FACE and PRICE, its values on this dimension are grouped with the DOWN and THOUGHT values in contrast to FACE and PRICE, which fall on the other side of the plot. The sign of the dimensions is arbitrary, with negative PC1 values in this particular PCA model corresponding to speakers with high positive DOWN, GOAT, THOUGHT values (in other words, speakers with more "traditional Philadelphian" values of these vowels). I extract each speaker's PC1 value (their location on the $\mathrm{x}$-axis in Figure 3) and call it the "reversal dimension" for more intuitive discussion, because $\mathrm{PC} 1$ primarily reflects information about how advanced each speaker is on the correlated reversing changes taken together. The remainder of my discussion in this section focuses on this single dimension taken from the PCA. 


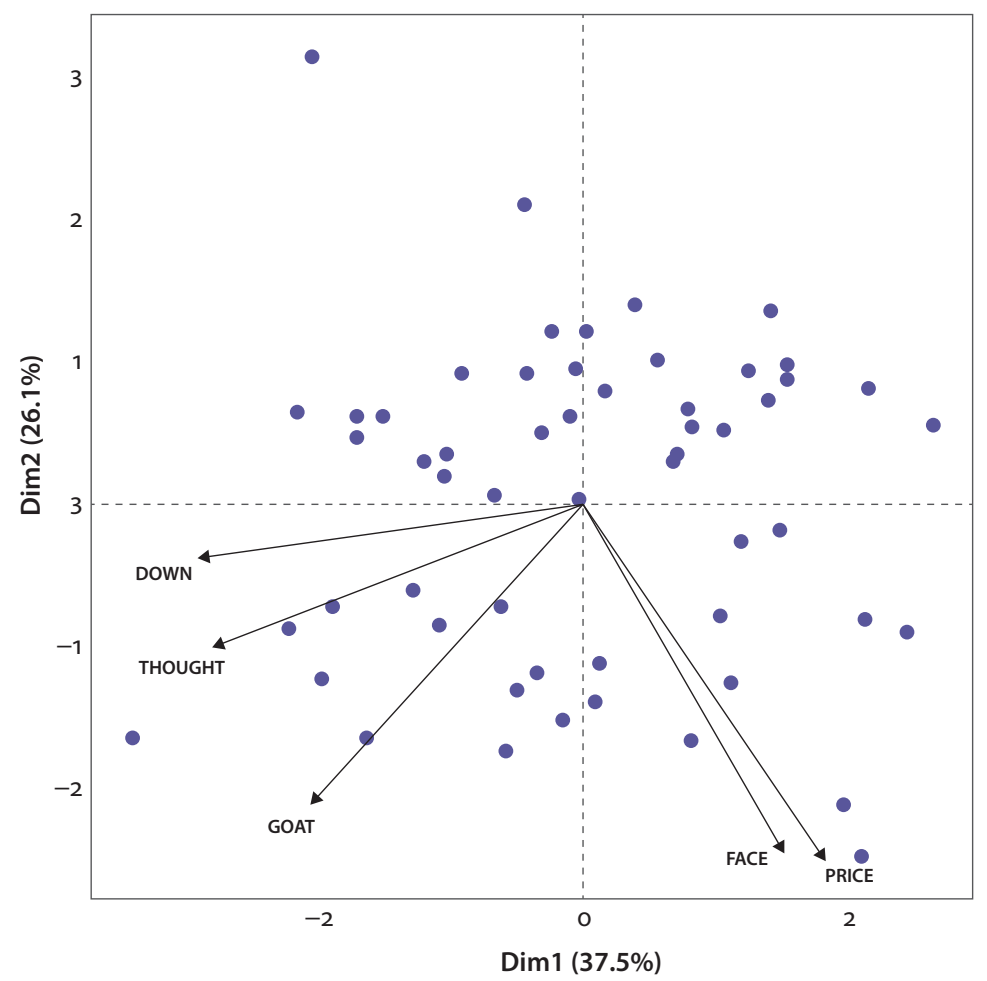

Figure 3. Plot of variables contributing to the first and second principal components of the PCA and individual observations in those dimensions. The "reversal dimension" corresponds to values on the $\mathrm{x}$-axis

\subsection{Results}

Having extracted the speaker-specific reversal dimension values, I then correlate these values with the speaker-specific values on the other individual differences measures discussed in Section 5.1. These correlations are plotted in Figure 4, where we see that there is no evidence for a general relationship between reversal dimension and extraversion (Pearson's $R=-0.01, p=0.91)$ social network size $(R=0.004$, $p=0.98)$, or AQ $(R=-0.16, p=0.24){ }^{2}$ In other words, the individual-differences predictors I have explored here offer little value in capturing speaker variability along the reversal dimension.

2. The p-values for these correlations are calculated using permutation tests as described in Section 4.1. 


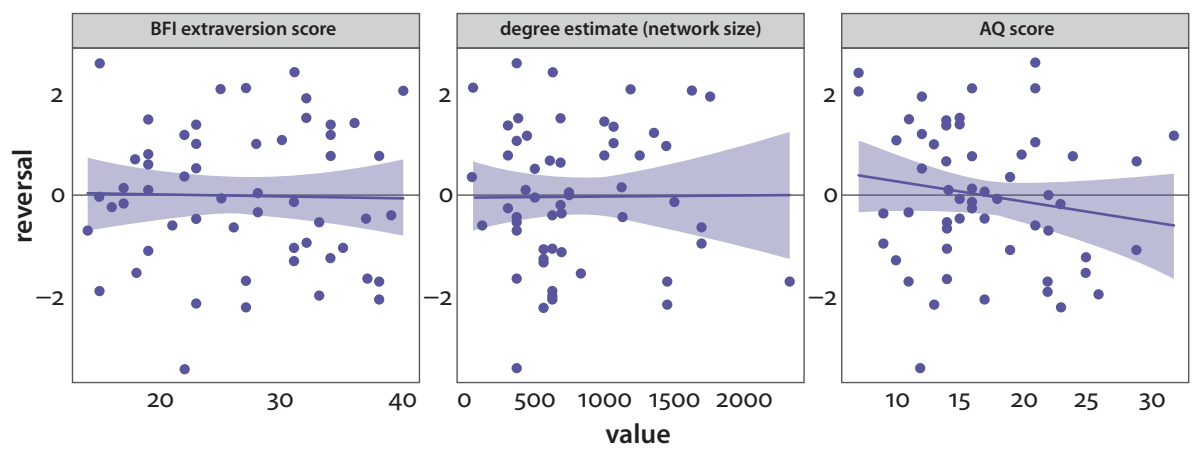

Figure 4. Pearson correlations between individual differences measures and reversal dimension

There are several possible reasons to consider for this trio of null results. One possibility is that the underlying constructs are indeed related to participation in the vowel change reversals, but I have done a poor job measuring those constructs. This seems most likely in the case of the social network size measure, where several layers of estimation go into the value that is calculated using the scale-up degree calculation (there are more accurate ways to measure degree, but the rapid scale-up technique was chosen as expedient in the context of a quite long exploratory battery). However, the fact that these intuitively-interrelated individual differences measures correlate significantly with one another suggests that there is signal in the measures even though they are clearly only estimates of underlying constructs. Another possibility is that the study is underpowered with respect to the detection of these correlations. The extremely small $\mathrm{R}$ values for extraversion and network size do not bode well for this proposal, but it could plausibly be the case that the small effect of $A Q$ is a true one that is not significant only because we do not have enough participants. We have no particular basis on which to guess the expected effect size of something like extraversion or AQ on a vowel change, and therefore cannot calculate the power directly. I do note that the number of individuals included here is comparable to some of the laboratory experiments in which AQ is a significant predictor (Stewart \& Ota 2008; Yu et al. 2011). Another possibility is that the reversal dimension itself is a noisy measure. Even the strongest of the pairwise correlations observed in the PNC data are at best moderate in absolute terms, so it is not surprising that even the first principal component in the PCA (that is, the reversal dimension) captures less than $40 \%$ of the variance. This noisiness may also contribute to the null results.

The more interesting possibility is that I have not included the right predictors or predictor combinations to capture individual variability on the reversal dimension. Recall that the predictors were selected on the basis of existing claims in the 
literature about the relationship between these measures and either fieldwork-based sociolinguistic observations about sound change leaders or laboratory-based hypotheses about sound change mechanisms. However, many different precise predictions could be (and in some cases have been) put forward about the relationship between these traits and language change; here I have undertaken only a preliminary investigation about whether there are direct relationships between each predictor alone and the change dimension of interest here. Extraversion may need to be combined with other personality dimensions, such as empathy (Yu 2013), to see its effect on change. It is well established that social network structure influences language change, suggesting that to understand individual differences in these terms we would need to go beyond the simple effect of speakers' personal network degrees (Milroy 1980; Milroy \& Milroy 1985, 1992; Dodsworth \& Kohn 2012; Dodsworth 2014; Sharma 2017, inter alia); this type of social-structural influence should probably be seen as distinct, however, from mechanisms related to an individual's amount of exposure to many different speakers as discussed in the multiple Lev-Ari papers cited above. In any case, what we see here is that the simple procedure of operationalizing traits suggested by the literature on language change and using them to predict individual differences in change advancement is not an entirely promising pathway.

\section{Discussion}

The overall picture emerging from this pair of studies is one where there is in fact a great deal of interspeaker covariation to be found in a bird's-eye view on the speech community's history, yet we have little grasp of the source of that covariation when we zoom in to a slice of the community. When we try to correlate the most robust individual differences in the sound changes with other speaker-level traits, we have so far found little to enlighten us. Moreover, it remains unclear how the covariation patterns relate to either the general diachronic trajectory of the changes or to the sociolinguistic questions of change leadership that I raised in Section 1.

As I discussed briefly in Section 1, it is not uncommon to relate correlational patterns between changes to questions of change leadership, such as a potential need to allow for different people leading different changes. But of course, the practice of assessing interspeaker change correlations throughout a sample of the community overlaps only partially with the goal of identifying speakers who are leading multiple changes. The study of interspeaker covariation between changes makes sense primarily if we think that for any given change, individual differences are not noise but rather represent a meaningful continuum of innovativeness to conservativeness (which may or may not be change-specific). This kind of analysis, 
characterizing all speakers in terms of their quantitative degree of advancement on some change, is different than identifying individuals who are notably advanced. In the latter case, such distinctively innovative individuals might be identified with Labov's notion of saccadic leaders, speakers who "stand out in sharp contrast to others in their sociolinguistic behavior" (2001: 384). When Labov sketches a portrait of the leaders of language change, he makes clear that he is discussing saccadic leaders - and that he is doing so because they "appear to be agents of further advance of the sound changes" (2001:384). The general idea that some people are leaders of language change in the sense that they are especially influential, as it suffuses the sociolinguistic literature, thus seems to be in line with this saccadic conception of leadership.

But seeing a potential role for saccadic leaders as linguistic influencers does not entail that the traits that might make some people stand out linguistically are also the traits that are at play in determining every speaker's place on the innovativeness continuum. It is not even clear whether saccadic leaders represent the far end of the same innovativeness cline as their less influential peers. From this perspective, it is not necessarily surprising that the reversal dimension values do not correlate with individual non-linguistic traits like social network size or extraversion. These predictors were chosen in the hopes that they might serve as viable measures to operationalize the traits of linguistic leaders. But if we attempt to connect individual differences observed in the lab with portraits of leaders from sociolinguistic studies, we should not expect to find success unless we are confident that we have brought the right speakers into the lab - while a sample like the LLC project may or may not have even one saccadic leader in it. Denis makes a related point in his study of innovator gregariousness: saying that linguistic innovators are likely to be gregarious is not the same as saying that gregarious people must be innovators (Denis 2011: 67). While I agree with this point, I observe that it also somewhat undercuts the explanatory weight we might wish to put on individual traits in language change. Even if we could establish that, for example, extraversion is a precondition for saccadic leadership, it doesn't tell us which of many, many extraverted people in the world actually become linguistic leaders, and therefore suggests that extraversion itself has at best an auxiliary role to play in models of how language change advances.

So far I have been arguing that quantifying speaker-specific degree of innovativeness throughout a community (and subsequently correlating this measure across multiple changes) is not likely to shed much light on leadership questions. But this is not to say that this kind of analysis should not be pursued. On the contrary, I believe the covariation results discussed in Section 4 point strongly toward individual differences in degree of innovativeness as a level of sociolinguistic analysis that deserves more in-depth attention. When we compare the interspeaker covariation analysis with the aggregate community trajectories, we see that there 
is substantial information in the pattern of within-span correlations that is not captured at the community level. The covariation information does appear to be related in some way to the overall diachronic trajectories of the changes. A number of major covariation reorganizations take place in the same window of time where the shifts in DOWN and GOAT reverse course (i.e., span 3): the continuing changes come to correlate positively with each other, FACE shifts from weak negative to weak positive correlations with the reversing changes, and the weak positive correlations between PRICE and the reversing changes strengthen. But what I find most notable is that the reversing change correlations arise well before those changes actually reverse. Because the correlations temporally precede the diachronic reversal point, we should consider the possibility that interspeaker covariation may drive, rather than merely reflect, diachronic outcomes.

Our limited understanding of interspeaker covariation is a lacuna in the quantitative sociolinguistics literature. The diachronic stability of the covariation patterns in this paper, as well as their seeming connection to diachronic inflections at the whole community level, suggest that the coherence literature is very much pointing in a promising direction, and that our response to null and inconsistent results across case studies should be to pursue an account of when and where we do find coherence, rather than to give up the search. At the same time, questions about whether speaker-level coherence can be found throughout the community might fruitfully be kept distinct from questions about the role of particularly influential individuals in language change. Ultimately, if we can make progress toward quantifying the distribution of speaker-level profiles across the community, we may be able to bridge the gap between the characterization of single speakers and the study of community sociolinguistic stratification in aggregate.

\section{Acknowledgements}

Thanks for research assistance and feedback on this work go to Elisha Cooper, Wei Lai, Ruaridh Purse, Lacey Wade, Yosiane White, and Robert Wilder, as well as many undergraduate research assistants. I am grateful to audiences at ICLaVE|10, the 5th Workshop on Sound Change, Princeton, and Villanova for feedback on this paper, as well as to Cesko Voeten for statistical input and an anonymous reviewer for additional comments. Thanks also to the ICLaVE|10 organizers for inviting me to present this work at what was truly an excellent conference. All errors that remain are, of course, my own. 


\section{Funding}

This material is based on work supported by the National Science Foundation under Grant Number 1627972, "Cognitive characteristics of the leaders of language change.".

\section{References}

Baron-Cohen, Simon, Sally Wheelwright, Richard Skinner, Joanne Martin \& Emma Clubley. 2001. The Autism-Spectrum Quotient (AQ): Evidence from Asperger Syndrome/HighFunctioning Autism, males, females, scientists and mathematicians. Journal of Autism and Developmental Disorders 31. 5-17. https://doi.org/10.1023/A:1005653411471

Bates, Douglas, Martin Mächler, Ben Bolker \& Steve Walker. 2015. Fitting linear mixed-effects models using lme4. Journal of Statistical Software 67(1). 1-48. https://doi.org/10.18637/jss.v067.io1

Becker, Kara. 2016. Linking community coherence, individual coherence, and bricolage: The co-occurrence of (R), raised BOUGHT and raised BAD in New York City English. Lingua 172-173. 87-99. https://doi.org/10.1016/j.lingua.2015.10.017

Brysbaert, Marc \& Boris New. 2009. Moving beyond Kučera and Francis: A critical evaluation of current word frequency norms and the introduction of a new and improved word frequency measure for American English. Behavioral Research Methods 41(4). 977-90. https://doi.org/10.3758/BRM.41.4.977

Denis, Derek. 2011. Innovators and innovation: Tracking the innovators of 'and stuff' in York English. Penn Working Papers in Linguistics: Selected Papers from NWAV 39 17(2).

Dodsworth, Robin. 2014. Network embeddedness and the retreat from Southern vowels in Raleigh. University of Pennsylvania Working Papers in Linguistics 20(2). 41-50.

Dodsworth, Robin \& Mary Kohn. 2012. Urban rejection of the vernacular: The SVS undone. Language Variation and Change 24. 221-45. https://doi.org/10.1017/So954394512000105

Drager, Katie \& Jennifer Hay. 2012. Exploiting random intercepts: Two case studies in sociophonetics. Language Variation and Change 24. 59-78. https://doi.org/10.1017/So954394512000014 Feehand, Dennis M. \& Matthew J. Salganik. 2014. The Networkreporting Package. http:// cran.r-project.org/package $=$ networkreporting

Fruehwald, Josef. 2013. The phonological influence on phonetic change. University of Pennsylvania: Ph.D. thesis.

Fruehwald, Josef. 2019. Is phonetic target uniformity phonologically, or sociolinguistically grounded? In Marija Tabain, Paul Warren, Sasha Calhoun \& Paola Escudero (eds.), Proceedings of the 19th International Congress of Phonetic Sciences, Melbourne, Australia 2019, 681-85. Canberra, Australia: Australasian Speech Science Technology Association Inc.

Goldberg, Lewis R. 1992. The development of markers for the Big-Five factor structure. Personality Assessment 4(1). 26-42.

Guy, Gregory R. 2013. The cognitive coherence of sociolects: How do speakers handle multiple sociolinguistic variables? Journal of Pragmatics 52. 63-71.

https://doi.org/10.1016/j.pragma.2012.12.019

Guy, Gregory R. \& Frans Hinskens. 2016. Linguistic coherence: Systems, repertoires and speech communities. Lingua 172-173. 1-9. https://doi.org/10.1016/j.lingua.2016.01.001 
Haeri, Niloofar. 1991. Sociolinguistic variation in Cairene Arabic: Palatalization and the 'Qaf' in the speech of men and women. University of Pennsylvania: Ph.D. thesis.

John, Oliver P. \& Sanjay Srivastava. 1999. The Big-Five trait taxonomy: History, measurement, and theoretical perspectives. In Lawrence A. Pervin \& Oliver P. John (eds.), Theory and Research (Handbook of Personality 2), 102-38. New York: Guilford Press.

Kassambara, Alboukadel \& Fabian Mundt. 2017. Factoextra: Extract and visualize the results of multivariate data analyses. https://CRAN.R-project.org/package=factoextra

Kingston, John, Stephanie Rich, Alice Shen \& Shifra Sered. 2015. Is perception personal? In The Scottish Consortium for ICPhS 2015 (ed.), Proceedings of the 18th International Congress of the Phonetic Sciences, paper 887. Glasgow: The University of Glasgow.

Labov, William. 2001. Principles of Linguistic Change, Vol. 2. Social Factors. Oxford: Blackwell.

Labov, William \& Ingrid Rosenfelder. 2011. The Philadelphia Neighborhood Corpus of LING 560 Studies, 1972-2010.

Labov, William, Ingrid Rosenfelder \& Josef Fruehwald. 2013. One hundred years of sound change in Philadelphia: Linear incrementation, reversal, and reanalysis. Language 89(1). 30-65. https://doi.org/10.1353/lan.2013.0015

Lev-Ari, Shiri. 2017. Talking to fewer people leads to having more malleable linguistic representations. PLoS ONE 12(8). e01835593. https://doi.org/10.1371/journal.pone.0183593

Lev-Ari, Shiri. 2018a. Social network size can influence linguistic malleability and the propagation of linguistic change. Cognition 176. 31-39. https://doi.org/10.1016/j.cognition.2018.03.003

Lev-Ari, Shiri. 2018b. The influence of social network size on speech perception. Quarterly Journal of Experimental Psychology 71(10). 2249-60. https://doi.org/10.1177/1747021817739865

Lev-Ari, Shiri. 2018c. People with larger social networks are better at predicting what someone will say but not how they will say it. Language, Cognition and Neuroscience 34(1). 101-14. https://doi.org/10.1080/23273798.2018.1508733

Maclagan, Margaret A., Elizabeth Gordon \& Gillian Lewis. 1999. Women and sound change: Conservative and innovative behavior by the same speakers. Language Variation and Change 11. 19-41. https://doi.org/10.1017/So954394599111025

McCormick, Tyler H., Matthew J. Salganik \& Tian Zheng. 2010. How many people do you know? Efficiently estimating personal network size. Journal of the American Statistical Association 105(489). 59-70. https://doi.org/10.1198/jasa.2009.apo8518

Milroy, James. 1993. On the social origins of language change. In Charles Jones (ed.), Historical Linguistics: Problems and Perspectives. London: Routledge.

Milroy, James \& Lesley Milroy. 1985. Linguistic change, social network and speaker innovation. Journal of Linguistics 21. 339-84. https://doi.org/10.1017/So022226700010306

Milroy, Lesley. 1980. Language and social networks. Oxford: Basil Blackwell.

Milroy, Lesley \& James Milroy. 1992. Social network and social class: Toward an integrated sociolinguistic model. Language in Society 21(1). 1-26. https://doi.org/10.1017/Soo47404500015013

Nevalainen, Terttu, Helene Raumolin-Brunberg \& Heikki Mannila. 2011. The diffusion of language change in real time: Progressive and conservative individuals and the time depth of change. Language Variation and Change 23. 1-43. https://doi.org/10.1017/So954394510000207

Oushiro, Livia. 2016. Social and structural constraints in lectal cohesion. Lingua 173-173. 116-30. https://doi.org/10.1016/j.lingua.2015.10.015

Rosenfelder, Ingrid, Josef Fruehwald, Keelan Evanini \& Jiahong Yuan. 2011. FAVE Program Suite [Forced Alignment and Vowel Extraction]. University of Pennsylvania. fave.ling.upenn.edu. Sharma, Devyani. 2017. Scalar effects of social networks on language variation. Language Variation and Change 29. 393-418. https://doi.org/10.1017/So954394517000205 
Sneller, Betsy. 2015. A community divided: Co-occurrence in retreat from local features. Poster presented at UKLVC 10, University of York, Sept. 2.

Stewart, Mary E. \& Mitsuhiko Ota. 2008. Lexical effects on speech perception in individuals with 'autistic' traits. Cognition 109. 157-62. https://doi.org/10.1016/j.cognition.2008.07.010

Tamminga, Meredith. 2019. Interspeaker covariation in Philadelphia vowel changes. Language Variation and Change 31(2). 119-133. https://doi.org/10.1017/So954394519000139

Thorburn, Jennifer. 2014. Dialect development in Nain, Nunatsiavut: Emerging English in a Canadian Aboriginal community. St. John's Memorial University of Newfoundland: Ph.D. thesis.

Wagner, Suzanne Evans \& Ashley Hesson. 2014. Individual sensitivity to the frequency of socially meaningful linguistic cues affects language attitudes. Journal of Language and Social Psychology 33(6). 651-66. https://doi.org/10.1177/0261927X14528713

Waters, Cathleen \& Sali Tagliamonte. 2017. Is one innovation enough? Leaders, covariation, and language change. American Speech 92(1). 23-40. https://doi.org/10.1215/00031283-4153186

Yu, Alan C. L. 2013. Individual differences in socio-cognitive processing and the actuation of sound change. In Alan C. L. Yu (ed.), Origins of sound change: Approaches to phonologization, 201-27. Oxford: Oxford University Press. https://doi.org/10.1093/acprof:oso/9780199573745.003.0010

Yu, Alan C. L., Carissa Abrego-Collier \& Morgan Sonderegger. 2013. Phonetic imitation from an individual-difference perspective: Subjective attitude, personality and 'autistic' traits. PLoS ONE 8(9). e74746. https://doi.org/10.1371/journal.pone.0074746

Yu, Alan C. L., Julian Grove, Martina Martinovic \& Morgan Sonderegger. 2011. Effects of working memory capacity and 'autistic' traits on phonotactic effects in speech perception. In Wai Sum Lee (ed.), Proceedings of the International Congress of the Phonetic Sciences XVII, Hong Kong: International Congress of the Phonetic Sciences, 2236-2239. 



\title{
Ethnic variation in real time
}

\section{Change in Australian English diphthongs}

\author{
James Grama ${ }^{1}$, Catherine E. Travis ${ }^{2}$ and Simon Gonzalez ${ }^{2}$ \\ ${ }^{1}$ University of Duisburg-Essen $/{ }^{2}$ Australian National University
}

\begin{abstract}
Ethnic and ethnolectal variation in migrant communities have received much attention, but the manifestation and longevity of this variation is not yet well understood. Capitalising on Barbara Horvath's foundational study of social variation in Australian English, and a comparable, recent corpus of sociolinguistic interviews (Sydney Speaks 2010s), we present a real-time test of ethnic variation in the speech of approximately 170 Australians over a 40 -year period. We examine the speech of Anglo-, Italian- and Chinese-Australians, focusing on five diphthongs considered to be characteristic of Australian English. Analyses of over 20,000 tokens reveal no wholesale differences among ethnic groups, but they do reveal some differences in the progression and social conditioning of changes over time, which we argue are best understood in relation to the social nature of the changes undergone.
\end{abstract}

Keywords: ethnolects, ethnic variation, diphthongs, Australian English, language change, gender, socio-economic status

\section{Ethnic and ethnolectal variation}

A prominent question in sociolinguistics has been the role of ethnic minorities in variation and change. Apparent time studies have provided evidence that ethnic minorities may help drive change forward, from Labov's pioneering studies in New York $(1966,1972)$ and Horvath's study of Sydney, Australia (Horvath 1985), to more recent work in other major urban centres (e.g., Cheshire, Jacomine \& Adger 2015; Gross et al. 2016). It has also been observed that ethnic minorities may make use of distinct ways of speaking that characterise them as members of a particular ethnic group, using what are known as "ethnolects", or, where multiple ethnicities are involved, "multiethnolects" (Clyne 2000). Ethnolectal variation has been described in Multicultural London English (e.g., Cheshire et al. 2011), Kiezdeutsch in Berlin (e.g., Wiese 2009), and varieties spoken in Australia (Clyne, Eisikovits \& Tollfree 2001, 
2002) and Toronto, Canada (Hoffman \& Walker 2010). As migrant communities tend to undergo language shift towards the majority variety over time, such ethnically driven variation has been associated with identity, where the (multi)ethnolect is considered to serve "as a means of establishing a distinctive linguistic identity" for second or third generation migrants who may no longer speak the community language (Clyne, Eisikovits \& Tollfree 2002: 134).

While we might predict influence of the immigrant language on the ethnolectal variety, there is work to suggest precisely the opposite, where members of migrant communities exhibit patterns of use consistent with change "in a direction quite different from what would have been predicted from the structure of the immigrant language" (Labov 2008: 318). In her foundational study in Sydney, Australia, Horvath proposed that teenage Greek- and Italian-Australians were ahead in a change towards more "general" Australian English vowel realisations, moving away from both "broad" speech, associated with the working class, and "cultivated" speech, associated with the middle class and British Received Pronunciation (1985: 94). She interpreted this as Greek- and Italian-Australians differentiating themselves from their first-generation migrant parents' accented vowels; in using these newer forms, rather than indexing their ethnic identity, they appeared to be making an effort to "sound Australian" (Horvath 1985: 176). Wong and Hall-Lew similarly report that Chinese Americans in San Francisco and New York City adopt regional patterning, and that in doing so, they "construct a local, mainstream identity, thereby distinguishing themselves from foreign-born Chinese New Yorkers" (2014: 37). Similar observations have been reported for Turkish and Moroccan youths in Holland (van Meel, Hinskens \& van Hout 2014) and diverse ethnic groups in Sweden (Gross et al. 2016), where the linguistic behaviour of ethnic minorities has been accounted for in terms of regional and social differences in the majority community rather than influence from the minority languages.

In this paper, we present a real time test of the longevity of ethnic variation, capitalising on sociolinguistic interviews recorded in Sydney in the late 1970s (cf., Horvath 1985), and comparing these with an analogous set of interviews made in the late 2010s. We consider the speech of three ethnic groups - Anglo-Australians (the hegemonic community), Italian-Australians (an established migrant community), and Chinese-Australians (a newer community) - and compare their patterning for five diphthongs - FLEECE, FACE, GOAT, MOUTH, and PRICE. ${ }^{1}$ These diphthongs are of particular value for a study of ethnic variation over time in Australia, as they

1. These vowels can be broadly captured in the IPA developed for Australian English as / $\mathrm{i}$, æI, əษ, æว, aə/ (see Cox \& Palethorpe 2007). Given the variation in these vowels, we follow standard practice in sociophonetics and use the lexical set labels which capture the category without presupposing a given pronunciation (Wells 1982). 
form the basis for the socio-stylistic variation along the broad/general/cultivated continuum (cf., Mitchell \& Delbridge 1965), they were the focus of Horvath's analysis of Australian English across ethnic groups in the 1970s, and they are known to have undergone change over time (Cox \& Palethorpe 2012). We report on the patterning over time for the majority ethnic group, Anglo-Australians, which we compare with the patterning of the Italian and Chinese communities. There are some apparent ethnic differences, but once these are contextualised over time and in relation to broader social conditioning, we find that they are best understood as responding to wider social patterns rather than as a specific expression of ethnic affiliation or orientation.

\section{Variation in Australian English}

While Australian English exhibits "relative regional homogeneity" (cf., Cox \& Palethorpe 2012: 299), social variation across gender and class has been identified. This is particularly so for the five diphthongs considered here, with "cultivated" realisations being traditionally associated with females and higher levels of education, and "broad" realisations with males and lower levels of education (cf., Mitchell \& Delbridge 1965: 33). The so-called "broadness continuum" of Australian diphthongs has contracted over time, with a shift to more "general" Australian English, a change which has been interpreted as a manifestation of Australia's move away from an exonormative model of British orientation towards an endonormative Australian model (Schneider 2007: 124). This re-orientation to domestically prescribed norms has reified largely positive attitudes linking the "general" Australian sociolect with an Australian identity (Bradley \& Bradley 2001: 280), and ascribing it a degree of overt prestige.

Variation across ethnic lines has also received some attention. Exploring ethnolects in Australia, Clyne, Eisikovits and Tollfree $(2001,2002)$ describe phonological, lexical and morphosyntactic features typical of Greek-, Yiddish-, and German-Australian English. Quantitative analyses of ethnic variation have identified differences in fronting of $/ \theta /$ and deletion of word-initial $/ \mathrm{h} /$ by Italian-Australians (Horvath 1985: 102-103), lengthening of word final (er) by Greek-Australians (e.g., teacher, remember, Grama, Travis \& Gonzalez 2020; Kiesling 2005), patterning of the PRICE and GOAT vowels by Greek-, Italian-, and Lebanese-Australians (Kiesling 2001), and realisation of $/ 1 /$, voice onset time and VC rhyme by Lebanese-Australians (Clothier 2019; Clothier \& Loakes 2018; Cox \& Palethorpe 2006). Other studies, however, have found no evidence of ethnic variation. For high rising terminals in 1970s Sydney, "virtually complete assimilation" of the Anglo patterns were found for Greek- and Italian-Australians (Guy et al. 1986: 40). Likewise, in this same 
dataset, for the five diphthongs under study here, Greek- and Italian-Australian realisations were not found to be qualitatively different from Anglo-Australians (Horvath \& Sankoff 1987: 191-193).

However, Greek- and Italian-Australians overall were ahead in the shift towards general Australian English, which Horvath interpreted as an attempt to "remove themselves as far as possible from the low prestige of being a migrant" (1985: 95). Differences across ethnic groups were also found in social conditioning, in that gender and class impacted the vowel realisations of Anglo teenagers, but not those of Greek and Italian teenagers (1985: 81). In this way, then, "ethnicity ... remain[ed] a distinctive social variable" (1991: 315$)$ inasmuch as it represented a diminished sensitivity to dominant social norms of class and gender. This gives rise to questions of how ethnic differences may be manifested, how they may change over time, and how they interact with other social factors.

\section{Changing ethnic diversity in Australia}

While Australia was highly multilingual prior to colonisation, it is today a predominantly English-speaking country, in which the majority of its some 24 million people are Anglo-Celtic monolingual English speakers. Over the past 40 years, however, there has been an influx of migrants from diverse backgrounds; the latest census conducted in 2016 reported that just over one half of the population was born in Australia to Australian-born parents, and 49\% were either born overseas themselves, or have at least one parent born overseas (Australian Bureau of Statistics 2016). The makeup of this population has also changed substantially, in particular with the phasing out of the White Australia Policy in the 1970s (a policy which restricted migration to people of European ancestry, favouring immigrants from Britain in particular). The increasing diversity in Australia between the 1970s and the 2000s was described at the time as "one of the most important transformations of Australian society" (Khoo 2003: 258); this period falls within that covered by this study, rendering it a particularly relevant timeframe in which to examine ethnic variation over time.

An indication of ethnic diversity is language spoken in the home, as reported in the five-yearly national census. In 1970s Australia, some 12\% of the population reported speaking a community language at home (Australian Bureau of Statistics 1981). ${ }^{2}$ The most widely spoken languages were Italian and Greek, spoken by people who had come to Australia as part of post-World War II migration schemes (Jupp 2001). Speakers of these two languages together accounted for nearly one third of

2. "Community language" is the preferred term in Australia, corresponding to what is often referred to as minority, immigrant, or heritage language (cf., Clyne 1991). 
all community language speakers at that time (Italian 17\%, Greek 12\%) (Australian Bureau of Statistics 1991, the first year for which comparable data for individual languages is available). The third most widely spoken community language was Cantonese (accounting for $7 \%$ of the population of community language speakers), owing primarily to migrants from Hong Kong, who came to Australia under a Business Migration program conducted in the 1980s (Jupp 2001: 218). Today, close to one quarter of the Australian population speaks a language other than English at home (Australian Bureau of Statistics 2016), and the most widely spoken community languages across the country have changed. Mandarin is overwhelmingly the most widely spoken, followed by Arabic, Cantonese, and Vietnamese, and then by Italian and Greek. Italian and Greek now each account for approximately $6 \%$ of all community language speakers, about half of the proportion they represented in the 1991 census.

We focus here on Sydney, an ideal location in which to test questions surrounding ethnicity and language change, as Australia's largest city (with a population of close to five million), and as the most diverse (where some $38 \%$ of the population report speaking a language other than English at home) (cf., Benson \& Hatoss 2019). Furthermore, this was the location for the legacy data available to us, thus allowing for the real time comparison.

\section{Data for the study of ethnic variation over time}

The data for this study come from two comparable corpora of sociolinguistic interviews, recorded over two time periods, and compiled under the umbrella of Sydney Speaks (Travis, Grama \& Gonzalez In Progress): the Sydney Social Dialect Survey, collected by Horvath in the late 1970s (Horvath 1985), and Sydney Speaks 2010s, under compilation from 2016. Here, we report on the patterning of some 23,000 vowel tokens from 173 speakers drawn from these corpora.

\subsection{Participants}

Participants were all living in Sydney at the time of the interview, and, for the 2010s data, were also born there or had moved there before the age of six, and had spent all or most of their lives there (this information is not available for the 1970s data). This population is stratified according to age, gender, ethnicity, and socio-economic status, as summarised in Table 1.

Four age groups are represented: for the 1970s participants, Adults (most of whom were born in the 1930s) and Teenagers (born 1960s), and for the 2010s, Adults (born 1960s, the same period as the 1970s Teenagers) and Young Adults (born 1990s). 
Three ethnic groups are represented: Anglo-, Italian- and Chinese-Australians, with distinct time-depth for each group, as seen in Table 1, in accordance with their migration history. We use the term "Anglo" as a short-hand for Anglo-Celtic Australians who were born and raised in Australia; for the 2010s, these speakers are minimally fourth generation Australians (that is, their parents and at least three of four grandparents were born and raised in Australia). ${ }^{3}$

As noted above, the Italian-Australian community is a well-established migrant community that has been in Australia since the post-World War II period. The 1970s teenagers included in the study are largely the children of these migrants. The 1970s teens and 2010s Adults are all second-generation Italian-Australians, defined here as having either been born in Australia or arrived before the age of six. The migration history of this community means that there is a relatively small population of second-generation Young Adults in the 2010s, and we have therefore included third-generation Italian-Australians for this age group. (This is the case for three of the twelve Italian Young Adults.)

The Chinese participants are all second-generation Australians, whose parents speak Cantonese and were born and raised primarily in Hong Kong, but also Guangzhou, China. Though the Mandarin-speaking community is now the largest migrant community in Australia, we selected the Cantonese-background community due to its greater time-depth, as described above. We refer to these participants as being of Chinese, rather than Cantonese, background, in accordance with their self-identification as "Australian Born Chinese" (ABC), and because not all participants speak Cantonese. Given the migration history of this community, the adult second-generation population today is relatively small (cf., Australian Bureau of Statistics 2016), and thus we restrict our analysis to Young Adults, born in Australia around the 1990s.

We apply a three-way distinction for socio-economic class, which, following Horvath, we label Lower Working Class, Upper Working Class and Middle Class (1985: 47). For the 1970s data, we use the categories to which participants had originally been assigned, determined on the basis of occupation (cf., Horvath 1985: 46). For the 2010s, we use a composite measure based on occupation, education level, suburb, and school type, which we collapse into three levels for comparability with the 1970s data.

3. Six of the 51 Anglo participants in the 2010s corpus had one grandparent who was born outside Australia in another English-speaking country. We also note that one participant had an Aboriginal-Australian grandparent. We did not set out to exclude indigenous Australians from our sample; the resulting Anglo sample is largely an artefact of Sydney's demographics, where just $1.5 \%$ of the population identifies as Aboriginal and/or Torres Strait Islander (Australian Bureau of Statistics 2016). 
As can be seen in Table 1, there is a representative sample of class and gender groups for Anglo and Italian Teenagers in the 1970s, and Anglos in the 2010s. As the 2010s corpus is under compilation, we lack representation across socioeconomic class for the Young Italians, and we therefore leave class comparisons for contemporary Young Italians for a future study. Additionally, we lack Lower Working Class participants of Chinese background. This is not due to a sampling bias, but rather is representative of the community, in which its members tend to be very well educated, hold high-status occupations, and live in wealthier suburbs in Sydney (as gleaned from recent census data, Australian Bureau of Statistics 2016). The high socio-economic status of this community is important for interpreting the patterns we observe in the data, as we will see below.

Table 1. Participants by age, gender, ethnicity and socio-economic status

\begin{tabular}{|c|c|c|c|c|c|c|c|c|c|}
\hline & \multicolumn{4}{|c|}{$1970 s$} & \multicolumn{4}{|c|}{$2010 s$} & \multirow{3}{*}{$\begin{array}{c}\text { Total } \\
\text { speakers / } \\
\text { ethnicity } \\
\text { \& class }\end{array}$} \\
\hline & \multicolumn{2}{|c|}{$\begin{array}{c}\text { Adults } \\
\text { b. 1930s } \\
32-64 \text { y/o }\end{array}$} & \multicolumn{2}{|c|}{$\begin{array}{c}\text { Teens } \\
\text { b. 1960s } \\
12-18 \text { y/o }\end{array}$} & \multicolumn{2}{|c|}{$\begin{array}{c}\text { Adults } \\
\text { b. } 1960 \mathrm{~s} \\
42-61 \text { y/o }\end{array}$} & \multicolumn{2}{|c|}{$\begin{array}{c}\text { Young adults } \\
\text { b. 1990s } \\
18-31 \text { y/o }\end{array}$} & \\
\hline & Female & Male & Female & Male & Female & Male & Female & Male & \\
\hline \multicolumn{10}{|l|}{ Anglos } \\
\hline Middle & 4 & 3 & 4 & 4 & 4 & 2 & 4 & 5 & 30 \\
\hline Upper Working & 4 & 3 & 3 & 4 & 5 & 6 & 5 & 5 & 35 \\
\hline Lower Working & 4 & 2 & 5 & 4 & 5 & 3 & 3 & 4 & 30 \\
\hline \multicolumn{10}{|l|}{ Italians } \\
\hline Middle & & & 3 & 3 & 2 & 3 & 1 & 0 & 12 \\
\hline Upper Working & & & 4 & 4 & 4 & 4 & 5 & 5 & 26 \\
\hline Lower Working & & & 5 & 5 & 3 & 4 & 1 & 0 & 18 \\
\hline \multicolumn{10}{|l|}{ Chinese } \\
\hline Middle & & & & & & & 5 & 7 & 12 \\
\hline Upper Working & & & & & & & 6 & 4 & 10 \\
\hline $\begin{array}{l}\text { Total speakers / } \\
\text { age \& gender }\end{array}$ & 12 & 8 & 24 & 24 & 23 & 22 & 30 & 30 & 173 \\
\hline
\end{tabular}

\subsection{Speech data}

To test for change over time, we rely on spontaneous speech data. Both corpora use the well-established method of the sociolinguistic interview, involving an unstructured set of topics, aimed at getting the participant talking while paying minimal attention to their speech (Labov 1984: 32-42). To enhance the naturalness of the speech and the possibility of recording ethnolectal features - the use of which may be inhibited with outsiders (cf., Clyne, Eisikovits \& Tollfree 2002) - the 2010s 
interviews were conducted by community members who recorded their friends, extended family members, and friends of friends. Below is an excerpt from one such interview with a Young Chinese-Australian woman about how she came to work in a tutoring centre.

Amanda: .. I only went there to help,

because my sister had to go there for tutoring.

.. That was the .. very beginning of me being at that tutor centre to begin with.

.. cause,

... my sister needed tutoring,

.. so she went there,

.. and because she had $t$---

needed to go there extra in the holidays,

.. she can't go by herself,

so I had to go with her.

[SydS_CYF_025: 37:59-38:15] ${ }^{4}$

The 1970s interviews lasted around 45 minutes, and the 2010s interviews from 60 to 90 minutes. We selected approximately thirty minutes (or 5,000 words of speech) to transcribe from each speaker, providing a total of some 70 hours of speech, and 750,000 words for the analyses presented here.

We produced time-aligned orthographic transcriptions in ELAN (Lausberg \& Sloetjes 2009). To prepare the vowels for analysis, the data were then force aligned using a local build of LaBB-CAT (Fromont \& Hay 2012). Vowels in grammatical words and unstressed syllables were excluded from the analysis, and, to control for lexical effects, no more than four instances of any one word were taken per speaker. The remaining 140,000 vowel tokens were manually checked by trained phoneticians, and boundaries were adjusted to ensure accurate demarcation of vowel boundaries.

To capture dynamic vowel behaviour, F1 and F2 measurements were taken at 11 equidistant points along the vowel using a script built with the rPraat (Borril \& Skarnitzl 2016) and PraatR (Albin 2014) packages in R (R Development Core Team 2019). ${ }^{5}$ Formant values were then normalised following Lobanov (1971) on the basis of all vowel measurements.

4. This information gives the corpus, recording code and number, and time stamps of the beginning and end of the excerpt.

5. The formant settings were manually set for each vowel, for each speaker; formant tracks were hand-checked for a subsample of tokens, and settings were adjusted as needed to produce the most accurate formant trackings. Greater adjustments were required for the 1970s recordings, which were made on cassette recorders and were of poorer quality than the 2010 s digitally recorded data. 
This process yielded approximately 51,000 tokens of the target diphthongs FLEECE, FACE, GOAT, MOUTH and PRICE - in a variety of phonological contexts. To control for the effect of phonological environment, we focus here on vowels in pre-obstruent position, the most well-represented context in the data. Table 2 gives the total number of vowel tokens per type, along with the most frequent words in which the vowel occurs in the data analysed.

Table 2. Distribution of vowel types

\begin{tabular}{lrl}
\hline Vowel & Number & Five most frequent words \\
\hline FLEECE & 6,206 & people, even, speak, need, teacher \\
FACE & 7,420 & make, made, take, maybe, place \\
GOAT & 3,227 & close, suppose, goes, road, spoke \\
MOUTH & 914 & house, allowed, south, thousand, houses \\
PRICE & 5,561 & like, five, quite, right, side \\
Total & 23,328 & \\
\hline
\end{tabular}

\section{Australian English in real time}

We begin our exploration of ethnolectal variation over time by considering the speech of the youngest cohort, and the only age group for which we can compare the behaviour of all three ethnic groups: Anglo-, Italian- and Chinese-Australians. The longitudinal nature of the corpus allows us to contextualise what we observe for this group in terms of broader changes that have taken place in Australian English from the 1970s, taking account of patterns of social variation among Anglo-Australians.

\subsection{Ethnic variation in Young Adult Australians in the 2010s}

The patterning of the 2010s Young Anglo-, Italian-, and Chinese-Australians $(n=60)$ is given in Figure 1, which shows the mean behaviour across speakers of each diphthong over its trajectory. As can be seen, the vowel realisations of the Italians, the more established migrant group, are virtually identical to those of the Anglos, and while the Chinese are also similar, there are some differences specifically for FLEECE, FACE and MOUTH - both FLEECE and FACE occupy higher and fronter positions, and Mouth occupies a backer position for Chinese-Australians than for Anglo- or Italian-Australians.

Initially, this patterning may appear to be evidence of ethnolectal variation among Chinese-Australians, but once we contextualise it in relation to both changes over time in Australian English and the social nature of this patterning, a different interpretation emerges. 

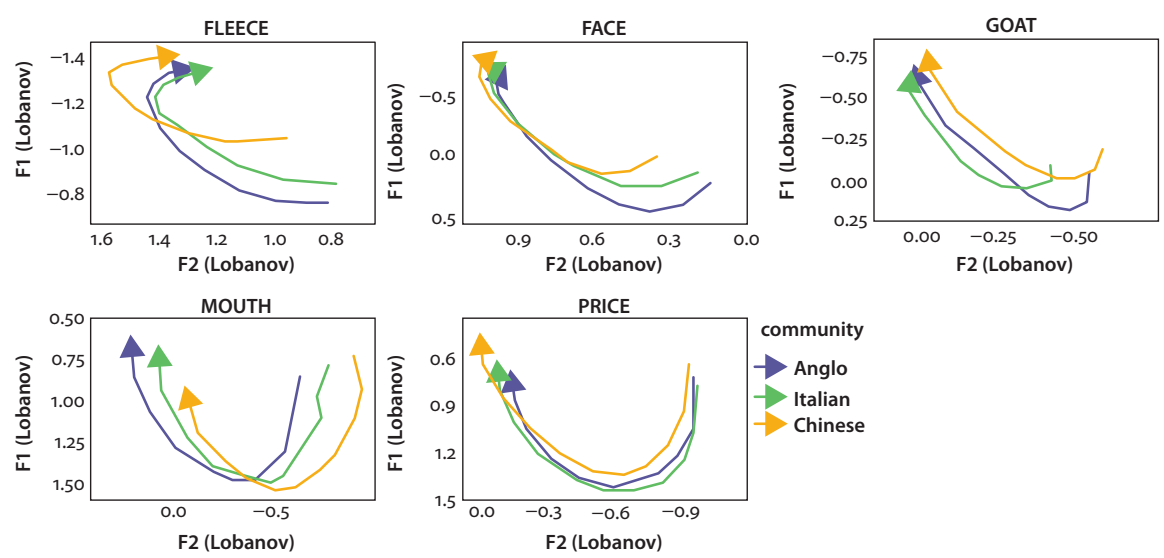

Figure 1. Mean diphthong trajectories for 2010s Young Adults by ethnicity

\subsection{Anglo-Australians over time}

To examine change over time, we plot in Figure 2 the mean vowel trajectories of the oldest and youngest Anglo participants in the sample - 1970s Adults and 2010s Young Adults $(n=46)$. Clear from the figure is that each of the diphthongs has changed radically over time: FLEECE and FACE have fronted and raised; GOAT has backed and raised; MOUTH has lowered and backed; and PRICE has lowered and fronted. ${ }^{6}$ Many of these changes are similar to changes over time identified in analyses of more controlled contexts, from wordlists employing the hVD frame to read passages (see, e.g., Butcher 2012; Cox 1999). ${ }^{7}$

Once we situate the apparent ethnolectal differences in the youngest group seen in Figure 1 in relation to the changes over time in Figure 2, we observe that Young Chinese-Australians are at the leading edge of a general shift in Australian English diphthongs. This finding parallels Horvath's observation that migrant teenagers were leading the same change in the 1970s (1985: 94). To understand this more fully, we examine the social nature of these changes, considering social class and gender over time.

Figure 3 depicts change over time broken down by class, and Figure 4 by gender for all Anglo participants $(n=95)$. Here, we focus just on the vowel nucleus (the $20 \%$ measurement through the vowel). The horizontal axis represents change over

6. There are also changes in the trajectory length of FLEECE, MOUTH, and PRICE over time, which we do not address here.

7. As a reviewer notes, the change in these diphthongs is reminiscent of a reversal of the Diphthong Shift described for London (cf. Kerswill, Torgersen \& Fox 2008). 


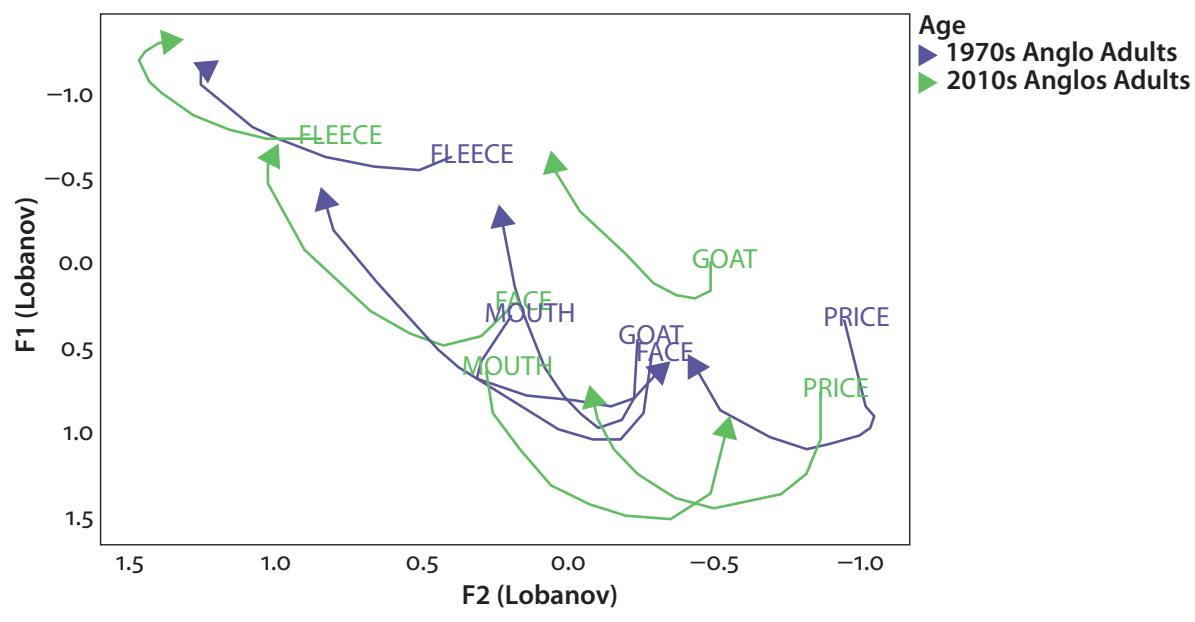

Figure 2. Mean diphthong trajectories for Anglo-Australians by age: 1970s Adults and 2010s Young Adults
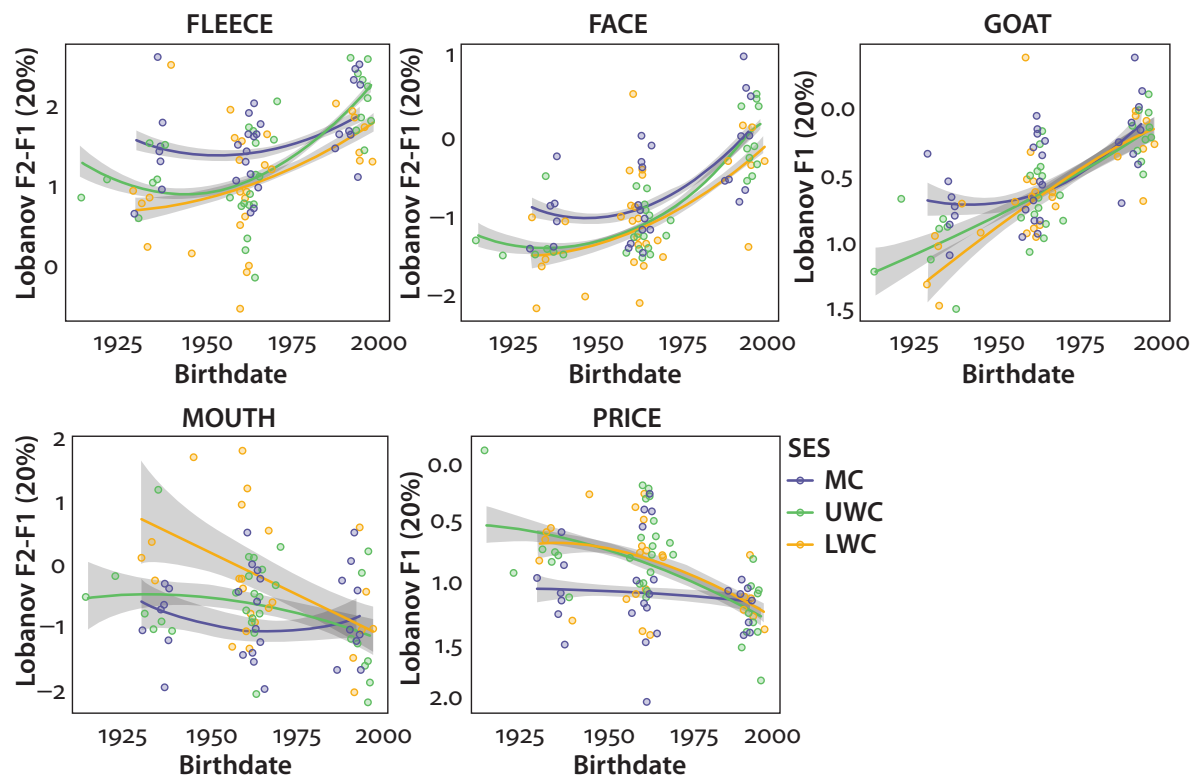

Figure 3. Mean diphthong nuclei over birthdate for Anglo-Australians by socio-economic status $(\mathrm{MC}=$ Middle Class, $\mathrm{UWC}=$ Upper Working Class, LWC $=$ Lower Working Class) 

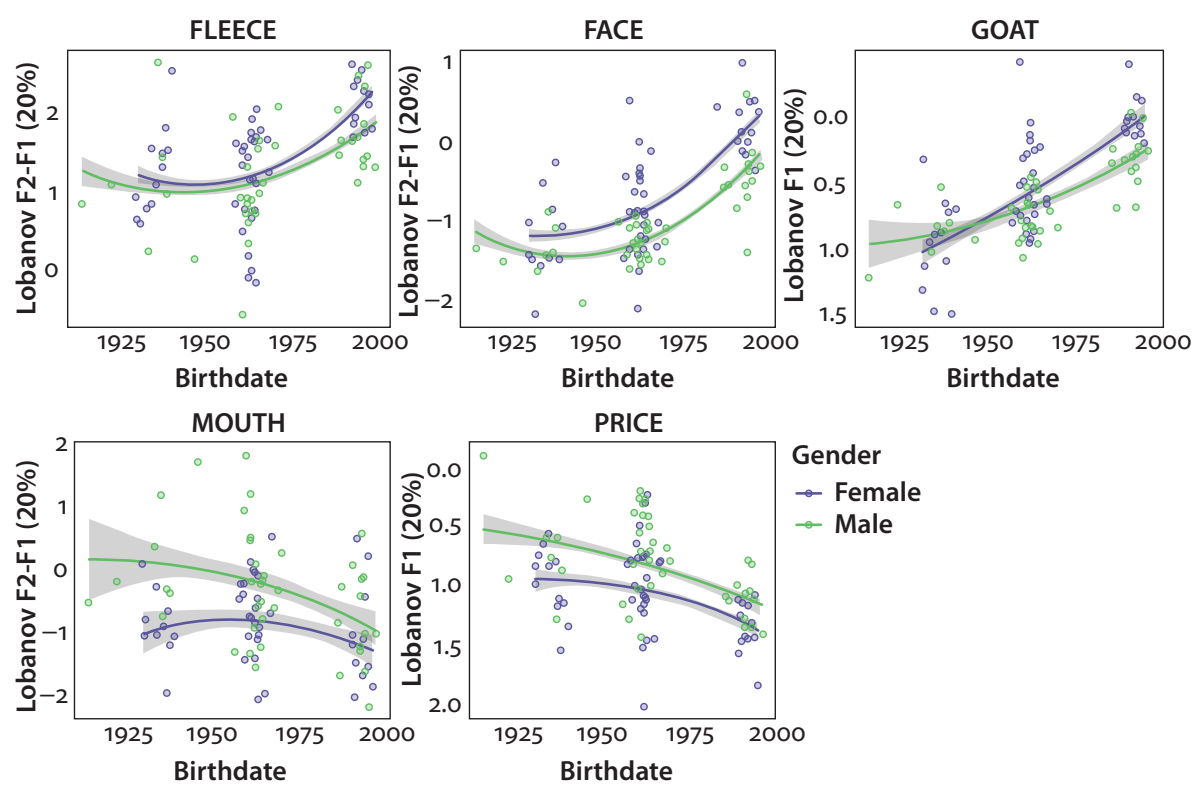

Figure 4. Mean diphthong nuclei over birthdate for Anglo-Australians by gender

time by birthdate (note that the 1970s Teens and 2010s Adults are collapsed here, as they share the same birthdates). On the vertical axis, for GOAT and PRICE, we plot F1, and for FLEECE, FACE, and MOUTH, we capture movement along the front diagonal by plotting the difference between F2 and F1 (following Dodsworth \& Benton 2017:377). This allows us to meaningfully depict the changes of different vowels in similar ways - higher on the vertical axis corresponds to higher, and for FLEECE, FACE, and MOUTH, also fronter, realisations.

We glean three things from Figure 3 about the role of social class in this change. First, 1970s participants show clear class differences: Working Class 1970s Adults produce realisations that are noticeably distinct from their Middle Class counterparts. In FLEECE, for example, Lower Working Class speakers produce the lowest, most centralised realisations, Middle Class speakers produce the highest, frontest realisations, and Upper Working class speakers are in between. All vowels show a generally similar pattern, though to varying degrees. Second, these distinctions contract over time, such that class differences are much less pronounced for 2010 s Young Adults than for 1970s Adults.

Third, and of particular interest to us here, is that Middle Class speakers are ahead of both Upper and Lower Working class speakers in the change. For each vowel, the observed movement over time is away from realisations that, in the 1970s, characterised working class speech, and towards realisations that typified 
the Middle Class. In some cases (namely PRICE and MOUTH), this has meant that the Middle Class has undergone relatively little change over time. In this way, these sound changes can be interpreted socially as a move away from working class vowel realisations.

Figure 4 depicts the change by gender. Unlike class differences, which contract over time, gender differences are retained, as predicted by Horvath (1985: 176). Both men and women have participated in the changes over time, but for each diphthong, women are in advance of men. The direction of the change in terms of gender, then, is away from male realisations.

Taking account of both class and gender, we can characterise the observed sound changes as a move away from working class, male vowel realisations, or away from "broad" vowels, towards a more overtly prestigious, "general" Australian English. The stability of the Middle Class for some vowels supports previous suggestions that the change is not in the direction of "cultivated" realisations, that is, towards British Received Pronunciation, but towards unique Australian variants (e.g., Cox \& Palethorpe 2012: 313, Horvath 1985: 91).

This then provides a social context within which to interpret the variation that we observed among the 2010s Young speakers (Figure 1) - the Chinese-Australians differentiate themselves from Anglo-Australians in the sense that they are less broad; that is, their vowels are the most differentiated from historically working class, male realisations. Their orientation towards the overtly prestigious variants for the dominant group corresponds with their social characteristics described above, as a solidly middle class community.

We address the impact of gender below, but first, what of the Italian-Australians, who have greater social distribution, and whose diphthong realisations pattern more closely to those of Anglos?

\subsection{Anglo and Italians over time}

For the Anglo- and Italian-Australians, three time points are available for comparison: 1970s Teens, 2010s Adults, and 2010s Young Adults. For these analyses, we focus on a subsample $(n=89)$ that excludes Lower Working Class speakers, as the proportionally greater number of Lower Working Class Anglos than Italians may weaken comparability.

Linear mixed-effects models were conducted using lme4 (Bates et al. 2019), fit separately to F1 and F2 at the $20 \%$ mark with centred vowel duration, and a threeway interaction between age (1970s Teens, 2010s Adults, 2010s Young Adults), community (Anglo, Italian) and gender (female, male) as predictors, and with speaker and word as random intercepts. Model fit was assessed by comparing 
models via ANOVA with and without the relevant interactions. Non-significant three-way interactions were simplified into multiple two-way interactions, and pruned if non-significant. In the summaries we present below, we include some non-significant main effects as predictors to aid in comparison across models. Plots of models were obtained using sjplot (Lüdecke \& Schwemmer 2018), and $p$-values were derived via Wald-statistics approximation.

Here, we present results for FLEECE and FACE as examples of the general changes identified in Section 5.2. The models fit to FLEECE are reported in Table 3 for F1 and Table 4 for F2, and to FACE in Table 5 for F1 and Table 6 for F2. Figure 5 plots the estimates from the models fit to FLEECE and FACE, showing F1 and F2 over time by gender, for Anglos and Italians; model estimates are on the vertical axis, where higher values correspond to higher or fronter (that is, less broad) vowels.

We begin with FLEECE. It is evident from the results here that both Anglos and Italians participate in the raising and fronting of FLEECE over time described in Section 5.2, but there are some differences in the way this change progresses. In terms of height (F1), gender and ethnicity have no significant impact on realisations, indicating that the raising of FLEECE is a community-wide change. The same is not so for F2. First, while men and women exhibit fronting over time, men tend to produce backer FLEECE than women (seen in the lower F2 estimate), for all but the 2010s Anglo Adults. Furthermore, the Italians and the Anglo males show significant incremental raising across the three age groups. The Anglo women, on the other hand, are relatively stable from the 1970s Teens to 2010s Adults, only fronting in the 2010s Young group. For F2 then, we see that Anglo men and women have fronted at different rates, while Italians have fronted incrementally at each time interval. Though there have been differences across the communities at different points in time, no such differences are retained long term, resulting in the similarities we see today.

Table 3. Linear mixed-effects regression model fit to F1 of FLEECE $(n=3,351)$, Anglos and Italians over time

\begin{tabular}{lcccc}
\hline Predictors & Estimates & Standard error & $t$ & $p$-value \\
\hline Intercept (=1970 Anglo male Teens) & -0.397 & 0.064 & -6.210 & - \\
2010s Adults & -0.218 & 0.052 & -4.195 & $<\mathbf{0 . 0 0 1}$ \\
2010s Young Adults & -0.446 & 0.070 & -6.362 & $<\mathbf{0 . 0 0 1}$ \\
Italian & -0.067 & 0.063 & -1.075 & 0.282 \\
Female & -0.018 & 0.061 & -0.296 & 0.767 \\
duration (centred) & 0.775 & 0.181 & 4.279 & $<\mathbf{0 . 0 0 1}$ \\
\hline
\end{tabular}


Table 4. Linear mixed-effects regression model fit to F2 of FLEECE $(n=3,351)$, Anglos and Italians over time

\begin{tabular}{lcccc}
\hline Predictors & Estimates & Standard error & $t$ & $p$-value \\
\hline Intercept (=1970 Anglo male Teens) & 0.364 & 0.087 & 4.171 & - \\
2010s Adults & 0.371 & 0.120 & 3.097 & $\mathbf{0 . 0 0 2}$ \\
2010s Young Adults & 0.654 & 0.113 & 5.768 & $<\mathbf{0 . 0 0 1}$ \\
Italian & 0.135 & 0.114 & 1.185 & 0.236 \\
Female & 0.418 & 0.124 & 3.362 & $\mathbf{0 . 0 0 1}$ \\
duration (centred) & 0.655 & 0.183 & 3.575 & $<\mathbf{0 . 0 0 1}$ \\
2010s Adults:Female & -0.432 & 0.169 & -2.562 & $\mathbf{0 . 0 1 0}$ \\
2010 Young Adults:Female & -0.158 & 0.165 & -0.958 & 0.338 \\
2010s Adults:Italian & -0.271 & 0.135 & -2.009 & $\mathbf{0 . 0 4 5}$ \\
2010s Young Adults:Italians & -0.088 & 0.171 & -0.515 & 0.607 \\
Female:Italian & -0.168 & 0.173 & -0.969 & 0.333 \\
2010s Adults:Female:Italian & 0.472 & 0.225 & 2.096 & $\mathbf{0 . 0 3 6}$ \\
2010s Young Adults:Female:Italian & 0.046 & 0.249 & 0.814 & 0.854 \\
\hline
\end{tabular}

Table 5. Linear mixed-effects regression model fit to F1 of FACE $(n=3,880)$, Anglos and Italians over time

\begin{tabular}{lcccr}
\hline Predictors & Estimates & Standard error & \multicolumn{1}{c}{$t$} & \multicolumn{1}{c}{$p$-value } \\
\hline Intercept (=1970s Anglo male Teens) & 1.055 & 0.078 & 13.516 & - \\
2010s Adults & -0.001 & 0.098 & -0.007 & 0.995 \\
2010s Young Adults & -0.460 & 0.095 & -4.819 & $<\mathbf{0 . 0 0 1}$ \\
Italian & 0.135 & 0.097 & 1.394 & 0.163 \\
Female & -0.316 & 0.059 & 5.344 & $<\mathbf{0 . 0 0 1}$ \\
duration (centred) & 3.593 & 0.207 & 17.316 & $<\mathbf{0 . 0 0 1}$ \\
2010s Adults:Italian & -0.212 & 0.118 & -1.798 & 0.072 \\
2010s Young Adults:Italians & -0.253 & 0.142 & -1788 & 0.074 \\
\hline
\end{tabular}

Table 6. Linear mixed-effects regression model fit to F2 of FACE $(n=3,880)$, Anglos and Italians over time

\begin{tabular}{lccrr}
\hline Predictors & Estimates & Standard error & \multicolumn{1}{c}{$t$} & \multicolumn{1}{c}{$p$-value } \\
\hline Intercept (=1970s Anglo male Teens) & -0.179 & 0.045 & -4.000 & - \\
2010s Adults & -0.009 & 0.039 & -0.226 & 0.821 \\
2010s Young Adults & 0.530 & 0.049 & 10.929 & $<\mathbf{0 . 0 0 1}$ \\
Italian & 0.051 & 0.042 & 1.198 & 0.231 \\
Female & 0.213 & 0.042 & 5.103 & $<\mathbf{0 . 0 0 1}$ \\
duration (centred) & -0.460 & 0.143 & -3.226 & $\mathbf{0 . 0 0 1}$ \\
\hline
\end{tabular}



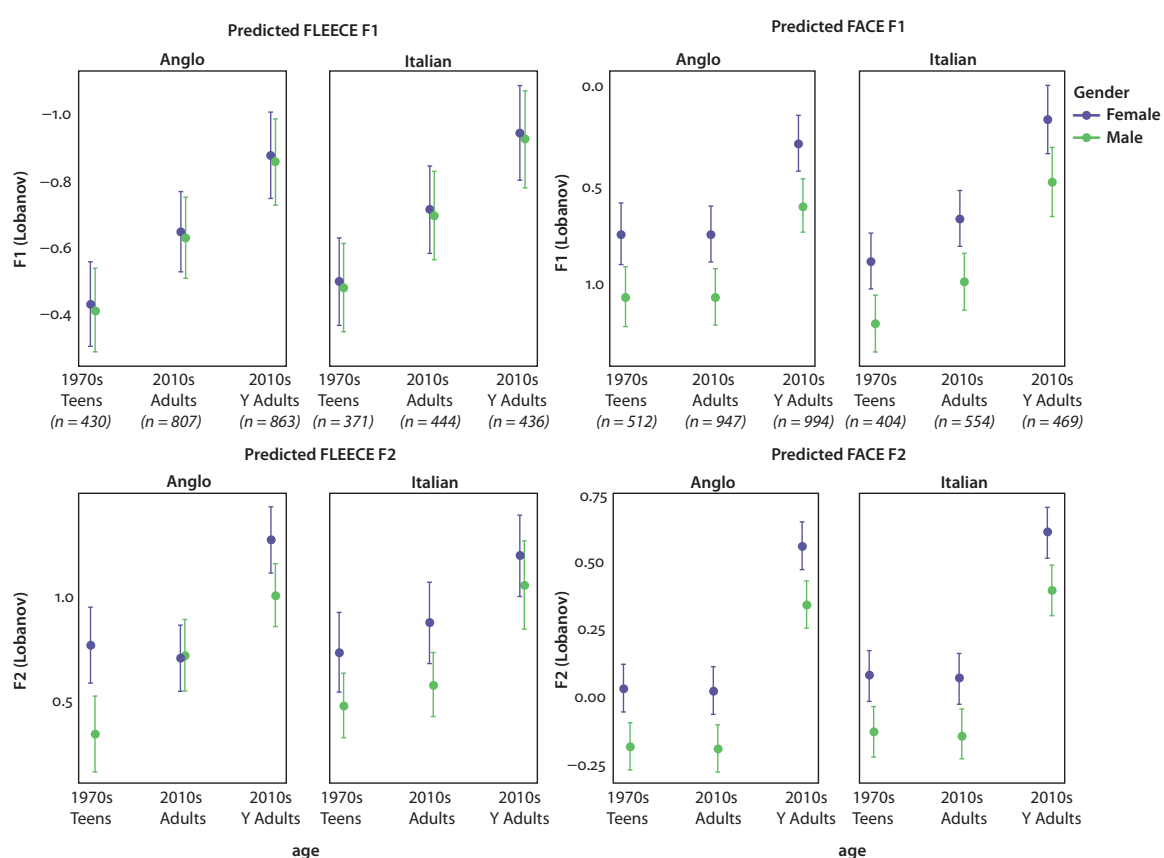

Figure 5. Predicted F1 (top) and F2 (bottom) of FLEECE (left) and FACE (right) for Anglos and Italians, with separate estimates for women and men

For FACE, we again observe general raising and fronting over time, consistent with what we saw in Section 5.2, and again, this holds for both Anglos and Italians. The change takes place a generation later than for FLEECE; the vowel is stable between the 1970s Teens and 2010s Adults for both communities, prior to the raising and fronting observed in the youngest group. This holds for all but F1 for the Italians, who exhibit incremental raising at each time point. As with FLEECE, changes to FACE have taken slightly different trajectories for Anglos and Italians, but there is relatively little difference between the two ethnic groups today.

Overall then, FLEECE and FACE are impacted by age and gender, and while both Anglo- and Italian-Australians undergo parallel changes over time, the groups differ somewhat in their uptake of these changes (consistent with what Horvath observed for 1970s Teenagers, in some cases leading the change, and in some cases with a less pronounced gender distinction than that of the Anglo-Australians (1985: 91-95)). Today, any community differences that might have existed have been lost, with the Anglos and Italians patterning very similarly for these two vowels. We find similar behaviour for GOAT, MOUTH, and PRICE (though for reasons for space, we do not present those results here). In general, across these five 
diphthongs, Italians pattern alongside Anglos, and gender differences are always larger than ethnic differences. Remaining to be seen is how the Chinese-Australians pattern according to gender.

\subsection{Ethnic and gender variation in Young Adult Australians in the 2010s}

We return now to the 2010s Young Adults, paying special attention to whether the differences for ethnicity that we identified in Section 5.1 are borne out once we consider gender independently. To illustrate, we again focus on the nuclei of FLEECE and FACE and restrict the sample to Upper Working and Middle Class speakers (in this case 2010s Young Adults, $n=52$ ). Identical linear mixed-effects models were fit to F1 and F2 at the $20 \%$ mark, with centred vowel duration, and an interaction between gender and ethnicity as predictors, and speaker and word as random intercepts. Table 7 and Table 8 show the output from the models fit to FLEECE F1 and F2, respectively, and Table 9 and Table 10 that from the models fit to FACE F1 and F2. Figure 6 shows plots derived from those models for both vowels.

Within-gender comparisons of Anglo and Italian vowels indicate no significant differences between the two ethnic groups, corroborating the findings from Section 5.3: Anglo and Italian women pattern similarly, as do Anglo and Italian men, and for both groups, men produce broader realisations than women (lower and backer FLEECE and FACE). But while vowel realisations for Chinese Young women parallel those of Anglos and Italians, the same is not so of the Chinese men, who produce higher and fronter FLEECE, and higher FACE than Anglo and Italian men, placing their realisations more in line with those of women. For GOAT, MOUTH, and PRICE, we similarly find that Chinese men and women tend to behave as a single group, while Anglos and Italians exhibit robust gender differences with males tending to produce broader realisations. In other words, broader diphthong realisations are associated with Anglo and Italian, but not Chinese, men.

Once again, when presented in isolation, the distinct behaviour of the Chinese males may appear to be evidence for ethnolectal variation. But interpreting it in relation to the broader social conditioning provides an alternative account. Young Chinese-Australians do not conform to the dominant Australian gender norms for diphthong realisations, in that both men and women orient strongly to the linguistic behaviour characteristic of middle-class Australians. And this orientation is precisely in the direction that the entire community has shifted over time. For Young Chinese-Australian men and women today, then, "sounding Australian" (Horvath 1985: 176) is tied to overtly prestigious linguistic behaviour, in line with the socio-economic status of this community. 
Table 7. Linear mixed-effects regression model fit to F1 of FLEECE $(n=2,131)$, 2010s Young Adult Anglos, Italians, and Chinese

\begin{tabular}{lccrc}
\hline Predictors & Estimates & Standard error & \multicolumn{1}{c}{$t$} & $p$-value \\
\hline Intercept (=Anglo females) & -0.939 & 0.073 & -12.906 & - \\
Italian & 0.024 & 0.114 & 0.212 & 0.832 \\
Chinese & -0.112 & 0.097 & -1.159 & 0.247 \\
Male & 0.149 & 0.099 & 1.508 & 0.132 \\
duration (centred) & 0.161 & 0.186 & 0.864 & 0.388 \\
Italian:Male & -0.193 & 0.163 & -1.180 & 0.238 \\
Chinese:Male & -0.303 & 0.135 & -2.244 & $\mathbf{0 . 0 2 5}$ \\
\hline
\end{tabular}

Table 8. Linear mixed-effects regression model fit to F2 of FLEECE $(n=2,131)$, 2010s Young Adult Anglos, Italians, and Chinese

\begin{tabular}{lccrc}
\hline Predictors & Estimates & Standard error & $t$ & $p$-value \\
\hline Intercept (=Anglo females) & 1.276 & 0.072 & 17.732 & - \\
Italian & -0.064 & 0.110 & -0.579 & 0.563 \\
Chinese & 0.054 & 0.094 & 0.572 & 0.568 \\
Male & -0.252 & 0.096 & -2.628 & $\mathbf{0 . 0 0 9}$ \\
duration (centred) & 2.145 & 0.197 & 10.869 & $<\mathbf{0 . 0 0 1}$ \\
Italian:Male & 0.115 & 0.159 & 0.725 & 0.468 \\
Chinese:Male & 0.259 & 0.131 & 1.975 & $\mathbf{0 . 0 4 8}$ \\
\hline
\end{tabular}

Table 9. Linear mixed-effects regression model fit to F1 of FACE $(n=2,539)$, 2010s Young Adult Anglos, Italians, and Chinese

\begin{tabular}{lccrc}
\hline Predictors & Estimates & Standard error & \multicolumn{1}{c}{$t$} & $p$-value \\
\hline Intercept (=Anglo females) & 0.197 & 0.098 & 2.022 & - \\
Italian & -0.128 & 0.154 & -0.835 & 0.404 \\
Chinese & -0.035 & 0.131 & -0.264 & 0.792 \\
Male & 0.427 & 0.134 & 3.194 & $\mathbf{0 . 0 0 1}$ \\
duration (centred) & 2.905 & 0.202 & 14.356 & $<\mathbf{0 . 0 0 1}$ \\
Italian:Male & 0.035 & 0.222 & 0.158 & 0.874 \\
Chinese:Male & -0.470 & 0.182 & -2.580 & $\mathbf{0 . 0 1 0}$ \\
\hline
\end{tabular}

Table 10. Linear mixed-effects regression model fit to F2 of FACE $(n=2,539)$, 2010s Young Adult Anglos, Italians, and Chinese

\begin{tabular}{lcccc}
\hline Predictors & Estimates & Standard error & $t$ & $p$-value \\
\hline Intercept (=Anglo females) & 0.554 & 0.065 & 8.537 & - \\
Italian & 0.138 & 0.101 & 1.364 & 0.173 \\
Chinese & 0.093 & 0.086 & 1.084 & 0.278 \\
Male & -0.193 & 0.088 & -2.203 & $\mathbf{0 . 0 2 8}$ \\
duration (centred) & 0.554 & 0.161 & 3.432 & $\mathbf{0 . 0 0 1}$ \\
Italian:Male & -0.186 & 0.146 & -1.277 & 0.202 \\
Chinese:Male & 0.067 & 0.119 & 0.558 & 0.577 \\
\hline
\end{tabular}



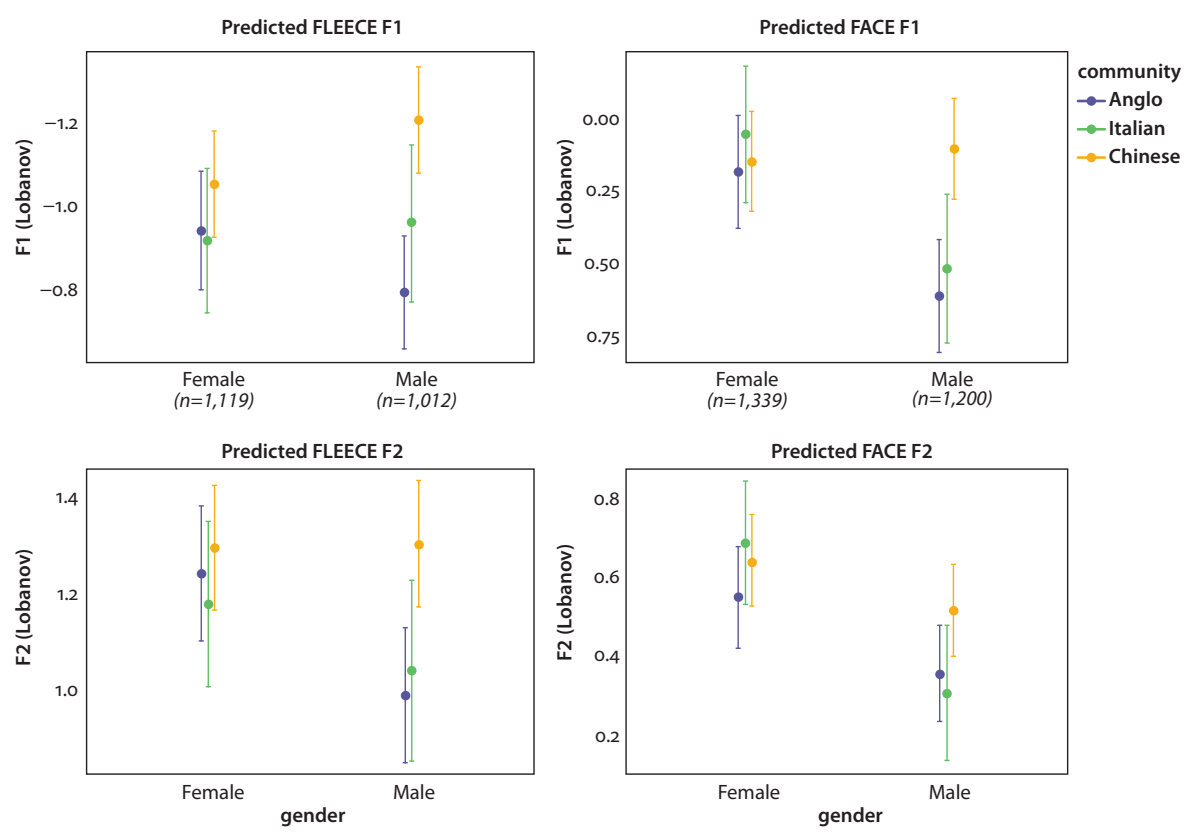

Figure 6. Predicted fleECE (left) and FACE (right) in F1 (top) and F2 (bottom), 2010s Young Adult Anglo, Italian, and Chinese men and women

\section{Migrants and the progression of change}

Overall, we have found little support for the longevity of ethnic differences. Instead, we observe remarkable similarities in the vowel realisations of Anglo-, Italianand Chinese-Australians in Sydney today. This suggests a shared vocalic system across these diverse groups, consistent with what has been reported for these same communities in major urban centres in North America (Becker 2014; Hoffman 2010; Wong \& Hall-Lew 2014). We have also observed a largely shared system across Anglo-, Italian- and Chinese-Australians today for other variables studied in this data set, including quotative choice (Lee 2020) and word-final -er (Grama, Travis \& Gonzalez 2020). Thus, whether, and where, ethnolectal variation lies in this community remains to be seen, but other phonetic features, and in particular consonantal realisations and prosody, may be areas worthy of future investigation.

Here, we have seen a general move away from broad (working class male) diphthong realisations for Anglo-Australians over time, resulting in a contraction of class differences, alongside a retention of gender differences, with males as a group producing consistently broader vowel realisations. Despite small differences over time between Italian- and Anglo-Australians in the progression of these changes, they have nevertheless proceeded largely in parallel, such that today, the two groups 
pattern very similarly. Chinese-Australians, on the other hand, do exhibit some differences, particularly with respect to social conditioning. The Chinese-Australians studied here do not evince the gender distinctions evident in the speech of Angloand Italian-Australians. We note that Italian-Australians in the 1970s show less of a gender distinction than Anglos, and Horvath also reported diminished social conditioning for 1970s Italian and Greek teenagers (1985: 81). This would suggest that while newer migrant groups may be less sensitive to the social norms of the dominant group, over time they may come to adopt those norms, something which can be tested for the Chinese community in the future.

The lack of a gender distinction for the Chinese-Australians studied here is seen in that both females and males produce diphthong realisations that conform to prestige norms typical of higher socio-economic classes. This is consistent with the middle-class orientation of this community, and with the observation that "upwardly mobile ethnic minority groups favor the accent of the dominant majority, especially in contexts where the advantages associated with the majority are salient" (Callan, Gallois \& Forbes 1983: 423). This patterning does not appear to be unique to Australian Chinese. In a study of the change towards increased rhoticity in New York City, Becker found that Chinese New Yorkers strongly favoured the overtly prestigious /r/-ful variant (2014: 157). In both cases, this situates the Chinese as vanguard adopters of changes in progress, and it may be that, in this way, they epiphenomenally push change forward, in a similar fashion to what Horvath proposed for Greek- and Italian-Australian teenagers in 1970s Australia (1985: 94).

As noted above, "ethnolectal" variation has been tied to an expression of ethnic identity. But for the Chinese-Australians studied here, rather than marking their "Chinese-ness", they appear to be responding to the linguistic norms of that section of society with which they closely identify and associate, namely middle class Australia. This is in contrast to the typical interpretation of ethnolects as nonstandard varieties (cf., Eckert 2008: 26-28), and indicates that ethnolectal variation is closely related to the social standing of different ethnic groups, as they are sensitive to the social patterning of linguistic variation around them.

As Eckert notes, "there is no obvious way to distinguish between a dialect with ethnic features and an ethnolect" (2008: 27). What we have seen here leads us to conclude that patterns of ethnic variation must be studied in relation to variation and change in the broader community, as ethnicity cannot be considered independently from other social factors. Here, by contextualising the patterning observed today in relation to that observed over 40 years in real time and from a broad cross-section of Australian society, we find differences in the social conditioning of the diphthongs of Australian English for these three ethnic groups, suggesting that their linguistic behaviour can best be explained as a response to broader social norms. 


\section{Acknowledgements}

We gratefully acknowledge support from the ARC Centre of Excellence for the Dynamics of Language and the Sydney Speaks team. We also thank Chloé Diskin-Holdaway and James Walker for their insightful comments, and two anonymous reviewers for feedback on the paper.

\section{References}

Albin, Aaron. 2014. PraatR: An architecture for controlling the phonetics software "Praat" with the R programming language. Journal of the Acoustical Society of America 135(4). 2198. https://doi.org/10.1121/1.4877175

Australian Bureau of Statistics. 1981. Census of Population and Housing. http://www.abs.gov. au/AUSSTATS/abs@.nsf/DetailsPage/2103.01981?OpenDocument. (25 September, 2015).

Australian Bureau of Statistics. 1991. Census of Population and Housing. https://www.abs.gov. au/AUSSTATS/abs@.nsf/DetailsPage/2101.01991. (25 September, 2015).

Australian Bureau of Statistics. 2016. 2016 Census QuickStats. http://quickstats.censusdata.abs. gov.au/census_services/getproduct/census/2016/quickstat/036?opendocument. (12 March, 2019).

Bates, Douglas, Martin Mächler, Ben Bolker, Steve Walker, Rune Haubo Bojesen Christensen, Henrik Singmann, Bin Dai, Fabian Scheipl, Gabor Grothendieck, Peter Green, \& John Fox. 2019. Ime4: Linear mixed-effects models using 'Eigen' and S4. R package, version 1.1-121.

Becker, Kara. 2014. (r) we there yet? The change to rhoticity in New York City English. Language Variation and Change 26. 141-168. https://doi.org/10.1017/So954394514000064

Benson, Phil \& Anikó Hatoss. 2019. Multingual Sydney: A city report. In Alice Chik, Phil Benson \& Robin Moloney (eds.), Multilingual Sydney, 13-25. London/New York: Routledge.

Bořil, Tomáš \& Radek Skarnitzl. 2016. Tools rPraat and mPraat. In Petr Sojka, Aleš Horák, Ivan Kopeček \& Karel Pala (eds.), Text, speech, and dialogue, 367-374. Cham: Springer International Publishing. https://doi.org/10.1007/978-3-319-45510-5_42

Bradley, David \& Maya Bradley. 2001. Changing attitudes to Australian English. In David Blair \& Peter Collins (eds.) English in Australia, 271-286. Amsterdam/Philadelphia: John Bejnamins. https://doi.org/10.1075/veaw.g26.25bra

Butcher, Andrew. 2012. Changes in the formant frequencies of vowels in the speech of South Australian females 1945-2010. In Felicity Cox, Katherine Demuth, Susan Lin, Kelly Miles, Sallyanne Palethorpe, Jason Shaw \& Ivan Yuen (eds.), Proceedings of the 14th Australasian International Conference on Speech Science and Technology, 69-72. Sydney.

Callan, Victor J., Cynthia Gallois, \& Paula A. Forbes. 1983. Evaluative reactions to accented English: Ethnicity, sex role and context. Journal of Cross-Cultural Psychology 14(4). 407-426. https://doi.org/10.1177/0022002183014004002

Cheshire, Jenny, Nortier Jacomine, \& David Adger. 2015. Emerging multiethnolects in Europe. Queen Mary's OPAL [Occasional Papers Advancing Linguistics] 33.

Cheshire, Jenny, Paul Kerswill, Sue Fox, \& Eivind Torgersen. 2011. Contact, the feature pool and the speech community: The emergence of Multicultural London English. Journal of Sociolinguistics 15(2). 151-196. https://doi.org/10.1111/j.1467-9841.2011.00478.x 
Clothier, Josh. 2019. A sociophonetic analysis of /l/ darkness and Lebanese Australian ethnic identity in Australian English. In Sasha Calhoun, Paola Escudero, Marija Tabain \& Paul Warren (eds.), Proceedings of the 19th International Congress of Phonetic Sciences (ICPhS), 1888-1892. Melbourne, Australia: Australasian Speech Science and Technology Association Inc.

Clothier, Josh \& Debbie Loakes. 2018. Coronal stop VOT in Australian English: Lebanese Australians and mainstream Australian English speakers. In Julien Epps, Joe Wolfe, John Smith \& Caroline Jones (eds.), Proceedings of the 17th Australasian International Conference on Speech Science and Technology, 13-16. Sydney: Australasian Speech Science and Technology Association Inc.

Clyne, Michael. 1991. Community languages: The Australian experience. Cambridge: Cambridge University Press. https://doi.org/10.1017/CBO9780511597084

Clyne, Michael. 2000. Lingua franca and ethnolects in Europe and beyond. Sociolinguistica 14. 83-89. https://doi.org/10.1515/9783110245196.83

Clyne, Michael, Edina Eisikovits, \& Laura Tollfree. 2001. Ethnic varieties of Australian English. In David Blair \& Peter Collins (eds.), English in Australia, 223-238. Amsterdam: John Benjamins. https://doi.org/10.1075/veaw.g26.21cly

Clyne, Michael, Edina Eisikovits, \& Laura Tollfree. 2002. Ethnolects as in-group varieties. In Anna Duszak (ed.), Us and others: Social identities across languages, discourses and cultures, 133-157. Philadelphia, PA: John Benjamins. https://doi.org/10.1075/pbns.98.o9cly

Cox, Felicity. 1999. Vowel change in Australian English. Phonetica 56(1-2). 1-27. https://doi.org/10.1159/000028438

Cox, Felicity \& Sallyanne Palethorpe. 2006. A preliminary acoustic phonetic examination of Lebanese Australian English. Australian Journal of Psychology 58 (Suppl. 1). 5. [Abstract]

Cox, Felicity \& Sallyanne Palethorpe. 2007. Illustrations of the IPA: Australian English. Journal of the International Phonetic Association 37(3). 341-350.

https://doi.org/10.1017/S0025100307003192

Cox, Felicity \& Sallyanne Palethorpe. 2012. Standard Australian English: The sociostylistic broadness continuum. In Raymond Hickey (ed.), Standards of English: Codified varieties around the world, 294-317. Cambridge: Cambridge University Press. https://doi.org/10.1017/CBO9781139023832.016

Dodsworth, Robin \& Richard A. Benton. 2017. Social network cohesion and the retreat from Southern vowels in Raleigh. Language in Society 46. 371-405.

https://doi.org/10.1017/So047404517000185

Eckert, Penelope. 2008. Where do ethnolects stop? International Journal of Bilingualism 12(1-2). 25-42. https://doi.org/10.1177/13670069080120010301

Fromont, Robert \& Jennifer Hay. 2012. LaBB-CAT: An annotation store. Proceedings of the Australasian Language Technology Workshop, 113-117.

Grama, James, Catherine E. Travis, \& Simon Gonzalez. 2020. Ethnolectal and community change ov(er) time: Word-final (er) in Australian English. Australian Journal of Linguistics 40(3). 346-368. https://doi.org/10.1080/07268602.2020.1823818

Gross, Johan, Sally Boyd, Therese Leinonen, \& James A. Walker. 2016. A tale of two cities (and one vowel): Sociolinguistic variation in Swedish. Language Variation and Change 28(2). 225-247. https://doi.org/10.1017/So954394516000065

Guy, Gregory R., Barbara M. Horvath, Julia Vonwiller, Elaine Daisley, \& Inge Rogers. 1986. An intonational change in progress in Australian English. Language in Society 15(1).23-52.

https://doi.org/10.1017/So047404500011635 
Hoffman, Michol F. 2010. The role of social factors in the Canadian Vowel Shift: Evidence from Toronto. American Speech 85(2). 121-140. https://doi.org/10.1215/00031283-2010-007

Hoffman, Michol F. \& James A. Walker. 2010. Ethnolects and the city: Ethnic orientation and linguistic variation in Toronto English. Language Variation and Change 22(1). 37-67. https://doi.org/10.1017/So954394509990238

Horvath, Barbara. 1985. Variation in Australian English: The sociolects of Sydney. Cambridge: Cambridge University Press.

Horvath, Barbara. 1991. Finding a place in Sydney: Migrants and language change. In Suzanne Romaine (ed.), Language in Australia, 304-317. Cambridge: Cambridge University Press. https://doi.org/10.1017/CBO9780511620881.023

Horvath, Barbara \& David Sankoff. 1987. Delimiting the Sydney speech community. Language in Society 16(2). 179-204. https://doi.org/10.1017/Soo47404500012252

Jupp, James. 2001. The Australian people: An encyclopedia of the nation, its people and their origins, 2nd edn. Cambridge: Cambridge University Press.

Kerswill, Paul, Eivind Torgersen, \& Susan Fox. 2008. Reversing "drift": Innovation and diffusion in the London diphthong system. Language Variation and Change 20(3). 451-491. https://doi.org/10.1017/So954394508000148

Khoo, Siew-Ean. 2003. A greater diversity of origins. In Siew-Ean Khoo \& Peter McDonald (eds.), The transformation of Australia's population: 1970-2030, 158-184. Sydney: UNSW Press.

Kiesling, Scott Fabius. 2001. Australian English and recent migrant groups. In David Blair \& Peter Collins (eds.), English in Australia, 239-257. Amsterdam: John Benjamins. https://doi.org/10.1075/veaw.g26.22kie

Kiesling, Scott Fabius. 2005. Variation, stance and style: Word-final -er, high rising tone, and ethnicity in Australian English. English World-Wide 26(1). 1-42.

https://doi.org/10.1075/eww.26.1.02kie

Labov, William. 1966. The social stratification of English in New York City. Washington DC: Center for Applied Linguistics.

Labov, William. 1972. Sociolinguistic patterns. Oxford: Basil Blackwell.

Labov, William. 1984. Field methods of the project on linguistic change and variation. In John Baugh \& Joel Sherzer (eds.), Language in use: Readings in sociolinguistics, 28-53. Englewood Cliffs, NJ: Prentice Hall.

Labov, William. 2008. Mysteries of the substrate. In Miriam Meyerhoff \& Naomi Nagy (eds.), Social lives in language: Sociolinguistics and multilingual speech communities, 315-326. Amsterdam/Philadelphia: John Benjamins. https://doi.org/10.1075/impact.24.19lab

Lausberg, Hedda \& Han Sloetjes. 2009. Coding gestural behavior with the NEUROGES-ELAN system. Behavior Research Methods, Instruments, \& Computers 41(3). 841-849. http://tla. mpi.nl/tools/tla-tools/elan/

Lee, Esther. 2020. Quotatives over time: A study in ethnic variation. Honours thesis, Australian National University.

Lobanov, Boris M. 1971. Classification of Russian vowels spoken by different speaker". Journal of the Acoustical Society of America 49. 606-608. https://doi.org/10.1121/1.1912396

Lüdecke, Daniel \& Carsten Schwemmer. 2018. sjPLot: Data visualization for statistics in social science. R package version 2.6.1. https://strengejacke.github.io/sjPlot/

Mitchell, A. G. \& Arthur Delbridge. 1965. The speech of Australian adolescents: A survey. Sydney: Angus and Robertson. 
R Development Core Team. 2019. R: A language and environment for statistical computing. Vienna, Austria: R Foundation for Statistical Computing, http://www.R-project.org

Schneider, Edgar W. 2007. Postcolonial English: Varieties around the World. Cambridge: Cambridge University Press. https://doi.org/10.1017/CBO9780511618901

Travis, Catherine E., James Grama, \& Simon Gonzalez. In Progress. Sydney Speaks Corpora. Australian Research Council Centre of Excellence for the Dynamics of Language, Australian National University: http://www.dynamicsoflanguage.edu.au/sydney-speaks/

van Meel, Linda, Frans Hinskens, \& Roeland van Hout. 2014. Variation in the realization of /عi/ by Dutch youngsters: from local urban dialects to emerging ethnolects?. Dialectologia et Geolinguistica 22(1). 46-74.

Wells, John C. 1982. Accents of English. Cambridge: Cambridge University Press. https://doi.org/10.1017/CBO9780511611759

Wiese, Heike. 2009. Grammatical innovation in multiethnic urban Europe: New linguistic practices among adolescents. Lingua 119(5). 782-806. https://doi.org/10.1016/j.lingua.2008.11.002

Wong, Amy Wing-mei \& Lauren Hall-Lew. 2014. Regional variability and ethnic identity: Chinese Americans in New York City and San Francisco. Language and Communication 35. 27-42.

https://doi.org/10.1016/j.langcom.2013.11.003 


\section{Index}

A

accent $36-49,169-171,173-175$ acceptability deficit $37,39,49$ accommodation $87,252-253$ acquisition $\quad$ 5-6, 16-17, 196-199 see first language; second language

age $59-69,72,76-77,88,275$, 295, 301-306

analysis of variance 60,254 , 261-264, 303

apparent time $64,66,68,72$ aspiration $80-82,102$ attitude $36-39,45,48-49$, $138,140,163-164,176,249$, 263, 293

B

Basque 227-243

bilingual(ism) 12, 14, 16-18, 28, 31, 231, 239-240, 242 see also multilingual(ism)

biodeutsch 111-130

C

chain shift $\quad 57,65,70-73$

Chinese 292-293, 296-300, 307-310

cluster analysis $\quad 136-137,210-$ 213, 216-224

coherence $135-137,146,151-158$, 270-286

constructionalisation 197-199 contact: dialect $\sim 58,69,73$, 247-265; language $\sim 11-31$, 181, 185, 200, 202, 227-228, 239, 242, 248, 260, 263 convergence $16,19,23-24,135$, $154,159,163$

corpus $86,119-120,139-140$, $185-186,232-233$ correlation $53,237,273-286$

correspondence analysis 137 ,

$$
\text { 213-214 }
$$

\section{D}

Danish 79-103, 196; Jutlandic $79-80,82-84,102-103$

dialect contact see contact diffusion $163,175,210,212,216$, 228, 243

diglossia 230, 232-233, 238, 243 diphthong $25,57,60-61,65$, $140,162,164,291-310$

discourse $114-123,130$

divergence 55

Dutch 11-31, 35-49, 85, 137, 182

\section{E}

English 36-41, 49; American 269-286; as a lingua franca 37, 48; Australian 291-310; British 53-73, 161-177

enregisterment $164,172,174$ ethnicity $112-113,114-115$, 126-128, 130, 183, 189-19o, 291-310

ethnographic 145,253 experiment[al] 279-280, 283

\section{F}

first language $12,15,23,42,253$ formants $62,64,90,93,176$, $254,257,298,311$

frequency $143-144,147-148$, $187,233-236,255-260,263-$ 264,275

French 35-49, 240

Frisian 11-31
G

gender [grammatical] 22 gender [social] 59-60, 62, 72 $99,103,156,168,192-194$, 202, 255, 257, 261-265, 275, 294, 295, 297, 300, 303-304, 306-307, 309-310

generalised additive mixed modelling $80,93,98,103$ geographical variation 12,55 , 79-103, 150, 162, 175-176, 209-224, 292-293

German 102, 111-130, 135-158 183, 186, 196; Swabian 137-158 grammaticalisation $198 \mathrm{see}$ also constructionalisation

Greek: Cappadocian 247-251, 253-257, 259-265; modern standard 249, 252, 255, 260-265

\section{$\mathrm{H}$}

historical (socio)linguistics 11-31, 199-202, 227-243, 248-250

I

identification of varieties $17-18,30,37,40-58,156-157$, $171,210-212$

identity $16-17,37,39,112-114$, $116-118,130,156,163-165$, $168-177,263,292-293,296$ ideology $36,38,48,112,114$, 117-118, 121, 125, 127-130 immigration see migration indexicality $164-165,188-189$, 193, 200, 202 innovation 19-20, 26, 29, 150, 184, 197-199, 202, 228, 236, $243,269,273,275-276,285$ 
intelligibility $37,40,48,82$ isogloss $80,84,209-210$

Italian 291-310

J

judgement $\quad 40-41,48-49$

Jutlandic see Danish

K

koineisation $183 \quad 249,263-265$

\section{L}

language contact see contact

language shift 13, 15, 18, 20, 24, 30, 292

leaders $\quad 72,269-285$

levelling $69,72-73,143,150$, $154,158,163,262-264$

lexical variation $21-22,184$, 190, 196, 209-224, 255-256, 259, 263

lifespan change 150,158

linear mixed-effects model

43-46, 275, 303-305, 307-308

literacy $231-233,238$

logistic regression $43-44,144$

\section{M}

merger $\quad 53-73,162,167,271$

migration 16, 111-113, 115-128, $138,182-185,195,198-199$,

202, 247, 249, 262, 265, 291-

296, 299-300, 309-310

Mišótika see Greek, Cappadocian

mixed languages $\quad$ 14-18

morphological variation

22, 29, 140-141, 143-145

multiethnolect $182-184,190$

multilingual(ism) 12, 30, 294

see also bilingual(ism)
$\mathrm{N}$

national identity 113

normalisation $59-60,166$,

$$
\text { 253-254, 273, } 298
$$

O

Occitan 209-224

$\mathbf{P}$

perception 12,14

phonological variation:

consonant 79-104,141;

vowel 2, 6, 20, 25, 27, 29,

53-73, 90-93, 99, 102, 140-

$141,161-162,164,166-167$,

247-265, 271-283, 291-309

prestige $\quad 162-163,172-174$

293-294

principal components analysis

144, 279, 281

pronoun 20, 181-203, 227-243

Q

questionnaire 41

\section{R}

real time $7,106,109,155,158$,

291, 295, 297, 301, 305, 310

regional variation see

geographical variation

relative clauses $\quad 26,227-243$

\section{S}

salience $164,169,195,203$

school 162, 165, 168-170, 174,

$176,231,252-253,296$

second language $\quad 16-17,30,184$, 198-199

socio-economic status $\quad 58,139$,

175, 191-192, 295-297

Spanish 41, 227, 229, 233,

239-240 speech community 70,82 ,

135-136, 158, 184, 199, 270, 274,284

standardisation $\quad 21,136$, 149-150, 227, 230, 258

statistical techniques see analysis of variance; cluster analysis; correlation; correspondence analysis; generalized additive mixed modelling; linear mixed-effects model; logistic regression; principal components analysis; $t$-test

style-shifting $\quad 174-176$

Swabian see German

Swedish: Rinkeby $182,184,186$; Stockholm 182-186, 191-193, 195, 200-202

syntactic variation 16,29 , 187-188, 200, 227-230, 233$235,238-243$

\section{$\mathrm{T}$}

t-test $\quad 63-64,167-168$

Town Frisian 11-31

Turkish $123,128,129,181,185$, 188, 190, 194-195, 198-199, $203,248-263$

V

verb 141-143, 194-199

voice onset time $79-82,84$, 90-103

vowels see mergers; normalisation; phonological variation

W

word see lexical variation 
This volume contains a selection of papers from the 1oth International Conference on Language Variation in Europe (ICLaVE 10), which was organized by the Fryske Akademy and held in Leeuwarden/Ljouwert (the Netherlands) in June 2019. The editors have selected thirteen papers on a wide range of language varieties, geographically ranging from Dutch-Frisian contact varieties in Leeuwarden to English in Sydney, Australia. The selection includes traditional quantitative and qualitative approaches to different types of linguistic variables, as well as state-of-the-art techniques for the analysis of speech sounds, new dialectometrical methods, covariation analysis, and a range of statistical methods. The papers are based on data from traditional sources such as sociolinguistic interviews, speech corpora and newspapers, but also on hip hop lyrics, historical private letters and administrative documents, as well as re-analyses of dialect atlas data and older dialect recordings. The reader will enjoy the vibrant diversity of language variation studies presented in this volume.

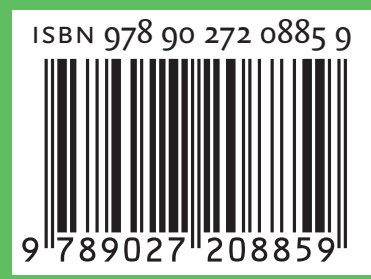

\section{John Benjamins Publishing Company}

